\title{
DESARROLLO DE ALIMENTOS TIPO SNACK DE BAJO CONTENIDO GRASO A PARTIR DE DISCOS DE MANZANA VERDE
}

Tesis doctoral presentada por

MARÍA JOSÉ TAVERA QUIROZ

ante la Facultad de Ingeniería de la

Universidad Nacional de La Plata

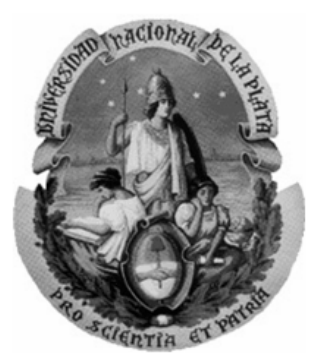

como requisito de grado para la obtención del grado académico de

DOCTOR EN INGENIERÍA

Directora: Dra. Ing. Nora Bertola

Codirectora: Dra. Ing. Adriana Pinotti

Jurado de Tesis: Dra. Laura Ramallo

Dra. Sonia Sgroppo

Dra. Sonia Viña

Fecha de defensa: Abril 23 de 2015

La Plata, Buenos Aires 


\section{RESUMEN}

Esta investigación se basó en el desarrollo de productos tipo snack bajos en grasa a partir de manzana verde Granny Smith (Malus domestica). En el Capítulo 1 se realizó la caracterización de la materia prima, la geometría del producto y en el Capítulo 2 se estudió el agregado de diferentes sales de calcio y escaldado con vapor. Para observar el efecto del calcio sobre la matriz, grupos de muestra se sumergieron en soluciones de carbonato de calcio y lactato-gluconato de calcio. Posteriormente se escaldaron con vapor, se observó la microestructura y se determinó el contenido de calcio remanente. En esta primera etapa se concluyó que el agregado de calcio al tejido de la manzana mejoró la textura para un posterior tratamiento térmico y además fortificó el alimento, ya que el calcio absorbido permaneció incluido en los poros del tejido, lo cual se observó a través de microscopía electrónica de barrido y a través de análisis de las cenizas.

En el Capitulo 3 se desarrollaron snacks a partir de manzanas verdes estudiando diferentes alternativas de cocción (fritado, horneado o su combinación) con el objetivo de obtener productos con menor contenido graso que los tradicionales pero con las propiedades que los consumidores valoran en los mismos, como el color y la textura crocante. Para ello se analizó el efecto del método de cocción sobre los parámetros de color, textura, humedad y $\mathrm{a}_{\mathrm{w}}$. Asimismo se determinó la temperatura de transición vítrea $\left(\mathrm{T}_{\mathrm{g}}\right)$ a través de calorimetría diferencial de barrido (DSC) y análisis dinámico mecánico (DMA). Las rodajas de manzanas se sumergieron en soluciones de lactato-gluconato de calcio y de carbonato de calcio al 2,5\% y se escaldaron con vapor. A continuación las muestras se sumergieron en soluciones acuosas de maltodextrina (M) y fructosa $(\mathrm{F})$ al $30 \% \mathrm{p} / \mathrm{p}$ con relaciones M:F de 1:1, $2: 1$ y 1:2. A cada una de las soluciones se agregó ácido ascórbico al 2\%. Utilizando únicamente fritura como método de cocción no fue posible 
obtener un producto con adecuadas características sensoriales. Las condiciones de cocción que permitieron obtener un snack crocante fueron horneado a $100^{\circ} \mathrm{C}$ y prehorneado a $100^{\circ} \mathrm{C}$ seguido de fritado durante $1 \mathrm{~min}$. La solución de impregnación formulada con $15 \%$ de maltodextrina y $15 \%$ de fructosa con pretratamiento de lactatogluconato de calcio, dio como resultado el snack de manzana horneado con mayor aceptabilidad por los consumidores en los diferentes atributos evaluados (color, sabor ácido, dulzor, textura). Sin embargo para el producto obtenido por combinación de horneado y fritado la solución de impregnación de mayor aceptabilidad fue la de $20 \%$ de maltodextrina y $10 \%$ de fructosa y pretratamiento con lactato-gluconato de calcio. La composición de la solución de azúcares utilizados afectó significativamente los valores de humedad y $\mathrm{a}_{\mathrm{w}}$, así como los de luminosidad ( $\left.\mathrm{L}^{*}\right)$ sólo en el caso de los productos obtenidos por la combinación de horneado y fritado (H/F). El contenido graso (determinado por Soxhlet) del snack obtenido por el método combinado $(\mathrm{H} / \mathrm{F})$ fue de $31 \%$. Del análisis térmico obtenido por DSC y DMA se observó que los snacks (horneados y horneados/fritos) tuvieron una temperatura de transición vitrea alrededor de $\operatorname{los} 40^{\circ} \mathrm{C}$. No obstante el snack frito, presentó pérdida de textura relacionada con el alto contenido graso. Con el horneado se obtuvo un producto con valores más bajos de humedad y $\mathrm{a}_{\mathrm{w}}$. Se realizaron determinaciones de actividad antioxidante y contenido de vitamina $\mathrm{C}$ para evaluar las pérdidas durante el horneado. El contenido de vitamina $\mathrm{C}$ aumentó respecto a la fruta fresca con el escaldado en presencia de calcio; el incremento fue aún más pronunciado en las rodajas impregnadas con la mezcla maltodextrina/fructosa en relación 1:1 y ácido ascórbico.

Los resultados obtenidos en esta primera etapa de tesis doctoral fueron publicados por los autores:

María José Tavera-Quiroz; Marina Urriza; Adriana Pinotti; Nora Bertola. (2014). Development and characterization of a baked snack 
from rings of green apples. Food Bioprocess Technology, 7 (8): 22182227.

En el Capitulo 4 se analizaron las características físicas, químicas y sensoriales de snacks horneados obtenidos a partir de manzanas verdes utilizando isomalt como azúcar de bajo índice glucémico, con menor aporte de calorías (2 kcal/g) y no cariogénico. La solución de impregnación formulada con 10\% de maltodextrina y $20 \%$ de isomalt y pretratamiento con lactato-gluconato de calcio, dio como resultado el snack de manzana con mayor aceptabilidad en los atributos evaluados (color, sabor ácido, dulzor, textura). Para el producto obtenido con esta formulación el contenido de calcio fue de $216,5 \mathrm{mg} / 100 \mathrm{~g}_{\mathrm{ms}}$ y el contenido de ácido ascórbico de $27 \mathrm{mg} / \mathrm{g}_{\mathrm{ms}}$, estos valores resultaron superiores a los de la manzana fresca. Los snacks con isomalt presentaron valores de $\mathrm{T}_{\mathrm{g}}$ entre 60 y $100^{\circ} \mathrm{C}$, siendo más altos respecto al control horneado en el cual está temperatura se ubicó alrededor de $11^{\circ} \mathrm{C}$. Este producto constituye una buena alternativa para mantener una dieta rica en calcio y antioxidantes como la vitamina $\mathrm{C}$, sin agregar calorías a la dieta.

Los resultados obtenidos en este capítulo fueron publicados recientemente por los autores:

María José Tavera-Quiroz; Marina Urriza; Adriana Pinotti; Nora Bertola. (2015). Baked snack from green apples with addition of isomalt. LWT-Food Science and Technology. 62: 1004-1010.

En el Capítulo 5, se investigó la estabilidad durante el almacenamiento y el acondicionamiento a diferentes humedades relativas de los snacks, seleccionados en capitulos anteriores. Para el snack con isomalt las isotermas de adsorción mostraron un patrón de comportamiento de menor higroscopicidad en las regiones de baja actividad acuosa. Resultados similares se encontraron para la textura (pérdida de crocancia) y la $\mathrm{T}_{\mathrm{g}}$. El snack con fructosa mostró un 
comportamiento mayormente higroscópico y un tiempo de vida útil menor comparado con el snack con Isomalt. El tiempo de almacenamiento seleccionado a partir del análisis de humedad, textura y $\mathrm{T}_{\mathrm{g}}$ para los snacks de fructosa e isomalt fue de 30 y 120 días, respectivamente. Estos resultados indicaron que el snack obtenido con maltodextrina/isomalt, es un alimento más estable a los cambios ambientales, además de saludable.

A partir del snack con isomalt y conociendo las múltiples propiedades de los recubrimientos comestibles en el mejoramiento de la calidad de los alimentos, en el Capítulo 6 se realizaron diferentes experimentos para la obtención de un alimento probiótico a partir de manzana var. Granny Smith y coberturas de metilcelulosa inoculadas con Lactobacillus plantarum. Se tuvo en cuenta además que isomalt aporta fibra soluble como prebiótico. Los ensayos se realizaron a partir de los snacks previamente horneados a $140^{\circ} \mathrm{C}$ y las temperaturas ensayadas para el secado de la cobertura de metilcelulosa fueron: 60, $80,100^{\circ} \mathrm{C}$ y $140^{\circ} \mathrm{C}$. Se evaluó el aspecto y las propiedades mecánicas de los snacks obtenidos, así como la viabilidad de los microorganismos en las diferentes etapas del proceso y durante la digestión gastrointestinal in vitro. Las propiedades mecánicas de las muestras secas se vieron afectadas por los niveles de humedad alcanzados en el proceso, resultando con mayor viabilidad las muestras secadas a menor temperatura $\left(60^{\circ} \mathrm{C}\right)$. Con el secado a mayor temperatura se obtuvieron buenas propiedades mecánicas. Sin embargo, se vio afectada la viabilidad del microorganismo, la cual disminuyó respecto del secado a $60^{\circ} \mathrm{C}$. Los snacks obtenidos se almacenaron envasados a $20^{\circ} \mathrm{C}$ y $60 \%$ HR y se sometieron a condiciones gastrointestinales simuladas. Las curvas de fuerza-desplazamiento mostraron un patrón típico de materiales frágiles hasta 90 días. La $\mathrm{T}_{\mathrm{g}}$ siguió una tendencia similar, de acuerdo con un contenido de humedad constante. Los resultados de un panel sensorial demostraron que el recubrimiento de los snacks con probióticos inmovilizados no alteró sus propiedades organolépticas. 
Hasta los 90 días de almacenamiento, el snack presentó una carga de lactobacilos por encima del mínimo necesario para obtener los beneficios del consumo de probiótico. Teniendo en cuenta la composición de los snacks, incluyendo probióticos y prebióticos, los resultados obtenidos en esta investigación son de gran importancia para el desarrollo de alimentos funcionales.

Debido a la importancia de realizar un trabajo exhaustivo de investigación tanto del snack funcionalizado como de las características de la película de metilcelulosa como sistema modelo de la cobertura, se publicaron los resultados en el artículo:

María José Tavera-Quiroz, Nelson Romano, Pablo Mobili, Adriana Pinotti, Andrea Gómez-Zavaglia, Nora Bertola.(2015). Green apple baked snacks functionalized with edible coatings of methylcellulose containing Lactobacillus plantarum. Journal of Functional Foods. Aceptado para su publicación.

Un estudio anexo a esta tesis doctoral (Anexo 2), se basó en la investigación de las propiedades de las películas de metilcelulosa. En el mismo se desarrollaron y caracterizaron películas biodegradables a base de metilcelulosa ( $\mathrm{MC}$ ), observando el efecto del agregado de sorbitol como plastificante, con el objetivo de hacer un paralelo entre las mismas y su aplicación como recubrimiento en los snacks de manzana. Las soluciones de metilcelulosa (A4M) se prepararon al 1,5\% p/v a $80^{\circ} \mathrm{C}$. Las concentraciones de sorbitol analizadas fueron $0,25,0,5,0,75$ y $1 \%$. En todos los casos se obtuvieron películas transparentes y flexibles. Se evaluaron las propiedades microestructurales, térmicas y mecánicas a través de DSC, DMTA, FTIR y SEM a efectos de determinar la temperatura de transición vítrea y realizar ensayos de tensióndeformación. Además se determinó la permeabilidad al vapor de agua de acuerdo con la norma ASTM E96, con el fin de establecer la utilidad de la cobertura durante el almacenamiento, lo cual es un factor crítico 
en el desarrollo de un producto. Se evaluó el contenido de humedad y la solubilidad de las películas en agua a diferentes temperaturas. Las películas de MC sin plastificante presentaron un valor de $\mathrm{T}_{\mathrm{g}}$ alrededor de $198^{\circ} \mathrm{C}$, mientras que la $\mathrm{T}_{\mathrm{g}}$ de las películas con plastificante disminuyó a $170^{\circ} \mathrm{C}$ para concentraciones de sorbitol entre 0,25 y 1\% $\mathrm{p} / \mathrm{p}$. La información obtenida por DSC se correlacionó con ensayos de barrido de frecuencia que se realizaron entre -100 y $230^{\circ} \mathrm{C}$ para la obtención de la tan $\delta$, el módulo de almacenamiento y el módulo de pérdida. También se registraron los espectros FTIR de las películas entre 4000 a $400 \mathrm{~cm}^{-1}$. Los espectros de FTIR mostraron mayor contenido de agua a medida que aumentó el contenido de plastificante, lo cual se observó con el aumento del pico entre 1580 y $1700 \mathrm{~cm}^{-1}$. Esto se pudo relacionar con el contenido de humedad de las muestras que correspondió a valores entre 6,75 y 10,54\% para cantidades de plastificante desde 0 a $1 \%$, respectivamente. A $25^{\circ} \mathrm{C}$ las películas resultaron solubles y a $100^{\circ} \mathrm{C}$, la solubilidad aumentó con el incremento del contenido de plastificante, desde un $18 \%$ para la película sin plastificar hasta un $40 \%$ para $1 \%$ de sorbitol. Además se realizaron ensayos de esfuerzo-deformación a $25^{\circ} \mathrm{C}$, para la determinación del módulo elástico de las diferentes formulaciones. El módulo elástico disminuyó con la incorporación de plastificante, lo cual indica que la adición de sorbitol facilita la movilidad macromolecular en la matriz. Estos resultados se informaron en la siguiente publicación:

Tavera-Quiroz, M. J., Lecot, J., Bertola, N., \& Pinotti, A. (2013). Stability of methylcellulose based films after being subjected to different conservation and processing temperatures. Materials Science and Engineering: C, 33, 2918-2925.

Con el fin de mejorar las propiedades funcionales de las matrices obtenidas, se estudió el efecto del agregado de ácidos orgánicos como el ácido cítrico en la formulación de películas de metilcelulosa. Este aditivo, además de su capacidad como conservante puede actuar como 
reticulante de la matriz de MC. Los estudios realizados sobre las propiedades microestructurales (DSC, FTIR) y de barrera (permeabilidad al vapor de agua y a los gases) de las películas confirmaron que la capacidad entrecruzante del material se favorece en presencia de ácido cítrico. La formulación con mejores propiedades: baja permeabilidad al vapor de agua y al oxígeno, menor capacidad de hinchamiento, mayor resistencia a la ruptura fue la resultante de combinar MC con sorbitol $0,25 \%$ y agregado de $5 \%$ AC ( $/ p / p \mathrm{MC})$, como sistema modelo de recubrimientos comestibles. Los resultados obtenidos se presentaron en el siguiente trabajo:

M.J. Tavera Quiroz, N. Bertola, A. Pinotti. Influencia del agregado de ácido citrico sobre las propiedades fisicoquimicas de peliculas de metilcelulosa. I Workshop de Polimeros Biodegradables y Biocompuestos 2013, Facultad de Ingeniería, UNMdP, Mar del Plata.

A partir de los resultados de este trabajo de investigación se obtuvieron snacks de manzana verde con aporte de calcio y ácido ascórbico, formulados a partir de fructosa y de carbohidratos complejos como isomalt, maltodextrina, como opciones saludables para distintos tipos de consumidores: niños y adolescentes sanos, personas con dificultades para metabolizar carbohidratos simples y aquellas que quieran mejorar sus hábitos de consumo y disminuir la ingesta de calorias. Además el desarrollo de un sistema sinérgico entre snack/cobertura con bacterias lácticas permitió el desarrollo de un producto innovador como alternativa para el consumo de probióticos en un alimento no lácteo, funcional y saludable. 


\section{AGRADECIMIENTOS}

Agradezco a Dios y a todas las personas que me acompañaron en este camino y que hicieron posible el desarrollo de esta tesis doctoral.

A mis directoras, Nora y Adriana, por su confianza, su apoyo permanente y sus enseñanzas.

A CONICET, a la Facultad de Ingeniería, al CIDCA, y a su directora por permitirme culminar esta etapa de mi formación.

A Marina, por toda la colaboración en el laboratorio, las tardes de cafecito y sus charlas cargadas de buena energía.

A los técnicos del CIDCA: Javier Lecot, Daniel Russo, Claudio Reyes. Gracias por tantas horas dedicadas a mis ensayos.

Al grupo de Microbiología del CIDCA conformado por Andrea, Pablo y Nelson, por dar el ejemplo de que se puede trabajar en equipo.

A Nati Graiver, por darme la bienvenida y responder mis dudas siempre con una sonrisa.

A la Dra. Ale García por su amabilidad y sus buenos consejos.

A Sandrita, porque más que mi compañera de laboratorio, eres una amiga.

A Martín, amigo incondicional.

A todos los chicos del CIDCA que conocí durante estos años y con quienes tuve la suerte de trabajar de alguna $u$ otra forma. Amigos que llevaré siempre conmigo: Nelson, Anabel, Flor, Nati, Leo, Sil, Cintia, Eli. A Juliana y Mafe. Gracias por hacerme saber que siempre puedo contar con uds.

A mis padres y mis hermanos. Papi y mami gracias por su confianza, su apoyo y su sacrificio. Moni y Humbe son los mejores hermanos que la vida me pudo regalar, gracias por su amor incondicional. 
Al resto de mi familia, a los que están y a los que no están. Gracias por que ustedes nos completan.

A Juan y Negrita, por recorrer juntos este camino 


\section{TABLA DE CONTENIDO}

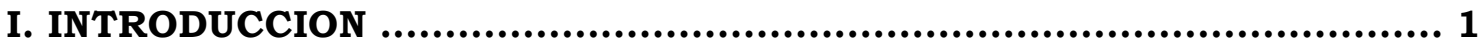

II. OBJETIVOS ................................................................................20

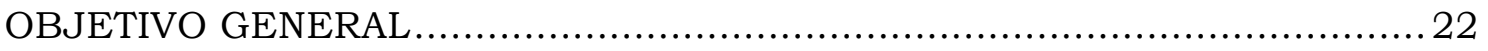

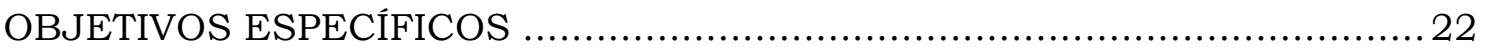

III. ANILLOS CROCANTES DE MANZANA VERDE ....................................24

CAPITULO 1. CARACTERIZACION FISICOQUIMICA DE LA MATERIA PRIMA: MANZANA VERDE GRANNY SMITH (Malus domestica) 26

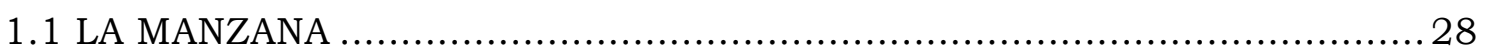

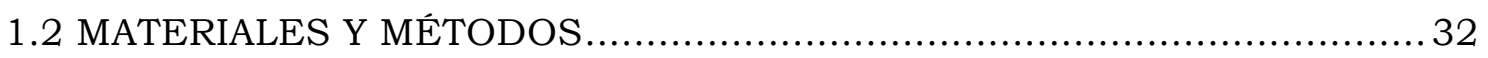

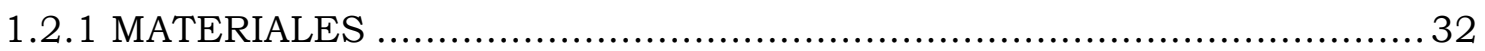

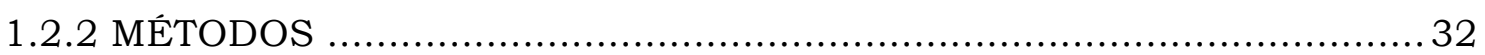

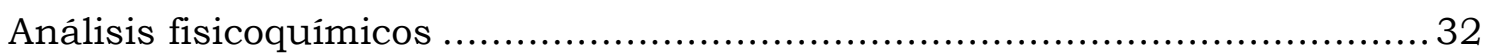

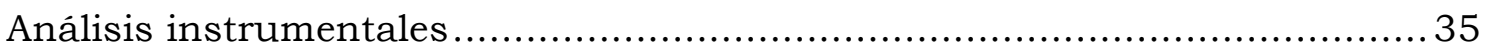

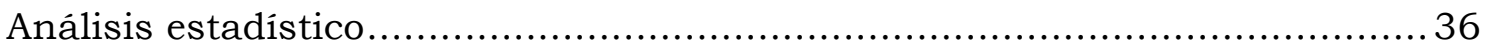

1.3 RESULTADOS Y DISCUSIÓN

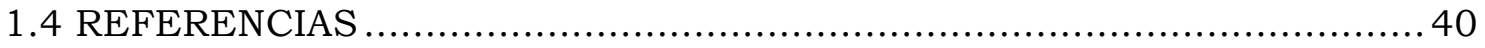

CAPÍTULO 2. ESTUdIO DE DIFERENTES ALTERNATIVAS TECNOLOGICAS PARA DESARROLLAR UN SNACK DE MANZANA DE ÓPTIMA CALIDAD ...44

2.1 EFECTO DEL PRETRATAMIENTO CON SALES DE CALCIO SOBRE LAS PROPIEDADES NUTRICIONALES, MICROESTRUCTURA, TEXTURA Y COLOR

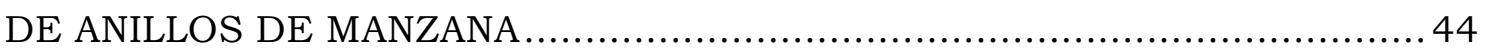

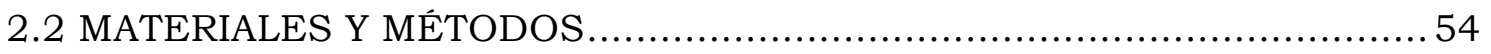

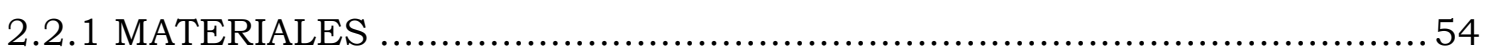

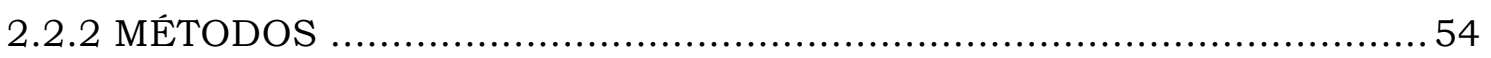

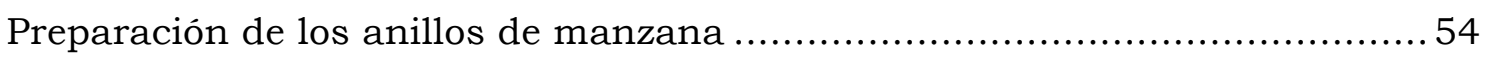

Selección del tiempo/temperatura de horneado .......................................... 54

Pretratamientos aplicados sobre los anillos de manzana ................................5 54

Determinación de las propiedades fisicoquímicas ........................................ 55

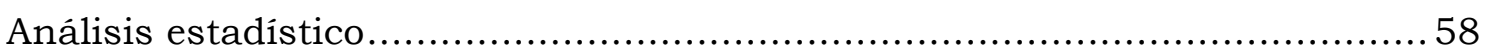

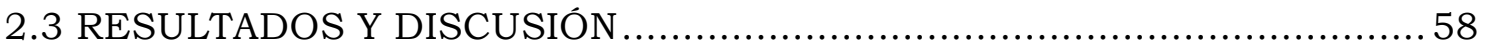

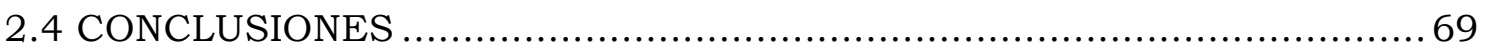


CAPITULO 3. DESARROLLO DE ANILLOS CROCANTES DE MANZANA FORMULADOS CON FRUCTOSA Y MALTODEXTRINA A PARTIR DE DIFERENTES TÉCNICAS DE COCCIÓN: HORNEADO, FRITADO Y SU COMBINACIÓN ..........................................................................78

3.1 CONSIDERACIONES GENERALES …....................................... 80

3.2 SELECCIÓN DEL TIEMPO ÓPTIMO DE TRATAMIENTO DE ANILLOS DE MANZANA IMPREGNADOS CON SOLUCIONES DE MALTODEXTRINA:

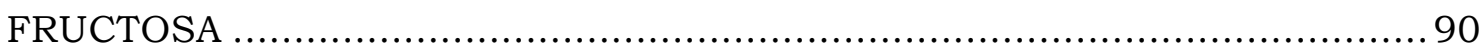

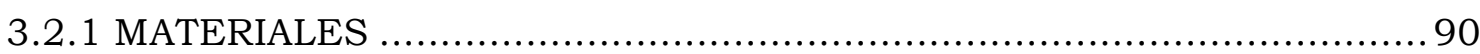

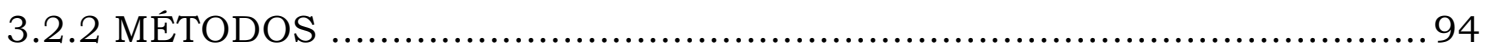

Impregnación de los anillos de manzana con soluciones de maltodextrina y fructosa 94

Determinación de la pérdida de peso en función del tiempo de inmersión en las soluciones de azúcares ........................................................... 95

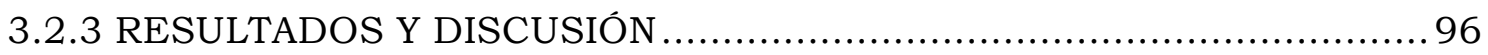

Selección del tiempo óptimo de tratamiento de los anillos de manzana en las

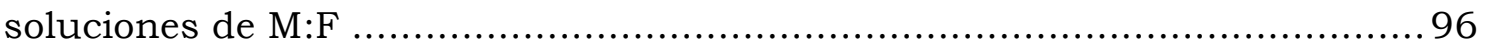

3.3. DESARROLLO DE UN SNACK DE MANZANA VERDE OBTENIDO POR DIFERENTES TÉCNICAS DE COCCIÓN: FRITADO CONVENCIONAL /

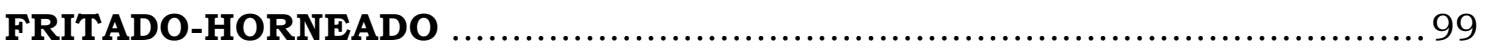

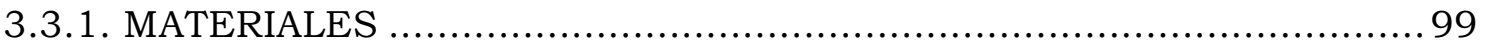

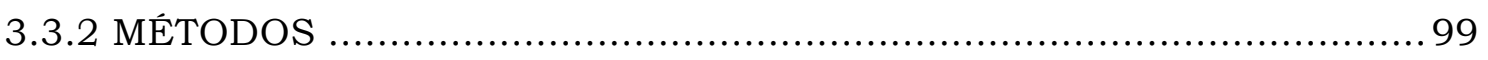

Análisis de las propiedades fisicoquímicas................................... 102

Análisis de las propiedades térmicas ............................................ 103

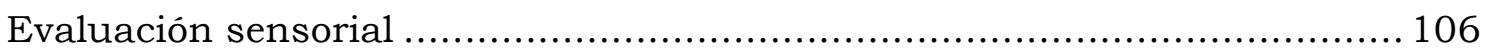

Análisis de las propiedades nutricionales ........................................ 108

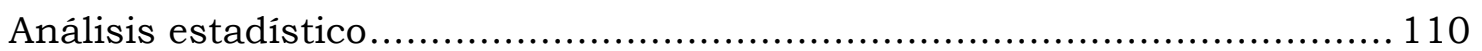

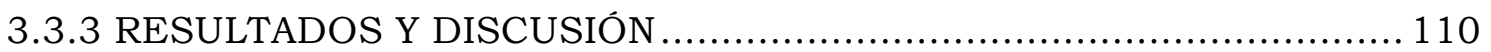

Condiciones de cocción seleccionadas .............................................. 110

Propiedades físicas de los snacks obtenidos...................................... 112

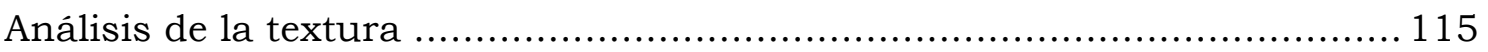

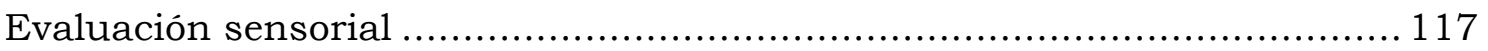

Análisis de las propiedades térmicas ........................................... 118

Contenido graso ..................................................................... 120 


\subsection{DESARROLLO DE SNACKS HORNEADOS A PARTIR DE DIFERENTES}

FORMULACIONES DE MALTODEXTRINA: FRUCTOSA

3.4.1 MATERIALES .................................................................. 123

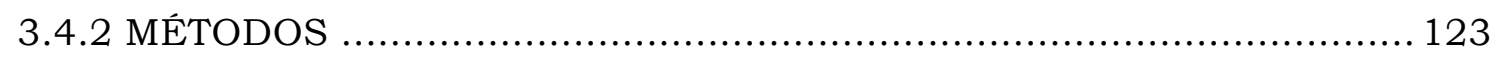

Proceso de horneado ............................................................... 123

Determinación de las propiedades fisicoquímicas e instrumentales............ 124

Análisis de la microestructura ........................................................ 124

Análisis de las propiedades funcionales de los snacks seleccionados ......... 127

Determinación del contenido de azúcares y de ácido ascórbico por cromatografia líquida de alta resolución (HPLC) .................................. 127

Determinación de la capacidad antioxidante total (TAC) y el contenido de

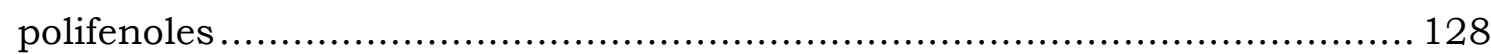

Contenido de polifenoles totales ............................................ 131

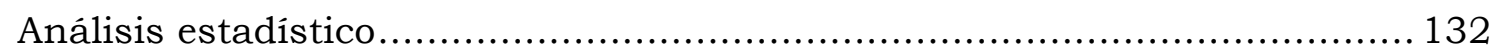

3.4.3 RESULTADOS Y DISCUSIÓN .............................................. 133

Propiedades fisicoquímicas de los snacks obtenidos ........................... 133

Propiedades térmicas de los anillos de manzana .................................... 139

Análisis por componentes principales (PCA) de los parámetros sensoriales e instrumentales ................................................................ 147

Análisis de las propiedades funcionales del snack seleccionado ................ 149

Contenido de carbohidratos...................................................... 149

Contenido de ácido ascórbico ..................................................... 151

Actividad antioxidante y contenido de polifenoles de los snacks y el control 155

3.5 CONCLUSIONES ......................................................... 158

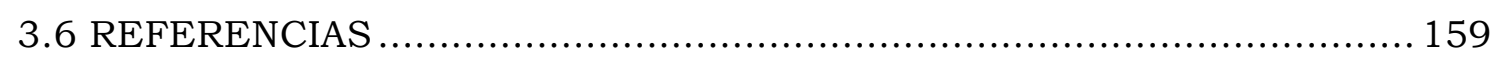

CAPITUlO 4. DESARROLlo DE ANILlos CROCANTES DE MANZANA REDUCIDOS EN CALORIAS UTILIZANDO ISOMALT .......................178

4.1 CONSIDERACIONES GENERALES .......................................... 180

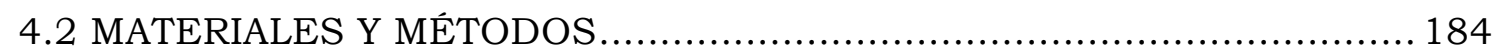

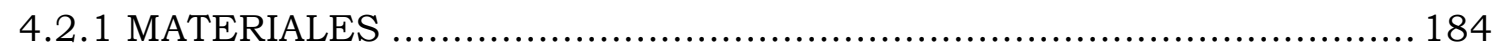

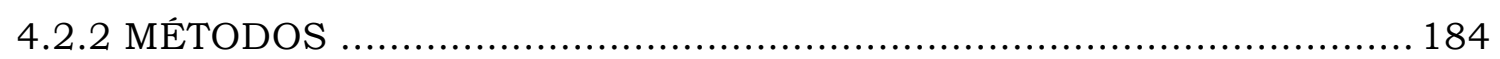

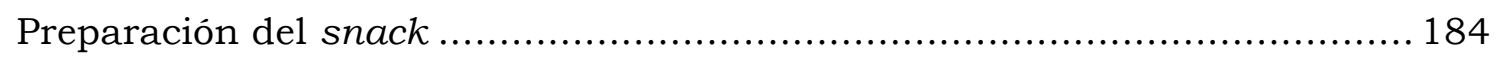

Determinación de la pérdida de peso en función del tiempo de inmersión en las soluciones de azúcares ........................................................... 184

Obtención de los snacks: Horneado ............................................... 184

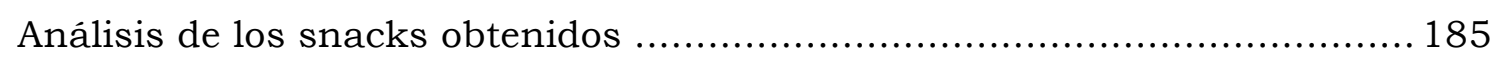




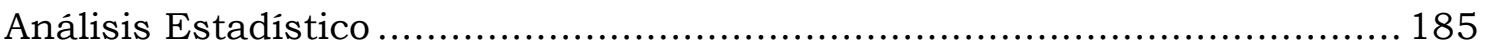

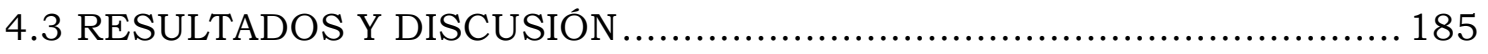

Propiedades fisicoquímicas de los snacks obtenidos............................. 185

Análisis de la microestructura por SEM........................................ 191

Análisis de las propiedades térmicas ......................................... 192

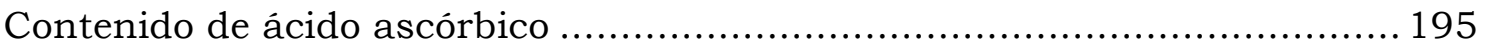

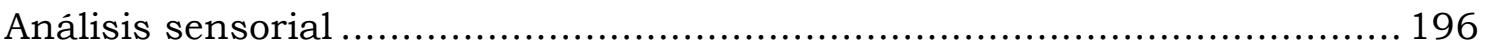

Análisis por componentes principales (PCA) de los datos sensoriales e

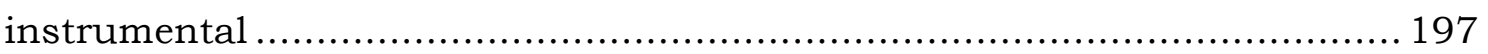

Determinación de actividad antioxidante .......................................... 201

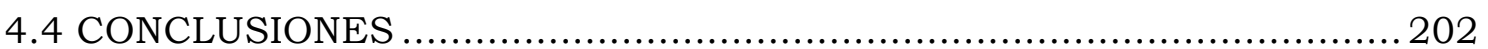

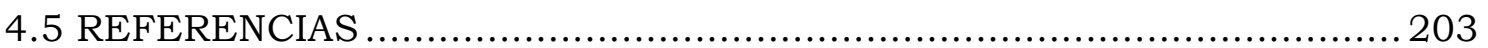

CAPITULO 5. ANÁlISIS DE CALIDAD DE LOS SNACKS SELECCIONADOS:

Estabilidad durante el almacenamiento y tiempo de vida útil .............206

5.1 CONSIDERACIONES GENERALES ........................................... 208

5.2 INFLUENCIA DE LOS CARBOHIDRATOS EN LAS PROPIEDADES MECÁNICAS, HIGROSCOPICIDAD E ISOTERMA DE SORCIÓN DE LOS

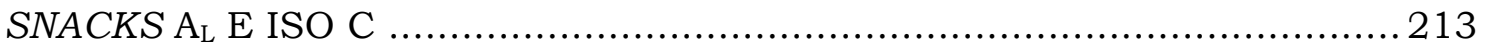

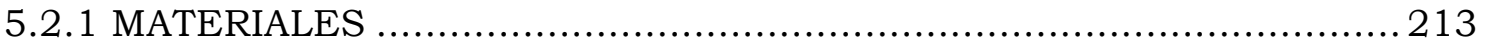

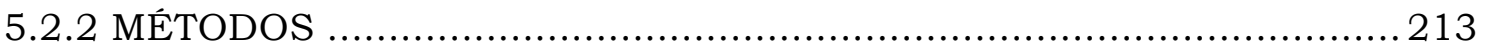

Análisis de las propiedades mecánicas de los snacks por DMA .................2 213

Evaluación de la higroscopicidad ................................................. 214

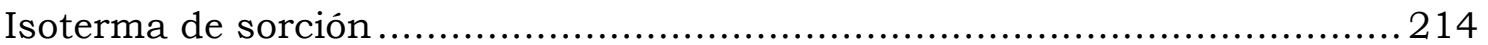

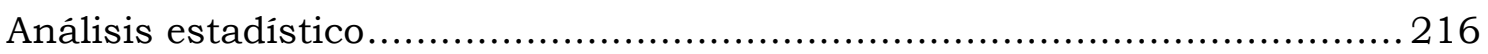

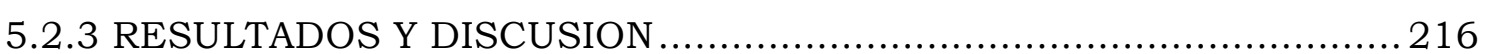

Influencia de los carbohidratos en las propiedades mecánicas ..................2 216

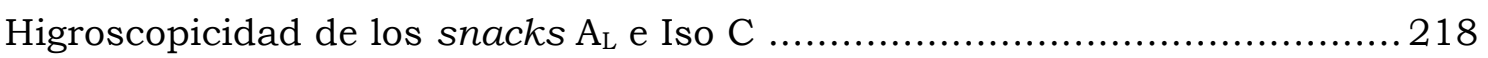

Isotermas de adsorción de agua ..................................................... 220

Parámetros críticos sobre las propiedades mecánicas: humedad, actividad de

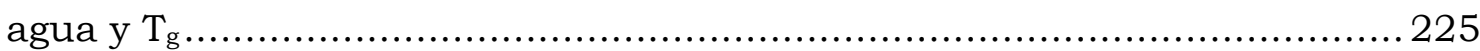

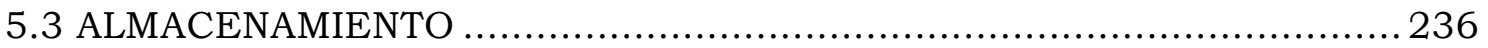

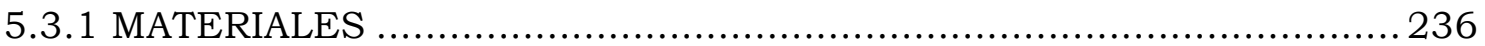

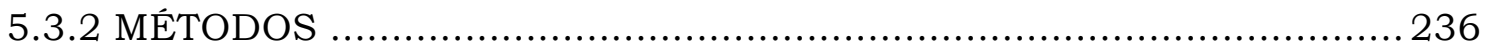

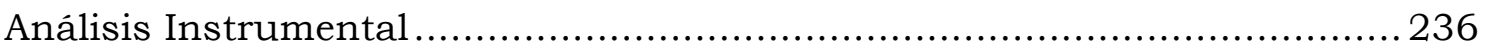

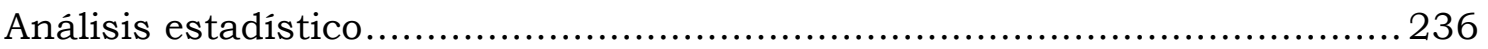

5.3.3 RESULTADOS Y DISCUSIÓN ........................................... 237 
Almacenamiento de los snacks a $20^{\circ} \mathrm{C}$ y $60 \%$ HR envasados

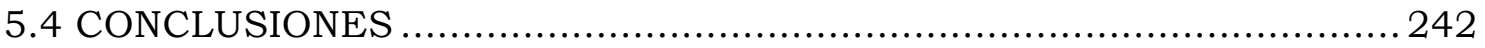

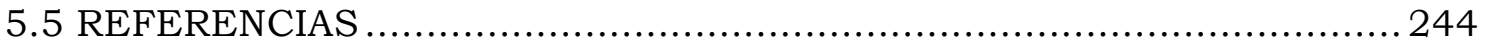

CAPÍtulo 6. OBTENCIÓN DE UN SNACK FUNCIONAL A PARTIR DE LA APLICACIÓN DE RECUBRIMIENTOS DE METILCELULOSA COMO SOPORTE DE BACTERIAS LÁCTICAS .....................................250

6.1 CONSIDERACIONES GENERALES ............................................ 252

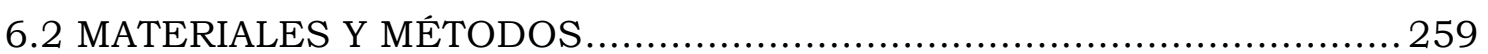

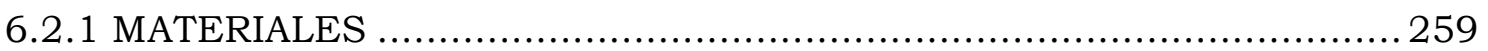

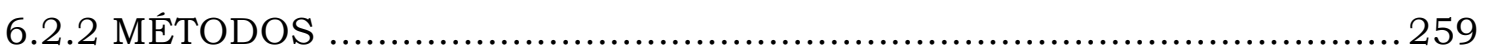

Preparación de los cultivos de bacterias lácticas probióticas ..................... 259

Preparación de las soluciones filmogénicas............................................ 259

Preparación de los snacks de manzana recubiertos ............................... 260

Determinación de las propiedades fisicoquímicas, térmicas y nutricionales de

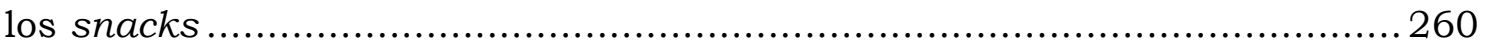

Análisis de la superficie de los snacks por SEM ................................. 260

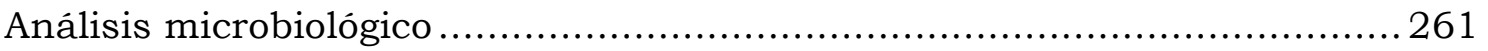

Determinación de la viabilidad bacteriana ........................................ 261

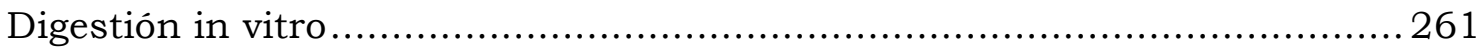

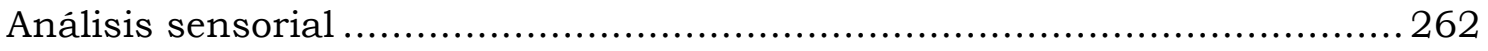

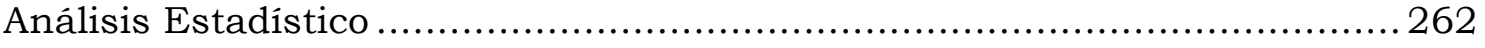

6.3 RESULTADOS Y DISCUSIÓN ............................................... 263

Selección de las condiciones de secado del recubrimiento sobre los snacks. 263

Propiedades físicas, químicas y nutricionales de los snacks recubiertos y el

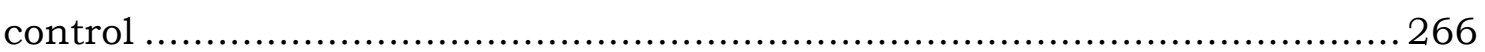

Contenido de ácido ascórbico .................................................. 270

Propiedades térmicas de los snacks recubiertos................................... 271

Análisis de la superficie por microscopía electrónica de barrido ................2273

Propiedades microbiológicas: Viabilidad celular y digestión in vitro............. 274

Panel Sensorial ............................................................................. 277

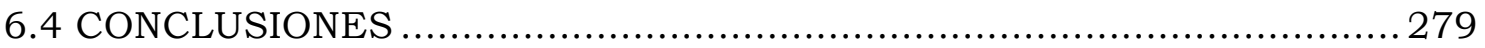

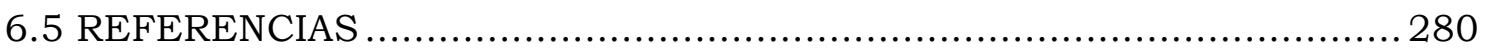

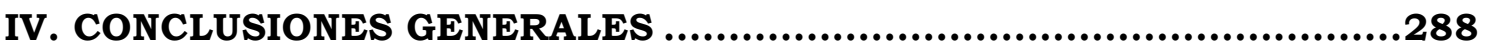

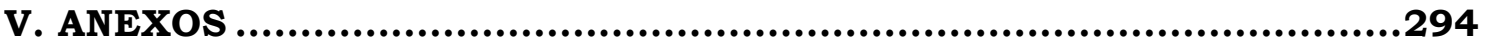

ANEXO 1. FICHA TÉCNICA DEL ENVASE BOPP/BOPP. ..........................2 296 
ANEXO 2. CARACTERIZACIÓN DE LAS PELICULAS OBTENIDAS A PARTIR DE SOLUCIONES DE METILCELULOSA COMO SISTEMA MODELO DE LOS RECUBRIMIENTOS 300 


\section{LISTA DE FIGURAS}

Figura 1. Termograma típico de un polímero amorfo 12

Figura 2. Método de punción aplicado sobre la manzana var. Granny Smith (Malus domestica)

Figura 3. Perfil de textura de las manzanas Granny Smith obtenido a través de penetrometría

Figura 4. Papel del calcio en la estructura de la pared celular - Modelo de la caja de huevos 50

Figura 5. Proceso de obtención de anillos de manzana con calcio 55

Figura 6. Sonda y sistema de apoyo de la muestra en los ensayos para analizar la textura de las muestras con y sin calcio 57

Figura 7. Contenido de calcio $\left(\mathrm{g} \mathrm{Ca}^{+2} / 100 \mathrm{~g}_{\text {cenizas }}\right.$ ) de los anillos de manzana impregnados con carbonato y lactato-gluconato de calcio durante diferentes tiempos

Figura 8. Muestras de manzana pretratadas a 2, 15 y $60 \mathrm{~min}$ con a. Carbonato de calcio; b. Lactato-gluconato de calcio. 62

Figura 9. Anillos de manzana horneadas pretratadas a 2, 5, 10, 15 y $30 \mathrm{~min}$ con a. Carbonato de calcio, b. Lactato-gluconato de calcio 63

Figura 10. Curvas obtenidas del ensayo de fuerza-desplazamiento para los anillos de manzana tratados con calcio durante 2 min, comparadas con muestras horneadas sin tratamiento.

Figura 11. a. Fuerza máxima $(\mathrm{N})$, b. Pendiente de la curva fuerzadesplazamiento $(\mathrm{N} / \mathrm{mm})$ de anillos de manzana tratadas con sales de calcio (carbonato y lactato- gluconato) a distintos tiempos.

Figura 12. Rodajas de manzana tratadas con carbonato de calcio: a. 2 min $(400 x)$, b. $15 \min (400 x)$, c. $30 \min (400 x)$ y d. Corte transversal (30 min) (200x).

Figura 13. Rodajas de manzana tratadas con lactato gluconato de calcio: a. 2 $\min (400 x)$, b. $10 \min (400 x)$, c. $15 \min (400 x)$ y d. $15 \min (1300 x)$

Figura 14. Mecanismo del proceso de fritura, visto desde la sección de una

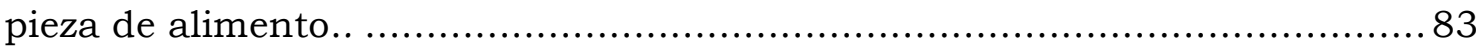

Figura 15. Estructura molecular de la fructosa................................ 90

Figura 16. Estructura química de maltodextrinas ................................ 93 
Figura 17. Curvas de pérdida de peso (g) en función del tiempo (min) para anillos de manzana sometidos a tratamiento con las soluciones de maltodextrina: fructosa y sales de calcio........................................ 96

Figura 18. Colorimetro Minolta CR-400 Series ................................. 103

Figura 19. Soporte tipo "Dual cantilever" utilizado para obtener las propiedades viscoelásticas de los snacks en un DMA Q800...................... 106

Figura 20. Planilla de evaluación sensorial utilizada para evaluar preferencias de snacks. ................................................................................... 108

Figura 21. Extractor de grasa método Soxhlet....................................... 109

Figura 22. Fotografias de los snacks seleccionados por el método de cocción de horneado/fritado. a. $A_{H / F}$, b. $B_{H / F}, c . C_{H / F}$

Figura 23. Curvas de fuerza-desplazamiento de los snacks: a. $A_{H / F}, B_{H / F}$ y b. $\mathrm{C}_{\mathrm{H} / \mathrm{F}} \mathrm{y}$ control. 116

Figura 24. Frecuencia relativa (\%) de las respuestas dadas por los consumidores en el panel de preferencia de snacks. 118

Figura 25. Termograma de barrido de frecuencia obtenido por DMA del snack B $_{\text {H/F. }}$ (Frec. 5, 10, 15 y $20 \mathrm{~Hz}$ )

Figura 26. Variación del peso (g) y la pérdida de agua (\%) de las muestras durante el prehorneado a $100^{\circ} \mathrm{C}$ de los snacks $\mathrm{M}: \mathrm{F}(1: 1)$.

Figura 27. Cromatograma de ácido ascórbico presente en el extracto del snack de manzana $\mathrm{B}_{\mathrm{H} / \mathrm{F}}$. 122

Figura 28. Proceso de obtención de los snacks horneados de manzana verde a partir de impregnación en soluciones de M:F: A (1:1), B (2:1) y C (1:2). 124

Figura 29. Planilla de evaluación sensorial utilizada para evaluar los snacks obtenidos 126

Figura 30. a. Snacks $A_{C}, B_{C}, y C_{C}$ y b. Snacks $A_{L}, B_{L}, C_{L}$ obtenidos por horneado.

Figura 31. Curvas de fuerza-desplazamiento de los snacks $A_{C}, A_{L}$ y el control 136

Figura 32. Curvas de fuerza-desplazamiento de los snacks $B_{C}, B_{L}, C_{C}$ y $C_{L} .137$ Figura 33. Micrografias obtenidas por SEM a. Control sin pretratamientos, b. c y d. Snacks de manzana tratadas con calcio y maltodextrina/fructosa 1:1, $1: 2,2: 1$ respectivamente. 138

Figura 34. Termogramas obtenidos por DSC para a. Manzanas frescas y anillos de manzana horneados sin pretratamientos (control) y b. Snacks obtenidos. 140 
Figura 35. Módulo de pérdida (MPa) obtenido por DMA a $10 \mathrm{~Hz}$. para los snacks $\mathrm{A}_{\mathrm{L}}, \mathrm{B}_{\mathrm{L}}$ y $\mathrm{C}_{\mathrm{L}}$ 142

Figura 36. Diagrama radial de los resultados obtenidos para cada atributo en la evaluación sensorial de los snacks y el control. 145

Figura 37. Análisis de componentes principales (PCA) de: a. Parámetros sensoriales y b. Parámetros instrumentales utilizados para diferenciar los diferentes snacks obtenidos. 148

Figura 38. Contenido de fructosa, glucosa y sacarosa de los snacks $A_{L} y A_{C}$, obtenidos por HPLC. 150

Figura 39. Curva de calibración de ácido ascórbico $(2-200 \mu \mathrm{g} / \mathrm{ml})$, obtenida por HPLC. Los símbolos corresponden a los datos experimentales y la línea a la regresión lineal $\left(R^{2}=0,999\right)$.

Figura 40. Contenido de ácido ascórbico inicial de la manzana fresca y de los snacks antes y después del horneado.

Figura 41. Curva de \%Inhibición de DPPH para los extractos de snacks $A_{C} y$ $\mathrm{A}_{\mathrm{L}}$. 157

Figura 42. Conversión de sacarosa en Isomalt. 181

Figura 43. Snacks horneados a $140^{\circ} \mathrm{C}$ : a. Control; b. Iso A; c. Iso B, d. Iso C 187

Figura 44. Curvas de fuerza-desplazamiento de: snack Iso $\mathrm{C}$ y el control horneado a $140^{\circ} \mathrm{C}$. 190

Figura 45. Micrografias obtenidas por SEM para el snack Iso: a. 200x, b.500x, c. Espesor a 200x. 191

Figura 46. Microanálisis por dispersión de energía de rayos $X$ (EDX), de la micrografia del snack Iso $\mathrm{C}$ a 4000x. 192

Figura 47. Termogramas obtenidos por DSC para: a. Snacks Iso A, Iso B e Iso $\mathrm{C}(\mathrm{M}: \mathrm{I}=1: 1,1: 2,2: 1$ respectivamente), b. Isomalt en estado anhidro.... 193

Figura 48. Módulo de pérdida ( $\left.\mathrm{E}^{\prime}\right)(\mathrm{MPa})$ obtenido por DMA a $10 \mathrm{~Hz}$ para los snacks Iso $\mathrm{A}$, Iso $\mathrm{B}$ e Iso $\mathrm{C}$. 194

Figura 49. Diagrama radial de los resultados obtenidos para cada atributo en la evaluación sensorial de los snacks Iso A, Iso B e Iso C y los controles horneados a $100^{\circ} \mathrm{C}$ y $140^{\circ} \mathrm{C}$. 196

Figura 50. Análisis de componentes principales (PCA) de: a. Parámetros sensoriales y b. Parámetros instrumentales utilizados para diferenciar snacks tratados con M:I y controles horneados a 100 y a $140^{\circ} \mathrm{C}$. 198 
Figura 51. Curva de \% Inhibición de DPPH para el extracto de snacks Iso C.

Figura 52. Fotografia del "dual cantilever" utilizado en el ensayo esfuerzodeformación en el equipo DMA Q800.

Figura 53. Promedio de los valores obtenidos del ensayo de esfuerzodeformación isotérmico para los snacks $\mathrm{A}_{\mathrm{L}}$ e Iso C: a. Fuerza estática, b. \% de deformación de la muestra antes de la ruptura.

Figura 54. Ganancia de peso de los snacks $A_{L}$ e Iso $C$ almacenadas durante 30

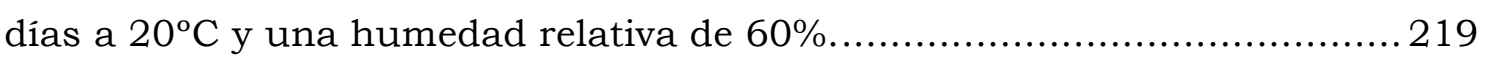

Figura 55. Isoterma de sorción de los snacks $A_{L}$ e Iso C.. ...................... 222

Figura 56. Isoterma de sorción higrométrica de los snacks $A_{L}$ e Iso C........ 224

Figura 57. Curvas de fuerza-desplazamiento de snacks recién preparados y acondicionados a distintas \%HR de: a. Snack $\mathrm{A}_{\mathrm{L}}$; b. Snack Iso C. 226

Figura 58. Termogramas de DSC del snack Iso $\mathrm{C}$ acondicionado a distintas HR: a. Temperaturas de transición vítrea obtenidas del $2^{\circ}$ scan; b. Entalpía de fusión obtenidas en el primer scan. 229

Figura 59. Relación de isoterma de sorción - $T_{g}$ para: a. snack $A_{L}$; b.snack Iso C.

Figura 60. Relación de las propiedades térmicas $\left(\mathrm{T}_{\mathrm{g}}\right)$ (triángulos), propiedades mecánicas (desplazamiento) (círculos) y contenido de agua de los snacks: a. $\mathrm{A}_{\mathrm{L}}$; b. Iso C. 233

Figura 61. Valores de pendiente de la recta obtenidos para el snack Iso C a distintos contenidos de humedad. 234

Figura 62. Snacks envasados en envases flexibles de BOPP a $20^{\circ} \mathrm{C}$ y $60 \% \mathrm{HR}$. 237

Figura 63. Evolución de la humedad para el snack $A_{L}$ e Iso $C$, almacenado durante 150 dias a $20^{\circ} \mathrm{C}$ y $60 \% \mathrm{HR}$. 238

Figura 64. Curvas de textura durante el almacenamiento de $A_{L}$ a 30 y 60 días almacenado. 240

Figura 65. Curvas de textura durante el almacenamiento de Iso C a 30 y 150 días almacenado. 240

Figura 66. Contenido de ácido ascórbico de los snacks $\mathrm{A}_{\mathrm{L}}$ e Iso $\mathrm{C}$ almacenados a $30,60,90,120$ y 150 días. 241

Figura 67. Viabilidad de las bacterias lácticas durante el secado de la cobertura sobre el snack de manzana. 264 
Figura 68. Snacks recubiertos con películas de MC y L. plantarum CIDCA 83114

Figura 69. Perfil de textura de los snacks con y sin cobertura almacenados: a. 0, 30, 60 dias y control recién preparado; b. 0, 30, 90 dias y control recién preparado y almacenado durante 150 días.

Figura 70. Termogramas de DSC obtenidos de los snacks con recubrimiento de MC con L. Plantarum almacenados durante 0, 15 y 60 días. 272

Figura 71. Imágenes obtenidas por SEM de snacks con recubrimiento de MC con L. Plantarum CIDCA 83114 a diferentes resoluciones (a, b y c) y snacks sin cobertura (d). 273

Figura 72. Sección central de la micrografia del snack recubierto (2000 x). 274 Figura 73.Viabilidad celular de las bacterias lácticas en snacks recubiertos: a. Almacenados a 0, 30, 60 y 90 dias; b. Almacenados expuestos a condiciones gástricas e intestinales simuladas in vitro. 275

Figura 74. Frecuencia relativa de las respuestas de los consumidores ante los snacks con y sin cobertura de MC y L. Plantarum. 278

Figura 75. Estructura química de la metilcelulosa 303

Figura 76. Celda de permeabilidad conteniendo gel de sílice como desecador con la película ensamblada. 310

Figura 77. Clamp de tensión utilizado para los ensayos mecánicos en el equipo DMA Q800.

Figura 78. Películas obtenidas a partir de las soluciones de metilcelulosa 1,5 $\%$ sin agregado de plastificante (MC) y películas de metilcelulosa con sorbitol $0,25,0,5 \%$.

Figura 79. Evolución de la permeabilidad al vapor de agua en las películas de metilcelulosa con diferentes concentraciones de sorbitol, recién preparadas y almacenadas. 318

Figura 80. Propiedades mecánicas de películas de metilcelulosa con y sin sorbitol evaluadas a $25{ }^{\circ} \mathrm{C}$ por DMA..

Figura 81. Módulo de elasticidad Ec como una función de la concentración de sorbitol..

Figura 82. Dependencia del módulo elástico (Ec) de las películas de metilcelulosa (con y sin agregado de sorbitol) con la temperatura.

Figura 83. Efecto de la concentración de sorbitol en los espectros mecánico - dinámico de las películas de metilcelulosa (Frec $=5 \mathrm{~Hz}$.) 324 
Figura 84. Espectros de FTIR de a. MC polvo y películas de MC y MC - 0,5 S; b. Películas de MC con y sin agregado de plastificante.

Figura 85. Espectros FTIR de películas de metilcelulosa con diferentes concentraciones de sorbitol en la región de 1700-1580 $\mathrm{cm}^{-1}$ 328

Figura 86. Micrografias obtenidas por SEM de las películas: a. MC; b. MC$0,25 \mathrm{~S}$ 329

Figura 87. Películas de $\mathrm{MC}-0,25 \mathrm{~S}$ con agregado de ácido cítrico 5\% (p/p MC).

Figura 88. Espectros de FTIR de ácido cítrico anhidro en polvo 331

Figura 89. Espectros de FTIR de a. Películas de MC con y sin agregado de plastificante y AC 5 y $10 \%$ AC; b. Ampliación de la zona de absorción entre $1800-1500 \mathrm{~cm}^{-1}$

Figura 90. Capacidad de hinchamiento de las películas de MC con sorbitol con agregado de $5 \%$ AC. 335 


\section{LISTA DE TABLAS}

Tabla 1. Contenido de humedad, cenizas, $\mathrm{pH}, \mathrm{a}_{\mathrm{w}} \mathrm{y}$ fuerza máxima de las manzanas var. Granny Smith 37

Tabla 2. Características de sales de calcio usadas en la industria 51

Tabla 3. Resultados obtenidos de humedad y $\mathrm{a}_{\mathrm{w}}$ para anillos de manzana con calcio y sin calcio horneados a distintos tiempos.

Tabla 4. Contenido de calcio en las muestras tratadas con carbonato/lactatogluconato de calcio a distintos tiempos de inmersión....

Tabla 5. Contenidos de humedad inicial y cambios en el contenido de grasa en alimentos de origen vegetal y animal.

Tabla 6. Valores obtenidos para $\mathrm{ML} \infty, \mathrm{A}\left(\mathrm{min}^{-1}\right)$ y tiempo de impregnación con azúcares (min) a partir de Ec. (4), correspondiente al modelo de Azuara y col., 2002

Tabla 7. Evaluación de temperaturas-tiempo de fritado, aplicados sobre anillos de manzana 100

Tabla 8. Propiedades fisicas de snacks obtenidos por horneado/fritado y del control obtenido por fritado.....

Tabla 9. Parámetros de color del control y de los snacks obtenidos por horneado/fritado y fritado formulados con $\mathrm{M}: \mathrm{F}(1: 1,2: 1,1: 2)$.

Tabla 10. Valores de $\mathrm{T}_{\mathrm{g}}\left({ }^{\circ} \mathrm{C}\right)$ obtenidos por DSC para los snacks de manzana 119

Tabla 11. Parámetros de color del control y de los snacks obtenidos por horneado a $100{ }^{\circ} \mathrm{C}$

Tabla 12. Propiedades físicas de los snacks y el control 134

Tabla 13. Resultados obtenidos del análisis sensorial para el control y los snacks A, B y C tratados con lactato gluconato y carbonato de calcio, formulados por inmersión en soluciones de maltodextrina/fructosa 1:1, 2:1 y $1: 2$, respectivamente

Tabla 14. Carbohidratos totales y calorias por porción de 100 g productos formulados con manzana 151

Tabla 15. Capacidad antioxidante expresada como equivalente de Trolox (TEAC) de snacks $\mathrm{A}_{\mathrm{L}} \mathrm{y} \mathrm{A}_{\mathrm{C}}$ en relación a la manzana fresca. 155

Tabla 16. Valores obtenidos para $M L \infty$, A $\left(\mathrm{min}^{-1}\right)$ y tiempo de impregnación con azúcares (min) a partir de Ec. (4), correspondiente al modelo de Azuara y col., 2002 . 186 
Tabla 17. Humedad y fuerza en la ruptura de los snacks obtenidos por horneado a $140^{\circ} \mathrm{C}$

Tabla 18. Parámetros de color del control y de los snacks obtenidos por horneado a $140^{\circ} \mathrm{C}$ 188

Tabla 19. Porcentaje de ácido ascórbico retenido antes y después del horneado a $140^{\circ} \mathrm{C}$ en los anillos de manzana tratados con M:I y el control.. 195 Tabla 20. Resultados obtenidos del análisis sensorial para el control y los snacks Iso A, Iso B e Iso C....

Tabla 21. Carbohidratos totales y contenido calórico por porción de $100 \mathrm{~g}$ de productos frescos y formulados a base de manzana 201

Tabla 22. Higroscopicidad de los snacks $A_{L}$ e Iso C a $60 \%$ HR y $20^{\circ} \mathrm{C}$ obtenida a partir de la Ec. (16) 219

Tabla 23. Temperatura de transición vítrea de los snacks $A_{L}$ e Iso $C$ acondicionados a diferentes humedades relativas 228

Tabla 24. Evolución de la actividad acuosa para el snack $A_{L}$ e Iso $C$, almacenado a $20^{\circ} \mathrm{C}$ y $60 \% \mathrm{HR}$ 239

Tabla 25. Contenido de humedad, color y BI (indice de pardeamiento) del control (sin cobertura) y los snacks recubiertos con películas de MC con $L$. plantarum almacenados durante 90 dias a $20^{\circ} \mathrm{C}$ y $60 \% \mathrm{HR}$. 266

Tabla 26. Parámetros de textura de los snacks recubiertos con película de MC con L. plantarum y el control Iso C almacenados durante 90 dias a $20{ }^{\circ} \mathrm{C}$ y $60 \%$ HR 268

Tabla 27. Valores de humedad y solubilidad de películas de metilcelulosa con diferentes concentraciones de sorbitol 316

Tabla 28. Efecto del agregado de sorbitol sobre la permeabilidad al vapor de agua en las películas de MC 317

Tabla 29. Valores de $\mathrm{T}_{\mathrm{g}}$ para las películas de $\mathrm{MC} 1,5 \%$ con agregado de plastificante (0-1\%), obtenidos por DSC 324

Tabla 30. Propiedades de barrera y \% de material soluble $\left(100^{\circ} \mathrm{C}\right)$ de las películas de $\mathrm{MC}-0,25 \mathrm{~S}$ con diferentes concentraciones de ácido cítrico 334 
I.

INTRODUCCION

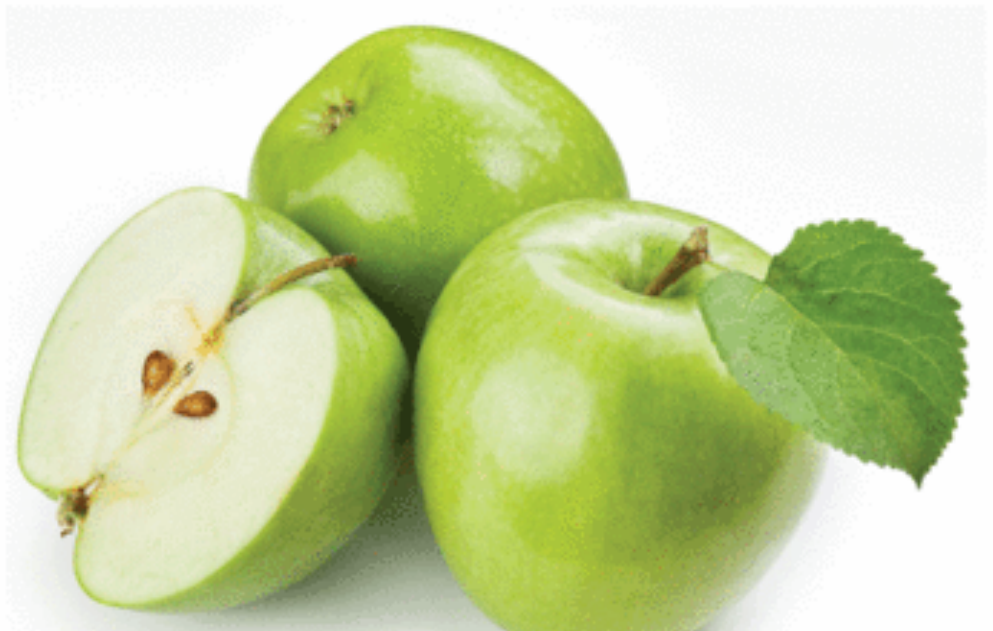



Existe una tendencia mundial hacia un mayor consumo de frutas y hortalizas, motivado fundamentalmente por una creciente preocupación por una dieta más equilibrada, con menor proporción de carbohidratos, grasas y aceites y con una mayor participación de la fibra dietaria, vitaminas y minerales. Esto se fundamenta, en parte, en las menores necesidades calóricas de la vida moderna, caracterizada por un mayor confort y sedentarismo. Otro factor que determina esta tendencia es la mayor conciencia de la importancia de la dieta en la salud y longevidad y la simplificación en la tarea de preparar la comida diaria. Hasta la década del 60 aproximadamente, en los Estados Unidos, la preparación del almuerzo o cena requería unas 2 horas y era planificada con anticipación. Actualmente requiere menos de una hora (Morgan, 1983). La creciente oferta de frutas y hortalizas industrializadas y otros alimentos preparados es en parte responsable de este acortamiento del tiempo dedicado a la cocina. Probablemente el hecho más significativo que acelera esta tendencia es la creciente incorporación de la mujer en trabajos de tiempo completo, que le restan tiempo para comprar y preparar alimentos, además de tener mayor poder adquisitivo. Sumado a la simplificación en la preparación de alimentos también ha influido la constitución de hogares unipersonales, aumento en los servicios de comida rápida (fast food) y preparada (catering) y la creciente segmentación del mercado a través del incremento en las formas, colores, sabores, formas de preparación y/o envases, en la que un producto es presentado.

Relacionado a los factores mencionados anteriormente se encuentra el creciente aumento de la obesidad y el sobrepeso. Según la Organización Mundial de la Salud (OMS) el sobrepeso y la obesidad se definen como una acumulación anormal o excesiva de grasa que puede ser perjudicial para la salud y constituye el mayor problema de salud pública en el ámbito mundial por su creciente prevalencia y por sus consecuencias sobre la expectativa y la calidad de vida futura. Según las estimaciones recientes de la OMS en 2014, más de 1900 millones de 
adultos de 18 o más años tenían sobrepeso, de los cuales, más de 600 millones eran obesos. Lo cual significa que en general, alrededor del $13 \%$ de la población mundial adulta (un $11 \%$ de los hombres y un $15 \%$ de las mujeres) eran obesos. La prevalencia mundial de la obesidad se ha multiplicado por más de dos entre 1980 y 2014. En 2013, más de 42 millones de niños menores de cinco años de edad tenían sobrepeso. $\mathrm{Si}$ bien el sobrepeso y la obesidad tiempo atrás eran considerados un problema propio de los países de ingresos altos, actualmente ambos trastornos están aumentando en los países de ingresos bajos y medianos, en particular en los entornos urbanos (OMS, 2014). En los países en desarrollo con economías emergentes (clasificados por el Banco Mundial en países de ingresos bajos y medianos) el incremento porcentual del sobrepeso y la obesidad en los niños ha sido un $30 \%$ superior al de los países desarrollados. La obesidad infantil seguirá muy probablemente en la edad adulta, por lo que es de vital importancia examinar los factores determinantes en los primeros años de vida ya que los individuos con sobrepeso y obesidad poseen mayor riesgo de desarrollar enfermedades crónicas. La causa fundamental del sobrepeso y la obesidad es un desequilibrio energético entre calorias consumidas y gastadas. En el mundo, se ha producido un aumento en la ingesta de alimentos hipercalóricos que son ricos en grasa, sal y azúcares pero pobres en vitaminas, minerales y otros micronutrientes. También se ha generado un descenso en la actividad física como resultado de la naturaleza cada vez más sedentaria de muchas formas de trabajo, de los nuevos modos de desplazamiento y de una creciente urbanización. A menudo los cambios en los hábitos de alimentación y actividad física son consecuencia de cambios ambientales y sociales asociados al desarrollo y de la falta de políticas de apoyo en sectores como la salud, agricultura, transporte, planeamiento urbano, medio ambiente, procesamiento, distribución y comercialización de alimentos, y educación. Los hábitos de alimentación durante la infancia permiten establecer comportamientos saludables y así evitar el sobrepeso y la obesidad. Los resultados de los múltiples estudios que relacionan la 
dieta y las enfermedades crónicas han puesto de manifiesto la necesidad de definir, con la mayor precisión posible, lo que es una dieta sana en términos de alimentos y nutrientes. Las principales caracteristicas de lo que actualmente se considera una alimentación saludable están bien establecidas. La constante investigación en este tema ha demostrado que las dietas que mejor se adaptan a estos objetivos son aquellas que se basan principalmente en el consumo de frutas, verduras, hortalizas, cereales y leguminosas, utilizando con moderación los alimentos de origen animal (Ferro y James, 1997; OMS, 2014). Se han estudiado desde hace varios años los beneficios de los productos vegetales en la reducción del riesgo de diferentes enfermedades como el cáncer, enfermedades cardiovasculares, cataratas y otras (National Research Council, 1989), además de contribuir a la reducción del peso.

\section{Nuevas tendencias de consumo de snacks}

Como ya se ha mencionado, cada vez más los consumidores muestran una mayor conciencia por su salud a la hora de seleccionar sus alimentos, aumentando el interés por consumir alimentos saludables, con altos niveles de vitaminas, minerales y fibras. Esta tendencia se ha visto reforzada por las recomendaciones realizadas por diferentes organismos de gran impacto social, como la Organización Mundial de la Salud (OMS) o el Instituto Nacional del Cáncer de Estados Unidos. El consumo de frutas y hortalizas es considerado como un indicador de hábitos dietarios que conducen a una buena salud. Los fitoquímicos presentes en los mismos juegan un importante rol en este proceso. Las frutas constituyen un grupo de alimentos indispensable para la salud y bienestar, especialmente por su aporte de fibra, vitaminas, minerales y sustancias de acción antioxidante (vitamina C, vitamina $\mathrm{E}$, betacaroteno, licopeno, luteína, flavonoides como las antocianinas, etc.). La gran diversidad de especies, con sus distintas propiedades sensoriales (sabor, aroma, color, textura, etc.) y la distinta 
forma de prepararlas, hacen de ellas productos de gran aceptación por parte de los consumidores.

Se entiende por snack aquel producto de fácil consumo, accesible, de tamaño pequeño, sólido o líquido, que requiere poca o ninguna preparación antes de su consumo y cuya finalidad es satisfacer la sensación de hambre que se produce entre comidas. Los alimentos tipo snack deben ser seguros y libre de productos químicos peligrosos y otras sustancias tóxicas, microorganismos patógenos, no perecedero, que no requieran refrigeración para su conservación, envasados y listos para consumir, por lo general en trozos pequeños, y de textura crocante (Lusas y Rooney, 2002).

Según un estudio realizado por Nielsen ${ }^{1}$ en el año 2014 los consumidores globales gastaron $\$ 347$ mil millones de dólares en snacks entre 2013 y 2014, con un incremento de 2\% anual. Mientras Europa (USD \$167 mil millones) y Norteamérica (USD \$124 mil millones) suman la mayor cantidad de ventas de snacks en todo el mundo, las ventas anuales están creciendo más rápido en las grandes regiones en desarrollo. Asia Pacífico (USD \$46 mil millones) y Latinoamérica (USD \$30 mil millones) incrementaron 4\% y $9 \%$ respectivamente, mientras las ventas en Medio Oriente/África ( $\$ 7$ mil millones) aumentaron 5\%. Recientemente se ha observado una marcada tendencia al aumento del consumo de snacks saludables frente a los comunes, siendo los principales atributos buscados por el consumidor: ausencia de grasas trans, bajo contenido de calorías, azúcar y sodio, y aporte de vitaminas y minerales. Los snacks a base de ingredientes naturales son calificados por el $45 \%$ de los consumidores como muy importantes. Los atributos incluidos en el estudio que tuvieron en cuenta los consumidores al

\footnotetext{
${ }^{1}$ Encuesta global de la consultora Nielsen sobre Snacking -Septiembre de 2014

${ }^{2}$ Este capítulo del trabajo se realizó en conjunto con el Lic. Nelson Romano, el Dr. Pablo Mobili y la Dra. Andrea Gómez-Zavaglia, integrantes del Laboratorio de Microbiología del Centro de Investigación y Desarrollo en Criotecnología de
} 
momento de responder fueron la ausencia de colorantes artificiales (44\%), que no sean productos genéticamente modificados $(43 \%)$ y sin sabores artificiales (42\%). Otro de los atributos valorados por los consumidores de snacks es que preferiblemente su fuente de obtención no sean carbohidratos.

Los snacks de frutas se perciben como alimentos sanos, al igual que las frutas naturales, pero con la ventaja de incluir otros aspectos valorados por los consumidores como el sabor, la textura, el color y la facilidad para almacenarlos. Teniendo en cuenta lo anteriormente expuesto la elaboración de alimentos tipo snack de bajo contenido graso a partir de frutas como la manzana puede ser una alternativa más saludable respecto a los snacks tradicionales.

\section{Producción y consumo de manzanas a nivel global y local}

Según datos del Programa Nacional de Frutales del INTA, la producción mundial de manzanas es de 60 millones de toneladas y en los últimos años ha registrado un crecimiento de 9\% (USDA, 2011). La mitad de la producción mundial corresponde a China, seguido de la Unión Europea (11 millones de toneladas), Estados Unidos (4,2 millones de toneladas), Turquía (2,5 millones de toneladas) e India (1,9 millones de toneladas). Argentina ocupa el noveno lugar como productor.

En Argentina se producen 1,8 millones de toneladas de frutas pomáceas, de las cuales la mitad es manzana y sólo se exporta un 25\%. El $85 \%$ de la producción de manzana se concentran en el Alto Valle de Río Negro y Neuquén y en el Valle Medio de Río Negro. El resto se genera en el Valle de Uco (Mendoza), 25 de Mayo (La Pampa) y el Valle del Tulum (San Juan) entre otros. Se estima que la superficie cultivada con manzana supera las 27000 ha (Informe sectorial Ministerio de Agricultura, 2010). El principal destino de esta producción es el mercado fresco y un porcentaje se envía a industria para la producción de jugos, sidra, pulpa y mermeladas. En Argentina se consumen en 
promedio $8 \mathrm{~kg}$ de manzana fresca por habitante y por año, valores bajos comparados con China y la Unión europea. En el país son escasas las campañas nacionales de promoción del consumo. El $80 \%$ de la manzana consumida en el mercado interno corresponde a Red Delicious, el $12 \%$ a Granny Smith y el $5 \%$ a Gala. El excedente se exporta a Brasil con el 27\%, Rusia 18\%, Argelia 13\%, Holanda 10\% y otros países $32 \%$. Dentro de estos los principales son EE.UU, Bélgica, Polonia y Suecia (Funbapa, Anuario Estadístico 2010). Sin embargo, en los ultimos años las exigencias del mercado externo en cuanto a controles fitosanitarios y el reemplazo por cultivos de mayor rentabilidad han desplazado este cultivo. Como una estrategia para promover el cultivo de manzana, el Programa Nacional de Frutales (INTA) propone generar valor agregado $\mathrm{y}$ con ello aumentar la producción. Uno de los productos obtenidos por la industrialización de la manzana, es el producto deshidratado. Se comercializa bajo distintas formas (cubitos, rodajas, cubos con cáscara, trozos, gajos, cubos sin aditivos y polvos). Los principales compradores son empresas que la utilizan como insumo, especialmente en repostería, cereales para el desayuno, productos snack, servicios de comida. Existen sólo 2 empresas en el país que elaboran alrededor de 1200 toneladas de manzana deshidratada anuales, a partir de las variedades Granny Smith y Red Delicious. EE.UU. compra el $80 \%$ de la manzana deshidratada argentina (Bruzone, 2011).

La tendencia actual de consumo de alimentos con calidad funcional (biocomponentes) y la necesidad de desarrollar productos atractivos para personas con regimenes especiales, justifica el estudio de las características físicas y funcionales de productos sometidos a tecnologías térmicas para obtener nuevos alimentos. El desarrollo de un producto atractivo para segmentos de mercado variados que incluyen personas que deseen cambiar ocasionalmente sus hábitos de consumo, mediante el uso de variedades producidas a nivel nacional, permite revalorizar el uso de la manzana producida en Argentina y brinda a los 
productores una alternativa innovadora de valor agregado que favorece a la comercialización de la manzana nacional.

Por medio de procesos como la deshidratación osmótica, se pueden obtener snacks de frutas, que son alimentos estables, con baja actividad de agua y de sabor y textura agradables. Estos han llegado a ser parte importante de la dieta de consumidores. Sin embargo, presentan altos contenidos de azúcar. Por otra parte haciendo enfásis en la necesidad de limitar el consumo de productos de alto contenido graso los avances en investigación de snacks de frutas obtenidos por fritado apuntan a utilizar aceites no hidrogenados evitando así el consumo de grasas saturadas y grasas trans. Existe un creciente interés en desarrollar snacks de frutas y hortalizas como zanahoria (Liu-Ping y otros, 2006), mango (Da Silva y Moreira, 2008), kiwi (Gómez Pinedo, 2013) y manzana (Shyu y Hwang, 2001). Algunos de estos productos (chips de batata, chips de manzana, chips de papa azul) se fríen al vacío siendo menor el rendimiento de absorción de aceite (menos sabor a grasa) con una mayor retención del color y del sabor natural (Da Silva y Moreira, 2008; Gómez Pinedo, 2013).

La manzana posee características importantes desde el punto de vista dietético y funcional. Es reconocida por ser un alimento estimulante de la función intestinal debido a su elevado contenido de pectina, fibra y ácido málico; además se considera antioxidante debido a que posee gran cantidad de flavonoides. Algunas investigaciones han indicado que las manzanas contienen niveles elevados de compuestos biológicamente activos que pueden ayudar a proporcionar protección contra el cáncer (Seipel y col., 2009, Khanizadeh y col., 2008). El contenido y la composición de los polifenoles presentes en las manzanas son importantes ya que contribuyen a la calidad sensorial de la fruta fresca y de los productos procesados de manzana. Es además fuente discreta de vitamina $\mathrm{E}$ o tocoferol y aporta una escasa cantidad de vitamina C. Un 85\% de la composición de la manzana es agua. Los 
azúcares, la mayor parte fructosa y en menor proporción, glucosa y sacarosa, son los nutrientes más abundantes.

\section{Transformaciones físicas y reacciones involucradas en el desarrollo de alimentos tipo snack}

Durante la elaboración de alimentos tipo snack ocurren transformaciones físicas relacionadas con los componentes de la materia prima, el contenido de agua, las variables temperatura y método de cocción utilizado, ya sea por deshidratación osmótica, fritado, horneado o extrusión. Estos fenómenos producen cambios de estructura, de lo cual resulta un producto final con determinadas características. De manera que la calidad del mismo dependerá de la posibilidad de romper, crear y transformar estructuras, que además definan la textura deseada.

La estructura física de un biomaterial está definida por sus principales componentes: lípidos, carbohidratos, agua, proteínas; así como por el tipo de procesamiento y almacenamiento al cual es sometido. Las transiciones de fase y estado durante estas etapas tienen efectos significativos en las propiedades fisicas del material. En termodinámica, las transiciones de fase y estado se clasifican de acuerdo con los cambios abruptos o discontinuidades que sufren ciertas funciones de estado a la temperatura de transición. En las transiciones de primer orden, las funciones entalpía, entropía y volumen (relacionadas con la primera derivada de la energía libre con respecto a la temperatura) muestran un cambio abrupto a la temperatura de la transición. En las transiciones de segundo orden, las funciones termodinámicas entalpía, entropía y volumen tienen un valor constante al variar la temperatura, pero hay una discontinuidad en la capacidad calorífica, el coeficiente de expansión térmica y el coeficiente de compresibilidad a la temperatura de la transición, y constituyen cambios de estado sin cambios de fase. Las transiciones que ocurren entre los tres estados de agregación (sólido, líquido y gaseoso) son 
cambios de fase de primer orden (Roos, 1995b). Las transiciones de primer orden más comunes en alimentos incluyen la fusión y la cristalización de agua, azúcares o lípidos. La desnaturalización de proteínas y gelatinización, son procesos fuera del equilibrio y por lo tanto no pueden describirse en términos de transiciones termodinámicas, pero guardan semejanza con los cambios de fase correspondientes a la fusión. Muchos alimentos deshidratados contienen componentes en estado amorfo (Roos y Karel, 1991d). El aspecto de este tipo de materiales (vidrios) es el de un sólido rígido quebradizo que puede pasar al estado de liquido sobreenfriado dependiendo de la temperatura y de la presencia de agua. El cambio entre los estados vítreo y líquido sobreenfriado se conoce como transición vitrea $\left(\mathrm{T}_{\mathrm{g}}\right)$ y corresponde a una temperatura a la cual los vidrios empiezan a ablandarse y fluir (Sperling, 2005). La transición vítrea tiene ciertas características de las transiciones de segundo orden. Sin embargo, se trata de un cambio de estado, y no de fase, entre estados de no equilibrio, que ocurre en un rango de temperatura, el cual depende de la velocidad de calentamiento, de la historia térmica del producto, de la masa molar y del contenido de agua (Roos, 1998). Por lo general, un alimento en estado vítreo es considerado estable, lo cual es de gran importancia para las características texturales de los alimentos crocantes como papas fritas, galletitas y snacks extrudados (Limy col., 2001). A temperaturas superiores a la $\mathrm{T}_{\mathrm{g}}$, el material se torna más deformable debido a la flexibilidad parcial de sus moléculas. En este sentido la $T_{g}$ se considera como un punto crítico para los cambios que involucran la estabilidad de sistemas amorfos (Roos y Karel, 1992). Además existen fundamentos que permiten afirmar que la transición vítrea es un fenómeno de características cinéticas y no termodinámicas (Roos, 1998).

La movilidad de un sistema puede ser afectada por la adición de un agente plastificante. En los sistemas biológicos el plastificante más importante es el agua. El agua en los alimentos produce un aumento 
del volumen libre y por lo tanto tiene el efecto de reducir la $\mathrm{T}_{\mathrm{g}}$ del sistema. La adición de carbohidratos de alto peso molecular, se puede usar para alterar la $\mathrm{T}_{\mathrm{g}} \mathrm{y}$ retrasar los cambios físicos, ya sea durante el procesamiento o almacenamiento. Una interesante aplicación del estudio de la transición vitrea es el entendimiento de las propiedades de textura (Nelson y Labuza, 1992). Algunos materiales de bajo contenido de agua son frágiles mientras permanecen en el estado vítreo (Slade y Levine, 1995). A medida que los componentes absorben agua no todas sus propiedades se afectan de la misma manera, en el rango bajo a intermedio de humedades algunas propiedades mecánicas muestran un máximo en función del contenido de agua, mientras que la $\mathrm{T}_{\mathrm{g}}$ disminuye continuamente (Chang y col., 2000).

En el estudio de sistemas alimenticios y en especial los snacks, la mayoría de los estudios evidencian que existen efectos combinados de la transición vitrea, el contenido de agua, actividad de agua, temperatura y la concentración de reactivos, sobre la estructura del producto final y la velocidad de reacciones químicas (Buera y Karel, 1995; Farroni, 2011).

Para el desarrollo de snacks es importante tener en cuenta la actividad de agua. Este término representa la fuerza impulsora para la migración de agua desde el ambiente hacia el alimento y viceversa, y entre los componentes de una mezcla. Por lo tanto, en el almacenamiento de productos deshidratados es especialmente importante conocer las características de sorción del material. En el equilibrio, la actividad de agua está relacionada con el contenido acuoso a una temperatura constante a través de la isoterma de sorción de agua. A partir de esta curva se pueden definir la ocurrencia y cinética de fenómenos tales como el crecimiento de microorganismos $y$ diferentes reacciones químicas indeseables como la pérdida de textura y la oxidación lipídica. 
Para el análisis del cambio de las propiedades térmicas, las técnica más utilizada es la calorimetría diferencial de barrido (DSC). Por calorimetría diferencia de barrido se puede detectar la transición vitrea en base al cambio en el calor específico. En esta técnica, la muestra se calienta a una velocidad constante en una cápsula sellada, y se mide la diferencia de calor absorbido o entregado por la muestra respecto de una cápsula vacía que se utiliza como referencia. En la Figura 1 se muestra un esquema de un termograma obtenido por DSC, dónde se manifiesta la transición vítrea, y los eventos de relajación, los cuales se presentan como eventos endotérmicos (cristalización) o exotérmicos (fusión de cristales).

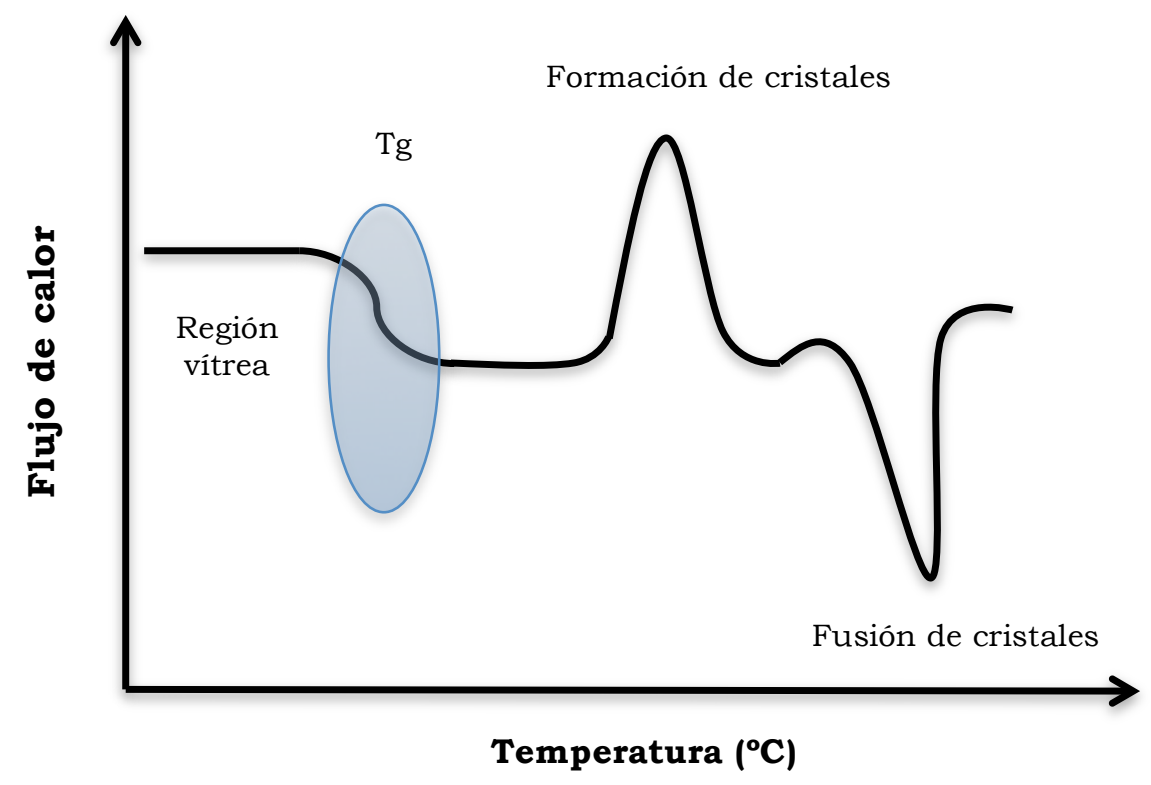

Figura 1. Termograma típico de un polímero amorfo (Adaptado de Roos, 1992)

Existen otras técnicas para determinar $\mathrm{T}_{\mathrm{g}}$, como análisis dinámicos termomecánicos (DMTA), análisis termodieléctricos (DETA) y técnicas espectroscópicas como la resonancia magnética nuclear (RMN). 


\section{Reacciones químicas durante la elaboración de snacks}

Los cambios dependientes de los tratamientos tiempo/temperatura a que son sometidos los alimentos tanto durante su producción como en el almacenamiento tienen importancia nutricional y son críticos para definir la aceptabilidad sensorial por parte de los consumidores (Farroni, 2011). La reacción de Maillard, la caramelización y la oxidación del ácido ascórbico son algunos de los cambios químicos que llevan a la formación de una variedad de compuestos que incluyen sabores, aromas y colores que son de importancia fundamental en la calidad de los alimentos, en especial, los snacks. Estas reacciones permiten que los consumidores perciban el sabor y el color dorado típico de los productos de este tipo. En cierta forma estas reacciones pueden traer ventajas y/o desventajas a nivel nutricional. Por ejemplo algunos productos que se forman de la reacción de Maillard han sido asociados a efectos nocivos para la salud (furfural) y otros pueden tener efectos benéficos como por ejemplo capacidad antioxidante (Yilmaz y Toledo, 2005).

Cuando se calientan azúcares puros en forma anhidra o en solución, estos se descomponen formando un pigmento pardo de naturaleza polimérica, conocido como caramelo (Fennema, 1996). Los azúcares reductores, los lípidos insaturados, el ácido ascórbico y los compuestos fenólicos pueden considerarse como los reactivos primarios. La oxidación del ácido ascórbico para formar furfural y sus productos de polimerización es catalizada por bajo $\mathrm{pH}$ y altas temperaturas, se acelera por la presencia de oxígeno y el pardeamiento es acompañado por la pérdida de valor nutritivo al destruirse la vitamina C (Fennema, 1996). Generalmente para determinar el grado de pardeamiento se pueden realizar diversos análisis que van desde el seguimiento de productos de la reacción de Maillard en etapas iniciales o intermedias de la reacción hasta la medida del grado de pardeamiento que se basa en la medida objetiva del color. De los sistemas propuestos el más difundido es el de CIE (Commision Internationale de L’Eclairage) 
en el cual el color es indicado por tres variables $\mathrm{X}, \mathrm{Y}, \mathrm{Z}$ conocidas como los valores triestimulo y que representan los colores primarios imaginarios. En los snacks, el color es muy importante para la percepción del consumidor, por lo tanto cuando se aplican tratamientos térmicos es necesario establecer límites o escalas de percepción en las cuales el alimento tenga las características deseadas por el consumidor sin detrimento de su calidad nutricional.

\section{Factores de calidad asociados a las preferencias del consumidor}

Entre los factores de calidad asociados a los alimentos que influyen en la preferencia del consumidor pueden encontrarse la apariencia, la combinación de sabor y aromas, la textura y el valor nutricional. Esto es especialmente importante en alimentos de características crujientes o crocantes como los snacks. La aplicación del término textura viene de Matz (1962), quien la define como "la experiencia compleja que se deriva de las sensaciones de la piel de la boca, después de la ingestión de alimentos, y está relacionada con la densidad, viscosidad, superficie, tensión y otras propiedades físicas del material que constituye la muestra". La textura puede definirse como una variedad de propiedades mecánicas, acústicas y estructurales que percibe el ser humano, como una característica física distintiva de los alimentos (Fiszman, 2013). Esta propiedad depende por completo de la composición y disposición de los elementos que constituyen al alimento. La textura se puede evaluar a partir de métodos químicos (contenido de almidón, relación grados Brix/acidez en frutas para determinar el grado de maduración), visuales y estructurales (forma, tamaño y distribución de partículas por microscopia), instrumentales (acústicos y mecánicos).

En el caso de los alimentos tipo snack, la textura está asociada al ruido, a la fractura (frágil, quebradizo) a las características físicas (seco, no compacto, no gomoso) y a la frescura (cocinado en su punto) (Fiszman, 2013). Para medir el carácter crujiente se pueden realizar pruebas sensoriales o instrumentales. El test de ruptura ha resultado 
ser una prueba altamente eficaz en la determinación de la crocancia (Salvador y col., 2009; Tavera Quiroz y col., 2012). Un alimento crocante se caracteriza por el comportamiento frágil durante la fractura, la cual se produce a bajas fuerzas de ruptura y con múltiples eventos de fractura distinguibles (Duizer, 2001; Luyten y col., 2004).

Por último las propiedades sensoriales cumplen un rol determinante en el desarrollo de un producto. El consumidor es el principal encargado de establecer la calidad final a través de la aceptabilidad que este tenga sobre el mismo. Las pruebas de evaluación sensorial permiten en el desarrollo de nuevos productos establecer las características "ideales", en este caso de un snack a base de fruta para que pueda ser consumido con alto grado de satisfacción. Por ejemplo, el color y la apariencia son el primer contacto que tiene el consumidor con un alimento, condicionado por sus preferencias e influyendo en su elección de aceptar o rechazar el alimento. Existen distintos niveles de entrenamiento de los sujetos que llevan a cabo las mediciones sensoriales. La utilidad de las pruebas sensoriales depende del resultado que se busque o el tipo de prueba que se necesita realizar (ASTM 1968). En el desarrollo de nuevos productos son ideales los paneles de consumidores. Estos se eligen entre la población teniendo en cuenta que sean consumidores del producto que se va a evaluar. Son ideales para estimar la aceptabilidad de un producto y la intensidad de los atributos en escalas simples siguiendo determinadas consignas en la elaboración del formulario (Fiszman, 2013). El diseño de la prueba debe ser lo suficientemente claro y ajustado para disminuir el número de repeticiones. La interpretación de los resultados debe realizarse mediante pruebas estadísticas que permitan obtener el grado de aceptación de los consumidores ante lo que están evaluando (Fiszman, 2013).

Para el desarrollo adecuado de productos innovadores es necesario tener en cuenta las características de los materiales a 
emplear y factores como la materia prima, los ingredientes de la formulación del producto y las transformaciones dinámicas a las que los mismos son sometidos durante el proceso de elaboración y/o almacenamiento. Por otra parte, la caracterización de los cambios físicos y químicos que ocurren en las distintas etapas de los procesos de elaboración y/o durante el almacenamiento permiten controlar adecuadamente los sistemas con el fin de optimizar el desarrollo del mismo. Esto podría causar impacto en la industria de productos tipo snacks y se orienta a aumentar el valor agregado de materias primas de origen nacional con impacto sobre la salud de los consumidores, gracias a la incorporación de materias primas y formulaciones destinadas a proveer efectos benéficos en la salud de quienes consuman estos productos.

\section{REFERENCIAS}

ASTM (1968). Basic Principles of Sensory Evaluation. Standard Technical Publication 433, American Society for Testing and Materials: 110.

Buera, M. D. P., Karel M. (1995). Effect of physical changes on the rates of nonenzymic browning and related reactions. Food Chemistry, 52(2): 167-173.

Bruzone, I. (2011). Cadenas de valor: manzana y pera. Alimentos argentinos. Secretaria de Agricultura, Ganadería y Pesca, 20-24.

Chang, Y.P., Cheah, P.B., Seow, C.C. (2000). Plasticizingantiplasticizing effects of water on physical properties of tapioca starch films in the glassy state. Journal of Food Science, 65(3): 445-451.

Da Silva, P., Moreira, R. (2008). Vacuum frying of high-quality fruit and vegetable based snacks. LWT - Food Science and Technology, 41(10): 1758-1767.

Duizer, L. (2001). A review of acoustic research for studying the 
sensory perceptionof crisp, crunchy and crackly textures. Trends in Food Science and Technology, 12: 17-24.

Farroni, A. (2011). Transformaciones estructurales y fisicoquímicas de maíces argentinos en la producción de alimentos obtenidos por procesos de gelatinización-laminación. Tesis doctoral. Universidad de Buenos Aires. Área Química Industrial. Facultad de Ciencias Exactas. Departamento de Industrias.

Ferro-Luzzi, A., James, PH. Diet and health: brief summary of our present knowledge and description of the present European situation in terms of diet, health and their relationship. In: A Trichopoulou (Ed). Nutrition in Europe. Final report. STOA. European Parliament, Directorate for General Research, Luxemburgo, 1997. p.2-38.

Fiszman, S. (2013). Curso: Evaluación de Textura en Alimentos. Universidad Nacional de Litoral. Santa Fe. Noviembre de 2013.

Gómez Pinedo, S. (2013). Efecto de las condiciones de fritura a vacío en el procesado de chips de kiwi (Actidinia chinensis). Tesis Master en Ciencia y Tecnología de los Alimentos. Universidad Politecnica de Valencia.

INTA. Programa Nacional de Frutales. (2011). Cadenas frutales de pepitas. Estación experimental Agropecuaria Alto Valle.

Khanizadeh, S., Tsao, R., Rekika, D., Yang, R., Charles, M. T. Vasantha Rupasinghe, H. P. (2008). Polyphenol composition and total antioxidant capacity of selected apple genotypes for processing. Journal of Food Composition and Analysis, 21(5): 396-401.

Lim, S. T., Chang, E. H., Chung, H. J. (2001). Thermal transition characteristics of heat-moisture treated corn and potato starches. Carbohydrate Polymers, 46(2): 107-115.

Lusas, E., Rooney, L. (2002). Snacks Food Processing. CRC Press, Boca Raton, FL. 
Luyten, H., Plijter, J. J., Van Vliet, T. (2004). Crispy/crunchy crusts of cellular solid foods: a literature review with discussion. Journal of Texture Studies, 35: 445-492.

Morgan, K. J. (1983). The role of snacking in the American diet. Cereal Foods World, 28(5): 305-306.

Matz S.A (1962). Food texture. Westport, CT, AVI Publishing Co, Inc.

National Research Council. Diet and health. Implications for reducing chronic disease risk. Report of the Committee on Diet and Health, Food and Nutrition Board, Commission of Life Sciences. National Academy Press. Washington, DC, 1989.

Nelson Katherine A, Labuza T. P. (1992). Relationship between water and lipid oxidation rates. En: Lipid Oxidation in Food, American Chemical Society, 500: 93-103.

Organización Mundial de la Salud (OMS). (2014). Informe sobre la situación mundial de las enfermedades no transmisibles. $p$ 16.WHO/NMH/NVI/15.1.

Roos, Y. H. (1992). Reaction kinetics and thermodynamics in food systems; Part II, Phase transitionsand transformations. Handbook of Food Engineering. D. Lund y D. Heldman. New York, Marcel Dekker.

Roos, Y. H. (1995a). Characterization of food polymers using state diagrams.Journal of Food Engineering, 24(3): 339-360.

Roos, Y. H. (1995b). The physical state of amorphous materials. En: Phase Transitions in Foods. J. S. Taylor. New York, Academic Press: 26-34 y 193.

Roos, Y. H. (1998). Role of water in phase transition phenomena in foods. Phase/State Transitions in Foods. M. Rao y R. W. Hartel, Marcel Dekker. 
Salvador, A., Varela, P., Sanz, S., Fiszman, S. (2009). Understanding potato chips crispy texture by simultaneous fracture and acoustic measurements, and sensory analysis. LWT - Food Science and Technology, 42: 763-767.

Seipel, M., Pirovani, M., Güemes, D., Gariglio, N., Piagentini, A., (2009). Características fisicoquímicas de los frutos de tres variedades de manzanas cultivadas en la Región Centro-Este de la Provincia de Santa Fe, Revista FAVE, 8(1): 27-36.

Shyu, S.L., Hwang, L.S. (2001). Effects of processing conditions on the quality of vacuum fried apple chips. Food Research International, 34: 133-142.

Slade, L., Levine, H. (1995). Water and the glass transition Dependence of the glass transition on composition and chemical structure: Special implications for flour functionality in cookie baking. Journal of Food Engineering, 24(4): 431-509.

Sperling, L. H. (2005). Introduction to Physical Polymer Science. New York, Jhon Wiley \& Sons.

Tavera-Quiroz, M.J., Urriza, M., Pinotti, A., Bertola, N. (2012). Plasticized methylcellulose coating for reducing oil uptake in potato chips. Journal of the Science of Food and Agriculture, 92(7): 1346-1353.

World Cancer Research Fund-American Institute for Cancer Research. Food, nutrition and the prevention of cancer: a global perspective. Washington, 1997.

Yilmaz, Y., Toledo, R. (2005). Antioxidant activity of water-soluble Maillard reaction products. Food Chemistry, 93(2): 273-278. 
II.

\section{OBJETIVOS}





\section{OBJETIVO GENERAL}

Desarrollar un alimento tipo snack crocante a partir de anillos de manzana verde (Granny Smith).

\section{OBJETIVOS ESPECÍFICOS}

$\checkmark \quad$ Estandarizar y caracterizar manzanas verdes Granny Smith como materia prima para la obtención de productos tipo snacks.

$\checkmark \quad$ Investigar el efecto de diferentes pretratamientos que permitan optimizar el proceso de desarrollo del alimento tipo snack (escaldado con vapor, pretratamientos con sales de calcio).

$\checkmark \quad$ Evaluar el proceso de impregnación con fructosa y maltodextrina en distintas concentraciones sobre anillos de manzana, para la obtención de snacks por diferentes métodos de cocción: horneado, fritado o por horneado/fritado.

$\checkmark$ Estudiar la impregnación con diferentes concentraciones de azúcares de digestión lenta (isomalt) y maltodextrinas sobre anillos de manzana, para la obtención de un alimento tipo snack bajo en calorías.

Analizar las propiedades físicas, químicas y sensoriales de los snacks obtenidos a partir de la formulación seleccionada de fructosa/maltodextrina e isomalt/maltodextrina.

$\checkmark \quad$ Determinar la estabilidad de los snacks obtenidos a partir de isotermas de sorción.

$\checkmark \quad$ Estudiar y comparar la evolución de las propiedades físicas, químicas y organolépticas durante el almacenamiento de los snacks seleccionados. 
$\checkmark \quad$ Desarrollar snacks a partir de la formulación seleccionada como óptima recubiertos con películas de metilcelulosa y Lactobacillus plantarum, como alternativa de alimento "listo para consumir", saludable y funcional.

$\checkmark$ Caracterizar los recubrimientos simulando un sistema tipo película a través del estudio de sus propiedades fisicoquimicas, microestructurales, mecánicas y de barrera. 
III.

ANILLOS CROCANTES DE MANZANA VERDE 
CAPITULO 1.

CARACTERIZACIÓN FISICOQUÍMICA DE LA MATERIA PRIMA: MANZANA VERDE GRANNY SMITH (Malus domestica) 



\subsection{LA MANZANA}

\section{Origen de las manzanas en el mundo}

Aunque se desconoce el origen exacto del manzano, se cree que procede del cruzamiento y selección de varias especies de manzanos silvestres europeos y asiáticos. Probablemente el manzano nació de forma natural en las regiones montañosas de Asia media (Cáucaso), pudiendo haberse originado hace más de 15.000 - 20.000 años (InfoAgro, 2010).

La manzana es una fruta pomácea comestible que proviene del fruto del manzano (Malus domestica), árbol de la familia de las rosáceas. Esta familia incluye más de 20.000 especies de plantas herbáceas, arbustos y árboles distribuidos en regiones templadas de todo el mundo. La facilidad de adaptación de este árbol a diferentes climas y suelos, el valor nutritivo de sus frutos y la resistencia a las bajas permiten cultivarlo en gran escala en todos los países de clima relativamente frío (InfoAgro, 2010). La piel puede ser de color verde, amarilla o rojiza, y la pulpa, harinosa o crujiente, presenta sabores que varian entre ácido y dulce. Contiene en su interior semillas de color marrón oscuro. El tejido de la manzana es muy esponjoso, debido a la presencia de espacios intercelulares que se mantienen conectados entre sí y que llegan a ocupar el 25-30\% del volumen total del tejido (Albors, 2002). La manzana aporta hidratos de carbono fundamentalmente en forma de azúcares como fructosa, glucosa y sacarosa. Asimismo contiene cantidades apreciables de fibra, tanto soluble como insoluble, siendo esta última la más abundante que hace de este alimento un eficaz regulador de enfermedades del intestino grueso. La fibra soluble (pectina) tiene por su parte actividad hipocolesterolémica. Las manzanas son una importante fuente de diversos flavonoides como los flavonoles, catequinas y proantocianidinas. También son una fuente de antioxidantes polifenólicos responsables de la mayor parte de la actividad antioxidante de la fruta. El consumo regular de manzanas en 
una dieta contribuye de manera significativa a la ingesta de polifenoles (Vrhovsek y col., 2004). Algunos estudios estiman que la principal fuente de proantocianidinas en la dieta americana son las manzanas con el 32,0\% (Gu y col., 2004).

Dentro de las principales variedades se destacan:

$\checkmark \quad$ Golden Delicious. El fruto es grande y de color amarillo dorado, de carne blanca amarillenta y jugosa, de excelente conservación natural y en frío. El pedúnculo es largo y la piel delgada y resistente, cubierta con lenticelas grisáceas. Es una excelente polinizadora para la mayoría de las variedades comerciales. Se trata de una variedad muy productiva.

Red Delicious. El fruto es de buen tamaño, de color más o menos intenso, con un punteado amarillo, carne azucarada, jugosa, ligeramente acidulada y muy aromática, de excelente conservación. Se trata de una variedad de crecimiento vertical y de floración semi-tardia. Es la variedad más importante cultivada en Argentina y Chile.

$\checkmark \quad$ Gala. Procedente de Nueva Zelanda es una de las variedades favoritas para consumir en fresco. Tiene forma de corazón y la cáscara es de un color distintivo amarillo anaranjado con lineas rojas. Es una variedad híbrida que se obtuvo de la cruza Red Delicious con Kidds Orange Red consiguiendo una manzana muy dulce con textura crujiente, de excelente calidad.

$\checkmark \quad$ Fuji. El fruto firme, crujiente, con mucho jugo y dulce hacen de esta variedad una excelente elección de manzana para comer en fresco. El sabor de la manzana Fuji mejora cuando se almacena. El color de su cáscara varía de amarillo verde con líneas rojas a un color rojo intenso. Fue creado en Japón mediante un cruce entre las variedades Red Delicious y Ralls Janet. 
$\checkmark \quad$ Granny Smith. Es una variedad de origen australiano. En el año 1868 en Australia, una anciana llamada Mary Ann Smith produjo por primera vez esta variedad, por lo que en honor a su creadora se dio su nombre (Valpiana, 1997). Es una especie muy usada en el hemisferio sur. Los frutos se cosechan en marzo. Los árboles son vigorosos, precoces en la fructificación y muy productivos. Se poliniza con Golden Delicious y suelen hacerse plantaciones con estas dos variedades exclusivamente. La manzana de la variedad Granny Smith es de calibre grande, esférica y simétrica. Tiene piel de color verde intenso que se vuelve más claro en la madurez, con numerosas lenticelas de color blanquecino. La pulpa es blanca, compacta, consistente y jugosa, con sabor acidulado (Infoagro, 2006). Quiles (2002) señala que el tamaño y la forma de las células de la manzana Granny Smith son variables; cerca de la piel son grandes y redondeadas y a medida que se aproximan al corazón son más pequeñas y alargadas. Las células de manzana fresca están unidas pared con pared mediante una lámina media perfectamente delimitada constituida por materiales cementantes, principalmente pectina y hemicelulosa. Mavroudis y col. (1998) concluyeron que en esta misma variedad de manzana prácticamente no se observan diferencias en la densidad de espacios intercelulares, entre la región más cercana a la piel y la más cercana al corazón.

Para la elaboración de distintos productos industriales a base de manzana se requieren características particulares de la materia prima en lo que refiere a estado sanitario, forma, tamaño y composición química. La disponibilidad de manzanas se da en un extenso período a lo largo del año. La variedad Granny Smith es una de las más estables, debido a que puede ser almacenada en cámaras frigorificas por un amplio periodo de tiempo en atmósfera convencional, a temperaturas entre $-0,5$ a $0,5^{\circ} \mathrm{C}$. El periodo de almacenamiento es de 7 a 9 meses, y en atmósfera controlada, a una temperatura de 0 a $0,5{ }^{\circ} \mathrm{C}$ se puede almacenar entre 10 a 12 meses. Esta fue una de las razones por la cual se eligió dicha variedad para la producción de un snack a base de fruta. 
Las manzanas más comercializadas son aquellas cuyo calibre va desde los 75 milímetros hasta los 85 o más y su peso oscila desde los 170 hasta los 250 gramos. Según Mitcham y col. (2008) y Bourles y col. (2009), el índice de madurez óptimo de manzanas aptas para consumo y comercialización está determinado por un contenido de sólidos solubles en un rango de 9,5 a $17^{\circ} \mathrm{Brix}, \%$ de acidez entre 0,2 y1,2, $\mathrm{pH}$ entre 3 y 4,2 y contenido de agua entre 80 y $90 \%$.

Para el desarrollo de productos de buena calidad, se requiere que la materia prima cumpla con los estándares requeridos por la industria. El contenido de materia seca, el contenido de sólidos solubles, la acidez, la actividad acuosa y la textura crujiente del fruto son indicadores de calidad y tienen importancia como criterios de selección. Teniendo en cuenta estas premisas, se llevaron a cabo determinaciones de estos parámetros para caracterizar la materia prima y asegurar un producto final con características propias de un snack de fruta.

\section{Objetivo}

El objetivo de esta sección fue caracterizar y estandarizar la materia prima a utilizar durante el desarrollo de los snacks de manzana. 


\subsection{MATERIALES Y MÉTODOS}

\subsubsection{MATERIALES}

\section{Materia prima}

Se trabajó con manzanas var. Granny Smith (Malus domestica), adquiridas en el mercado local seleccionadas por tamaño y apariencia, diámetro entre 8 y $10 \mathrm{~cm}$ y piel color verde intenso sin defectos superficiales. Se analizaron lotes de muestras de 10 manzanas y las medidas se hicieron por duplicado.

\subsubsection{MÉTODOS}

\section{Análisis fisicoquímicos}

En las manzanas se analizaron el contenido de humedad, contenido de sólidos solubles, $\mathrm{pH}$, acidez titulable y contenido de cenizas. Adicionalmente, se realizaron medidas instrumentales de actividad acuosa y textura.

\section{Determinación de contenido de humedad}

E1 contenido de humedad de los alimentos varía considerablemente. El agua es el principal constituyente en la mayoría de los productos alimenticios. La materia seca que permanece en el alimento posteriormente a la remoción del agua se conoce como sólidos totales. El contenido de humedad es un factor de calidad en la conservación de algunos productos, ya que afecta la estabilidad de frutas y vegetales deshidratados, leches deshidratadas, huevo en polvo, papas deshidratadas y especias.

El contenido de agua en la materia prima fue determinado por duplicado según el método 20.013 (AOAC, 1980) para frutas ricas en azúcar. Las muestras fueron colocadas en una estufa de vacío a una presión de $50 \mathrm{~mm} \mathrm{Hg}$ ya una temperatura de $60^{\circ} \mathrm{C}$ y secadas hasta alcanzar peso constante. Teniendo en cuenta el agua evaporada, la humedad se calculó a partir de la Ecuación 1 como la diferencia de peso 
de la muestra antes y después de ser sometida al secado, determinada con una balanza analitica METTLER (AB 204, sensibilidad 0,0001 g).

$$
\text { Humedad }\left(\mathrm{g}_{\mathrm{agu}} / 100 \mathrm{~g}_{\mathrm{ms}}\right)=\frac{\left(\mathrm{PesO}_{\mathrm{mh}}-\mathrm{PesO}_{\mathrm{ms}}\right)}{(\text { Peso ms })} \times 100 \quad \text { Ec. } 1
$$

Donde, Pesomh es el peso de la muestra antes del secado y Pesoms es el peso de la muestra después del secado.

\section{Determinación del contenido en sólidos solubles}

La determinación de los sólidos solubles de la manzana fresca ( ${ }^{\circ}$ Brix) se realizó mediante la medida del índice de refracción de la fracción líquida de las muestras previamente homogeneizadas. Se efectuaron tres lecturas de los ºrix (refractómetro Hanna HI96801, sensibilidad $0,01^{\circ} \mathrm{Brix}$ ) a $20^{\circ} \mathrm{C}$. La fracción másica de sólidos solubles en la muestra fue calculada mediante la Ecuación 2.

$$
\mathrm{X}_{\mathrm{s}}=\frac{{ }^{\circ} \text { Brix } \mathrm{X}_{\mathrm{w}}}{100-{ }^{\mathrm{o} B \text { Brix }}} \times 100 \quad \text { Ec. } 2
$$

Donde, $\mathrm{X}_{\mathrm{s}}$ es la fracción másica de sólidos solubles (ss) (gss/gmuestra) y $\mathrm{X}_{\mathrm{w}}$ es la fracción másica de agua (gagua/gmuestra)

\section{Determinación del pH y acidez titulable}

La acidez es un indicador que expresa el contenido de ácidos libres en una matriz, el cual se expresa como el porcentaje del ácido predominante de la matriz. En el caso de los frutos está dado por el ácido cítrico o ácido málico. El método consiste en determinar la acidez por medio de una titulación ácido-base con una solución alcalina estandarizada, expresando los resultados de la acidez titulable como el equivalente en masa de ácido cítrico o málico. Dicha acidez puede incluir la acidez natural y la desarrollada. Para la determinación de la acidez titulable se colocaron $20 \mathrm{ml}$ de extracto de manzana cruda en un 
vaso de precipitado y se mantuvo bajo agitación constante. La acidez se determinó a través de una titulación con $\mathrm{NaOH} 0,1 \mathrm{~N}$ y se expresó en porcentaje de ácido málico según la norma AOAC 942.15. El pH de la materia prima (previamente triturada) se determinó con un pH-metro $(\mathrm{HACH}$, sensION ph3) con un electrodo de contacto. Previamente, el equipo fue calibrado con soluciones tampón ( $\mathrm{pH} 9,2,7,0$ y 4,0) a una temperatura de $20^{\circ} \mathrm{C}$.

\section{Determinación del contenido de cenizas}

La determinación de cenizas hace mención al análisis de residuos inorgánicos que quedan después de la ignición u oxidación completa de la materia orgánica de un alimento. La ceniza remanente es el residuo inorgánico y la medición de la ceniza total es útil en el análisis de alimentos, ya que se pueden determinar diversos minerales contenidos en la muestra. Algunos errores involucrados en la determinación de las cenizas en seco son: la pérdida de ceniza debido a la intensidad con que arde la flama en el momento de quemar la muestra al aire y el cambio gradual en las sales minerales con el calor, como el cambio de carbonatos a óxidos, adhesión de las muestras con un contenido alto de azúcares, lo cual puede ocasionar pérdidas y/o fusión del carbón de partes no oxidadas atrapadas de la muestra. La técnica que se utilizó fue la de cenizas en seco, la cual consistió en calcinar la muestra al aire y posteriormente en una mufla para eliminar todo el material orgánico.

\section{Método}

1. Llevar a peso constante una cápsula de porcelana por cada muestra a analizar, previamente incinerar cualquier residuo que esta pueda contener dejando durante $2 \mathrm{~h}$ en la mufla a una temperatura de $900^{\circ} \mathrm{C}$. 2. Dejar enfriar la cápsula en un desecador durante 15 a 20 minutos, sin cerrar el desecador totalmente, ya que el calor puede provocar que la tapa se proyecte y se rompa.

3. Pesar la cápsula en balanza analitica e identificar. Anotar el peso. 
4. Pesar en la cápsula 1-2 gramos de la muestra. Registrar el peso exacto.

5. Preincinerar la muestra exponiéndola a la flama del mechero de Bunsen.

6. Incinerar la muestra en la mufla a $550^{\circ} \mathrm{C}$ durante 8 horas.

7. Pesar la cápsula con cenizas (ya no deben estar negras, si lo están incinerar otra media hora) en la misma balanza que se utilizó inicialmente. Anotar el peso. El contenido de cenizas se determinó a partir de la ecuación 3:

$$
\% \text { Cenizas }(\mathrm{bs})=\frac{\text { Peso cenizas }}{\text { Peso muestra }} \times 100
$$

\section{Análisis instrumentales}

\section{Determinación de la actividad acuosa}

La actividad de agua puede ser considerada una medida indirecta del agua que está disponible en un producto para participar de reacciones de deterioro o crecimiento microbiano y puede ser descripta como la relación de la presión parcial de vapor de agua (p) del alimento dividida por la presión de vapor del agua pura ( $\mathrm{p}_{\mathrm{o}}$ ) a la misma temperatura $\left(a_{\mathrm{w}}=\mathrm{p} / \mathrm{p}_{\mathrm{o}}\right)$. Su valor varía entre 0 y 1 .

La actividad acuosa se determinó con el equipo Aqualab 3TE, previamente calibrado con soluciones salinas saturadas. Para simular las condiciones del medio, se ajustó la temperatura a $25^{\circ} \mathrm{C}$. El ensayo se realizó por triplicado sobre las manzanas previamente trituradas.

\section{Análisis de Textura}

Durante la maduración, los azúcares y otros componentes de la manzana sufren importantes modificaciones. Todos estos procesos influyen en los cambios que se producen durante el almacenamiento, transporte y procesamiento, afectando el contenido de sólidos (ablandamiento) y su valor nutritivo. Con el fin de evaluar la resistencia 
del tejido de la manzana cruda, se realizó la medida de textura con un texturómetro TA.XT2, Stable Micro Systems utilizando el método de punción (Billy y col., 2008; Bourles y col., 2009) (Figura 2). Se empleó una sonda $\mathrm{P} / 5$ de $2 \mathrm{~mm}$ de diámetro. Los ensayos se realizaron con rodajas de manzana de $2 \pm 0,5 \mathrm{~cm}$ de espesor. La velocidad de ensayo y de pre-ensayo fueron de $1 \mathrm{~mm} / \mathrm{s}$ mientras la velocidad de post-ensayo se fijó en $10 \mathrm{~mm} / \mathrm{s}$. La distancia de avance fue de $10 \mathrm{~mm}$. En cada rodaja se analizaron 5 puntos. Los ensayos se realizaron por triplicado.

A partir de la gráfica obtenida se calculó la primera fuerza de fractura o punto de cedencia y la fuerza máxima de ruptura.Se calculó el modulo elástico representado en el gráfico por la pendiente de la recta antes de la primera fractura y asociado a la firmeza de la fruta.

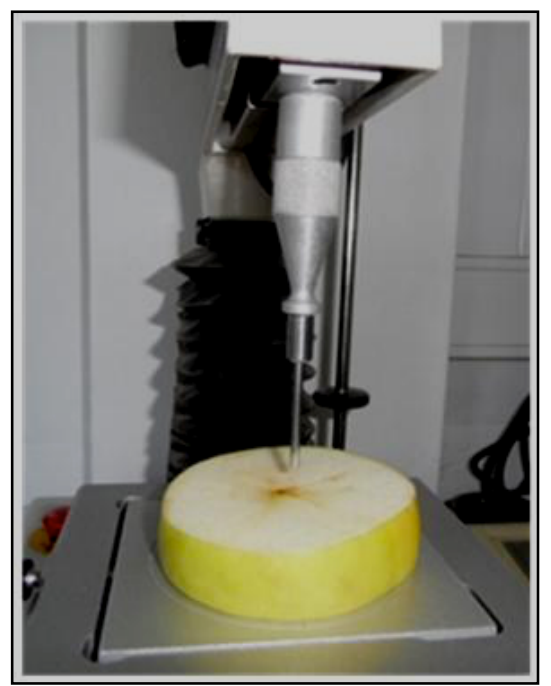

Figura 2. Método de punción aplicado sobre la manzana var. Granny Smith (Malus domestica)

\section{Análisis estadístico}

Los resultados obtenidos fueron evaluados estadisticamente a través del software SYSTAT 12 (SYSTAT, Inc., Evanston, IL, EE.UU.) (Wilkinson y Coward, 2000), mediante análisis de varianza (ANAVA). Cuando los datos presentaron diferencias entre sí, se realizó la 
comparación de medias mediante el test de LSD de Fisher a un nivel de significación de 0,05.

\subsection{RESULTADOS Y DISCUSIÓN}

\section{Caracterización de la materia prima}

La Tabla 1 muestra los valores experimentales de humedad, los ${ }^{\circ}$ Brix de la fracción líquida, $\mathrm{pH}$ y acidez titulable que caracterizan los diferentes lotes de manzana fresca utilizada durante el desarrollo de este trabajo. Además se observan los valores de actividad acuosa $\left(a_{w}\right)$ y fuerza máxima de ruptura. Estos valores se correlacionan con los parámetros de calidad para la variedad de manzana empleada (Martínez-Monzó, 1998; Lavilla y col., 1999).

Tabla 1. Contenido de humedad, cenizas, $\mathrm{pH}, \mathrm{a}_{\mathrm{w}} \mathrm{y}$ acidez titulable de las manzanas var. Granny Smith

\begin{tabular}{lr}
\hline Humedad (gagua $\left./ 100 \mathrm{~g}_{\mathrm{ms}}\right)$ & $85,3(1,0)^{*}$ \\
$\mathrm{a}_{\mathrm{w}}$ & $0,970(0,001)$ \\
\%Cenizas $\left(\mathrm{g}_{\text {cenizas }} / 100 \mathrm{~g}_{\mathrm{ms}}\right)$ & $0,25(0,05)$ \\
${ }^{\circ} \mathrm{Brix}$ & $11,0(1,0)$ \\
$\mathrm{pH}$ & $3,4(0,2)$ \\
Acidez titulable (\% ácido málico) & $0,44(0,03)$ \\
\hline
\end{tabular}

*Valores entre paréntesis indican desviación estándar

Las manzanas mostraron uniformidad de forma y ausencia de deformaciones en la superficie del fruto. Presentaron una forma ovalada, con un diámetro medio entre 8 y $10 \mathrm{~cm}$, lo cual proporcionó rebanadas circulares de tamaño uniforme. De acuerdo a los resultados, la variedad utilizada tuvo un contenido de materia seca de 15,0 $\pm 0,3$ $\mathrm{g}_{\mathrm{ss}} / \operatorname{lo0g}_{\mathrm{m}}$. El contenido de materia seca es uno de los factores más importantes tanto para consumo fresco como para el procesado porque determina directamente el rendimiento de la pulpa en la producción. De 
acuerdo a Arnaldos (2008), la humedad es un indicador de senescencia de los frutos. Valores por encima del 90\% indican un marcado deterioro de la calidad del fruto.

Según datos de la FAO (2000) los sólidos solubles en la manzana deben ser al menos $10{ }^{\circ}$ Brix para cumplir con la calidad gustativa y asegurar que no exista una maduración excesiva. Dolz (2008) informó que este parámetro puede variar entre 10 y 23,6 ${ }^{\circ}$ Brix. En las manzanas verdes el flavor se determina por la proporción de ácido, azúcares y la textura (Lavilla y col., 1999). Los valores obtenidos de pH fueron similares a los obtenidos por Seipel y col. (2009). Según estos autores, valores bajos de $\mathrm{pH}$ derivan en valores elevados de acidez y afirman que el porcentaje de ácido málico puede variar entre 0,20\% hasta 1,84\%. Esta afirmación coincide con los datos presentados en la Tabla 1, donde se observan los valores de acidez de la variedad Granny Smith, los cuales resultaron ser más altos comparados con otras variedades estudiadas (Paredes, 2012). Ramírez y Pacheco (2011) concluyeron que esta característica contribuye a controlar el desarrollo microbiano y por ende, a una mayor duración después de la cosecha.

Los valores obtenidos para la fuerza de fractura, la fuerza máxima de ruptura, y la pendiente de la recta fueron 4,9 $\pm 1,4 \mathrm{~N}, 5,4 \pm 1,0$ $\mathrm{N}$, y $5,2 \pm 2,0 \mathrm{~N} / \mathrm{mm}$. En la Figura 3 se puede observar que la fuerza necesaria para romper la estructura en la capa superficial de la muestra es similar a la ejercida por el punzón en el avance hacia el interior de la muestra. Esto se refleja en un aumento de la fuerza inicial hasta alcanzar un valor máximo, el cual se mantiene describiendo una meseta. 


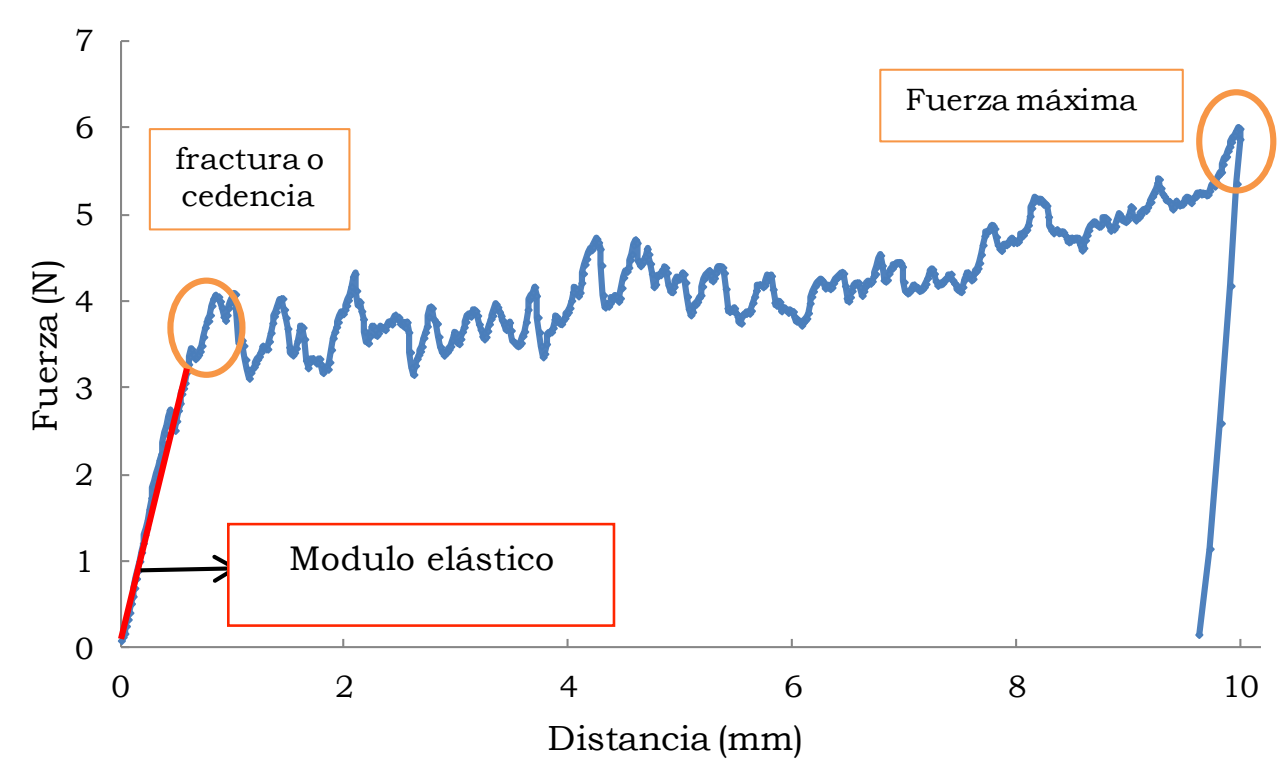

Figura 3. Perfil de textura de las manzanas Granny Smith obtenido a través de penetrometría

Las curvas de fuerza-deformación típicas durante la penetración fueron similares a las obtenidas por Grotte y col. (2001) y Varela y col. (2007). Un perfil de la curva altamente irregular con muchos picos debido a los numerosos eventos de fractura se produce a menudo por los productos que se perciben como crujientes. En el caso de las frutas a medida que el tiempo de almacenamiento aumenta (aumenta el tiempo de maduración), las curvas se perciben más suavizadas (Varela y col., 2007). En general, los datos se correspondieron con los de frutos de entre 2 y 4 semanas de almacenamiento después de la cosecha (Vaysse y col., 2000). Bourles y col. (2009) obtuvieron valores entre 3,2 y 4,1 N/mm de firmeza para las muestras más resistentes, los cuales son comparables con los obtenidos para las muestras ensayadas. Los resultados indican que las manzanas de estas características mantendrian su resistencia y estructura firme durante el procesamiento.

La variedad Granny Smith que es de amplia difusión comercial para su consumo en fresco tiene características de firmeza favorables 
para su procesamiento por lo que se utilizó en este trabajo de tesis como materia prima para el desarrollo de los snacks.

\subsection{REFERENCIAS}

AOAC Official methods of analysis. (1980). Official method of Analysis of AOAC International, ed. 13. Washington DC: Association of official analytical chemists.

AOAC Official Method 942.15. (2005). Acidity (Titrable) of Fruit Products. Official method of Analysis of AOAC International, ed. 18, 37, p. 10 .

Albors, A. (2002). Estudio de perfiles composicionales y estructurales en tejido de manzana (var. Granny Smith) deshidratada. Tesis Doctoral. Universidad Politécnica de Valencia.

Alzamora, S.M., Castro, M., Nieto, A., Vidales, S., Salvatori. D. (2000). The role of tissue microstructure in the texture of minimally processed fruits. In:Minimally processed fruits and vegetables, 153-171. Aspen Publishers Inc., Gaithersburg, Maryland.

Alzamora, S.M., Salvatori, D., Tapia, M., López-Malo, A., WeltiChanes, J., Fito, P. (2005). Novel functional foods from vegetable matrices impregnated with biologically active compounds. Journal of Food Engineering, 67: 205-2014.

Arnaldos, P. (2008). Algunos aspectos matemáticos relacionados con la predicción de la calidad de frutas y hortalizas en atmósferas modificadas. Tesis previa a la obtención del título en Ingeniero Agronómo, Universidad Politécnica de Cartagena, 1 - 16.

Barrett, D.M., Beate L. (2012). Advanced preservation methods and nutrient retention in fruits and vegetables. Journal of Science and Food Agricultural, 92: 7-22. 
Brands, C., Boekel, M.(2001). Reactions of monosaccharides during heating of sugar-casein Systems: Buiding of a reaction Networt Model. Journal Agriculture Food Chemistry, 49(10): 4667-4675.

Billy, L., Mehinagic, E., Royer, G., Renard, C., Arvisene, T.G., Prost C., Jourjon F. (2008). Relationship between texture and pectin composition of two apple cultivars during storage. Postharvest Biology Technology, 47: 315-324.

Bourles, E., Mehinagic, E., Courthaudon, J.L., Jourjon, F. (2009). Impact of vacuum cooking process on thetexture degradation of selected apple cultivars. Journal of Food Engineering and Physical Properties, 74 (9): 512-518.

Dolz, P. (2008). Evaluación de la calidad de fruto en manzano: Estudio de métodos no destructivos de análisis. Proyecto H.204.49, Escuela Universitaria Politécnica La Almunia de Doña Godina, Zaragoza, España, pp. $32-42$.

Grotte, M., Duprat, F., Loonis, D., Pietri, E. (2001). Mechanical properties of theskin and the flesh of apples. International Journal of Food Properties, 4:149-161.

Gu, L.W., Kelm, M.A., Hammerstone, J., Beecher, G.,Holden, J., Haytowitz, D., Gebhardt, S., Prior, R.L. (2004). Concentrations of proanthocyanidins in common foods and estimations of normal consumption. Journal of Nutrition, 34: 613-617.

Lavilla, T., Puy, J., López, M.L., Recasens, I., Vendrell, M. (1999). Relationships between volatile production, fruit quality, and sensory evaluation in Granny Smith apples stored in different controlledatmosphere:treatments by means of multivariate analysis. Journal of Agricultural and Food Chemistry, 47: 3791-3803.

Martinez-Cervera, S., Salvador, A., Sanz, T. (2014). Comparison of different polyols as total sucrose replacers in muffins: Thermal, 
rheological, texture and acceptability properties. Food Hydrocolloids, 35:1-8.

Martínez-Monzó, J. (1998). Cambios físico-químicos en manzanas Granny Smithasociados a la impregnación a vacío aplicaciones en congelación. Tesis Doctoral. Universidad Politécnica de Valencia. España.

Mavroudis, N., Gekas, V., Sjöholm, I. (1998). Osmotic dehydration of apples. Shrinkage phenomena and the significance of initial structure on mass transfer rates. Journal of Food Engineering, 38: 101-123.

Mitcham, E., Crisosto, C., Kader, A. (2013). Manzana: Granny Smith: Recomendaciones para Mantener la Calidad Postcosecha. UCD Postharvest Technology. Department of Plant Sciences, University of California, Davis.

Paredes, E.T. (2012). Estudio del proceso de horneado con microondas y su efecto sobre la textura instrumental del fruto de cuatro variedades de manzana (Pyrus l.). Proyecto previo a la obtención del Título de Ingeniera Agroindustrial. Escuela Politécnica Nacional. Quito, Ecuador.

Quiles, A. (2002). Impacto de la penetración de materiales exógenos en la microestructura del parénquima de manzana (Malus communis, L). Tesis Doctoral. Universidad Politécnica de Valencia.

Ramírez, A., Pacheco, E. (2011) Composición química y compuestos bioactivos presentes en pulpas de piña, guayaba y guanabana, Redalyc, 36 (1): 75-81.

Saftner, R.A., Bai, J., Abbott, J.A., Lee, Y.S. (2003). Sanitary dips with calcium propionate, calcium chloride, or a calcium amino acid chelate maintain quality and shelf stability of fresh-cut honey dewchunks. Postharvest Biology and Technology, 29 (3): 257-269. 
Seipel, M., Pirovani, M., Güemes, D., Gariglio, N., Piagentini, A., (2009). Características fisicoquímicas de los frutos de tres variedades de manzanas cultivadas en la Región Centro-Este de la Provincia de Santa Fe, Revista FAVE, 8 (1): 27- 36.

Sousa, M., Canet, W., Alvarez, M., Fernández, C. (2007). Effect ofprocessing on the texture and sensory attributes of raspberry (cv. Heritage) and blackberry (cv. Thornfree). Journal of Food Engineering, 78: 9-21.

Valpiana, T. (1997). La manzana, Editorial IBIS-Alimentos sanos, Barcelona, España, pp. 24 - 27, 34 - 44.

Varela, P., Salvador, A., Fiszman, S. (2007). Changes in apple tissue with storage time: Rheological, textural and microstructural analyses. Journal of Food Engineering, 78: 622-629.

Vaysse, P., Scandella, D., Masseron, A., Mathieu, D., Trillot, M., Marion, M. (2000). Recognizing apple and pear varieties. 1st ed. Orleans: Technical Institute for Fruits and Vegetables Publishing. 119 p.

Vrhovsek, U., Rigo, A., Tonon, D., Mattivi, F. (2004).Quantitation of Polyphenols in Different Apple Varieties. Journal of Agricultural and Food Chemistry, 52: 6532-6538.

http:/ / www.infoagro.com/frutas/frutas_tradicionales/manzana.h $\operatorname{tml}$ 
CAPÍtulo 2.

ESTUDIO DE DIFERENTES ALTERNATIVAS TECNOLOGICAS PARA DESARROLLAR UN SNACK DE MANZANA DE ÓPTIMA CALIDAD 



\subsection{EFECTO DEL PRETRATAMIENTO CON SALES DE CALCIO SOBRE LAS PROPIEDADES NUTRICIONALES, MICROESTRUCTURA, TEXTURA Y COLOR DE ANILLOS DE MANZANA}

En el desarrollo de productos basados en frutas es importante la aplicación de pretratamientos para prevenir el deterioro de la materia prima durante las diferentes etapas del procesamiento. Estos pretratamientos se realizan para inactivar enzimas no deseables en el proceso y/o para mantener la estructura del tejido vegetal firme y así obtener productos de mayor calidad. El tratamiento térmico con vapor aplicado sobre las frutas, en este caso, manzanas, tiene como principal objetivo lograr la inactivación de la enzima polifenoloxidasa, la cual es una enzima endógena. Esta enzima entra en contacto con el tejido de la fruta cuando es cortado o procesado. En consecuencia, los polifenoles sufren una oxidación enzimática y se generan una serie de compuestos pardos que inciden negativamente en el tejido haciéndole perder integridad celular (Toivonen y Brummel, 2008). Esta reacción genera un doble efecto negativo: provoca el oscurecimiento de la pulpa, debido a las quinonas generadas que se encuentran sujetas a futuras reacciones conduciendo a la formación de pigmentos oscuros y esto a su vez favorece la pérdida de los polifenoles presentes. Por otro lado el tratamiento térmico moderado afecta la integridad del tejido y la estructura celular, aumentando la susceptibilidad al proceso de deterioro. Este fenómeno disminuye la firmeza del tejido debido a la pérdida de la integridad estructural de las paredes celulares, lámina media y membrana celular.

Estos cambios se reflejan a nivel macroscópico como pérdida de peso por los procesos de exudación, aumento en la intensidad de la tasa respiratoria, aumento en la producción de etileno, presencia de alteraciones microbiológicas, ablandamiento y pérdidas de sabor, aroma y valor nutritivo. Muchas de estas modificaciones se pueden reducir con tratamientos adicionales como: 
- La incorporación de calcio mediante inmersión en soluciones acuosas de sales, a través de las cuales se busca preservar el tejido celular retrasando la senescencia y reduciendo el ablandamiento del tejido. Asimismo la adición de calcio es usada para controlar el desarrollo de alteraciones fisiológicas, debido a que el calcio interactúa con las pectinas formando una red polimérica que fortalece la pared celular (Luna-Guzmán y col., 2000; Hewajulige y col., 2003; Lamikanra y col., 2005; Solomon y col., 2006; Manganaris y col., 2007).

- El empleo de agentes antioxidantes para evitar el oscurecimiento superficial y la aplicación de compuestos antimicrobianos para prevenir la proliferación de microorganismos causantes de alteraciones (Rojas-Graü y col., 2006; Rojas-Graü y col., 2008).

- El envasado bajo atmósferas modificadas que permiten controlar los procesos respiratorios típicos de los tejidos vivos y retardar la senescencia (Rocculi, y col., 2004; Rapisarda y col., 2006; OmsOliu y col., 2006; Allende y col., 2007; Bhande, y col., 2008).

- La aplicación de luz ultravioleta como alternativa para la reducción de carga microbiana y de la actividad enzimática (Alothman y col., 2009; Artés-Hernández y col., 2010).

- El empleo de películas y recubrimientos comestibles como barreras que reducen la difusión de gases (Pérez-Gago y col., 2006; Olivas y col., 2007; Rojas-Graü y col., 2007; Rojas-Graü y col., 2008).

\section{Pretratamientos con sales de calcio}

Las sales de calcio forman parte del conjunto de agentes mejoradores y/o conservantes de las características nutricionales y de calidad de las frutas y vegetales mínimamente procesados. Son comúnmente usadas en la industria como agentes reafirmantes, mejoradores de la textura (Martín-Diana y col., 2007) y antipardeantes. Se usan especialmente en la elaboración de tomates en conserva, pepinos y otros vegetales, y producen la reducción del oscurecimiento 
en manzanas, pimientos, fresas, tomates y melocotones. Numerosos investigadores han estudiado el efecto del pretratamiento con sales de calcioen distintos sistemas vegetales, analizando su influencia desde el punto de vista de las propiedades mecánicas (Vanegas y Antonio, 2004; Sousa y col., 2007) y de las características nutricionales (Alzamora y col.,2005). El calcio se emplea para preservar la estructura de los tejidos vegetales (Saftner y col., 2003; Quiles y col., 2004). A su vez, reduce la actividad respiratoria, la producción de etileno y el desarrollo de microorganismos (Luna-Guzmán y col., 1999; Saftner y col., 2003). La incorporación de calcio en las frutas minimamente procesadas puede mejorar su calidad y vida útil (Barret y col., 2012).

El efecto del calcio sobre la textura puede ser explicado por diferentes mecanismos: 1) sirve como vehículo de unión a las sustancias pécticas en la pared celular y lámina media, formándose pectato cálcico que aporta firmeza al tejido reduciendo el ablandamiento y la pérdida de agua, 2) estabiliza la membrana celular, ejerciendo un papel regulador sobre su permeabilidad y sobre el transporte de sustancias involucradas en la senescencia y 3) aumenta la turgencia celular (Luna-Guzmán y col., 2000; Saurel, 2004). Esta acción reafirmante del calcio, al mismo tiempo contribuye a una reducción de la liberación de la polifenoloxidasa y sus sustratos después del corte contribuyendo a la reducción del pardeamiento (Lamikanra y col., 2002).

La aplicación de calcio sobre frutas y hortalizas se puede hacer a través de inmersión, que consiste en sumergir el producto en una solución de calcio con o sin agitación, seguido por la eliminación del exceso de solución. Este tratamiento favorece la dispersión de la solución en la superficie del vegetal y permite retirar las enzimas y sustratos liberados durante el proceso de corte, evitando reacciones de oxidación (Soliva-Fortuny y Martín-Belloso, 2003; Martín-Diana y col., 2007). Cuando el tratamiento con calcio se realiza a través de inmersión 
del producto sumado a tratamientos térmicos (vapor y/o agua caliente), permite que se active la enzima pectinmetilesterasa, desmetilando las pectinas de la pared celular y la lámina media, favoreciendo la unión de los iones $\mathrm{Ca}^{2+}$ endógenos o exógenos con los grupos carboxílicos libres (desmetilados) de los polímeros de pectinas existentes, estabilizando la pared celular y mejorando la firmeza (Grant y col., 1973, Luna-Guzmán y col., 1999). El complejo calcio-pectina actúa como un cemento intracelular que proporciona firmeza al tejido vegetal. Otra enzima que puede estar involucrada en este proceso es la poligalacturonasa, cuya expresión o actividad, al parecer es reducida por el calcio evitando el ablandamiento. La lámina media consiste en una capa rica en compuestos de naturaleza péctica de consistencia gelatinosa que forman la interfase entre las paredes celulares de células vecinas. Interiormente a ésta se encuentra la pared celular primaria y la cual está compuesta principalmente por substancias pécticas lábiles al calor y actúa como un adhesivo y resiste fuerzas de compresión y tensión (Van Buggenhout y col., 2009).

El calcio puede actuar como componente estructural de las paredes y membranas celulares como puente de unión intermolecular en la estabilización de la pectina-proteína en la lámina media de los tejidos vegetales y como cofactor de varias enzimas (Barcelo y col., 2001). El mantenimiento de la estructura de la pared celular depende particularmente del enlace del calcio con los componentes pécticos de la lámina media formando el pectato cálcico. El enlace del calcio a las pectinas se produce a través de la unión del grupo carboxílico o de los grupos hidroxílicos a diversos polisacáridos mediante uniones electrostáticas o coordinadas formando una red que incrementa su fuerza mecánica (Luna-Guzmán y col., 2000). Asimismo, los iones de calcio también pueden contribuir a la firmeza del tejido mediante un incremento en la integridad de la membrana, consiguiéndose el mantenimiento o aumento de la presión de turgencia en la célula (Mignani y col., 1995). Según el modelo de "la caja de huevos" que se 
muestra en la Figura 4 (Grant y col., 1973; Brett y Waldrom, 1990), la asociación entre las pectinas de bajo grado de metilación y los iones de calcio provoca la formación de estructuras poliméricas con alta reticulación. Como consecuencia, los productos vegetales que contienen pectinas con un grado de metilación bajo, después de los tratamientos con calcio, muestran consistencias más altas o si es fluido, un incremento en la viscosidad aparente (Luna-Guzmán y col., 2000).

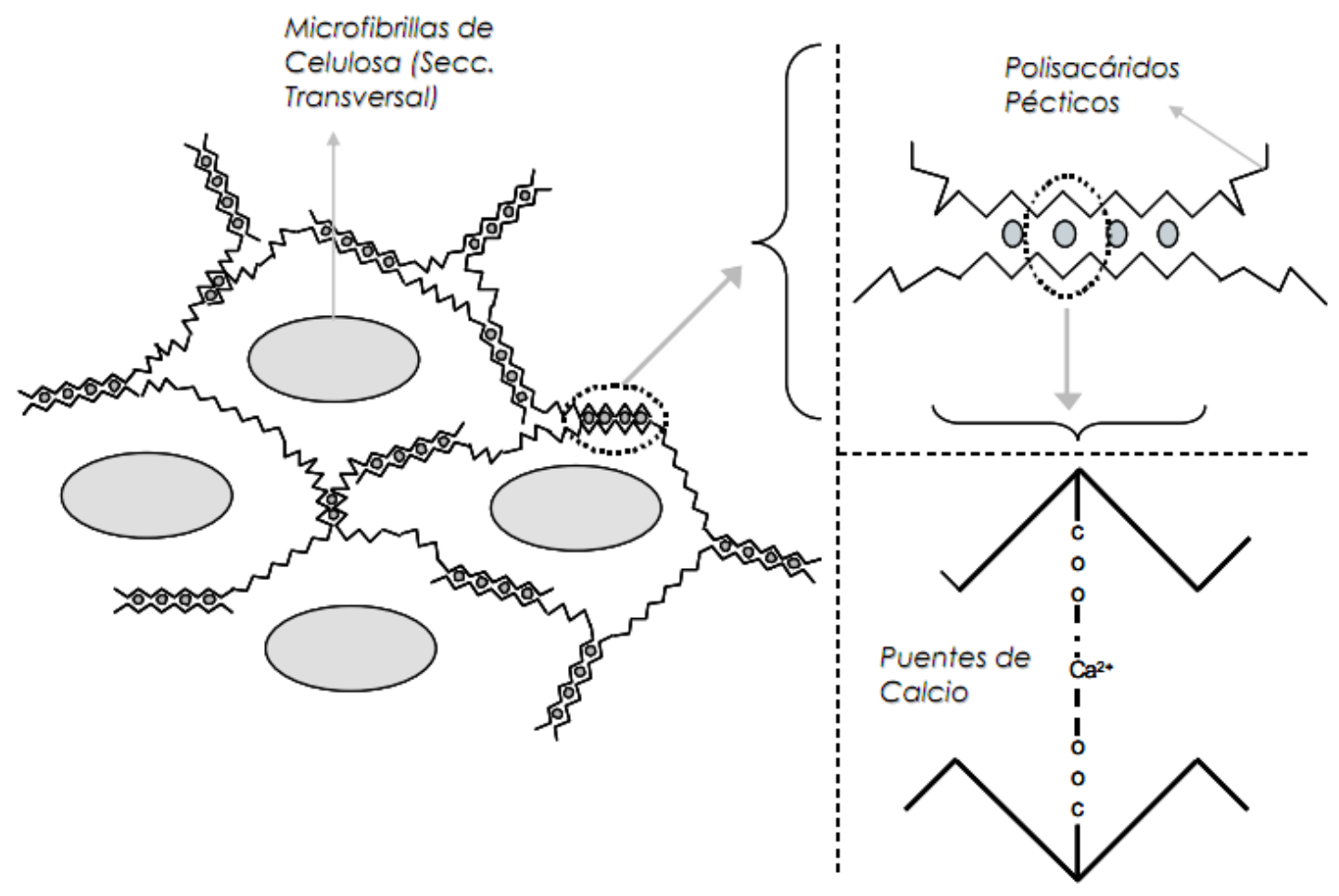

Figura 4. Papel del calcio en la estructura de la pared celular - Modelo de la caja de huevos (Grant y col., 1973; Brett y col., 1990).

La aplicación de tratamientos térmicos provoca la ruptura de las membranas, la descompartimentalización de los componentes celulares y la degradación de las pectinas de la lamina media y de la pared celular que contribuyen más aún a la pérdida de su firmeza (Rosli y col., 2004). Al incrementarse la actividad de la pectinmetilesterasa (PME) endógena, se produce cierta desmetilación de las pectinas, creándose pectinas de bajo grado de metilación o bajometoxilo, que 
gelifican formando puentes de entrecruzamiento en presencia de iones calcio agregados, dando lugar a estructuras más firmes y resistentes. Así, diversas frutas registran mejoras en el mantenimiento de la textura cuando se escaldan a temperaturas que refuerzan la actividad de la PME endógena o exógena (Luna-Guzmán y col., 2000; Lamikanra y col., 2004-2007; Aguayo y col., 2008; Liu y col., 2009). Para mantener la vida útil de frutas y vegetales se emplean diferentes fuentes de calcio. El carbonato y el citrato de calcio son las principales sales adicionadas a los alimentos por su alto contenido de este mineral (Martín-Diana y col., 2007). Otras formas de calcio utilizadas en la industria de alimentos son lactato gluconato, cloruro, fosfato, propionato $\mathrm{y}$ gluconato de calcio, empleándose como preservadores y mejoradores de textura (Luna-Guzmán y col., 2000; Manganaris y col., 2007). La selección de la fuente apropiada depende de varios factores como biodisponibilidad, solubilidad, cambios en sabor e interacción con otros ingredientes. Algunas sales de calcio, como el gluconato, el lactato y el lactato gluconato de calcio, tienen buena solubilidad pero bajo contenido de dicho mineral (Tabla 2).

Tabla 2. Características de sales de calcio usadas en la industria*

\begin{tabular}{|c|c|c|c|}
\hline Producto & $\begin{array}{c}\text { Solubilidad a } \\
25^{\circ} \mathrm{C}(\mathrm{g} / \mathrm{L})\end{array}$ & Sabor & $\begin{array}{c}\text { Contenido de } \\
\text { calcio (\%) }\end{array}$ \\
\hline Carbonato de calcio & Insoluble & $\begin{array}{l}\text { Untuoso, } \\
\text { alimonado }\end{array}$ & $40-90$ \\
\hline Fosfato de calcio & Insoluble & $\begin{array}{l}\text { Arenoso, } \\
\text { suavemente dulce }\end{array}$ & $17-38$ \\
\hline $\begin{array}{l}\text { Citrato tricálcico (4 } \\
\mathrm{H}_{2} \mathrm{O} \text { ) }\end{array}$ & 0,2 & Neutral & 21 \\
\hline $\begin{array}{l}\text { Lactato gluconato } \\
\text { de calcio }\left(5 \mathrm{H}_{2} \mathrm{O}\right)\end{array}$ & 9,3 & Suavemente dulce & 13 \\
\hline $\begin{array}{l}\text { Lactato gluconato } \\
\text { de calcio }\end{array}$ & $45-50$ & Neutral & $10-13$ \\
\hline Gluconato de calcio & 3,5 & Suave, neutral & 9 \\
\hline
\end{tabular}

*Gestner G. (2002). El desafio de la fortificación. Énfasis Alimentación $N^{\circ} 4$. 
La solubilidad de las sales de calcio está fuertemente influida por el pH del sistema ya que se incrementa cuando el pH decrece. El lactato gluconato de calcio se provee como un pentahidrato, conteniendo un $13 \%$ de calcio. Tiene una excelente solubilidad, razón por la cual es el más utilizado en bebidas a fin de conseguir los niveles necesarios para los requerimientos nutricionales de calcio (Gestner, 2002). Sin embargo, sales altamente solubles generan más iones calcio libres en solución, los cuales están más disponibles para reaccionar, pudiéndose formar sedimentos de calcio con el tiempo. Es necesario, entonces, mantener controlado el pH y adicionar agentes quelantes (Gestner, 2002).

El gluconato de calcio también muestra buena solubilidad, aunque su contenido de calcio es bajo (9\%). Sin embargo, sus propiedades neutrales de sabor, alta velocidad de disolución y bajo contenido de agua lo vuelve una fuente de calcio para preparaciones instantáneas como polvos para bebidas fortificadas, permitiendo altas cantidades de calcio por porción. La combinación de lactato con gluconato de calcio genera una sal soluble que muestra propiedades muy interesantes; su solubilidad está basada en la sinergia de sus componentes. Esto da como resultado una solubilidad de 45 a $50 \mathrm{~g} / \mathrm{L}$, dependiendo de la proporción de la mezcla. Esta alta solubilidad se debe a la habilidad de las mezclas de los iones de lactato y gluconato para formar complejos metaestables con iones de calcio en solución, lo que proporciona beneficios adicionales (Gestner, 2002). Debido a la mejor estabilidad de las bebidas fortificadas con lactato gluconato de calcio, las mismas pueden fortificarse sin adicionarles agentes quelantes Además, se pueden alcanzar mayores concentraciones de calcio, incluso en aplicaciones críticas como los jugos de uva y de arándano, bebidas a base de té y premezclas concentradas (Gestner, 2002). Esta sal como fuente de calcio es muy importante debido a su biodisponibilidad relativamente alta y el sabor neutro que imparte a los productos donde es utilizada, especialmente, frutas. 


\section{Aspectos nutricionales}

Desde el punto de vista nutricional, el calcio es un mineral clave en el cuerpo humano, necesario para el normal crecimiento y desarrollo del esqueleto, así como también de los dientes, nervios, músculos y de las funciones enzimáticas. En el metabolismo óseo tanto el calcio como la vitamina D son esenciales. Como la capacidad del cuerpo para absorber calcio disminuye con la edad, es vital tener la cantidad necesaria de calcio para envejecer sanamente. Los requerimientos varian durante la vida del individuo y entre distintos grupos de población. En este sentido, el Instituto Nacional de Salud de EE.UU. (NIH) definió valores específicos para cada grupo poblacional. Por ejemplo, el consumo de calcio debe ser de $1000 \mathrm{mg} /$ día para adultos (25-65 años) y de $1500 \mathrm{mg} /$ día para ancianos (mayores de 65 años) o mujeres que amamantan. Existen distintas opciones para evitar la deficiencia de calcio. Una de ellas es mediante el incremento del consumo diario de este mineral a través de una dieta balanceada que cuente con alimentos ricos en calcio, como la leche y sus derivados y ciertos vegetales (brócoli, repollo chino y legumbres). Otra posibilidad consiste en consumir alimentos fortificados con calcio, como un valor agregado del producto (Cabo Masip, 2008).

\section{Objetivos}

Los objetivos de este capítulo fueron evaluar el efecto del pretratamiento con carbonato y lactato-gluconato de calcio, sobre la textura, color, microestructura y contenido de calcio remanente en la manzana fresca y en anillos de manzana horneados. 


\subsection{MATERIALES Y MÉTODOS}

\subsubsection{MATERIALES}

Manzanas Granny Smith (Malus domestica) adquiridas en el mercado local, se seleccionaron por tamaño y apariencia. Para los ensayos se utilizaron manzanas estandarizadas (85\% humedad y $11 \pm 1$ ${ }^{\circ}$ Brix) las cuales fueron almacenadas entre 4 y $6{ }^{\circ} \mathrm{C}$ hasta su uso. Para la aplicación de los pretratamientos, se utilizaron lactato-gluconato de calcio (grado alimenticio, Jungbunzlauer, Alemania) y carbonato de calcio (grado analítico, Mallinckrodt Chemical Works, EE.UU.).

\subsubsection{MÉTODOS}

\subsubsection{Preparación de los anillos de manzana}

Las manzanas fueron lavadas y secadas con una toalla de papel. Se cortaron en rodajas de espesor de $2 \pm 0,2 \mathrm{~mm}$ perpendiculares al núcleo de la fruta usando un procesador doméstico (Yelmo, Argentina). Con un sacabocados de $35 \mathrm{~mm}$ de diámetro se cortaron discos y se retiró el centro de cada una con un punzón de $10 \mathrm{~mm}$ de diámetro. Los anillos de manzana obtenidos se secaron con toalla de papel. Los anillos fueron divididos en grupos de 10 muestras cada uno.

\subsubsection{Selección del tiempo/temperatura de horneado}

Se utilizó un horno de convección forzada Multiequip HCE-3 (Argentina). Grupos de 10 muestras con y sin pretratamientos fueron sometidos a cocción para determinar la temperatura y el tiempo óptimo de horneado. Se probaron tres temperaturas $\left(80,100\right.$ y $\left.140^{\circ} \mathrm{C}\right)$. Luego de horneadas las muestras se dejaron enfriar a temperatura ambiente y se almacenaron a $20^{\circ} \mathrm{C}$.

\subsubsection{Pretratamientos aplicados sobre los anillos de manzana}

Los anillos de manzana obtenidos se dividieron en 2 grupos y se realizó la inmersión de 10 anillos en soluciones al 2,5\% (p/v) de carbonato de calcio (CC) o lactato-gluconato de calcio (CL) durante 2, 5, $10,15,30$ y 60 min a temperatura ambiente con agitación manual. 
Para ambos casos las muestras, luego de transcurrido el tiempo correspondiente a cada ensayo, fueron tratadas térmicamente con vapor a $121^{\circ} \mathrm{C}$ durante $3 \mathrm{~min}$ (Demarchi, 2010) utilizando una vaporera doméstica (Oster, Argentina). Los anillos de manzana se enfriaron en un baño de hielo y se hornearon (Figura 5).

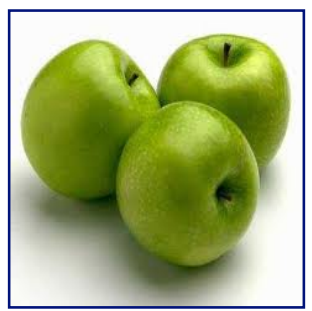

Manzana fresca cv. Granny Smith

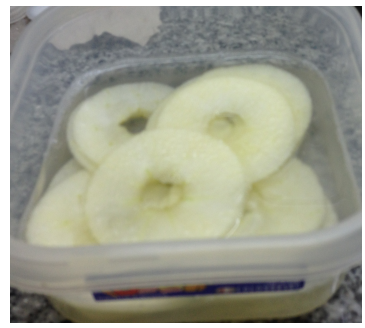

Inmersión en sales de calcio

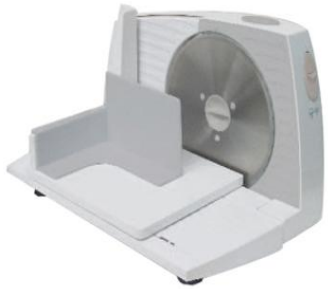

Preparación de los anillos de manzana: cilindro externo e

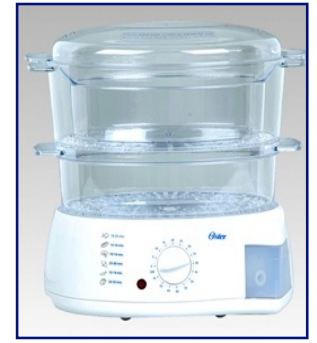

Tratamiento con vapor interno
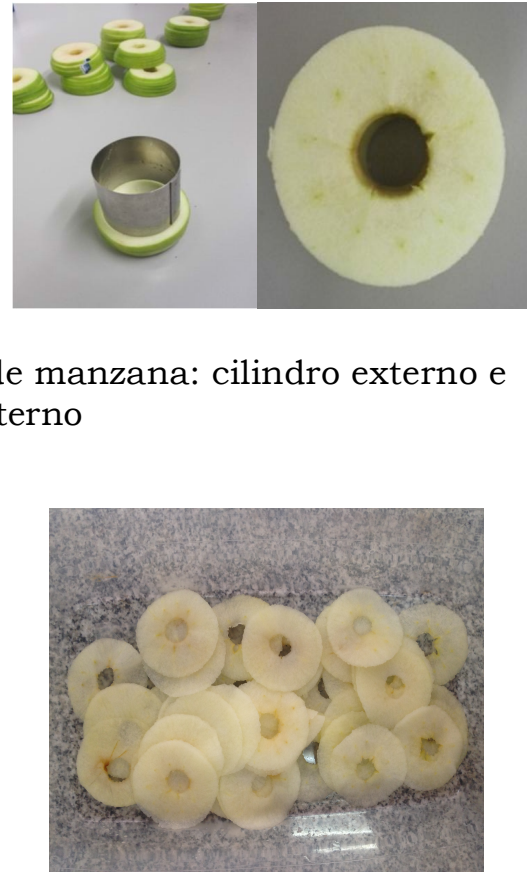

Anillos de manzana con calcio

Figura 5. Proceso de obtención de anillos de manzana con calcio

\subsubsection{Determinación de las propiedades fisicoquímicas $y$ microestructurales}

Los anillos de manzana horneados con y sin pretratamiento con carbonato y/o lactato-gluconato de calcio, se analizaron para determinar el contenido de humedad (método AOAC, 1980), de cenizas (Harbers, 1998) y de calcio. Se observó la microestructura a través de microscopía electrónica de barrido (SEM) y se realizaron medidas 
instrumentales de actividad acuosa (equipo Aqualab 3TE) tal como se describió en el Capítulo 1.

\section{Determinación del contenido de calcio}

El contenido de calcio fue medido por espectrofotometría de absorción atómica. Se seleccionaron los anillos de manzana tratados durante 2, 15 y 60 min para realizar esta determinación. Las muestras previamente secadas en estufa, fueron llevadas a una mufla hasta la obtención de cenizas blancas (Harbers, 1998). Las cenizas obtenidas fueron disueltas en $\mathrm{HCl} 2 \mathrm{~N}$, luego esta solución fue filtrada y llevada a un volumen de $25 \mathrm{ml}$. Se agregó cloruro de lantano ( $\left.\mathrm{LaCl}_{3}\right)$ para eliminar interferencias debidas a la presencia de sulfatos. Las soluciones obtenidas fueron analizadas usando un espectrofotómetro de absorción atómica AA 6200 (Shimadzu, Japón) empleando una longitud de onda de 422,7 $\mathrm{nm}$, un ancho de rendija de 0,5 $\mathrm{nm}$ y llama de aire/acetileno. Las determinaciones se realizaron por duplicado. Los resultados se expresaron en $\mathrm{gCa} / 100 g_{\text {cenizas. }}$.

\section{Análisis de textura}

La textura es uno de los atributos primarios que conforman la calidad sensorial de los alimentos y es el resultado de la acción de estímulos de distinta naturaleza, ya sean mecano-receptores, táctiles y en ciertos casos auditivos y visuales sobre la estructura de un alimento. La medida de textura depende principalmente de la percepción de la respuesta del alimento cuando actúan sobre él determinadas fuerzas durante la masticación o la manipulación previa a la ingestión (Szczesniak, 2002).

Para medir la textura de las muestras, se realizó un test de ruptura, donde se cuantificaron las características mecánicas relacionadas con la dureza y rigidez del producto, asociadas a la crocancia. En el ensayo la dureza es la fuerza máxima requerida para romper la muestra (Choy y col., 2012). La crocancia se relaciona con fracturas abruptas bajo la aplicación de una fuerza relativamente baja (la primera fuerza de 
ruptura) (Huang y col., 2011; Tavera-Quiroz y col., 2012). Para realizar el test se utilizó una sonda semi-esférica de $5 \mathrm{~mm}$ de diámetro $(\mathrm{P} / 5 \mathrm{~S})$, la cual se utiliza para medir las características de fracturabilidad en productos tipo snack. La muestra fue apoyada sobre un cilindro hueco con un orificio de $3 \mathrm{~cm}$ de diámetro (HDP/CFS). El cual se utilizó como soporte de la muestra en los ensayos de penetración. El soporte permitió la localización exacta y la alineación de la muestra con la sonda. La sonda semi-esférica se mueve hacia abajo sobre la muestra, situada sobre el soporte circular, hasta el punto de fractura (Figura 6).

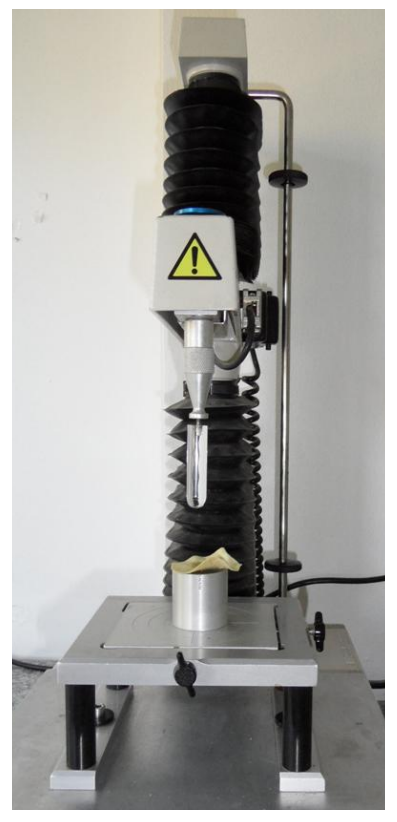

Figura 6. Sonda y sistema de apoyo de la muestra en los ensayos para analizar la textura de las muestras con y sin calcio

El ensayo se realizó a una velocidad de $1 \mathrm{~mm} / \mathrm{s}$ hasta la ruptura. Se analizaron 10 muestras para cada tiempo de pretratamiento. Los parámetros evaluados a partir de las respectivas curvas fuerzadeformación obtenidas del ensayo fueron:

> Fuerza máxima ( $\mathrm{F}$ máx): máxima fuerza $(\mathrm{N})$ requerida por la sonda para atravesar la muestra hasta la primera fractura. 
$>$ Desplazamiento $(\mathrm{d})$ : distancia $(\mathrm{mm})$ recorrida por la sonda hasta lograr atravesar la muestra.

$>$ Pendiente: evaluada en el tramo lineal inicial de la curva de fuerza-desplazamiento $(\mathrm{N} / \mathrm{mm})$.

\section{Microscopia electrónica de barrido}

Con el objetivo de observar la microestructura se examinaron muestras con y sin agregado de sales de calcio, mediante SEM (LEO 1420VP, Carl Zeiss SMT AG, Alemania) sin revestimiento metálico y bajo vacío. Las muestras fueron analizadas con aumentos de $150 \mathrm{x}, 300$ $\mathrm{x}, 600$ x y $1200 \mathrm{x}$.

\subsubsection{Análisis estadístico}

Se realizó un análisis de varianza (ANAVA) para evaluar el efecto de los factores analizados utilizando el programa Systat 12 (Systat software Inc., USA). Para los ensayos de comparación de medias se empleó el test de menor diferencia significativa (LSD) con $P<0,05$.

\subsection{RESULTADOS Y DISCUSIÓN}

Los resultados obtenidos de humedad, $\mathrm{a}_{\mathrm{w}} \mathrm{y}$ observaciones de las características físicas de los anillos de manzana una vez finalizado el horneado se muestran en la Tabla 3.

En el desarrollo de productos tipo snack, las características organolépticas (color, textura, sabor) son las propiedades de mayor importancia en la aceptabilidad por parte de los consumidores habituales. El color de los alimentos influye de manera primordial en la aceptación de los mismos. Su calidad depende del grado de estabilidad de los pigmentos presentes y de los posibles cambios químicos que pueden desarrollarse (DeMan, 1999). 
Tabla 3. Resultados obtenidos de humedad y $\mathrm{a}_{\mathrm{w}}$ para anillos de manzana con calcio y sin calcio horneados a distintos tiempos.

\begin{tabular}{|c|c|c|c|c|}
\hline $\begin{array}{l}\mathrm{T}\left({ }^{\circ} \mathrm{C}\right) / \text { tiempo } \\
\text { de horneado } \\
(\min )\end{array}$ & Sal de calcio & $\begin{array}{c}\text { Humedad } \\
\text { (gagua/ } 100 g_{\text {muestra) }}\end{array}$ & $\mathbf{a}_{\mathbf{w}}$ & Observaciones \\
\hline $80 / 75$ & - & $12,2(2,0)$ & $0,45(0,03)$ & $\begin{array}{l}\text { No se observar } \\
\text { cambios de color }\end{array}$ \\
\hline $100 / 60$ & - & $9,4(1,0)$ & $0,47(0,04)$ & $\begin{array}{l}\text { Color amarillo } \\
\text { /caramelización }\end{array}$ \\
\hline $140 / 40$ & - & $4,5(0,02)$ & $0,39(0,02)$ & Quemadas \\
\hline $80 / 75$ & Carbonato & $10,2(1,0)$ & $0,50(0,05)$ & $\begin{array}{c}\text { No se observan } \\
\text { cambios en el } \\
\text { color- Depósitos } \\
\text { de calcio } \\
\text { superficial }\end{array}$ \\
\hline $100 / 60$ & Carbonato & $9,8(0,01)$ & $0,49(0,01)$ & $\begin{array}{l}\text { Caramelización- } \\
\text { Depósitos de } \\
\text { calcio en la } \\
\text { superficie. Mayor } \\
\text { firmeza }\end{array}$ \\
\hline $140 / 40$ & Carbonato & $3,5(0,05)$ & $0,32(0,02)$ & Quemadas \\
\hline $80 / 75$ & $\begin{array}{c}\text { Lactato } \\
\text { gluconato- }\end{array}$ & $6,5(0,05)$ & $0,43(0,02)$ & $\begin{array}{l}\text { No se observan } \\
\text { cambios de color }\end{array}$ \\
\hline $100 / 60$ & $\begin{array}{c}\text { Lactato } \\
\text { gluconato- }\end{array}$ & $5,8(0,02)$ & $0,42(0,02)$ & Caramelización \\
\hline $140 / 40$ & $\begin{array}{c}\text { Lactato } \\
\text { gluconato- }\end{array}$ & $2,2(1,0)$ & $0,33(0,01)$ & Quemadas \\
\hline
\end{tabular}


Las coloraciones pardas son debidas básicamente a reacciones de caramelización y de pardeamiento no enzimático. La reacción de pardeamiento no enzimático está determinada por la temperatura, la actividad de agua y el pH, así como por la presencia de los sustratos necesarios para la reacción, como lo son los azúcares reductores, las aminas, el ácido ascórbico, etc. El pardeamiento no enzimático además de desencadenar colores pardos en el producto, provoca el desarrollo de aromas y sabores los cuales serán deseables o indeseables dependiendo del alimento.

Teniendo en cuenta lo expresado anteriormente, se seleccionó la temperatura de $100^{\circ} \mathrm{C}$ y tiempo de horneado de 60 min para las muestras con pretratamiento tanto con lactato-gluconato como carbonato de calcio. Las muestras sometidas a esta temperatura tuvieron un mejor desarrollo de color y aromas, producto de la caramelización de los azúcares presentes en la manzana. A una mayor temperatura de horneado se observó la formación de compuestos pardos en exceso, lo cual además indica una mayor pérdida de nutrientes y desarrollo de color y aroma indeseables.

No se encontraron diferencias significativas en los valores de actividad acuosa $(\mathrm{P}>0,05)$ entre las muestras horneadas tratadas con sales de calcio y las muestras sin pretratamiento. Se observó una disminución de la humedad con el aumento de la temperatura de horneado $\left(140^{\circ} \mathrm{C}\right)$. Los valores más bajos de este parámetro se encontraron para anillos de manzana obtenidos por impregnación con lactato-gluconato de calcio comparado con las muestras tratadas con carbonato y las muestras sin pretratamiento, en todo el rango de temperaturas de horneado ensayadas $\left(80,100\right.$ y $\left.140^{\circ} \mathrm{C}\right)$.

Una vez seleccionados la temperatura y el tiempo de horneado, se determinó el contenido de calcio sobre las rodajas de manzana horneadas luego de ser pretratadas con las sales de calcio a distintos 
tiempos. Los resultados expresados en $\mathrm{g} \mathrm{Ca}^{+2} / 100 \mathrm{~g}_{\text {cenizas }}$ se observan en la Figura 7. En la Tabla 4 se presentan los resultados del contenido de calcio en las muestras secas.

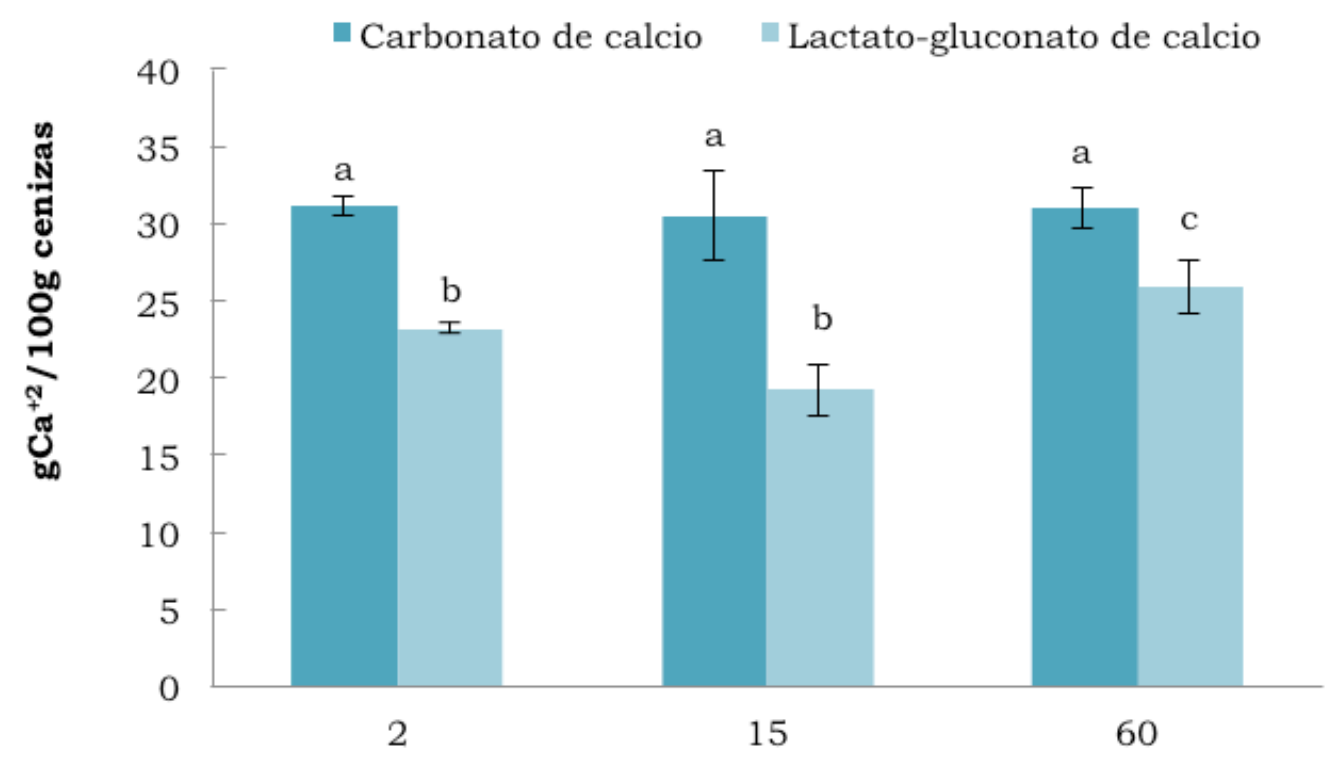

Tiempo de inmersión (min)

Figura 7. Contenido de calcio ( $\mathrm{g} \mathrm{Ca}^{+2} / 100 \mathrm{~g}_{\text {cenizas }}$ ) de los anillos de manzana impregnados con carbonato y lactato-gluconato de calcio durante diferentes tiempos. $a, b, c$ Letras diferentes indican diferencias significativas $(P<0,05)$.

Tabla 4. Contenido de calcio en las muestras tratadas con carbonato/lactatogluconato de calcio a distintos tiempos de inmersión

\begin{tabular}{lcc}
\hline \multicolumn{1}{c}{ Sal de calcio } & $\begin{array}{c}\text { Tiempo de inmersión } \\
(\mathbf{m i n})\end{array}$ & $\begin{array}{c}\text { Contenido de calcio } \\
\left(\mathbf{m g ~ C a} \mathbf{+ 2} / \mathbf{1 0 0} \mathbf{g}_{\mathbf{m s}}\right)\end{array}$ \\
\hline Carbonato & 2 & $2045,0(0,6)^{\mathrm{c}}$ \\
Lactato-gluconato & 15 & $678,2(0,4)^{\mathrm{a}}$ \\
\hline Carbonato & & $2103,0(2,9)^{\mathrm{c}}$ \\
Lactato-gluconato & 60 & $661,6(1,6)^{\mathrm{a}}$ \\
\hline Carbonato & & $3004,2(1,3)^{\mathrm{d}}$ \\
Lactato-gluconato & & $1238,1(1,70)^{\mathrm{b}}$ \\
\hline
\end{tabular}

$a, b, c, d$ Letras diferentes indican diferencias significativas $(P<0,05)$. Valores entre paréntesis indican la desviación estándar $(n=3)$. 
El contenido promedio de calcio en la manzana fresca fue de 40,0 mgCa ${ }^{+2} / \operatorname{loog}_{\mathrm{ms}}$. A partir de los datos obtenidos se observaron diferencias significativas $(\mathrm{P}<0,05)$ entre los distintos tiempos de impregnación (2, 15 y $60 \mathrm{~min})$ y entre las sales de calcio utilizadas. A tiempos largos de inmersión se observó una pérdida de firmeza y una degradación del tejido de la manzana debido al tratamiento prolongado y la agitación (Figura 8).
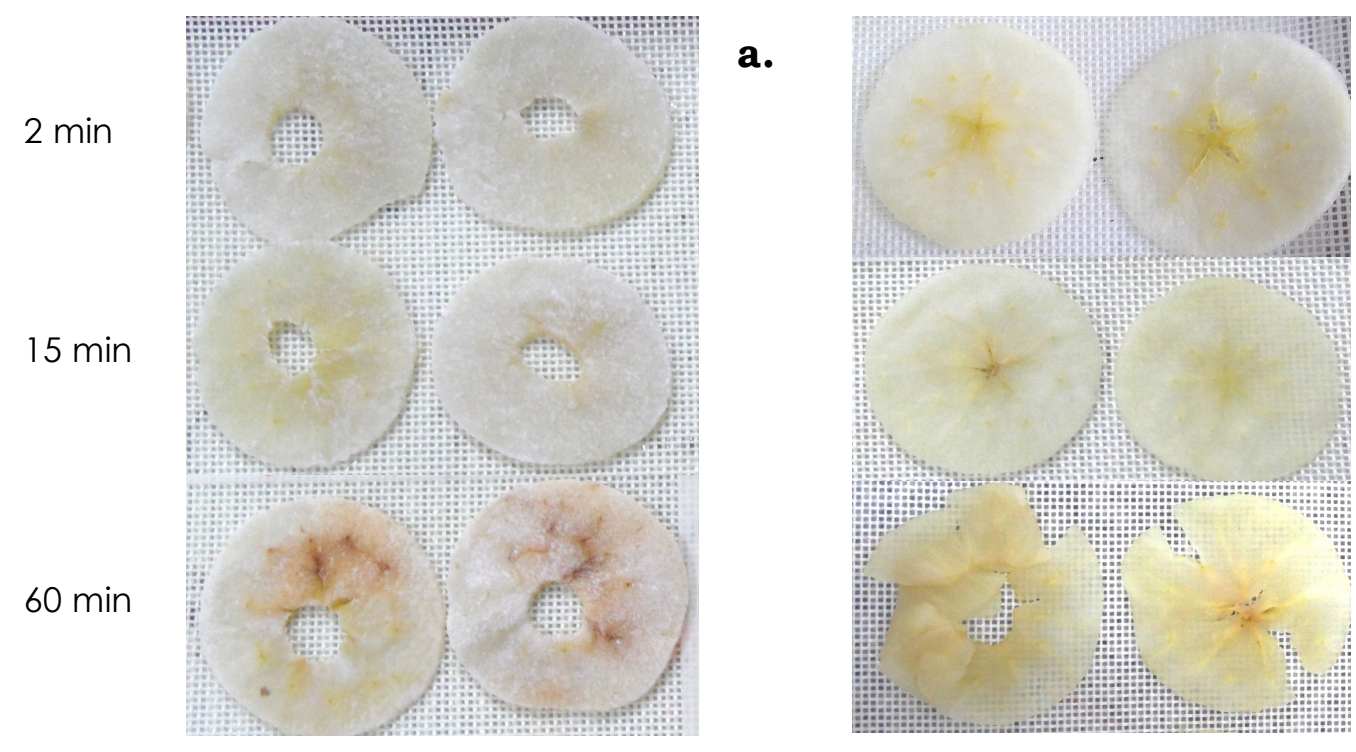

b.

Figura 8. Muestras de manzana pretratadas a 2, 15 y 60 min con a. Carbonato de calcio; b. Lactato-gluconato de calcio.

Los resultados obtenidos para el contenido de calcio mostraron que las muestras de manzana impregnadas con carbonato contienen más cantidad de calcio que los tratados con lactato-gluconato, para todos los tiempos de inmersión ensayados. El carbonato, si bien aporta un mayor contenido de $\mathrm{Ca}^{+2}$, tiene valores de solubilidad más bajos comparados con el lactato-gluconato de calcio. Como consecuencia, el mineral se mantiene sobre la superficie de la rodaja y lleva a que el producto horneado presente una coloración blancuzca y opaca, poco agradable para el consumidor. El lactato-gluconato además de poseer una alta solubilidad, no genera residuos superficiales. Por esta razón el tejido desarrolla un proceso de caramelización más efectivo (Figura 9). 


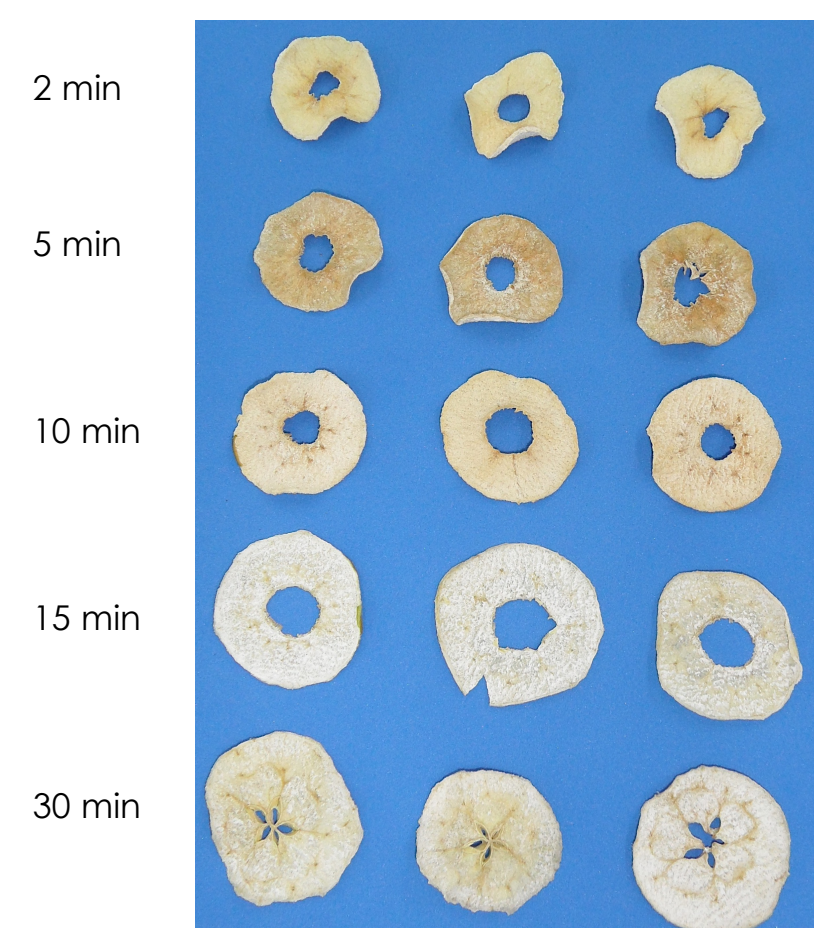

a.

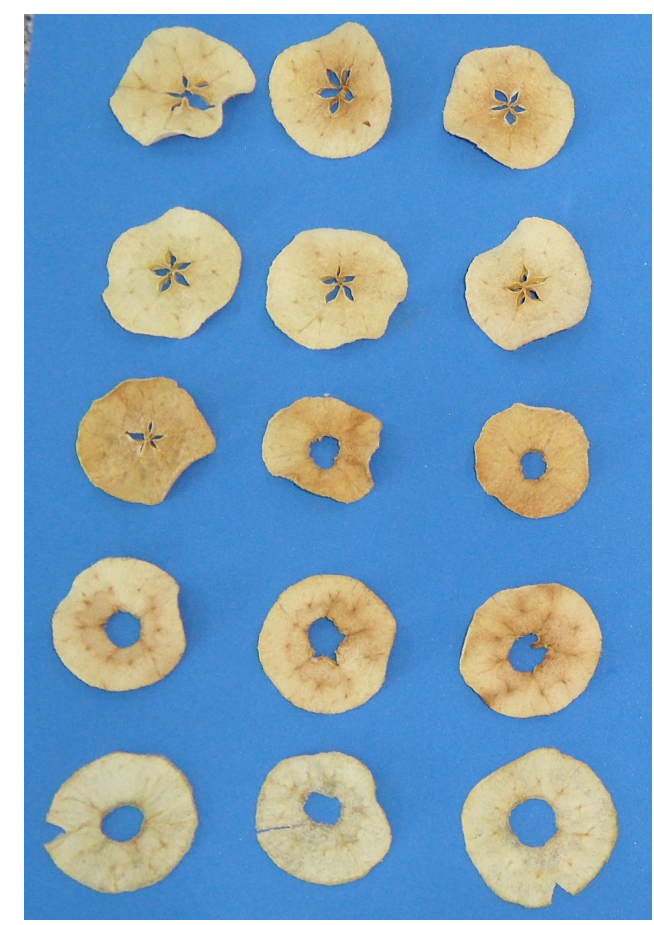

b.

Figura 9. Anillos de manzana horneadas pretratadas a 2, 5, 10, 15 y $30 \mathrm{~min}$ con a. Carbonato de calcio, b. Lactato-gluconato de calcio

La ingesta de $\mathrm{Ca}^{+2}$ diaria recomendada (RDA) está comprendida entre 1000 y $1300 \mathrm{mg}$ por día. Una porción de $20 \mathrm{~g}$ de snack tratados con lactato-gluconato de calcio proporcionaría el equivalente a $150 \mathrm{mg}$ de $\mathrm{Ca}^{+2}$, la misma cantidad que aporta media taza de yogur (Cabo Masip y col., 2008). Según el Código Alimentario Argentino (CAA) los alimentos fortificados deben aportar entre el 20 y el $100 \%$ de los requerimientos diarios recomendados. En consecuencia, se tendría un indicio de que un producto tratado con lactato-gluconato de calcio podría rotularse como alimento fortificado. Además teniendo en cuenta que este mineral tiene una alta resistencia al calor, es de esperar que no se vea afectado por el proceso de cocción de la matriz soporte (Fuertes y Navarro, 2011).

\section{Análisis de la textura de las muestras tratadas con las sales de calcio}

En la Figura 10 se muestran las curvas obtenidas a partir del ensayo de ruptura para las muestras tratadas con calcio y muestras sin 
tratar. En la Figura 11 a y b se presentan los resultados de fuerza máxima $(\mathrm{N})$ y de la pendiente de la curva fuerza-desplazamiento $(\mathrm{N} / \mathrm{mm})$ en función del tiempo de tratamiento para las dos sales de calcio utilizadas en este estudio.

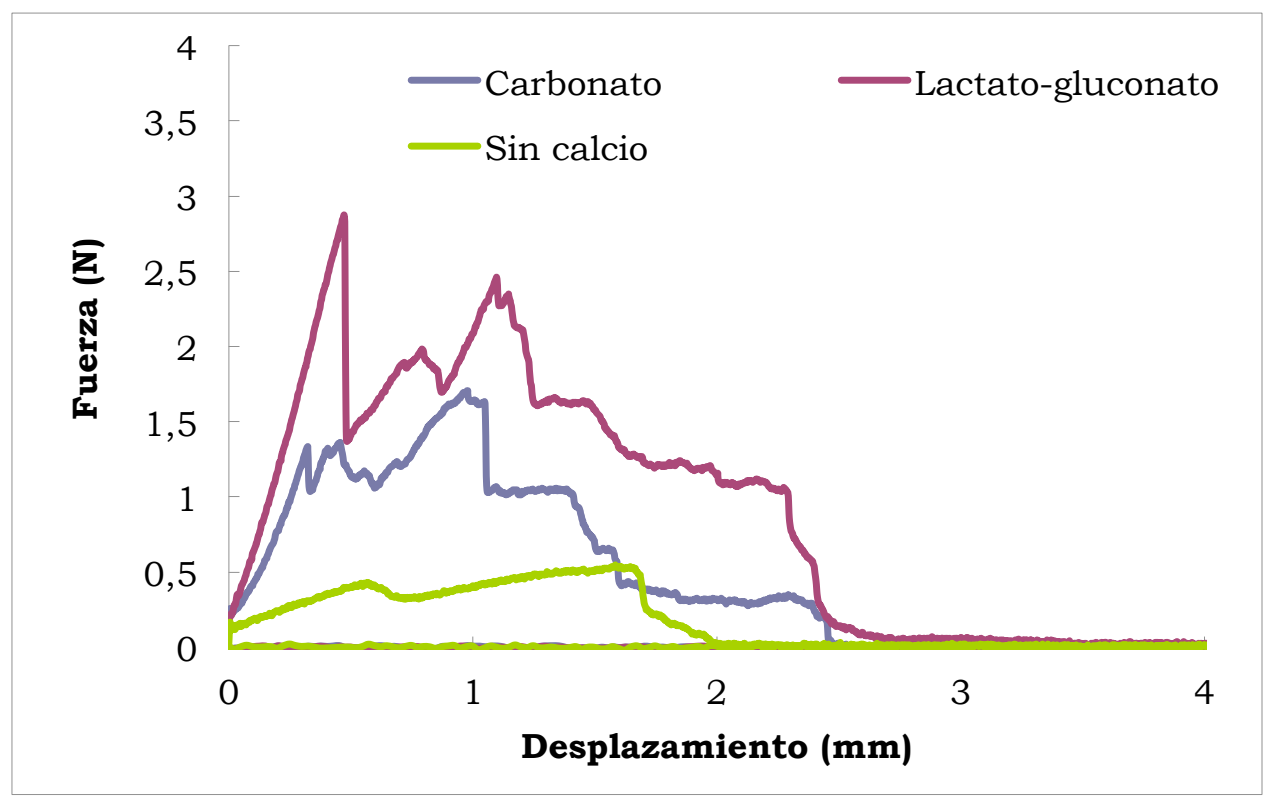

Figura 10. Curvas obtenidas del ensayo de fuerza-desplazamiento para los anillos de manzana tratados con calcio durante 2 min, comparadas con muestras horneadas sin tratamiento.

Las muestras impregnadas con calcio presentaron un comportamiento con múltiples fracturas, asociadas a los diferentes picos que aparecen después de la primera fractura. Esta forma de la curva se observa en productos porosos y quebradizos. Según Contreras (2006), la fuerza máxima está relacionada con la resistencia del producto a la fractura o dureza, mientras que la pendiente inicial se relaciona con el módulo de elasticidad o resistencia a la deformación de la muestra. Para las muestras horneadas sin tratamiento con calcio, los valores de fuerza máxima y de la pendiente fueron $1,0 \mathrm{~N}$ y $0,8 \mathrm{~N} / \mathrm{mm}$, respectivamente (Figura 11 a y b). 


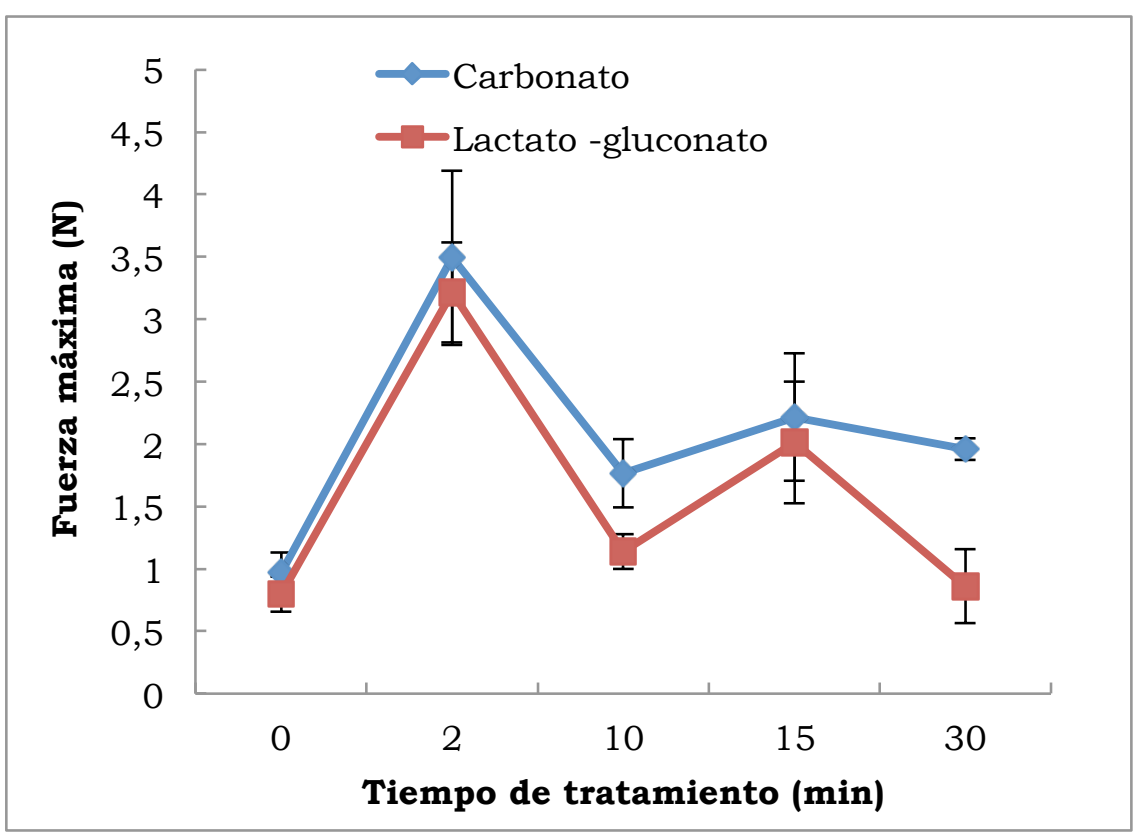

a.

b.

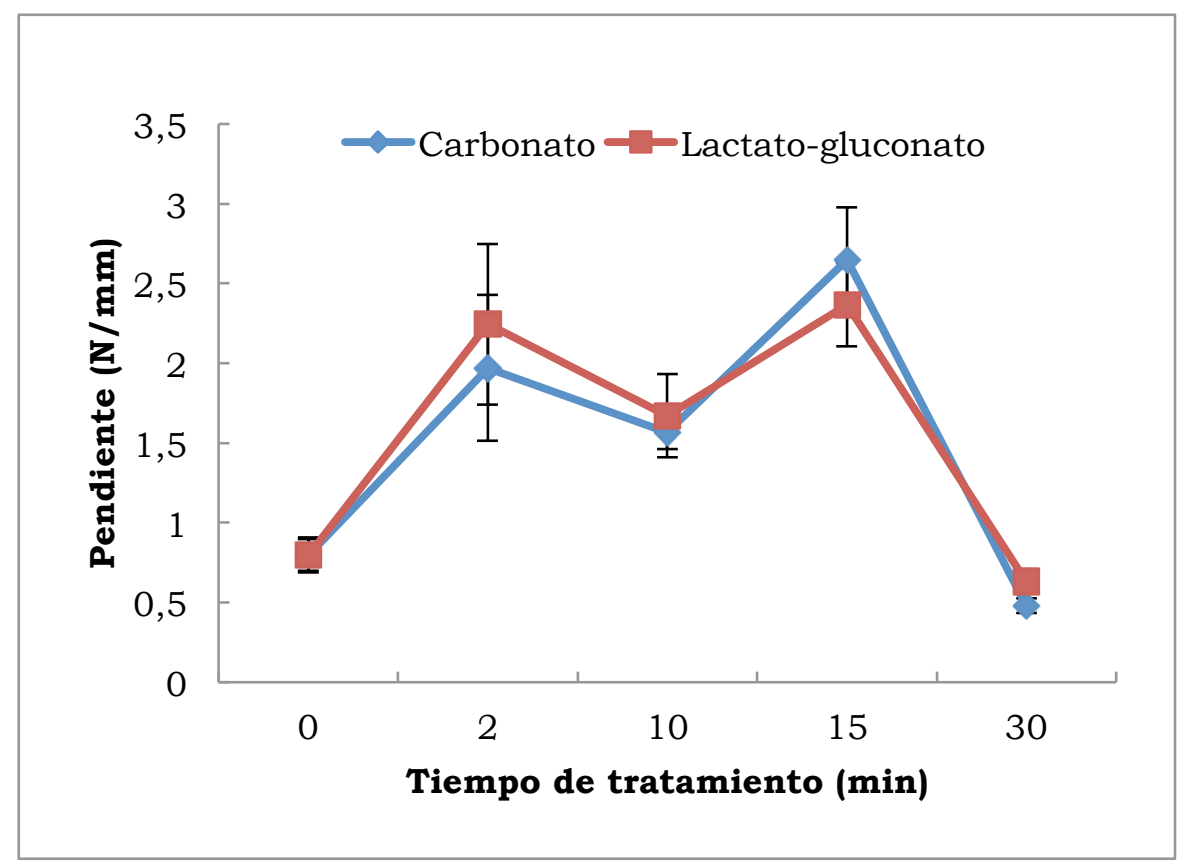

Figura 11. a. Fuerza máxima (N), b. Pendiente de la curva fuerzadesplazamiento $(\mathrm{N} / \mathrm{mm})$ de anillos de manzana tratadas con sales de calcio (carbonato y lactato- gluconato) a distintos tiempos. 
Al evaluar el efecto del tiempo de tratamiento con calcio se observó que la impregnación de las muestras con calcio aumentó la firmeza del tejido respecto del valor obtenido para la manzana sin tratamiento con calcio mientras el tiempo no superó los 30 min (Figura 11 b). Una vez que el tiempo de tratamiento fue $\geq 30 \mathrm{~min}$, se observó un cambio negativo en la pendiente, asociada con la firmeza. El mayor valor de la fuerza máxima se obtuvo para un tiempo de tratamiento de 2 min por lo tanto se seleccionó este tiempo de inmersión. Por otro parte no se observaron diferencias significativas entre las dos sales de calcio estudiadas $(\mathrm{P}>0,05)$.

La pérdida de firmeza, acompañada de la disminución de la fuerza máxima de ruptura, puede ser consecuencia de una degradación de la estructura originada por el tratamiento prolongado, la agitación del medio y la geometría de las muestras. Anino y col. (2006) informaron que el calcio actúa en dos formas opuestas, mientras una mantiene las paredes de las células a través de la reticulación de los polímeros de pectina, la otra causa la interrupción interna grave de las membranas celulares y una considerable reducción en la firmeza de tejido. Estos autores observaron un ablandamiento del tejido de la manzana después de 6 h de impregnación con calcio en una solución isotónica de glucosa.

A pesar de que el calcio puede favorecer la textura de los tejidos de la muestra mediante la formación de pectato, las concentraciones por encima de 1,5\% también puede generar plasmólisis celular, aumento de la disolución de pectina y la consecuente reducción de la firmeza del producto tal como ha sido reportado por Castelló y col. (2009), Ferrari y col. (2010) y Lovera y col. (2011). Los resultados obtenidos a partir del análisis de los parámetros de textura se correlacionaron con el aumento del contenido de calcio en las muestras. Para el caso del carbonato al tener una menor solubilidad comparado con otras sales de calcio, generó una capa sobre el tejido de la muestra haciéndola más firme a tiempos cortos de inmersión. Sin embargo, a medida que aumentó el 
tiempo de tratamiento esta sal de calcio forma depósitos sobre la superficie de las rodajas, provocando daño estructural. Además, al depositarse sobre la superficie, evita que durante el horneado se pueda lograr la caramelización de los azúcares presentes en la muestra. Fuertes y Navarro (2011) establecieron que para ciertos alimentos cuando se fortifican con carbonato de calcio, este compuesto puede conferirles un sabor residual amargo, debido a que los aniones carbonato impactan en el sabor. Adicionalmente, el proceso térmico libera dióxido de carbono del carbonato, lo cual es indeseable (Weaver, 1998). En el caso del lactato-gluconato de calcio, tal como se dijo anteriormente su mayor solubilidad le permitió penetrar en la matriz de forma más eficiente. Sin embargo, el exceso en el tiempo de tratamiento y la concentración de la sal en la solución también generaron pérdida de textura.

\section{Micrografias obtenidas por SEM}

En las micrografias obtenidas por SEM (Figura 12 y 13) se pueden observar las partículas de calcio retenidas y distribuidas sobre una matriz aireada y porosa. En el caso de las muestras con carbonato, se observa el calcio formando una capa superficial, mientras que para las muestras tratados con lactato-gluconato, el calcio parece encontrarse distribuido homogéneamente en los poros de la matriz formando parte de la estructura, tal y como se puede ver en la Figura 13. Fuertes y Navarro (2011) obtuvieron resultados similares en matrices de hidrocoloides. 


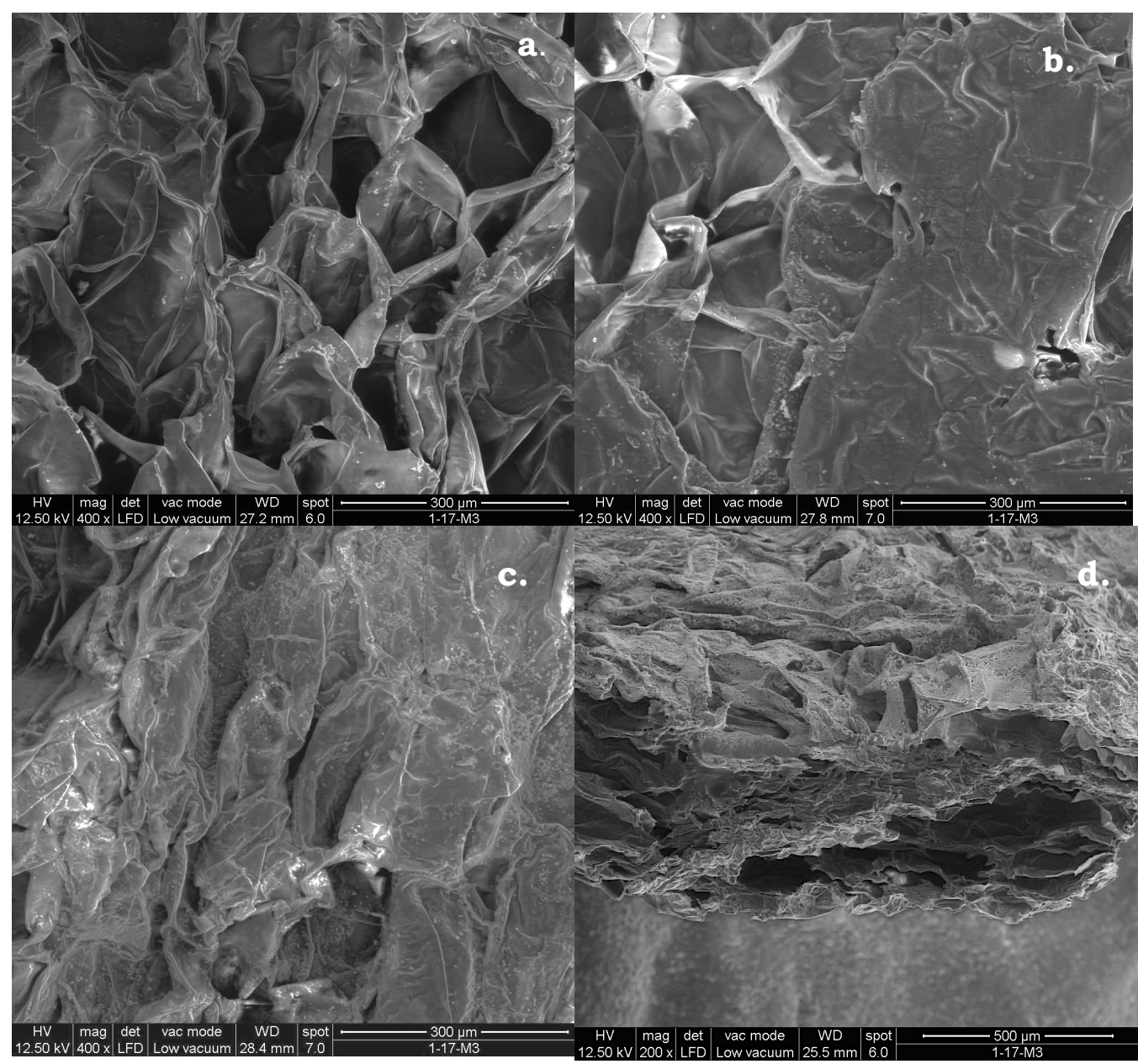

Figura 12. Rodajas de manzana tratadas con carbonato de calcio: a. 2 min $(400 \mathrm{x})$, b. $15 \min (400 \mathrm{x})$, c. $30 \min (400 \mathrm{x})$ y d. Corte transversal (30 $\mathrm{min})$ (200x). 


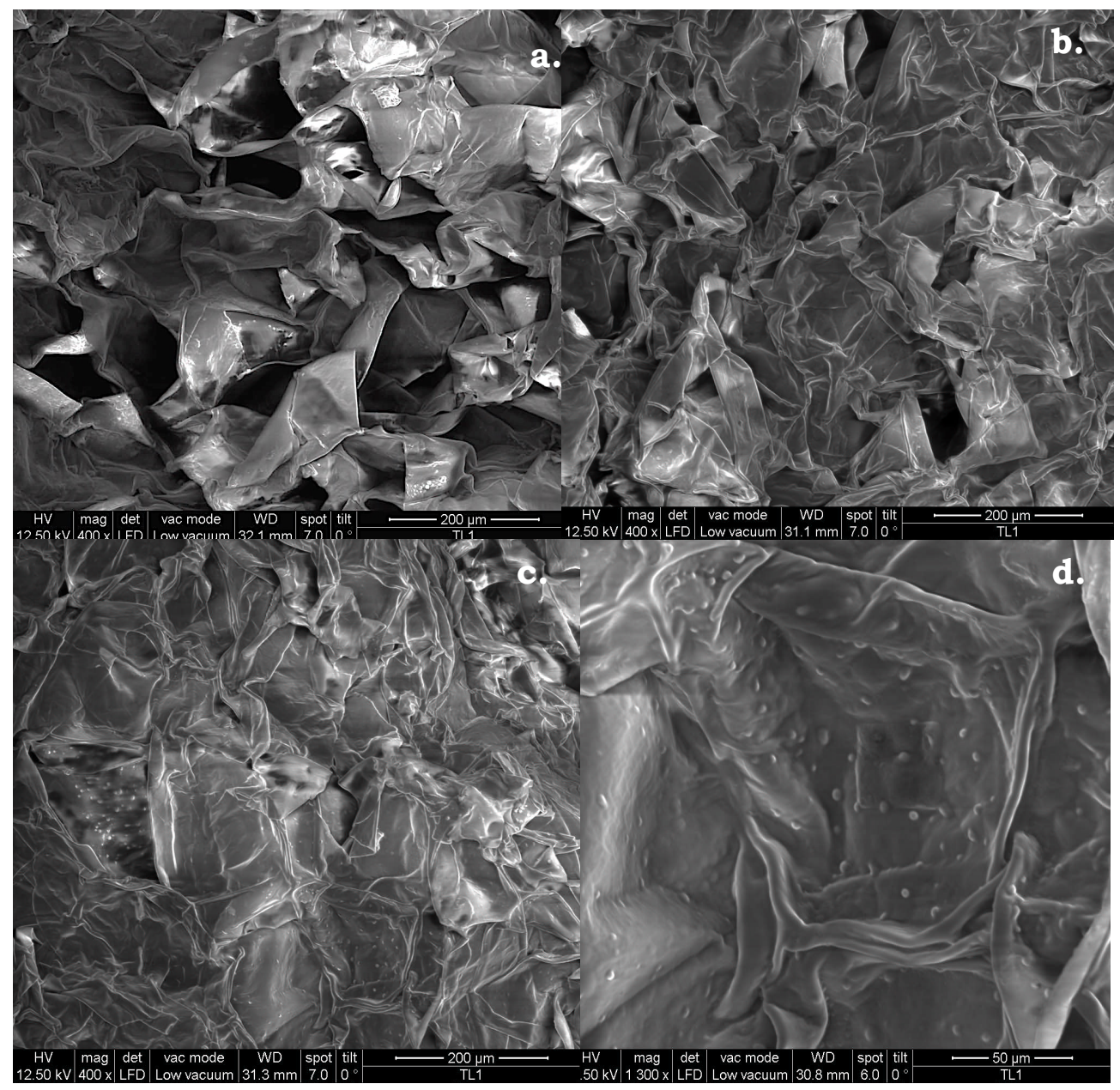

Figura 13. Rodajas de manzana tratadas con lactato-gluconato de calcio: a. 2 $\min (400 x)$, b. $10 \min (400 x)$, c. $15 \min (400 x)$ y d. $15 \min (1300 x)$.

\subsection{CONCLUSIONES}

Teniendo en cuenta el desarrollo de color producto de la caramelización de los azúcares presentes en la manzana, la temperatura de horneado de los anillos de manzana seleccionada fue $100^{\circ} \mathrm{C}$ y el tiempo de $60 \mathrm{~min}$.

En cuanto a los atributos de calidad se encontró una incidencia negativa en el color cuando las muestras se trataron con carbonato de calcio. Se observó un aumento de la resistencia del tejido en el ensayo 
de textura durante los primeros minutos de impregnación, independientemente de la sal de calcio utilizada.

El tratamiento de los anillos de manzana con lactato-gluconato de calcio permitió obtener un aumento en la firmeza y una absorción de calcio en el tejido sin afectar el color de las muestras, debido a la mayor solubilidad de esta sal de calcio en solución.

Los tratamientos con sales de calcio dependen principalmente de la sal seleccionada. A iguales condiciones de temperatura, tiempo y concentración de la solución, el contenido final de Ca fue mayor en la fruta pretratada con carbonato de Ca que en la tratada con lactatogluconato de $\mathrm{Ca}$. Si bien se obtuvieron valores más altos en cuanto al contenido de calcio con el uso de carbonato, los niveles de este mineral alcanzados con lactato-gluconato permitirian rotular el producto obtenido como alimento fortificado, teniendo en cuenta que aún resta confirmar los valores remanentes en el producto final.

\subsection{REFERENCIAS}

AOAC Official methods of analysis. (1980). Association of Official Analytical Chemists (13th ed), Washington, DC.

Aguayo, E., Escalona, V., Artés, F. (2008). Effect of hot water treatment and various calcium salts on quality of fresh-cut 'Amarillo' melon. Postharvest Biology and Technology, 47: 397-406.

Anino, S.V., Salvatori, D.M., Alzamora, S.M. (2006). Changes in calcium level and mechanical properties of apple tissue due to impregnation with calcium salts. Food Research International, 39: 154164.

Alothman, M., Bhat, R., Karim A.A. (2009). UV radiation-induced changes of antioxidant capacity of fresh-cut tropical fruits. Innovative Food Science \& Emerging Technologies, 10(4): 512-516. 
Alzamora S.M., Castro, M., Nieto, A., Vidales, S., Salvatori D. (2000). The rol of tissue microestructure in the textura of minimally processed fruits, Minimally processed fruits and vegetables/ed. S. M. Alzamora, M. S. Tapia and A. López Malo, Aspen Publishers Inc., Gaithersburg, Maryland, 153-171.

Alzamora, S.M., Salvatori, D., Tapia, M., López-Malo, A., WeltiChanes, J., Fito, P. (2005). Novel functional foods from vegetable matrices impregnated with biologically active compounds. Journal of Food Engineering, 67: 205-2014.

Allende, A., Marin, A., Buendia, B., Tomás-Barberán, F., Gil, M.I. (2007). Impact of combined postharvest treatments (UV-C light, gaseous $\mathrm{O}_{3}$, super atmospheric $\mathrm{O}_{2}$ and high $\mathrm{CO}_{2}$ ) on health promoting compounds and shelf-life of strawberries. Postharvest Biology and Technology, 46(3): 201-211.

Artés-Hernández, F., Robles, P.A., Gómez, P.A, Tomás-Callejas, A., Artés F. (2010). Low UV-C illumination for keeping overall quality of fresh-cut watermelon. Postharvest Biology and Technology, 55(2): 114120 .

Barcelo, J., Nicolas, G., Sabater, B., Sánchez-Tamés, R. (2001). Fisiología vegetal. Madrid: Editorial Piramide.

Bartolomé, L., G., Hoff, J. E. (1972). Firming of potatoes: biochemical effect of preheating. Journal of Agriculture and Food Chemistry, 20: 266-270.

Bhande, S.D, Ravindra, M.R., Goswami, T.K. (2008). Respiration rate of banana fruit under aerobic conditions at different storage temperatures. Journal of Food Engineering, 87(1): 116-123.

Brett, C., Waldrom, K. (1990). Physiology and biochemistry of plant cell walls. Inglaterra: Ed.Chapman \& Hall. 
Cabo Masip, T., Alentado Morell, N., Dalmau Serra, J. (2008). Nuevas recomendaciones diarias de ingesta de calcio y vitamina D: revención del raquitismo nutricional. Acta Pediátrica Española, 66 (5): 233-236.

Castelló, M.L., Igual, M., Fito, P.J., Chiralt, A.(2009). Influence of osmotic dehydration on texture, respiration and microbial stability of apple slices (var. Granny Smith). Journal of Food Engineering, 91(1): 19.

Código Alimentario Argentino. ANMAT. Alimentos de régimen o dietéticos. Capítulo XVII. Artículos 1339-1390. Actualizado 3/2013.

Contreras, C. (2006). Influencia del método de secado enparámetros de calidad relacionados con la estructura y el color de manzana y fresa deshidratadas. Tesis doctoral. Universidad Politécnica de Valencia (España).

DeMan, J. (1999). Principles of Food Chemistry. 3 ed. Aspen Publication, Maryland (USA).

Demarchi, S. (2010). Desarrollo de un gel péctico deshidratado de manzana reducido en calorías. Trabajo final. Facultad de Ciencias Exactas. Licenciatura en Tecnología de Alimentos. Universidad Nacional de La Plata (Argentina).

Ferrari, C.C., Carmello-Guerreiro, S.M., Bolini, H.M.A., Hubinger, M.D. (2010). Structural changes, mechanical properties and sensory preference of osmodehydrated melon pieces with sucrose and calcium lactate solutions. International Journal of Food Properties, 13: 112-130.

Fuertes, S., Navarro, A. (2011). Caracterización de barras de cerealfortificadas con calcio y vitamina $\mathrm{C}$ protegidos en una matriz dehidrocoloides. XIII Congreso CyTAL-AATA. Octubre 19-21. Buenos Aires (Argentina). 
Grant, G. T., Morris, E. R., Rees, D. A., Smith, P. J. C., Thom, D. (1973). Biological interactions between polysaccharides and divalent caitons: The egg-box model. FEBS Letters, 32: 195-198.

Harbers, L. H. (1998). Ash analysis. In M. A. Gaithersburg \& S. S.Nielsen (Eds.), Food analysis (2nd ed., pp. 141-165). Aspen: Publishers Inc.

Hewajulige, I.G.N, Wijeratnam, R.S., Wijesundera, R.L.C, Abeysekere M. (2003). Fruit calcium concentration and chilling injury during low temperature storage of pineapple. Journal of the Science of Food and Agriculture, 83(14): 1451-1454.

Lamikanra, O., Bett-Garber, K.L., Ingram, D.A., Watson, M.A. (2005). Use of Mild Heat Pretreatment for Quality Retention of Fresh-cut Cantaloupe Melon. Journal of Food Science, 70(1): 53-57.

Lovera, N. N., Buceta, N.N, Salvadori, V.O. Efecto del pretratamiento con sales de calcio sobre las propiedades nutricionales, de textura y color del mamón (carica papaya 1.). XIII Congreso CYTAL AATA. Buenos Aires, Argentina, 19-21 de octubre 2011.

Luna-Guzmán, I., Barrett, D.M. (2000). Comparison of calcium chloride and calcium lactate effectiveness in maintaining shelf stability and quality of fresh-cut cantaloupes. Postharvest Biology and Technology, 19(1): 61-72.

Manganaris, G.A, Vasilakakis, M., Diamantidis, G., Mignani I. (2007). The effect of postharvest calcium application on tissue calcium concentration, quality attributes incidence of flesh browning and cell wall physicochemical aspects of peach fruits. Food Chemistry, 100(4): 1385-1392.

Mignani, I., Greve L. C., Ben-Arie, R., Stotz, H.U., Li, C., Shackel K. A., Labavitch, J.M. (1995).The effects of GA3 and divalent cations on aspects of pectin metabolism and tissue softening in ripeningtomato pericarp. Physiologia Plantarum, 93(1): 108-115. 
Olivas, G.I, Mattinson, D.S, Barbosa-Cánovas, G.V. (2007). Alginate coatings for preservation of minimally processed Gala apples. Postharvest Biology and Technology, 45(1): 89-96.

Oms-Oliu, G., Aguiló-Aguayo, I., Martín-Belloso, O. (2006). Inhibition of Browning on Fresh-cut Pear Wedges by Natural Compounds. Journal of Food Science, 71(3): 216-224.

Pérez-Gago, M.B, Serra, M., Río, M.A. (2006). Color change of fresh-cut apples coated with whey protein concentrate-based edible coatings. Postharvest Biology and Technology, 39(1): 84-92.

Rapisarda, P., Caggia, C., Lanza, C.M., Bellomo, S.E., Pannuzzo, P., Restuccia, C. (2006). Physicochemical, Microbiological, and Sensory Evaluation of Minimally Processed Tarocco Clone Oranges Packaged with 3 Different Permeability Films. Journal of Food Science, 71(3): 299306.

Rocculi, P., Romani, S., Rosa, M.D. (2004). Evaluation of physicochemical parameters of minimally processed apples packed in nonconventional modified atmosphere. Food Research International, 37(4): 329-335.

Rojas-Graü, M.A., Raybaudi-Massilia, R.M., Soliva-Fortuny, R.C, Avena-Bustillos, R.J., McHugh, T.H., Martín-Belloso, O. (2007). Apple puree-alginate edible coating as carrier of antimicrobial agents to prolong shelf-life of fresh-cut apples. Postharvest Biology and Technology, 45(2): 254-264.

Rojas-Graü, M.A., Sobrino-López, A., Soledad Tapia, M., MartínBelloso, O. (2006). Browning Inhibition in Fresh-cut'Fuji' Apple Slices by Natural Antibrowning Agents. Journal of Food Science, 71(1): 59-65.

Rojas-Graü, M.A., Soliva-Fortuny, R., Martín-Belloso, O. (2008). Effect of Natural Antibrowning Agents on Color and Related Enzymes in Fresh-Cut Fuji Apples as an Alternative to the Use of Ascorbic Acid. Journal of Food Science, 73(6): 267-272. 
Rojas-Graü, M.A., Tapia, M.S, Martín-Belloso, O. (2008). Using polysaccharide-based edible coatings to maintain quality of fresh-cut Fuji apples. LWT - Food Science and Technology, 41(1): 139-147.

Rosli, H.G., Civello, P.M., Martinez, G. A. (2004). Changes in cell wall composition of three Fragaria $\mathrm{x}$ ananassa cultivars with different softening rate during ripening. Plant physiology and biochemistry: PPB/ Societe francaise de physiologie vegetale, 42(10): 823-831.

Saurel, R. (2004). Improving the texture of processed vegetable by vacuum infusion. In: D. Kilcast, Texture in Food: Solid Foods (pp. 364 387). England: CRC Press.

Szczesniak A. S. (2002). Texture is a sensory property. Food Quality and Preference, 13: 215-225.

Soliva-Fortuny, R.C, Martín-Belloso, O. (2003). New advances in extending the shelf-life of fresh-cut fruits: a review. Trends in Food Science \& Technology, 14(9): 341-353.

Solomon, E., Huang, L., Sites, J., Annous, B. (2006a). Thermal inactivation of Salmonella on cantaloupes using hot water. Journal of Food Science, 71(2): 25 - 30 .

Sousa, M., Canet, W., Alvarez, M., Fernández, C. (2007). Effect of processing on the texture and sensory attributes of raspberry (cv. Heritage) and blackberry (cv. Thornfree). Journal of Food Engineering, 78: 9-21.

Toivonen, P.M.A, Brummel, D.A. (2008). Review: Biochemical bases of appearance and texture changes in fresh-cut fruit and vegetables. Postharvest Biology and Technology, 48: 1-14.

Van Buggenhout, S., Sila, D.N., Duvetter, T., Van Loey, A., Hendrickx, M. (2009). Pectins in Processed Fruits and Vegetables: Part III-Texture Engineering. Comprehensive Reviews in Food Science and Food Safety, 8(2): 105-117. 
Vanegas, G., Antonio, J. (2004). Efecto de la aplicación de soluciones de cloruro de calcio $\left(\mathrm{CaCl}_{2}\right)$ sobre la vida de almacenamiento y calidad del fruto de mango (Mangifera Indica L) variedad Van Dyke. Congreso Internacional de Ciencia y Tecnología de los Alimentos, Córdoba, Argentina.

Weaver, C. (1998). Calcium in Food Fortification Strategies. International Dairy Journal, 8: 443-449. 

CAPITULO 3.

DESARROLLO DE ANILLOS CROCANTES DE MANZANA FORMULADOS CON FRUCTOSA Y MALTODEXTRINA A PARTIR DE DIFERENTES TÉCNICAS DE COCCIÓN: HORNEADO, FRITADO Y SU COMBINACIÓN 



\subsection{CONSIDERACIONES GENERALES}

El desarrollo de un snack a base de frutas está basado en la sinergia de distintos procesos para lograr un producto final con un balance adecuado entre las características organolépticas y nutricionales. El snack debe cumplir la función de satisfacer, dar saciedad y a su vez ofrecer una alternativa saludable y ser una propuesta atractiva al consumidor desde el punto de vista sensorial. Las operaciones unitarias más asiduamente utilizadas en los procesos de obtención de snacks convencionales son el fritado y el secado por aire caliente. Durante el secado ocurre una transferencia simultánea de calor y masa a través de la membrana plasmática y de la pared celular, acompañada de un cambio de fase. Este método se utiliza debido a que permite la reducción de la actividad acuosa, lo que a su vez minimiza los riesgos de desarrollo de microorganismos en el producto final. Además permite la reducción del costo de transporte y almacenamiento del producto obtenido. Sin embargo, la remoción del agua a altas temperaturas y durante largos tiempos, puede ocasionar descensos en las propiedades nutricionales y sensoriales, afectando principalmente el color, el sabor y los fitoquímicos presentes (vitaminas, polifenoles, antioxidantes, etc.) (Mandala y col., 2005). Además de los pretratamientos mencionados en la sección anterior (escaldado e impregnación con calcio), varios autores han estudiado otras alternativas para conseguir un balance adecuado de color, sabor y evitar daños debido a los tratamientos térmicos (secado por aire caliente, fritado convencional y a vacío, entre otros).

Actualmente se han realizado estudios que utilizan otros pretratamientos como la deshidratación osmótica que se usa en forma combinada con secado por aire caliente o fritado. Con la deshidratación osmótica se logra una importante reducción del contenido de agua inicial sin daños en la estructura y adiciona solutos que estabilizan aún más el alimento (Paulo y col., 2006). En este proceso el fruto es puesto en contacto con una solución concentrada de alcohol, sales y/o 
azúcares, estableciéndose una doble transferencia de materia: agua desde el producto hacia la solución junto con sustancias naturales (azúcares, vitaminas, pigmentos) y, en sentido opuesto, solutos de la solución hacia el fruto. En consecuencia el fruto pierde agua (ML), gana sólidos solubles (SG) y reduce su volumen (VR) (Spiazzi y Mascheroni, 2001). Esta opción induce diferencias en los índices de calidad, textura, color y sabor de los productos finales.

Por otra parte, los productos fritos son consumidos en gran cantidad en todo el mundo. En Estados Unidos el consumo per cápita de snacks es de 15 kilos, mientras que en Argentina es de 1,25. Los productos de mayor consumo son las papas fritas, abarcando un $42 \%$ del mercado, seguido de palitos salados con un $13 \%$, chizitos $10 \%$ y el restante 35\% entre pellets, frutos secos, tortillas y otros (Diario La Nación, 2013). El desarrollo de nuevos productos debe adaptarse a las tendencias en los hábitos de consumo de la población. En los últimos años, la tendencia de los consumidores hacia alimentos con bajo contenido de grasa ha forzado a la industria de los snacks a elaborar productos con estas cualidades. Tradicionalmente, gran parte de los alimentos tipo snacks son elaborados utilizando la fritura como método de cocción lo que produce una considerable absorción de aceite. Con el fin de disminuir la incorporación de aceite y de minimizar las pérdidas nutricionales, varios autores han sugerido diferentes métodos previos a la operación de fritado (Joshi y col., 2010; Tavera Quiroz y col., 2012). Al freír productos delicados como frutas, es necesario un pretratamiento para proporcionar una textura adecuada (estructura firme) a los anillos antes de que puedan ser procesados térmicamente. A menudo, la deshidratación osmótica (DO) es utilizada en combinación con fritura al vacío para mejorar la calidad de snacks de frutas (Da Silva y Moreira, 2008). Da Silva y col. (2008) utilizaron la impregnación de anillos de mango con soluciones de maltodextrina y ácido cítrico para conseguir una mejor retención de color y sabor durante el fritado a vacío. Shyu y col. (2001) lograron disminuir los tiempos de fritado y 
mejorar la textura cuando impregnaron anillos de manzana en soluciones con fructosa. El secado y la impregnación de frutas con diferentes azúcares han demostrado ser beneficiosos para la consecución de las características deseadas en productos tipo snack, tales como la mejora de sabor, color, textura, vida útil (Fito y col, 2001). Se ha demostrado en papas fritas que el pre secado y la inmersión en solución de sacarosa redujo el contenido de aceite en un 30\% y aumentó el dulzor de las mismas (Mai Tran y col., 2007). Además se ha encontrado que la combinación de impregnación con secado por aire es una buena propuesta para el desarrollo de productos secos a base de frutas con efectos benéficos para la salud como la introducción de probióticos y de otros nutrientes (Betoret y col., 2003).

En el desarrollo de esta investigación se analiza la adición de solutos a los anillos de manzana permitiendo aumentar la estabilidad del snack durante el almacenamiento, reducir el tiempo de horneado, fritado y/o su combinación y otorgar color y sabor ideales a productos de este tipo.

La fritura es un proceso multifuncional en el que están involucradas reacciones físicas y químicas, incluidas gelatinización del almidón, desnaturalización de proteínas, evaporación de agua y formación de una corteza crocante. El proceso de fritura implica la transferencia simultánea de calor y masa. El calor se transfiere desde el aceite al alimento, mientras que la humedad se transfiere desde el interior del alimento hacia el aceite. Una vez que la humedad se evapora desde el interior del alimento, quedan espacios vacíos, los cuales son ocupados por el aceite. Consecuentemente, ocurre un proceso de deshidratación parcial y localizado en la parte externa del producto, la que se transforma progresivamente en una corteza dura. El aceite penetra en las capas superficiales del alimento, donde es retenido por diversos mecanismos y pasa a constituir parte del producto. Lo que diferencia el horneado del fritado es que los coeficientes convectivos de 
transferencia de calor son menores en el horneado y, aunque se produce una deshidratación superficial y formación de corteza, no existe absorción de aceite (Aguilera, 1997).

La fritura se realiza a altas temperaturas durante tiempos cortos, y puede ser descrita acorde a la Figura 14.

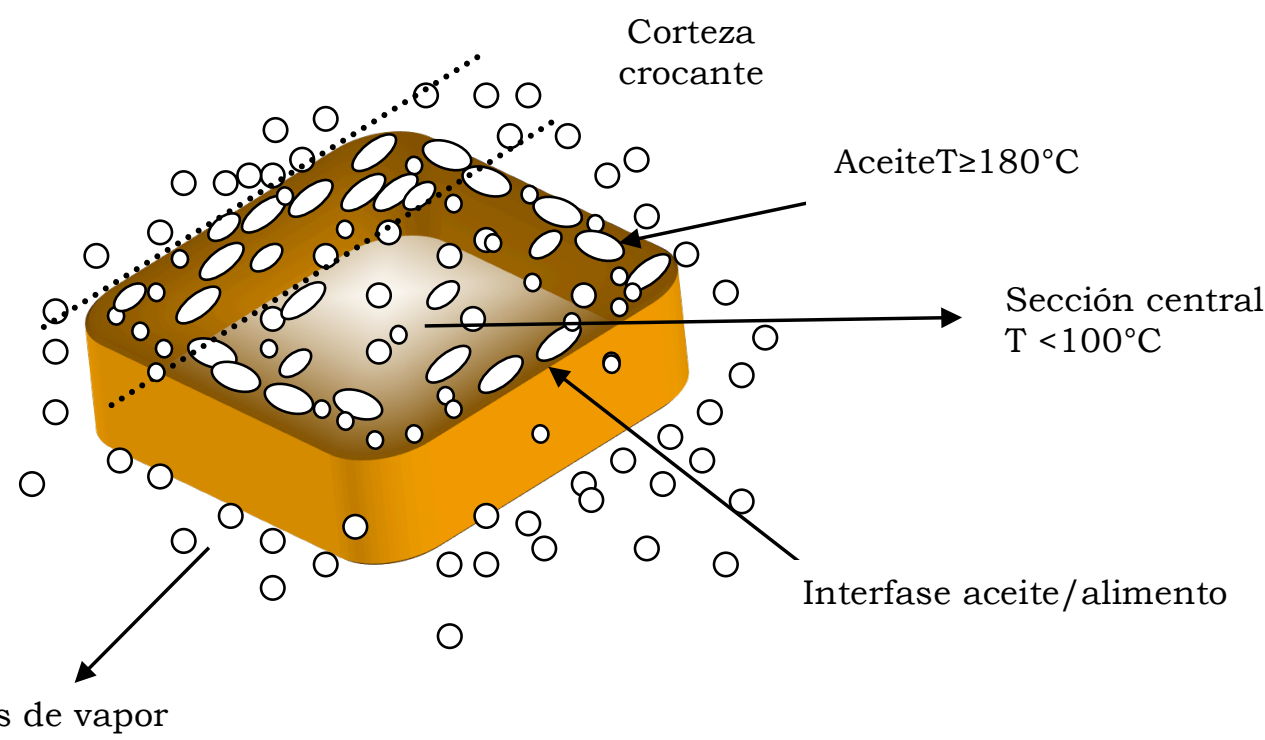

Figura 14. Mecanismo del proceso de fritura, visto desde la sección de una pieza de alimento. Adaptado de Aguilera (1997).

Una vez que se sumerge el alimento en el aceite caliente (150$220^{\circ} \mathrm{C}$ ), la temperatura en la superficie del mismo aumenta rápidamente. Existen dos modelos básicos de transferencia de calor en el proceso de la fritura: convección y conducción. El calor se transfiere desde el aceite a la superficie del producto a través de la convección y luego este se transfiere desde la superficie hasta el centro por conducción. Las propiedades térmicas de los alimentos como el calor específico y la conductividad térmica afectan la velocidad con la cual se realiza dicha transferencia, además de la viscosidad del aceite y las condiciones de agitación en la freidora (Aguilera, 1997). El agua es un factor importante en la transferencia de calor por convección; la que se encuentra en la parte central del material migra hacia afuera y 
sustituye a la que se pierde por deshidratación en la superficie. A medida que se produce el cambio de fase de agua líquida a vapor, la energía térmica del aceite disminuye (Blumenthal y Stier, 1991). Gracias a la capacidad del agua para disminuir la energía térmica del aceite, la temperatura del alimento puede llegar a aproximadamente $100^{\circ} \mathrm{C}$, aunque la temperatura del aceite pueda estar alrededor de los $180^{\circ} \mathrm{C}$. Cuando el agua sale de la parte interna del producto y entra en contacto con el aceite caliente se forman burbujas que se mueven con fuerza en el seno del aceite, causando turbulencias (Innawong y col., 2004). Estas condiciones de turbulencia favorecen la transferencia de calor (mientras existan estas condiciones habrá convección forzada). La cantidad de burbujas de vapor de agua disminuye con el aumento de tiempo de fritura y la disminución en la cantidad de humedad en el producto. Mientras esto ocurre varias reacciones tienen lugar como reacción de Maillard, gelatinización del almidón y cocción, generando las características organolépticas deseadas en este tipo de productos como la textura y el color que se forman en la corteza (Mellema, 2003).

La absorción de aceite en el producto está influenciada por su temperatura, calidad y composición, tiempo de fritura, contenido de humedad superficial del alimento, así como también por los pre y post tratamientos realizados al mismo (Saguy, 1995). Muchos estudios han demostrado que la mayor cantidad de aceite se encuentra en la región superficial para el caso de las papas fritas (Pedreschi y col., 2008) y que después del proceso de fritura se produce una mayor absorción (enfriamiento) lo que indica que la pérdida de humedad y la absorción de aceite no son fenómenos sincronizados (Ufheil y Escher, 1996).

El modo y la intensidad de eliminación del agua en función de las propiedades del producto y los parámetros del proceso son factores determinantes en la absorción de aceite. El control de la cantidad absorbida (en relación con la geometría de la estructura porosa), la ubicación del aceite en las aberturas hechas por el agua y el momento 
durante el cual esto ocurre, dependen de la presión de vapor de agua en los poros. Esto también depende de las propiedades del aceite involucrado, de la adhesión, las fuerzas de drenaje y las condiciones de retiro del producto del baño de aceite. Se ha observado que el contenido de aceite es alto, incluso para muy cortos tiempos de fritura en diferentes productos (se supone que la pérdida de humedad es baja) (Tabla 5) (Aguilera, 1996;1997; Nunes y Moreira, 2009)

Tabla 5. Contenidos de humedad inicial y cambios en el contenido de grasa en alimentos de origen vegetal y animal.

\begin{tabular}{lcc}
\hline ALIMENTO & HUMEDAD ( bs) & $\Delta$ GRASA( *) \\
\hline Banana pelada & 76,5 & $+24,0$ \\
Berenjena sin cáscara & 37,0 & $+56,3$ \\
Piña rebanadas & 87,0 & $+43,2$ \\
Papas peladas & 85,7 & $+18,7$ \\
Miga de pan blanco & 37,0 & $+56,3$ \\
Higado de vacuno & 69,5 & $+8,7$ \\
Chuleta de cerdo magra & 71,4 & $+6,8$ \\
Chorizo de vacuno & 52,7 & $-11,6$ \\
*Luego de fritura a $175^{\circ} \mathrm{C}$ por 70 s. Fuente. Mackinson y col, 1987 Citado por
\end{tabular}
Aguilera en Temas en Tecnología de Alimentos, Cyted, Vol 1. Pág 191. 1997

Como se ha mencionado, existen ciertos factores como la temperatura de fritado, la forma y humedad del producto, que influyen en la absorción de aceite. Dentro de cierto rango de temperaturas, el aumento de la temperatura de fritura disminuye la absorción de aceite, pero en general el efecto no es significativo (Aguilera, 1997). En cuanto al tiempo de tratamiento, cada tipo de snack tiene un tiempo específico de fritura. Si se excede ese tiempo, el resultado será un contenido mayor de aceite en el producto terminado, además de sabor y color indeseables para el consumidor. Entre $185^{\circ} \mathrm{C}$ y $200^{\circ} \mathrm{C}$, se ha encontrado que el tiempo es independiente de la temperatura. Cuando la fritura se produce a temperaturas muy bajas se obtendrán productos aceitosos y 
crudos, debido a un efecto remojo (Boucher, 1990). Las grasas y los aceite son los responsables del desarrollo del sabor y la textura características (Moreira y col., 1999). El aceite es un factor importante para determinar la calidad final de los alimentos fritos. Durante la fritura se alcanzan temperaturas desde $180^{\circ} \mathrm{C}$ hasta más de $200^{\circ} \mathrm{C}$. Estas temperaturas elevadas y su uso repetido incrementan la susceptibilidad a la degradación térmica y oxidativa. Los productos de descomposición sumados a la temperatura del aceite, la cantidad de usos, el tipo de alimentos, la presencia de oxígeno, el agua, el diseño y mantenimiento de los equipos de fritura son factores que afectan la velocidad de degradación del aceite. Esta degradación puede prolongar el tiempo de fritura y reducir el valor nutritivo final del producto aumentando la absorción de aceite (Baskou y Elmadfa, 1999).

En cuanto a la forma, cuanto mayor es la relación superficie/ masa del producto, mayor es la absorción de aceite, existiendo una relación lineal de acuerdo a Gamble y Rice (1988). La rugosidad de la superficie también influye en la retención de aceite (mecanismo de tensión interfacial); cuanto mayor es el daño que se genere con el corte a nivel celular, mayor también será la absorción.

Asimismo, muchos estudios han sugerido que altos contenidos de humedades iniciales resultan en una mayor absorción de aceite. Aguilera (1997) sostiene que un contenido menor de humedad, sobre todo en las capas externas del producto resulta en una menor evaporación de agua y por lo tanto menor porosidad interna donde se podría llegar a ubicar el aceite absorbido. En los últimos años, los procedimientos que se han propuesto para reducir la cantidad de aceite absorbido en papas fritas han sido novedosos. Rubnov y Saguy (1997) propusieron añadir fructosa a un producto de papa reestructurado el cual resultó en un cambio de las propiedades de superficie, con una reducción de aceite absorbido después de freír. También se ha utilizado la técnica de remojo de papas a la francesa en soluciones de $\mathrm{NaCl}$ lo 
cual podría llegar a reducir la absorción de aceite en un 15\% (Moyano y col., 2002; Bunger y col., 2003). El escaldado y el secado son los tratamientos más usados para disminuir la absorción de aceite porque además evitan pardeamientos enzimáticos y no enzimáticos (manzanas, papas). En las papas tipo chips, el escaldado mejora el color y la textura, y podría reducir la absorción de aceite por la gelatinización del almidón de la superficie. En otros estudios la deshidratación del alimento condujo a un menor contenido de humedad lo que también redujo la absorción de aceite (Kozempel, 1991). Moyano y Pedreschi (2005) evaluaron el efecto de la absorción de aceite, previo escaldado y/o pre secado en horno de convección a $60^{\circ} \mathrm{C}$, en papas fritas $\mathrm{y}$ obtuvieron menor absorción en las papas a las que aplicaron el último pretratamiento. Las posibles explicaciones para esta reducción incluyen una menor superficie del alimento generada por los tratamientos térmicos y un alisado de la superficie (Dana y Saguy, 2006). Durante el escaldado se gelatiniza el almidón en la superficie del producto y cuando es sometido a secado, se deshidrata y forma una costra que impide la entrada de aceite durante la fritura (Aguilera, 1997). Freír al vacío también es una opción prometedora que ha demostrado potencial para obtener productos fritos con bajo contenido en aceite y características deseadas como la textura y el sabor característicos (Garayo y Moreira, 2002; Mariscal y Bouchon, 2008; Dueik y col., 2010). La fritura al vacío es un proceso que se lleva a cabo en un sistema cerrado, por debajo de la presión atmosférica, haciendo posible reducir sustancialmente el punto de ebullición de agua, y por lo tanto, la temperatura de fritura. Las bajas temperaturas empleadas y una exposición mínima al oxígeno, hacen que el deterioro del aceite sea menor y se conserven nutrientes del alimento (Garayo y Moreira, 2002; Fan y col., 2005 a y b; Shyu y col., 2005; Da Silva y Moreira, 2008). Otro método que ha sido objeto de estudio recientemente es la fritura con aire caliente. Con esta forma de cocción se busca obtener productos fritos, a través de una emulsión que contiene gotitas de aceite en una corriente de aire caliente. El proceso tiene lugar en una cámara en la 
que el producto está continuamente en movimiento, para promover el contacto homogéneo entre el mismo y el medio externo. Así, el alimento se deshidrata gradualmente, mientras aparece la corteza típica de los productos fritos. El producto final contiene un $80 \%$ menos de aceite frente al mismo producto obtenido con fritado convencional (Heredia y col., 2010). Sin embargo, este tipo de procesos, podría afectar varios aspectos sensoriales como la palatabilidad, color, brillo, etc. (Heredia y col., 2014).

El proceso de horneado produce cambios en la microestructura, contribuyendo a disminuir el contenido de humedad inicial y por lo tanto modifica la textura. La textura ha sido reconocida como uno de los más importantes atributos de calidad en los alimentos tipo snacks y durante la deshidratación de frutas y vegetales se asocia fuertemente con la composición y estructura de las paredes de las células. La pérdida de agua es acompañada por la pérdida de presión interna y las contracciones del tejido celular el cual se ablanda. Esta presión se conoce como la presión de turgencia y desempeña un papel importante en las propiedades texturales de los tejidos vegetales (Ramos y col., 2003). Una alternativa para mitigar los efectos del proceso de horneado sobre el tejido de la fruta, otorgar al producto características organolépticas atractivas para el consumidor y mantener las propiedades nutricionales es la utilización de diversos pretratamientos para evitar el pardeamiento enzimático y mejorar la firmeza del tejido.

\section{Objetivos}

Desarrollar un snack crocante a partir de anillos de manzana verde utilizando diferentes pretratamientos (escaldado con vapor de agua, impregnación con sales de calcio, impregnación con fructosa, maltodextrinas y ácido ascórbico). 
Determinar la concentración óptima de solutos (fructosa y maltodextrina) para obtener un snack con características sensoriales y físicas adecuadas para el consumidor.

Estudiar diferentes alternativas de cocción (fritado, horneado o su combinación) con el fin de obtener un producto con menor contenido graso que los snacks tradicionales pero con las propiedades que los consumidores valoran en los mismos, como el color y la textura crocante y con buen aporte de ácido ascórbico.

Analizar en conjunto la influencia de los pretratamientos aplicados sobre la calidad y propiedades antioxidantes del producto obtenido.

Con el fin de aportar mayor claridad acerca del estudio realizado en cada etapa, este Capítulo se dividió en tres secciones:

1. Selección del tiempo óptimo de tratamiento de los anillos de manzana en las soluciones de maltodextrina: fructosa de distintas concentraciones.

2. Desarrollo de un snack por fritado o la combinación horneado/fritado a partir de las formulaciones maltodextrina:fructosa y pretratamientos con sales de calcio.

3. Desarrollo de un snack horneado a partir de distintas formulaciones de maltodextrina: fructosa y pretratamientos con sales de calcio. 


\subsection{SELECCIÓN DEL TIEMPO ÓPTIMO DE TRATAMIENTO DE ANILLOS DE MANZANA IMPREGNADOS CON SOLUCIONES DE MALTODEXTRINA: FRUCTOSA}

\section{MATERIALES Y MÉTODOS}

\subsubsection{MATERIALES}

Para este ensayo se utilizaron anillos de manzana Granny Smith previamente escaldados con vapor e impregnados con lactato-gluconato y carbonato de calcio durante $2 \mathrm{~min}$.

Para los pretratamientos se utilizó levulosa (fructosa), maltodextrina DE 15,4\% (grado alimenticio, Parafarm, Argentina) y ácido ascórbico (grado alimenticio, Parafarm, Argentina).

\section{Solutos utilizados en la formulación del snack de manzana verde}

\section{Fructosa}

La fructosa es un monosacárido con fórmula química $\mathrm{C}_{6} \mathrm{H}_{12} \mathrm{O}_{6}$ similar a la de la glucosa. La fructosa difiere por la presencia de un grupo cetónico unido al carbono 2 de la molécula, en tanto la glucosa presenta un grupo aldehído en el carbono 1 (Figura 15).

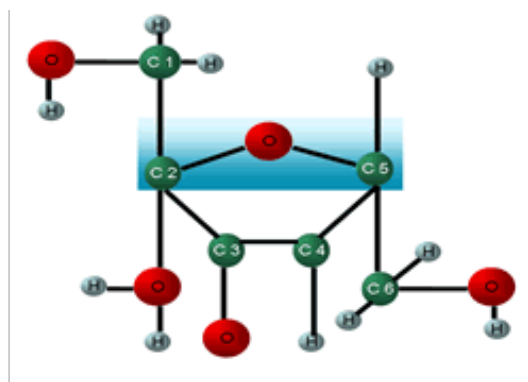

FRUCTOSA

Figura 15. Estructura molecular de la fructosa.

Su principal fuente es la sacarosa o azúcar de mesa, que proviene en general de la caña de azúcar o de la remolacha azucarera. Otras fuentes de fructosa son la miel de abeja y las frutas como dátiles, higos, manzanas, uvas, fresas y moras. 


\section{Ventajas y desventajas de la fructosa}

Al igual que la sacarosa, la fructosa se encuentra en el grupo de endulzantes nutritivos reconocidos por la FDA (Food and Drug Administration) como GRAS (generalmente reconocidos como seguros). Ambos azúcares proveen $4 \mathrm{kcal} / \mathrm{g}$. Sin embargo, su poder edulcorante es 173, mientras que para la glucosa es 74 y 100 para la sacarosa (American Dietetic Association, 2004). Además de las fuentes naturales se encuentra en alimentos industrializados a través del uso de jarabes de alta fructosa en bebidas carbonatadas, cereales, salsas, galletas, mermeladas, jugo, frutas en almíbar, entre otros. En la actualidad, la fructosa ha reemplazado a la sacarosa en muchos alimentos y bebidas por su poder edulcorante (se requiere menor cantidad de este carbohidrato para lograr obtener el mismo dulzor), bajo costo y sus propiedades funcionales (favorece la caramelización y la reacción de Maillard) (Manayay y col., 2013). Dentro de las ventajas del uso de la fructosa se destaca su poco efecto significativo sobre la glucemia (tiene un índice glucémico de 20 en comparación con un índice glucémico de 100 para la glucosa) (Pérez-Cruz y col., 2007). La fructosa como azúcar de digestión lenta, es absorbida por el hígado donde se almacena en forma de glucógeno, para ser utilizada cuando el organismo lo requiera. Por lo tanto, es muy útil en personas que desarrollan actividad física prolongada. Sin embargo debido a que la fructosa acaba transformándose en glucosa, no se considera un endulzante recomendable para personas con diabetes. En 1976 se hizo la recomendación del uso de fructosa en el tratamiento y control del paciente con diabetes mellitus ya que ofrecía una producción limitada de insulina y menor respuesta glucémica (Mehnert, 1976). En los últimos años se ha reconocido que el consumo de cantidades de fructosa que aporten un 25\% o más de la ingesta diaria de calorias, puede ocasionar desórdenes en el metabolismo de los lípidos y sintomas gastrointestinales (Gross y col., 2004; Basciano y col., 2005; Havel, 2005). Los efectos indeseables en la salud relacionados con la fructosa y con otros hidratos de carbono son ocasionados por un exceso en su 
consumo. Influyen desde la cantidad consumida hasta la composición, efectos de procesamiento y su ingestión con otros componentes de la alimentación que pueden modificar sus características fisiológicas y bioquímicas. En este caso el consumo de fructosa debe mantenerse en el contexto de una dieta saludable. La actual recomendación de la WHO (World Health Organization) (2002) es que el consumo de azúcares debe representar menos del $10 \%$ de la ingesta calórica total diaria. En directrices recientes se formula la misma recomendación, pero además se indica que si la ingesta calórica total diaria se reduce a menos del 5\% se obtendrán beneficios adicionales. Un 5\% de la ingesta calórica total equivale a 25 gramos de azúcar al día para un adulto con un índice de masa corporal normal. Los límites de ingesta de azúcares que se sugieren se aplican a todos los monosacáridos (glucosa y fructosa) y disacáridos (sacarosa) (WHO, 2014).

Desde el punto de vista nutricional, la fructosa ofrece ciertas ventajas sobre otros azúcares. Sin embargo es un azúcar altamente higroscópico (Crane, 1990) y el alimento en el cual se encuentre mayoritariamente tiende a aumentar su viscosidad. Para compensar este efecto pueden utilizarse maltodextrinas.

\section{Maltodextrinas}

Las maltodextrinas son productos de hidrólisis de almidones, mediante procesos enzimáticos o hidrólisis ácida. Están integradas por polisacáridos nutritivos, no dulces, constituidos por una mezcla de carbohidratos con diferente grado de polimerización. Las moléculas de D-glucosa se encuentran unidas principalmente por enlaces glucosídicos $\alpha(1-4)$, con grado de dextrosa equivalente (DE) inferior a 20. (Figura 16). 


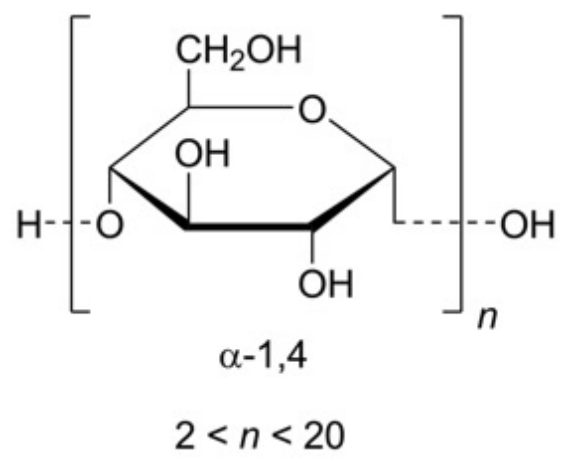

Figura 16. Estructura química de maltodextrinas

Generalmente están clasificadas de acuerdo con su equivalente de dextrosa $(\mathrm{DE})$, el cual determina su capacidad de reducción que está inversamente relacionado con su peso molecular medio (BeMiller y Whistler, 1996). El grado de dextrosa equivalente (DE) es una medida de la cantidad de azúcares reductores presentes con respecto a la glucosa, expresado como un porcentaje sobre una base seca. Una maltodextrina con un DE de 10 tendría 10\% de la potencia de reducción de la glucosa. Estas consisten en una mezcla de sacáridos con una amplia distribución de peso molecular (polisacáridos y oligosacáridos) y en su mayoría están disponibles en forma de polvo blanco o soluciones concentradas. Pueden ser clasificadas como carbohidratos de sustitución (como polímeros de glucosa, azúcares modificados y mezclas de hidrocoloides). Aportan $4 \mathrm{kcal}$ o $16,80 \mathrm{~kJ} / \mathrm{g}$ pero no contribuye al dulzor. Entre sus propiedades funcionales más importantes se incluyen las propiedades de aumento de volumen, gelificantes, cristalización, aumento de la capacidad de dispersión en polvos, crioprotectores, control de dulzor e higroscopicidad, control del oscurecimiento no enzimático. También ayudan a controlar la textura, la higroscopicidad y la densidad en algunos alimentos (Shamek y col., 2002).

Las maltodextrinas son utilizadas principalmente en productos que presentan dificultades para su deshidratación, como jugo de frutas, condimentos y endulzantes. Reducen los problemas de adherencia y aglomeración durante el almacenamiento mejorando así la estabilidad de los mismos (Bhandari y col., 1993; Silva; y col., 2006; Mosquera, 
2010a). Entre los polimeros comestibles de interés para la obtención de productos menos higroscópicos, las maltodextrinas son especialmente útiles debido a su elevada solubilidad en soluciones acuosas, baja viscosidad y altos valores de temperatura de transición vítrea como consecuencia de su alto peso molecular (Roos, 1995). Varios autores han estudiado el papel de estos compuestos en su aplicación a los procesos de secado con relación a la adherencia e higroscopicidad. Bhandari y col. (1997) encontraron una correlación entre el cambio de estado y el proceso de secado de azúcares y zumos de frutas utilizando maltodextrina como aditivo. Estos investigadores describieron un diseño empírico para optimizar la cantidad a utilizar en alimentos ricos en azúcares. Otros autores han descrito el uso de maltodextrinas como agentes deshidratantes de frutas, como tratamiento previo al secado. La aplicación de soluciones hipertónicas de moléculas de gran tamaño que no pueden atravesar la pared celular provoca la retracción de las paredes celulares externas, que se deforman y colapsan (Kim y col., 2009a; Wang y col., 2011b). Piotrowski y col. (1999) observaron una reducción en el tiempo de secado de manzanas recubiertas con maltodextrinas y deshidratadas osmóticamente. Por lo tanto, las maltodextrinas pueden tener un uso eficaz en la deshidratación de frutas, sin aportar mayor contenido de calorias.

\subsubsection{MÉTODOS}

\subsubsection{Impregnación de los anillos de manzana con soluciones de maltodextrina y fructosa}

Grupos de 10 anillos de manzana se sumergieron en soluciones acuosas de maltodextrina y fructosa. Las soluciones fueron preparadas mezclando maltodextrina $(\mathrm{M})$ y fructosa $(\mathrm{F})$ con agua destilada $(30 \%$ $\mathrm{p} / \mathrm{v})$, a $30^{\circ} \mathrm{C}$ y manteniendo agitación constante para permitir la disolución total.

La relación fruta a solución fue de 1/20 (Azuara y col., 2002). La solución A tuvo una relación entre los azúcares $\mathrm{M}: \mathrm{F}$ de 1:1, la solución 
B 2:1 y la C 1:2. A cada una de las soluciones se le agregó ácido ascórbico al 2\% (p/v) previo a la inmersión de las muestras.

\subsubsection{Determinación de la pérdida de peso en función del tiempo de inmersión en las soluciones de azúcares}

El tiempo óptimo de tratamiento osmótico de las muestras de manzana en las soluciones de azúcares de M:F se determinó para las distintas concentraciones usadas: A (1:1), B (2:1) y C (1:2).

En cada experiencia, se sumergieron anillos de manzana de masa constante y se pesaron a intervalos regulares entre los 0 y $120 \mathrm{~min}$. A cada tiempo las muestras se extrajeron, se secaron sobre papel de filtro, se pesaron, y se regresaron a la solución para continuar el proceso. Al finalizar el ensayo, sobre cada una de las muestras se analizó el contenido de humedad por el método AOAC (1980) a $70^{\circ} \mathrm{C}$ en estufa de vacío hasta peso constante (gagua/ $100 g_{\text {muestra}}$ ). Asimismo se determinó el contenido de sólidos solubles, con un refractómetro Hanna HI96801 (Hanna, Argentina) y según el método de la AOAC (1980). Los análisis de las muestras se hicieron por triplicado.

Las curvas obtenidas para la pérdida de peso (ML) como una función del tiempo se ajustaron a través de un modelo empírico similar al desarrollado por Azuara y col. (1992). Esta ecuación (Ec. 4) requiere dos parámetros de ajuste MLo y A.

$$
\mathrm{ML}=\frac{\mathrm{At}(\mathrm{ML} \infty)}{1+\mathrm{At}} \quad \text { Ec. } 4
$$

Donde $\mathrm{t}$ es el tiempo de inmersión (min); MLo es la pérdida de peso en el equilibrio (g); y A es un parámetro empírico $\left(\mathrm{min}^{-1}\right)$, que se puede definir como la constante de velocidad, relacionada con la pérdida de peso. 


\subsubsection{RESULTADOS Y DISCUSIÓN}

Selección del tiempo óptimo de tratamiento de los anillos de manzana en las soluciones de M:F

A partir de los resultados obtenidos se observó que la pérdida de peso de los anillos de manzana aumentó en función del tiempo de tratamiento osmótico. Las curvas obtenidas de pérdida de peso (g) en función del tiempo de tratamiento (min) fueron modeladas según la Ec. 4.

La Figura 17 muestra el ajuste de los datos experimentales y los predichos por el modelo para todas las formulaciones estudiadas $\left(R^{2}=0,99\right)$.

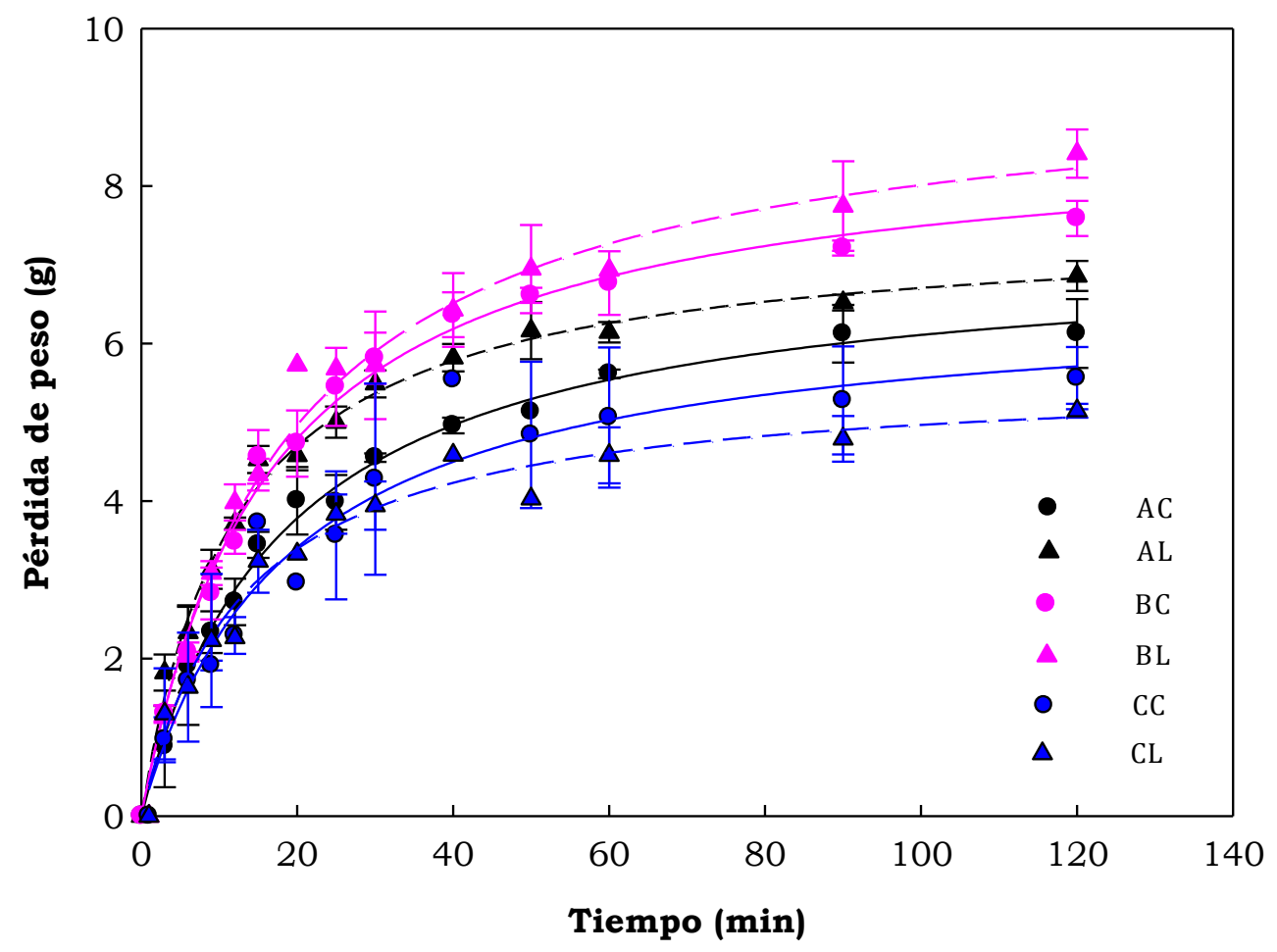

Figura 17. Curvas de pérdida de peso (g) en función del tiempo (min) para anillos de manzana sometidos a tratamiento con las soluciones de maltodextrina: fructosa y sales de calcio. Valores experimentales de $A_{C}, A_{L}, B_{C}$, $\mathrm{B}_{\mathrm{L}}, \mathrm{C}_{\mathrm{C}}, \mathrm{y}_{\mathrm{L}}$ (símbolo) y modelo (línea). L : lactato-gluconato, C: carbonato 
A partir de la ecuación se obtuvieron los valores de ML $\infty$ y de la constante A y se calculó el tiempo necesario para alcanzar la reducción del 50\% del peso inicial de la muestra. Este tiempo, seleccionado como el tiempo óptimo de tratamiento en soluciones de azúcares, se obtuvo como la inversa de A y osciló entre 10 y 19 min (Tabla 6).

Tabla 6. Valores obtenidos para $\mathrm{ML} \infty, \mathrm{A}\left(\mathrm{min}^{-1}\right)$ y tiempo de impregnación con azúcares (min) a partir de Ec. (4), correspondiente al modelo de Azuara y col., 2002.

\begin{tabular}{ccccc}
\hline Muestra & Re1. M: F & ML $\infty(\mathbf{g})$ & $\mathbf{A ~ ( m i n ~}^{-\mathbf{1})}$ & $\begin{array}{c}\text { Tiempo de } \\
\text { impregnación } \\
\text { (min) }\end{array}$ \\
\hline $\mathrm{A}_{\mathrm{C}}$ & $1: 1$ & $7,4^{\mathrm{a}, \mathrm{b}}$ & $0,058^{\mathrm{a}}$ & 17 \\
$\mathrm{~A}_{\mathrm{L}}$ & $1: 1$ & $7,5^{\mathrm{a}, \mathrm{b}}$ & $0,085^{\mathrm{b}}$ & 12 \\
$\mathrm{~B}_{\mathrm{C}}$ & $2: 1$ & $8,8^{\mathrm{b}, \mathrm{c}}$ & $0,062^{\mathrm{a}}$ & 16 \\
$\mathrm{~B}_{\mathrm{L}}$ & $2: 1$ & $9,5^{\mathrm{c}}$ & $0,052^{\mathrm{a}}$ & 19 \\
$\mathrm{C}_{\mathrm{C}}$ & $1: 2$ & $6,6^{\mathrm{a}}$ & $0,053^{\mathrm{a}}$ & 18 \\
$\mathrm{C}_{\mathrm{L}}$ & $1: 2$ & $5,7^{\mathrm{a}}$ & $0,100^{\mathrm{b}}$ & 10 \\
\hline
\end{tabular}

L : lactato-gluconato, C: carbonato

$a, b, c$ Letras diferentes indican diferencias significativas.

Los resultados muestran que la pérdida de peso a tiempo infinito $(\mathrm{ML} \infty)$ resultó independiente de la sal de calcio utilizada $(\mathrm{P}>0,05)$. Sin embargo si hubo un efecto significativo $(\mathrm{P}<0,05)$ de la composición de la mezcla de azúcares. Cuanto mayor fue el porcentaje de maltodextrina en la solución, mayor fue la pérdida de peso y por lo tanto de agua $(\mathrm{C}<\mathrm{A}<\mathrm{B})$. Para los valores de la constante A $\left(\mathrm{min}^{-1}\right)$ se observaron diferencias significativas, siendo mayor la constante de velocidad relacionada con la pérdida de peso para el carbonato de calcio que para el lactato-gluconato $(\mathrm{P}<0,05)$. Se observaron diferencias significativas en los valores de $\mathrm{A}\left(\mathrm{min}^{-1}\right)$ para $\mathrm{A}_{\mathrm{L}}$ y $\mathrm{C}_{\mathrm{L}}$ respecto de las demás formulación de azúcares $(\mathrm{P}<0,05)$. 
Las características de un producto deshidratado son altamente influenciadas por la ganancia de sólidos. La absorción de azúcares durante la deshidratación osmótica modifica la composición y el sabor del producto final, en algunos casos, con efectos deseables (Azuara y col., 1998). Sin embargo, una absorción de azúcar excesiva es indeseable, debido al impacto negativo en el perfil nutricional y además el producto no podría ser rotulado como producto "natural" (Azuara y col., 2002).

Teniendo en cuenta este criterio, se estableció el tiempo de impregnación en soluciones de azúcar como el tiempo en el que la pérdida de peso (ML) fuese del 50\% de ML $\infty$. Los resultados obtenidos indicaron que este varió entre 10 y $19 \mathrm{~min}$, dependiendo de la formulación estudiada. El tiempo promedio de tratamiento establecido en este trabajo fue de 15 min para todas las formulaciones.

Azuara y Beristain (2002) encontraron que el aumento de ML en el tiempo se debe a que la ganancia de sólidos es menor que la pérdida de agua. El alto peso molecular de la maltodextrina constituye un obstáculo para su penetración en el tejido de la manzana. Esto sugiere que este tipo de solutos pueden formar una capa densa en la superficie del disco de manzana y producir un gradiente de concentración lo que aumenta la migración de agua desde la manzana hacia la solución concentrada. De acuerdo con esta explicación, cuanto mayor es la concentración de maltodextrina en la formulación, mayor será la pérdida de agua $(\mathrm{ML} \infty)$. Además la adición de solutos de alto peso molecular permite controlar la incorporación de solutos específicos de bajo peso molecular, obtener mejores características sensoriales y mejorar la deshidratación de la fruta. 


\subsection{DESARROLLO DE UN SNACK DE MANZANA VERDE OBTENIDO POR DIFERENTES TÉCNICAS DE COCCIÓN: FRITADO CONVENCIONAL / FRITADO-HORNEADO}

\section{MATERIALES Y MÉTODOS}

\subsubsection{MATERIALES}

Se utilizaron anillos de manzana con los pretratamientos descriptos en la sección 3.2.

Para la fritura se utilizó aceite de girasol de procedencia nacional (Natura, Argentina).

\subsubsection{MÉTODOS}

\subsubsection{Métodos de cocción}

\section{Pretratamientos}

Se realizaron diferentes pretratamientos como escaldado, impregnación con sales de calcio, inmersión en las soluciones de azúcares y ácido ascórbico (AA). Además se prepararon muestras control, que consistieron en anillos de manzana sin pretratamientos con el fin de observar el efecto de los pretratamientos durante las operaciones de cocción a estudiar.

\section{Fritado}

Las experiencias de fritura en condiciones atmosféricas se realizaron en una freidora eléctrica de tipo doméstico (Moulinex A08, capacidad 2,5 1). Una vez que el aceite de fritura llegó a la temperatura deseada $\left(180^{\circ} \mathrm{C}\right)$, se ubicaron diez anillos de manzana en la canastilla de fritura, hasta que alcanzó el punto final de burbuja (Dueik y col., 2010). Una vez transcurrido el tiempo de fritado de cada experiencia, la canasta se elevó, para que escurriera el exceso de aceite, y posteriormente las muestras se sacaron de la freidora y se dejaron enfriar a temperatura ambiente sobre papel absorbente para eliminar el exceso de aceite remanente. Las muestras fueron separadas en 3 
grupos de 10 anillos de manzana para cada tratamiento realizado (Tabla 7).

\section{Método combinado (horneado/fritado)}

Se realizaron ensayos a $100^{\circ} \mathrm{C}$ durante diferentes tiempos de horneado (Tabla 7), seguido de fritado convencional. El tiempo de fritado se estableció en base a consideraciones de desarrollo de color y textura de las muestras.

Tabla 7. Evaluación de temperaturas-tiempo de fritado, aplicados sobre anillos de manzana

\begin{tabular}{|c|c|c|c|}
\hline Muestra & Pretratamientos & $\begin{array}{c}\text { Tiempo de } \\
\text { fritado }\end{array}$ & Observaciones \\
\hline 1. & $\begin{array}{c}\text { Sin escaldar } \\
\text { Inmersión en } \mathrm{CaCO}_{3} \\
2,5 \%-2 \mathrm{~min}\end{array}$ & $1 \mathrm{~min}$ & $\begin{array}{c}\text { Colapso de la textura, } \\
\text { caramelización excesiva } \\
\text { (oscuras) }\end{array}$ \\
\hline 2. & $\begin{array}{c}\text { Secado con papel } \\
\text { Inmersión en } \mathrm{CaCO}_{3} \\
2,5 \%-2 \mathrm{~min} \\
\text { Escaldado } 3 \mathrm{~min}\end{array}$ & $1 \mathrm{~min}$ & $\begin{array}{c}\text { Colapso de la textura, } \\
\text { caramelización } \\
\text { moderada }\end{array}$ \\
\hline 3. & $\begin{array}{c}\text { Secado con papel } \\
\text { Inmersión } \mathrm{CaCO}_{3} \\
2,5 \% \\
\text { Escaldado } 3 \mathrm{~min} \\
\text { Inmersión en } \mathrm{M}: \mathrm{F} \\
(1: 2) \text { y } 2 \% \mathrm{AA}\end{array}$ & $\begin{array}{l}* 1 \min \\
* * 2 \min \end{array}$ & $\begin{array}{c}* \text { Textura gomosa, poco } \\
\text { desarrollo de } \\
\text { caramelización } \\
\text { Exceso de aceite } \\
\text { **Textura gomosa- } \\
\text { caramelización deseada } \\
\text { Exceso de aceite }\end{array}$ \\
\hline 4. & $\begin{array}{l}\text { Secado con papel } \\
\text { Inmersión } \mathrm{CaCO}_{3} \\
2,5 \% \\
\text { Escaldado } 3 \mathrm{~min} \\
\text { Inmersión en } \mathrm{M}: \mathrm{F} \\
\quad(1: 1) \text { y } 2 \% \mathrm{AA} \\
\end{array}$ & $\begin{array}{l}* 1 \min \\
* * 2 \min \end{array}$ & $\begin{array}{c}{ }^{*} \text { Gomosas-poco } \\
\text { desarrollo de color } \\
\text { Exceso de aceite } \\
{ }^{* *} \text { Caramelización } \\
\text { excesiva }\end{array}$ \\
\hline 5. & $\begin{array}{l}\text { Secado con papel } \\
\text { Inmersión } \mathrm{CaCO}_{3} \\
2,5 \% \\
\text { Escaldado } 3 \mathrm{~min} \\
\text { Inmersión en } \mathrm{M}: \mathrm{F} \\
(2: 1) \text { y } 2 \% \mathrm{AA} \\
\end{array}$ & $\begin{array}{l}* 1 \min \\
* * 2 \min \end{array}$ & $\begin{array}{l}{ }^{*} \text { Crocante (por zonas) } \\
\text { caramelización deseada } \\
\text { Exceso de aceite } \\
{ }^{* *} \text { Crocantes- } \\
\text { caramelización excesiva }\end{array}$ \\
\hline
\end{tabular}




\begin{tabular}{|c|c|c|c|}
\hline 6. & $\begin{array}{c}\text { Secado con papel } \\
\text { Inmersión lactato- } \\
\text { gluconato } 2,5 \% \\
\text { Escaldado } 3 \mathrm{~min} \\
\text { Inmersión en M:F } \\
(1: 2) \text { y } 2 \% \mathrm{AA} \\
\end{array}$ & $1 \mathrm{~min}$ & $\begin{array}{l}\text { Textura gomosa- } \\
\text { caramelización deseada } \\
\text { Exceso de aceite }\end{array}$ \\
\hline 7. & $\begin{array}{l}\text { Secado con papel } \\
\text { Inmersión lactato- } \\
\text { gluconato } 2,5 \% \\
\text { Escaldado } 3 \mathrm{~min} \\
\text { Inmersión en M:F } \\
(1: 1) \text { y } 2 \% \mathrm{AA}\end{array}$ & $1 \mathrm{~min}$ & $\begin{array}{l}\text { Gomosas-poco } \\
\text { desarrollo de color } \\
\text { Exceso de aceite }\end{array}$ \\
\hline 8. & $\begin{array}{l}\text { Secado con papel } \\
\text { Inmersión lactato- } \\
\text { gluconato } 2,5 \% \\
\text { Escaldado } 3 \mathrm{~min} \\
\text { Inmersión en M:F } \\
(2: 1) \text { y } 2 \% \mathrm{AA}\end{array}$ & $1 \mathrm{~min}$ & $\begin{array}{l}\text { Crocante (en algunas } \\
\text { zonas de la muestra), } \\
\text { caramelización deseada } \\
\text { Exceso de aceite }\end{array}$ \\
\hline 9. & $\begin{array}{c}\text { Secado con papel } \\
\text { Inmersión } \mathrm{CaCO}_{3} \\
2,5 \% \\
\text { Escaldado } 3 \mathrm{~min} \\
\text { Inmersión en } \mathrm{M}: \mathrm{F} \\
(2: 1) \text { y } 2 \% \mathrm{AA}\end{array}$ & $\begin{array}{c}\text { Prehorneado } \\
10 \\
\mathrm{~min} / \text { fritado } \\
1 \mathrm{~min}\end{array}$ & $\begin{array}{c}\text { Crocantes, } \\
\text { caramelización excesiva } \\
\text { Exceso de aceite }\end{array}$ \\
\hline 10. & $\begin{array}{l}\text { Secado con papel } \\
\text { Inmersión lactato- } \\
\text { gluconato } 2,5 \% \\
\text { Escaldado } 3 \mathrm{~min} \\
\text { Inmersión en M:F } \\
(1: 2) \text { y } 2 \% \mathrm{AA}\end{array}$ & $\begin{array}{c}\text { Prehorneado } \\
10 \\
\mathrm{~min} / \text { fritado } \\
1 \mathrm{~min}\end{array}$ & $\begin{array}{c}\text { Gomosas, } \\
\text { caramelización deseada } \\
\text { (no uniforme) }\end{array}$ \\
\hline 11. & $\begin{array}{l}\text { Secado con papel } \\
\text { Inmersión lactato- } \\
\text { gluconato } 2,5 \% \\
\text { Escaldado } 3 \mathrm{~min} \\
\text { Inmersión en M:F } \\
(1: 1) \text { y } 2 \% \mathrm{AA}\end{array}$ & $\begin{array}{c}\text { Prehorneado } \\
10 \\
\mathrm{~min} / \text { fritado } \\
1 \mathrm{~min}\end{array}$ & $\begin{array}{c}\text { Crocante (en la zona } \\
\text { externa de la rodaja), } \\
\text { caramelización deseada } \\
\text { (no uniforme) }\end{array}$ \\
\hline 12. & $\begin{array}{l}\text { Secado con papel } \\
\text { Inmersión lactato- } \\
\text { gluconato } 2,5 \% \\
\text { Escaldado } 3 \mathrm{~min} \\
\text { Inmersión en M:F } \\
(2: 1) \text { y } 2 \% \mathrm{AA}\end{array}$ & $\begin{array}{c}\text { Prehorneado } \\
10 \\
\mathrm{~min} / \text { fritado } \\
1 \mathrm{~min}\end{array}$ & $\begin{array}{l}\text { Crocantes, } \\
\text { caramelización deseada }\end{array}$ \\
\hline
\end{tabular}




\subsubsection{Análisis de las propiedades fisicoquímicas y térmicas de los snacks obtenidos por el método de cocción seleccionado}

\section{Humedad y actividad acuosa $\left(a_{w}\right)$}

La humedad se determinó mediante secado en estufa de vacío a $70^{\circ} \mathrm{C}$ hasta pesada constante. La actividad acuosa fue medida en un equipo Aqualab 3TE (Decagon Devices, Inc., Estados Unidos). Ambas determinaciones se hicieron por triplicado.

\section{Análisis de textura}

Se determinó los parámetros de textura según el método descrito en el Capítulo 2.

\section{Análisis de color}

La fuente de luz en el equipo garantiza una iluminación uniforme del producto para todas las mediciones. El "observador" del colorímetro es un conjunto de tres fotocélulas filtradas para coincidir exactamente con las funciones del observador estándar, por lo que las condiciones son uniformes para todas las mediciones. Generalmente se utiliza la escala CIELab (Comission International de L' Eclaraige) cuyos parámetros son definidos como luminosidad $\left(\mathrm{L}^{*}\right)$ donde 0 es negro y 100 es blanco y los parámetros de cromaticidad a* (rojo - verde) y b* (amarillo - azul). Como es sabido, los valores positivos de a* son rojos y los negativos verdes y para $b^{*}$ los valores positivos corresponden al color amarillo y los negativos al azul. El color superficial de las muestras se determinó con un colorímetro Minolta CR-400 Series (Osaka, Japón) (Figura 18), calibrado con un plato blanco estándar ( $\mathrm{Y}=$ 93,2, $\mathrm{x}=0,3133, \mathrm{y}=0,319)$. 


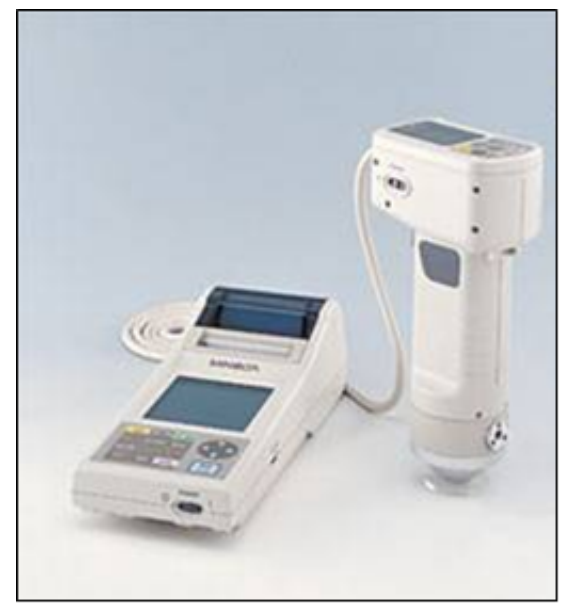

Figura 18. Colorímetro Minolta CR-400 Series

A partir de los parámetros obtenidos se calculó el Browning Index (BI) (indice de pardeamiento) (Ec. 5 y Ec. 6), que representa la pureza del color marrón. El BI se calculó a partir de las ecuaciones 5 y 6 :

$$
\begin{gathered}
\mathrm{BI}=\frac{[100(x-0.31)]}{0,172} \quad \text { Ec. } 5 \\
x=\frac{(\mathrm{a} *+1,75 \mathrm{~L} *)}{(5,645 \mathrm{~L}+\mathrm{a} *-3,012 \mathrm{~b} *)} \quad \text { Ec. } 6
\end{gathered}
$$

El ensayo se realizó sobre 6 unidades de cada uno de los snacks obtenidos y el control. Se realizaron 3 determinaciones sobre cada muestra.

\section{Análisis de las propiedades térmicas}

\section{Calorimetria Diferencial de Barrido Modulada}

La calorimetría diferencial de barrido modulada (MDSC), a diferencia de los analizadores térmicos convencionales, proporciona mayor sensibilidad para detectar las transiciones que experimenta un material sometido a un programa de calentamiento o enfriamiento. La técnica utiliza dos velocidades de calentamiento simultáneas, una lineal que brinda información similar al DSC convencional, y otra modulada o sinusoidal que permite medir simultáneamente la capacidad calorífica 
de la muestra y diferenciar entre los eventos reversibles (dependientes de la capacidad calorífica) e irreversibles (dependientes del tiempo y la temperatura) que experimenta la muestra. Una de las ventajas de la técnica de MDSC es que permite obtener una mayor resolución de transiciones complejas o eventos muy próximos al poder distinguir entre los eventos reversibles o no reversibles. Esto se debe a que en muchos casos, dependiendo de las características del material las transiciones térmicas se solapan en una misma región, no siendo posible diferenciarlos mediante la técnica de DSC convencional.

Una transición como la transición vítrea constituye un evento reversible y se determina como la temperatura en el punto medio de inflexión de la línea de base de la señal del flujo de calor reversible. En ocasiones es conveniente identificar y eliminar la historia térmica del material para poder medir correctamente sus propiedades, o identificar en los termogramas otras transiciones. Esto se puede lograr sometiendo al material a un primer calentamiento $y$ a continuación a un enfriamiento a una velocidad adecuada.

Las propiedades térmicas de los snacks de manzana, del control y del tejido de la fruta fresca se determinaron mediante el uso de un equipo de Calorimetria Diferencial de Barrido (DSC) Q100. El equipo es controlado por un módulo TA 5000 (TA Instruments, New Castle, EE.UU.) con un sistema de enfriamiento a base de $\mathrm{N}_{2}$, con un caudal de $20 \mathrm{ml} / \mathrm{min}$. Se pesaron 6-7 mg de muestra en cápsulas de aluminio. Se hicieron corridas por triplicado de cada una de las muestras, utilizando una cápsula de aluminio vacía como referencia. El ensayo se realizó como se describe en Tavera-Quiroz y col. (2012). El primer barrido se realizó desde -70 hasta $200^{\circ} \mathrm{C}$. Seguidamente la muestra se enfrió a una velocidad de $20^{\circ} \mathrm{C} / \mathrm{min}$ hasta $-70^{\circ} \mathrm{C}$ y se realizó un segundo barrido entre -70 y $250^{\circ} \mathrm{C}$. Se utilizó calorimetría diferencial de barrido modulada para obtener los termogramas a partir de los cuales se 
obtuvo la temperatura de transición vítrea $\left(\mathrm{T}_{\mathrm{g}}\right)$ utilizando el software Universal Analysis 2000 V1.7 F (TA Instruments, New Castle, EE.UU.).

\section{Ensayos mediante Análisis Mecánico Dinámico}

La técnica de análisis dinámico mecánico, DMA, permite estudiar las propiedades viscoelásticas de los materiales, difiriendo de los ensayos mecánicos convencionales dado que estos trabajan fuera del rango de viscoelasticidad lineal, donde la muestra sufre modificaciones estructurales permanentes. El DMA es una de las técnicas de análisis térmico utilizada para estudiar la influencia de la estructura molecular sobre las propiedades físicas de los materiales, permitiendo obtener información sobre la $T_{g}$. Además, se caracteriza por su sensibilidad para detectar cambios en la movilidad interna molecular, no detectables por otras técnicas de análisis térmico. Si bien la $\mathrm{T}_{\mathrm{g}}$ se puede estimar a través de MDSC, la técnica de DMA también es apropiada para el estudio de la transición vítrea de materiales, dado que permite analizar las contribuciones de las distintas fases, o componentes.

En los ensayos de DMA, la muestra es sometida a un esfuerzo, en forma de torque, flexión o tensión, de amplitud pequeña, que varía sinusoidalmente con el tiempo. Si el material es perfectamente elástico, toda la energía mecánica que se le aplique se transforma en energía potencial que se recupera, mientras que si el material se comporta como un líquido, la energía se disipa en forma de calor y no se almacena. En un material viscoelástico ambos comportamientos están presentes, y al aplicar un esfuerzo sinusoidal, la deformación resultante será también sinusoidal (si el esfuerzo es suficientemente pequeño como para que el comportamiento sea lineal) pero estará desfasada respecto del esfuerzo. Este desfasaje es consecuencia del tiempo necesario para que ocurra la reorganización molecular y se relaciona con los fenómenos de relajación. A la temperatura y frecuencia a la que el material sufre una relajación, la componente real del módulo de almacenamiento disminuye abruptamente y el módulo de pérdida 
presenta un máximo. La tan $\delta$, que representa el desfasaje entre el esfuerzo y la deformación, también atraviesa un máximo a temperaturas superiores al módulo de pérdida.

Los ensayos mediante análisis mecánico dinámicos (DMA) se realizaron usando un equipo DMA Q800 (TA Instruments, Nueva Castle, EE.UU.) siguiendo el método de Rivero y col. (2012). Se realizó una deformación dinámica a distintas frecuencias $(1,3,5,10,15$ y $20 \mathrm{~Hz}$ ) usando un soporte tipo dual cantilever con apoyo central (Figura 19).

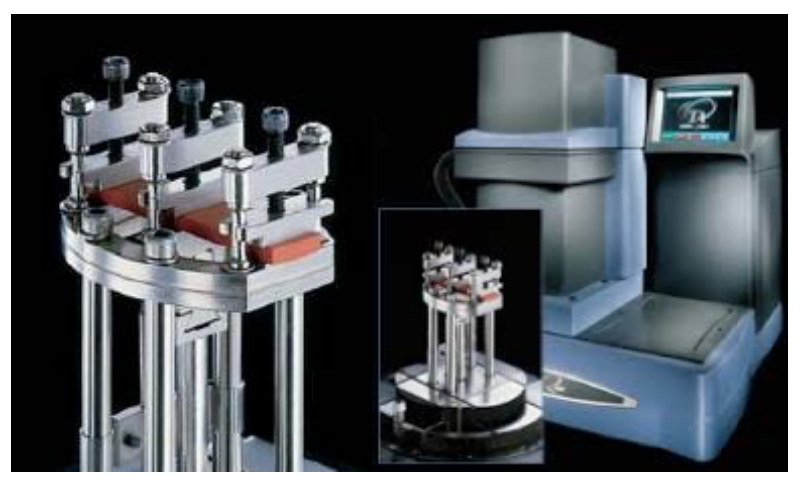

Figura 19. Soporte tipo "Dual cantilever" utilizado para obtener las propiedades viscoelásticas de los snacks en un DMA Q800.

Se prepararon muestras de snack con tamaño y forma adecuados para este tipo de ensayo; las mismas se cortaron (antes de la cocción) con una geometría rectangular de $55 \mathrm{~mm}$ de longitud, $10 \mathrm{~mm}$ de ancho y $2 \mathrm{~mm}$ de espesor. Los ensayos se realizaron entre -100 y $200^{\circ} \mathrm{C}$ a 5 ${ }^{\circ} \mathrm{C} / \mathrm{min}$, con una isoterma de $10 \mathrm{~min}$ a $-100^{\circ} \mathrm{C}$. De estos ensayos se obtuvieron las curvas de módulo de almacenamiento ( $\left.E^{\prime}\right)$, módulo de pérdida (E") y tan $\delta\left(\mathrm{E}^{\prime \prime} / \mathrm{E}^{\prime}\right)$ en función de la temperatura. El análisis de las curvas se realizó con el software de Universal Analysis 2000.

\subsubsection{Evaluación sensorial}

La división de Evaluación Sensorial del Instituto de Tecnólogos de Alimentos de Estados Unidos (IFT) define la evaluación sensorial como la disciplina científica utilizada para evocar, medir, analizar e interpretar las reacciones a aquellas características de alimentos $u$ 
otras sustancias que son percibidas por los sentidos. El análisis sensorial es un auxiliar muy importante en el control y perfeccionamiento de la calidad de los alimentos, a diferencia del análisis físico-químico o microbiológico, que dan una información parcial acerca de alguna de las propiedades. Esta evaluación permite formar una idea global del producto de forma rápida, informando sobre aspectos importantes como es el grado de aceptación o rechazo, el reconocimiento de distintos atributos o las diferencias existentes entre determinados productos, entre otros aspectos, por parte de los consumidores (ISETA, 2007). Existen ciertas cualidades sensoriales que se perciben por medio de un único sentido, como el caso del color y la vista. Sin embargo muchas otras pueden ser detectadas por dos o más sentidos, de forma secuencial o simultánea. En el caso de los snacks, los consumidores están mayormente sensibilizados con la textura, el color y el sabor.

Se realizó un test de preferencia, en el cual los panelistas debían clasificar las muestras. Con el mismo se buscó conocer la preferencia o rechazo hacia el producto. El ensayo se realizó con un panel no entrenado de 20 personas, en un recinto cerrado, con buena ventilación e iluminación. A las personas seleccionadas para la prueba, se les indicó que debían hacer una evaluación global de color, textura y sabor de cada una de los snacks a probar. Las muestras, preparadas en el momento, fueron evaluadas a través de la planilla presentada a continuación (Figura 20): 


\section{PANEL DE PREFERENCIA DE SNACKS DE MANZANA}

Nombre:....

Evaluador $\mathbf{N}^{\circ}$ :

Ud. recibirá 3 muestras codificadas de snack de manzana. Por favor ordénelas según su grado de preferencia, escribiendo el código de la muestra que más le gusta a la izquierda siguiendo hacia la derecha con la que le gusta menos.

Gusta más

Gusta menos

Observaciones:

Figura 20. Planilla de evaluación sensorial utilizada para evaluar preferencias de snacks.

\subsubsection{Análisis de las propiedades nutricionales de los snacks seleccionados}

\section{Determinación del contenido graso}

El contenido graso se determinó sobre las muestras secas a través del método de extracción semi continuo Soxhlet (AOAC Método 963.15, 1995). El extractor Soxhlet (Figura 21) es un módulo de vidrio utilizado para la extracción de compuestos, generalmente de naturaleza lipídica, contenidos en un sólido a través de un solvente afín. El solvente utilizado fue una mezcla de éter etílico: éter de petróleo en relación 1:1.

Las muestras se trituran previamente en un mortero de vidrio, se disponen en cartuchos de papel filtro y se introducen en los tubos de extracción. Los balones se calientan por medio de una manta calefactora, provocando la evaporación del solvente, pasando a través de la derivación exterior al condensador. Cuando el solvente condensa, cae gota a gota en el depósito interior, donde se encuentra el cartucho con la muestra sólida y anhidra. El solvente caliente contacta con el sólido y empieza a producirse la extracción. El solvente que se va condensando se acumula en el interior del extractor, y cuando el nivel alcanza el de la válvula interior, el líquido es succionado y devuelto al 
balón inferior. Los balones continúan calentándose y el solvente es destilado de nuevo, en un proceso cíclico (durante varias horas), lo que permite que se realicen múltiples extracciones de las muestras.

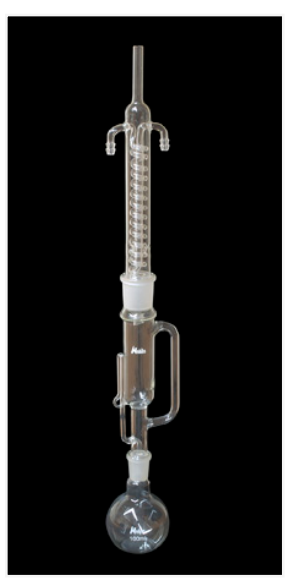

Figura 21. Extractor de grasa método Soxhlet.

El contenido de grasa se determinó según:

$$
\mathrm{G}=\frac{\left(\mathrm{Pb}_{\mathrm{a}}-\mathrm{Pb}_{\mathrm{b}}\right)}{\mathrm{m}} \times 100 \quad \text { Ec. } 7
$$

Donde, G es el contenido de grasa (g/ 100 g muestra seca), $\mathrm{Pb}_{\mathrm{a}}$ es el peso de balón + grasa (g), $\mathrm{Pb}_{\mathrm{b}}$ es el peso de balón (g) y $\mathrm{m}$ es el peso de muestra seca $(\mathrm{g})$.

\section{Contenido de ácido ascórbico por HPLC}

La determinación de ácido ascórbico (AA) se realizó a partir de un procedimiento de elución isocrática a $245 \mathrm{~nm}$ con detector UV-visible. Un gramo de muestra previamente congelada se mezcló con $5 \mathrm{ml}$ de una solución acuosa al 5\% (p/v) de ácido metafosfórico $\left(\mathrm{HPO}_{3}\right)$ (Sigma Aldrich, EE.UU.) durante 15 min y se centrifugó durante 10 min a 2000 rpm (Rolco CM 2036, Argentina). Las separaciones se llevaron a cabo en una columna C18 RP-5 mm de 150 a 4,6 mm (WAT 045905, Irlanda), a un caudal de $1 \mathrm{ml} /$ mina $25^{\circ} \mathrm{C}$. La fase móvil utilizada fue una mezcla de $0,5 \%$ (p/v) de $\mathrm{HPO}_{3}$ : acetonitrilo (93:7) (Nojavan y col., 2008). Los 
resultados obtenidos fueron comparados con una curva de calibración entre 2-200 $\mu \mathrm{g} / \mathrm{ml}$ y se expresaron como $\mathrm{mg} \mathrm{AA} / \mathrm{g}$ muestra.

\subsubsection{Análisis estadístico}

Para cada ensayo los resultados obtenidos fueron evaluados estadísticamente a través del software SYSTAT (SYSTAT, Inc., Evanston, IL, EE.UU.) (Wilkinson, 2000), mediante análisis de varianza (ANAVA). Cuando los datos presentaron diferencias entre sí, se realizó la comparación de medias mediante el test de LSD de Fisher a un nivel de significación de 0,05.

\subsubsection{RESULTADOS Y DISCUSIÓN}

\section{Condiciones de cocción seleccionadas}

A partir de los ensayos realizados se observó que el secado de la superficie y el escaldado favorecieron la caramelización moderada de las muestras, la cual se ve afectada por el exceso de azúcares simples en la superficie de la muestra y cuando se excede el tiempo de fritura de 2 min. En los anillos de manzana que fueron tratados con lactatogluconato de calcio y las distintas formulaciones de M:F se logró el desarrollo de una caramelización moderada. Utilizando únicamente fritura como método de cocción no fue posible obtener un producto con buenas características sensoriales cuando se utilizó fructosa en la formulación, por lo que los análisis de las propiedades físicas y químicas no se realizaron sobre estas muestras.

Los métodos a partir de los cuales se obtuvieron productos tipo snacks con caracteristicas adecuadas de color y textura fueron los denominados con los números 10, 11 y 12 según lo descrito en la Tabla 8. Los mismos incluyeron impregnación con sales de calcio, inmersión en soluciones acuosas de maltodextrina (M) y fructosa (F) a $30^{\circ} \mathrm{C}$ durante 15 min. Se probaron las tres relaciones diferentes de M:F al $30 \%(\mathrm{p} / \mathrm{v})$, con ácido ascórbico agregado. Para la cocción se seleccionó un horneado de $10 \mathrm{~min}$ y fritado convencional durante $1 \mathrm{~min}$. El tiempo se seleccionó en base a las consideraciones de color y textura de las muestras. 
Los snacks obtenidos a partir de las distintas formulaciones de fructosa y maltodextrina mediante del uso del método combinado (horneado /fritado) se denominaron $A_{H / F}, B_{H / F}, C_{H / F}$ (Figura 22). En la Figura 22 se observa escasa uniformidad en el color de las muestras, la cual puede ser ocasionada por acumulación de azúcares reductores en la superficie. Los anillos de manzana tuvieron un contenido de agua inicial de $85 \%$ (bh). Se presume que un menor contenido de humedad, especialmente, en las capas externas del producto, resulta en menor evaporación de agua y por lo tanto menor porosidad donde ubicar el aceite absorbido (Altonaga, 2007). Adicionalmente, la inmersión del alimento en soluciones hipertónicas permite la transferencia de agua por ósmosis, debido a que su estructura celular actúa como una membrana semipermeable (Resnick y Chirife, 1983). Esto permite explicar la necesidad de realizar tratamientos de inmersión en soluciones azucaradas y el prehorneado previo a la fritura atmosférica sobre los anillos de manzana.

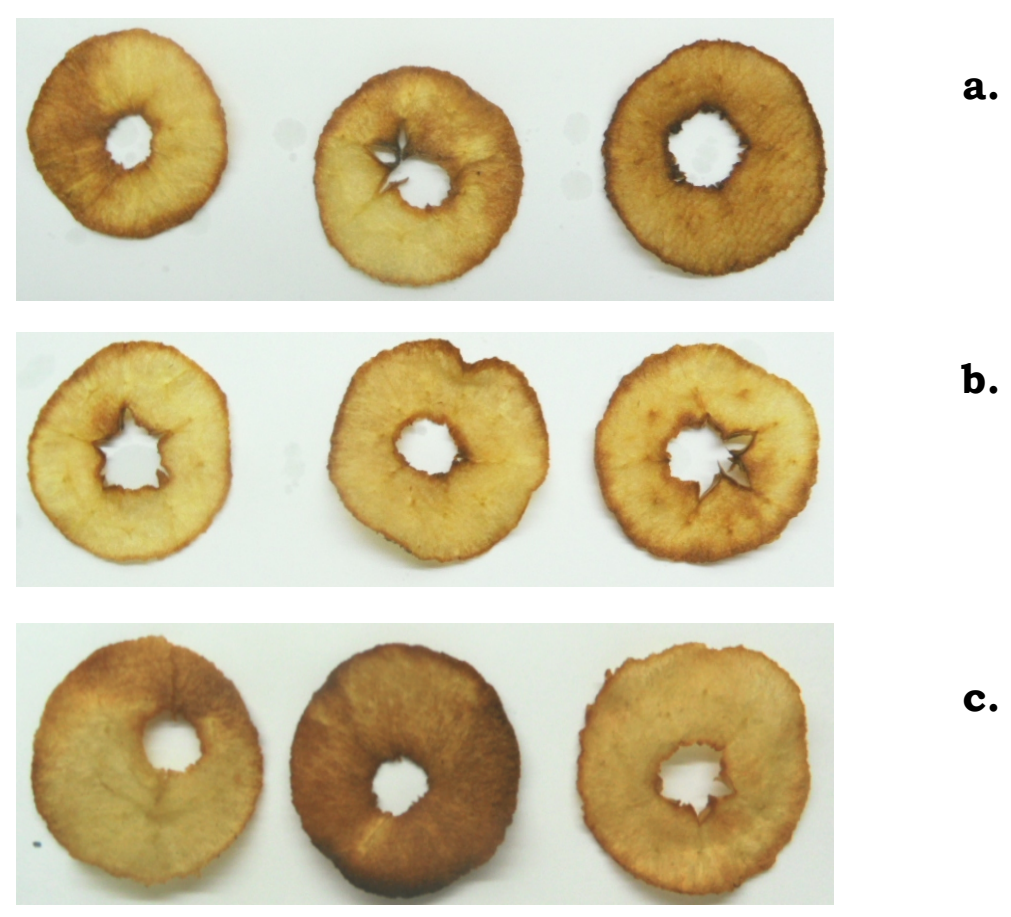

Figura 22. Fotografias de los snacks seleccionados por el método de cocción de horneado/fritado. a. $\mathrm{A}_{\mathrm{H} / \mathrm{F}}, \mathbf{b} . \mathrm{B}_{\mathrm{H} / \mathrm{F}}, \mathbf{c}_{\mathrm{H} / \mathrm{F}}$ 
De esta forma se lograron productos con características favorables, como lo son, una menor absorción de aceite, desarrollo de color y textura similar a productos tipo snack, comparados con un control frito sin pretratamientos con calcio y azúcares.

\section{Propiedades físicas de los snacks obtenidos}

Los resultados de las propiedades físicas (parámetros de color L*, $\mathrm{a}^{*}, \mathrm{~b}^{*}$, humedad y $\mathrm{a}_{\mathrm{w}}$ ) de cada uno de los snacks y de una muestra control sólo sometida al proceso de fritado sin la aplicación de pretratamientos, se observan en la Tabla 8 y 9.

Tabla 8. Propiedades físicas de snacks obtenidos por horneado/fritado y del control obtenido por fritado

\begin{tabular}{|c|c|c|}
\hline Snack & $\begin{array}{c}\text { Humedad } \\
\left.\text { (gagua } / 100 g_{\text {ms }}\right)\end{array}$ & $\mathbf{a}_{\mathbf{w}}$ \\
\hline Control $\mathrm{F}$ & $7,3^{c}(0,5)$ & $0,547 \mathrm{c}(0,02)$ \\
\hline $\mathrm{A}_{\mathrm{H} / \mathrm{F}}$ & $1,8^{\mathrm{b}}(0,4)$ & $0,420^{a}(0,01)$ \\
\hline $\mathrm{B}_{\mathrm{H} / \mathrm{F}}$ & $1,4^{\mathrm{a}}(0,2)$ & $0,438^{\mathrm{b}}(0,01)$ \\
\hline $\mathrm{C}_{\mathrm{H} / \mathrm{F}}$ & $2,3^{\mathrm{b}}(0,1)$ & $0,445^{\mathrm{b}}(0,01)$ \\
\hline
\end{tabular}

$a, b, c$ Letras diferentes indican diferencias significativas $(P<0,05)$. Valores entre paréntesis corresponden a la desviación estándar $(n=3)$.

Los resultados presentados en la Tabla 8 indicaron que las muestras obtenidas con fase grasa por horneado/fritado tuvieron valores más bajos de humedad respecto al control frito sin pretratamientos. Los valores de $\mathrm{a}_{\mathrm{w}}$ mostraron diferencias significativas $(\mathrm{P}<0,05)$ entre el control y los snacks, presentando una tendencia similar. Los snacks obtenidos por fritado/horneado obtuvieron valores de humedad menores al 3\%. De acuerdo a Moreira y col. (1999) los productos fritos deben tener un contenido de humedad del 10\% (base seca) o menores para lograr una vida útil aceptable. 
El snack $\mathrm{B}_{\mathrm{H} / \mathrm{F}}$ presentó los valores más bajos de humedad, por tener mayor contenido de maltodextrina en su formulación, lo cual indicó que el proceso de cocción utilizado removió satisfactoriamente la cantidad de agua necesaria del producto.

En la Tabla 9 se detallan los parámetros de color obtenidos a través del colorimetro, en la escala CIELAB:

Tabla 9. Parámetros de color del control y de los snacks obtenidos por horneado/fritado y fritado formulados con $\mathrm{M}: \mathrm{F}(1: 1,2: 1,1: 2)$

\begin{tabular}{lcccc}
\hline \multicolumn{1}{c}{ Snack } & $\mathbf{L}^{*}$ & $\mathbf{a}^{*}$ & $\mathbf{b}^{*}$ & $\mathbf{B I}$ \\
\hline Control $_{\mathrm{F}}$ & $43,0^{\mathrm{a}}(1,5)$ & $3,6^{\mathrm{a}}(0,5)$ & $11,1^{\mathrm{a}}(1,2)$ & $35,1^{\mathrm{a}}(0,2)$ \\
$\mathrm{A}_{\mathrm{H} / \mathrm{F}}$ & $60,0^{\mathrm{b}}(1,5)$ & $3,3^{\mathrm{a}}(0,5)$ & $26,7^{\mathrm{b}}(1,3)$ & $60,3^{\mathrm{b}}(0,5)$ \\
$\mathrm{B}_{\mathrm{H} / \mathrm{F}}$ & $60,0^{\mathrm{b}}(1,5)$ & $4,0^{\mathrm{a}, \mathrm{b}}(0,4)$ & $27,5^{\mathrm{b}}(0,7)$ & $63,9^{\mathrm{c}}(0,6)$ \\
$\mathrm{C}_{\mathrm{H} / \mathrm{F}}$ & $59,0^{\mathrm{b}}(1,7)$ & $5,7^{\mathrm{c}}(0,6)$ & $29,1^{\mathrm{b}}(1,1)$ & $71,9^{\mathrm{d}}(1,0)$ \\
\hline
\end{tabular}

$a, b, c, d$ Letras diferentes indican en la misma columna diferencias significativas. * Valores entre paréntesis corresponden a la desviación estándar ( $n=6)$.

El color es un factor importante en el procesamiento de alimentos tipo snack. El color amarillo-dorado característico de productos fritos es un parámetro de calidad primordial para el consumidor. Asimismo L* es un parámetro crítico en la industria de la fritura y es generalmente utilizado como un factor de control de calidad. Valores bajos de este parámetro indican reacciones de pardeamiento no enzimático y de degradación de ácido ascórbico, que puede ser degradado adicionalmente a compuestos de color pardo (por ejemplo, furfural) (Belitz y col., 2004). Los snacks mostraron mayores valores del parámetro $L^{*}$ respecto al control, siendo las diferencias significativas $(\mathrm{P}<0,05)$. En cuanto al parámetro de cromaticidad a* (verde-rojo) el snack obtenido a partir de la solución de Maltodextrina: Fructosa 1:2 $\left(\mathrm{C}_{\mathrm{H} / \mathrm{F}}\right)$ presentó los valores más altos y fue significativamente diferente a 
los demás snacks y al control $(\mathrm{P}<0,05)$. Mariscal y col. (2008) demostraron que durante la fritura atmosférica de chips de manzana, los valores de $\mathrm{L}^{*}$ disminuyen y los de $\mathrm{a}^{*}$ aumentan, cambiando de valores negativos (más cercano al verde) a valores positivos (color rojo), como resultado de la reacción de Maillard. Otros resultados similares fueron encontrados por Santina Romani y col. (2009) y García y col. (2002) trabajando con papas bastón a $180^{\circ} \mathrm{C}$. Serpen y Gokmen (2009) señalaron que desde el punto de vista práctico, en términos de aceptación de los consumidores, un valor de $\mathrm{a}^{*}$ (CIE) superior a 20 indica una papa de color marrón en vez de color amarillo dorado.

El parámetro $b^{*}$ (color amarillo-azul) fue significativamente más alto en los snacks en cuya preparación se incluyó el tratamiento con azúcares que para el control sin pretratamientos. Los snacks $\mathrm{A}_{\mathrm{H} / \mathrm{F}} \mathrm{y} \mathrm{B}_{\mathrm{H} / \mathrm{F}}$ presentaron un valores de BI entre 60 y 64, mientras que para $\mathrm{C}_{\mathrm{H} / \mathrm{F}}$ el BI obtenido fue significativamente más alto. Se evaluaron muestras sin impregnación de azúcares para determinar la influencia de los mismos en la formación de color durante el fritado y se obtuvo un BI promedio de 35,0. López-Malo y col. (1998) encontraron valores similares de BI en el rango de 50 a 57 para manzanas deshidratadas osmóticamente. Para los productos obtenidos por métodos combinados (horneado/fritado), se observó que las reacciones de desarrollo de color están mayormente afectadas, cuando se incrementa el contenido de azúcares reductores en su formulación. Esto se ve reflejado en un aumento en los valores obtenidos para los parámetros de cromaticidad $\mathrm{a}^{*} \mathrm{y}$ b*.

Algunos autores informan que la formación de color pardo se inicia cuando el contenido de humedad disminuye por debajo de 6-12\% (Mai Tran y col., 2007). Se ha informado que en el fritado convencional de papas hasta alcanzar $2 \%$ de humedad, la formación de color depende del contenido de azúcares reductores presentes y de la temperatura del aceite de fritado. Una acumulación excesiva de estos azúcares resulta en valores mayores de $a^{*} y$ de $B I$ asociados a la formación de 
compuestos de la reacción de Maillard. Márquez y Añon (1986) y Nunes y Moreira (2009) encontraron que la fructosa juega un papel más importante en la aumento de color de papas fritas que la glucosa. Según Mai Tran y col. (2007) la acumulación de los azúcares reductores del tubérculo influye en el pardeamiento excesivo de papas a la francesa y papas fritas. De acuerdo a esto, se observó que para el snack $\mathrm{C}_{\mathrm{H} / \mathrm{F}}$, la utilización de mayor contenido de fructosa en su formulación, contribuyó a que las muestras desarrollaran una coloración excesiva.

\section{Análisis de la textura}

La textura de los snacks se obtuvo a través del test de ruptura, donde se observó la curva fuerza-desplazamiento de cada grupo de muestras analizadas (Figura 23 a y b).

Las curvas fuerza-desplazamiento de los snacks $\mathrm{A}_{\mathrm{H} / \mathrm{F}}$ y $\mathrm{B}_{\mathrm{H} / \mathrm{F}}$ representadas en la Figura 23 a obtenidas de muestras recién preparadas, exhiben un aspecto dentado con varios eventos de fractura, típico de los alimentos crujientes (Vicente, 1998, Chen y col., 2005; Varela y col., 2006; Tavera Quiroz y col., 2012; Taniwaki y col., 2012). En los resultados obtenidos se observaron valores de fuerza máxima inferiores a $5 \mathrm{~N}$ a bajas deformaciones. Valores de fuerza máxima mayores o iguales a $4 \mathrm{~N}$ se consideran indicadores de gomosidad (Nunes y Moreira, 2009). Los snacks $A_{H / F}$ y $B_{H / F}$ fueron claramente más frágiles que $\mathrm{C}_{\mathrm{H} / \mathrm{F}} \mathrm{y}$ el control. El valor de la primera fuerza de ruptura y la deformación para todas las muestras analizadas fueron similares, las curvas de $A_{H / F}$ y $B_{H / F}$ mostraron caídas repentinas de propagación rápida. Mientras tanto $\mathrm{C}_{\mathrm{H} / \mathrm{F}}$ mostró un perfil crocante inicial donde la primera fractura se produjo al inicio del ensayo (Figura 23 b). Sin embargo, alcanzó mayor deformación antes de la ruptura total. 
a.
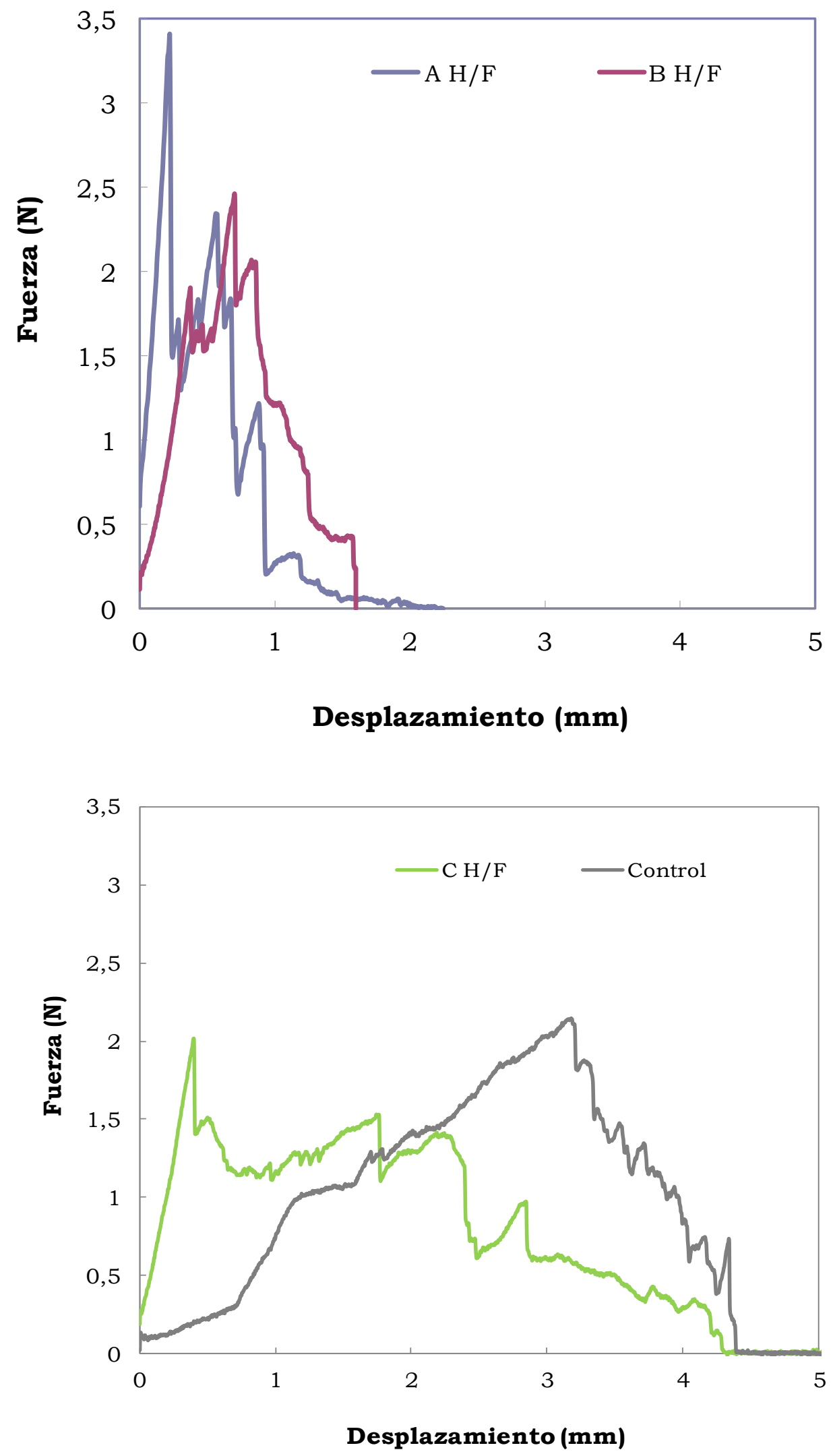

b.

Figura 23. Curvas de fuerza-desplazamiento de los snacks: a. $A_{H / F}, B_{H / F}$ y b. $\mathrm{C}_{\mathrm{H} / \mathrm{F}} \mathrm{y}$ control. 
Para el control, se observó una curva heterogénea, donde la primera fractura se produjo a una deformación superior. Esta forma de la curva es típica de productos más elásticos y por ende, menos quebradizos y con mayor humedad (Figura 23 b) (Varela y col., 2006, 2007).

En base a lo anteriormente explicado, los snacks tratados con mayor contenido de maltodextrina en la formulación presentaron una buena calidad en la textura (recién preparados) independientemente del tipo de cocción utilizada. Los resultados fueron similares a los obtenidos por Huang y col. (2011) estudiando la textura de chips de papas y manzanas. Nunes y Moreira (2009) encontraron que pretratamientos con maltodextrinas disminuyeron los valores defuerza máxima en chips de mango.

\section{Evaluación sensorial}

Se realizó un ensayo de evaluación sensorial de los snacks seleccionados: $\mathrm{A}_{\mathrm{H} / \mathrm{F}}, \mathrm{B}_{\mathrm{H} / \mathrm{F}}$ y $\mathrm{C}_{\mathrm{H} / \mathrm{F}}$ obtenidos por el método de horneado/fritado.

De acuerdo a los resultados de preferencia del panel sensorial la solución de impregnación que obtuvo la mayor preferencia fue la de $20 \%$ de maltodextrina y $10 \%$ de fructosa $\left(\mathrm{B}_{\mathrm{H} / \mathrm{F}}\right)$ y la de menor preferencia fue $10 \%$ de maltodextrina y $20 \%$ de fructosa $\left(\mathrm{C}_{\mathrm{H} / \mathrm{F}}\right)$. Por otra parte la muestra con M:F 1:1 (15\% de maltodextrina y 15\% de fructosa) no fue aceptada ni rechazada por los panelistas, según las respuestas analizadas. En la Figura 24, se graficó el porcentaje de las respuestas "Gusta más" respecto al total de respuestas obtenidas para cada snack evaluado. 


\section{"Gusta más"}

$=\mathrm{AH} / \mathrm{F} \quad \mathrm{BH} / \mathrm{F} \| \mathrm{CH} / \mathrm{F}$

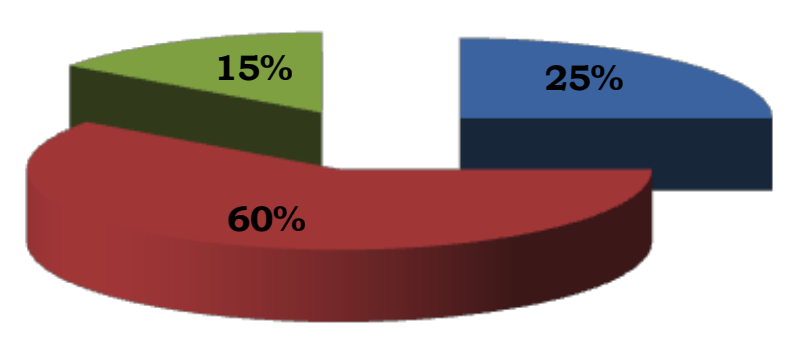

Figura 24. Frecuencia relativa (\%) de las respuestas dadas por los consumidores en el panel de preferencia de snacks.

El snack $\mathrm{B}_{\mathrm{H} / \mathrm{F}}$ obtuvo la mayor cantidad de respuestas positivas. Sin embargo al igual que las otras muestras evaluadas presentó un colapso de su estructura luego de transcurrido cierto tiempo desde su preparación, lo cual estaría relacionado con el alto contenido graso y los productos de la reacción de Maillard generados durante el fritado a altas temperaturas en presencia de azúcares reductores. Los panelistas coincidieron en que todas las muestras presentaban sabor graso persistente en la boca. Según Moreira y col. (2009) y Mariscal y col. (2008) la fritura convencional por sí sola produce una disminución de la calidad de la fruta sometida a este proceso y por lo tanto del snack derivado de la misma. La textura y el color se deterioran completamente, por lo que es necesario buscar alternativas como la fritura a vacío o por aire caliente

\section{Análisis de las propiedades térmicas}

La temperatura del proceso de relajación asociada a la temperatura de transición vitrea $\left(\mathrm{T}_{\mathrm{g}}\right)$ se determinó a través de la técnica de DSC y el pico máximo del módulo de pérdida (E") de las curvas obtenidas por DMA. En los frutos, las transiciones vitreas se detectan debido a la presencia de azúcares, incluyendo la glucosa, fructosa, sacarosa, y biopolímeros (Vega-Gálvez y col., 2012). A partir de los 
termogramas obtenidos por DSC se obtuvieron las temperaturas de transición vítrea $\left(\mathrm{T}_{\mathrm{g}}\right)$ de los snacks analizados (Tabla 10)

Tabla 10. Valores de $T_{g}\left({ }^{\circ} \mathrm{C}\right)$ obtenidos por DSC para los snacks de manzana

\begin{tabular}{cc}
\hline Snack & $\mathbf{T}_{\mathbf{g}}\left(^{\circ} \mathbf{C}\right)$ \\
\hline $\mathrm{A}_{\mathrm{H} / \mathrm{F}}$ & $40,0^{\mathrm{a}}$ \\
$\mathrm{B}_{\mathrm{H} / \mathrm{F}}$ & $46,2^{\mathrm{b}}$ \\
$\mathrm{C}_{\mathrm{H} / \mathrm{F}}$ & $44,6^{\mathrm{b}}$ \\
\hline
\end{tabular}

${ }^{a, b}$ Letras diferentes indican diferencias significativas $(P<0,05)$.

Por DMA se encontraron resultados similares a los obtenidos por DSC analizando las curvas de módulo de pérdida (pico máximo de la curva) asociadas con las propiedades viscoelásticas de los productos obtenidos (Figura 25).

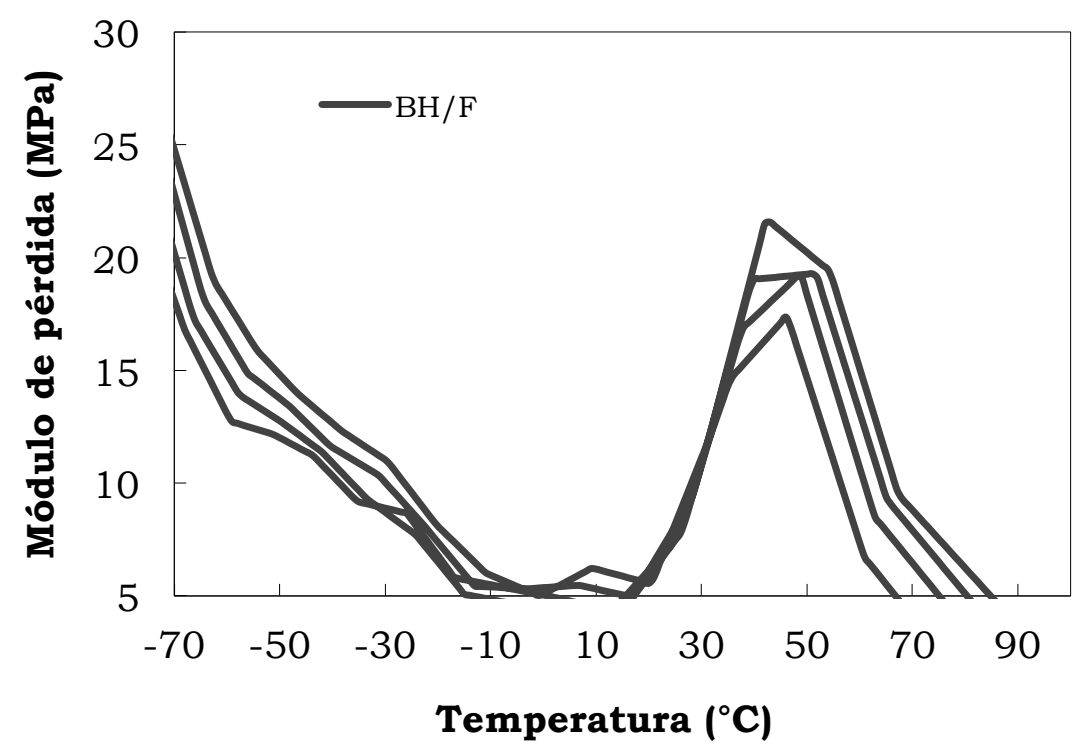

Figura 25. Termograma de barrido de frecuencia obtenido por DMA del snack $\mathrm{B}_{\mathrm{H} / \mathrm{F}}($ Frec. 5, 10, 15 y $20 \mathrm{~Hz})$.

Se observó que los snacks presentaron valores de $\mathrm{T}_{\mathrm{g}}$ altos respecto a los frutos sin pretratamientos. El snack con mayor valor de $\mathrm{T}_{\mathrm{g}}$ fue el $\mathrm{B}_{\mathrm{H} / \mathrm{F}}$, el cual contiene una mayor proporción de maltodextrina en su formulación. Sin embargo, al contener una fase grasa y baja humedad, los snacks pierden su estructura rápidamente. Se considera que 
pequeños cambios ambientales de humedad y temperatura afectan a estos productos de manera significativa, alterando su estructura y promoviendo reacciones indeseables. Farroni (2011) informó que los principales cambios en las propiedades mecánicas y en la textura oral de copos de maíz ocurrieron antes de la transición vitrea o en la zona muy cercana a esta y por lo tanto es posible que dependa además de los cambios de humedad y temperatura ambiente, de los ingredientes y/o separación de fases (lípidos, agua).

Teniendo en cuenta que el snack $\mathrm{B}_{\mathrm{H} / \mathrm{F}}$ mostró humedad más baja, $\mathrm{T}_{\mathrm{g}}$ más alta y una mayor aceptabilidad sensorial, respecto a los demás snacks obtenidos, este se seleccionó para continuar su análisis con otras determinaciones.

\section{Contenido graso}

Se determinó el contenido graso de la muestra que presentó una mejor relación de propiedades organolépticas (uniformidad en el color, olor, textura) y sensoriales, así como del control frito sin pretratamientos. El contenido graso determinado por Soxhlet para el control fue de $57,6 \% \pm 0,5$ (b.s), mientras que para $\mathrm{B}_{\mathrm{H} / \mathrm{F}}$ fue de $31,0 \%$ $\pm 2,5$ (b.s). Algunas investigaciones informan que chips de papas, maíz y tortillas contienen entre un 30 y 40\% de grasa (Choe y col., 2007). Moreira, y col. (1995) demostraron que la mayor retención de aceite en el producto tiene lugar cuando la mayor cantidad de agua ha salido del mismo. Como se mencionó anteriormente durante la fritura, el agua y el vapor de agua que rellenan los capilares de mayor tamaño en el alimento son desplazados por el aceite caliente. Por lo tanto la reducción del contenido de aceite absorbido en los anillos de manzana sin pretratamientos (control) comparada con la de productos que sí tuvieron algún tipo de tratamiento previo a la fritura, estaría relacionada con la disminución del contenido de humedad inicial de la muestra. Este menor contenido de humedad antes del fritado fue debido al horneado previo y al tratamiento con las soluciones de azúcar. 
Cuando las muestras se sometieron a una deshidratación previa en soluciones hipertónicas los anillos de manzana perdieron entre un 40$50 \%$ de su contenido de agua inicial en el tiempo de tratamiento estimado (15 min). Es necesario aclarar que los anillos de manzana control tenían un contenido de agua inicial entre 82 y 85\% (gagua/ $\left.100 g_{m}\right)$. Mientras tanto, los anillos de manzana prehorneados a $100^{\circ} \mathrm{C}$ durante $10 \mathrm{~min}$, mostraron una disminución en el contenido de agua de un 30\% (flechas negras en la Figura 26) cuando fueron tratados con soluciones de M:F

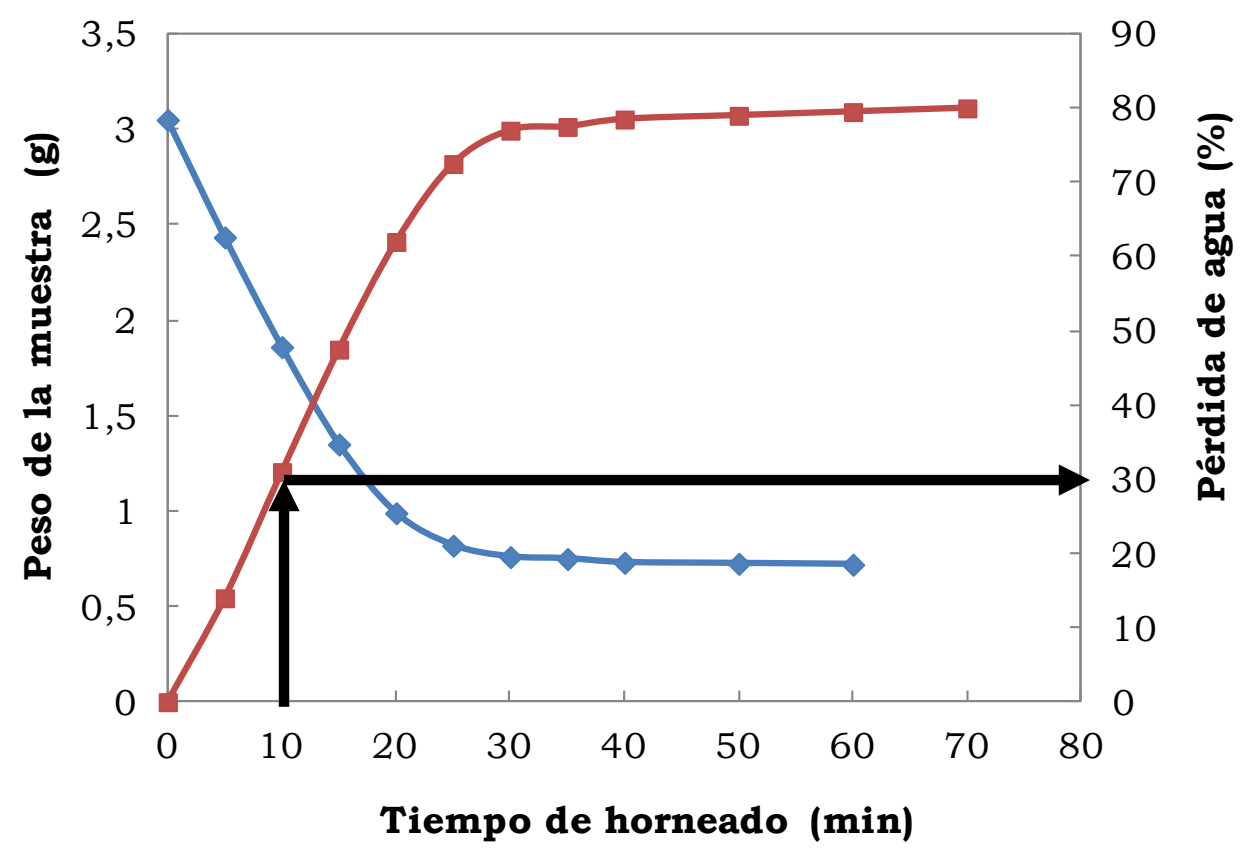

Figura 26. Variación del peso (g) y la pérdida de agua (\%) de las muestras durante el prehorneado a $100^{\circ} \mathrm{C}$ de los snacks $\mathrm{M}: \mathrm{F}$ (1:1). La curva azul indica la variación del peso de los anillos de manzana durante el horneado. La curva roja indica la pérdida de agua durante el horneado.

Sin embargo, los anillos de manzana sometidos a fritura son matrices higroscópicas con contenidos altos de grasa. Por lo tanto estos productos son de elevado contenido energético, destinados a consumidores con altas exigencias de calorías. Rodríguez y col. (2013) informaron que la absorción de grasas de un snack de banano fresco frito aumentó su contenido de aceite debido al intercambio agua/ aceite 
en el momento de la fritura, mientas que para un snack de banano osmodeshidratado el valor de contenido de grasa fue menor. Herrera (2008) desarrolló hojuelas de piña fritas con contenidos de grasa promedio de $20 \%$ (b.s). Ikoko y col. (2007) y Singthong y col. (2009) informaron resultados similares a los obtenidos en este estudio.

\section{Contenido de ácido ascórbico (AA)}

La cuantificación del contenido de ácido ascórbico se realizó mediante la comparación del área bajo la curva del cromatograma del snack $\mathrm{B}_{\mathrm{H} / \mathrm{F}}$, con la del estándar externo. La metodología utilizada resultó adecuada para las muestras estudiadas ya que los cromatogramas obtenidos mostraron a tiempos iguales, picos de elución bien definidos y buena línea de base. El contenido de ácido ascórbico del snack obtenido por $\mathrm{H} / \mathrm{F}$ fue de $3,7 \mathrm{mg} / \mathrm{g}_{\mathrm{ms}}$, siendo aproximadamente el $10 \%$ del AA incorporado por el tejido de la fruta (Figura 27).

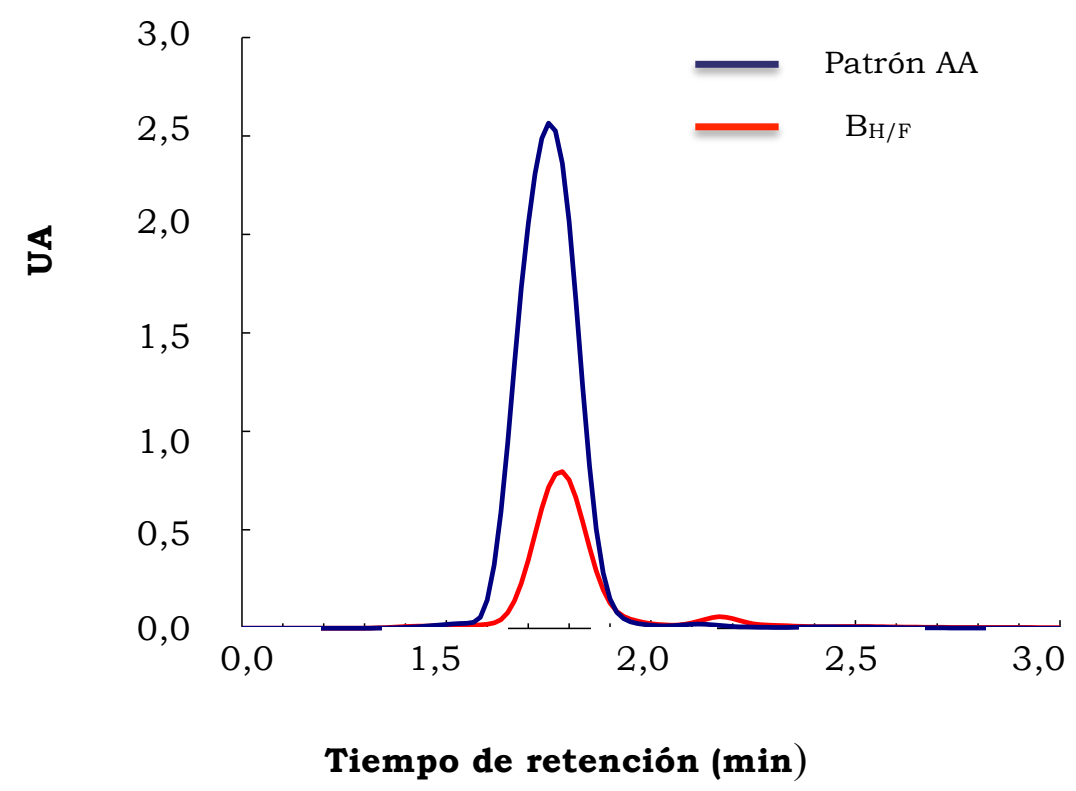

Figura 27. Cromatograma de ácido ascórbico presente en el extracto del snack de manzana $\mathrm{B}_{\mathrm{H} / \mathrm{F}}$.

La fritura por ser un tratamiento que involucra altas temperaturas favorece la pérdida de vitamina C. Varios autores informaron resultados similares. Entre ellos, Herrera (2008) observó 
pérdidas importantes de carotenoides en hojuelas de piña fritas. Rodríguez y col. (2013) informaron pérdidas totales de vitamina A y parciales de vitamina $\mathrm{C}$ en banano durante el proceso de fritura. Según estos autores las pérdidas en el snack de banano frito se debieron al carácter termolábil de la vitamina C y la solubilidad en lípidos de la vitamina A. En el mismo sentido, Villamizar y col. (2010) encontraron que durante la fritura atmosférica de chips de mango, las pérdidas de vitamina $\mathrm{C}$ fueron de $94 \%$ respecto a la pulpa de mango sin procesar.

\subsection{DESARROLLO DE SNACKS HORNEADOS A PARTIR DE DIFERENTES FORMULACIONES DE MALTODEXTRINA: FRUCTOSA}

\section{MATERIALES Y METODOS}

\subsubsection{MATERIALES}

Se utilizaron anillos de manzana con los pretratamientos descriptos en la sección 3.2.

\subsubsection{MÉTODOS}

\subsubsection{Proceso de horneado}

Los anillos de manzana se sometieron a un proceso de horneado durante $1 \pm 0,1 \mathrm{~h}$, usando un horno de convección forzada Multiequip HCE-3 a $100{ }^{\circ} \mathrm{C}$ (Ariston, Argentina). Los snacks obtenidos a partir de la impregnación con el lactato-gluconato de calcio y tratados con las soluciones de maltodextrina: fructosa con una proporción de 1:1, 2:1 y $1: 2$, se denominaron $A_{L}, B_{L}$ y $C_{L}$, respectivamente. Los formulados a partir de los mismos pretratamientos con azúcares y carbonato de calcio fueron rotulados como $\mathrm{A}_{\mathrm{C}}, \mathrm{B}_{\mathrm{C}} \mathrm{y} \mathrm{C}_{\mathrm{C}}$. Anillos de manzana horneados sin pretratamientos de calcio y azúcares fueron utilizados como control. En la Figura 28 se describe el proceso de obtención de los snacks de manzana. 


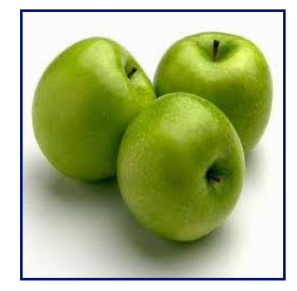

Manzana fresca cv. Granny Smith

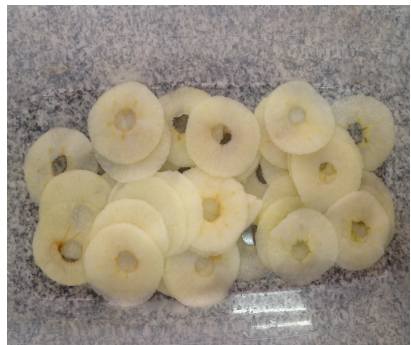

Anillos de manzana con calcio impregnados con soluciones de maltodextrina: fructosa al 30\% $\mathrm{p} / \mathrm{v}$

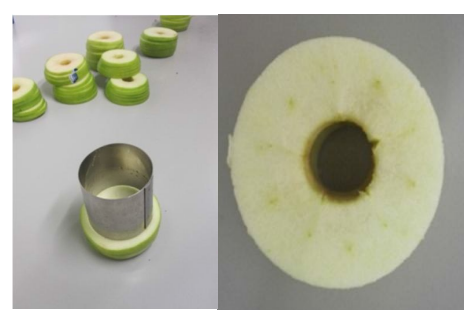

Preparación de los anillos de manzana

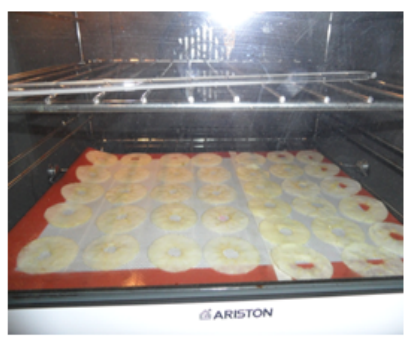

Horneado $1 \mathrm{~h}$ a $100^{\circ} \mathrm{C}$
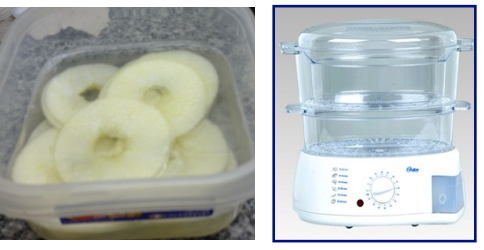

Inmersión en sales de calcio y tratamiento con vapor

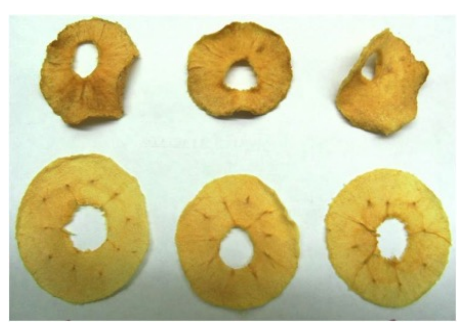

Snacks obtenidos con M:F A, B y $\mathrm{C}$ (der a izq.) Carbonato (superior), Lactato-gluconato (inferior).

Figura 28. Proceso de obtención de los snacks horneados de manzana verde a partir de impregnación en soluciones de M:F: A (1:1), B (2:1) y C (1:2).

\subsubsection{Determinación de las propiedades fisicoquimicas e instrumentales}

Se evaluaron la humedad, actividad acuosa, textura y color de los snacks obtenidos por horneado y el control, siguiendo la metodología descrita en la sección anterior (Capítulo 3- sección 3.3).

\section{Análisis de la microestructura}

Se realizaron observaciones por SEM a bajo vacío con diferentes aumentos para observar la estructura del tejido de la manzana después del horneado.

\subsubsection{Evaluación sensorial}

En estudios con consumidores, se busca saber el porqué de la preferencia o rechazo hacia un producto mediante el empleo de preguntas dirigidas a atributos particulares (ISETA, 2007). En este caso particular, que involucra el desarrollo de un producto novedoso, se 
realizó una prueba de aceptabilidad por atributos a través de una escala hedónica.

\section{Fundamento y diseño de la prueba}

El ensayo se realizó en dos etapas. En una primera reunión un panel de 50 consumidores con experiencia en análisis sensorial evaluó 4 muestras (una muestra control y una muestra de cada snack $\mathrm{A}_{\mathrm{L}}, \mathrm{B}_{\mathrm{L}}$, $\mathrm{C}_{\mathrm{L}}$ ), codificadas con números aleatorios de tres dígitos. En una segunda experiencia se evaluaron las muestras $A_{C}, B_{C}, C_{C}$ y el control. Previo al desarrollo de la prueba se les indicó a los panelistas que antes y después de probar cada una de las muestras debian enjuagarse la boca con agua. Se evaluaron aceptabilidad general, color, textura, dulzor y sabor ácido utilizando una escala hedónica de 9 puntos para cada uno. Se pidió a cada evaluador que otorgara un puntaje a cada una de las muestras. De ambos ensayos se obtuvo el snack con mayor aceptabilidad.

\section{Metodologia}

\section{Selección de evaluadores}

Se seleccionaron 50 personas adultas dentro del personal del CIDCA (Conicet-La Plata), entre 25 y 55 años de edad. El grupo estaba compuesto por $70 \%$ de mujeres y 30\% de hombres, consumidores habituales de snacks, con experiencia en pruebas sensoriales y sin entrenamiento previo en el reconocimiento de los atributos a evaluar. A cada uno le fue entregada una planilla con una escala hedónica (disgusta/gusta) donde debían evaluar cada atributo (Figura 29).

\section{Preparación de las muestras}

A cada evaluador se le sirvió una muestra de cada uno de los snacks a evaluar y del control (recién preparadas), en bandejas transparentes con el número correspondiente a cada evaluador. Previamente las muestras se habían codificado con números de tres dígitos utilizando una tabla de números aleatorios. El ensayo se realizó en una zona aislada, con buena ventilación e iluminación de tal forma 
que no hubiese interferencia externa que afectaran las muestras y/o influenciara a los evaluadores.

\section{ENSAYO DE ACEPTABILIDAD POR ATRIBUTOS DE SNACKS DE MANZANA}

Nombre:

$\mathbf{N}^{\circ}$ Evaluador:

Fecha:

Ud. encontrará tres muestras codificadas con números de tres dígitos en cada bandeja. Por favor evalúe la aceptabilidad de cada atributo marcando con una cruz sobre la escala. Tenga en cuenta que primero debe evaluar todos los atributos de una muestra antes de pasar a la siguiente.

Muestra $\underline{\mathbf{5 8 9}}$

Aceptabilidad General

Disgusta Gusta

Sabor

Color

Textura

En una escala de 1 a 9 qué puntaje le pondría a la muestra:

\section{Muestra 786}

Aceptabilidad General

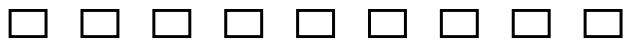

Sabor

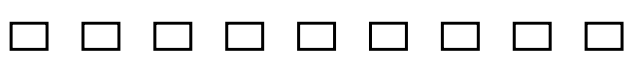

Color

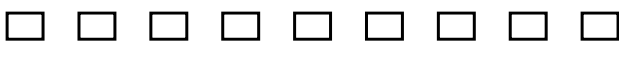

Textura

$\checkmark$ En una escala de 1 a 9 qué puntaje le pondría a la muestra:

\section{Muestra 245}

Aceptabilidad General

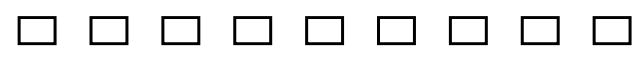

Sabor

Color

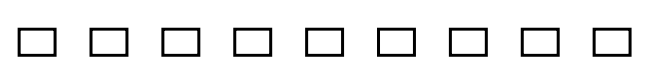

Textura

$\checkmark$ En una escala de 1 a 9 qué puntaje le pondría a la muestra:

Figura 29. Planilla de evaluación sensorial utilizada para evaluar los snacks obtenidos 


\subsubsection{Análisis de las propiedades funcionales de los snacks seleccionados}

Después de la realización del análisis sensorial, dos snacks (uno formulado con carbonato $y$ otro con lactato de calcio) fueron seleccionados y sobre los mismos se realizaron estudios adicionales como contenido de azúcares, ácido ascórbico, capacidad antioxidante y contenido de polifenoles totales.

\section{Determinación del contenido de azúcares y de ácido ascórbico por cromatografia liquida de alta resolución (HPLC)}

La determinación del contenido de azúcar de los snacks previamente seleccionados por el panel de consumidores y de la manzana fresca se realizó por cromatografia líquida de alta resolución (HPLC- por sus siglas en inglés) en un equipo Waters (Malasia), modelo R-414 a partir del método de Dolenc y Stampar (1997). Dos gramos de cada una de las muestras previamente congeladas en nitrógeno se mezclaron con $10 \mathrm{ml}$ de agua destilada. Esta mezcla fue homogeneizada con un vortex (IKA Vortex, Argentina) y se mantuvo bajo agitación constante durante $45 \mathrm{~min}$. A continuación, el homogeneizado se centrifugó durante $15 \mathrm{~min}$ a $15000 \mathrm{rpm}$ (Rolco CM2036, Argentina).Los sobrenadantes se filtraron con membranas Millipore de 0,45 $\mu \mathrm{m}$ (Millipore Corporation, Francia). Se inyectaron $20 \mu \mathrm{l}$ de cada uno de los extractos de las muestras a analizar en el detector de índice de refracción (IR). La separación de los azúcares (glucosa, fructosa y sacarosa) se realizó con una columna amino MicrosorbR0086700, (KNAUER, Alemania) a $35{ }^{\circ} \mathrm{C}$, con un caudal de $1,2 \mathrm{ml} / \mathrm{min}$ y usando una fase móvil de acetonitrilo (Merck, Alemania) /agua destilada (70:30). Los azúcares presentes en cada muestra se identificaron y cuantificaron utilizando estándares externos a partir de una curva de calibración (5 a $30 \mathrm{mg} / \mathrm{ml}$ ) de fructosa, glucosa y sacarosa (Sigma, Argentina). Los resultados se expresaron como g carbohidrato/100 g muestra. 
La determinación del contenido de ácido ascórbico se realizó siguiendo la metología utilizada en la sección 3.3 de este Capítulo.

\section{Determinación de la capacidad antioxidante total (TAC) y el contenido de polifenoles}

El término antioxidante hace referencia a cualquier sustancia que estando presente en una concentración baja comparada con la de un sustrato oxidable, retarda o inhibe la oxidación de dicho sustrato, ya que es capaz de neutralizar la acción oxidante de los radicales libres mediante la liberación de electrones que son captados por estos (Fennema, 1996). En el caso de los alimentos, la oxidación es una de las mayores causas de deterioro en productos con alto contenido graso, causando rancidez, pérdida de la calidad nutricional, color, sabor y textura.

En relación al uso de polifenoles naturales como antioxidantes, diversos autores han recopilado distintos trabajos referidos a su utilización e interpretación de mecanismos de acción de estas sustancias (Brand-Williams y col., 1995; Moure y col., 2001; Paixão y col., 2007). Por otra parte, según las reacciones químicas involucradas, los ensayos de capacidad antioxidante pueden ser divididos en dos categorias: i) transferencia de un átomo de hidrógeno y ii) transferencia de un electrón desapareado. La mayoría de los mecanismos de transferencia de un átomo de hidrógeno se aplica a un esquema de reacción competitiva en el cual el antioxidante y el sustrato compiten por los radicales peróxidos generados.

En los ensayos de determinación de la actividad antioxidante mediante espectroscopía se emplean reactivos que al interactuar con el antioxidante provocan una disminución de la absorbancia proporcional a la concentración remanente y la actividad antioxidante del compuesto en estudio. Existen diversos métodos para medir la capacidad antioxidante cuyos resultados brindan información del mecanismo 
propio de la reacción involucrada (Antolovich y col., 2002; Gülcin y col., 2010; Moure y col., 2001). Entre los distintos métodos existentes se destacan el ensayo de TEAC (Capacidad antioxidante expresada en equivalentes Trolox) basado en la captación por los antioxidantes del radical catión $\mathrm{ABTS}^{\bullet+}$ generado en el medio de reacción. Por otro lado, el ensayo de $\mathrm{DPPH}$ es un método rápido y sencillo y a diferencia del ensayo TEAC no es necesario preparar previamente el reactivo ya que el $\mathrm{DPPH}$ se comercializa en la forma de radical y sólo requiere su disolución.

Por otra parte, uno de los métodos más empleados para la determinación de polifenoles totales es el de Folin Ciocalteu, siendo este ensayo un ejemplo típico de transferencia de un electrón desapareado (Paixão y col., 2007). Los valores relativos obtenidos por esta técnica generalmente correlacionan bien con los demás métodos cuando se comparan muestras similares (Singleton y col., 1999).

Las determinaciones de capacidad antioxidante se realizaron sobre las manzanas frescas y los snacks obtenidos. Para el caso del ensayo de polifenoles totales, la medida se realizó sin agregado de ácido ascórbico, para evitar interferencias. Dos gramos de cada muestra, previamente congelado en nitrógeno, se mezclaron con $10 \mathrm{ml}$ de etanol al 96\% bajo agitación constante durante $40 \mathrm{~min}$. El homogeneizado se centrifugó y se recogió el sobrenadante. La capacidad antioxidante de los extractos de alimentos se analizó por triplicado a través del método de DPPH (Brand-Wiliams y col., 1995; Sánchez-Moreno y col., 1998) y por ABTS $^{\bullet+}$ (Re y col., 1999). A continuación se describen cada uno de los métodos utilizados:

\section{Método ABTS ${ }^{\bullet+}$ (Acido 2,2-azino-bis-3-etilbenzotiazolin-6-sulfónico)}

La generación del radical ABTS $^{\cdot+}$ constituye la base de uno de los métodos espectrofotométricos que han sido aplicados para medir la actividad antioxidante total de soluciones o sustancias puras y mezclas 
acuosas. El radical cromóforo ABTS $^{\bullet+}$ verde-azul se obtiene tras la reacción de ABTS (Sigma Aldrich, USA) $7 \mathrm{mM}$ con persulfato potásico $\left(\mathrm{K}_{2} \mathrm{~S}_{2} \mathrm{O}_{8}\right)$ 2,45 mM. La adición de los antioxidantes al radical preformado lo reduce a ABTS. De esta manera el grado de decoloración como porcentaje de inhibición del radical catión ABTS $^{\cdot+}$ está determinado en función de la concentración y el tiempo. La oxidación con persulfato potásico se lleva a cabo a temperatura ambiente $\left( \pm 25^{\circ} \mathrm{C}\right)$, en ausencia de luz, durante $16 \mathrm{~h}$. El persulfato potásico y el ABTS reaccionan estequiométricamente (1:0.5). Una vez formado el radical ABTS $^{\cdot+}$ se diluye con etanol hasta obtener un valor de absorbancia de $0,7( \pm 0,1)$ a una longitud de onda de 754 nm (máxima absorción). Las muestras filtradas se diluyen con etanol hasta que se produce una inhibición entre el 20 y el 80\%, en comparación con la absorbancia del blanco, tras añadir $20 \mu \mathrm{L}$ de la muestra. A $980 \mu \mathrm{L}$ de dilución del radical $\mathrm{ABTS}^{\bullet+}$ así generado se le determina la $\mathrm{A}_{754}$ a $30^{\circ} \mathrm{C}$, se añade 20 $\mu \mathrm{L}$ de la muestra y se mide de nuevo la $\mathrm{A}_{754}$ pasado 1 minuto. La absorbancia se mide de forma continua hasta transcurridos 7 minutos.

En este trabajo de tesis se realizó una curva de calibración con un antioxidante de referencia (Trolox) a una concentración de 0-15 $\mu \mathrm{M}$ (concentración final) en etanol, bajo las mismas condiciones. Los resultados se expresaron en $\mathrm{Mm}_{\mathrm{TEAC}} / \mathrm{g}_{\mathrm{ms}}$ (TEAC: actividad antioxidante equivalente a Trolox).

\section{Método DPPH}

El fundamento del método DPPH desarrollado por Brand-Willams y col. (1995) consiste en la capacidad de una sustancia antioxidante de reducir el radical DPPH (2,2-Difenilo-1-picrilhidrazilo), el cual tiene un electrón desapareado. Una vez preparado, el reactivo es de color azulvioleta, decolorándose hacia amarillo pálido por la reacción cuando la sustancia antioxidante es capaz de "captar" al radical y reducirlo. Esta reacción presenta el máximo de absorbancia a $517 \mathrm{~nm}$. Por diferencia de absorbancia (antes y después de la reacción) se determina el 
porcentaje de captación de radical libre DPPH a una concentración de $25 \mathrm{mg} / \mathrm{L}$.

Para obtener los valores de porcentaje de inhibición del radical, a 3,9 $\mathrm{ml}$ de DPPH disuelto en etanol al 96\%, se añadieron 0,1 $\mathrm{ml}$ de la muestra. Se homogenizó cuidadosamente y se mantuvo en oscuridad durante 30 minutos. Los extractos fueron evaluados a diferentes concentraciones entre 0,2 y $20 \mathrm{mg} / \mathrm{ml}$ y comparados con vitamina $\mathrm{C}$. Las medidas de absorbancia se realizaron antes de añadir la muestra $\left(\mathrm{A}_{0}\right)$ y pasados los 30 y 60 minutos $\left(\mathrm{A}_{\mathrm{f}}\right)$. Los resultados para determinar el \%inhibición (\% I)(Ec. 8) del radical se expresaron como:

$$
\% I=\frac{\left(A_{f}-A_{0}\right)}{A_{0}} \times 100 \quad \text { Ec. } 8
$$

\section{Contenido de polifenoles totales}

El contenido de polifenoles se obtuvo a través del método de Folin-Ciocalteu (Singleton y col., 1999), que determina la capacidad que tienen los polifenoles para reducir el Mo(VI) a Mo (V). El método espectrofotométrico para la determinación de fenoles totales se fundamenta en el carácter reductor del reactivo de Folin. El mismo es una mezcla de ácidos: fosfowolfrámico y fosfomolibdíco en medio básico, que se reducen al oxidar los compuestos fenólicos presentes en la matriz, originando óxidos azules de wolframio y molibdeno. Como resultado de tal reacción, el reactivo de color amarillo adquiere un intenso color azul que se mide con el espectrofotómetro.

La absorbancia del color azul desarrollado se mide a $765 \mathrm{~nm}$. En la técnica utilizada (Massolo y col., 2011) se siguió el siguiente procedimiento:

1. En tubos de $10 \mathrm{ml}$ agregar agua destilada en un volumen necesario para completar un volumen final de $2500 \mu 1$. 
2. Seguidamente colocar el volumen del extracto de cada muestra a evaluar $(50 \mu 1)$ y la serie de volúmenes de la solución estándar (0$200 \mu 1)$ para construir la curva de calibración. Agitar con vortex.

3. Colocar $50 \mu \mathrm{l}$ del reactivo de Folin-Ciocalteau (Sigma Aldrich, USA) diluido 1:1 con agua destilada en cada tubo y agitar. Dejar reposar por 3 minutos.

4. Agregar $100 \mu \mathrm{l}$ de $\mathrm{CO}_{3} \mathrm{Na}_{2}(20 \% \mathrm{p} / \mathrm{v})$ diluido en $\mathrm{NaOH} 0,1 \mathrm{~N}$. Agitar con vortex.

5. Dejar reaccionar 90 minutos en oscuridad y a temperatura ambiente.

6. Leer la absorbancia a $765 \mathrm{~nm}$.

Los resultados de las muestras se obtuvieron utilizando una curva de calibración obtenida a partir del ensayo realizado con ácido clorogénico como patrón $(0,2 \mathrm{mg} / \mathrm{ml})$ y se expresaron en $\mathrm{mg}$ ácido clorogénico/ $100 \mathrm{~g}$ muestra. Para todas las determinaciones se utilizó un espectrofotómetro Hitachi U-1900 (Reino Unido).

\subsubsection{Análisis estadístico}

Para cada ensayo, los resultados obtenidos fueron evaluados estadísticamente a través del software SYSTAT (SYSTAT, Inc., Evanston, IL, EE.UU.) (Wilkinson, 2000), mediante análisis de varianza (ANAVA). Cuando los datos presentaron diferencias entre sí, se realizó la comparación de medias mediante el test de LSD de Fisher a un nivel de significación de 0,05.

Se realizó un análisis de componentes principales (PCA) mediante el uso de software Infostat versión 2009 (Córdoba, Argentina). El análisis de PCA se le aplicó a la matriz de correlación de los valores medios de los parámetros sensoriales e instrumentales para ilustrar la relación entre las variables y muestras. 


\subsubsection{RESULTADOS Y DISCUSIÓN}

\section{Propiedades fisicoquimicas de los snacks obtenidos}

La Figura 30 a y b muestra imágenes de los snacks $\mathrm{A}_{\mathrm{C}}, \mathrm{B}_{\mathrm{C}}$ y $\mathrm{C}_{\mathrm{C}} \mathrm{y}$ $\mathrm{A}_{\mathrm{L}}, \mathrm{B}_{\mathrm{L}}, \mathrm{y} \mathrm{C}_{\mathrm{L}}$ obtenidos por horneado.

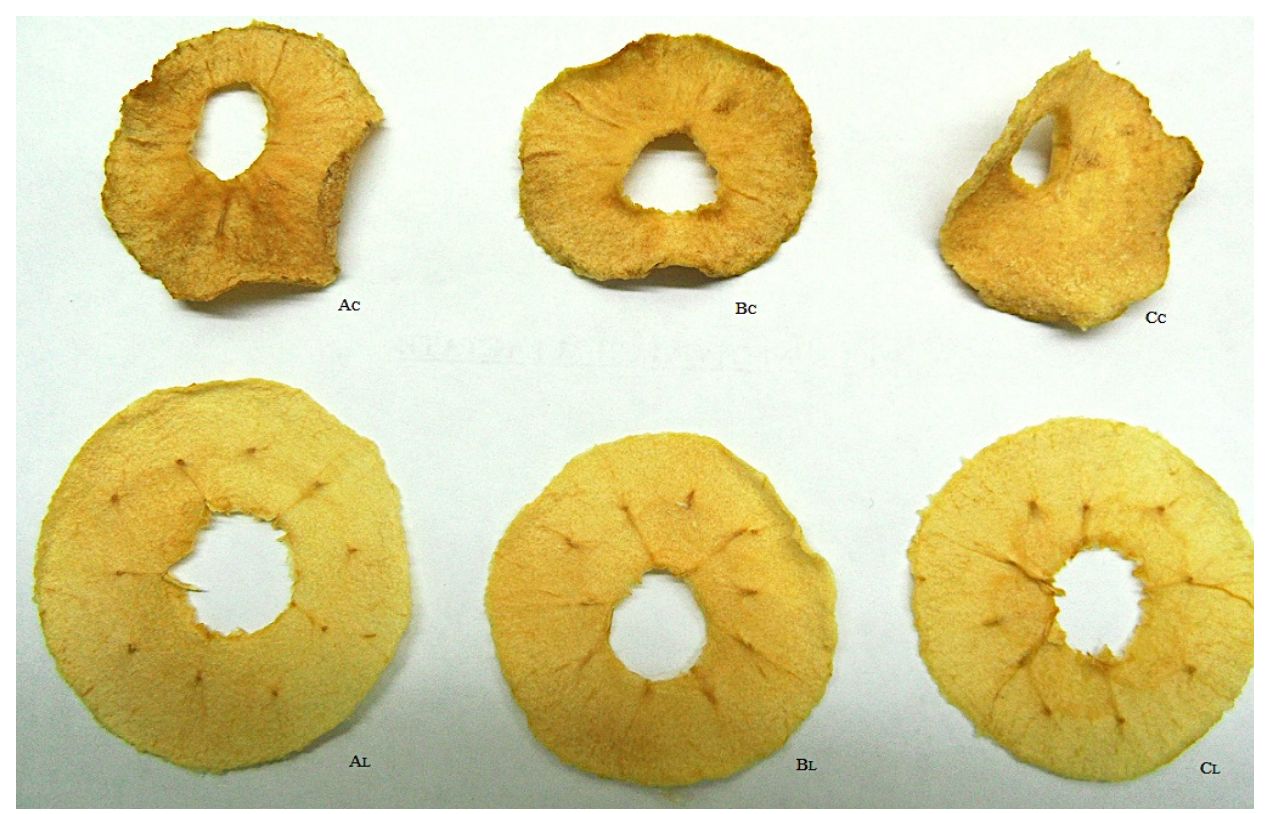

a.

b.

Figura 30. a. Snacks $A_{C}, B_{C}, y C_{C}$ y b. Snacks $A_{L}, B_{L}, C_{L}$ obtenidos por horneado.

En la Tabla 11 se detallan los valores de los parámetros de color de los snacks obtenidos y el control. Las propiedades físicas de textura (dureza), humedad y a se presentan en la Tabla 12. Considerando los parámetros de color, los valores de $L^{*}$ sólo presentaron diferencias significativas con el control. Los snack no mostraron diferencias significativas $(\mathrm{P}>0,05)$ independientemente de la relación $\mathrm{M}: \mathrm{F}$ y de la sal de calcio utilizada. El snack $A_{L}$ mostró el valor más bajo de b* (el color amarillo disminuyó en comparación con las otras muestras). Se observó el efecto de la sal de calcio utilizada, siendo los valores de $b^{*}$ distintos entre las muestras preparadas con lactato-gluconato y carbonato $(\mathrm{P}<0,05)$ (Tabla 11). 
Tabla 11. Parámetros de color del control y de los snacks obtenidos por horneado a $100{ }^{\circ} \mathrm{C}$

\begin{tabular}{llcccc}
\hline Muestra & M: $\mathbf{F}$ & $\mathbf{L}^{*}$ & $\mathbf{a}^{*}$ & $\mathbf{b}^{*}$ & $\mathbf{B I}$ \\
\hline Control & - & $73,0^{\mathrm{b}}(3,5)$ & $1^{\circ} 8^{\mathrm{a}}(0,9)$ & $25,0^{\mathrm{c}}(2,0)$ & $42,9^{\mathrm{c}}(0,9)$ \\
$\mathrm{A}_{\mathrm{L}}$ & $1: 2$ & $66,0^{\mathrm{a}}(3,0)$ & 3 , $^{\mathrm{b}}(1,2)$ & $18,2^{\mathrm{a}}(0,9)$ & $33,0^{\mathrm{a}}(0,5)$ \\
$\mathrm{B}_{\mathrm{L}}$ & $1: 1$ & $66,0^{\mathrm{a}}(2,4)$ & 3 , $^{\mathrm{b}}(1,1)$ & $20,0^{\mathrm{b}}(1,2)$ & $38,7^{\mathrm{b}}(0,6)$ \\
$\mathrm{C}_{\mathrm{L}}$ & $2: 1$ & $63,0^{\mathrm{a}}(2,9)$ & $4,1^{\mathrm{b}}(1,4)$ & $21,0^{\mathrm{b}}(1,4)$ & $39,2^{\mathrm{b}}(0,7)$ \\
$\mathrm{A}_{\mathrm{C}}$ & $1: 2$ & $64,0^{\mathrm{a}}(5,8)$ & $4,7^{\mathrm{b}}(0,8)$ & $35,2^{\mathrm{c}}(2,1)$ & $80,4^{\mathrm{d}}(0,9)$ \\
$\mathrm{B}_{\mathrm{C}}$ & $1: 1$ & $67,0^{\mathrm{a}}(2,5)$ & $6,4^{\mathrm{c}}(0,9)$ & $37,0^{\mathrm{c}}(1,4)$ & $83,7^{\mathrm{d}}(0,7)$ \\
$\mathrm{C}_{\mathrm{C}}$ & $2: 1$ & $67,0^{\mathrm{a}}(3,1)$ & $5,9^{\mathrm{c}}(0,6)$ & $39,0^{\mathrm{c}}(3,0)$ & $89,0^{\mathrm{e}}(1,4)$ \\
\hline
\end{tabular}

$a, b, c, d$ Letras diferentes indican diferencias significativas. *Valores entre paréntesis corresponden a la desviación estándar $(n=6)$.

Tabla 12. Propiedades físicas de los snacks y el control

\begin{tabular}{|c|c|c|c|c|}
\hline Snack & $\mathbf{M}: \mathbf{F}$ & $\begin{array}{c}\text { Fuerza de ruptura } \\
\text { (N) }\end{array}$ & $\begin{array}{c}\text { Humedad } \\
\text { (gagua } / 100 g_{m s} \text { ) }\end{array}$ & $\mathbf{a}_{\mathrm{w}}$ \\
\hline Control & - & $0,9 \mathrm{a}(0,5)^{*}$ & $9,4 \mathrm{~b}(1,9)$ & $0,45^{\mathrm{b}}(0,03)$ \\
\hline $\mathrm{A}_{\mathrm{L}}$ & $1: 2$ & $2,2^{\mathrm{b}}(1,0)$ & 1,7 a $(0,05)$ & $0,31^{a}(0,02)$ \\
\hline $\mathrm{B}_{\mathrm{L}}$ & $1: 1$ & $2,5^{b}(0,5)$ & $2,1^{a}(0,4)$ & $0,32^{a}(0,01)$ \\
\hline $\mathrm{C}_{\mathrm{L}}$ & $2: 1$ & $4,7^{\mathrm{c}}(1,9)$ & $2,2^{\mathrm{a}}(0,05)$ & $0,35^{\mathrm{a}}(0,01)$ \\
\hline $\mathrm{A}_{\mathrm{C}}$ & $1: 2$ & $2,5^{b}(1,4)$ & $2,4^{\mathrm{a}}(0,4)$ & $0,34^{a}(0,02)$ \\
\hline $\mathrm{B}_{\mathrm{C}}$ & $1: 1$ & $5,0^{c}(2,6)$ & $2,1^{\mathrm{a}}(0,2)$ & $0,36^{a}(0,02)$ \\
\hline $\mathrm{C}_{\mathrm{C}}$ & $2: 1$ & $4,4^{\mathrm{c}}(2,1)$ & $2,3^{\mathrm{a}}(0,8)$ & $0,36^{a}(0,01)$ \\
\hline
\end{tabular}

$a, b, c, d, e$ Letras diferentes indican diferencias significativas. * Valores entre paréntesis corresponden a la desviación estándar $(n=2)$. 
El índice de pardeamiento o browning index (BI) se informa como un parámetro importante en procesos donde el pardeamiento enzimático o no enzimático ocurre, este parámetro relacionando los parámetros de color (a*, b* y L*) (Guerrero y col., 1996; Schebor y col., 1999; Jalaee y col., 2011). Como se puede observar en la Tabla 11, el BI refleja las diferencias de color entre cada una de las muestras producidas por la caramelización. Como ya se ha estudiado anteriormente (Fennema, 1996) la intensidad de la reacción de Maillard aumenta con la cocción a altas temperaturas, la presencia de azúcares reductores y el $\mathrm{pH}$ alcalino $(\mathrm{pH}>7)$. En este caso las muestras con carbonato mostraron los valores más altos de BI debido a la alcalinidad de la solución de tratamiento ( $\mathrm{pH}=7,01)$. López-Malo y col. (1998) encontraron valores de BI que oscilaban entre 50 y 57 para manzanas deshidratadas osmóticamente.

En cuanto al contenido de humedad los snacks tratados con lactato-gluconato no mostraron diferencias significativas $(\mathrm{P}>0,05)$ en comparación con el grupo sometido a impregnación con carbonato. El control presentó un mayor contenido de humedad comparado con las demás muestras (Tabla 12). Joshi y col. (2010) informaron valores de humedades entre 3,45 y 5,45\% trabajando en snacks de manzana deshidratada sin pretratamientos.

Las propiedades mecánicas de los alimentos tipo snack están relacionadas con la calidad y la preferencia del consumidor (Farroni, 2011). El agua es un importante constituyente de los alimentos y afecta la calidad, estabilidad y propiedades fisicoquímicas, además de las propiedades reológicas. Este efecto es especialmente importante en alimentos de baja humedad con estructura porosa (cereales de desayuno, galletas horneadas, papas fritas, entre otros). Estos alimentos están caracterizados por su textura crocante la cual es muy importante para la aceptabilidad sensorial. Como es sabido, la fuerza máxima a la rotura y la crocancia están inversamente relacionadas 
(Huang y col., 2011). La crocancia está determinada por las fracturas que se producen durante el ensayo. Si las fracturas son abruptas bajo la aplicación de una fuerza relativamente pequeña (la primera fuerza) el alimento tendrá un perfil crocante (Huang y col., 2011; Tavera-Quiroz y col., 2012).

Un mayor contenido de humedad afecta la calidad sensorial. Si los consumidores perciben el alimento con una textura diferente o gomosa, esto se traduciria en "pérdida de calidad". La Figura 31 representa las curvas de fuerza-desplazamiento para el control y los snacks $A_{L}$ y $A_{C}$.

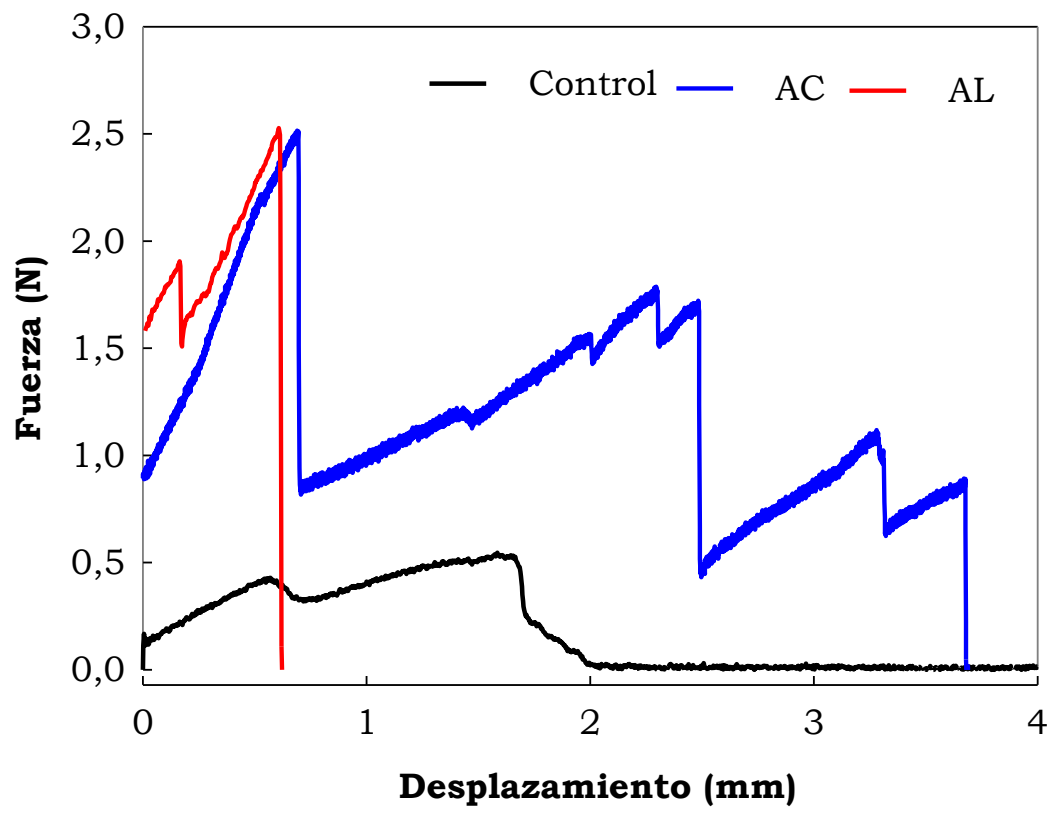

Figura 31. Curvas de fuerza-desplazamiento de los snacks $A_{C}, A_{L}$ y el control

Para $A_{C}$, se puede observar un perfil de fracturas a lo largo del ensayo, mientras que para $A_{L}$, el patrón fue similar pero se desarrolló en menor tiempo. Sin embargo, el control exhibió una curva suave sin la aparición de caídas pronunciadas, infiriéndose que presentó una menor crocancia. Las curvas obtenidas para los demás snacks evaluados mostraron patrones similares a la textura crocante de $A_{C} y A_{L}$ (Figura 32). 


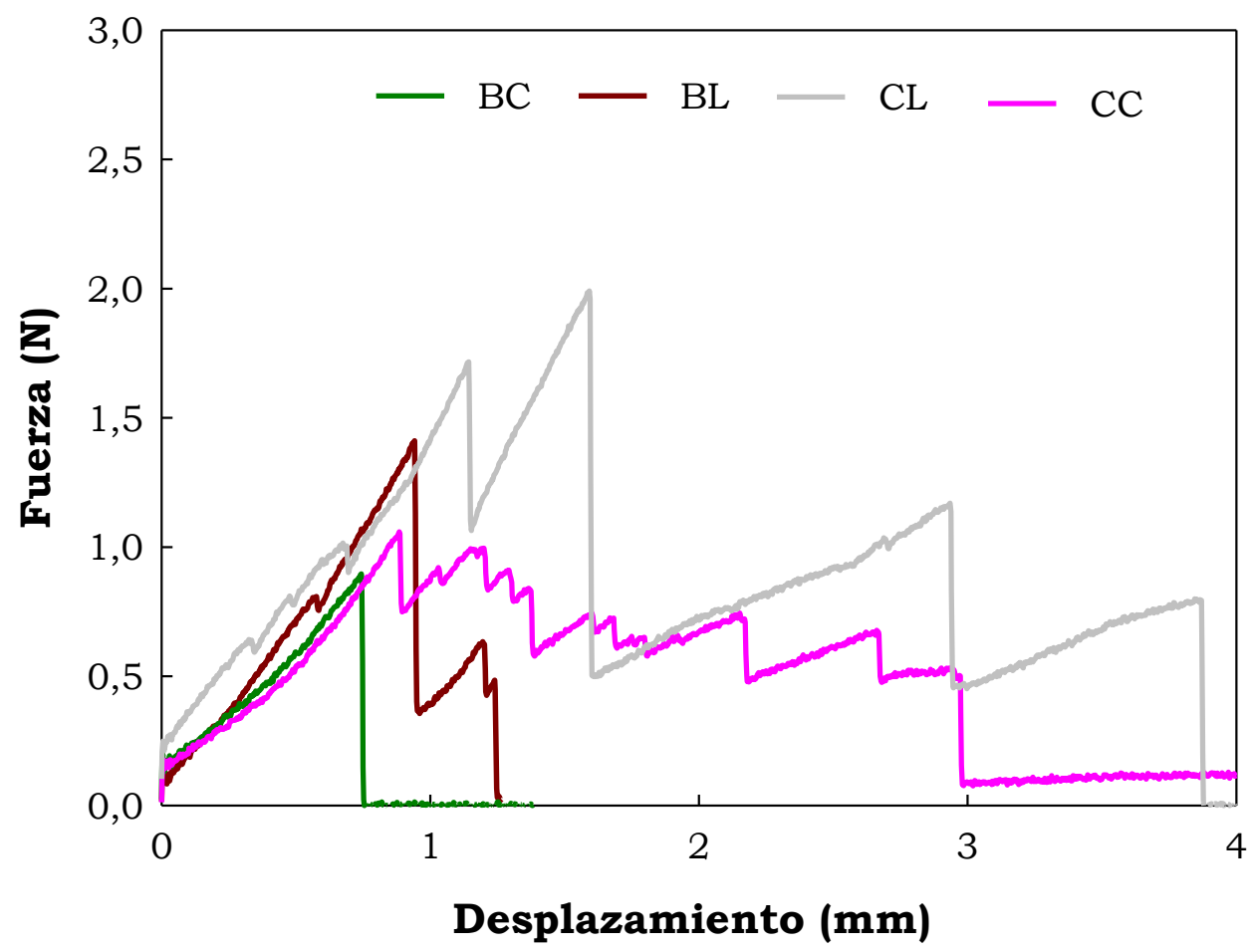

Figura 32. Curvas de fuerza-desplazamiento de los snacks $\mathrm{B}_{\mathrm{C}}, \mathrm{B}_{\mathrm{L}}, \mathrm{C}_{\mathrm{C}}$ y $\mathrm{C}_{\mathrm{L}}$

La crocancia está relacionada directamente a las propiedades mecánicas y de fracturabilidad de los alimentos sólidos, a su macro y microestructura y al sonido que se produce durante la fractura cuando estos productos son masticados (Varela y col., 2009; Yven ycol., 2010). Si el material es frágil requiere de la aplicación de una mínima fuerza para romperse (Vincent, 1998). En estos casos la fractura ocurre rápidamente, comparable al proceso de masticación cuando se produce la descarga repentina de los músculos. Este comportamiento se observó durante el ensayo como una caída repentina (vertical) de la fuerza, en una curva de fuerza-desplazamiento.

Valenzuela y Aguilera (2015), encontraron que la adición de maltodextrina disminuyó la higroscopicidad de laminados de manzana y aumentó la crocancia. Estos autores demostraron que la adición de $15 \%$ de maltodextrina tuvo un efecto considerable en la fuerza y 
deformación en el punto de fractura. Afirmaron que la adición de este carbohidrato influye en la organización estructural de la matriz del alimento, controla las propiedades mecánicas y por lo tanto su frescura.

En la Figura 33 se muestran las micrografias obtenidas con el SEM de los snacks horneados.
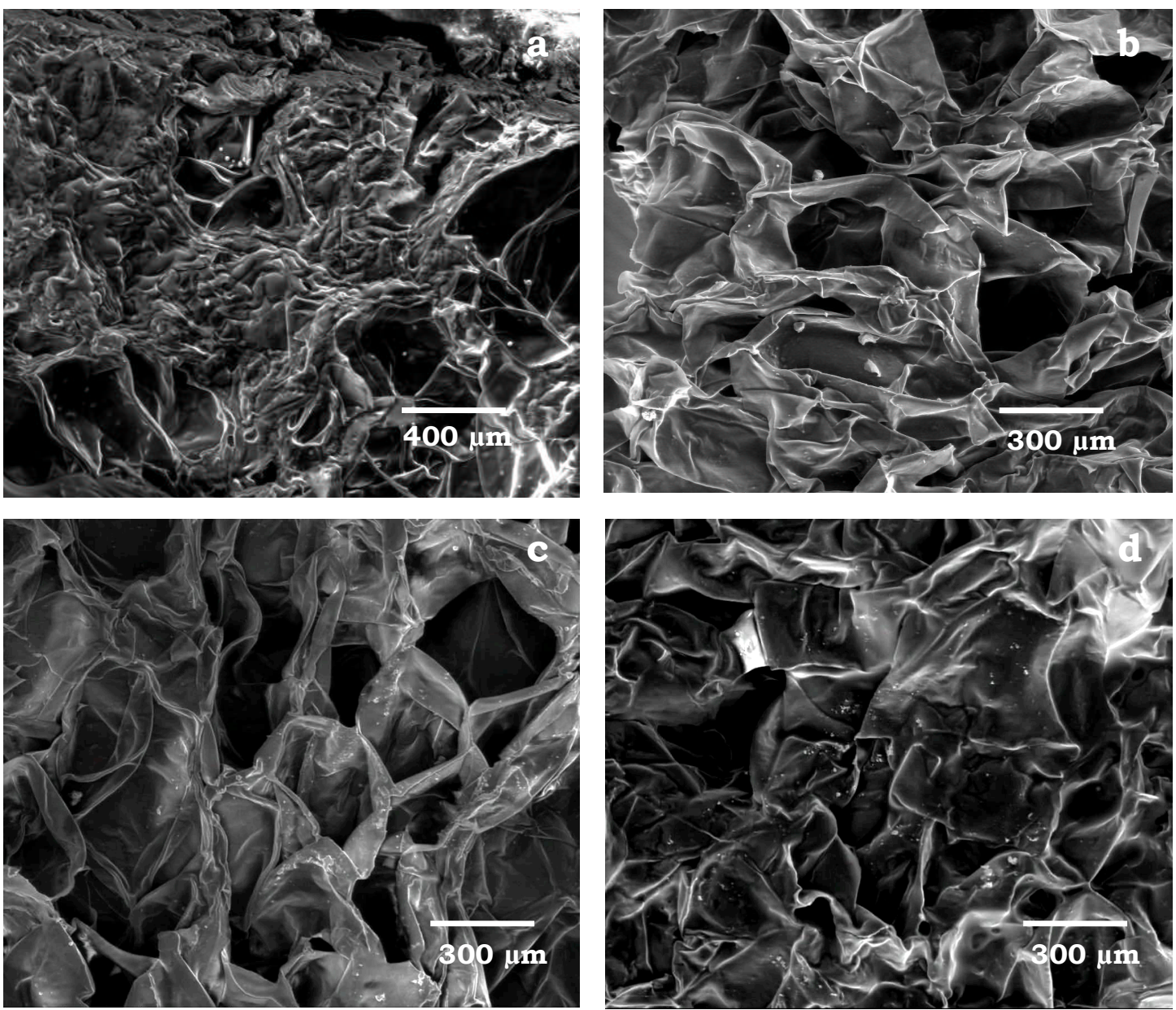

Figura 33. Micrografias obtenidas por SEM a. Control sin pretratamientos, b.

c y d. Snacks de manzana tratadas con calcio y maltodextrina/fructosa $1: 1$, $1: 2,2: 1$ respectivamente.

Se observó que las muestras sin ningún pretratamiento mostraron un tejido altamente colapsado con una distribución no uniforme de poros, mientras que para las muestras horneadas se observaron poros con partículas de calcio retenidas y distribuidas en toda la estructura y una masa aireada. Esto se pudo relacionar con los 
perfiles de textura. La formación de poros durante el horneado se debe posiblemente a la evolución del vapor de agua dentro de las muestras. Este cambio, a su vez conduce al desarrollo de la presión interna y la rotura del tejido, resultando en la formación de poros. Estos poros pueden afectar no sólo a las propiedades de transporte, tales como la difusividad de gases y líquidos en las muestras, sino también la textura. Prachayawarakorn y col. (2008) informaron resultados similares en un trabajo realizado con anillos de banana secadas con aire caliente a diferentes temperaturas, en los cuales se observó un aumento de la porosidad con el tratamiento térmico aplicado.

\section{Propiedades térmicas de los anillos de manzana}

Para la manzana fresca, el valor de temperatura de transición vítrea se encontró alrededor de $-40{ }^{\circ} \mathrm{C}$ en concordancia con lo informado por Bai y col. (2001). A partir de los termogramas de DSC, la temperatura de transición vitrea para los anillos de manzana sin pretratamientos y horneados (control) se obtuvo alrededor de $8,5{ }^{\circ} \mathrm{C}$ (Figura 34 a). En tanto la $\mathrm{T}_{\mathrm{g}}$ de los snacks osciló entre 45 y $52{ }^{\circ} \mathrm{C}$ como se muestra en la Figura 34 b. También se obtuvo la $\mathrm{T}_{\mathrm{g}}$ para cada uno de los compuestos puros utilizados (fructosa y maltodextrina). Para la fructosa pura en estado sólido la $\mathrm{T}_{\mathrm{g}}$ fue encontrada alrededor de los $10^{\circ} \mathrm{C}$, mientras que la maltodextrina presentó un valor de $\mathrm{T}_{\mathrm{g}}$ alrededor de $132^{\circ} \mathrm{C}$, consistente con el DE informado. 

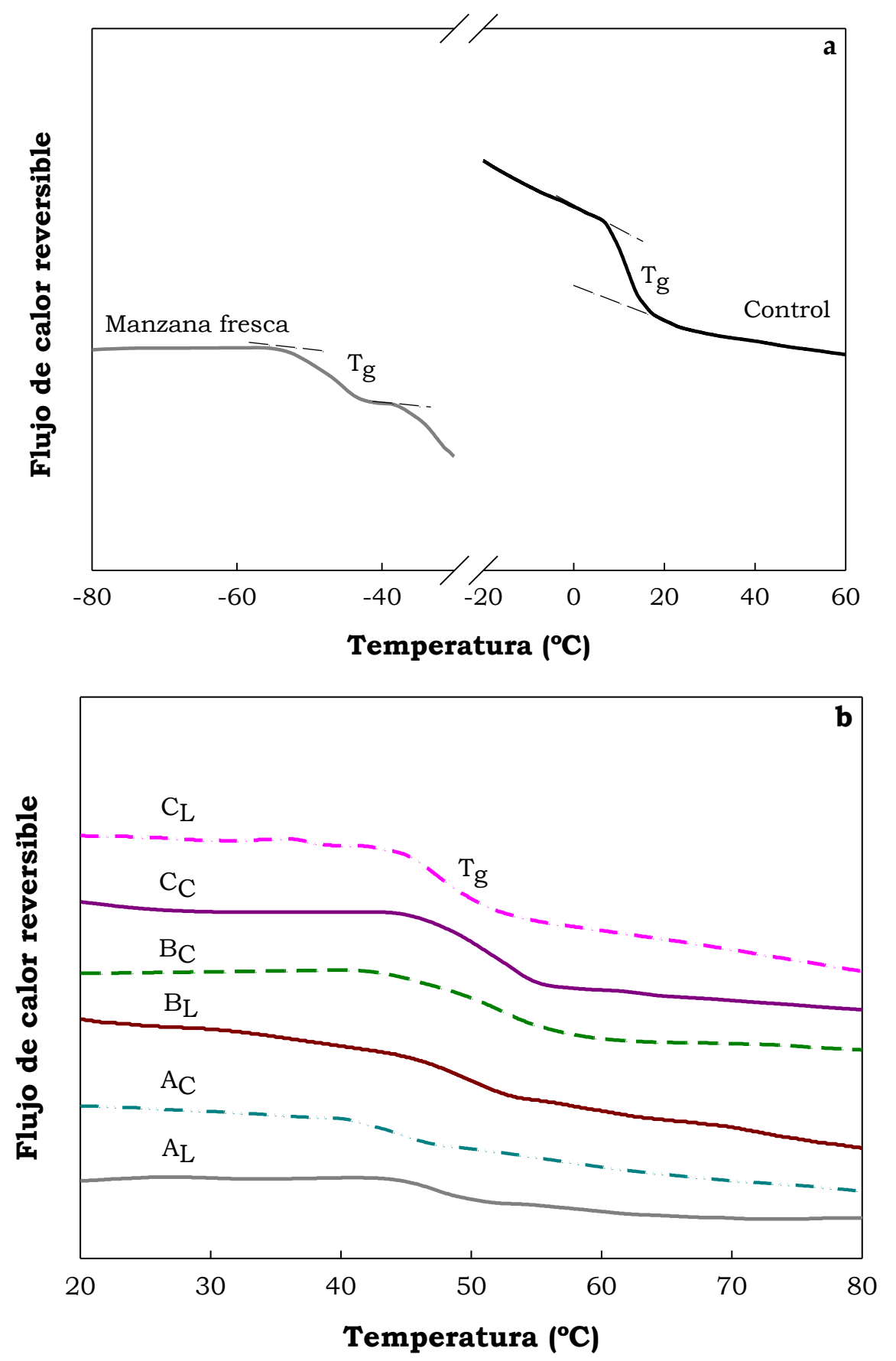

Figura 34. Termogramas obtenidos por DSC para a. Manzanas frescas y anillos de manzana horneados sin pretratamientos (control) y b. Snacks obtenidos.

Esto demuestra que los tratamientos aplicados a los anillos de manzana aumentaron la $\mathrm{T}_{\mathrm{g}}$. Sin embargo, los valores de la $\mathrm{T}_{\mathrm{g}}$ para las muestras de los distintos snacks no difieren significativamente entre sí 
$(\mathrm{P}>0,05)$. Un mayor contenido de humedad del control explicaría el menor valor de $\mathrm{T}_{\mathrm{g}}$ respecto a las muestras sometidas a los diferentes pretratamientos. Una de las aplicaciones más importantes del estudio de la transición vítrea es la comprensión de la relación que tienen las propiedades de textura de sistemas alimenticios y los cambios que ocurren durante el procesamiento y almacenamiento (Nelson y Labuza, 1994).

Algunos materiales con bajo contenido de agua son frágiles mientras permanecen en el estado vitreo (Slade y Levine, 1995). A medida que absorben agua no todas sus propiedades se afectan de la misma manera. En el rango bajo a intermedio de humedades algunas propiedades mecánicas muestran un máximo en función del contenido de agua, mientras que la $\mathrm{T}_{\mathrm{g}}$ disminuye continuamente (Chang y col., 2000). Existe entonces una relación entre el estado amorfo y la cinética de las reacciones quimicas. La movilidad molecular en un sistema amorfo puede estar afectada por la adición de compuestos de bajo peso molecular, que actúan como plastificantes, estos aumentan la flexibilidad y extensibilidad. Para el caso del control, al no tener agregado de polímeros específicos (maltodextrinas), y bajo la aplicación de tratamiento térmico (horneado) se concentran los azúcares presentes en el tejido, mayoritariamente, fructosa y glucosa (bajo peso molecular). Estos compuestos de bajo peso molecular tienen un efecto sobre la $\mathrm{T}_{\mathrm{g}}$ del sistema, provocando corrimientos hacia valores de temperatura menores. En los sistemas biológicos el plastificante más importante es el agua (Roos, 1992). A medida que aumenta el contenido de agua, disminuye la $\mathrm{T}_{\mathrm{g}}$ y la transición de un sistema vítreo a uno sobreenfriado se puede dar tanto por aumento de la temperatura como por el contenido de agua (Farroni, 2011). La adición de polisacáridos con alto peso molecular, tal como maltodextrinas, mejora la temperatura de transición vítrea, facilitando el pasaje de la muestra al estado vítreo (Bonazzi y Dumoulin, 2011; Fabra y col. 2011). El aumento de $\mathrm{T}_{\mathrm{g}}$ en los snacks hace que el producto sea más estable a temperatura ambiente, 
ampliando el rango de humedad relativa en la que las muestras mantienen la textura crocante. Contreras y col. (2005), trabajando con cilindros de manzanas secadas con aire caliente y pretratadas con jugo de manzana, informaron valores de $\mathrm{T}_{\mathrm{g}}$ alrededor de $40^{\circ} \mathrm{C}$. Estos resultados concuerdan con los obtenidos por Sonthipermpoon y col. (2006), quienes encontraron que los valores de $\mathrm{T}_{\mathrm{g}}$ de plátano en escamas aumentaron con la adición de maltodextrina. Del mismo modo, la adición de maltodextrina a puré de manzana provocó un aumento de los valores de $\mathrm{T}_{\mathrm{g}}$ situándose en el rango entre 10 y $30^{\circ} \mathrm{C}$, dependiendo de la cantidad de maltodextrina agregada (Jakubczyk y col., 2010). A través de la técnica de DMA, se observaron dos relajaciones ( $\alpha$ y $\beta$ ). Los valores de $\mathrm{T}_{\mathrm{g}}$ (obtenidos a través del punto máximo del módulo de pérdida) se encontraron a 40,50 y $60{ }^{\circ} \mathrm{C}$ (aproximadamente) para $A_{L}$, $\mathrm{B}_{\mathrm{L}} \mathrm{C}_{\mathrm{L}}$, respectivamente (Figura 35 ).

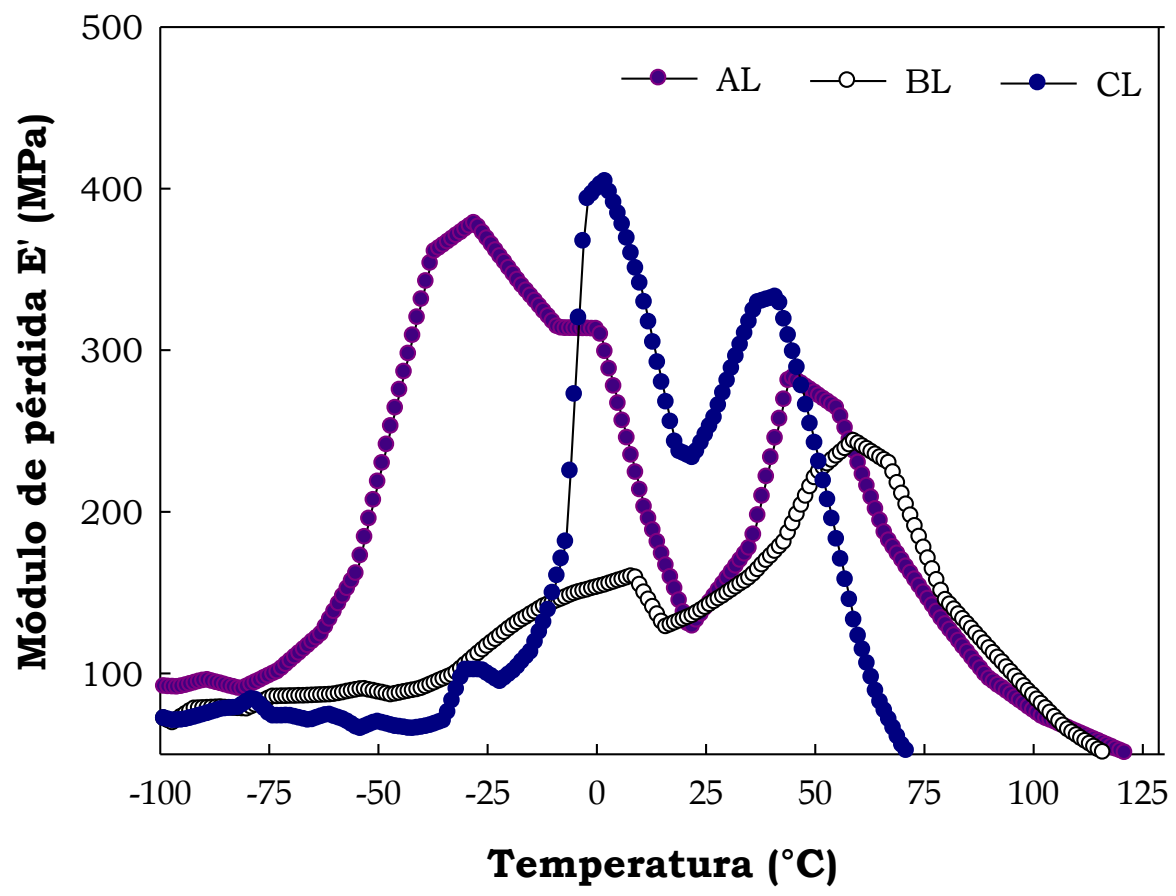

Figura 35. Módulo de pérdida (MPa) obtenido por DMA a $10 \mathrm{~Hz}$. para los snacks $\mathrm{A}_{\mathrm{L}}, \mathrm{B}_{\mathrm{L}}$ y $\mathrm{C}_{\mathrm{L}}$.

Cuando se aplica una perturbación oscilatoria a un material y se mide la respuesta del mismo en función de la temperatura, las curvas de respuesta pueden mostrar cambios en los módulos elásticos o de 
almacenamiento (E') y el de pérdida o viscoso (E”) y en la tangente de delta $(\tan \partial)$. El punto medio de la caída del modulo de almacenamiento o el máximo de la componente viscosa (módulo de pérdida) y de la curva de $\tan \partial$, permite determinar la temperatura de transición vítrea $\left(T_{\mathrm{g}}\right)$. Este método da información sobre las relajaciones sub-vítreas $(\beta, \gamma)$ y aquellas relacionadas con las transición vítrea $(\alpha)$. La relajación $\alpha$ es la más intensa y está asociada a una movilidad generalizada y cooperativa de segmentos de cadena. Las relajaciones sub-vítreas o secundarias están generalmente asociadas a movimientos locales que pueden ser internos a grupos laterales, ocurrir entre la cadena principal y grupos laterales o representar un cambio de conformación de una parte de la cadena principal. Así, las transiciones secundarias provienen generalmente del movimiento local de unidades constitutivas de la cadena principal o asociadas a movimientos de cadenas en zonas de bajo nivel de entrecruzamiento o a monómeros que no hayan reaccionado (Fernández-Carretero y col., 2010; Tavera Quiroz y col., 2013; Romano y col., 2014).

En este caso, debido a una rápida caída del módulo de almacenamiento durante el ensayo, no fue posible obtener la curva de $\tan \partial$ (relación entre ambos módulos). En las curvas obtenidas, las muestras con mayor contenido de maltodextrina $(\mathrm{B}>\mathrm{A}>\mathrm{C})$ presentaron corrimientos del punto máximo del módulo de pérdida hacia temperaturas más altas (relajaciones $\alpha$ ). Para el caso de las transiciones sub-vitreas $(\beta, \gamma)$, los resultados indicaron que las muestras con mayor contenido de fructosa mostraron relajaciones más pronunciadas entre -10 y $0^{\circ} \mathrm{C}$ mientras que para la muestra con mayor contenido de maltodextrina la relajación fue de menor intensidad y se evidenció a mayor temperatura. Estas relajaciones previas a la transición vítrea pueden deberse a la presencia de agua (relajación típica) u otro plastificante presente en la muestra (mayor contenido de fructosa). Zhou y col. (2009) afirmaron que la presencia de varias relajaciones a lo largo del rango de temperatura evaluado estaría asociada al movimiento 
molecular de las cadenas poliméricas existentes en films de papa y maíz con diferente contenido de sacarosa. Esto conduce a cambios en la viscoelasticidad de los polimeros presentes, a medida que aumenta la temperatura. Además estos autores encontraron que las relajaciones fueron más significativas en las curvas de módulo de pérdida. También observaron que a medida que el contenido de sacarosa aumentó la transición se produjo a temperaturas más bajas. Este comportamiendo fue similar al observado en los snacks a medida que aumentó el contenido de fructosa en la formulación.

En sintesis, el uso de aditivos en la elaboración de productos permite modificar diferentes propiedades del mismo y lograr mayores tiempos de conservación, en rangos de humedades más amplios. Esto es debido a que la mayoría de los polisacáridos que constituyen las maltodextrinas no puede penetrar las membranas celulares debido a su alto peso molecular. En consecuencia, la contribución de este polisacárido al contenido de sólidos solubles se debe a la entrada de mono y disacáridos en cantidades necesarias para actuar como estabilizadores de la matriz y para la obtención de productos de baja humedad.

\section{Análisis sensorial}

En la Figura 36 se muestra un gráfico tipo radial dónde se representan todas las propiedades sensoriales evaluadas para los snacks y el control. 


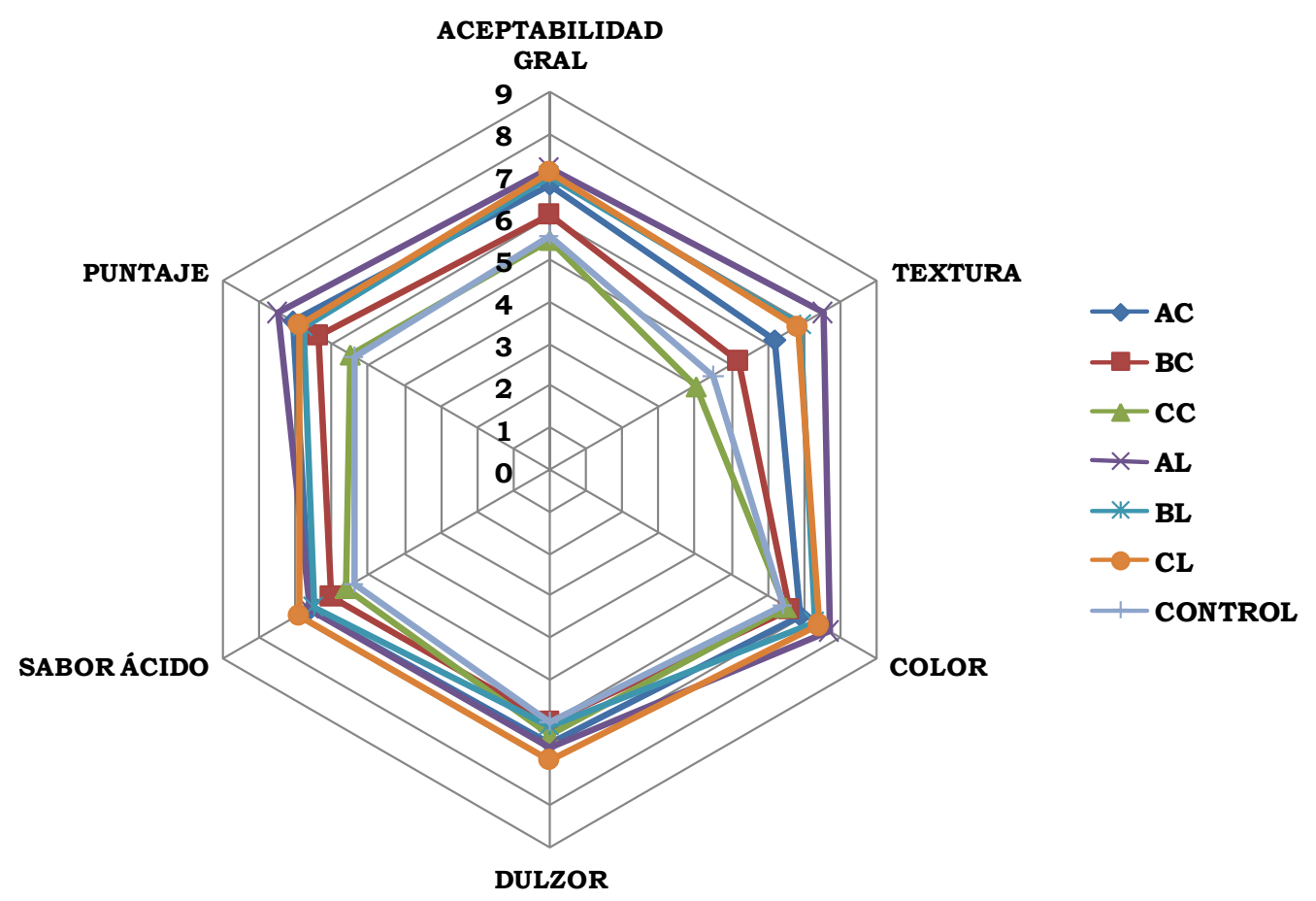

Figura 36. Diagrama radial de los resultados obtenidos para cada atributo en la evaluación sensorial de los snacks y el control

Se pudo observar que las muestras obtuvieron puntajes medios en la escala utilizada (entre 5-7), exceptuando las muestras control y el snack $\mathrm{C}_{\mathrm{C}}$ que obtuvieron los valores más bajos para la textura, aceptabilidad, sabor y puntaje. Se debe aclarar que la mayoría de los consumidores prefirieron los snacks con textura crocante.

En cuanto al dulzor y el color los consumidores puntuaron a todas las muestras con valores superiores a 6 . No se encontraron diferencias para estos atributos entre los snacks A, B, y C, independientemente de la sal de calcio utilizada $(\mathrm{P}>0,05)$. Esto podría deberse al efecto compensatorio de la mezclas de los azúcares y en el caso del control al efecto de la concentración y caramelización de la fructosa durante el horneado. En la Tabla 13 se detallan los valores medios de las respuestas dadas por los consumidores. Para el snack $\mathrm{A}_{\mathrm{L}}$ se obtuvieron las puntuaciones más altas en cuanto a aceptabilidad 
general y puntaje final otorgado (círculo rojo), mientras que el control y el snack $\mathrm{C}_{\mathrm{C}}$ tuvieron la calificación más baja (círculo verde).

Tabla 13. Resultados obtenidos del análisis sensorial para el control y los snacks A, B y C tratados con lactato gluconato y carbonato de calcio, formulados por inmersión en soluciones de maltodextrina/fructosa 1:1, 2:1 y $1: 2$, respectivamente

\section{Snack Aceptabilidad Textura Color Dulzor Sabor ácido Puntaje}

\begin{tabular}{lllllll}
\hline Control & $5,6^{\mathrm{a}}(1,4)$ & $4,5^{\mathrm{a}}(1,7)$ & $6,4^{\mathrm{a}}(1,8)$ & $6,0^{\mathrm{a}}(1,8)$ & $5,4^{\mathrm{a}}(2,0)$ & $5,4^{\mathrm{a}}(1,7)$ \\
$\mathrm{A}_{\mathrm{L}}$ & $7,2^{\mathrm{c}}(1,5)$ & $7,5^{\mathrm{d}}(1,7)$ & $7,7^{\mathrm{d}}(1,5)$ & $6,6^{\mathrm{a}, \mathrm{b}}(1,9)$ & $6,6^{\mathrm{b}, \mathrm{c}}(1,9)$ & $7^{\mathrm{c}}(1,3)$ \\
$\mathrm{B}_{\mathrm{L}}$ & $7,0^{\mathrm{c}}(1,7)$ & $6,9^{\mathrm{c}}(1,7)$ & $7,3^{\mathrm{b}, \mathrm{c}, \mathrm{d}}(1,6)$ & $6,1^{\mathrm{a}}(2,0)$ & $6,5^{\mathrm{b}, \mathrm{c}}(2,0)$ & $6,8^{\mathrm{b}}(1,6)$ \\
$\mathrm{C}_{\mathrm{L}}$ & $7,1^{\mathrm{c}}(1,7)$ & $6,8^{\mathrm{c}}(2,1)$ & $7,4^{\mathrm{c}, \mathrm{d}}(2,1)$ & $6,9^{\mathrm{b}}(1,8)$ & $6,9^{\mathrm{c}}(1,8)$ & $6,9^{\mathrm{b}}(1,4)$ \\
$\mathrm{A}_{\mathrm{C}}$ & $6,8^{\mathrm{b}, \mathrm{c}}(1,7)$ & $6,2^{\mathrm{b}, \mathrm{c}}(2,5)$ & $6,9^{\mathrm{a}, \mathrm{b}, \mathrm{c}}(1,8)$ & $6,5^{\mathrm{a}, \mathrm{b}}(1,9)$ & $6,6^{\mathrm{b}, \mathrm{c}}(2,0)$ & $7,1^{\mathrm{b}, \mathrm{c}}(1,7)$ \\
$\mathrm{B}_{\mathrm{C}}$ & $6,1^{\mathrm{a}, \mathrm{b}}(1,4)$ & $5,2^{\mathrm{b}}(2,2)$ & $6,6^{\mathrm{a}, \mathrm{b}}(1,8)$ & $6,0^{\mathrm{a}}(1,6)$ & $6,0^{\mathrm{a}, \mathrm{b}}(1,9)$ & $6,4^{\mathrm{b}}(1,5)$ \\
$\mathrm{C}_{\mathrm{C}}$ & $5,5^{\mathrm{a}}(1,9)$ & $4,0^{\mathrm{a}}(2,0)$ & $6,5^{\mathrm{a}}(1,7)$ & $6,3^{\mathrm{a}, \mathrm{b}}(1,8)$ & $5,6^{\mathrm{a}}(1,6)$ & $5,5^{\mathrm{a}}(1,7)$ \\
\hline
\end{tabular}

$a, b, c, d$ Letras diferentes en la misma columna indican diferencias significativas. *Valores entre paréntesis corresponden a la desviación estándar $(n=50)(P<0,05)$

En general, los snacks formulados con lactato-gluconato de calcio obtuvieron mayores puntuaciones que los formulados con carbonato de calcio. El snack con mayor puntaje obtenido fue el formulado con M:F (1:1). Resultados similares fueron encontrados por Azuara y col. (2002) en productos a base de manzana elaborados con sacarosa/maltodextrina (S:M). Estos autores observaron que cuando se utilizaron las formulaciones de 100:0 ó 10:90 (S:M) los puntajes otorgados por el panel de consumidores fueron los más bajos. Para los productos donde se utilizaron soluciones osmóticas con concentraciones de 90:10 (S:M) los puntajes obtenidos fueron más 
altos. Estos resultados explican que las mezclas con alto contenido de maltodextrina favorecen la pérdida de compuestos orgánicos responsables del sabor y el color y los consumidores perciben muestras con sabor menos parecido al "natural". En contraste, cuando el contenido de sacarosa es alto se produce un dulzor excesivo.

\section{Análisis por componentes principales (PCA) de los parámetros sensoriales e instrumentales}

El análisis por componentes principales (PCA) de los resultados obtenidos a partir de los ensayos instrumentales y del análisis sensorial se realizó con el fin de establecer una relación entre los parámetros. La Figura 37 a y b muestra los gráficos en dos dimensiones utilizados para visualizar y agrupar las relaciones entre las muestras, los atributos sensoriales y las medidas instrumentales a través de la varianza.

Los gráficos de correlación CPA agruparon a los snacks en dos grupos principales. Los snacks formulados con lactato-gluconato se ubicaron a la derecha, lo que indica que obtuvieron la calificación más alta en los atributos evaluados. A su vez, los productos formulados con con esta sal de calcio, se separaron de los snacks preparados con carbonato, y esta separación se dio a lo largo de CP1 (85\% de la varianza). Snacks preparados con la adición de lactato-gluconato mostraron valores positivos de $\mathrm{CP} 1$, así como el snack $\mathrm{A}_{\mathrm{C}}$, mientras que $\mathrm{B}_{\mathrm{C}}, \mathrm{C}_{\mathrm{C}} \mathrm{y}$ el control presentaron valores negativos. $\mathrm{A}_{\mathrm{L}}$ se ubicó a la derecha, lo que indicó que esta muestra se explica mejor en términos de aceptabilidad, textura, y color, presentado los valores más altos para estos atributos. Entre los anillos de manzana tratados con carbonato, Ac presentó los mayores valores para todas las variables estudiadas, mientras que $\mathrm{B}_{\mathrm{C}} \mathrm{y} \mathrm{C}_{\mathrm{C}}$ presentaron los valores más bajos. 

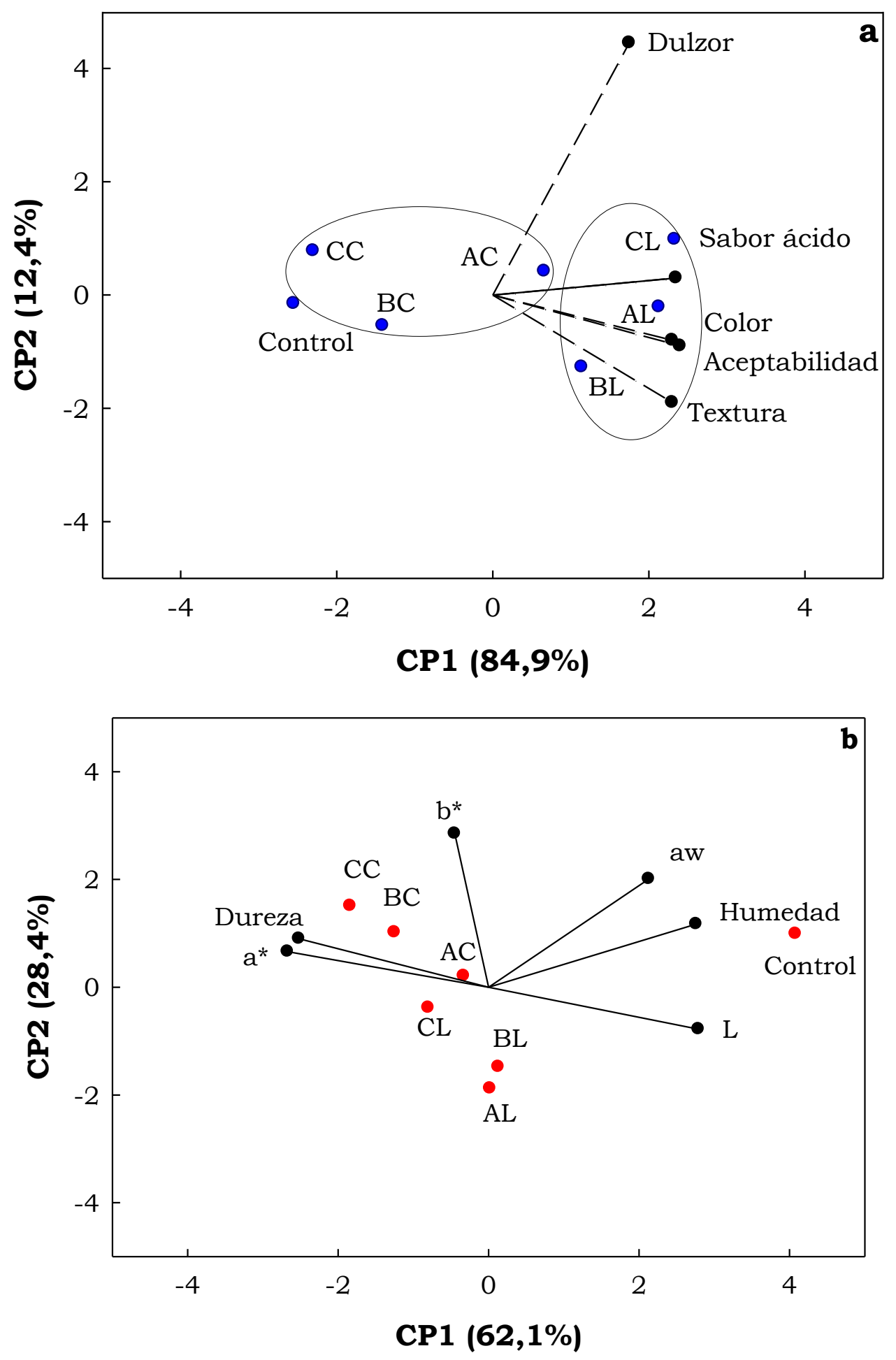

Figura 37. Análisis de componentes principales (PCA) de: a. Parámetros sensoriales y b. Parámetros instrumentales utilizados para diferenciar los diferentes snacks obtenidos.

En la Figura 37 a, CP1 y CP2 explican el 85 y el 12\% de la varianza, respectivamente. CP1 representa 99\% de la aceptabilidad y 
del puntaje general, el 97\% de la acidez, 93\% de la textura y color, mientras que CP2 corresponde al 80\% del dulzor. En la Figura 37 b, se observan las contribuciones de cada muestra exponiendo que la variabilidad explicada por el primer componente fue del 62\% y el segundo 28\%. En este caso, fue observado un comportamiento similar al anterior. Los snacks con lactato-gluconato se separaron de los tratados con carbonato. Esto se produjo principalmente a lo largo del eje CP2 (28,4\%). El control se interpretó mejor en términos de humedad y $L^{*}$, mientras que $\mathrm{B}_{\mathrm{C}}$ y $\mathrm{C}_{\mathrm{C}}$ se asociaron con $\mathrm{b}^{*}$, $\mathrm{a}^{*}$, y el parámetro de dureza. $\mathrm{A}_{\mathrm{L}} \mathrm{y} \mathrm{B}_{\mathrm{L}}$ se localizaron equidistantes de todas las variables instrumentales consideradas.

\section{Análisis de las propiedades funcionales del snack seleccionado}

Teniendo en cuenta los puntajes obtenidos para todas las muestras analizadas, los snacks $A_{L}$ y $A_{C}$ fueron seleccionados para profundizar los estudios sobre capacidad antioxidante y contenido de polifenoles, de azúcares y de ácido ascórbico.

\section{Contenido de carbohidratos}

A través de las determinaciones realizadas por HPLC se obtuvo el contenido de fructosa, glucosa y sacarosa de los snacks $A_{C}$ y $A_{L}$. Para cada uno de los azúcares analizados se obtuvo la ecuación de la recta de calibración. Para la fructosa (Ec. 9), glucosa (Ec. 10) y sacarosa (Ec.11) se obtuvo la concentración en $\mathrm{mg} / \mathrm{ml}$ a partir de las ecuaciones que se describen a continuación, respectivamente:

$$
\begin{array}{cc}
y=19,554 \times\left(R^{2}=0,987\right) & \text { Ec. } 9 \\
y=56,481 \times\left(R^{2}=0,996\right) & \text { Ec. } 10 \\
y=54,009 \times\left(R^{2}=0,990\right) & \text { Ec. } 11
\end{array}
$$

En la Figura 38 se muestra el contenido de azúcares para cada snack 


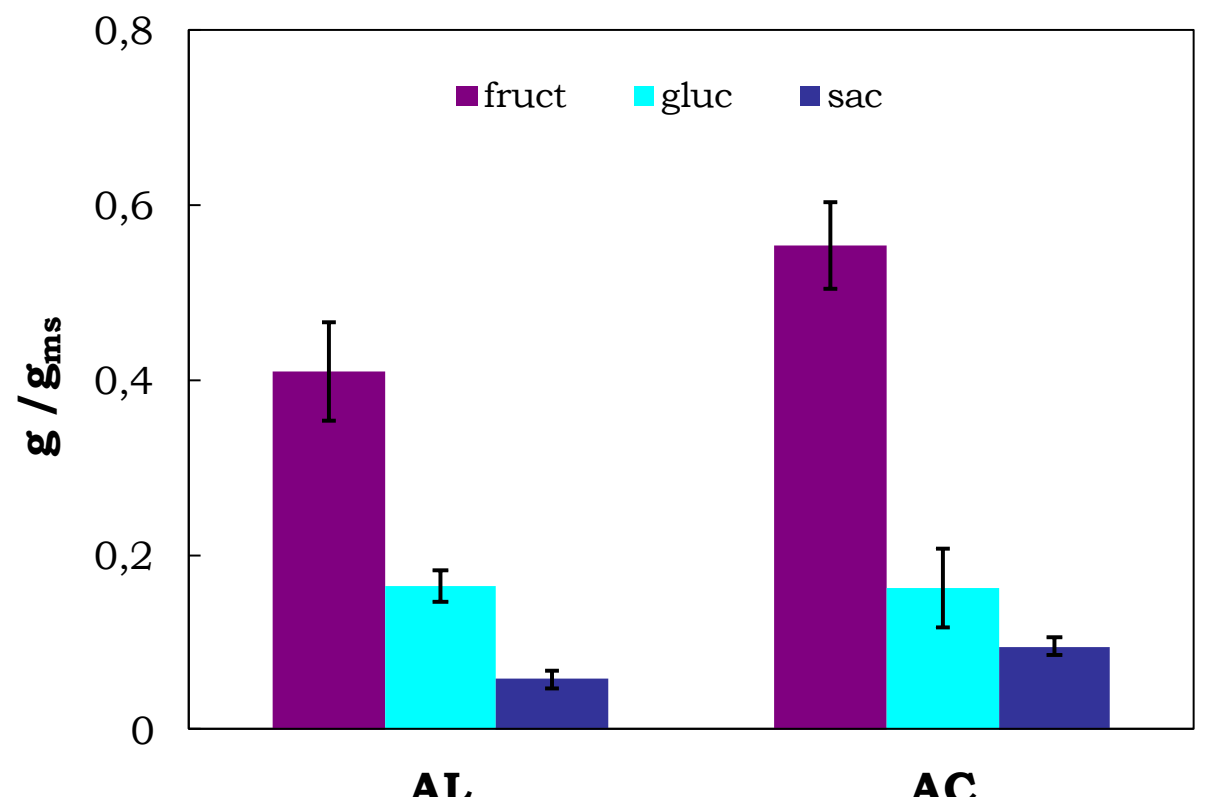

Figura 38. Contenido de fructosa, glucosa y sacarosa de los snacks $A_{L}$ y $A_{C}$, obtenidos por HPLC.

Sólo el contenido de fructosa presentó diferencias significativas $(P<0,05)$ entre los snacks, siendo para $A_{C}$ un $35 \%$ mayor que para $A_{L}$. En ambos snacks este fue el azúcar mayoritario, aunque contenian también cantidades menores de glucosa y sacarosa. Teniendo en cuenta que este trabajo centra su objetivo en el desarrollo de un producto saludable, en la Tabla 14 se presenta la comparación entre el contenido de carbohidratos totales de una porción de $100 \mathrm{~g}$ de snacks con otros productos del mismo tipo y sus respectivos aportes energéticos $(1 \mathrm{~g}$ carbohidrato aporta $4 \mathrm{kcal})$. 
Tabla 14. Carbohidratos totales y calorías por porción de $100 \mathrm{~g}$ productos formulados con manzana

\begin{tabular}{lccccc}
\hline \multicolumn{1}{c}{ Muestra } & $\begin{array}{c}\text { Carbohidratos } \\
\text { totales * }\end{array}$ & $\begin{array}{c}\text { Aporte } \\
\text { (kcal) }\end{array}$ & $\begin{array}{c}\text { Fructosa } \\
\text { (g) }\end{array}$ & $\begin{array}{c}\text { Glucosa } \\
\text { (g) }\end{array}$ & $\begin{array}{c}\text { Sacarosa } \\
\text { (g) }\end{array}$ \\
\hline $\begin{array}{l}\text { Manzana fresca } \\
\text { Granny Smith }\end{array}$ & 10,0 & 40,0 & 6,0 & 3,3 & 0,8 \\
Manzanas & 85,0 & 340,0 & 45,0 & 25,0 & 15,0 \\
deshidratadas & & & & & \\
Barras de & 70,0 & 278,0 & - & - & - \\
cereal SER & & & & 16,0 & 6,0 \\
manzana light & 63,0 & 252,0 & 41,0 & 17,0 & 9,0 \\
Snack A & 81,0 & 324,0 & 55,0 & & \\
Snack Ac & & & & & \\
\hline
\end{tabular}

* Los datos fueron tomados de los rótulos de cada una de las muestras comerciales.

De la tabla se pudo observar que el snack $A_{L}$ aporta el menor contenido de calorías (en base a los carbohidratos) aún comparado con productos rotulados como light. Ambos snacks obtenidos podrían ser una alternativa óptima para personas que desarrollan actividades moderadas debido a que tienen un aporte energético significativo. Además no aportan calorias en exceso al no estar formulados con ningún otro ingrediente altamente calórico (grasas, proteínas).

\section{Contenido de ácido ascórbico}

A partir de la relación lineal obtenida entre el área bajo la curva de los picos del estándar y las distintas concentraciones de ácido ascórbico, se obtuvo la ecuación utilizada para calcular la concentración de este antioxidante en las muestras (Figura 39). 


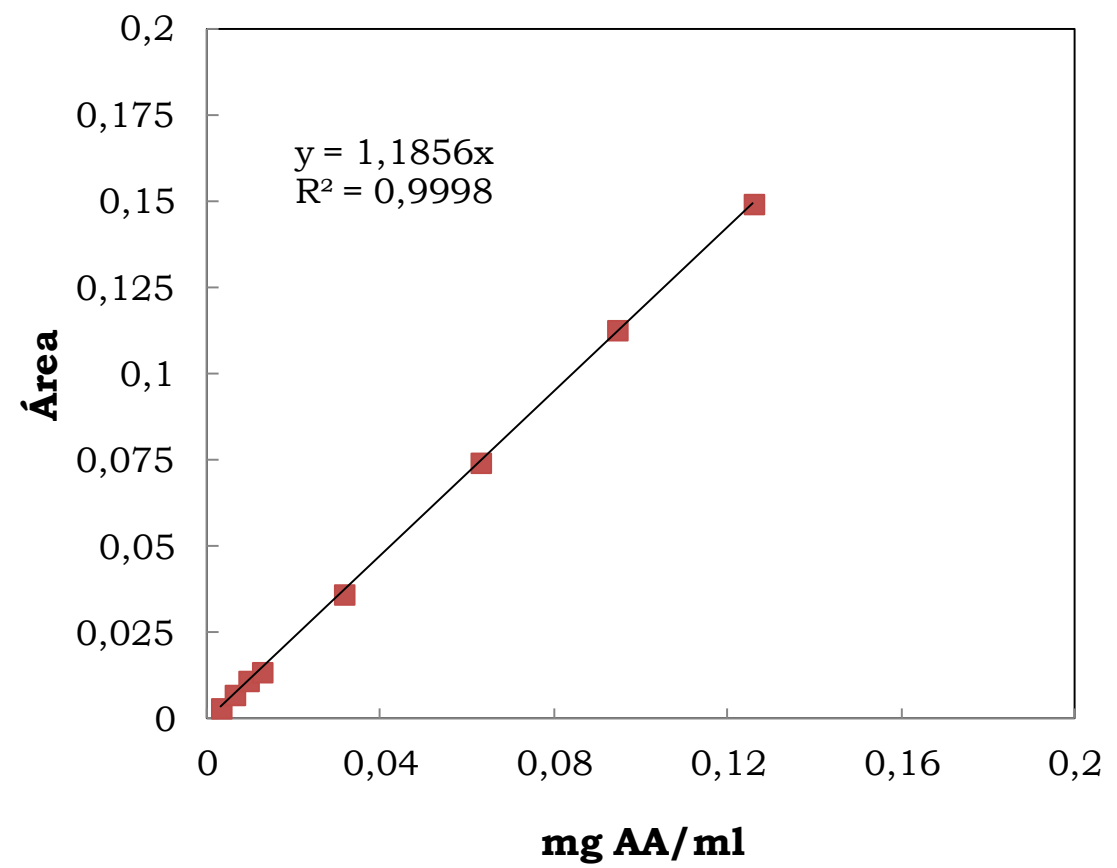

Figura 39. Curva de calibración de ácido ascórbico $(2-200 \mu \mathrm{g} / \mathrm{ml})$, obtenida por HPLC. Los símbolos corresponden a los datos experimentales y la línea a la regresión lineal $\left(\mathrm{R}^{2}=0,999\right)$.

La protección que las frutas y vegetales brindan contra las enfermedades degenerativas ha sido atribuida a su alto contenido de antioxidantes. Los radicales libres causan daño oxidativo a proteínas, lípidos y ácidos nucleicos. Es por esto que los antioxidantes desempeñan una función fundamental en la prevención de estas enfermedades, neutralizando su accionar. La capacidad antioxidante de frutas y vegetales está dada por el contenido en vitamina E, C y carotenos, así como el contenido de diferentes polifenoles. A diferencia de la mayoria de los mamíferos y otros animales, los seres humanos no poseen la habilidad para sintetizar su propia vitamina C. Por lo tanto, deben obtenerla a través de su dieta (Quest y Lisette, 2012). El ácido ascórbico, es un antioxidante esencial en la dieta humana y es ampliamente utilizado para la suplementación (Pallauf y col., 2013). Es conocida la actividad biológica de la vitamina $\mathrm{C}$ en el ser humano, $\mathrm{y}$ como la mayoría de los nutrientes, debe ser preservada durante las operaciones y procesos involucrados en los distintos métodos de conservación. Este micronutriente es muy sensible a diversas formas de 
degradación como la temperatura, la concentración de sal y azúcar, pH, oxígeno, presencia de enzimas, catalizadores metálicos y la concentración inicial del mismo. Todos estos factores están relacionados con las técnicas de proceso y con la composición del producto que se procese. En el caso de los snacks, debido al horneado, es de esperar que ocurra cierta degradación tanto de la vitamina que se encuentra presente en la manzana como de la agregada durante la impregnación. El pardeamiento no enzimático está relacionado con la pérdida de ácido ascórbico donde los productos de la reacción que siguen al primer paso de la destrucción del ácido ascórbico también son parte de la cadena del pardeamiento (Fuertes y Navarro, 2011). En algunos casos de secado y distintas formas de deshidratación, la velocidad de degradación del nutriente está asociada a la velocidad de eliminación de agua, y esto a su vez depende de la temperatura a la cual se procese el producto (Ochoa y col., 2002). En la Figura 40 se muestra el contenido promedio obtenido de ácido ascórbico de las muestras para las distintas etapas del procesamiento.

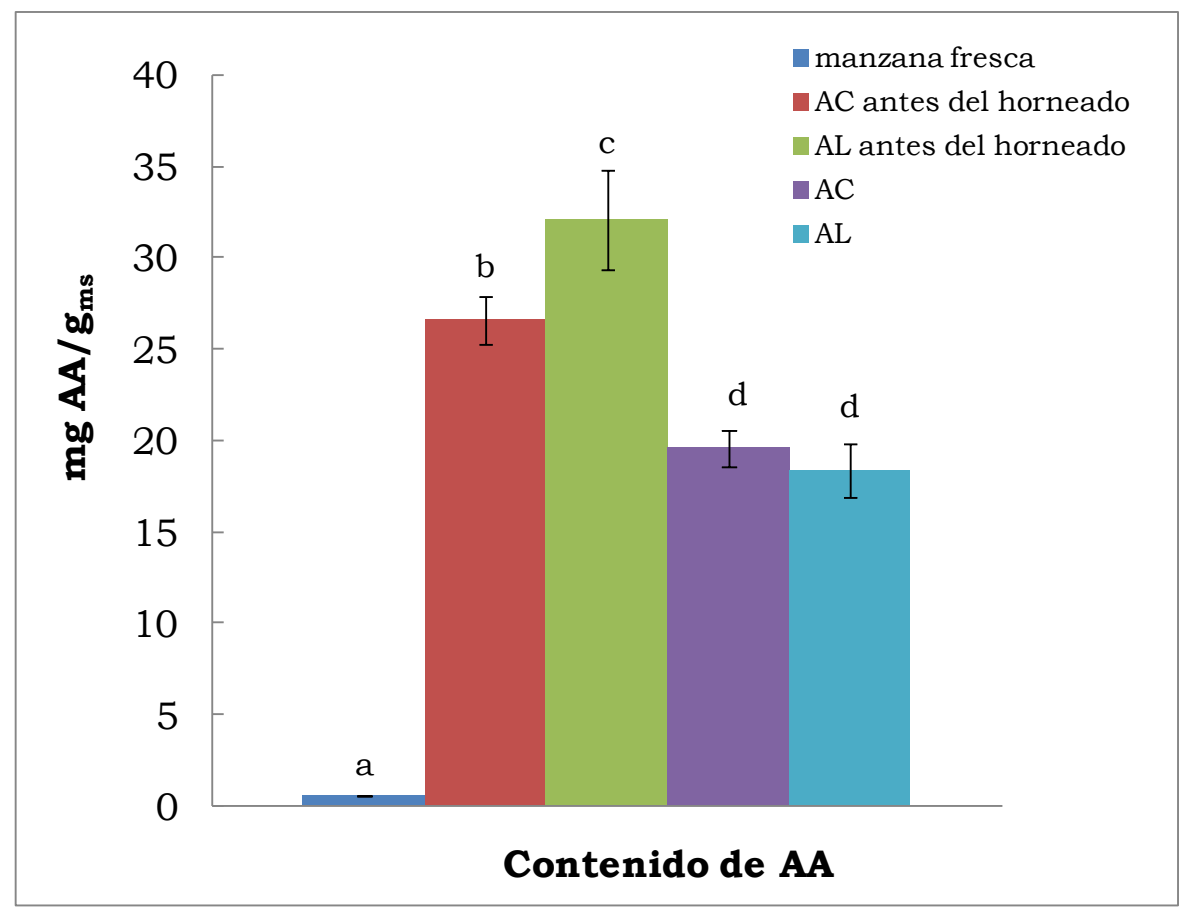

Figura 40. Contenido de ácido ascórbico inicial de la manzana fresca y de los snacks antes y después del horneado. 
La adición de ácido ascórbico durante la impregnación de los anillos de manzana promovió efectos beneficiosos ya que la cantidad absorbida por los snacks $\mathrm{A}_{\mathrm{L}} \mathrm{y} \mathrm{A}_{\mathrm{C}}$ fue significativamente mayor que la cantidad de ácido ascórbico presente en la fruta fresca $(\mathrm{P}<0,05)$. Se observa que existió una disminución entre el 30-40\% del contenido de AA retenido por los anillos de manzana durante la impregnación, por efecto del horneado. Hay que tener en cuenta que este micronutriente se encuentra disuelto en el solvente (agua) de la muestra y una vez que se hornea, la pérdida de vitamina C está ligada a la reducción del agua presente, las altas temperaturas, la superficie expuesta y la presencia de oxígeno (Lesková y col., 2006). Sin embargo, los snacks retuvieron aproxidamente dos tercios de la cantidad del ácido ascórbico añadido, obteniendo valores finales en las muestras de aproximadamente 20 $\mathrm{mg} / \mathrm{g}_{\mathrm{ms}}$. Esta amplia retención podría deberse al uso de altas temperaturas a tiempos cortos durante el horneado, lo que aumentaría la velocidad de evaporación del agua y reduciría el tiempo de exposición de la muestra al ambiente evitando la oxidación. Fuertes (2011) observó el efecto protector parcial de una matriz soporte de pectina sobre la vitamina $\mathrm{C}$ durante el horneado de barras de cereal. Este hecho podría deberse a las características de dicha matriz, ya que al ser homogénea y continua permitió una retención parcial del compuesto bioactivo atrapándolo en la red, ya sea en la fase continua o en los intersticios. Resultados similares fueron encontrados por Quintero y col. (2012) en laminados de rosa mosqueta obtenidos por secado a $70^{\circ} \mathrm{C}$.

En Argentina, la ingesta diaria recomendada (IDR) para vitamina $\mathrm{C}$ es de $45 \mathrm{mg}$ (Código Alimentario Argentino). La IDR se basa principalmente en la prevención de una enfermedad por deficiencia, más que en la prevención de enfermedades crónicas o en la promoción de una salud óptima. Para hombres y mujeres sanos, y con el fin de promover beneficios adicionales a la salud, se recomienda una ingesta diaria de vitamina C mayor a $100 \mathrm{mg}$ (Quest y Lysette, 2012). Consumir diariamente cinco porciones de frutas y verduras aportarian cerca 200 
mg. Algunos suplementos multivitamínicos proveen alrededor de $60 \mathrm{mg}$ de vitamina C. El consumo de $20 \mathrm{~g}$ del snack de manzana desarrollado cubriria los requerimientos de la IDR.

\section{Actividad antioxidante y contenido de polifenoles de los snacks y el control}

E1 contenido de polifenoles totales (CPT) de las muestras horneadas sin la adición de ácido ascórbico aumentó con respecto a la fruta fresca, como se observa en la Tabla 15. La actividad antioxidante expresada como TEAC resultó ser análoga a lo encontrado por Kunradi Vieira y col. (2009). Resultados similares fueron encontrados por SunWaterhouse y col. (2010) quienes informaron el aumento en el contenido de polifenoles y la actividad antioxidante de barras de cereal con frutas agregadas. Estos autores lo atribuyeron a la ruptura de complejos fenoles-proteínas y a la formación de productos de condensación durante la cocción con potencial actividad antioxidante (compuestos intermediarios de la reacción de Maillard), lo cual genera un aumento en el contenido de polifenoles totales en las muestras que fueron sometidas a tratamientos con altas temperaturas.

Tabla 15. Capacidad antioxidante expresada como equivalente de Trolox (TEAC) de snacks $A_{L} y A_{C}$ en relación a la manzana fresca.

\begin{tabular}{cccc}
\hline Muestra & Sal de calcio & CPT & TEAC \\
& - & $5,5^{\mathrm{a}}(0,6)$ & $0,04^{\mathrm{a}}(0,03)$ \\
\hline Manzana & Lactato- & $9,4^{\mathrm{b}}(0,2)$ & $0,7^{\mathrm{b}}(0,1)$ \\
Snack $\mathrm{A}_{\mathrm{L}}$ & gluconato & & $1,38^{\mathrm{c}}(0,02)$ \\
& Carbonato & $7,2^{\mathrm{c}}(0,1)$ & \\
\hline
\end{tabular}

$a, b, c$ Letras diferentes indican diferencias significativas $(P<0,05)$ Valores entre paréntesis corresponden a la desviación estándar $(n=3)$ 
Miglio y col. (2007) encontraron comportamientos similares durante la cocción de vegetales durante tiempos cortos. Estos autores concluyeron que la temperatura genera la disrupción de complejos carotenoides-proteínas, haciendo que los carotenoides se liberen más fácilmente, aumentando así la actividad antioxidante de las muestras. Mazzeo y col. (2011) encontraron resultados similares. Otras investigaciones afirman que a temperaturas de secado mayores de $40^{\circ} \mathrm{C}$, la degradación de los fenoles totales es menor (Vega-Gálvez y col., 2012).

En los anillos de manzana horneados la actividad antioxidante obtenida por DPPH fue entre 20 y 40 veces mayor que la de la manzana fresca. Vega-Gálvez y col. (2012) informaron un aumento de la capacidad antioxidante de anillos de manzanas secadas con aire caliente, respecto al producto fresco, lo cual estaría relacionado con la generación y acumulación de compuestos antioxidantes derivados de la reacción de Maillard. Se observó una reducción del 100\% de radical DPPH para una concentración de $100 \mathrm{mg}_{\text {Snack }} / \mathrm{ml}$ del extracto etanólico, independientemente de la sal de calcio utilizada. En contraste, las manzanas frescas sólo redujeron un 20\% el radical DPPH para la misma concentración de muestra en el extracto (Ec. 7). Esto se correlaciona con los resultados obtenidos por HPLC para el contenido de ácido ascórbico.

Para obtener valores comparables para ambos snacks, se graficó \% Inhibición del radical DPPH frente a las concentraciones de $\mathrm{mg}$ Snack/ml extracto (Figura 41). 


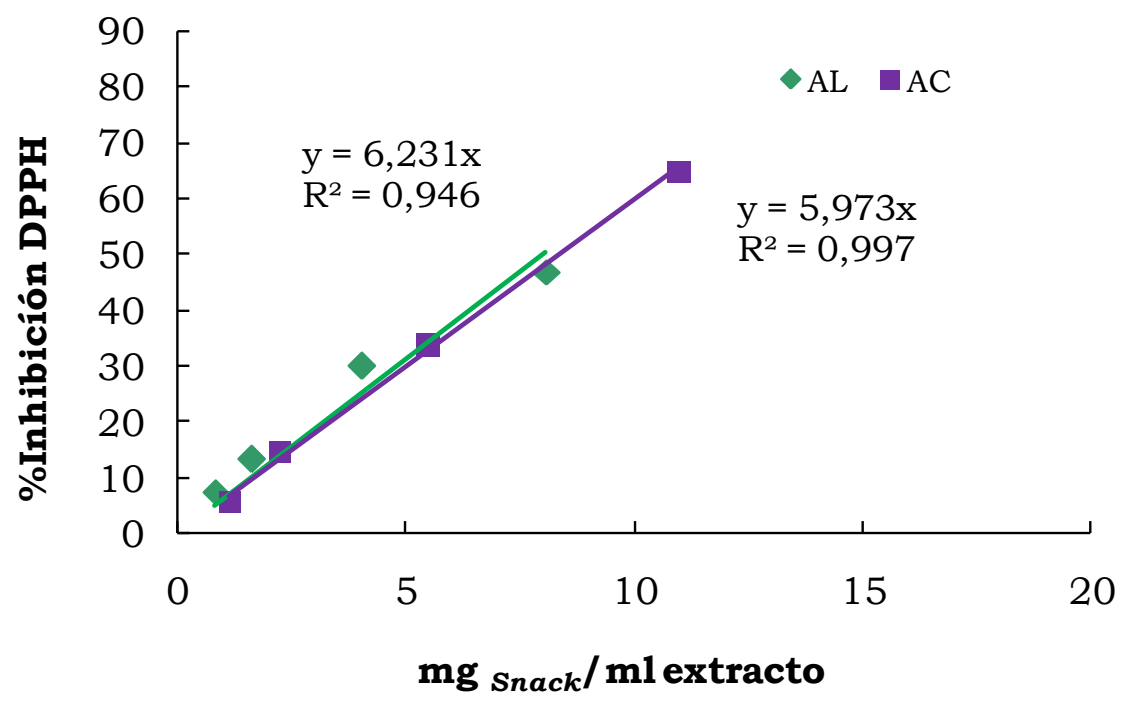

Figura 41. Curva de \% Inhibición de DPPH para los extractos de snacks $A_{C} y$ $\mathrm{A}_{\mathrm{L}}$.

Se graficaron los datos hasta donde el \% I fue lineal. A partir de la ecuación de la recta se obtuvieron los valores de $\mathrm{EC}_{50}$, que corresponde a la cantidad de muestra necesaria para reducir en un $50 \%$ el radical DPPH. Para $A_{C}$ el $\mathrm{EC}_{50}$ fue de 8,37 y para $A_{L}$ 7,07 $\mathrm{mg}$ snack/ml extracto. Esto indicaría que el snack $A_{L}$ tiene una mayor actividad antioxidante, debido a que se necesitaría menor cantidad de muestra para inhibir en un $50 \%$ al radical. Por otra parte, teniendo en cuenta que $1 \mathrm{~g}$ de snack contiene aproximadamente $20 \mathrm{mg}$ AA, se obtuvo un valor de $\mathrm{EC}_{50}$ para $\mathrm{A}_{\mathrm{L}}$ de 0,16 y 0,14 $\mathrm{mg} \mathrm{AA} / \mathrm{ml}$ extracto para $\mathrm{A}_{\mathrm{C}}$. No se encontraron diferencias significativas para los valores de $\mathrm{EC}_{50}$ entre ambas muestras $(\mathrm{P}>0,05)$. Estos valores se compararon con diluciones seriadas de un estándar puro de AA (1,35 mg AA/ml), para el cual se obtuvo un valor de $\mathrm{EC}_{50}$ de $0,087 \mathrm{mg} \mathrm{AA} / \mathrm{ml}$ extracto. De esto se destaca que la actividad antioxidante de los snacks está dada por el contenido de AA remanente en las muestras.

A partir de lo anteriormente expuesto, el producto obtenido de la formulación $\mathrm{M}: \mathrm{F}$ 1:1 $\left(\mathrm{A}_{\mathrm{C}} \mathrm{y} \mathrm{A}_{\mathrm{L}}\right)$, reúne las características para ser un snack saludable. Presentó buenas propiedades de textura, color y alta 
aceptabilidad sensorial por parte de los consumidores, además de un balance entre el contenido de AA y contenido de polifenoles, determinante en productos basados en frutas. Durante los pretratamientos de los anillos de manzana con sales de calcio, la muestra con lactato-gluconato presentó un contenido más bajo respecto al pretratamiento con carbonato de calcio. Teniendo en cuenta este resultado, se determinó sobre la muestra el contenido de calcio remanente siguiendo el método descrito en el Capítulo 2, obteniéndose un valor de $221,8 \pm 0,6 \mathrm{mg} \mathrm{Ca} / 100 \mathrm{gms}$.

\subsection{CONCLUSIONES}

El método de cocción más adecuado para obtener un snack formulado con fructosa y maltodextrina incorporando una fase grasa, fue el horneado seguido de fritura atmosférica. Sin embargo, no se consiguió una buena calidad del producto en cuanto a contenido graso y textura.

Considerando que la fritura incorpora materia grasa al alimento, y por lo tanto reduce su valor nutricional, el horneado presentaría mayores beneficios. Esta última operación permitió una mejor conservación de las características nutricionales y organolépticas de la manzana, minimizando la ocurrencia del pardeamiento no enzimático, la degradación del ácido ascórbico y mejorando el color. Asimismo permitió el desarrollo de una textura similar a la de los productos fritos convencionales.

Debido a la importancia que tienen los snacks en los hábitos de consumo y a la creciente tendencia de los consumidores hacia comidas más saludables, los snacks de manzana horneados podrian ser una alternativa más sana frente a otros productos preparados con la adición de sodio y obtenidos por procesos de fritura. 
El uso de maltodextrinas en la formulación, permitió mejorar la textura y aumentar la estabilidad de los anillos crocantes de manzana. Por ser un polisacárido de alto peso molecular, la maltodextrina generó un desplazamiento de la temperatura de transición vítrea a valores más altos en relación con los valores obtenidos para los anillos de manzana horneados y sin la adición de azúcares.

La impregnación de anillos de manzana verde con sales de calcio, carbohidratos de alto y bajo peso molecular (maltodextrina y fructosa), y ácido ascórbico dieron como resultado un producto tipo snack, sin grasa o sodio agregado y con alto grado de aceptabilidad por parte de los consumidores.

El análisis por componentes principales dio como resultado que el snack horneado con las mejores propiedades físicas, químicas y sensoriales fue $A_{L}$, preparado por impregnación en soluciones de lactato-gluconato de calcio y Maltodextrina / Fructosa en relación 1:1.

Si bien es conveniente que un producto pueda llegar a aportar cantidades significativas de calcio a los consumidores, también es necesario establecer un balance entre lo nutritivo y las características organolépticas. Por esta razón la sal de calcio seleccionada para ensayos posteriores fue el lactato-gluconato.

\subsection{REFERENCIAS}

AOAC Official methods of analysis. (1980). Association of Official Analytical Chemists (13th ed), Washington, DC.

AOAC Official Methods of Analysis. (1995). Ed., Arlington, VA, Vol. 2, Chapter 41 (Method 963.15 and 969.33, Supplement, March 1997). 
Aguilera, J.M., Ed. (1997). Fritura de alimentos: Temas en Tecnología de Alimentos. Alfaomega, CYTED. México.

Altonaga, M. (2007). Acción tecnológica de los ingredientes: empanados y rebozados. Área de Nuevos Alimentos y Biomoléculas. Unidad de Investigación Alimentaria. www.alimentatec.com. (20 enero, 2008).

Azuara, E., Cortes, R., Garcia, H. S., Beristain, C. I. (1992). Kinetic model for osmotic dehydration and its relationship with Fick's second law. International Journal of Food Science and Technology, 27: 239-242.

Azuara, E., Beristain, C. I. (2002). Osmotic dehydration of apples by immersion in concentrated sucrose/maltodextrin solutions. Journal of Food Processing and Preservation, 26: 295-306.

Bai, Y., Rahman, S., Perera, C., Smith, B., Melton, L. (2001). State diagram of apple slices; glass transition and freezing curves. Food Research International, 34: 89-95.

Basciano, H., Federico, L., Adeli K. (2005). Fructose, insulin resistance, and metabolic dislipidemia, Nutrition and Metabolism, 2(5): 341-355.

Belitz, H. D., Grosch, W., Schieberle, P. (2004). Food chemistry. Berlin:Springer.

Bell, L. N., Hageman, M. J. (1994). Differentiating between the effects of water activity and glass transition dependent mobility on a solid state chemical reaction: aspartame degradation. Journal of Agricultural and Food Chemistry, 42(11): 2398-2401.

Bell, L. N. (1996). Nonenzymatic browning in reduced-moisture amorphous systems as impacted by water activity and glass-rubber transition. ISOPOW VI Meeting, Santa Rosa, California. 
BeMiller, J. N., Whistler, R. L. (1996). Carbohydrates. In O. W. Fennema (Ed.), Food chemistry, (3rd ed.). New York: Marcel Dekker, Inc.

Betoret, N., Puente, L., Díaz, M. J., Pagán, M. J., García, M. J., Gras, M. L., Martínez-Monzó, J., Fito, P. (2003). Development of probiotic-enriched dried fruits by vacuum impregnation. Journal of Food Engineering, 56 (2-3): 273-277.

Bonazzi, C., Dumoulin, E. (2011). Quality changes in food materials asinfluenced by drying processes in modern drying technology. In E.Tsotsa, A. Mujumdar (Eds.), Product quality and formulation (Vol. 3). Weinheim: Wiley-VCH Verlag Grubtt \& Co KGaA.

Brand-Williams, W., Cuvelier, M.E., Berset, C. (1995). Use of a free radical method to evaluate antioxidant activity. Food Science and Technology, 28 (1): 25 -30.

Buera, M. D. P., Karel, M. (1995). Effect of physical changes on the rates of nonenzymatic browning and related reactions. Food Chemistry, 52(2): 167-173.

Bhandari, B.R., Senoussi, A., Dumoulin, E.D., Lebert,A. (1993).Spray drying of concentrated fruit juices, Drying Technology: An International Journal, 11(5): 1081-1092.

Bhandari, B. R., Roos, Y. H. (2003). Dissolution of sucrose crystals in the anhydrous sorbitol melt. Carbohydrate Research, 338 (4): 361-367.

Blumenthal, M.M., Stier, R. F. (1991). Optimization of deep-fat frying operations. Trends in Food Science \& Technology, 2: 144-148.

Boucher, L. (1990). Snack Food Association. Edible Oils Manual. Snack Food Association: 37. 
Bunger, A., Moyano, P.C, Rioseco, V.K. (2003). NaCl soaking treatment for improving the quality of French-fried potatoes. Food Research International, 36: 161-166.

Cabo Masip, T., Alentado Morell, N., Dalmau Serra, J. (2008). Nuevasrecomendaciones diarias de ingesta de calcio y vitamina D: prevención del raquitismo nutricional. Acta Pediátrica Española, 66(5): 233-236.

Chang, Y.P., Cheah, P.B., Seow, C.C. (2000). Plasticizingantiplasticizing effects of water on physical properties of tapioca starch films in the glassy state. Journal of Food Science, 65(3): 445-451.

Chen, J., Karlsson, C., Povey, M. (2005). Acoustic envelope detector for crispness assessment of biscuits. Journal of Texture Studies, 36 (2): 139-156.

Chirife, J. (1983), Fundamentals of the drying mechanism during air dehydration of foods. In Advances in Food Drying /ed. A.S. Majumdar/, Hemisphere Publishing Corporation: New York, pp.73-102.

Choe, E., Min, D.B. (1997). Chemistry of Deep-Fat Frying Oils. Journal of Food Science, 72(5): 77-86.

Choy, A.-L., May, B.K., Small, D.M. (2012). The effects of acetylated potato starch and sodium carboxymethyl cellulose on the quality of instant fried noodles. Food Hydrocolloids, 26: 2-8.

Contreras, C., Martín, M. E., Martinez-Navarrete, N., Chiralt, A.(2005). Effect of vacuum impregnation and microwave application on structural changes which occurred during air-drying of apple. LWTJournal of Food Science and Technology, 38: 471-477.

Crane, E. 1990. Bees and Beekeeping: Science, Practice and World Resource. IBRA. New York, U.S.A. 614p. 
Dana, D., Saguy, I. S. (2006). Review: Mechanism of oil uptake during deep-fat frying and the surfactant effect-theory and myth. Advances in Colloid and Interface Science, 128-130: 267-272.

Da Silva, P., Moreira, R. (2008). Vacuum frying of high-quality fruit and vegetable based snacks. LWT - Food Science and Technology, 41(10): 1758-1767.

Deng, Y., Zhao, Y. (2008). Effect of pulsed vacuum and ultrasound osmo-pretreatments on glass transition temperature, texture, microstructure and calcium penetration of dried apples (Fuji). LWT- Journal of Food Science and Technology, 41(9): 1575-1585.

Dueik, V., Robert, P., Bouchon P. (2010). Vacuum frying reduces oil uptake and improves the quality parameters of carrot crisps. Food Chemistry, 119: 1143-1149.

Dolenc, K., Stampar, F. (1997). An investigation of the application and conditions of analyses of HPLC methods for determining sugars and organic acids in fruits. Research Reports of Biotechnical Faculty, University of Ljubljana, 69: 99-106.

Fan, L., Zhang, M., Mujumdar, A.S. (2005a). Vacuum frying of carrots chips. Drying Technology, 23: 645-656.

Fan, L., Zhang, M., Xiao, G., Sun, J., Tao, Q. (2005b). The optimization of vacuumfrying to dehydrate carrot chips. International Journal of Food Science and Technology, 40: 911-919.

Fabra, M. J., Márquez, E., Castro, D., Chiralt, A. (2011). Effect of maltodextrins in the water content, water activity, glass transition relationships of noni (Morinda citrifolia L.) pulp powder. Journal of Food Engineering, 103: 47-51.

Farroni, A. (2011). Transformaciones estructurales y fisicoquímicas de maíces argentinos en la producción de alimentos obtenidos por procesos de gelatinización-laminación. Tesis doctoral. 
Universidad de Buenos Aires. Área Química Industrial. Facultad de Ciencias Exactas. Departamento de Industrias.

Fennema, O. (1996). Food Chemistry. New York, Marcel Dekker: 1144.

Fernández-Carretero, F. J., Riande, E., del Río, C., Sánchez, F., Acosta, J. L., Compan, V. (2010). Preparation and characterization of hybrid membranes based on Nafion ${ }^{\circledR}$ using partially sulfonated inorganic fillers. Journal of New Materials for Electrochemical Systems, 13: 83-93.

Fito, P., Chiralt, A., Barat, J. M., Andrés, A., Martínez-Monzó, J. Martínez-Navarrete, N. (2001). Vacuum impregnation for development of new dehydrated products. Journal of Food Engineering. 49 (4): 297-302.

Food and Nutrition Board, Institute of Medicine. Vitamin C. Dietary Reference Intakes for Vitamin C, Vitamin E, Selenium, and Carotenoids. Washington D.C.: National Academy Press; 2000: 95-185. (National Academy Press).

Fuertes, S, Navarro, A. (2011). Caracterización de barras de cerealfortificadas con calcio y vitamina $\mathrm{C}$ protegidos en una matriz dehidrocoloides. XIII Congreso CyTAL-AATA. Octubre 19-21. Buenos Aires (Argentina).

Gamble, M. H., Rice, P. (1988). The effect of slice thickness on potato crisp yield and composition. Journal of Food Engineering, 8(1): 31-46.

Garayo, J., Moreira, R. (2002). Vacuum frying of potato chips. Journal of Food Engineering, 55: 181-191.

Garcia, M. A., Ferrero, C., Bértola, N., Martino, M., Zaritzky, N (2002). Edible coatings from cellullose derivatives to reduce oil uptake in fried products. Innovative Food Science and Emerging Techonologies, 3: 391-397. 
Guerrero, S., Alzamora, S. M., Gerschenson, L. N. (1996). Optimization of a combined factors technology for preserving banana puree to minimize colour changes using response surface methodology. Journal of Food Engineering, 28: 307-322.

Gross L.S, Li L., Ford E.S., Liu S. (2004). Increased consumption of refined carbohydrates and the epidemic of type 2 diabetes in the United States: an ecologic assessment. American Journal Clinical Nutrition, 70: 774-779.

Harbers, L. H. (1998). Ash analysis. In M. A. Gaithersburg \& S. S. Nielsen (Eds.), Food analysis (2nd ed., pp. 141-165). Aspen: Publishers Inc.

Havel, P. (2005). Dietary fructose: Implications for deregulations of energy homeostasis and lipid/carbohydrate metabolism. Nutrition Review, 63: 133-157.

Heredia, A., Castelló, M. L., Andrés, A. (2010). Air Frying: a new process for healthier French fried potatoes. In Proceedings of the International Conference on Food Innovation (CD-Rom). Athens, Greece: Cosmosware.

Heredia, A., Castelló, M. L., Andrés, A. (2014). Evolution of mechanical and optical properties of French fries obtained by hot airfrying. LWT - Food Science and Technology, 57: 755-760.

Herrera Gutiérrez, K. (2008). Determinación de la vida útil de un producto con alto contenido de azúcares elaborado mediante fritura. Tesis de grado. Universidad de Costa Rica. Facultad de Ciencias Agroalimentarias-Escuela de Tecnología de Alimentos.

Huang, L., Min, Z., Mujumdar, A., Lim, R. (2011). Comparison of four drying methods for re-structured mixed potato with apple chips. Journal of Food Engineering, 103: 279-284. 
ISETA (2007). Curso Taller de Evaluación Sensorial en Alimentos. Insituto Superior de Tecnología Alimentaria. Departamento de Evaluación Sensorial: 10.

Ikoko, J., Kuri, V. (2007). Osmotic pre-treatment effect on fat intake reduction and eating quality of deep-fried plantain. Food Chemistry, 102:523-531.

Innawong, B., Mallikarjunan, P., Irudayaraj, J., Marcy, J. E. (2004). The determination of frying oil quality using Fourier transform infrared attenuated total reflectance. $L W T$ - Food Science and Technology, 37(1): 23-28.

Jalaee, F., Fazeli, A., Fatemian, H., Tavakolipour, H. (2011). Mass transfer coefficient and the characteristics of coated apples in osmotic dehydrating. Food and Bioproducts Processing, 89: 367-374.

Jakubczyk, E., Ostrowska-Ligeza, E., Gondek, E. (2010). Moisture sorption characteristics and glass transition temperature of apple puree powder. International Journal of Food Science \& Technology, 45(12): 2515-2523.

Joshi, A. P. K., Rupasinghe, H. P. V., Pitts, N. L. (2010). Comparison of nonfried apple snacks with commercially available fried snacks. Food Science Technology International, 17(3): 249-255.

Karmas, R., Buera, M. d. P., Karel, M. (1992). Effect of glass transition on rates of non-enzymatic browning in food systems. Journal of Agricultural and Food Chemistry, 40: 873.879.

Kim, M.H., K.S. Kim, Y.B. Song, W.J. Seo, K.B. Song. (2009a). Characteristics of apple, persimmon, and strawberry slices dried with maltodextrin. Journal of Food Science and Nutrition, 14: 367-372.

Khanizadeh, S., Tsao, R., Rekika, D., Yang, R., Charles, M.T., Rupasinghe, H. P. (2008). Polyphenol composition and total antioxidant 
capacity of selected apple genotypes for processing. Journal of Food Composition and Analysis, 21: 396-401.

Kunradi Vieira, F. G., Da Silva Campelo Borges, G., Copetti, C., Valdemiro Gonzaga, L. (2009). Activity and contents of polyphenolic antioxidants in the whole fruit, flesh and peel of three apple cultivars. Archivos Latinoamericanos de Nutrición, 59: 101-106.

López-Malo, A., Palou, E., Barbosa-Cánovas, G. V.,Welti-Chanes, J., Swanson, B. G. (1998). Polyphenoloxidase activity and color changes during storage of high hydrostatic pressure treated avocado puree. Food Research International, 31: 549-556.

Kozempel, M. F., Tomasula, P.M y Craig, Jr., J.C (1991). Correlation of moisture and oil concentration in French fries. LWT Food Science and Technology, 19: 346-348.

Lawson, H.W. 1985. Standards for fats \& oils. Westport, CT: AVI

Lesková, E., Kubíková, J., Kováčiková, E., Košická, M., Porubská, J., Holčiková, K. (2006). Vitamin losses: Retention during heat treatment and continual changes expressed by mathematical models. Journal of Food Composition and Analysis, 19 (4): 252-276.

López-Malo, A., Palou, E., Barbosa-Cánovas, G.V., Welti-Chanes, J., Swanson, B. G. (1998). Polyphenoloxidase activity and color changes during storage of high hydrostatic pressure treated avocado puree. Food Research International, 31(8): 549-556.

Mai Tran, T.T., Xiao Dong Chen, Southern, C. (2007). Reducing oil content of fried potato crisps considerably using a 'sweet' pretreatment technique. Journal of Food Engineering, 80: 719-726.

Mandala, I.G, Anagnostaras, E.F, Oikonomou, C.K. (2005). Influence of osmotic dehydration conditions on apple air-drying kinetics and their quality characteristics. Journal of Food Engineering, 69: 307316. 
Manzocco, L., Calligaris, S., Mastrocola, D., Nicoli, M., Lerici, C. (2001). Review of non enzymatic browning and antioxidant capacity in processed foods. Trends in Food Science and Technology, 11: 340-346.

Manayay Sánchez, D., Ibarz, A., Castillo Martinez, W., Palacios Ambrocio, L. (2013). Kinetics of the color difference and chroma in the thermal process pulp mango (Mangifera indica L.) Haden variety. Sciencia Agropecuaria, 4: 181 - 190.

Manzoni, C. "El Mercado de los snacks salados mueve millones". Diario La Nación. Domingo 28 de julio de 2013 | Publicado en edición impresa.

Márquez, G., Añón, M. C. (1986). Influence of reducing sugars and amino acids in the color development of fried potatoes. Journal of Food Science, 51(1): 157-160.

Mariscal, M., Bouchon, P. (2008). Comparison between atmospheric and vacuum frying of apple slices. Food Chemistry, 107: 1561-1569.

Massolo, J.F, Concellón, A, Chaves, A.R, Vicente, A.R. (2011). 1Methylcyclopropene (1-MCP) delays senescence maintains quality and reduces browning of non-climacteric egg plant (Solanum melongena L.) fruit. Postharvest Biology and Technology, 59(1): 10-15.

Mazzeo, T., N' Dri, D, Chiavaro, E, Visconti, A., Fogliano, V., Pellegrini, N. (2011). Effect of two cooking procedures on phytochemical compounds, total antioxidant capacity and colour of selected frozen vegetables. Food Chemistry, 128: 627-633.

Mehnert H. (1976). Sugar substitutes in the diabetic diet. Int $Z$ Vitam Ernahrungs forsch Beih, 15: 295-324.

Mellema, M. (2003). Mechanism and reduction of fat uptake in deep-fat fried foods. Trends in Food Science \& Technology, 14(9): 364373. 
Miglio, C., Chiavaro, E., Visconti, A., Fogliano, V., Pellegrini, N. (2008). Effects of different cooking methods on nutritional and physicochemical characteristics of selected vegetables. Journal of Agricultural and Food Chemistry, 56: 139-147.

Mosquera, L.H., Moraga, G., Martínez-Navarrete, N. (2010a). Effect of maltodextrin on the stability of freeze-dried borojo (Borojo apatinoi Cuatrec.) powder. Journal of Food Engineering, 97: 72 - 78.

Moreira, R., Castell-Pérez, M.E., Barrufet, M.A. (1999). Deep-fat frying: Fundamentals and applications. Gaithersburg, MD: Aspen Publishers Inc.

Moreira, R. G., Da Silva, P. F., Gomes, C. (2009). The effect of a de-oiling mechanism on the production of high quality vacuum fried potato chips. Journal of Food Engineering, 92(3): 297-304.

Moyano, P. C., Ríoseco, V. K., Gonzaléz, P. A. (2002). Kinetics of crust color changes during deep-fat frying of impregnated French fries. Journal of Food Engineering, 54: 249-255.

Moyano, P.C., Pedreschi, F. (2006). Kinetics of oil uptake during frying of potato slices: Effect of pre-treatments. LWT-Food Science and Technology, 39: 285-291.

Nelson, A., Labuza, T. P. (1992). Relationship between water and lipid oxidation rates. Lipid Oxidation in Food, American Chemical Society. 500: 93-103.

Nisha, P., Singhal, R. S., Pandit, A. (2006). Kinetic modelling of texture development in potato cubes (Solanum tuberosum L.), green gram whole (Vigna radiate L.) and red gram splits (Cajanus cajan L.). Journal of Food Engineering, 76: 524-530.

Nojavan, S., Khaliliana, F., MomenKiaiec, F., Rahimic, A., Arabanianc, A., Chalavia, S. (2008). Extraction and quantitative 
determination of ascorbic acid during different maturity stages of Rosa canina L. fruit. Journal of Food Composition and Analysis, 21: 300-305.

Nunes, Y., Moreira, R. G. (2009). Effect of osmotic dehydration and vacuum-frying parameters to produce high-quality mango chips. Journal of Food Science, 74(7): E355-E362.

Ochoa, M.R., Kesseler, A.G., Pirone, B.N., Márquez, C.A., De Michelis, A. (2002). Shrinkage during convective drying of whole Rose Hip (Rosa Rubiginosa L) fruits. LWT-Food Science and Technology, (36):

Paulo, C., Pagano, A.M, Mascheroni, R.H. (2006). Efecto de las condiciones de deshidratación sobre propiedades fisicoquímicas de manzanas Granny Smith. XXIII Congreso Interamericano de Ingeniería Química y V Congreso Argentino de Ingeniería Química.

Pallauf, K., Bendall, J. K., Scheiermann, C.,Watschinger, K., Hoffmann, J., Roeder, T., et al. (2013). Vitamin C and lifespan in modelorganisms. Food and Chemical Toxicology, 58: 255-263.

Pedreschi, F., León, J., Mery, D., Moyano, P., Pedreschi, R., Kaack, K., Granby, K. (2007). Color development and acrylamide content of pre-dried potato chips. Journal of Food Engineering, 79: 786793.

Pedreschi, F., Cocio, C., Moyano, P., Troncoso, E. (2008). Oil distribution in potato slices during frying. Journal of Food Engineering, 87(2): 200-212.

Pérez-Cruz, E., Serralde Zúñiga, A.E, Meléndez Mier, G. (2007). Efectos benéficos y deletéreos del consumode fructosa. Revista de Endocrinología y Nutrición, 15(2): 67-74.

Piotrowski, D., Lenart, A. Recent advances in the drying of apples under variable process conditions. In Processing Foods. Quality Optimization and Process Assessment; Oliveira, F.A.R., Oliveira, J.C.,Eds.; CRC Press: Boca Raton, FL, 1999; 229-248. 
Quest, A.F.G., Leyton, L. (2012). Instituto Linus Pauling de la Universidad Estatal de Oregon. Traducción Bayer Consumer Care AG, Basel, Switzerland.

Quintero Ruiz, N.A., Giner, S.A. Efecto del secado en el contenido de ácido ascórbico, sustancias fenólicas y antioxidantes totales en laminados de rosa mosqueta. Quintero Ruiz, N.A.; Giner, S.A. IV Congreso Internacional de Ciencia y Tecnología de Alimentos, Córdoba, Argentina. Libro de Trabajos Completos. Calidad Tecnológica, 293-299. Editores, Borneo, R.; León, A.E.; Sciarini,L; Steffolani, E. (2012). ISBN 978-950-33-1071-7.

Ramos, I. N., Silva, C. L., Sereno, A. M., Aguilera, J. M. (2004). Quantification of microstructural changes during first stage air drying of grape tissue. Journal of Food Engineering, 62: 159-164.

Re, R., Pellegrini, N., Proteggente, A., Pannala, A., Yang, M., RiceEvans, C. (1999). Antioxidant activity applying an improved ABTS radical cation decolorization assay. Free Radical Biology and Medicine, 26: 1231-1237.

Rivero, S., García, M. A., Pinotti, A. (2012). Heat treatment to modify the structural and physical properties of chitosan-based films. Journal of Agricultural and Food Chemistry, 60: 492-499.

Roos, Y. H. (1992). Reaction kinetics and thermodynamics in food systems; Part II, Phase transitions and transformations. Handbook of Food Engineering. D. Lund y D. Heldman. New York, Marcel Dekker.

Roos, Y. H., Himberg, M. J. (1994). Nonenzymic browning behavior, as related to glass transition, of a food model at chilling temperatures. Journal of Agricultural and Food Chemistry, 42(4): 893898.

Roos, Y. (1995). Phase transitions in foods. California: Academic PressInc. 
Romani, S., Rocculi, P., Mendoza, F., Dalla Rosa, M. (2009). Image characterization of potato chip appearance during frying. Journal of Food Engineering, 93: 487-494.

Rodriguez, G., Zuluaga, C.L, Puerta, L., Ruiz, V. (2013). Physicochemical parameters assessment in banana frying. Biotecnologia en el Sector Agropecuario y Agroindustrial, Universidad del Cauca, 11: $123-129$.

Rubnov, M., I.S. Saguy. (1997). Fractal analysis and crust water diffusivity of a restructured potato product during deep-fat frying. Journal of Food Science, 62: 135-154.

Saguy, I. S., Pinthus, E.J. (1995). Oil uptake during deep fat frying: Factors and mechanisms. Food Technology, 49(44): 142-152.

Sánchez-Moreno, C., Larrauri, J. A., Fulgencio, S. (1998). A procedure to measure the antiradical efficiency of polyphenols. Journal of the Science of Food and Agriculture, 76(2): 270-276.

Schebor, C., Buera, P., Karel, M., Chirife, J. (1999). Color formation due to non-enzymatic browning in amorphous, glassy, anhydrous, model systems. Food Chemistry, 65: 427-432.

Setiady, D., Tang, J., Younce, F., Swanson, B. A., Rasco, B. A., Clary, C.D. (2009). Porosity, color, texture and microscopic structure of russet potatoes dried using microwave vacuum, heated air, and freeze drying. ASABE Applied Engineering in Agriculture, 25(5): 719-724.

Serpen, A., Gökmen, V. (2009). Evaluation of the Maillard reaction in potato crisps by acrylamide, antioxidant capacity and color. Journal of Food Composition and Analysis, 22: 589-595.

Shamekh, S., Myllarinen, O., Poutanen, K., Forssell, P. (2002). Film formation properties of potato starch hydrolysates. Starch, 54: 2024. 
Shimada, Y., Roos, Y. H., Karel, M. (1991). Oxidation of methyllinoleate encapsulated in amorphous lactose based food model. Journal of Agricultural and Food Chemistry, 39: 637-641.

Shyu, S.L., Hwang, L.S. (2001). Effects of processing conditions on the quality of vacuum fried apple chips. Food Research. International, 34: $133-142$.

Shyu, S.L., Hau, L.B., Hwang, L.S. (2005). Effects of processing conditions on the quality of vacuum-fried carrot chips. Journal of the Science of Food and Agriculture, 85: 1903-1908.

Silva, M.A., Sobral, P.J.A., Kieckbusch, T. G. (2006). State diagrams of freeze-dried camu-camu (Myrciariadubia (HBK) Mc Vaugh) pulp with and without maltodextrin addition. Journal of Food Engineering, 77(3): 426-432.

Singleton, V.L., Orthofer, R., Lamuela-Raventós, R.M. (1999). Analysis of total phenols and other oxidation substrates and antioxidants by means of Folin-Ciocalteu reagent. Methods in Enzymology. Oxidants and Antioxidants Part A, 299: 152-178.

Singthong, J., Thongkaew, C. (2009). Using hydrocolloids to decrease oil absorption in banana chips. LWT - Food Science and Technology, 42: 1199-1203.

Slade, L., Levine, H. (1995). Water and the glass transition. Dependence of the glass transition on composition and chemical structure: Special implications for flour functionality in cookie baking. Journal of Food Engineering, 24(4): 431-509.

Sonthipermpoon, W., Suwonsichon, T., Wittaya-areekul, S., Wuttijumnong, P. (2006). Effect of maltodextrin on glass transition temperature and water activity of production banana flake. Kasetsart. Journal-Natural Science, 40: 708-715. 
Sousa, M., Canet, W., Alvarez, M., Fernández, C. (2007). Effect of processing on the texture and sensory attributes of raspberry (cv. Heritage) and blackberry (cv. Thornfree). Journal of Food Engineering, 78: 9-21.

Spiazzi, E.A, Mascheroni, R.H. (1997). Mass transfer model for osmotic dehydration of fruits and vegetables- I. Development of the simulation model. Journal of Food Engineering, 34: 387-410.

Sun-Waterhouse, D., Teoh, A., Massarotto, C., Wibisono, R., Wadhwa,S. (2010). Comparative analysis of fruit-based functional snack bars. Food Chemistry, 119(4): 1369-1379.

Ufheil, G., Escher, F. (1996). Dynamics of Oil Uptake during Deep-Fat Frying of Potato Slices. LWT- Food science and Technology, 29(7): 640-644.

Tan, B.K., Harris, N.D. (1995). Maillard reaction products inhibit apple polyphenoloxidase. Food Chemistry, 53: 267-273.

Taniwaki, M., Kohyama., K. (2012). Mechanical and acoustic evaluation of potato chip crispness using a versatile texture analyzer. Journal of Food Engineering, 112: 268-273.

Tavera-Quiroz, M.J., Urriza, M., Pinotti, A., Bertola, N. (2012). Plasticized methylcellulose coating for reducing oil uptake in potato chips. Journal of the Science of Food and Agriculture, 92(7): 1346-1353.

Tavera-Quiroz, M. J., Lecot, J., Bertola, N., Pinotti, A. (2013). Stability of methylcellulose based films after being subjected to different conservation and processing temperatures. Materials Science and Engineering: C, 33: 2918-2925.

Valenzuela, C., Aguilera, J.M. (2015). Effects of maltodextrins on hygroscopicity and crispness of apple leathers. Journal of Food Engineering, 144: 1-9. 
Varela, P., Chen, J., Fiszman, S., Povey, M.J.W. (2006). Crispness assessment of roasted almonds by an integrated approach to texture description: texture, acoustics, sensory and structure. Journal of Chemometrics, 20 (6-7): 311-320.

Varela, P., Salvador, A., Fiszman, S. (2009). On the assessment of fracture in brittle foods II. Biting or chewing?. Food Research International, 42(10): 1468-1474.

Vega-Gálvez, A., Ah-Hen, K., Chacana, M., Vergara, J., MartínezMonzo, J., García-Segovia, P. (2012). Effect of temperature and air velocity on drying kinetics, antioxidant capacity, total phenolic content, colour, texture and microstructure of apple (var. Granny Smith) slices. Food Chemistry, 132: 51-59.

Vincent, J. F. (1998). The quantification of crispness. Journal of the Science of Food and Agriculture, 78: 162-168.

Villamizar, R., Giraldo, G. (2010). Obtención y caracterización de un pasabocas a partir de una pasta a base de mango mediante fritura por inmersión. Revista Tumbaga, 1(5):149-164.

Yven, C., Guessasma, S., Chaunier, L., Della Valle, G., Salles, C. (2010). The role of mechanical properties of brittle airy foods on the masticatory performance. Journal of Food Engineering, 101(1): 85-91.

Wang, S.M., D.J. Yu, K.B. Song. (2011b). Quality characteristics of purple sweet potato (Ipomoea batatas) slices dehydrated by the addition of maltodextrin. Horticulture, Environment, Biotechnology, 52: 435-441.

World Health Organization (WHO)(2002). Innovative care for chronic conditions: building blocks for action. Geneva, World Health Organization, (unpublished document WHO/MNC/CCH/02.01).

World Health Organization (WHO) (2014). Reducing consumption of sugar-sweetened beverages to reduce the risk of childhood overweight 
and obesity: Biological, behavioral and contextual rationale. Tim Lobstein. Director of Policy, World Obesity Federation, London UK.

Zhou, Y. G., Wang, L. J., Li, D., Yan, P. Y., Li, Y. B., Shi, J., et al. (2009). Effect of sucrose on dynamic mechanical characteristics of maize and potato starch films. Carbohydrate Polymers, 76(2): 239-243. 

CAPITULO 4.

\section{DESARROLLO DE ANILLOS CROCANTES DE MANZANA REDUCIDOS EN CALORIAS UTILIZANDO ISOMALT}





\subsection{CONSIDERACIONES GENERALES}

La demanda habitual de alimentos bajos en calorias y que no provoquen efectos indeseables relacionados con el consumo de sacarosa estimula a la industria agroalimentaria en el continuo desarrollo de nuevos productos que satisfagan estas expectativas del consumidor. Una de las cuestiones que se plantea el mercado de alimentos naturales es el control del azúcar en sangre así como alimentos de bajo índice glucémico (Peinado y col., 2008). Los polioles presentan ventajas potenciales sobre la sacarosa como ingredientes de alimentos, ya que producen una respuesta glucémica baja, siendo aptos para diabéticos (Martínez-Cervera y col., 2014). Además, son no cariogénicos ya que son escasamente metabolizados por los microorganismos presentes en la boca (Ghosh y Sudha, 2012) y presentan menor aporte de calorias que la sacarosa. Olinger y Velasco (1996) describieron cambios favorables en la propagación de la reacción de Maillard cuando sustituyeron el azúcar en productos horneados por lactitol, maltitol, isomalt, sorbitol y polidextrosa, lo cual indica que es posible usar polioles como sustitutos de la sacarosa en productos en los cuales sea necesario el desarrollo de color.

La isomaltulosa (6-O-0-D-glucopiranosil-D-fructofuranosa) llamada también palatinosa ${ }^{\circledR}$ se utiliza en varios productos alimenticios como un azúcar nutritivo. Es el único azúcar que proviene de la sacarosa obtenida de la remolacha. Isomalt, producido por la reducción de la isomaltulosa, es una mezcla equimolar de OD-glucopiranosil-1,6D-sorbitol y OD-glucopiranosil-1,6-D-manitol. Se obtiene mediante un proceso de dos etapas: primero la sacarosa se transforma en isomaltulosa y posteriormente se hidrogena, usando un catalizador metálico (Figura 42). 


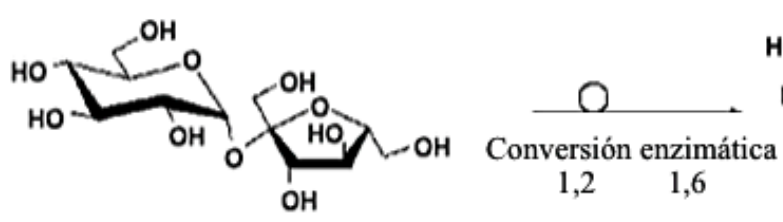

Sacarosa

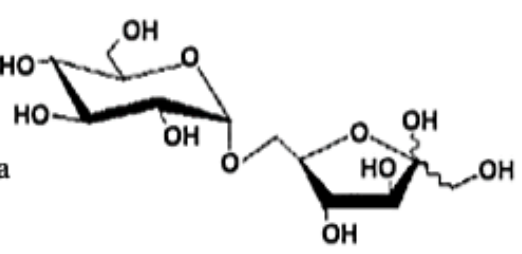

Isomaltulosa (palatinosa)
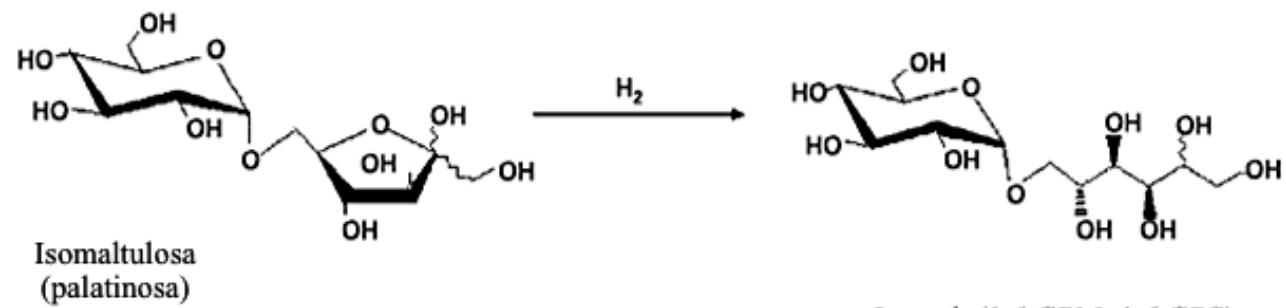

Isomalt (1,6 GPM, 1,6 GPS)

Figura 42. Conversión de sacarosa en Isomalt (Gostner y col., 2005).

Una enzima (Isomaltulosa sintasa) reacomoda la unión entre la glucosa y la fructosa en la sacarosa. En el segundo paso, se agregan dos hidrógenos a un oxígeno en la fructosa del disacárido. Aproximadamente la mitad de la fructosa original del disacárido se convierte en manitol y la otra mitad en sorbitol. Por lo tanto, isomalt contiene dos alcoholes disacáridos diferentes: el glucomanitol y el glucosorbitol. Los cambios moleculares que ocurren hacen que el isomalt sea química y enzimáticamente más estable que la sacarosa. La estabilidad del isomalt es la razón de muchos de sus beneficios para la salud y de la versatilidad de usos en distintos productos. Isomalt es una sustancia blanca, cristalina que contiene aproximadamente $5 \%$ de agua de cristalización. Tiene la mitad del poder edulcorante de la sacarosa (2 $\mathrm{kcal} / \mathrm{g})$, pero un dulzor similar. Resulta muy interesante su aplicación al desarrollo de alimentos para diabéticos y para deportistas por su lenta liberación de glucosa y fructosa. Proporciona energía durante un periodo significativamente más duradero y tiene apenas un leve efecto sobre los niveles de glucosa en sangre y de insulina en el cuerpo humano, y aun así es totalmente digerible (Hawai y col., 1989; Lina y col., 2002). La glucosa tiene un indice glucémico (IG) de 100, la 
sacarosa de 68, la fructosa de 23 e isomalt de 9. Es anticariogénico y no promueve el desarrollo de caries en los dientes, porque las bacterias de la boca no pueden convertir el isomalt en poliglucano, la sustancia a partir de la cual se sintetiza la placa dental (Jonker y col., 2002). Por lo tanto, las condiciones de acidez que llevan a la desmineralización de los dientes que ocurren luego de comer sacarosa y otros hidratos de carbono fermentables no ocurren con el isomalt. Gostner y col. (2005) sugieren que el compuesto isomalt podría ser considerado un prebiótico, gracias a que parte del mismo, resiste a la digestión en la parte superior del intestino, lo que evita su absorción y le permite continuar el colon, donde es degradado por bacterias. Otra propiedad importante es su capacidad para no absorber agua hasta alcanzar valores de actividad acuosa mayores a 0,85. Isomalt absorbe muy poca agua, razón por la cual los productos provenientes de procesos que se realizan con isomalt no presentan pegajosidad (Beck y Aramouni, 2000). Esto significa que las golosinas, por ejemplo, pueden ponerse en un paquete sin envolver cada unidad por separado, lo cual es práctico y atractivo para los consumidores ecológicos. Otra ventaja que deriva de esta propiedad es que, como los productos no absorben humedad, tienen un mayor período de caducidad y una mayor calidad del producto final. Otras propiedades interesantes son que mejora la transferencia de sabores en las comidas, se disuelve más lentamente en la boca, con lo cual las golosinas hechas con isomalt tienen un sabor más duradero, no tiene el efecto "refrescante" de otros polioles, que a veces no es deseado.

El poder edulcorante de isomalt depende de su concentración, su temperatura y la forma del producto en el que se utiliza. Cuando se utiliza solo, provee entre el 45 y el $65 \%$ del dulzor que tendría la misma cantidad de sacarosa. Ofrece no sólo dulzor a un producto alimenticio sino también volumen y textura. Además este puede calentarse sin perder el dulzor y sin descomponerse, ya que tiene un punto de fusión entre 145 y $150^{\circ} \mathrm{C}$. Por esta razón, se utiliza fundamentalmente en productos hervidos, horneados o que se someten a altas temperaturas. 
El uso de isomalt está aprobado en más de 80 países en todo el mundo, incluyendo EE. UU., Japón, Australia, Nueva Zelanda y los países de Europa del este. Isomalt se ha usado en Estados Unidos desde 1990. En EE. UU. y Europa es producido y comercializado por Beneo y Cargill, Inc. En el Código Alimentario Argentino (CAA) está incluido en la lista de aditivos autorizados para ser utilizados según las Buenas Prácticas de Fabricación (BPF). El Comité Mixto FAO/OMS de Expertos en Aditivos Alimentarios (JECFA) evaluó la seguridad del isomalt y concluyó que no hay necesidad de establecer una cifra (un límite) de ingesta diaria admisible (IDA), que es la categoría más segura a la que el JECFA puede asignar a un ingrediente. Isomalt ofrece beneficios acordes a los cambios en el estilo de vida y a las pautas contemporáneas para una dieta saludable. Amplía las opciones de alimentos para el creciente número de personas que buscan realizar mejoras moderadas en su dieta. Es ideal para quienes deseen adoptar un estilo de vida que podría incluir una dieta sin azúcar, pero disfrutando ocasionalmente de postres, golosinas y otros alimentos dulces durante las comidas o como refrigerios. Un snack a base de fruta e isomalt puede ser una alternativa de consumo para aquellas personas que buscan disminuir su ingesta diaria de calorias y/o para diabéticos.

\section{Objetivos}

Desarrollar un snack crocante a base de manzana verde reducido en calorias utilizando isomalt.

Determinar la concentración óptima de solutos (isomalt y maltodextrina) para obtener un snack con caracteristicas sensoriales y físicas adecuadas para el consumidor.

Evaluar las propiedades físicas, químicos y sensoriales del producto obtenido. 


\subsection{MATERIALES Y MÉTODOS}

\subsubsection{MATERIALES}

Los anillos de manzanas Granny Smith (humedad 85\% y sólidos solubles $11 \pm 1{ }^{\circ}$ Brix) se obtuvieron como se describe en el punto 2.2.2.1 del Capítulo 2.

Para la aplicación de los pretratamientos se utilizaron lactatogluconato de calcio (grado alimenticio, Jungbunzlauer, Alemania), maltodextrina (grado alimenticio, Parafarm) e isomalt (Palatinit).

\subsubsection{MÉTODOS}

\subsubsection{Preparación del snack}

Los anillos de manzana se sumergieron en una solución de lactato-gluconato de calcio (grado alimenticio, Jungbunzlauer) al 2,5\% (p/v) durante 2 min y luego fueron sometidos a escaldado con vapor. Por último los anillos de manzana se sumergieron en soluciones acuosas de maltodextrina (M) e isomalt (I) al 30\% (p/v) y $2 \%(\mathrm{p} / \mathrm{v})$ de ácido ascórbico.

\subsubsection{Determinación de la pérdida de peso en función del tiempo de inmersión en las soluciones de azúcares}

Se determinó el tiempo óptimo de tratamiento osmótico de las muestras de manzana en las soluciones de M:I con distintas concentraciones: A $(1: 1)$, B (2:1) y C (1:2), siguiendo el método descrito en el Capítulo 3- Sección 3.2.

\subsubsection{Obtención de los snacks: Horneado}

Los snacks se obtuvieron mediante secado en un horno de convección forzada Multiequip HCE-3 a $140{ }^{\circ} \mathrm{C}$ durante $30 \mathrm{~min}$. A los snacks obtenidos a partir de cada una de las formulaciones de M:I (1:1, 2:1 y 1:2) se les denominó Iso A, Iso B e Iso C, respectivamente. 


\subsubsection{Análisis de los snacks obtenidos}

Los métodos utilizados para analizar las muestras de los snacks con isomalt se describieron en el Capítulo 3- Sección 3.3 y 3.4. A los snacks preparados por inmersión en las soluciones Maltodextrina:Isomalt se les determinó: contenido de humedad y actividad acuosa, textura y color, propiedades térmicas y mecánicas por DSCM y DMA, propiedades funcionales (contenido de calcio, contenido de carbohidratos y ácido ascórbico y capacidad antioxidante por DPPH). Asimismo se observó la microestructura a través de SEM. Finalmente se realizó una prueba de evaluación sensorial de los snacks obtenidos y los controles (anillos de manzana horneados sin tratamientos con calcio y azúcares) horneados a 140 y a $100^{\circ} \mathrm{C}$.

\subsubsection{Análisis Estadístico}

Se realizó un análisis de varianza (ANAVA) utilizando el programa Systat. Para los ensayos de comparación de medias se empleó el test LSD con $P<0,05$. El análisis de componentes principales (PCA) se realizó con el software Infostat versión 2009 (Córdoba, Argentina).

\subsection{RESULTADOS Y DISCUSIÓN}

\section{Propiedades fisicoquímicas de los snacks obtenidos}

A partir de la ecuación de Azuara (Ec. 4) se modelaron las curvas de pérdida de peso en función del tiempo para cada una de las muestras inmersas en las soluciones de M:I y se obtuvieron los valores de ML $\infty$ y de la constante A. El tiempo de tratamiento fue establecido como el tiempo en el que la pérdida de peso ML resultó ser el 50\% del valor de MLo, tal como se explicó en el Capítulo 3-sección 3.2. Este tiempo, que se obtuvo como la inversa del parámetro A de la ecuación 4 (Capítulo 3-sección 3.2), osciló entre 12,5 y 18,5 min, valores similares a los obtenidos cuando se utilizó fructosa en lugar de isomalt en la solución osmótica (Tabla 16). 
Tabla 16. Valores obtenidos para $M L \infty, A\left(\mathrm{~min}^{-1}\right)$ y tiempo de impregnación con azúcares (min) a partir de Ec. (4), correspondiente al modelo de Azuara y col., 2002.

\section{Tiempo de}

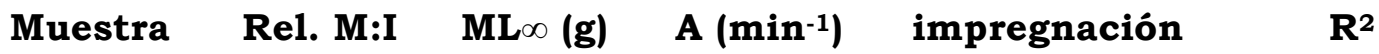
(min)

\begin{tabular}{cccccc}
\hline Iso A & $1: 1$ & $7,0^{\mathrm{a}}$ & $0,080^{\mathrm{b}}$ & $12,5^{\mathrm{a}}$ & 0,96 \\
Iso B & $2: 1$ & $6,2^{\mathrm{a}}$ & $0,058^{\mathrm{a}}$ & $17,2^{\mathrm{b}}$ & 0,95 \\
Iso C & $1: 2$ & $6,4^{\mathrm{a}}$ & $0,054^{\mathrm{a}}$ & $18,5^{\mathrm{b}}$ & 0,97 \\
\hline
\end{tabular}

$a, b$ Letras diferentes indican diferencias significativas.

Para la constante A $\left(\mathrm{min}^{-1}\right)$ se observaron diferencias significativas siendo mayor la constante de velocidad relacionada con la pérdida de peso para la muestra Iso A. Entre Iso $\mathrm{B}$ y $\mathrm{C}$ no se encontraron diferencias significativas $(P>0,05)$. De acuerdo a Della Rocca (2010) la combinación de dos o más solutos en la solución puede hacer más eficiente la deshidratación al proporcionar cada uno de ellos la ventaja que los caracteriza. En este caso se observó que la pérdida de peso ML $\infty$ resultó independiente de la formulación $(\mathrm{P}>0,05)$, debido a que ambos carbohidratos usados eran de mayor tamaño que los agentes osmóticos comunes como la sacarosa o la fructosa. Spiazzi y Mascheroni (2011) informaron que cuando se utilizan soluciones con solutos de mayor peso molecular, la ganancia de sólidos resulta despreciable respecto a los casos en que se usan solutos de menor peso molecular. En este trabajo se utilizó un tiempo promedio de 15 min para cada una de las formulaciones estudiadas.

Los snacks obtenidos luego de la inmersión en las distintas soluciones de M:I mostraron colores uniformes y menor desarrollo de caramelización, respecto al control (Figura 43). 


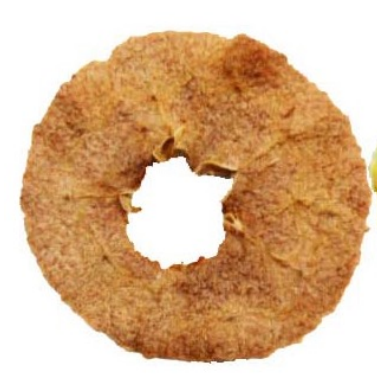

a

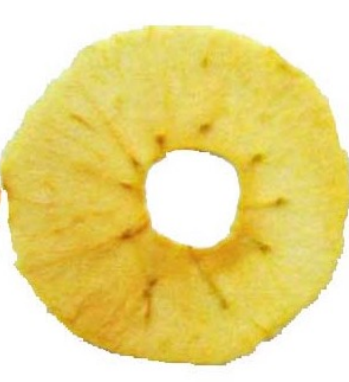

b
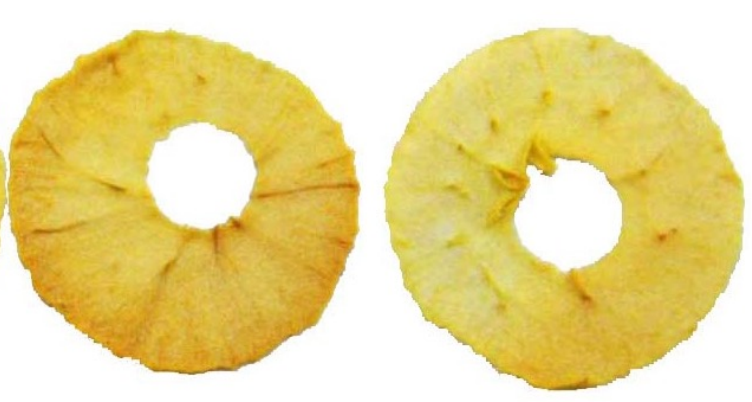

c

Figura 43. Snacks horneados a $140^{\circ} \mathrm{C}$ : a. Control; b. Iso A; c. Iso B, d. Iso C

En la Tabla 17 se muestran los valores promedios de humedad y de fuerza en la ruptura y en la Tabla 18 los parámetros de color de los snacks con isomalt y maltodextrina.

Tabla 17. Humedad y fuerza en la ruptura de los snacks obtenidos por horneado a $140^{\circ} \mathrm{C}$

\begin{tabular}{|c|c|c|c|}
\hline Snack & $\underset{\left(g_{\text {agua }} / 100 g_{\text {ms }}\right)}{\text { Humedad }}$ & $\mathbf{a}_{\mathbf{w}}$ & $\begin{array}{c}\text { Fuerza de } \\
\text { ruptura (N) }\end{array}$ \\
\hline Control & $7,7 \mathrm{~b}(0,5)$ & $0,60^{\mathrm{b}}(0,02)$ & $0,9^{a}(0,1)$ \\
\hline Iso $\mathrm{A}$ & $2,2^{\mathrm{a}}(0,2)$ & $0,43^{a}(0,01)$ & $1,2^{\mathrm{a}}(0,2)$ \\
\hline Iso $B$ & $1,9^{a}(0,8)$ & $0,42^{\mathrm{a}}(0,01)$ & $2,0^{\mathrm{b}}(0,2)$ \\
\hline Iso $\mathrm{C}$ & $1,8^{\mathrm{a}}(0,4)$ & $0,45^{\mathrm{a}}(0,02)$ & $1,0^{\mathrm{a}}(0,2)$ \\
\hline
\end{tabular}

a, b Letras diferentes indican diferencias significativas 
Tabla 18. Parámetros de color del control y de los snacks obtenidos por horneado a $140{ }^{\circ} \mathrm{C}$

\begin{tabular}{lcccc}
\hline \multicolumn{1}{c}{ Snack } & $\mathbf{L}^{*}$ & $\mathbf{a}^{*}$ & $\mathbf{b}^{*}$ & BI \\
\hline Control & $52,0^{\mathrm{b}}(5,8)$ & $10,5^{\mathrm{c}}(0,8)$ & $27,5^{\mathrm{c}}(0,8)$ & $86,4^{\mathrm{d}}(0,7)$ \\
Iso A & $66,0^{\mathrm{a}}(1,4)$ & $2,3^{\mathrm{a}}(0,7)$ & $20,8^{\mathrm{a}}(0,8)$ & $42,5^{\mathrm{a}}(0,9)$ \\
Iso B & $60,0^{\mathrm{a}}(1,5)$ & $0,8^{\mathrm{b}}(0,4)$ & $15,3^{\mathrm{b}}(0,4)$ & $29,6^{\mathrm{b}}(0,5)$ \\
Iso C & $65,0^{\mathrm{a}}(1,5)$ & $3,0^{\mathrm{a}}(0,6)$ & $21,6^{\mathrm{a}}(0,8)$ & $39,2^{\mathrm{c}}(0,6)$ \\
\hline
\end{tabular}

$a, b, c$ Letras diferentes indican diferencias significativas

Se observó que el control horneado sin ningún tratamiento presentó un contenido de humedad de 7,7\% (base seca). Después de los tratamientos previos con M:I, la humedad se redujo en promedio a un valor de $1,9 \%$ (base seca) y la actividad acuosa se redujo en un $27 \%$ en relación al control $(\mathrm{P}<0,05)$. Los parámetros de color mostraron un menor desarrollo del proceso de caramelización en los snacks comparado con el control, tal como se observa en la Figura 43.

Teniendo en cuenta el alto valor de BI obtenido para el control, se infiere que los pretratamientos tuvieron un efecto protector sobre el tejido de la manzana sometido a altas temperaturas. Cuando se calientan carbohidratos, especialmente azúcares en medio ácido, se produce la caramelización con una primera fase de deshidratación y formación de hidroximetilfurfural y una segunda de fragmentación y aparición de productos de bajo peso molecular, responsables del típico olor a caramelo.

Los azúcares experimentan hidrólisis, enolización, isomerización, deshidratación, fragmentación y oxidación. De este modo, se forman compuestos carbonílicos altamente reactivos que reaccionan entre sí dando polimeros insaturados de color pardo (Hodge y Osman, 1976). 
Como es sabido, la regla general dice que las pentosas son más reactivas que las hexosas (glucosa, fructosa) y estas a su vez más que los disacáridos reductores. Para el caso de los disacáridos no reductores como isomalt, primero debe haber una hidrólisis y por lo tanto son menos reactivos. Isomalt tiene la propiedad de caramelizar sin generar compuestos pardos, es decir que cuando funde genera productos claros o transparentes, mientras que la formación de color para las maltodextrinas responde a su grado de DE (Cruz y col., 1994). Sabiendo que las maltodextrinas están formadas por enlaces de D-glucosa y su grado de DE (dextrosa equivalente) se refiere al contenido de azúcares reductores, a medida que este último valor aumenta se favorecen las reacciones de oscurecimiento. Lo ideal es que este valor sea menor a 20. Esto explica por qué en el caso de los snacks con isomalt y maltodextrina (DE 15,4) la caramelización fue menor en relación al control (compuesto mayoritariamente por la fructosa propia de la manzana) y que para los snacks formulados con fructosa $\mathrm{y}$ maltodextrina (Capítulo 3-Sección 3.4.). Resultados similares fueron informados por Ronda y col. (2005). Estos autores observaron un menor desarrollo de la reacción de Maillard en productos horneados formulados con polioles.

La textura de los snacks mostró perfiles correspondientes a productos crocantes, similares a lo que se obtuvieron para los snacks formulados con fructosa y maltodextrina. La Figura 44 muestra las curvas de fuerza-desplazamiento para el control y el snack Iso C. E1 control horneado a $140^{\circ} \mathrm{C}$ exhibe una curva similar al control horneado a $100^{\circ} \mathrm{C}$, de tipo suavizado, sin la presencia de picos abruptos de ruptura. Mientras tanto el snack con mayor contenido de isomalt en su formulación presentó un patrón con múltiples rupturas, asociado con la crocancia. En cuanto a los snacks Iso A e Iso B, estos mostraron un perfil similar a Iso $\mathrm{C}$. El snack Iso C presentó un valor de pendiente de $1,3 \pm 0,3 \mathrm{~N} / \mathrm{mm}$ y una distancia a la primera ruptura de $1,14 \pm 0,08 \mathrm{~mm}$. Este valor fue similar para los snacks formulados con las demás 
concentraciones de Maltodextrina:Isomalt. Para el control no fue posible calcular el valor de la pendiente, debido a que la curva no sigue un patrón de linealidad lo cual es típico de productos gomosos. La distancia a la ruptura fue de $2,7 \pm 0,4 \mathrm{~mm}$, es decir, que el desplazamiento fue mayor para esta muestra.

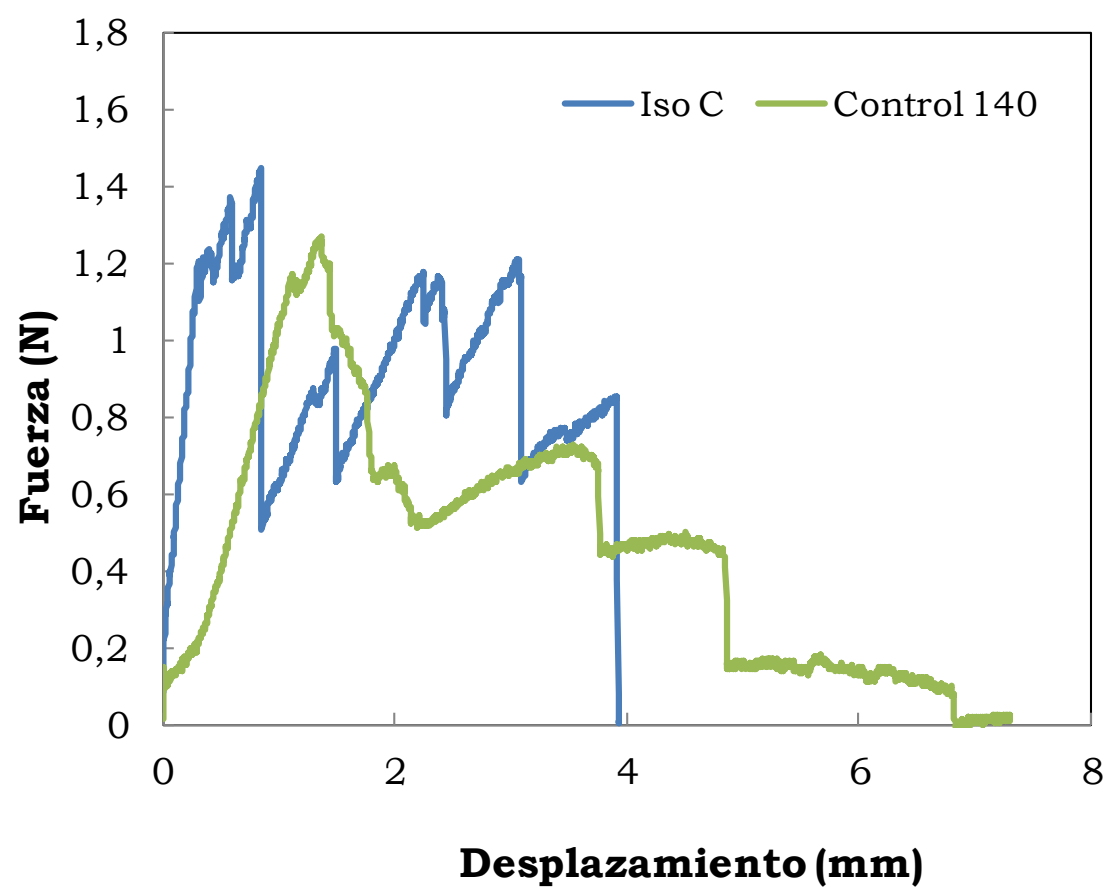

Figura 44. Curvas de fuerza-desplazamiento de: snack Iso $\mathrm{C}$ y el control horneado a $140^{\circ} \mathrm{C}$.

Durante el horneado, las altas temperaturas causan el colapso de la estructura, produciendo texturas más firmes y crocantes, que se rehidratan lentamente (Perera, 2005). En el caso específico de los chips, la característica textural más importante, que determina la calidad del producto, es la crocancia, inducida por el bajo contenido de humedad de este tipo de alimentos. Un material crocante se define como firme y fácil de romper cuando se deforma, emitiendo un sonido "crocante" (Krokida y col., 2001b). Cuando un alimento es crocante, la curva de fuerza-deformación es un reflejo de la energía aplicada o "liberada" por la muestra y va acompañada por la emisión de un sonido relacionado con la repentina liberación de energía (Fiszman, 2013). Al observar 
ambas curvas se deduce que el snack generó un mayor número de picos (eventos acústicos) durante el ensayo mecánico.

\section{Análisis de la microestructura por SEM}

En la Figura 45 se muestran las micrografias obtenidas con el SEM de los snacks obtenidos.
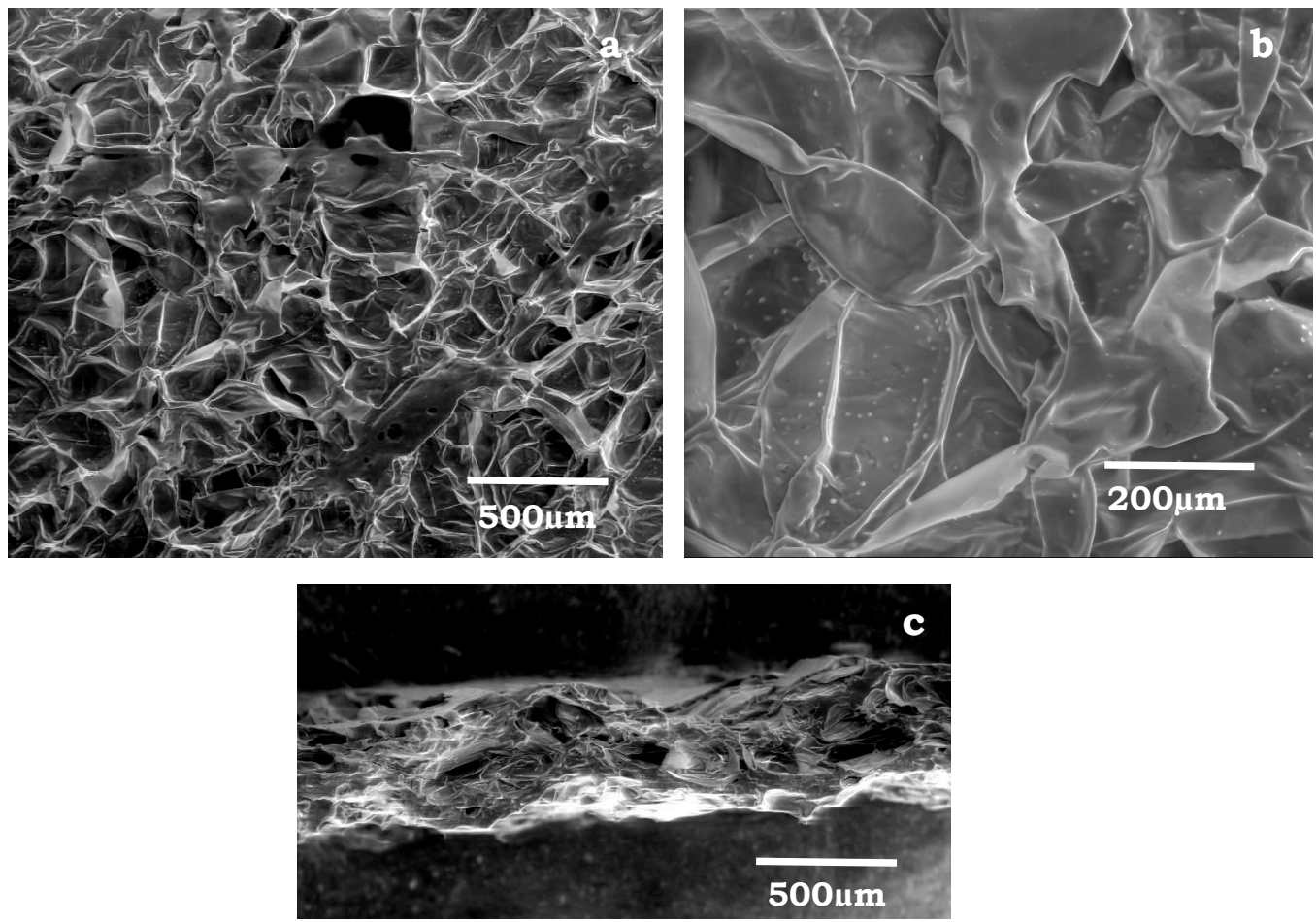

Figura 45. Micrografias obtenidas por SEM para el snack Iso: a. 200x, b.500x, c. Espesor a 200x.

Por medio de SEM se observó una estructura porosa y conservada del tejido de manzana, similar a lo observado en las muestras formuladas con fructosa, lo cual es típico de productos crocantes. En la Figura 46 se muestra el microanálisis de la muestra por dispersión de energía de rayos $\mathrm{X}(\mathrm{EDX})$, en el cual se obtuvo el espectro del calcio encapsulado en los poros del snack, formados durante el horneado. 


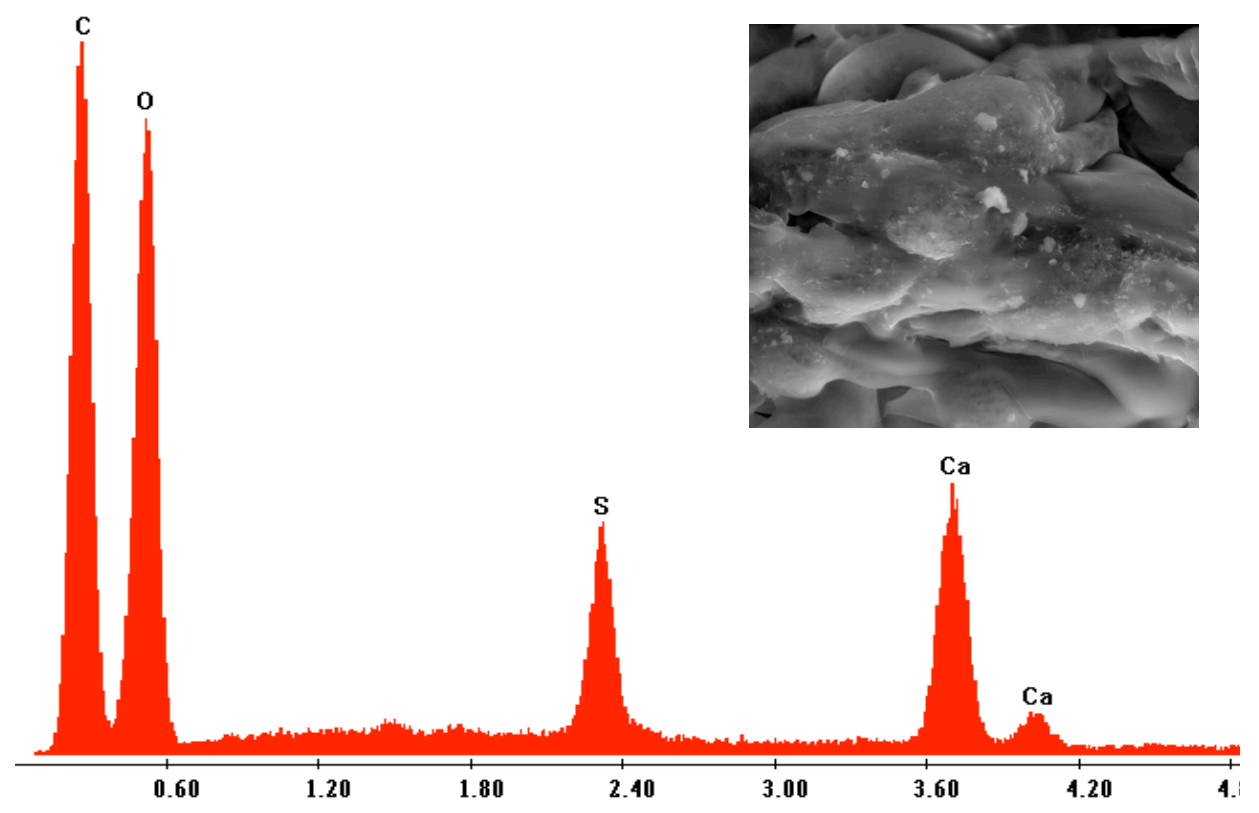

Figura 46. Microanálisis por dispersión de energía de rayos $X$ (EDX), de la micrografia del snack Iso $\mathrm{C}$ a 4000x.

\section{Análisis de las propiedades térmicas}

Analizando las curvas de flujo de calor en función de la temperatura obtenidas por DSC se obtuvieron valores de $\mathrm{T}_{\mathrm{g}}$ de $11^{\circ} \mathrm{C}$ para el control y 75,102 y $68^{\circ} \mathrm{C}$ para las muestras Iso A, Iso $\mathrm{B}$ e Iso $\mathrm{C}$ (Figura 47a).

Estos resultados se relacionaron con el contenido de humedad de las muestras. El uso de isomalt en combinación con maltodextrina llevó a obtener un producto más estable a temperatura ambiente, en comparación con los snacks obtenidos con las soluciones osmóticas de $\mathrm{M}: \mathrm{F}$, las cuales se encontraron alrededor de $45^{\circ} \mathrm{C}$. La $\mathrm{T}_{\mathrm{g}}$ de isomalt en estado anhidro, está por encima de la temperatura ambiente, encontrándose alrededor de $\operatorname{los} 60^{\circ} \mathrm{C}$; la maltodextrina presentó valores alrededor de los $132^{\circ} \mathrm{C}$. 


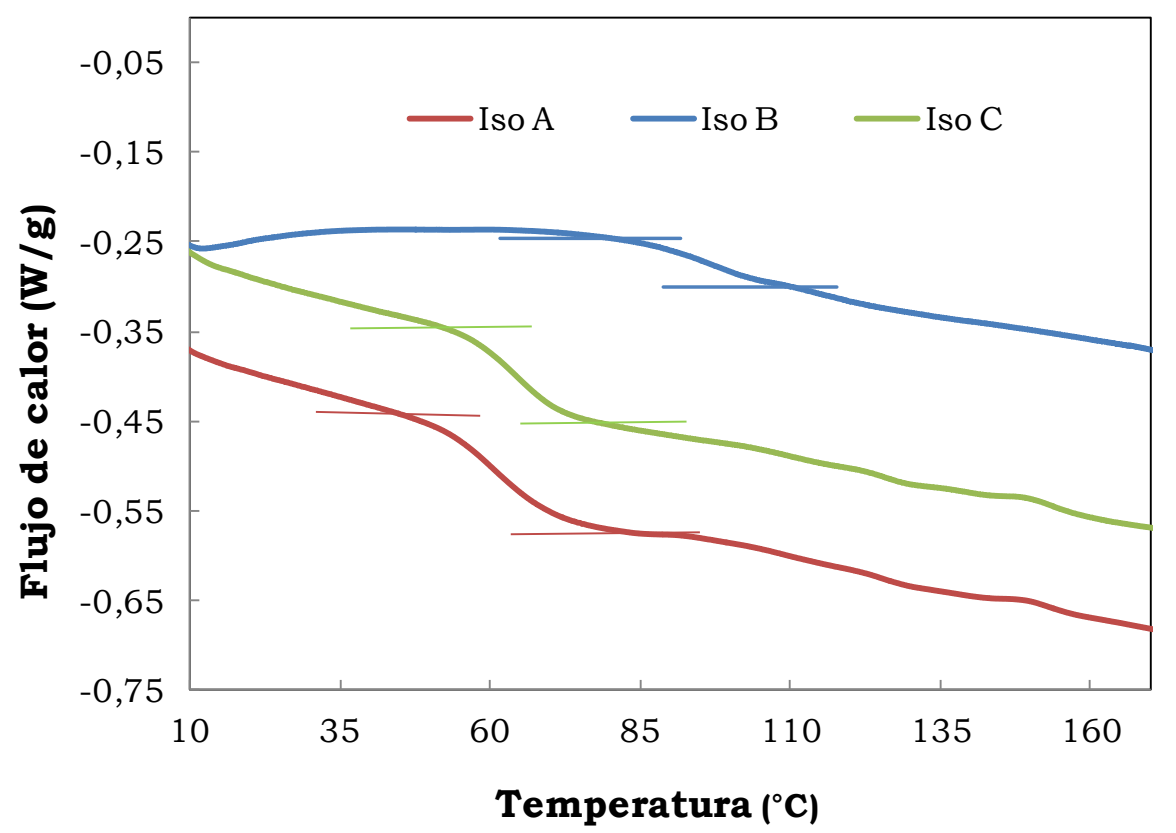

a.

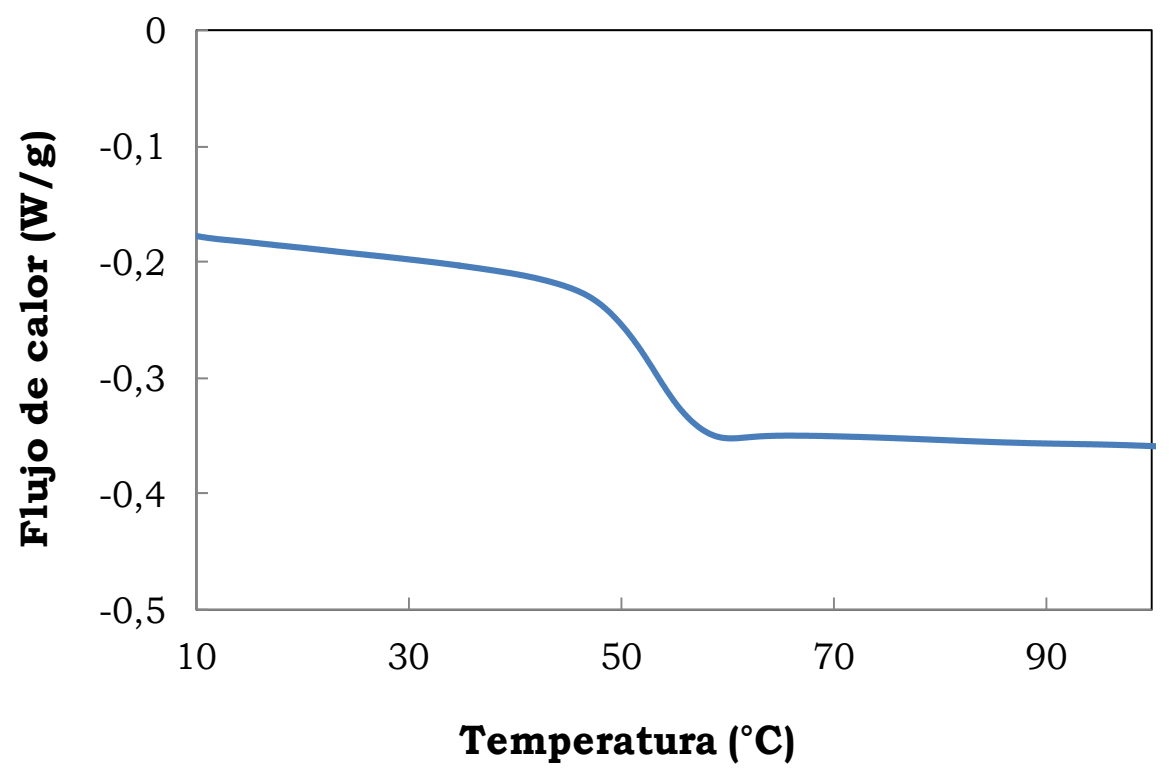

Figura 47. Termogramas obtenidos por DSC para: a. Snacks Iso A, Iso B e Iso C (M:I =1:1, 1:2, 2:1 respectivamente), b. Isomalt en estado anhidro.

Si se tiene en cuenta que los alimentos son sistemas complejos, en los que los dos componentes principales son agua y sólidos totales, resulta válido afirmar que las mezclas de azúcares utilizadas desempeñan un papel importante en la estabilidad del producto. En el caso de los snacks impregnados con M:I se observó el desplazamiento de la $\mathrm{T}_{\mathrm{g}}$ de los snacks obtenidos a valores más altos de temperatura, 
respecto de los snacks donde se utilizaron soluciones osmóticas de M:F. Asimismo el snack Iso $\mathrm{B}$, con mayor contenido de maltodextrina presentó corrimientos hacia valores superiores de temperatura, ampliando el rango de humedad relativa en la que estos productos pueden mantener su calidad en términos de textura. Los resultados obtenidos por DMA mostraron una relajación a bajas temperaturas $(\beta)$ para el snack formulado con M:I de 1:1 (Iso A) en el gráfico de barridos de frecuencia $(\mathrm{Hz})$ (Figura 48). Este comportamiento fue similar a lo observado en el Capítulo 3-Sección 3.4. para el snack $A_{L}$

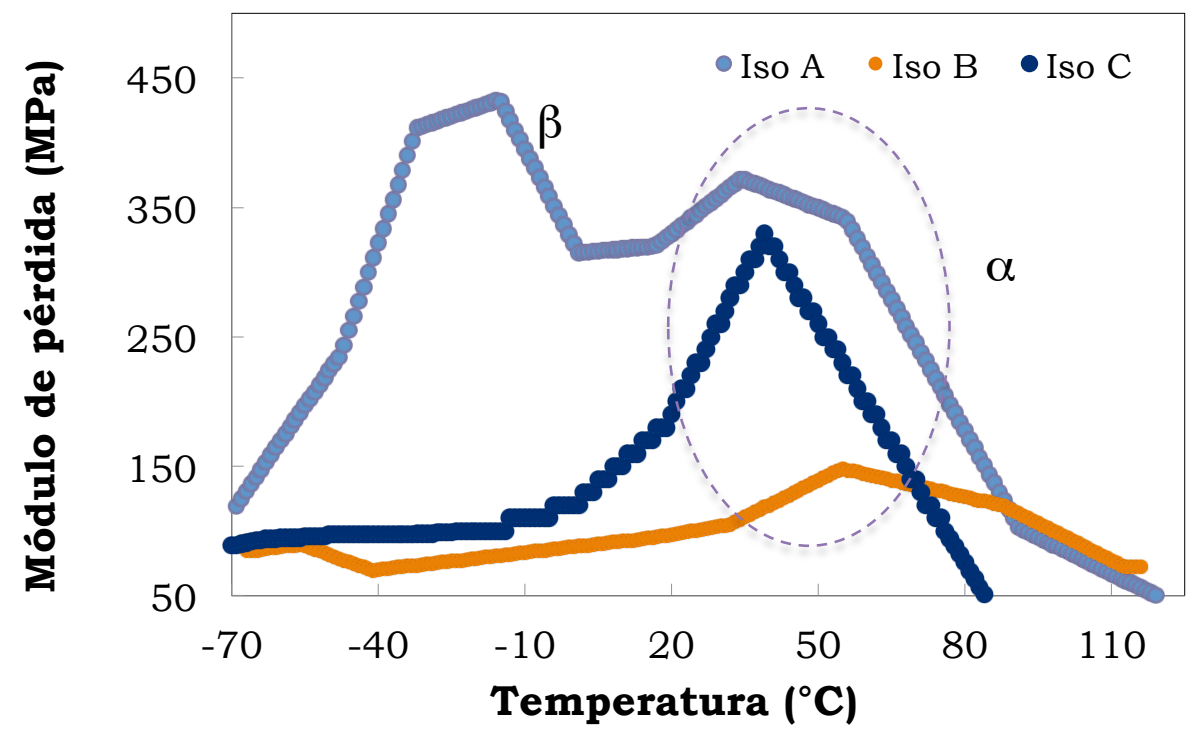

Figura 48. Módulo de pérdida ( $\left.\mathrm{E}^{\prime}\right)(\mathrm{MPa})$ obtenido por DMA a $10 \mathrm{~Hz}$ para los snacks Iso A, Iso B e Iso C.

En cuanto a los valores de $\mathrm{T}_{\mathrm{g}}$, se observó que Iso $\mathrm{A}$ e Iso $\mathrm{C}$ presentaron temperaturas de transición vítrea alrededor de los $40^{\circ} \mathrm{C}$. Para Iso $\mathrm{B}$, la $\mathrm{T}_{\mathrm{g}}$ se ubicó a una temperatura mayor a $50^{\circ} \mathrm{C}$ (línea naranja punteada). Los valores de $\mathrm{T}_{\mathrm{g}}$ obtenidos a partir de las curvas de DSC fueron más altos que los obtenidos por DMA. No fue posible observar la curva de tan delta, debido a una rápida caída de ambos módulos ( $\left.\mathrm{E}^{-} \mathrm{y} \mathrm{E}^{\prime \prime}\right)$. 


\section{Contenido de ácido ascórbico}

La Tabla 19 muestra el efecto del proceso de cocción sobre la cantidad de ácido ascórbico (AA) retenida para ambos, control y snacks.

Tabla 19. Porcentaje de ácido ascórbico retenido antes y después del horneado a $140^{\circ} \mathrm{C}$ en los anillos de manzana tratados con M:I y el control.

\begin{tabular}{cccc}
\hline Muestra & $\begin{array}{c}\text { mg AA/g } \\
\text { (antes horneado) }\end{array}$ & $\begin{array}{c}\text { mg AA/g } \\
\text { (después de horneado) }\end{array}$ & \% retención AA \\
\hline Control & $1,1^{\mathrm{a}}(0,1)$ & $0,20^{\mathrm{a}}(0,07)$ & $18,2^{\mathrm{a}}$ \\
IsoA & $54,5^{\mathrm{b}}(1,9)$ & $25,20^{\mathrm{b}}(0,04)$ & $46,2^{\mathrm{b}}$ \\
IsoB & $55,5^{\mathrm{b}}(1,1)$ & $31,0^{\mathrm{c}}(1,5)$ & $55,9^{\mathrm{c}}$ \\
IsoC & $50,5^{\mathrm{b}}(1,4)$ & $25,7^{\mathrm{b}}(1,6)$ & $50,8^{\mathrm{b}}$ \\
\hline
\end{tabular}

$a, b, c$ Letras diferentes indican diferencias significativas ( $n=3)$

La adición de ácido ascórbico a los anillos de manzana permitió conservar un elevado porcentaje de este micronutriente retenido en los snacks, el cual fue aproximadamente $50 \%$ mientras que para la fruta horneada sin tratamiento (control), resultó ser un 18\%. Además se observó que los snacks formulados con isomalt contenían cantidades similares de vitamina $\mathrm{C}$ a los snacks obtenidos a partir de fructosa. Esto podría deberse a un aumento en la velocidad de evaporación del agua presente en la muestra, ocasionado por aumento en la temperatura y por ende una disminución del tiempo de horneado. En este caso una porción de $20 \mathrm{~g}$ de snack formulado con isomalt cubriría requerimientos exigentes de AA según la Ingesta Diaria Recomendada (RDA). 


\section{Análisis sensorial}

Para todos los atributos analizados los snacks obtuvieron puntuaciones más altas en relación con los atributos del control horneado a $140^{\circ} \mathrm{C}$. Los consumidores otorgaron puntuaciones muy bajas a este control, debido a que presentó un color más intenso, similar a productos muy cocidos (Figura 49 y Tabla 20).

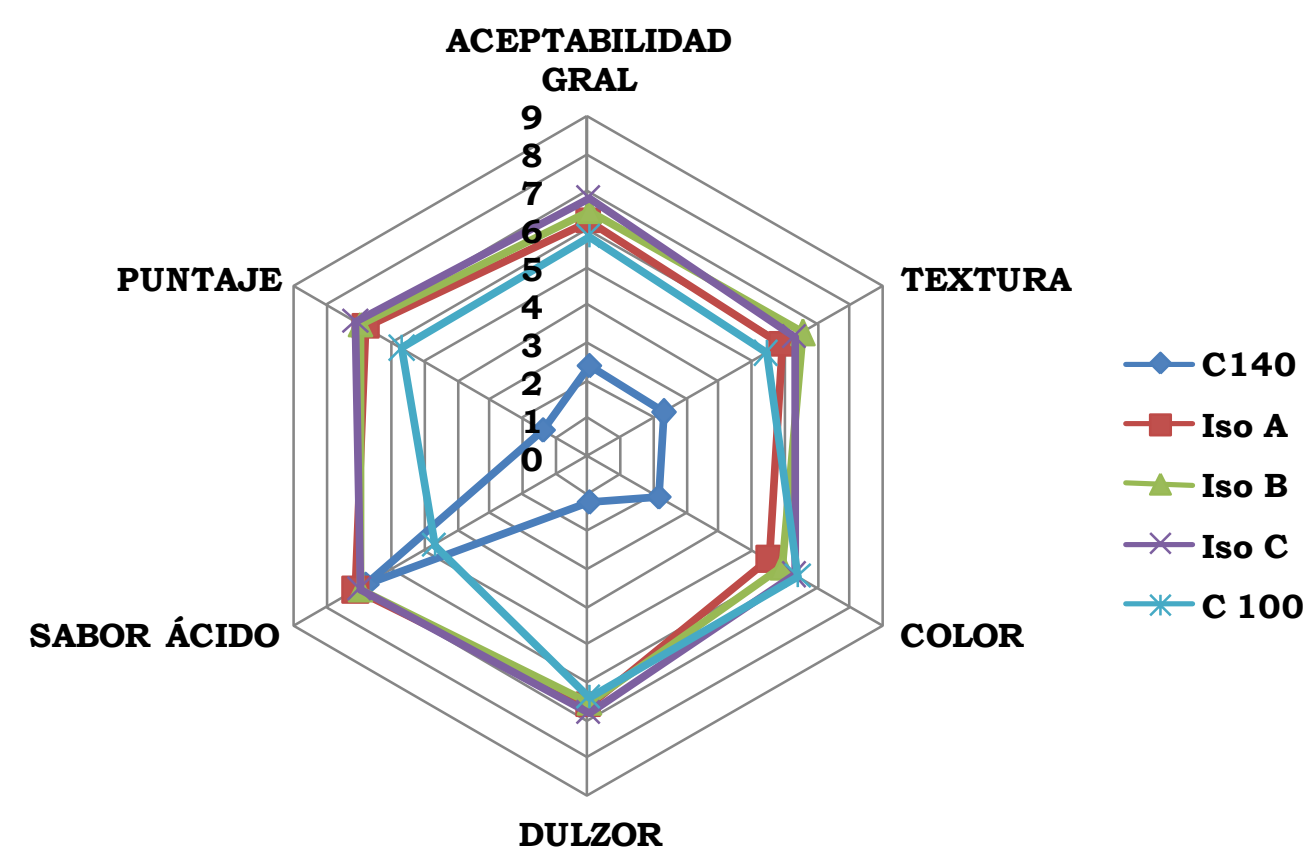

Figura 49. Diagrama radial de los resultados obtenidos para cada atributo en la evaluación sensorial de los snacks Iso A, Iso B e Iso C y los controles horneados a $100^{\circ} \mathrm{C}$ y $140^{\circ} \mathrm{C}$.

El cambio de color producido se explica por el desarrollo de la reacción de caramelización, la cual entre otros productos genera melanoidinas, que son pigmentos pardos (Davies y Labuza, 1997). La alteración del sabor es otro efecto de la reacción, por la generación de compuestos de bajo peso molecular que tienden a dar un gusto amargo a los alimentos sometidos a altas temperaturas (Berlitz y col., 2009). Por esta razón, la comparación también se llevó a cabo con los anillos de manzana horneados a $100^{\circ} \mathrm{C}$ como un control secundario. Los 
consumidores no encontraron diferencias significativas entre los snacks evaluados $(\mathrm{P}>0,05)$ que recibieron mayor puntuación que el control a $100^{\circ} \mathrm{C}$ (Tabla 20). Los puntajes obtenidos para los snacks evaluados se ubicaron en la zona media del gráfico radial entre los valores 6-7.

Tabla 20. Resultados obtenidos del análisis sensorial para el control y los snacks Iso A, Iso B e Iso C

\begin{tabular}{ccccccc}
\hline Snack & Aceptabilidad & $\begin{array}{c}\text { Sabor } \\
\text { ácido }\end{array}$ & Dulzor & Color & Textura & Puntaje \\
\hline $\begin{array}{c}\text { Control } \\
140^{\circ} \mathrm{C}\end{array}$ & $2,4^{\mathrm{a}}(0,3)$ & $2,3^{\mathrm{a}}(0,3)$ & $2,1^{\mathrm{a}}(0,3)$ & $1^{2} 2^{\mathrm{a}}(0,1)$ & $6,8^{\mathrm{b}}(0,2)$ & $1,4^{\mathrm{a}}(0,1)$ \\
Iso A & $6,2^{\mathrm{c}}(0,3)$ & $5,9^{\mathrm{b}}(0,3)$ & $5,5^{\mathrm{b}}(0,3)$ & $6,6^{\mathrm{b}}(0,3)$ & $7,1^{\mathrm{b}}(0,2)$ & $6,8^{\mathrm{c}}(0,2)$ \\
Iso B & $6,5^{\mathrm{c}}(0,3)$ & $6,5^{\mathrm{c}}(0,3)$ & $5,9^{\mathrm{b}}(0,3)$ & $6,5^{\mathrm{b}}(0,3)$ & $7,0^{\mathrm{b}}(0,3)$ & $7,0^{\mathrm{c}}(0,2)$ \\
Iso C & $6,8^{\mathrm{c}}(0,2)$ & $6,3^{\mathrm{c}}(0,3)$ & $6,3^{\mathrm{b}}(0,3)$ & $6,8^{\mathrm{b}}(0,3)$ & $7,0^{\mathrm{b}}(0,3)$ & $7,1^{\mathrm{c}}(0,2)$ \\
$\begin{array}{c}\text { Control } \\
100^{\circ} \mathrm{C}\end{array}$ & $5,8^{\mathrm{b}}(0,2)$ & $5,4^{\mathrm{b}}(0,2)$ & $6,4^{\mathrm{b}}(0,2)$ & $6,4^{\mathrm{b}}(0,3)$ & $4,7^{\mathrm{a}}(0,2)$ & $5,7^{\mathrm{b}}(0,2)$ \\
\hline
\end{tabular}

a, $b, c$ Letras diferentes indican diferencias significativas. *Valores entre paréntesis corresponden a la desviación estándar $(n=50)(P<0,05)$

\section{Análisis por componentes principales (PCA) de los datos sensoriales e instrumental}

Se establecieron relaciones de los datos instrumentales y sensoriales a través de gráficos de PCA (Principal Component Analysis) (Figura 50 a y b) y se compararon las influencias de las distintas variables, obteniéndose las diferencias y/o similitudes entre las muestras o grupos de muestra. Los gráficos de correlación explicaron el análisis sensorial CP1 (componente principal 1) y CP2 (componente principal 2) explicaron el 78 y $21 \%$ de la varianza, respectivamente (Figura 50a). 


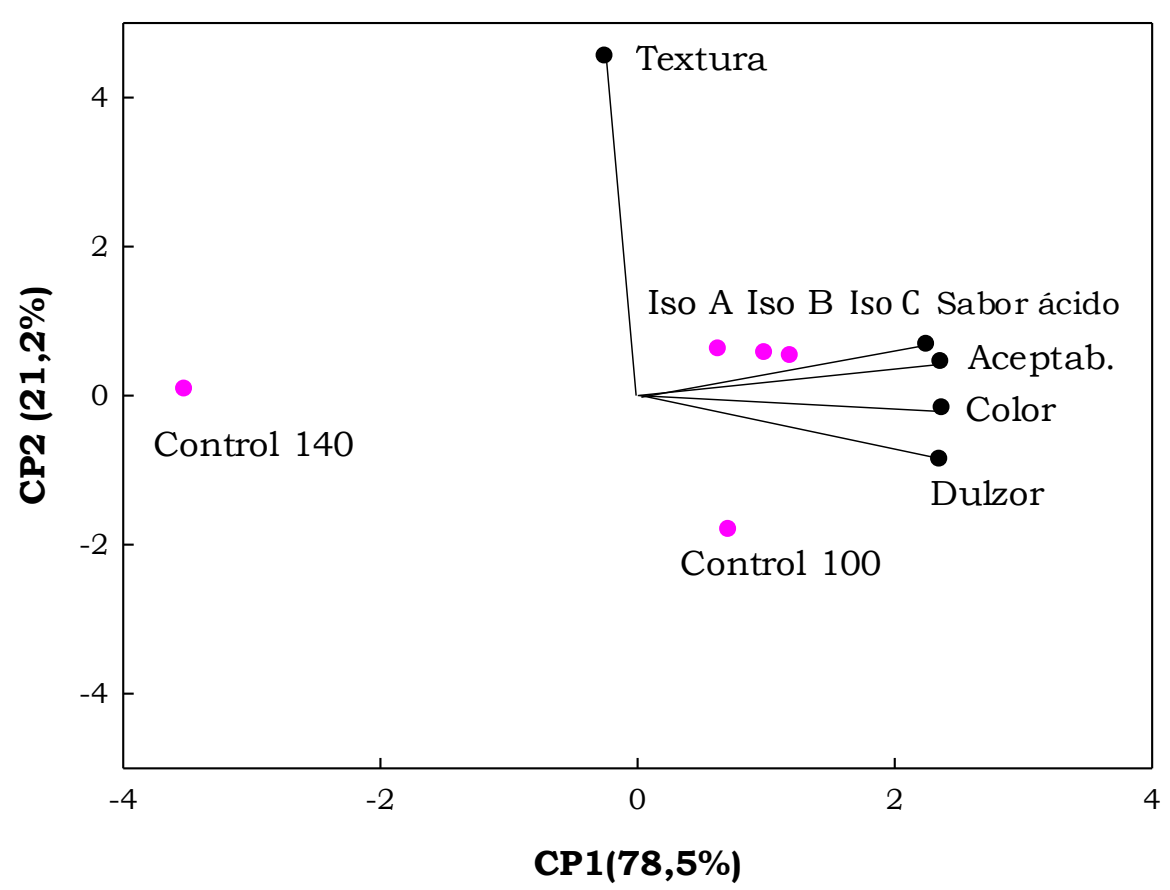

a.

b.

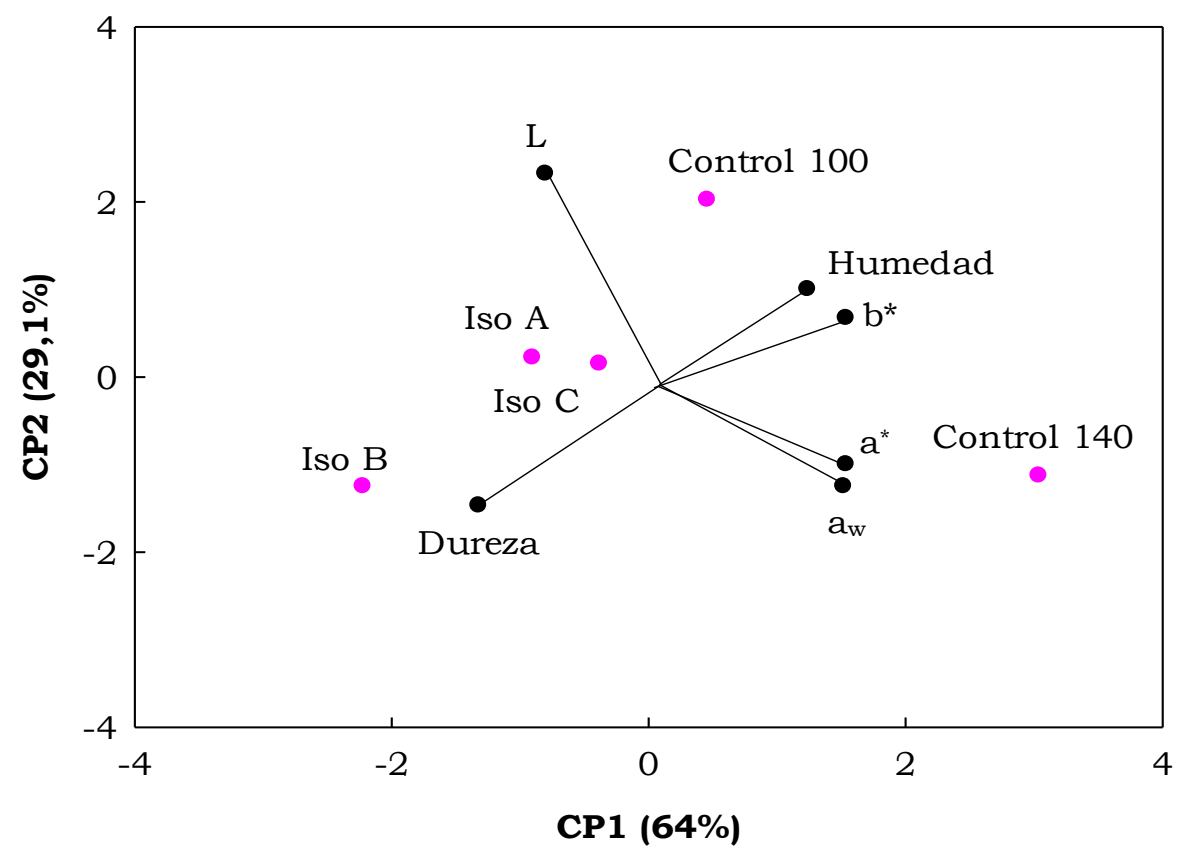

Figura 50. Análisis de componentes principales (PCA) de: a. Parámetros sensoriales y b. Parámetros instrumentales utilizados para diferenciar snacks tratados con M:I y controles horneados a 100 y a $140^{\circ} \mathrm{C}$. 
CP1 representó el 99\% de la apariencia, color y dulzor y 98\% de sabor ácido, mientras que CP2, el 99\% de la textura. Los snacks obtenidos a partir de soluciones de M:I se ubicaron a la derecha del gráfico, lo que indicó que obtuvieron las calificaciones más altas en los atributos evaluados, comparados con los controles. El atributo que caracterizó al control a $100^{\circ} \mathrm{C}$ fue el dulzor. Dado que el control horneado a $140^{\circ} \mathrm{C}$ recibió puntuaciones bajas en todos los atributos excepto en textura, su ubicación fue opuesta a todos los snacks. En la Figura 50 b se observó la relación entre los parámetros instrumentales y los snacks. Los controles se ubicaron próximos a los parámetros de humedad, $\mathrm{a}^{*} \mathrm{y} \mathrm{a}_{\mathrm{w}}$, lo que se correlaciona con los mayores valores obtenidos de estos parámetros experimentalmente. Contrario a los que se observa para los snacks que se ubicaron opuestos a estos atributos en el gráfico. Johnson y col. (2006) estudiaron diversas relaciones de sucralosa/maltodextrina e isomalt como un sustituto de azúcar en magdalenas. Un análisis de componentes principales realizado mostró que los atributos sensoriales de magdalenas preparadas con un $30 \%$ de Splenda Granular (sucralosa) y $70 \%$ de isomalt fueron similares al control con sacarosa $100 \%$.

Teniendo en cuenta que los consumidores no encontraron diferencias significativas para ninguno de los atributos y un mayor contenido de isomalt en la formulación mejoraría las propiedades higroscópicas, se seleccionó el snack Iso C para análisis posteriores.

\section{Análisis de las propiedades funcionales del snack Iso C}

El contenido de calcio del snack Iso C resultó ser de $217 \pm 5$ mgCa/100gms, determinado a través de absorción atómica de las cenizas blancas de la muestra.

\section{Determinación del contenido de azúcares}

Mediante las determinaciones realizadas por HPLC se obtuvo el contenido de fructosa, glucosa, sacarosa e isomalt del snack 
seleccionado. Para cada uno de los azúcares analizados se trazó la curva de calibración y se obtuvo la ecuación de la recta. Para la fructosa (Ec. 12), glucosa (Ec. 13) sacarosa (Ec.14) e isomalt (Ec.15) las concentraciones en $\mathrm{mg} / \mathrm{ml}$ se calcularon a partir de las ecuaciones correspondientes que se describen a continuación:

$$
\begin{array}{ll}
y=69,817 x+3,912\left(R^{2}=0,995\right) & \text { Ec. } 12 \\
y=65,960 x+1,80\left(R^{2}=0,996\right) & \text { Ec. } 13 \\
y=75,843 x-2,075\left(R^{2}=0,990\right) & \text { Ec. } 14 \\
y=28,084 x+2,516\left(R^{2}=0,999\right) & \text { Ec. } 15
\end{array}
$$

Los valores obtenidos para el contenido de carbohidratos fueron $0,20 g_{\text {isomalt }} / g_{m s}, 0,10 g_{\text {fructosa }} / g_{\mathrm{ms}}, 0,06 g_{\text {glucosa }} / g_{m s}$ y 0,02 $g_{\text {sacarosa }} / g_{m s}$. En el snack Iso $\mathrm{C}$ el contenido de azúcares proviene del isomalt agregado y la fructosa de la manzana. En la Tabla 21 se comparan el contenido de carbohidratos de las muestras de manzana fresca y los snacks $A_{L}, A_{C}$ e Iso $C$. 
Tabla 21. Carbohidratos totales y contenido calórico por porción de $100 \mathrm{~g}$ de productos frescos y formulados a base de manzana

\begin{tabular}{lcccccc}
\hline \multicolumn{1}{c}{ Muestra } & $\begin{array}{c}\text { Carbohidratos } \\
\text { totales }\end{array}$ & $\begin{array}{c}\text { Aporte } \\
\text { calórico } \\
\text { (kcal) }\end{array}$ & $\begin{array}{c}\text { Fructosa } \\
\text { (g) }\end{array}$ & $\begin{array}{c}\text { Glucosa } \\
\text { (g) }\end{array}$ & $\begin{array}{c}\text { Sacarosa } \\
\text { (g) }\end{array}$ & Isomalt \\
\hline $\begin{array}{l}\text { Manzana fresca } \\
\text { Granny Smith }\end{array}$ & 10,1 & 40,1 & 6,0 & 3,3 & 0,8 & - \\
Snack AL & 63,0 & 252,0 & 41,0 & 16,0 & 6,0 & - \\
Snack AC & 81,0 & 324,0 & 55,0 & 17,0 & 9,0 & - \\
Snack Iso C & 38,0 & 112,0 & 10,0 & 6,0 & 2,0 & 20,0 \\
\hline
\end{tabular}

Teniendo en cuenta que isomalt aporta sólo $2 \mathrm{kcal} / \mathrm{g}$, Iso C sería un producto reducido en calorías con relación a los snacks formulados con fructosa. McKemie (2008) informó resultados similares de un producto tipo "muffin" reemplazando la sacarosa por una mezcla de 30\% de Splenda Granular ${ }^{\circledR}$ (sucralosa) y 70\% de isomalt. Con este reemplazo obtuvo una reducción del 30\% de azúcares, lo cual permitió que el producto fuese declarado "reducido en azúcares".

\section{Determinación de actividad antioxidante}

Para obtener valores comparables de actividad antioxidante, se graficó el porcentaje (\%) de Inhibición del radical $\mathrm{DPPH}$ frente a las concentraciones de $\mathrm{mg}$ Snack/ $\mathrm{ml}$ extracto (Figura 51) 


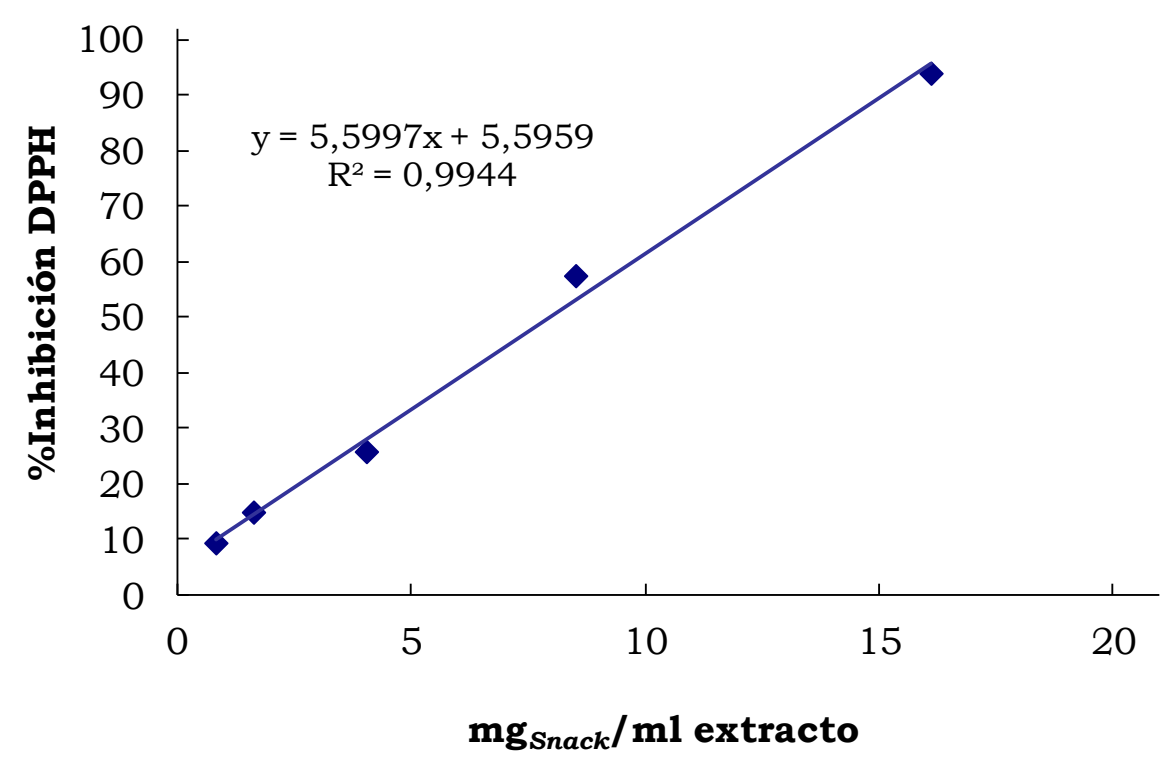

Figura 51. Curva de \% Inhibición de DPPH para el extracto de snacks Iso C.

Los resultados obtenidos por DPPH mostraron una alta actividad antioxidante correspondiente a una reducción del 95\% del radical DPPH para una concentración de $80,5 \mathrm{mg}$ Iso $\mathrm{C} / \mathrm{ml}$ del extracto etanólico. A partir de la ecuación de la recta obtenida se calculó la concentración necesaria para inhibir en un 50\% el radical DPPH, la cual resultó ser $7,9 \mathrm{mg}$ Iso $\mathrm{C} / \mathrm{ml}$ extracto. Teniendo en cuenta que $1 \mathrm{~g}$ de snack Iso $\mathrm{C}$ contenía aproximadamente 25,7 mg AA, se obtuvo un valor de EC $_{50}$ de $0,2 \mathrm{mg} \mathrm{AA} / \mathrm{ml}$ extracto. Estos resultados fueron similares a los obtenidos para los snacks formulados con fructosa y se correlacionaron con la cantidad de ácido ascórbico presente en la muestra. Esto permite afirmar que el snack formulado con isomalt tiene una alta actividad antioxidante en términos del ácido ascórbico agregado.

\subsection{CONCLUSIONES}

La presencia de isomalt permitió el horneado a altas temperaturas durante un corto tiempo sin detrimento de la calidad organoléptica y nutricional. Se obtuvo un producto innovador dado que aún no se ha utilizado isomalt en la formulación de snacks. 
Teniendo en cuenta que un mayor contenido de isomalt en la formulación mejoraría las propiedades higroscópicas, se seleccionó la solución de impregnación formulada con 20\% de isomalt y $10 \%$ de maltodextrina. El producto obtenido (Snack Iso C) presentó un buen balance en el contenido de azúcares (menor contenido de calorías) y buena actividad antioxidante.

Los snacks de manzana e isomalt presentaron valores de $\mathrm{T}_{\mathrm{g}}$ más altos respecto al control horneado y a los snacks obtenidos a partir de las formulaciones de fructosa y maltodextrina, con lo cual sería un producto menos susceptible a cambios en la temperatura y/o humedad de almacenamiento.

El snack Iso C, obtenido a partir de M:I (1:2) podría ser considerado un producto reducido en calorías. Este producto podría ser una buena alternativa para mantener una dieta rica en calcio y antioxidantes como la vitamina $\mathrm{C}$, sin agregar calorias a la dieta.

\subsection{REFERENCIAS}

Berlitz, H.D., Grosch, W., Schieberle, P. (2009). Food Chemistry, 4th revised and extended ed. 2009, XLIV, 1070 p. Berlin,Alemania: Springer-Verlag.

Cruz, M.T, Gallardo, N., Sánchez, R. (1994). Obtención de maltodextrinas por hidrólisis enzimática, Información Tecnológica, 5(1): 75-80.

Davies, C.G.A, Labuza, T.P. (1997). The Maillard Reaction: Application to Confectionery Products. Department of Food Science and Nutrition University of Minnesota, St. Paul, Minnesota, 55108.

Ghosh, S., Sudha, M. L. (2012). A review on polyols: new frontiers for health-based bakery products. International Journal of Food Sciences and Nutrition, 63(3): 372-379. 
Hodge, J., Osman, E. (1976). Carbohydrates. En: Principles of Food Science. Part I. En: Food Chemistry. O. Fennema, New York, Marcel Dekker. 41-138.

Jalaee, F., Fazeli, A., Fatemian, H., Tavakolipour, H. (2011). Mass transfer coefficient and the characteristics of coated apples in osmotic dehydrating. Food and Bioproducts Processing, 89: 367-374.

Jonker, D., Lina, B.A.R., Kozianowski, G. (2002). Week oral toxicity study with isomaltulose (Palatinose) in rats. Food Chemistry Toxicology, 40: 1383-1389.

Johnson, H.A., Swanson, R.B., Savage, E.M. (2006). Descriptive sensory analysis of yellow cupcakes prepared with nutritive and high intensity sweeteners. Journal of American Dietetic Association, 105(8): A48.

Krokida, M.K., Oreopoulou, V., Maroulis, Z.B.,Marinos-Kouris, D. (2001b). Effect of Pre-Treatment on Viscoelastic Behaviour of Potato Strips. Journal of Food Engineering, 50: 11-17.

Martinez-Cervera, S., Salvador, A., Sanz, T. (2014). Comparison of different polyols as total sucrose replacers in muffins: Thermal, rheological, texture and acceptability properties. Food Hydrocolloids, 35: $1-8$.

McKemie, R.J (2008). Functionality of sucralose/maltodextrin: isomalt blends in oat meal and chocolate chip cookies. B.S., Georgia Southern University.

McCormick, C., Prokes, S. (2009). Molecular Gastronomy: Materials Science in the Kitchen. MRS Bulletin, 34: 802-803. doi: $10.1557 / \operatorname{mrs} 2009.224$.

Olinger, P.M., Velasco, VS. (1996). Opportunities and advantages of sugar replacement. Cereal Foods World, 41(3): 110-117. 
Peinado I., Rosa E., Heredia A., Escriche, I., Andrés A. (2013) Influence of processing on the volatile profile of strawberry spreads made with isomaltulose. Food Chemistry, 138: 621-629.

Perera, C.O. (2005). Selected Quality Attributes of Died Foods. Drying Technology, 23: 717-730.

Rodríguez, V.M, Magro, E.S. (2008). Bases de la alimentación humana. ISBN 980-84-9745-215-1, Ed. Gesbiblo, S.L, España, 170171.

Ronda, F., Gómez, M., Blanco, C.A., Caballero, P. (2005). Effects of polyols and nondigestible oligosaccharides on the quality of sugar-free sponge cakes. Food Chemistry, 90: 549-555.

Romano, N., Tavera-Quiroz, M.J., Bertola, N., Mobili, P., Pinotti, A., Gómez-Zavaglia, A. (2014). Edible methylcellulose-based films containing fructo-oligosaccharides as vehicles for lactic acid bacteria. Food Research International, 64: 560-566.

Tavera-Quiroz, M.J., Urriza, M., Pinotti, A., Bertola, N. (2014). Development and characterization of a baked snack from rings of green apples. Food and Bioprocess Technology, 7: 2218-2227.

Vincent, J. F. (1998). The quantification of crispness. Journal of the Science of Food and Agriculture, 78: 162-168. 
CAPITULO 5.

\section{ANÁLISIS DE CALIDAD DE LOS SNACKS \\ SELECCIONADOS: Estabilidad durante el \\ almacenamiento y tiempo de vida útil}





\subsection{CONSIDERACIONES GENERALES}

La principal característica de los productos tipo snacks es su textura crujiente, siendo uno de los indicadores de calidad más importantes en el producto final. Otros parámetros que están estrictamente relacionados con la percepción de los consumidores son el color, el sabor y la estabilidad de los mismos durante el almacenamiento (Mendoza, 2007). Entre las distintas técnicas de deshidratación, el horneado y la fritura se utilizan tradicionalmente en la industria alimentaria, ya sea para desarrollar texturas, sabores y aromas únicos, como para aumentar la vida útil de los alimentos. En Capitulos anteriores se desarrollaron snacks a base de manzana elaborados mediante estas técnicas, incluyendo nutrientes importantes en la dieta durante la producción. Sin embargo, es necesario considerar el efecto de las altas temperaturas de los procesos de deshidratación en los atributos de calidad, que pueden desarrollar reacciones de deterioro e inducir a pérdida nutricional y organoléptica (Heldman y Lund, 2007).

La deshidratación de los alimentos induce a cambios microestructurales como encogimiento, porosidad, colapso, fractura y endurecimiento superficial (case hardening) (Aguilera, 2003), que determinan las propiedades sensoriales del producto final. Estas características son altamente dependientes del tipo de proceso y de la matriz alimentaria (Aguilera y Stanley, 1999). En el caso de la fritura por inmersión, Miranda y Aguilera (2006) describen cambios físicos y químicos, incluyendo la cristalización de la celulosa, degradación de pectina y gelatinización del almidón, que provocan cambios microestructurales en papas por las altas temperaturas. Los autores concluyen que la lamela media se desintegra y que los gránulos de almidón gelatinizan a temperaturas entre 60 y $80^{\circ} \mathrm{C}$, provocando que las células se separen y que la textura se suavice, mientras que la exposición a temperaturas mayores de $100^{\circ} \mathrm{C}$ causaría la formación de una costra seca de color marrón. Durante el secado con aire caliente, las altas temperaturas producen colapso de la estructura, generando 
productos con texturas más firmes y crocantes, que se rehidratan lentamente (Perera, 2005). En general la estabilidad hace referencia a la acción del producto bajo determinadas condiciones de prueba y el monitoreo del producto hasta su vencimiento. Además del tipo de cocción que se realice, las características intrínsecas del alimento son un factor importante a evaluar. Las propiedades mecánicas son especialmente importantes en alimentos de baja humedad con estructura celular o porosa, ya que están caracterizados por su textura crocante, relevante para su aceptabilidad sensorial. Cuando estos productos absorben agua se produce una pérdida de crocancia y un ablandamiento de los mismos afectando sus características sensoriales.

En la industria se suelen realizar ensayos de almacenamiento para determinar el tiempo de vida de anaquel de un alimento. Pueden llevarse a cabo bajo condiciones medio ambientales de temperatura y humedad, buscando evaluar la estabilidad básica del alimento o para determinar si el producto soportará un almacenamiento prolongado. Se pueden realizar pruebas aceleradas de vida útil, consistentes en colocar el producto bajo condiciones de temperatura y humedad relativa menores o mayores a lo que normalmente se emplearia.

Un producto tipo snack presenta diferentes formas de deterioro, entre las cuales se destacan la ganancia de humedad, oxidación de lípidos, pérdida de vitaminas, modificaciones de su textura, degradación del aroma. Los productos de este tipo comienzan a degradarse desde que son producidos. El oxígeno, la humedad y la temperatura ambiente favorecen distintas reacciones en el alimento, las cuales pueden ser de acción enzimática, microbiológicas o fisicoquímicas (pérdida o aumento de la humedad, oxidaciones). Los factores que más influyen en el tiempo de vida útil son:

- Humedad: los productos tipo snack, son altamente higroscópicos y se recomienda envasarlos una vez que alcanzan la temperatura 
ambiente. Durante este periodo, el contenido de agua se incrementa en aproximadamente $1 \%$ debido a la humedad ambiente. Lara (1999) informó que un incremento entre 1 y $2 \%$ en la humedad resulta positivo, puesto que se incrementa el peso, no se afecta la textura crocante y en algunos casos puede retardar la rancidez.

- Actividad de agua $\left(\mathrm{a}_{\underline{w}}\right)$ : este parámetro es importante porque se encuentra relacionado con la ganancia o pérdida de humedad, crecimiento de microorganismos y cinética de degradación de nutrientes. Las isotermas de sorción muestran la relación entre el contenido de agua y la actividad acuosa del mismo.

La calidad de los productos de este tipo depende también del envase que se utilice teniendo en cuenta la tasa de transmisión de vapor y la integridad en el sellado del mismo, entre otros aspectos. El deterioro del alimento puede ser controlado por la barrera que genera el envase. El objetivo del envasado es llevar el producto al consumidor final en óptimas condiciones. Por ejemplo, los chips de papa tienen una vida útil media de alrededor 75 dias, dependiendo de las temperaturas de almacenamiento, los materiales de envasado y/o la exposición a la luz directa o al aire (Gould, 1999). Los envases son utilizados para evitar cambios en el producto tales como:

- Pérdida de crocancia: el envase debe proveer una barrera al vapor de agua ambiente.

- Oxidación lipídica: en el caso de productos fritos, es importante que el envase proteja de la entrada de luz y oxígeno.

Para los productos tipo snack se pueden utilizar materiales de envasado que pueden ser films flexibles, semirrígidos o rígidos y deben cumplir con ciertas características. Entre estas propiedades las que se destacan un buen sellado y brillo, sin fugas, ni fallas, de suficiente 
rigidez para soportar la manipulación en el transporte, protección contra la humedad, impermeabilidad al oxígeno, barrera a la luz, entre otras. Los envases más utilizados son el polietileno de alta densidad, cloruro de polivinilo, polipropileno, poliestireno, poliéster, entre otros.

El tiempo transcurrido hasta la pérdida de la calidad física, química y sensorial es el tiempo de vida útil (Speigel, 1989). En la industria alimentaria la estabilidad de un alimento depende del cambio que sufren sus ingredientes, del proceso de manufactura, del material de envasado, de los gases circundantes y la distribución del producto en el mercado. Por esta razón es importante realizar un estudio detallado del alimento en el tiempo sometido a distintas condiciones y así establecer el tiempo óptimo en el cual el producto ofrece máxima calidad.

En Capitulos anteriores, se desarrollaron tres tipos de snacks a partir de anillos de manzana siendo los obtenidos por horneado aquellos que constituyeron la opción más saludable. En este capítulo se evaluaron las condiciones de estabilidad de los snacks horneados seleccionados ( $A_{L}$ e Iso $\left.C\right)$ en el tiempo, a través de medidas instrumentales. Los snacks obtenidos por fritado fueron descartados porque presentaron colapso estructural y alto contenido graso.

\section{Objetivos}

Observar la influencia de los carbohidratos utilizados en cada formulación sobre las propiedades mecánicas y la higroscopicidad de snacks horneados.

Determinar los parámetros de estabilidad de las muestras a través de la isoterma de sorción, observando el efecto de la ganancia de humedad y la variación de la temperatura de transición vítrea sobre la humedad en equilibrio. 
Calcular el tiempo de vida útil de los snacks envasados durante el almacenamiento, teniendo en cuenta los cambios de textura, $a_{w}$, humedad, y contenido de ácido ascórbico en el tiempo.

Teniendo en cuenta los objetivos planteados el Capítulo 4 se dividió en dos secciones:

1. Influencia de los carbohidratos en las propiedades mecánicas, higroscopicidad e isoterma de sorción de los snacks $A_{L}$ e Iso C.

2. Almacenamiento de los snacks 


\subsection{INFLUENCIA DE LOS CARBOHIDRATOS EN LAS PROPIEDADES MECÁNICAS, HIGROSCOPICIDAD E ISOTERMA DE SORCIÓN DE LOS SNACKS A $A_{L}$ ISO C}

\section{MATERIALES Y MÉTODOS}

\subsubsection{MATERIALES}

Los snacks $\mathrm{A}_{\mathrm{L}}$ e Iso $\mathrm{C}$ se obtuvieron como se detalló en los Capítulos anteriores. Para el ensayo de las propiedades mecánicas por DMA, las manzanas horneadas se cortaron según las dimensiones de la probeta estándar (60 × 13 × $3 \mathrm{~mm})$.

\subsubsection{MÉTODOS}

\subsubsection{Análisis de las propiedades mecánicas de los snacks por DMA}

Las propiedades mecánicas de los snacks $\mathrm{A}_{\mathrm{L}}$ e Iso $\mathrm{C}$, se analizaron a través de ensayos de esfuerzo - deformación por DMA, utilizando un dual cantilever (Figura 52).

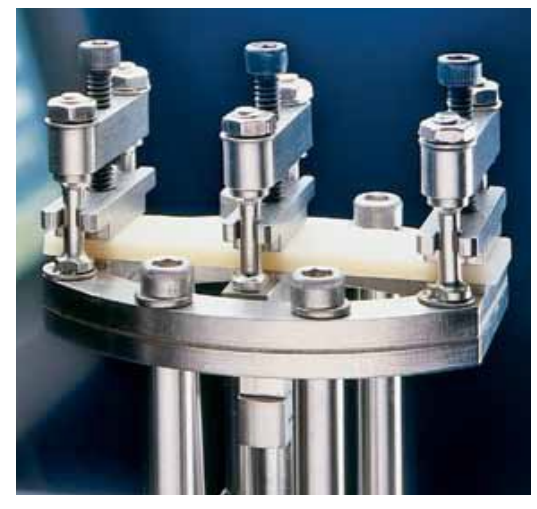

Figura 52. Fotografia del "dual cantilever" utilizado en el ensayo esfuerzodeformación en el equipo DMA Q800.

Las muestras obtenidas fueron equilibradas a $25{ }^{\circ} \mathrm{C}$ en una atmósfera de $\mathrm{N}_{2}$. Se mantuvo una isoterma durante $3 \mathrm{~min}$ a esta temperatura. Para obtener las curvas de tensión-deformación se aplicó una rampa de fuerza constante de 0,3 $\mathrm{N} / \mathrm{min}$ hasta la ruptura de la muestra. Se analizaron 10 muestras de cada snack. 


\subsubsection{Evaluación de la higroscopicidad}

La higroscopicidad es la capacidad que tiene el producto, para absorber la humedad ambiente. En el caso de productos secos obtenidos a partir de frutas, la glucosa y fructosa son los responsables de la fuerte interacción con las moléculas de agua debido a las terminales polares que presentan estas moléculas, las cuales le brindan mayor afinidad por el agua (Jayas y Das, 2004). Con el fin de evaluar la higroscopicidad de los snacks, se colocaron muestras de $A_{L}$ e Iso $\mathrm{C}$, recién preparadas, sin envasar, en recipientes cerrados herméticamente, los cuales previamente se saturaron con $\mathrm{NaBr}$ para lograr una humedad relativa ambiente de 60\%. En cada recipiente se colocaron placas de Petri conteniendo 10 snacks cada una. Los recipientes se almacenaron en una cámara a $20^{\circ} \mathrm{C}$. Se registró el aumento de peso de las muestras durante 30 días. La higroscopicidad (\%HG) se calculó a partir de la ecuación de Jaya y Das (2004) (Ec.16), expresada como:

$$
\% H G=\frac{b+H}{a-H} \times 100 \quad \text { Ec. } 16
$$

Donde, $\mathrm{b}$ es el aumento de peso en el tiempo (g), a es el peso inicial de la muestra (g) y $\mathrm{H}$ es el contenido de agua inicial de las muestras (g).

\subsubsection{Isoterma de sorción}

El agua contenida por un alimento ejerce una presión de vapor que es menor que la del agua pura a la misma temperatura que el alimento. La actividad acuosa $\left(\mathrm{a}_{\mathrm{w}}\right)$ es igual a la razón de la primera sobre la segunda presión. La isoterma de adsorción de humedad es la expresión de la relación funcional existente entre el contenido de humedad de un alimento (expresado como gagua/gss) y la actividad acuosa. El deterioro que acontece en los alimentos depende fuertemente 
de este parámetro. Los cambios que se producen incluyen el colapso de la estructura física, crecimiento microbiano, reacciones enzimáticas, pardeamiento no enzimático y peroxidación de lípidos. El "mapa" de estabilidad de los alimentos, propuesto por Labuza (1971) resume estos cambios. En este mapa se aprecia que el punto de máxima estabilidad de cualquier alimento es el de la monocapa. La comprensión de las isotermas de adsorción de humedad de alimentos es importante para el diseño y optimización de procesos industriales como el secado, envasado y almacenamiento. Por esta razón es crucial para modelar los cambios de humedad que tienen lugar durante la deshidratación y predecir la estabilidad y la vida útil de un producto (Jamali y col., 2006).

En este trabajo muestras de $1 \mathrm{~g}$ de cada tipo de snack se dispusieron en recipientes cerrados, sin circulación de aire, con diferentes atmósferas de sales saturadas: $\mathrm{LiCl}, \mathrm{MgCl}_{2}, \mathrm{~K}_{2} \mathrm{CO}_{3}, \mathrm{NaCl}, \mathrm{KCl}$ y $\mathrm{K}_{2} \mathrm{SO}_{4}$, que dan valores de humedad relativa $(\mathrm{RH})$ 11, 33, 43, 75, 85 y $97 \%$, respectivamente. El ensayo se realizó a $20 \pm 2{ }^{\circ} \mathrm{C}$, de acuerdo con la metodologia descrita por Demarchi y col. (2013).

Todas las isotermas se determinaron por triplicado. Las muestras se pesaron a intervalos regulares hasta alcanzar un peso constante. La actividad de agua se determinó por dos métodos, el método gravimétrico estático (por diferencia de peso hasta llegar al equilibrio) y el higrométrico mediante la medida del parámetro con el equipo Aqualab (Capítulo 3-sección 3.3). Una vez que se alcanzó el equilibrio de saturación de humedad, se realizó la determinación del contenido de agua de las muestras en estufa de vacío a $70^{\circ} \mathrm{C}$, hasta peso constante. Con estos datos se construyeron las correspondientes isotermas de sorción. Se ajustaron los datos experimentales mediante el modelo de GAB (Guggenheim-Anderson-de Boer). Se asumió que se había alcanzado el equilibrio cuando las variaciones en el contenido de 
humedad fueron menores a 0,003 gagua/gms. El modelo de GAB, fue expresado como:

$$
W=\frac{W m C \mathrm{~K} \text { aw }}{(1-\mathrm{K})(1-\mathrm{K} \mathrm{aw}+\mathrm{C} \mathrm{K} \text { aw })}
$$

Donde, W es la humedad de equilibrio a una actividad acuosa dada, $\mathrm{W}_{\mathrm{m}}$ es el contenido de humedad de la monocapa (gagua /gms) y C y K, parámetros de equilibrio dinámico de sorción.

Adicionalmente se evaluaron la textura y la temperatura de transición vítrea de cada una de las muestras una vez alcanzado el equilibrio.

\subsubsection{Análisis estadístico}

Para cada ensayo los resultados obtenidos fueron evaluados estadísticamente a través del software SYSTAT (SYSTAT, Inc., Evanston, IL, EE.UU.) (Wilkinson, 2000), mediante análisis de varianza (ANAVA). Cuando los datos presentaron diferencias entre sí, se realizó la comparación de medias mediante el test de LSD de Fisher a un nivel de significación de $\mathrm{P}<0,05$.

\subsubsection{RESULTADOS Y DISCUSION}

\section{Influencia de los carbohidratos en las propiedades mecánicas}

Mediante DMA se obtuvieron las curvas de fuerza estática en función de la deformación (\%) de los snacks $A_{L}$ e Iso C. Con el fin de comparar las propiedades mecánicas de ambas muestras, en condiciones controladas de temperatura y humedad, se graficaron los promedios de la fuerza estática $(\mathrm{N})$ y \% de deformación en el punto de ruptura (Figura 53 a y b). 


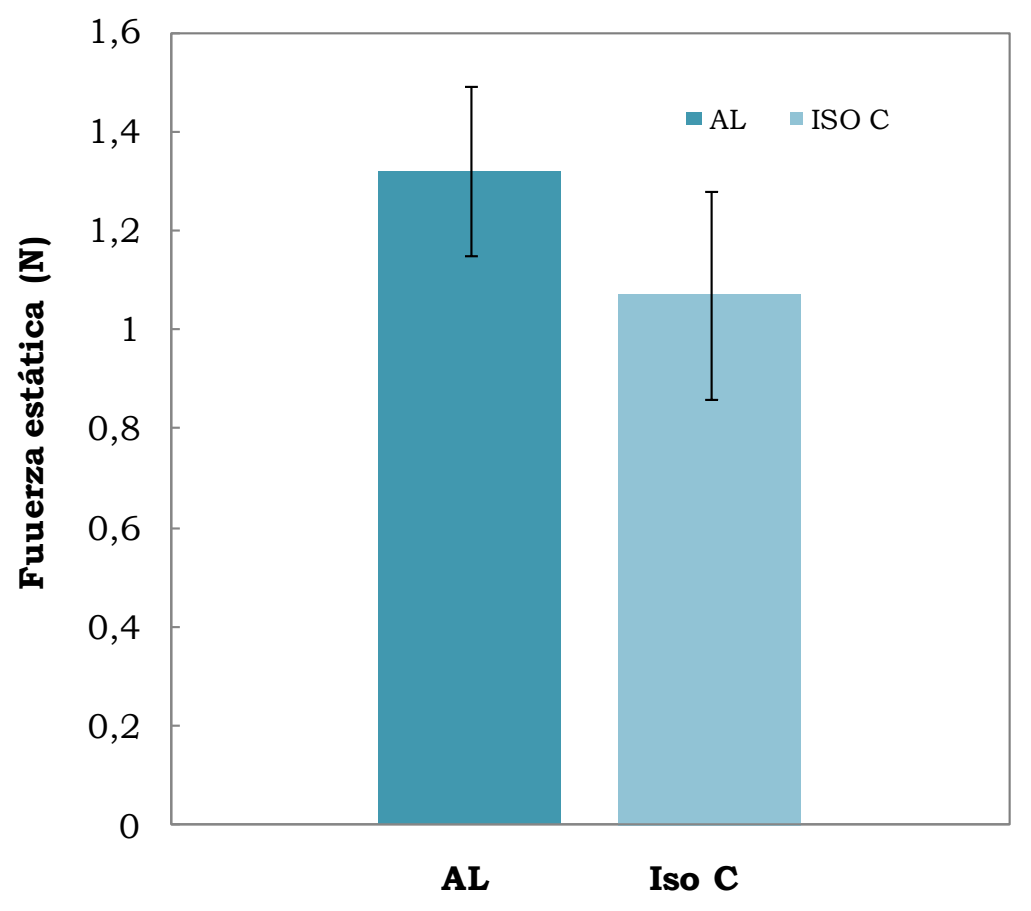

a.

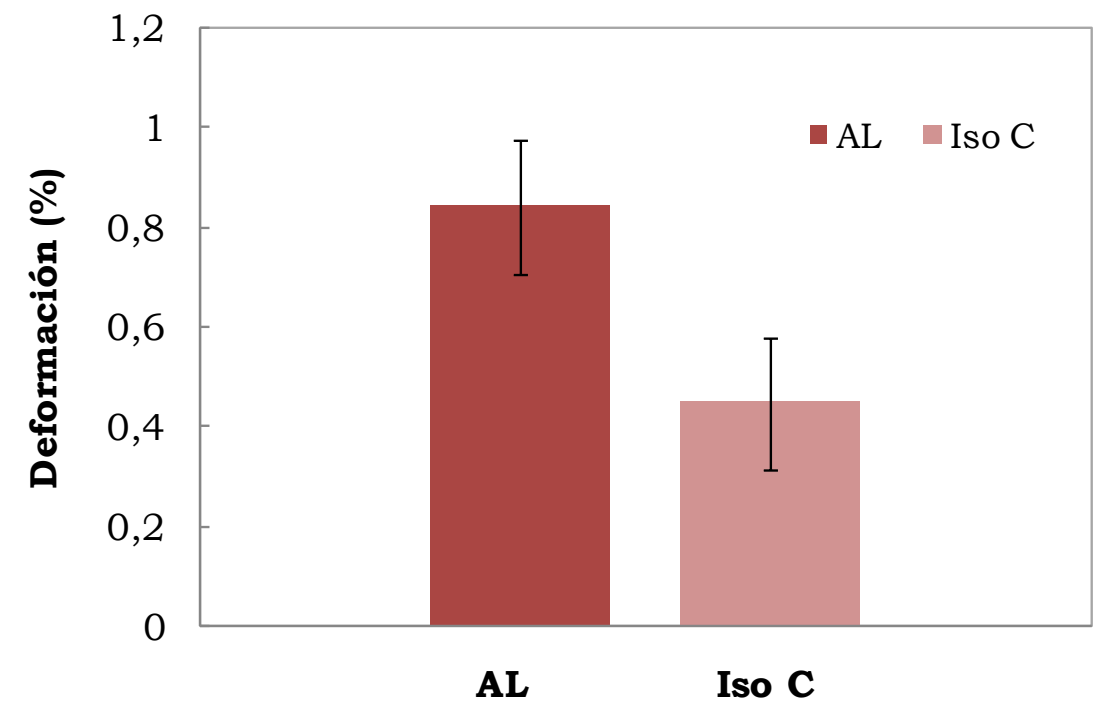

b.

Figura 53. Promedio de los valores obtenidos del ensayo de esfuerzodeformación isotérmico para los snacks $A_{L}$ e Iso C: a. Fuerza estática, b. \% de deformación de la muestra antes de la ruptura.

Se observó que si bien la fuerza necesaria para romper las muestras resultó similar para ambos snacks, la muestra $A_{L}$ se deformó aproximadamente un 35\% más que el snack Iso C, antes de llegar a la ruptura. Cuando una carga constante se aplica a un material, pueden 
ocurrir diferentes tipos de eventos que dan idea de las propiedades viscoelásticas del mismo. De acuerdo a la forma como se comportan los materiales se pueden clasificar como elásticos ideales, que no se relajan; viscosos ideales, que muestran una relajación instantánea; sólidos viscoelásticos, que relajan gradualmente $\mathrm{y}$ alcanzan un equilibrio a un estrés mayor que 0; mientras que para fluidos viscoelásticos, el estrés cae a cero (Steffe, 1992; Menard, 1999a).

En este ensayo en particular se observó que para ambos snacks hubo un aumento del estrés, hasta que la muestra alcanzó una deformación tal que el material cedió y alcanzó la ruptura, lo que indicó que ambos snacks respondieron como materiales viscoelásticos. Qian y col. (2010) realizaron ensayos mecánicos similares en muestras de batata y concluyeron que las curvas obtenidas responden a materiales de este tipo.

Para $A_{L}$ la ruptura se alcanzó a una mayor deformación, mientras que Iso $\mathrm{C}$ alcanzó la ruptura con menor esfuerzo y menor deformación de la muestra. Esto se podría relacionar con la plasticidad debida a la interacción del ambiente y los azúcares presentes.

\section{Higroscopicidad de los snacks $A_{L}$ e Iso C}

En la Figura 54 se observa que el snack formulado con fructosa alcanzó el equilibrio aproximadamente en 15 dias en un ambiente de humedad relativa (HR) de $60 \%$ y a $20{ }^{\circ} \mathrm{C}$, mientras que para el snack con isomalt, a partir de los 3 dias de almacenamiento no se observaron cambios significativos en la ganancia de peso a lo largo del tiempo. 


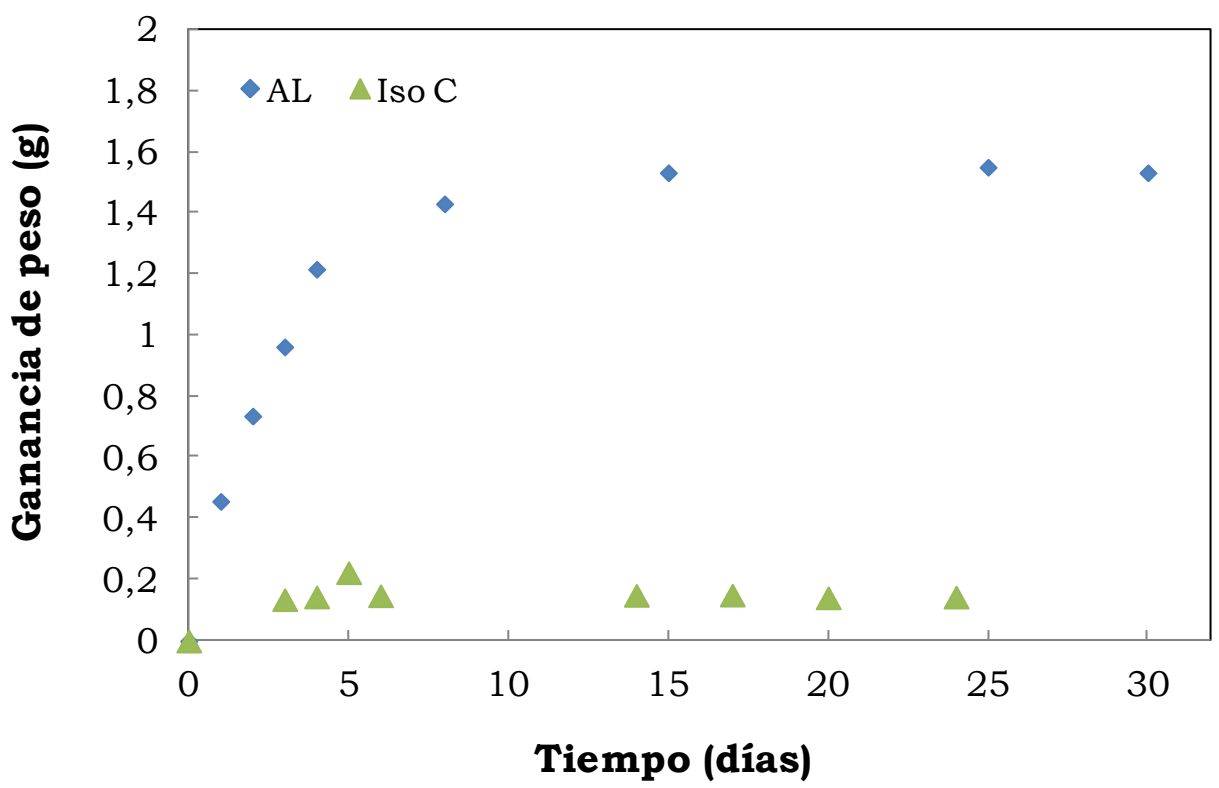

Figura 54. Ganancia de peso de los snacks $A_{L}$ e Iso $C$ almacenadas durante 30 dias a $20^{\circ} \mathrm{C}$ y una humedad relativa de $60 \%$.

Se calculó la higroscopicidad (HG) a partir de la ecuación 16 cuyos resultados son mostrados en la. De los resultados obtenidos se infiere que el snack con isomalt presentó muy baja higroscopicidad, mientras que en condiciones similares de humedad y temperatura $160 \%$ HR y $20^{\circ} \mathrm{C}$ ) el snack obtenido a partir de fructosa mostró una higroscopicidad significativamente mayor

Tabla 22. Higroscopicidad de los snacks $A_{L}$ e Iso C a $60 \%$ HR y $20^{\circ} \mathrm{C}$ obtenida a partir de la Ec. (16)

\begin{tabular}{lcccc}
\hline & $\mathbf{b}(\mathbf{g})$ & $\mathbf{a}(\mathbf{g})$ & $\mathbf{H}(\mathbf{g})$ & $\mathbf{\% H G}$ \\
\hline $\mathbf{A}_{\mathbf{L}}$ & $0,16^{\mathrm{b}}$ & $9,8^{\mathrm{b}}$ & $0,017^{\mathrm{a}}$ & $1,77^{\mathrm{b}}$ \\
Iso C & $0,02^{\mathrm{a}}$ & $8,1^{\mathrm{a}}$ & $0,018^{\mathrm{a}}$ & $0,45^{\mathrm{a}}$
\end{tabular}

$a, b$ Letras diferentes en la misma columna indican diferencias significativas $(P<0,05)$.

El valor de b, relacionado con la ganancia de peso en el tiempo, fue significativamente mayor en el snack $\mathrm{A}_{\mathrm{L}}$, formulado con fructosa y maltodextrina y se observó un mayor incremento de la pegajosidad como consecuencia de la disolución de los azúcares. La determinación 
de higroscopicidad contribuye a predecir el comportamiento del producto una vez envasado (López-Córdoba y col., 2014). El aumento del contenido de agua facilita el desarrollo de reacciones de degradación, las cuales a su vez se aceleran por el efecto del aumento de la temperatura (Schultheiss y Newman, 2009). Konopacka y col. (2002) sostienen que la alta higroscopicidad de manzanas secas puede explicarse sobre la base del alto contenido de carbohidratos (alrededor de $70 \%$ ) y sustancias pécticas. Además de la composición química, en el caso de los snacks de manzana, la alta porosidad juega un papel importante en la absorción de agua. Estos autores afirmaron que chips de manzana crocantes, sin grasa, formulados como un producto "listo para consumir" fueron muy sensibles al aumento de la humedad y perdieron la textura en menos de una hora cuando se expusieron a $20^{\circ} \mathrm{C}$ y $83 \% \mathrm{HR}$. Asimismo confirmaron que la ganancia de agua genera problemas en la producción, envasado y almacenamiento; y disminuye los limites de aceptabilidad de los consumidores del producto.

\section{Isotermas de adsorción de agua}

La cinética de adsorción explica los cambios en las propiedades químicas en el tiempo teniendo en cuenta la velocidad de estos cambios, a diferencia de las isotermas de sorción donde los datos termodinámicos proporcionan información sobre el estado final de un sistema (Valenzuela y col., 2015). Por ejemplo, dependiendo de la HR ambiente a la que se envase el producto, se puede estimar el tiempo antes que el producto sea inaceptable en términos de textura (Valenzuela y Aguilera, 2015). La presencia de agua y sus interacciones con otros componentes son factores importantes a tener en cuenta en la estabilidad de los alimentos. Se ha observado que varios tipos de alimentos con el mismo contenido de agua difieren significativamente en su estabilidad microbiológica y química. El término actividad de agua se desarrolló para considerar la intensidad con la que el agua se asocia con los distintos constituyentes no acuosos (Fennema, 1996). El agua unida fuertemente está menos disponible para las reacciones degradativas, 
como el crecimiento de hongos y reacciones hidrolíticas. El límite de esta región es la humedad de monocapa. A valores mayores de $\mathrm{a}_{\mathrm{w}}$, el agua existe en multicapas y la movilidad del sistema aumenta. La actividad de agua está relacionada con la humedad a través de la isoterma de sorción de agua. Estas curvas son herramientas útiles, ya que permiten obtener información de la plastificación o cristalización de un producto. Este concepto es usado extensivamente en la industria como indicador de calidad y seguridad. Sin embargo, diferentes autores (Karel y Saguy, 1991; Slade y Levine, 1991), propusieron que la estabilidad de un sistema también está relacionada con los cambios que se producen en las cercanías de la temperatura de transición vítrea. La influencia de la transición vítrea sobre cambios físicos como el colapso estructural, pegajosidad, apelmazamiento, liberación de flavors y pérdida de crocancia ha sido ampliamente estudiada (Roos, 1998a; Netto y col, 1998).

Teniendo en cuenta ambos conceptos, que abarcan dos fenómenos diferentes y complementarios, $a_{w}$ relacionado con las propiedades del solvente y $\mathrm{T}_{\mathrm{g}}$ relacionado con las propiedades termofísicas del material, es posible establecer mapas de estabilidad más completos. Se pueden predecir por ejemplo el punto de inicio de las reacciones de deterioro, tales como pardeamiento no enzimático, oxidación de lípidos, crecimiento microbiano, reacciones enzimáticas (Roos, 1998a).

Por las razones expuestas anteriormente, en el desarrollo de este trabajo se realizó la isoterma de sorción de ambos snacks y paralelamente la determinación de la temperatura de transición vítrea de las muestras y medidas de textura con el fin de establecer mapas de estabilidad integrados.

La isoterma de sorción obtenida por el método gravimétrico mostró una curva sigmoidea típica de un sistema amorfo (Figura 55). 


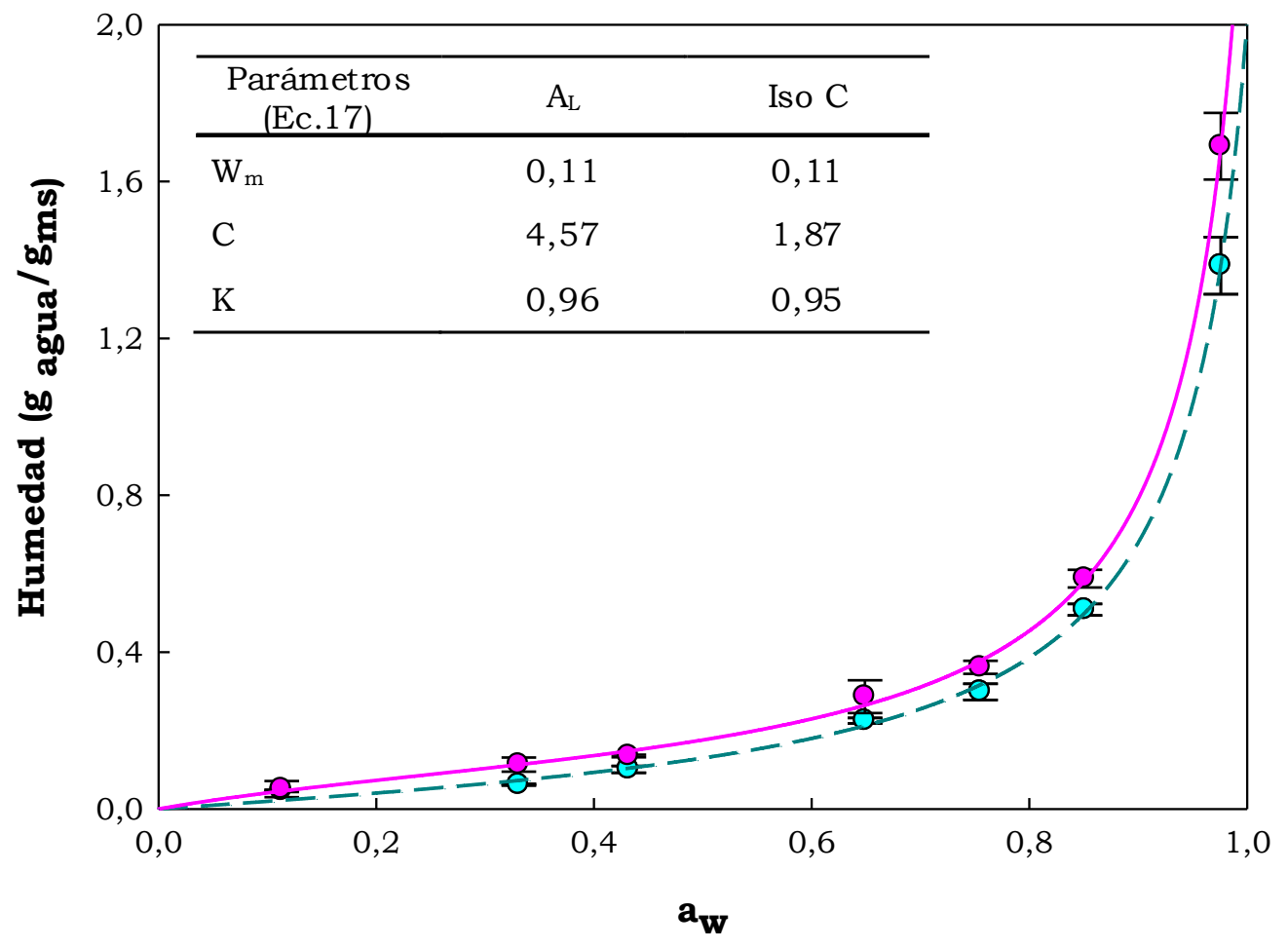

Figura 55. Isoterma de sorción de los snacks $A_{L}\left({ }^{\bullet}\right)$ e Iso $C\left(^{\bullet}\right)$. Los simbolos corresponden a los datos experimentales y las líneas al ajuste obtenido de la Ec. 17(Modelo de GAB; $\mathrm{R}^{2}=0,99$ ).

En este tipo de sistemas, las moléculas se encuentran en un ordenamiento al azar y están relativamente más libres para interactuar con el agua. Por lo tanto, la adsorción de agua a bajas a es mayor comparada con la de sistemas cristalinos. Las isotermas de adsorción obtenidas para ambos snacks fueron típicas de matrices con alto contenido de sólidos solubles y corresponden a la clasificación tipo III de BET (Rao y Rizvi, 1995). Las isotermas mostraron un patrón de comportamiento resistente en regiones de baja $a_{w}$, pero al exceder 0,6 de $a_{w}$ el contenido de humedad aumentó exponencialmente. El aumento de absorción de humedad observado en $\mathrm{a}_{\mathrm{w}}=0,6$ se puede atribuir a la adsorción de agua por disolución de los azúcares presentes (Konopacka y col., 2002). Otros autores han encontrado curvas de adsorción similares para frutas y matrices de alto contenido de azúcar (Sablani y col., 2004; Arévalo-Pinedo y col., 2006; Djendoubi y col., 2012; 
Demarchi y col., 2013; Romano y col., 2014). Las isotermas pueden dividirse generalmente en tres regiones, la región I corresponde a $a_{\mathrm{w}}<0,22$, se refiere a la adsorción de agua en la capa monomolecular $\left(\mathrm{W}_{\mathrm{m}}\right)$, la región II para $\mathrm{a}_{\mathrm{w}}$ entre 0,22 y 0,75 , correspondiente a la adsorción de agua en capas adicionales a la monocapa, y la región III entre 0,75 - 0,95, correspondiente a la condensación de agua en los poros del material seguida por la solubilidad del mismo (Van den Berg y col., 1981). Se observó en todas las isotermas que la humedad aumentó con el aumento de $\mathrm{a}_{\mathrm{w}}$, siendo mayor este aumento en valores de $\mathrm{a}_{\mathrm{w}}$ superiores a 0,43. Resultados similares se han reportado en el estudio de isotermas de sorción en otros alimentos de este tipo (Mohamed y col., 2004; Vega-Gálvez y col., 2006; Al-Muhtaseb y col., 2010). Los datos obtenidos fueron ajustados empleando el modelo de GAB, aplicado comúnmente en alimentos. Para que un modelo matemático sea satisfactorio debe ajustar lo mejor posible los datos experimentales en todo el rango de $a_{w}$, utilizando un mínimo de parámetros de ajuste (Coupland y col., 2000). Por esta razón el modelo GAB (Van den Berg y col., 1981) ha sido ampliamente utilizado ya que describe el comportamiento de la sorción en un amplio rango de $\mathrm{a}_{\mathrm{w}}(0,10-0,90)$. Los valores de los parámetros de la ecuación de GAB obtenidos se detallan en la tabla inserta en la Figura 55.

En la Figura 55 se observa que el comportamiento de ambos snacks fue similar en todo el rango de $\mathrm{a}_{\mathrm{w}}$ estudiado. Para el snack Iso C las humedades finales obtenidas fueron más bajas que para el snack $A_{L}$. Esto indicó que Iso $\mathrm{C}$ es menos higroscópico que $A_{L}$, a la misma $a_{w}$. A partir de la ecuación de GAB se fijaron los límites de humedad de almacenamiento para ambos snacks. A valores menores al de $\mathrm{W}_{\mathrm{m}}$, la velocidad de las reacciones químicas es lenta, debido a la lenta difusión de moléculas en la fase acuosa limitada (Nelson y Labuza, 1994). E1 valor de contenido de agua de la monocapa $\left(\mathrm{W}_{\mathrm{m}}\right)$ estimado fue de 0,11 $g_{\text {agua/gms }}$ para ambos snacks (Figura 55) correspondientes a una $a_{w}$ de 0,33 a $20^{\circ} \mathrm{C}$. Estos resultados fueron similares a los obtenidos para 
productos alimenticios hidrofilicos informados por Farroni (2011) quien obtuvo un valor de monocapa de $10,0 \%$ (b.s) para grits de maíz. Asimismo Iglesias y Chirife (1992) hallaron valores entre 5 y 8\% (b.s) en productos deshidratados a base de frutas. Fredericksen (2013) informó valores de $14,0 \%$ (bs) en uchuva secada a $60^{\circ} \mathrm{C}$ durante $72 \mathrm{hs}$, mientras que Pietro y Gordillo (2006) informaron valores de monocapa $\left(\mathrm{W}_{\mathrm{m}}\right)$ entre 9,2 y 14,0\% (b.s) en cereales para desayuno. Respecto a los parámetros $\mathrm{K}$ y $\mathrm{C}$ del modelo de GAB, se pudo observar que el parámetro K resultó independiente de la composición de las muestras, mientras que el parámetro $\mathrm{C}$, relacionado con la entalpía del sistema fue más bajo para Iso C. Para este snack los valores de $\mathrm{C}$ y $\mathrm{K}$ corresponden a la clasificación de tipo III, según Brunauer, la cual establece un rango entre $0<\mathrm{K}<1$ y $0 \leq \mathrm{C} \leq 2$ (Blahovec, 2004).

En la curva obtenida por el método higrométrico (Figura 56) se observó un comportamiento similar al obtenido por el método gravimétrico. Sin embargo, en el rango de baja $a_{w}(0,11-0,40)$, los valores experimentales en ningún caso fueron menores a 0,30 .

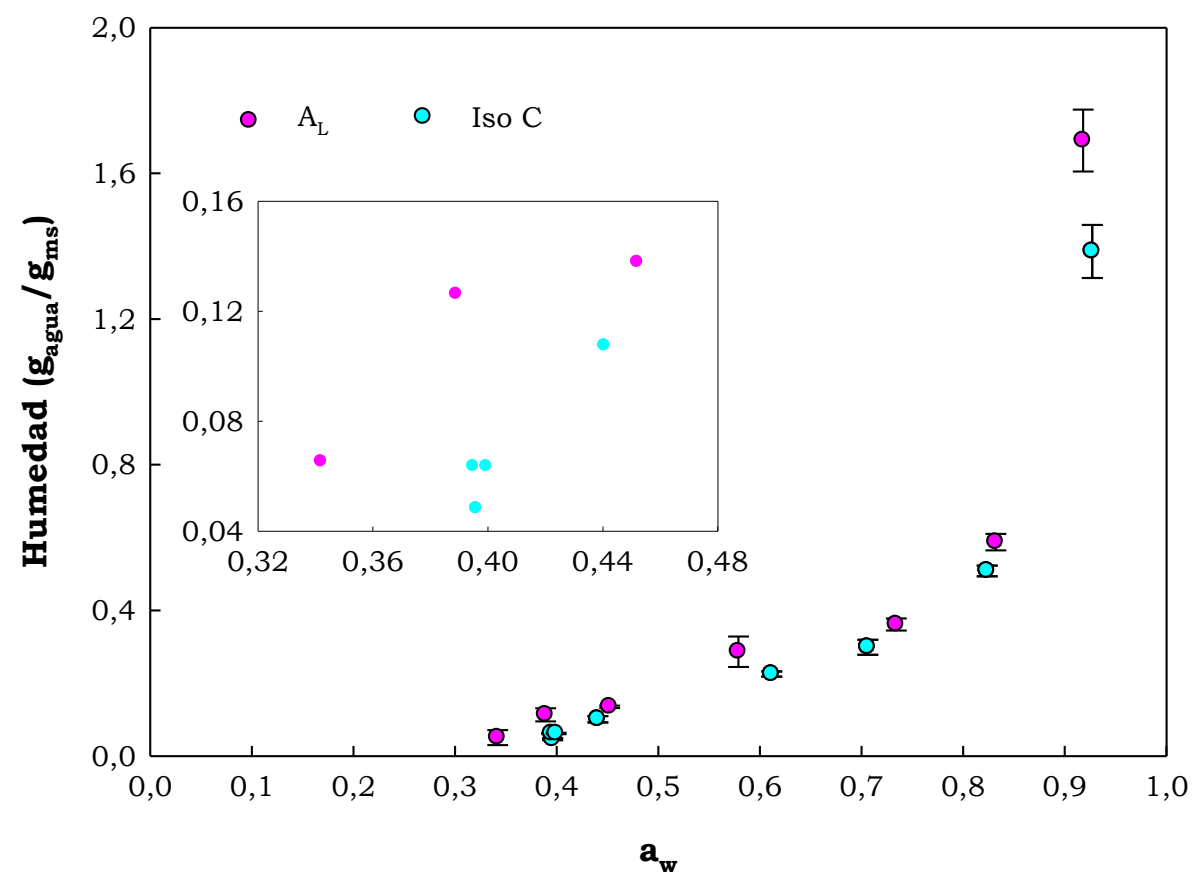

Figura 56. Isoterma de sorción higrométrica de los snacks $A_{L}$ e Iso C. 
Demarchi y col. (2013) describieron el mismo comportamiento e informaron que este fenómeno se podría atribuir a que en la zona de baja $\mathrm{a}_{\mathrm{w}}(0,11-0,22)$. Debido a la presencia de azúcares en la muestra, el coeficiente de difusión del agua es extremadamente bajo y se evita la adsorción o desorción en el corto período de tiempo requerido para la medida en el método higrométrico. Tavera Quiroz y col. (2011) informaron un comportamiento similar en papas chips con y sin coberturas de metilcelulosa.

\section{Parámetros criticos sobre las propiedades mecánicas: humedad, actividad de agua y $\mathbf{T}_{\mathrm{g}}$}

Anteriormente se mencionó que las propiedades mecánicas de los alimentos deshidratados están relacionadas con las propiedades de adsorción de vapor de agua. Las propiedades mecánicas de los productos de bajo contenido de humedad cambian drásticamente cuando se alcanza el contenido de humedad relacionada con el valor $\mathrm{a}_{\mathrm{w}}$ crítico. En este punto, hay un aumento en la movilidad del agua asociado con la transición vítrea. Para evitar cambios en las propiedades mecánicas de los alimentos, es decir, mantener una textura adecuada y evitar variaciones en los valores de $\mathrm{T}_{\mathrm{g}} \mathrm{y}$ la migración del agua, el $a_{\mathrm{w}}$ debe mantenerse por debajo de limites críticos (Katz y Labuza, 1981).

Con el fin de conocer los parámetros capaces de afectar la calidad, se evaluó la textura de los snacks una vez que las muestras llegaron a cada una de las humedades de equilibrio (Figura 57 a y b). A través de los resultados obtenidos de las curvas fuerza-desplazamiento se observó la evolución de la textura. La pérdida de calidad se obtuvo para el snack Iso C una vez que la humedad sobrepasó el 44\%, mientras que para $A_{L}$, la transición se produjo a $33 \%$ de $H R$, disminuyendo la crocancia por el aumento en el contenido de agua. 
a.

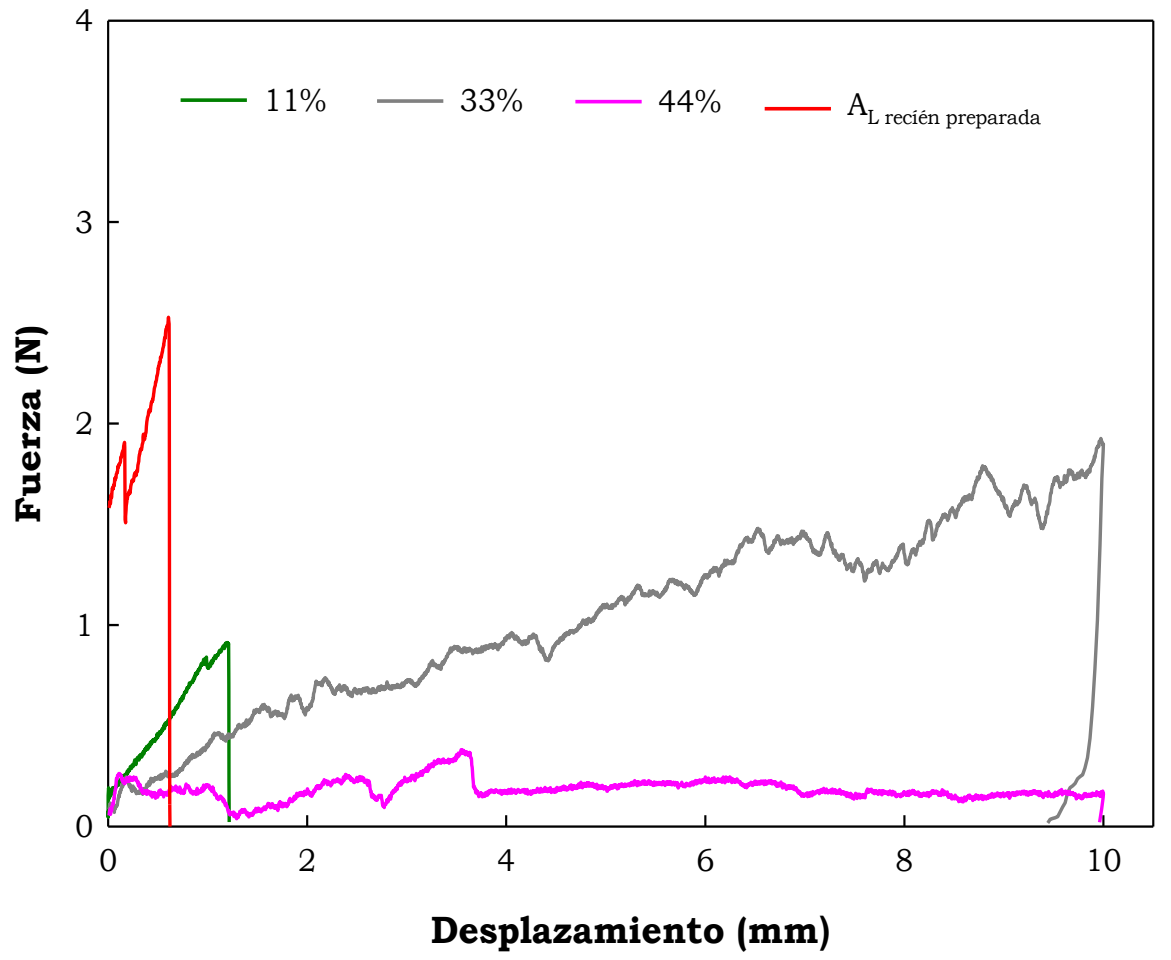

b.

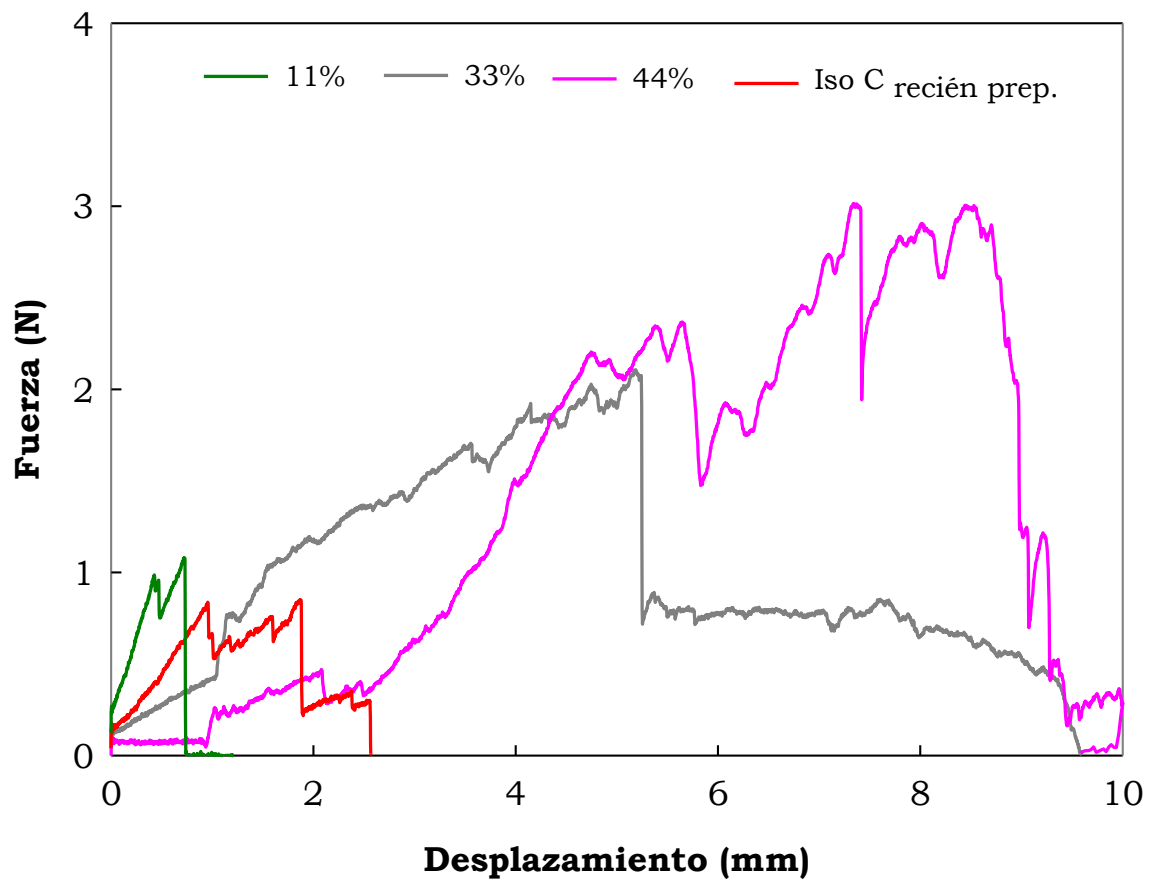

Figura 57. Curvas de fuerza-desplazamiento de snacks recién preparados y acondicionados a distintas \%HR de: a. Snack $A_{L}$; b. Snack Iso C. 
Los tratamientos térmicos aplicados y la presencia de fructosa en este producto $\left(A_{L}\right)$, indujeron a que la matriz fuese más susceptible a ser plastificada por el agua. La fuerza máxima de ruptura coincidió con la ruptura total de la muestra durante el ensayo y el émbolo tuvo un mayor desplazamiento a mayor deformación, lo cual indicó un aumento en la gomosidad de las muestras estabilizadas a estas humedades. Este comportamiento, representado por picos de ruptura menos pronunciados en las curvas fuerza-desplazamiento, se relacionó con la mayor afinidad por el agua de las muestras formuladas con fructosa comparadas con las formuladas con isomalt.

Las propiedades térmicas también se vieron afectadas por el aumento del contenido de agua en la estructura. Se observaron eventos como la disminución de la temperatura de transición vítrea $\mathrm{y}$ corrimientos de la temperatura del pico de fusión hacia valores más altos. Asimismo se produjo un aumento de la entalpía de fusión relacionada con la caramelización de los azúcares presentes (Farroni, 2011) como consecuencia del aumento del contenido de agua a medida que se incrementó el valor de $\mathrm{HR}$ al cual fueron expuestos ambos productos.

En la Tabla 23 se describe la evolución de los valores de temperatura de transición vitrea de los snacks con el aumento del contenido de agua en las muestras producto del acondicionamiento a diferentes humedades relativas. Se observó que el snack $A_{L}$ sólo mantuvo la estabilidad hasta 11\% HR. Una vez que sobrepasó el 33\% HR la $T_{g}$ presentó una tendencia hacia los valores de $T_{g}$ de los componentes mayoritarios en el sistema, en este caso, fructosa y agua. Algunos autores ubican la $\mathrm{T}_{\mathrm{g}}$ de la fructosa entre $10-13{ }^{\circ} \mathrm{C}$ y la del agua pura a $-135^{\circ} \mathrm{C}$ (Ross y Karel, 1991, Vásquez y col., 2013). El aumento en el contenido de agua plastificó el sistema de forma tal que alcanzó valores de $\mathrm{T}_{\mathrm{g}}$ por debajo de cero grados. Para Iso $\mathrm{C}$ se observó una tendencia similar. 
Tabla 23. Temperatura de transición vítrea de los snacks $A_{L}$ e Iso $C$ acondicionados a diferentes humedades relativas

\begin{tabular}{ccc}
\hline \%HR & $\mathbf{T}_{\mathbf{g}} \mathbf{A}_{\mathbf{L}}\left({ }^{\circ} \mathbf{C}\right)$ & $\mathbf{T}_{\mathbf{g}} \mathbf{I} \mathbf{s o} \mathbf{C}\left({ }^{\circ} \mathbf{C}\right)$ \\
\hline Recién preparado & $48,0^{\mathrm{e}}$ & $68,0^{\mathrm{d}}$ \\
11 & $46,1^{\mathrm{e}}$ & $70,7^{\mathrm{d}}$ \\
33 & $-9,7^{\mathrm{d}}$ & $69,7^{\mathrm{d}}$ \\
44 & $-11,5^{\mathrm{c}, \mathrm{d}}$ & $63,8^{\mathrm{c}}$ \\
75 & $-12,8^{\mathrm{c}}$ & $20,1^{\mathrm{b}}$ \\
84 & $-21,9^{\mathrm{b}}$ & --- \\
97 & $-43,5^{\mathrm{a}}$ & $-36,0^{\mathrm{a}}$
\end{tabular}

$a, b, c, d, e$ Letras diferentes en la misma columna indican diferencias significativas $(P<0,05)$

Los valores de temperatura de transición vítrea del Iso $\mathrm{C}$ no experimentaron un descenso pronunciado hasta que la muestra sobrepasó el 44\% de HR. Este hecho sustenta la hipótesis planteada en este trabajo que indicaría que este snack es un producto de características menos higroscópicas y es más estable a temperatura ambiente, mientras se encuentre en un ambiente de humedad controlada. Esto indica que la composición del alimento afecta la estabilidad física y química del mismo. Para el caso del snack Iso C, obtenido a partir de isomalt y maltodextrina, el efecto del peso molecular y la $\mathrm{T}_{\mathrm{g}}$ de los carbohidratos utilizados se manifiesta en un aumento en la estabilidad del producto. En el snack formulado con fructosa y maltodextrina fue posible obtener un producto seco durante un corto período una vez terminado el horneado. Sin embargo, sin el envasado adecuado no es posible mantener la estabilidad del mismo a temperatura ambiente. En el desarrollo de nuevos productos utilizar ingredientes que afectan la $T_{g}$ es probablemente uno de los factores más importante a tener en cuenta, especialmente, en el procesamiento de snacks (Roos, 1995; Konopacka y col., 2002). 
En la Figura 58 a se muestran los termogramas de DSC obtenidos para el snack Iso $\mathrm{C}$ que describen el corrimiento de la $\mathrm{T}_{\mathrm{g}}$ hacia menores valores.

a.

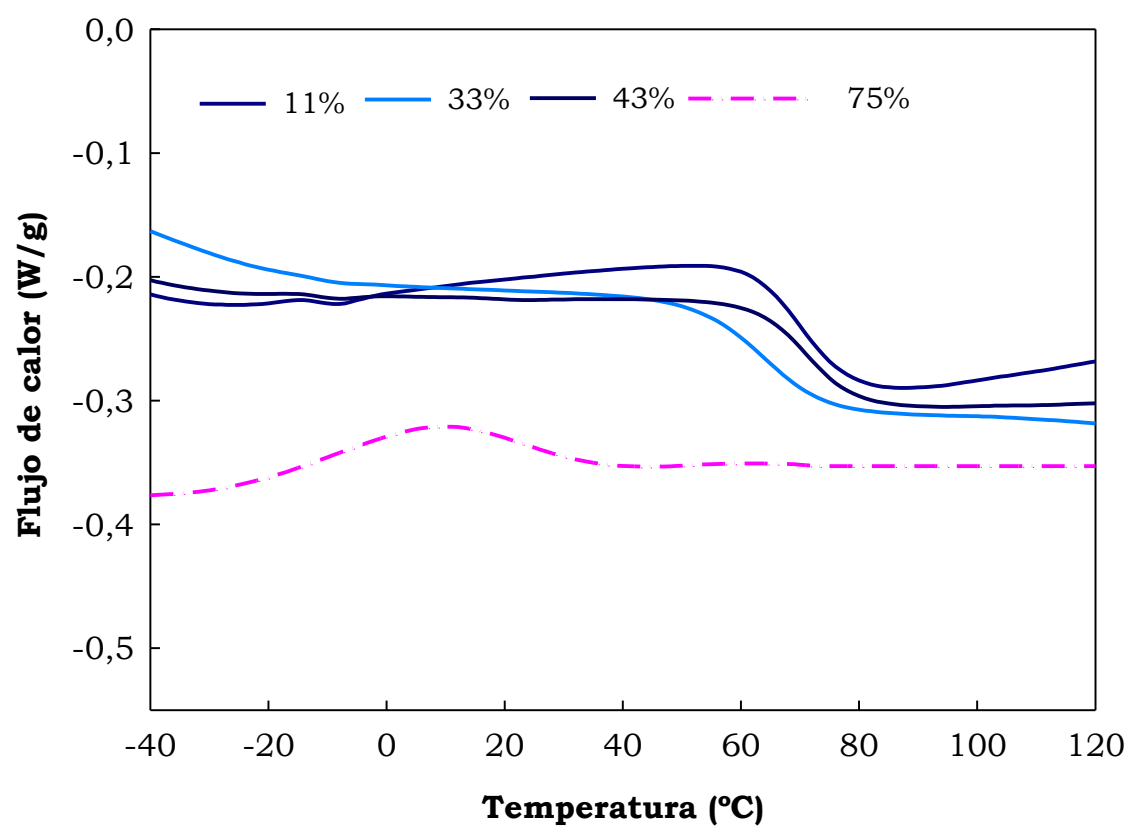

b.

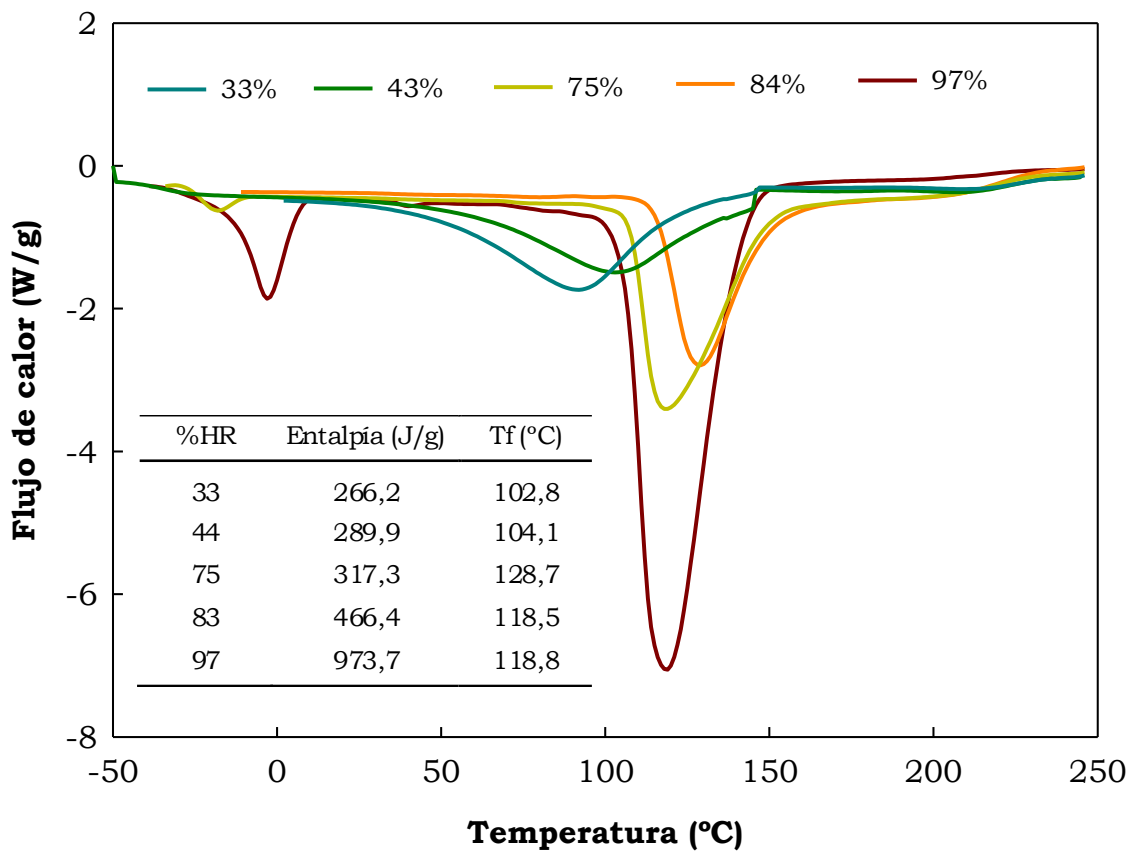

Figura 58. Termogramas de DSC del snack Iso $\mathrm{C}$ acondicionado a distintas HR: a. Temperaturas de transición vitrea obtenidas del $2^{\circ}$ scan; b. Entalpía de fusión obtenidas en el primer scan. 
La temperatura de transición del material se mantiene estable entre 11 y 33\% HR. Sin embargo, una vez que alcanzó el 44\% este valor disminuyó y cuando sobrepasó el 75\% HR esta disminución fue aún más pronunciada. Cuando el contenido de agua fue suficientemente alto (74, 84 y 97\% HR) (Figura 58 b), se observó un aumento de la entalpía de fusión entre 100 y $130^{\circ} \mathrm{C}$, producto de la reacción de caramelización, favorecida por el alto contenido de agua en las muestras y la temperatura. Aguilera y col. (1998) informaron una tendencia similar para los valores de entalpía relacionados con el contenido de agua en manzanas secas. Los alimentos secos están inicialmente cubiertos en su superficie interna (poros) y externa (superficie de las partículas) por una monocapa de moléculas de agua, que a cierta humedad constituye un limite de hidratación a partir del cual las interacciones agua-sustrato se pueden modificar. Esto no es deseable, ya que a medida que decrece la interacción agua-sustrato aumenta la $a_{w}$ (Martínez y col., 2000). Si al producto se le van incorporando moléculas de agua, éstas van quedando retenidas a la fase sólida mediante fuerzas de Van der Waals y puentes de hidrógeno con otras moléculas de agua, formando multicapas en la superficie interna y externa del material (Martínez y col., 2000). Cuando comienza a coexistir con este fenómeno la penetración de las moléculas de agua hacia el interior de la matriz sólida y se da la correspondiente movilización de solutos, comienza la solubilización de los materiales del alimento hasta que existe agua suficiente, se forma la fase acuosa y se deteriora la estructura inicial (Martínez y col., 2000).

Este comportamiento se vió reflejado en la relación humedad- $\mathrm{a}_{\mathrm{w}}{ }^{-}$ $T_{g}$ que muestran ambos snacks. En la Figura 59 se observa que a medida que el sistema se fue modificando por efecto del aumento en el contenido de agua, la inestabilidad del producto aumentó. Esta inestabilidad adquiere mayor importancia cuando los ingredientes de la formulación (como es el caso de la fructosa) favorecen la unión de moléculas de agua, facilitando el colapso de la estructura. Vásquez y col. (2013) afirmaron que las propiedades térmicas de arándanos 
liofilizados son dependientes del estado de agua libre y azúcares simples presentes en la pulpa y los mismos son sensibles a pequeños cambios que ocurren en el entorno, como el aumento de la HR.

a.

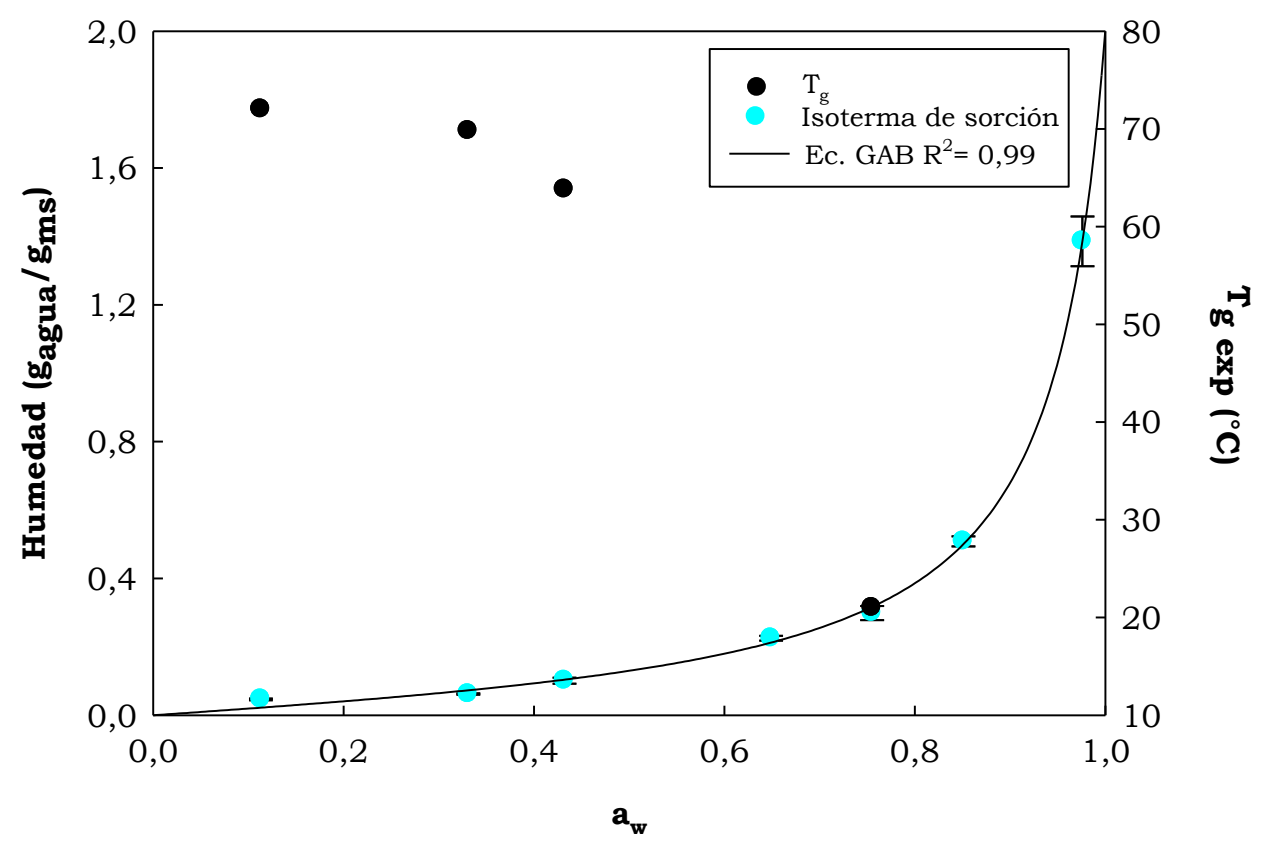

b.

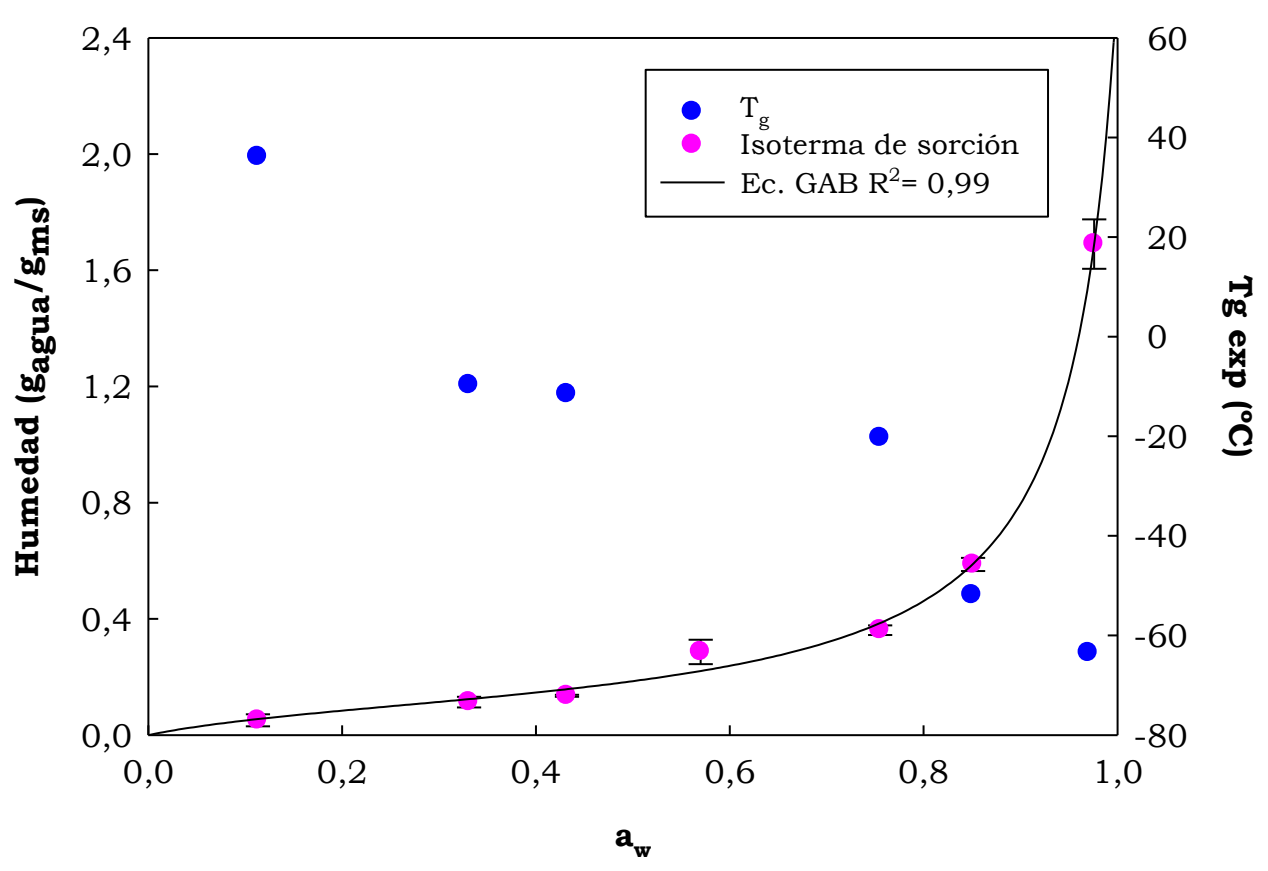

Figura 59. Relación de isoterma de sorción - $T_{g}$ para: a. Snack $A_{L}$; b. Snack Iso C. 
Con el objetivo de determinar con mayor claridad el punto limite que garantiza la calidad y estabilidad del producto, se compararon los valores de $\mathrm{T}_{\mathrm{g}}$ obtenidos por $\mathrm{DSC}$, con los valores de desplazamiento obtenidos de las curvas fuerza-desplazamiento (indicativo de la deformación que sufre la muestra antes de la ruptura) para cada snack acondicionado en cada una de las humedades relativas estudiadas. En la Figura 60 a y b, se observa que la exposición del producto a altas humedades sin el envasado adecuado genera un colapso de la textura, independientemente de la formulación que se analice, lo cual está representado en un aumento de la deformación de la muestra antes de romperse. El desplazamiento aumenta a medida que se incrementa el contenido de agua y esto a su vez se relaciona con la disminución de los valores de transición vítrea. Un ligero aumento en el valor de $\mathrm{a}_{\mathrm{w}}$ de las muestras, provocado por una leve humectación o aumento en la temperatura de almacenamiento, genera fenómenos indeseables asociados al cambio de estado vítreo a estado gomoso. Por esta razón, sería necesario emplear envases de muy baja permeabilidad al vapor de agua para mantener la calidad del producto, especialmente para $A_{L}$. Para el snack Iso C, en los valores cercanos a la humedad de monocapa (11\% b.s) se observó que el desplazamiento fue menor a bajas humedades, respecto a $A_{L}$ (Figura 60 b). Esto es similar a lo que ocurre durante el test de ruptura cuando la muestra recién preparada en estado vítreo se rompe fácilmente. Sin embargo, una vez que alcanzó el valor de humedad de monocapa se produjo un aumento en el recorrido del émbolo antes de la ruptura de la muestra y esto se relacionó a su vez, con la disminución de la $\mathrm{T}_{\mathrm{g}}$ del material. Según Salamanca-Grosso (2012) los alimentos preparados por deshidratación rápida o por liofilización muchas veces poseen estructuras metaestables. En ausencia del efecto plastificante de la humedad y temperaturas muy altas, la estructura persiste. Sin embargo, la adición de agua o el aumento de temperatura provocan el fenómeno de "colapso". Este fenómeno se define como el reacomodamiento de la estructura interna 
de un alimento debido a la movilidad de los componentes del sistema, con posteriores defectos sobre la calidad.

a.

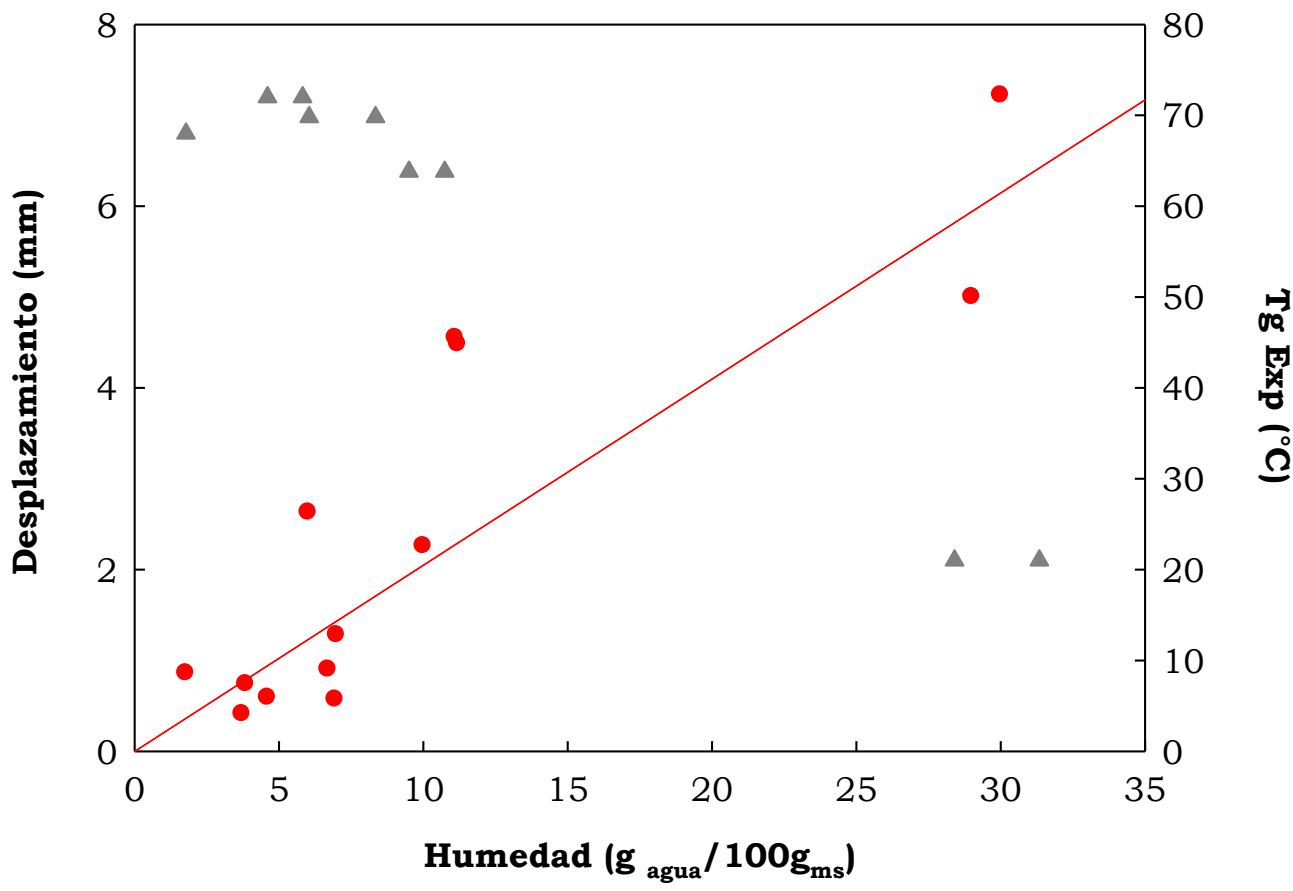

b.

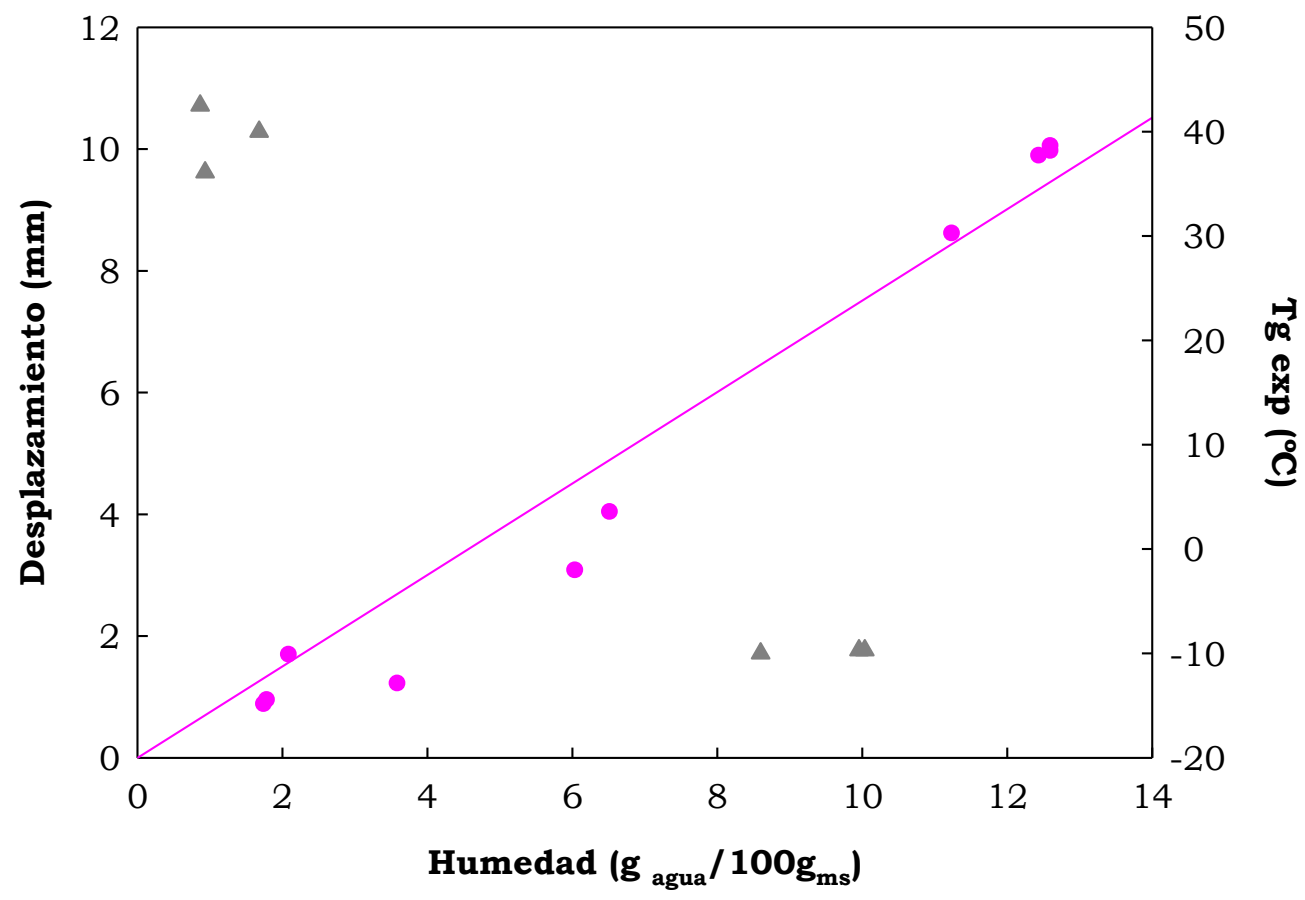

Figura 60. Relación de las propiedades térmicas $\left(\mathrm{T}_{\mathrm{g}}\right)$ (triángulos), propiedades mecánicas (desplazamiento) (círculos) y contenido de agua de los snacks: a. $\mathrm{A}_{\mathrm{L}}$; b. Iso C. (Las líneas indican la regresión lineal de los valores experimentales). 
Otro de los parámetros de textura que varió con el contenido de agua fue la pendiente de las curvas fuerza-desplazamiento (Figura 61). En ambos snacks las curvas se suavizaron una vez que sobrepasaron el contenido de agua crítico, lo cual ocasionó una brusca disminución de la pendiente de la curva. Hay que tener en cuenta que en los valores cercanos a la humedad de monocapa la muestra experimentó una alta variabilidad de los valores de pendiente. El snack Iso C comenzó a perder estructura y a volverse gomoso entre un 8-10\% (b.s) de contenido de agua.

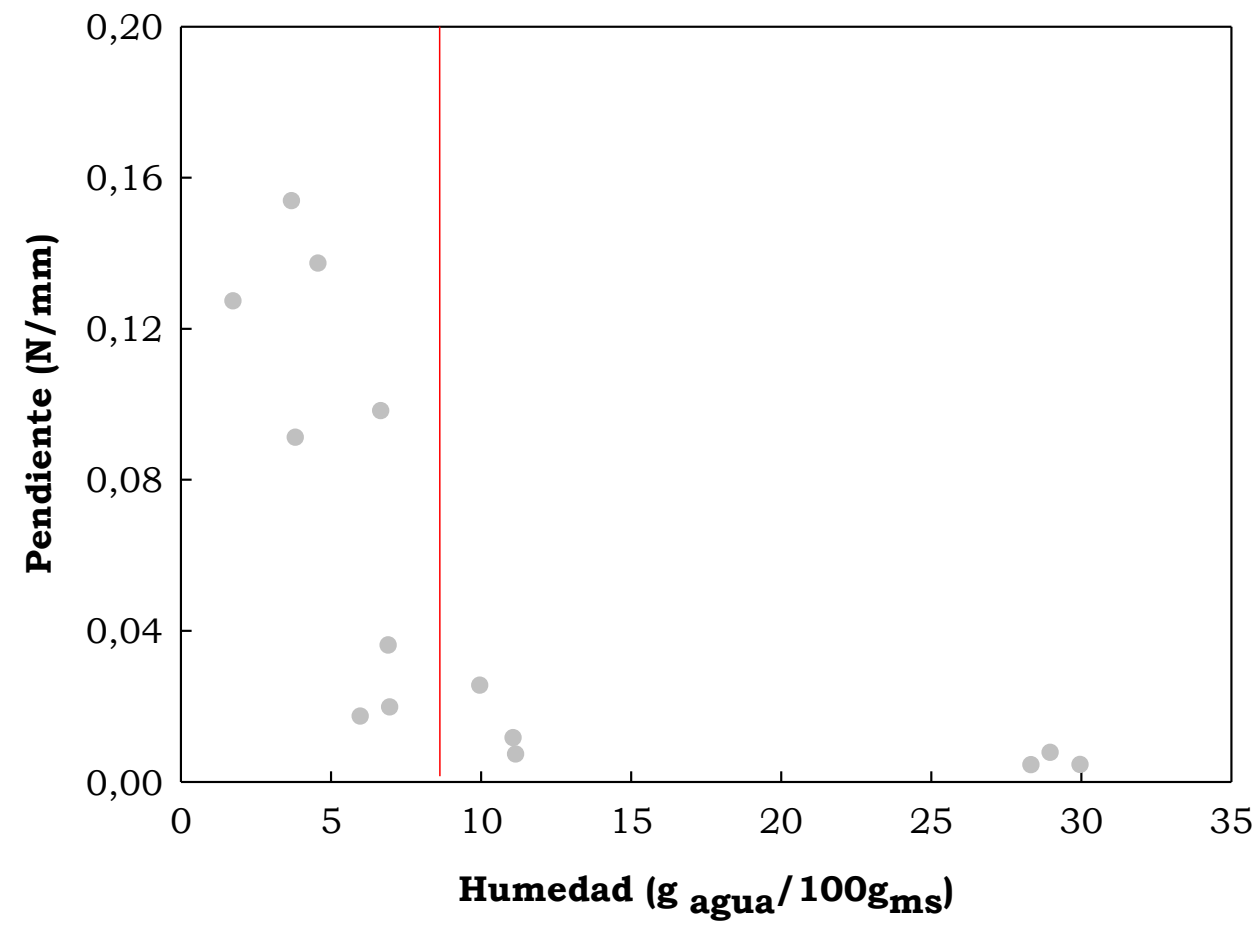

Figura 61. Valores de pendiente de la recta obtenidos para el snack Iso C a distintos contenidos de humedad.

El efecto de la hidratación en la crocancia ha sido evaluado por varios autores (Roos y col., 1998; Suwonsichon y Peleg, 1998; Peleg, 2003). Estos autores sostienen que el cambio de un material crujiente a un material deformable se debe al cambio de la transición vítrea del producto. 
La crocancia se asocia con el estado vítreo en los alimentos y su percepción se atribuye a la fractura de la matriz vitrea. Las propiedades mecánicas dependen no sólo de la estructura sino también del estado fisico del material de la pared celular. Estos cambios son inducidos en la pared celular por el equilibrio con soluciones salinas saturadas (Vickers y Bourne, 1976). Un aumento en el nivel de actividad de agua da lugar a una pérdida de crocancia. Esta pérdida puede ser medida por métodos instrumentales (Varela y col., 2009). La absorción de las moléculas de agua aumenta el volumen libre, que tiene un efecto de plastificación, lo cual mejora la movilidad y flexibilidad de las moléculas, por lo que el producto adquiere una textura suave (Roudaut y col., 1998, 2002). Estos cambios resultan en una reducción de la temperatura de transición vítrea por debajo de la temperatura ambiente, razón por la cual la dureza de los materiales disminuye (Roudaut y col., 2002). Los snacks de manzana son matrices celulares porosas, es decir que poseen una estructura consistente con una matriz sólida, rodeada de espacios de aire (Gondek y Lewicki, 2006; Chaunier y col., 2007) esta estructura puede ser observada en las micrografias de cortes transversales obtenidas por microscopía electrónica de barrido (Capítulo 3-sección 3.4. y Capítulo 4). Los sólidos celulares crujientes son dificiles de deformar pero se rompen fácilmente. El comportamiento mecánico de este tipo de materiales en función del contenido de agua ha sido explicado en detalle por Luyten y col. (2004) y Farroni (2011). En ambos trabajos los autores describieron que copos de maíz a contenidos de agua muy bajos se comportan como sólidos frágiles y la deformación necesaria para la ruptura es muy baja. Sin embargo cuando aumenta el contenido de agua se incrementa el valor del esfuerzo y aumenta la deformación. Muchos autores han realizado estudios similares en diferentes matrices alimenticias (Aguilera y col, 1993; Luyten y col., 2004; Farroni, 2011; Vásquez y col., 2013; Valenzuela y Aguilera, 2015). 


\subsection{ALMACENAMIENTO}

\subsubsection{MATERIALES}

Como material de envase se utilizó una película de polipropileno biaxialmente orientada (BOPP) metalizada (proporciona protección a la luz, para productos sensibles), alta barrera al vapor de agua, termosellable en la cara interna con temperatura de inicio de sellado de $105^{\circ} \mathrm{C}$ y adecuada para impresión y/o laminación. Está indicada especialmente para envasado de snacks y de alimentos que requieran barrera certificada a la humedad (VITOPEL S.A, Argentina) (Anexo 1).

\subsubsection{MÉTODOS}

Se utilizaron entre 30 y 40 muestras de los snacks $A_{L}$ e Iso C (aproximadamente $6 \mathrm{~g}$ ). Con el fin de estandarizar las muestras y disminuir el error en los ensayos a realizar, se mezclaron las muestras horneadas en un recipiente, y se envasaron lotes de entre 10 y 12 snacks. Cada batch fue envasado en forma independiente en los envases formados a partir de la película de BOPP, cada uno rotulado con la fecha de inicio del almacenamiento. Para cada tiempo de almacenamiento se envasaron dos lotes de muestra por separado, a $20^{\circ} \mathrm{C}$ y $60 \%$ de humedad relativa y se extrajeron muestras para su análisis a intervalos de tiempo determinados con antelación $(0,15,30$, $60,90,120,150$ dias).

\subsubsection{Análisis Instrumental}

Durante el almacenamiento se realizaron medidas de humedad, actividad acuosa, textura y estabilidad química del ácido ascórbico de los snack $A_{L}$ e Iso $C$ siguiendo los procedimientos utilizados en el Capítulo 3-sección 3.3.

\subsubsection{Análisis estadístico}

Para cada ensayo los resultados obtenidos fueron evaluados estadísticamente a través del software SYSTAT (SYSTAT, Inc., Evanston, IL, EE.UU.) (Wilkinson, 2000), mediante análisis de varianza (ANAVA). 
Cuando los datos presentaron diferencias entre sí, se realizó la comparación de medias mediante el test de LSD de Fisher a un nivel de significación de $\mathrm{P}<0,05$.

\subsubsection{RESULTADOS Y DISCUSIÓN}

\section{Almacenamiento de los snacks envasados a $20^{\circ} \mathrm{C}$ y $60 \% \mathrm{HR}$}

En la Figura 62 son mostradas las bolsas que se utilizaron para envasar los snacks

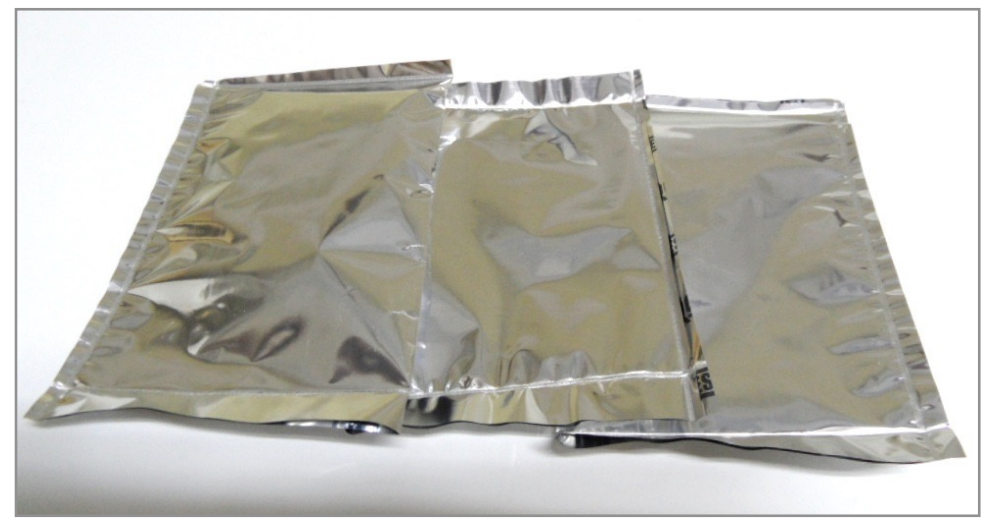

Figura 62. Snacks envasados en envases flexibles de BOPP a $20^{\circ} \mathrm{C}$ y $60 \% \mathrm{HR}$.

Durante el tiempo de almacenamiento se realizó el seguimiento de diferentes parámetros. Los resultados que se obtuvieron para humedad se muestran en la Figura 63.

E1 snack $\mathrm{A}_{\mathrm{L}}$, a los 30 días de almacenamiento mantuvo los valores de humedad inicial (día 0). Sin embargo, a los 60 días este parámetro comenzó a aumentar continuamente hasta los 150 días. Se observó una continua absorción de humedad hasta alcanzar aproximadamente 6 veces su contenido de humedad inicial a los 150 días de almacenamiento. El contenido de humedad del snack Iso C se incrementó continuamente presentando diferencias significativas $(\mathrm{P}<0,05)$ durante el período informado. Los valores de actividad acuosa no mostraron diferencias significativas hasta los 120 dias $(\mathrm{P}>0,05)$. A los 150 días el aumento en el contenido de agua condujo a un aumento del valor de $a_{w}$. 
Cuando se compararon las humedades de ambos productos se observaron diferencias significativas $(\mathrm{P}<0,05)$ para tiempos mayores a 60 días.

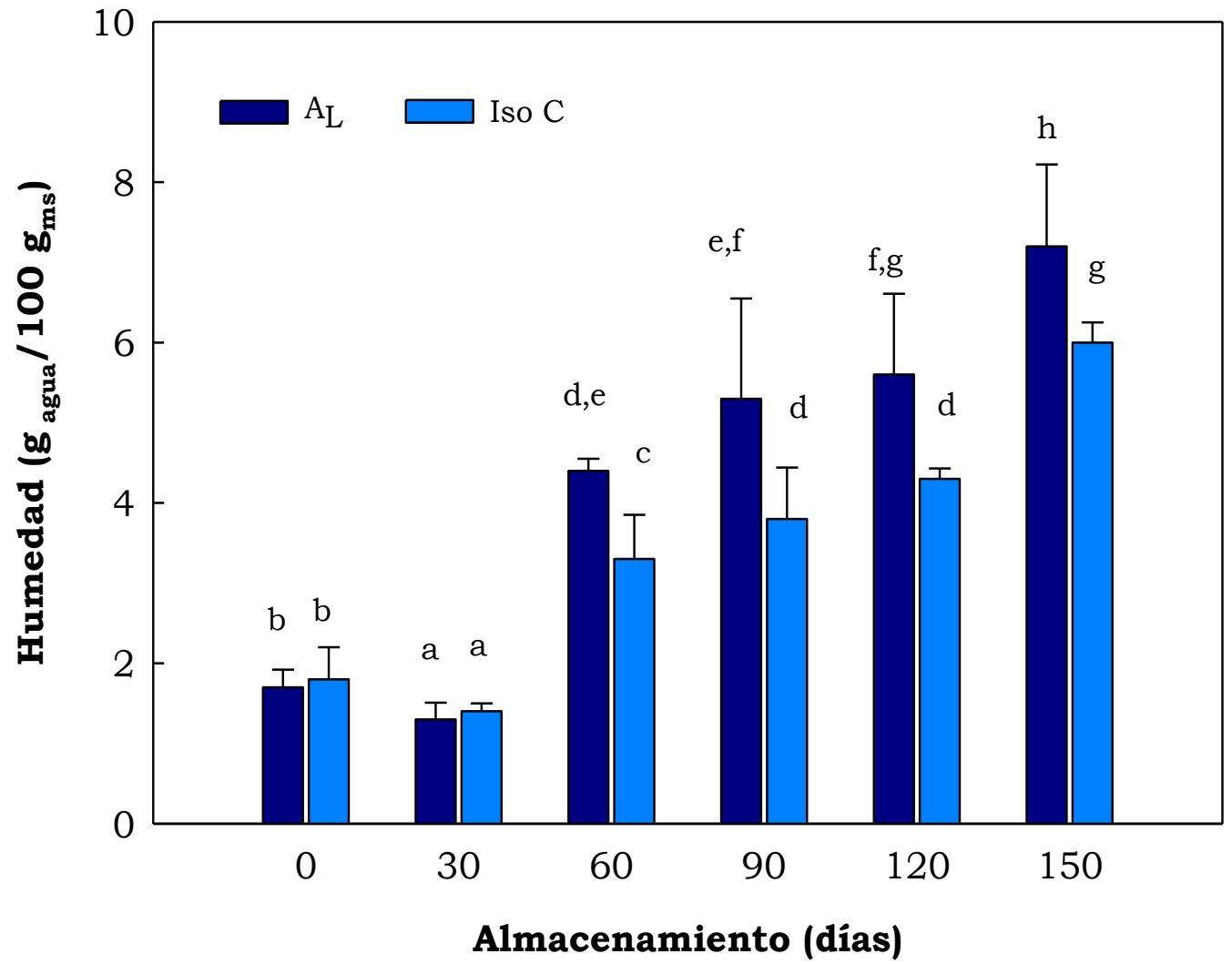

Figura 63. Evolución de la humedad para el snack $A_{L}$ e Iso $C$, almacenado durante 150 dias a $20^{\circ} \mathrm{C}$ y $60 \% \mathrm{HR}$.

Los valores de $a_{w}$ obtenidos para los snacks evaluados se muestran en la Tabla 24. Los valores obtenidos no presentaron diferencias significativas en ambos snacks en todos tiempos de almacenamiento estudiados $(\mathrm{P}>0,05)$. Este fenómeno de mínimas variaciones de actividad acuosa se observó también cuando se realizó la isoterma de sorción higrométrica para $A_{L}$ e Iso C. Los valores de actividad acuosa registrados por el equipo se mantuvieron entre 0,40 y 0,50 (Tabla 24). 
Tabla 24. Evolución de la actividad acuosa para el snack $A_{L}$ e Iso $C$, almacenado a $20^{\circ} \mathrm{C}$ y $60 \% \mathrm{HR}$

\begin{tabular}{ccc}
\hline $\begin{array}{c}\text { Tiempo de } \\
\text { almacenamiento } \\
\text { (dias) }\end{array}$ & $\mathbf{a}_{\mathbf{w}} \mathbf{A}_{\mathbf{L}}$ & $\mathbf{a}_{\mathbf{w}}$ Iso C \\
\hline 0 & $0,38^{\mathrm{a}}(0,01)$ & $0,45^{\mathrm{c}}(0,02)$ \\
30 & $0,44^{\mathrm{b}}(0,01)$ & $0,41^{\mathrm{a}}(0,01)$ \\
60 & $0,40^{\mathrm{a}}(0,01)$ & $0,40^{\mathrm{a}}(0,01)$ \\
90 & $0,43^{\mathrm{b}}(0,02)$ & $0,42^{\mathrm{b}}(0,02)$ \\
120 & $0,40^{\mathrm{a}}(0,02)$ & $0,44^{\mathrm{c}}(0,02)$ \\
150 & $0,47^{\mathrm{c}}(0,01)$ & $0,45^{\mathrm{c}}(0,02)$ \\
\hline
\end{tabular}

$a, b, c$ Letras diferentes en cada columna indican diferencias significativas $(P>0,05)$. Valores entre paréntesis indican desviación estándar $(n=2)$.

Las curvas de textura para ambos snacks a los 30 días de almacenamiento mostraron múltiples fracturas similares a los snacks recién preparados. Sin embargo, $A_{L}$ presentó perdida de crocancia a los 60 dias, mientras que Iso $\mathrm{C}$ mostró un colapso estructural después de 120 dias de almacenamiento (Figura 64 y 65 ). 


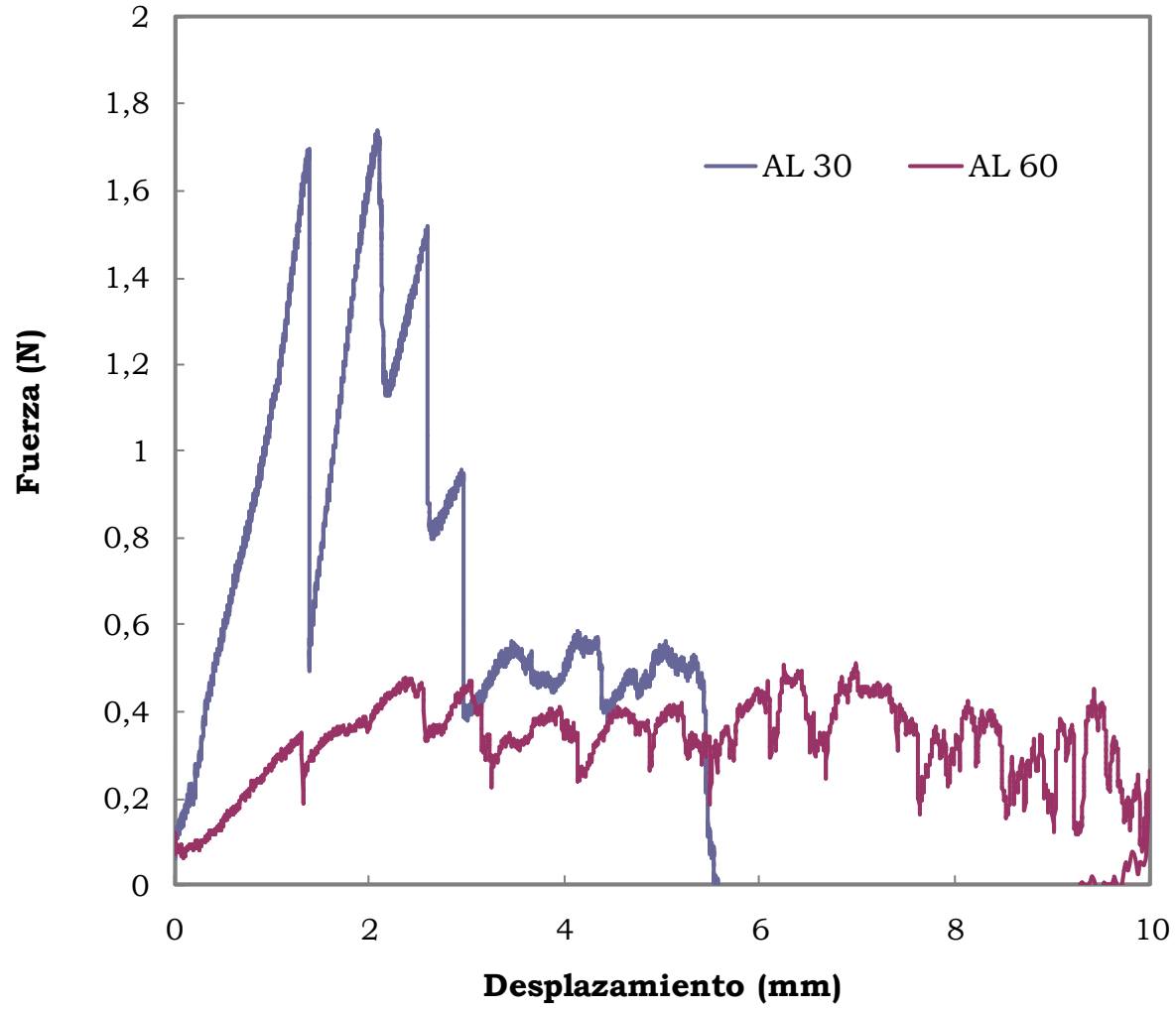

Figura 64. Curvas de textura durante el almacenamiento de $A_{L}$ a los 30 y 60 dias.

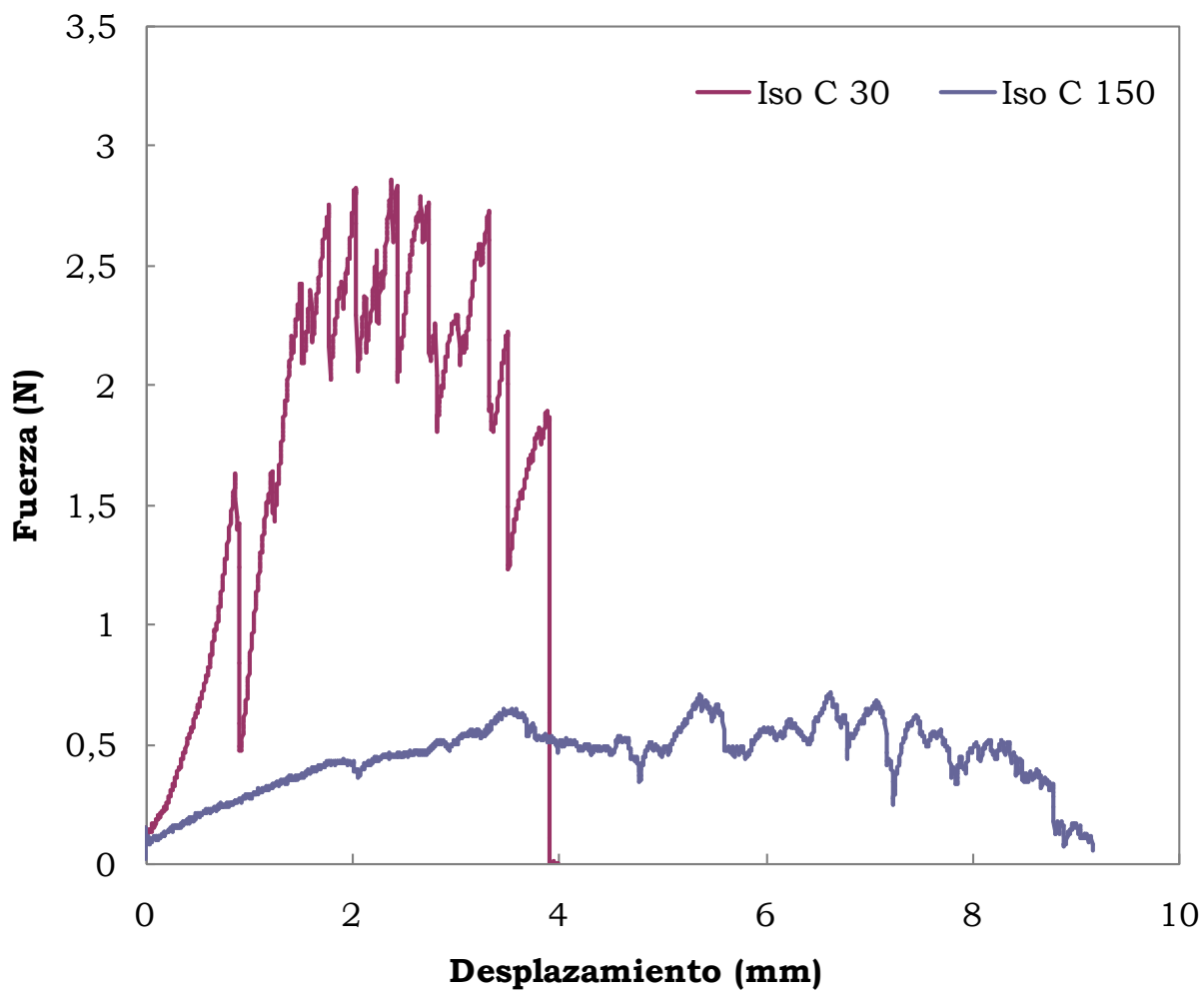

Figura 65. Curvas de textura durante el almacenamiento de Iso $\mathrm{C}$ a los $30 \mathrm{y}$ 150 días. 
No se observó un descenso pronunciado del contenido de ácido ascórbico durante el almacenamiento para ninguno de los snacks. Para los tiempos estudiados no se observaron diferencias significativas a hasta los 120 días $(\mathrm{P}<0,05)$, y el contenido de ácido ascórbico se mantuvo entre 20 y $30 \mathrm{mg}$ AA $/ g_{\mathrm{ms}}$. Valores similares se obtuvieron para los snacks recién horneados. A partir de estos resultados se puede inferir que el aumento en la humedad de los snacks no afectó el contenido de vitamina $\mathrm{C}$ durante el almacenamiento. Scherer y col. (2012) observaron una baja reducción del ácido ascórbico contenido en bebidas en polvo de jugo de naranja durante 14 días.

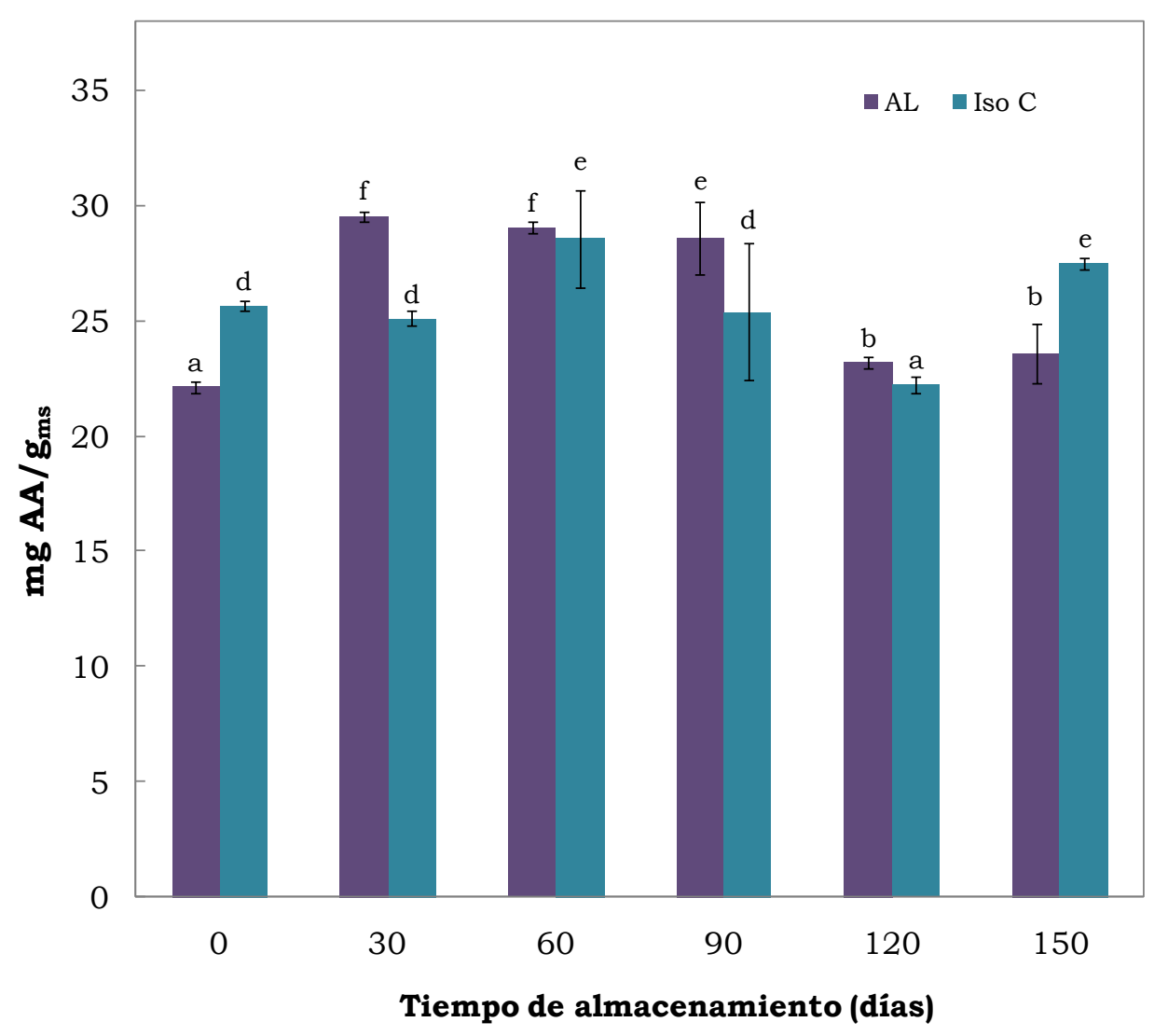

Figura 66. Contenido de ácido ascórbico de los snacks $\mathrm{A}_{\mathrm{L}}$ e Iso $\mathrm{C}$ almacenados durante $30,60,90,120$ y 150 dias.

El AA es conocido como una vitamina termolábil por lo que varios autores han estudiado la cinética de degradación térmica en jugos y frutas naturales, bajo diferentes condiciones de tratamiento (Johnson y 
Braddock, 1995; Vieira y Teixeira, 2000). Por ejemplo, la oxidación del AA a ácido dehidroascórbico y dicetogulónico, hace que se pierda la actividad vitamínica. Por esta razón el seguimiento de la variación en la concentración del AA en alimentos es relevante para establecer los mecanismos que afectan su estabilidad y por tanto influyen en el tiempo de vida útil de los mismos. Esta vitamina es muy sensible a diversas formas de degradación. Entre los numerosos factores que pueden influir en los mecanismos degradativos se pueden citar la temperatura, la concentración de sal y azúcar, el pH, el oxígeno, las enzimas, los catalizadores metálicos, la concentración inicial de ácido y la relación ácido ascórbico - ácido dehidroascórbico (su forma oxidada).

Todos estos factores están relacionados con las técnicas de procesamiento y con la composición del producto que se procesa. Anteriormente, se observó que los tratamientos térmicos implicados en la producción de los snacks, afectaron significativamente el contenido de $\mathrm{AA}$, reflejado en una pronunciada disminución de este nutriente, lo cual dependió de la velocidad de eliminación del agua en los anillos de manzana. Teniendo en cuenta que durante el almacenamiento de los snacks, el envase constituyó una barrera efectiva, gracias a su baja permeabilidad al oxígeno y que no ocurrieron cambios drásticos de la temperatura, era esperable que el contenido de ácido ascórbico se mantuviese estable en el tiempo estudiado.

\subsection{CONCLUSIONES}

A partir de la solución de Maltodextrina:Isomalt se pudo obtener un snack de manzana con características valoradas en productos de este tipo, como lo son el bajo aporte de calorias, crocancia, baja higroscopicidad y alta estabilidad durante 120 dias de almacenamiento.

Siendo los snacks obtenidos a partir de fructosa productos altamente higroscópicos, los mismos deben ser envasados porque 
después de un cierto tiempo, se hidratarán y su temperatura de transición vítrea caerá por debajo de la temperatura ambiente. E1 envase ofrece una ventaja para la conservación del producto final a temperatura ambiente, siempre y cuando el contenido de humedad se mantenga constante durante el almacenamiento.

El snack obtenido a partir de Maltodextrina:Fructosa, se mantuvo estable durante 30 días envasado y no presentó disminución del contenido de ácido ascórbico durante ese período de almacenamiento.

La técnica DMA resultó novedosa para el análisis de la textura de alimentos secos. A través de las curvas de esfuerzo-deformación a una temperatura fija se pudo obtener el perfil del comportamiento del material y observar los cambios en la textura.

La temperatura de transición vítrea $\left(\mathrm{T}_{\mathrm{g}}\right)$ de los snacks, obtenida a través de calorimetría diferencial de barrido (DSC) fue dependiente de la fracción de agua adsorbida. Contenidos de humedad altos disminuyeron la $\mathrm{T}_{\mathrm{g}}$ del producto, lo que confirmó la capacidad plastificante del agua sobre esta propiedad. La temperatura y humedad de almacenamiento del producto afectaron las características texturales del alimento.

Las isotermas de sorción obtenidas experimentalmente fueron de tipo III, de forma exponencial. El modelo de GAB fue adecuado para la descripción de las isotermas a $20{ }^{\circ} \mathrm{C}$, con un rango de actividad acuosa desde 0,11 hasta 0,95 .

El valor de humedad de monocapa resultó similar en ambos snacks. Sin embargo, la estabilidad de los productos durante el almacenamiento estaría gobernada por los azúcares mayoritarios presentes en los mismos. 
A través de la relación entre isotermas de sorción, temperatura de transición vítrea y contenido de humedad se pudieron obtener los parámetros críticos para cada uno de los snacks. A $20^{\circ} \mathrm{C}$, el snack Iso C debe almacenarse por debajo del 44\% HR y el snack $A_{L}$ a una HR del $11 \%$, para evitar pérdidas de calidad en la textura por las variaciones en la humedad.

\subsection{REFERENCIAS}

Al-Muhtaseb, A., Muhanned, A., Megahey, E., McMinn, W., Magee, T. (2010). Moisture adsorption isotherms of microwave-baked madeira cake.LWT - Food science and technology, 43: 1042-1049.

Aguilera, J.M., Cuadros, T.R., del Valle, J.M. (1998). Differential scanning calorimetry of low-moisture apple products. Carbohydrate Polymers, 37-. 79-86.

Aguilera, J.M., Levi, G., Karel, M. (1993). Effect of water content on theglass transition and caking of fish hydrolyzates. Biotechnology Progress, 9: 651-654.

Aguilera, J.M., Stanley, D.W. (1990). Microstructural Principles ofFood Processing and Engineering, Elsevier Applied Sci. Publ., London.

Arévalo-Pinedo, A., Dos Santos, F.L., Salles Arévalo, Z.D., Zuniga, A., Arévalo-Pinedo, R. (2006). Desorption isotherms for murici (Byrsonimasericea) and inga (Ingáedulis) pulps. Journal of Food Engineering, 76: 611-615.

Blahovec, J. (2004. Sorption isotherms in materials of biological origin mathematical and physical approach. Journal of Food Engineering, 65:489-495

Coupland, J.N., Shaw, N.B., Monahan, F.J., O'Riordan, D. O'Sullivan, M. (2000). Modeling the effect of glycerol on the moisture 
sorption behavior of whey protein edible films. Journal of Food Engineering, 43(1): 25-30.

Chaunier, L., Della Valle, G., Lourdin, D. (2007). Relationships between texture, mechanical properties and structure of corn flakes. Food Research International, 40(4): 493-503.

Demarchi, S. M., Quintero Ruiz, N. A., De Michelis, A., Giner, S. A. (2013). Sorption characteristics of rosehip, apple and tomato pulp formulations as determined by gravimetricand hygrometric methods. LWT - Food Science and Technology, 52(1): 21-26.

Djendoubi, N., Bonazzi, C., Boudhrioua, N., Kechaou, N., Courtois, F. (2012). Influence of sugar composition on water sorption isotherms and on glass transition in apricots. Journal of Food Engineering, 111: 403-411.

Farroni, A. (2011) Transformaciones estructurales y físicoquímicasde maíces argentinos en la producción de alimentos obtenidos por procesos de gelatinización-laminación. Tesis doctoral. Facultad de Ciencias Exactas y Naturales. Universidad de Buenos Aires.

Gondek, E., Lewicki, P.P. (2006). Antiplasticization of cereal-based products by water. Part II: Breakfast cereals. Journal of Food Engineering, 77(3): 644-652.

Iglesias, H.A., Chirife, J. (1982). Handbook of food isotherms. Academic Press, Inc. New York.

Jamali, A., Kouhila, M., Mohamed, L.A., Jaouhari, J.T., Abdenouri, N. (2006). Sorption isotherms of Chenopodium ambrosioides, leaves at three temperatures. Journal of Food Engineering, 72: $77-84$

Johnson, J., Braddock, R. (1995). Kinetics of ascorbic acid loss and non enzymatic browning in orange juice serum: Experimental rate constants. Journal of Food Science, 60: 502-505. 
Katz, E.E., Labuza, T.P. (1981). Effect of water activity on the sensory crispness and mechanical deformation of snack food products. Journal of Food Science, (46): 403-409.

Konopacka, D., Plocharski, W. (1999). Determination of sorption properties of fatfree apple chips and the trials of diminishing their hygroscopicity. Final repport for the Committee for Scientific Research, Poland (in Polish). Project No P06G 053. 43 pp.

Konopacka, D., Plocharski, W., Beveridge, T. (2002). Water sorption and crispness of fat-free apple chips. Journal of Food Science, 67 (1): 87-92.

Labuza, T. P. (1971). Properties of water and the keeping quality offoods. Memorias del III Congreso International de Ciencia y Tecnología de Alimentos, Washington, D.C., EUA.

López-Córdoba, A., Deladino, L., Agudelo-Mesa, L., Martino, M. (2014). Yerba mate antioxidant powders obtained by co-crystallization: Stabilityduring storage. Journal of Food Engineering, 124:158-165.

Luyten, H., Plijter, J. J., Van Vliet, T. (2004). Crispy/crunchy crusts of cellular solid foods: literature review with discussion. Journal of Texture Studies, 35(5): 445-492.

Mohamed, L.A., Kouhila, M., Jamali, A., Lahsasni, S., Mahrouz, M. (2004). Moisture sorption isotherms and heat of sorption of bitter orange leaves (Citrus aurantium). Journal of Food Engineering, 67: 491498.

Peleg, M. (2003). The mechanical properties of brittle, cellular and particulatedfoods.In: Proceedings of the 3rd International Symposium on Food Rheology and Structure, Zurich, Switzerland.

Prieto García, F., Gordillo Martínez, A. (2006). Evaluación de las isotermas de sorción en cereales para desayuno. Superficies y Vacio, 19(1): 12-19. 
Qian L., Dong, L., Li-jun., W., Necati, O., Zhi-huai., M. (2010). Dynamic viscoelastic properties of sweet potato studied by dynamic mechanical analyzer. Carbohydrate Polymers, 79: 520- 525.

Rao, M. A., Rizvi, S. S. H. (1995). Engineering properties of foods. New York, USA: Marcel Dekker Inc.

Roudaut, G., Dacremont, C., Meste, M.1. (1998). Influence of water on the crispness of cereal-based foods: acoustic, mechanical, and sensory studies. Journal of Texture Studies, 29(2): 199-213.

Roudaut, G., Dacremont, C., Valles Pamies, B., Colas, B., Le Meste, M. (2002). Crispness: a critical review on sensory and material science approaches. Trends Food Science and Technology, 13(6): 217227.

Romano, N., Tavera-Quiroz, M.J., Bertola, N., Mobili, P., Pinotti, A., Gómez-Zavaglia, A. (2014). Edible methylcellulose-based films containing fructo-oligosaccharides as vehicles for lactic acid bacteria. Food Research International, 64: 560-566.

Roos, Y.H. (1993). Water activity and physical state effects on amorphous food stability. Journal of Food Processing and Preservation, 16(6): 433-447.

Roos, Y., Karel, M. (1991). Applying state diagrams to food processing and development. Food Technology, 45(12): 66, 68.

Salamanca-Grosso, G. (2012). La transformación de los alimentos y el cambio en sus propiedades termofisicas. Revista de la Facultad de Química Farmacéutica, Universidad de Antioquia. Medellín, Colombia, ISSN 0121 - 4004 - ISSN e 2145-2660, 19(2): 1-106.

Slade, L., Levine, H. (1991). Beyond water activity: Recent advance based on an alternative approach to the assessment of food quality an safety. CRC Reviews Food Science Nutrition, 30: 115-360. 
Sablani, S. S., Kasapis, S., Rahman, M. S., Al-Jabri, A., Al-Habsi, N. (2004). Sorption isotherms and the state diagram for evaluating stability criteria of abalone. Food Research International, 37: 915-924.

Schultheiss, N., Newman, A. (2009). Pharmaceutical co-crystals and their physicochemical properties. Crystal Growth and Design, 9 (6): 2950-2967.

Scherer, R., Poloni Rybka, A.C, Ballus, C.A, Dillenburg Meinhart, A.,Teixeira Filho, J., Teixeira Godoy, H. (2012). Validation of a HPLC method for simultaneous determination of main organic acids in fruits and juices. Food Chemistry, 135: 150-154

Suwonsichon, T., Peleg, M. (1998). Instrumental and sensory detection of simultaneous brittleness loss and moisture toughening in three puffed cereals. Journal of Texture Studies, 29 (3): 255-274.

Van den Berg, C., Bruin, S. Water activity and its estimation in food systems. In: L.B. Rockland, F. \& Stewart. (Eds.), Water Activity: Influence on Food Quality. Academic Press, New York, 147-177. 1981.

Valenzuela, C., Aguilera, J.M. (2015). Effects of maltodextrin on hygroscopicity and crispness of apple leathers. Journal of Food Engineering, 144: 1-9.

Varela, P., Salvador, A., Fiszman, S. (2009). On the assessment of fracture in brittle foods II. Biting or chewing?. Food Research International, 42: 1468-1474.

Vásquez, C., Díaz-Calderón, P., Enrione, J., Matiacevich, S. (2013). State diagram, sorption isotherm and color of blueberries as afunction of water content. Thermochimica Acta, 570: 8- 15

Vega-Gálvez, A., Aravena, E.L, Lemus Mondaca, R. (2006). Adsorption isotherms of corn (Zea mays L) flour, Ciencia y Tecnología de Alimentos, 26: 821-827. 
Vickers, Z., Bourne, M. C. (1976). A psycho-acoustic theory of crispness. Journal of Food Science, 41: 1158-1164.

Vieira, M., Teixeira, A. (2000). Mathematical modelling of the thermal degradation kinetic of vitamin C in cupuacu nectar. Journal of Food Engineering, 43: 1-7. 
Capitulo 6.

OBTENCIÓN DE UN SNACK FUNCIONAL A PARTIR DE LA APLICACIÓN DE RECUBRIMIENTOS DE METILCELULOSA COMO SOPORTE DE BACTERIAS LÁCTICAS 



\subsection{CONSIDERACIONES GENERALES}

Un recubrimiento o película comestible se define como una o varias capas finas continúas de biopolímeros que actúan como barrera y que puede ser consumida por sus efectos inocuos sobre la salud. Puede ser dispuesto como cubierta o entre los componentes del alimento o ser un medio para transportar ingredientes de/hacia los alimentos y/o mejorar el manejo de los mismos. El recubrimiento puede ser aplicado sobre la superficie de los productos alimenticios por inmersión, aspersión o pincelado (Bourtoom, 2008). Por lo tanto, los recubrimientos y películas comestibles contribuyen a la conservación de alimentos ya que, dependiendo de sus características, proveen integridad estructural a los alimentos, retienen los componentes volátiles y pueden controlar la transferencia de humedad, de gases, la migración de los lípidos y ser soporte de aditivos y otros nutrientes (Guilbert y col., 1996; Campos y col., 2011). Por otra parte, actúan como barreras para controlar la transferencia de compuestos que transmitan sabores extraños, prevenir el deterioro de calidad y aumentar la vida útil de los alimentos (Bonilla y col., 2012). Estudios realizados demuestran que los recubrimientos comestibles aplicados a los alimentos antes de la fritura contribuyen a la retención de humedad y la menor transferencia de aceite durante el proceso (Park y col., 1995, Mallikarjunan y col., 1997; Holownia y col., 2000; Albert y col., 2002; García y col., 2002, 2004; Tavera Quiroz y col., 2012). La eficacia de estos sistemas ha sido ampliamente demostrada por varios autores que afirman que la aplicación de coberturas pueden retardar reacciones enzimáticas, físicas y químicas, debido a que las mismas generan una barrera termodinámica o fisica que retarda la transferencia de vapor de agua, oxígeno y la movilidad de solutos (Baldwin y col., 1996; Falguera y col, 2011; Atarés, y col., 2011). Tanto los polímeros en sí mismos como los solventes y aditivos utilizados para la formulación de los recubrimientos y películas comestibles deben ser considerados seguros y con sabor y color neutral, debido a que están en contacto directo con el alimento. Deben tener buenas cualidades sensoriales, alta eficiencia 
mecánica y de barrera, estabilidad bioquímica, fisicoquímica y microbiana, ser libres de tóxicos y contaminantes, seguros para la salud, de tecnología simple, de bajo costo de materiales y de procesos. En algunos casos la función principal de las coberturas está relacionada con el control de la pérdida/ganancia de humedad, debido a que se deben mantener ciertos niveles de $a_{w}$, que es un factor importante para mantener la calidad y seguridad del alimento (Talens y col., 2010).

Los hidrocoloides usados para películas y recubrimientos comestibles pueden ser clasificados de acuerdo a su composición, carga molecular y solubilidad en agua en:

- Polisacáridos. Estas películas tienen propiedades de barrera a los gases y pueden adherirse fácilmente a superficies de frutas y vegetales. Se han elaborado películas a partir de celulosa, pectina, almidón, alginatos, quitosano, carragenina, gomas y mezclas (Guzmán, 2003; García y col., 2004; Rivero y col., 2011). Estas matrices son de color claro, resistentes a altos niveles de esfuerzo, relativamente resistentes al paso del agua, no se ven afectadas por aceites, grasas o solventes orgánicos no polares (Guilbert, 1986). Entre los hidrocoloides más estudiados se destacan los derivados de la celulosa, principalmente metilcelulosa (MC) e hidroxipropil-metilcelulosa (HPMC). La capacidad de estas películas para limitar la transferencia de humedad es la clave para la producción de productos fritos de excelente textura. Se han realizado estudios con diferentes derivados de celulosa en la formulación de recubrimientos para disminuir el contenido de grasa en alimentos fritos, obteniéndose resultados favorables en cuanto a la reducción significativa del contenido de aceite de muestras de papas bastón y discos de masa (García y col., 2002; Tavera Quiroz y col., 2012). Otros estudios realizados por RimacBrncic y col. (2004) informaron que la utilización de recubrimientos de hidrocoloides en alimentos, especialmente 
carboximetilcelulosa debido a su carácter hidrofilico, sus buenas propiedades para formar películas, alta viscosidad $y$ comportamiento adhesivo combinados con tratamientos como el escaldado, resultó beneficioso para reducir el contenido de grasa de papas fritas tipo bastón.

- Proteinas. Las fuentes más comunes son caseína, zeína, soja, albúmina de huevo, lactoalbúmina, suero de leche, gluten de trigo y colágeno. Las películas de proteínas se adhieren fácilmente a superficies hidrofilicas pero en la mayoría de los casos no son resistentes a la difusión del agua. Otra desventaja es su sensibilidad a los cambios de $\mathrm{pH}$ por lo que deben limitarse a las condiciones óptimas de su formación (Baldwin, 1994). De acuerdo a Liang y col. (2015) y Khalil y col. (2015) las películas de zeína actúan como barreras a la humedad, pueden restringir el transporte de $\mathrm{O}_{2}$ y sirven como vehículos para los antioxidantes. En el mismo sentido, Guilbert (1996) encontró que si bien las películas de gluten de trigo son buenas barreras al $\mathrm{O}_{2}$ y al $\mathrm{CO}_{2}$, tienen alta permeabilidad al agua.

Cuando un polímero es aplicado a una superficie o matriz, dos tipos de fuerzas son las responsables de su acción, cohesión y adhesión. El grado de cohesión afecta las propiedades de la película como su densidad, porosidad, permeabilidad, flexibilidad y fragilidad (Guilbert, 1996). Por ejemplo en el caso de las películas proteicas cuando se exponen a un calor excesivo se afecta la cohesión, ya que las moléculas son inmovilizadas prematuramente provocando efectos como perforaciones y fracturas (Guzmán, 2003). En el caso de la obtención de matrices a partir de soluciones de concentración intermedia, generalmente resulta en el incremento de la fuerza cohesiva debido a la viscosidad óptima y solvatación del polímero (Bourtoom, 2008). También se pueden incorporar materiales que tengan influencia sobre las propiedades mecánicas, de barrera y sensoriales. Estos pueden ser 
plastificantes (ceras, aceites, ácidos grasos), conservantes químicos (ácido benzoico, acido sórbico) y/o surfactantes y emulsificantes (Campos y col., 2011). La influencia que tendrá el material incorporado sobre las propiedades de la película dependerá del grado de concentración, la estructura química, el grado de dispersión en la matriz y la interacción con los polímeros (Ortiz, 2006).

Los plastificantes afectan las propiedades mecánicas y la permeabilidad de las películas, alterando su estructura, la movilidad de la cadena y los coeficientes de difusión de gases o agua. Son compuestos de baja volatilidad que pueden ser añadidos para impartir flexibilidad a una película polimérica (Kester y Fennema, 1986). Los plastificantes que se utilizan en la industria de los alimentos incluyen monosacáridos, disacáridos y oligosacáridos (glucosa, jarabes de fructosa o glucosa, miel), polioles (sorbitol, glicerol, polietilenglicoles y los derivados del glicerol) y lipidos y derivados (ácidos grasos, monoacilgliceroles, derivados éster, fosfolípidos y surfactantes).

Durante la última década importantes investigaciones se han llevado a cabo en el área de producción de películas comestibles con mejores propiedades de barrera al vapor de agua y a los gases, mejora de las propiedades mecánicas y estudios de biodegradabilidad (Rivero y col., 2014; Khanzadi y col., 2015) Recientemente, se ha introducido a las películas y recubrimientos comestibles en un campo de investigación orientado a aportar funcionalidad a los alimentos, haciendo de estos materiales portadores eficientes de compuestos bioactivos como vitaminas, antioxidantes, antimicrobianos y probióticos (López de Lacey y col., 2012; Kanmani y Lim, 2013; Soukolis y col., 2014 b). En cuanto a películas comestibles como soporte de probióticos, Kanmani y Lim (2013) informaron de la alta viabilidad de múltiples cepas probióticas incorporadas en películas comestibles de almidón. López de Lacey y col. (2012) informaron que la inmovilización de bacterias lácticas en matrices de gelatina podría proporcionar una 
buena protección contra la pérdida de viabilidad durante al menos seis dias de almacenamiento en condiciones de refrigeración.

Según la FAO/OMS (2002) los probióticos son microorganismos vivos que cuando se administran en cantidades adecuadas $\left(10^{6}-10^{7}\right.$ UFC/g) pueden conferir beneficios para la salud del huésped. Algunos de estos beneficios atribuidos a los probióticos son: regulación de la movilidad del sistema tracto gastrointestinal, estimulación del sistema inmune, reducción de los niveles de colesterol, mejoría de la intolerancia a la lactosa y sindrome del intestino irritable, prevención de enfermedades cardiovasculares y diferentes formas de cáncer (Kumar y col., 2010; Saad y col., 2013; Chong, 2014). En general, los probióticos se consumen a través de productos alimenticios y representan una parte significativa del mercado de los alimentos funcionales (Tripathi y Giri, 2014). Las matrices más extendidas para la incorporación de los probióticos son productos lácteos, incluyendo yogures, leches fermentadas y postres a base de leche, leche en polvo para bebés recién nacidos, helados, mantequilla y diferentes tipos de queso (Champagne y col., 2005). Otros productos no lácteos, como la mayonesa, productos encapsulados, y alimentos fermentados de origen vegetal, también han sido utilizados como vehículos de probióticos (Champagne y col., 2005; Saad, 2006; Komatsu y col., 2008).

La conciencia de los consumidores sobre el impacto de los alimentos en la salud ha contribuido en gran medida a aumentar la demanda de alimentos funcionales (Tripathi y Giri, 2014). Como el consumo de snacks es un hábito bien establecido en todo el mundo, estos productos pueden representar una matriz apropiada para el suministro de bacterias probióticas (Noorbakhsh y col., 2013). Sin embargo, existen múltiples condiciones a superar como son las lesiones bacterianas y la pérdida de viabilidad derivadas de las condiciones de procesamiento de alimentos (tratamientos térmicos, estrés mecánico, deshidratación osmótica, etc) (Lapsiri y col., 2012; Bustos y Bórquez, 
2013) además de mantener las propiedades del snack (crocancia, textura, color, parámetros sensoriales). Por lo tanto, el desarrollo de snacks con probióticos incorporados requiere un estricto control de todos estos aspectos. Como se mencionó anteriormente, la incorporación de los probióticos en películas comestibles parecería ser una estrategia adecuada para inmovilizar estos microorganismos. Las aplicaciones de coberturas con probióticos en el campo de los alimentos no han sido estudiadas en gran extensión hasta el momento. Altamirano-Fortoul y col. (2012) obtuvieron panes funcionalizados combinando la microencapsulación de Lactobacillus acidophilus y coberturas de almidón, con una adecuada supervivencia de bacterias después del proceso de horneado y del almacenamiento. Soukulis y col. (2014 b) presentaron el desarrollo exitoso de panes recubiertos con soluciones de alginato de sodio y concentrado de proteína de suero lácteo conteniendo Lactobacillus rhamnosus GG. El recuento de bacterias lácticas presentes en el producto final fue suficiente para ser considerado probiótico.

En un artículo reciente, se ha demostrado que películas de metilcelulosa (MC) se comportan como matrices adecuadas para inmovilizar lactobacilos (Romano y col., 2014). La metilcelulosa es un polimero de bajo costo, comestible, con buenas propiedades como agente formador de películas que ha dado lugar a numerosas aplicaciones farmacéuticas y alimentarias (Li y col., 2002; Bodvik y col., 2010). La incorporación de fructooligosacáridos (FOS) en la matriz de la película contribuye a proteger a los microorganismos durante la deshidratación y almacenamiento, y también proporciona propiedades prebióticas a las películas obtenidas (Gibson y col., 2004; Romano y col., 2014). Un prebiótico es aquel compuesto que induce el crecimiento y la actividad de bifidobacterias y bacterias ácido-lácticas en el intestino humano (Van Loo y col., 1999). Otros polioles también podrían ser considerados prebióticos potenciales (Cummings y col., 2001). Soukulis y col. (2014 b) confirmaron que la incorporación de fibras prebióticas 
como inulina, fructooligosacáridos, polidextrosa y dextrinas, en películas comestibles tiene efectos beneficiosos sobre la estabilidad de células probióticas inmovilizadas durante el almacenamiento. Isomalt es un carbohidrato que se digiere parcialmente y algunas fracciones llegan al colon donde son fermentados por la microflora intestinal $(\mathrm{Ba}$, 1990; Langkilde y col., 1994; Livesey, 2003). Según Gostner y col. (2006) isomalt tuvo efecto bifidogénico en voluntarios sanos y por lo tanto puede ser considerado un carbohidrato prebiótico contribuyendo a mantener una flora intestinal saludable. Lactobacillus plantarum CIDCA 83114 es una cepa especialmente interesante por sus propiedades inhibidoras frente a E. coli O157:H7, Shigella y Salmonella (Hugo y col., 2008; Golowczyc y col., 2011a,b; Kakisu y col., 2013 a,b).

\section{Objetivos}

El objetivo propuesto en este capítulo fue desarrollar un snack funcional a partir de anillos crocantes de manzana verde con la adición de isomalt aplicando un recubrimiento de metilcelulosa al que se había incorporado Lactobacillus plantarum CIDCA $83114^{2}$.

\footnotetext{
${ }^{2}$ Este capítulo del trabajo se realizó en conjunto con el Lic. Nelson Romano, el Dr. Pablo Mobili y la Dra. Andrea Gómez-Zavaglia, integrantes del Laboratorio de Microbiología del Centro de Investigación y Desarrollo en Criotecnología de Alimentos (CIDCA), dentro del marco de la tesis doctoral.
} 


\subsection{MATERIALES Y MÉTODOS}

\subsubsection{MATERIALES}

Para la preparación de los recubrimientos se utilizó metilcelulosa (MC) A4M (Methocel, Dow Chemical Co, Estados Unidos) proporcionada por COLORCON S.A (Argentina), sorbitol (Merck, Estados Unidos), ácido cítrico (Biopac, Estados Unidos) y fructooligosacáridos (FOS) (p95 OraftiBeneo, Mannheim, Alemania). La cepa Lactobacillus plantarum CIDCA 83114 fue aislada a partir de gránulos de kéfir (Gómez-Zavaglia y col., 1999; Garrote y col., 2001) y conservada a $-80^{\circ} \mathrm{C}$ en $120 \mathrm{~g} / \mathrm{L}$ de sólidos lácteos no grasos.

\subsubsection{MÉTODOS}

\subsubsection{Preparación de los cultivos de bacterias lácticas probióticas}

Cepas de L. plantarum CIDCA 83114 se inocularon en caldo MRS a $30^{\circ} \mathrm{C}$ en aerobiosis, hasta alcanzar una concentración de aproximadamente $2 \times 10^{10} \mathrm{UFC} / \mathrm{ml}$. Luego, $100 \mathrm{ml}$ de cultivo se centrifugaron y se lavaron con una solución salina ( $\mathrm{NaCl}$ 0,85\% p/v), hasta obtener pellets de la bacteria láctica. Los pellets obtenidos se conservaron a $4^{\circ} \mathrm{C}$ hasta ser incorporados en la solución de hidrocoloide.

\subsubsection{Preparación de las soluciones filmogénicas}

Para la preparación de la solución filmogénica, 1,5 g de MC A4M se dispersaron en $50 \mathrm{ml}$ de agua destilada a $80^{\circ} \mathrm{C}$ bajo agitación constante durante $1 \mathrm{~h}$. Una vez que se obtuvo un sistema homogéneo, se completó el volumen hasta un total de $100 \mathrm{ml}$ con agua destilada fría y se mantuvo bajo agitación hasta que la solución alcanzó temperatura ambiente. Se agregaron $0,25 \%(\mathrm{p} / \mathrm{v})$ de sorbitol como plastificante (Anexo 2) y 5\% (p/p MC) de ácido cítrico, como agente entrecruzante de la matriz (Anexo 2). Los FOS se añadieron a la solución de hidrocoloide, hasta una concentración final de $30 \mathrm{~g} / \mathrm{L}$. La solución de metilcelulosa se esterilizó usando filtros estériles de 0,2 micras. Los pellets de la 
bacteria láctica $L$. plantarum se incorporaron a $4 \mathrm{ml}$ de la solución de MC.

\subsubsection{Preparación de los snacks de manzana recubiertos}

Un volumen de $100 \mu 1$ de solución de MC preparada de acuerdo a lo descripto en el punto 6.2.2.2 se aplicaron mediante pincelado sobre una de las caras de los snacks Iso C obtenidos como se describió en el Capítulo 4. Se evaluaron cinco combinaciones de temperatura/ tiempo para el secado de la cobertura: $140{ }^{\circ} \mathrm{C} / 3 \mathrm{~min} ; 100{ }^{\circ} \mathrm{C} / 5 \mathrm{~min} ; 80{ }^{\circ} \mathrm{C} / 20$ $\min , 60{ }^{\circ} \mathrm{C} / 50 \mathrm{~min}$ y $50{ }^{\circ} \mathrm{C} / 90 \mathrm{~min}$, en un horno de convección forzada Multiequip HCE-3. Para cada temperatura, el tiempo de secado se optimizó de forma que los snacks mantuvieran las propiedades que los caracterizan en cuanto a crocancia y evitando el detrimento de los microorganismos presentes. Una vez seleccionada la temperatura/tiempo de secado de la cobertura, se prepararon las muestras y se envasaron en bolsas de polipropileno biorientado (BOPP) termoselladas (Vitopel SA, Argentina). Se almacenaron en una cámara de temperatura controlada a $20{ }^{\circ} \mathrm{C}$ y humedad relativa del $60 \%(\mathrm{RH})$. Como controles se utilizaron snacks Iso $\mathrm{C}$ sin recubrimientos.

\subsubsection{Determinación de las propiedades fisicoquimicas, térmicas y nutricionales de los snacks}

Los parámetros de humedad, textura y color y las propiedades térmicas se determinaron tanto sobre las muestras recién preparadas como a lo largo del almacenamiento a los 15, 30, 45, 60 y 90 días, de acuerdo a la metodología explicada en el Capítulo 3- Sección 3.3. y 3.4.

Además se cuantificó el contenido de ácido ascórbico por HPLC en los snacks recién preparados siguiendo el método de Nojavan y col. (2008) modificado, explicado en el Capítulo 3- Sección 3.3.

\subsubsection{Análisis de la superficie de los snacks por SEM}

Las muestras sin y con el recubrimiento se analizaron por SEM con el fin de observar la presencia de las bacterias lácticas inmovilizadas en la cobertura de MC, sobre la superficie de los snacks. 
Las muestras de snacks se colocaron cuidadosamente sobre soportes de carbono (Agar Scientific, Stansted, Reino Unido), se recubrieron con una capa de carbono (Agar turbo carbon coater) y se observaron bajo vacío en el microscopio electrónico de barrido. Las imágenes fueron adquiridas a un voltaje de aceleración de $5 \mathrm{kV}$.

\subsubsection{Análisis microbiológico}

\section{Determinación de la viabilidad bacteriana}

Paralelamente a los ensayos físicos, químicos, térmicos $\mathrm{y}$ microestructurales llevados a cabo sobre el snack, se determinó la viabilidad de las bacterias. Para analizar la supervivencia de la cepa durante todo el ensayo, se trituraron suavemente 0,5 g del snack recubierto y se rehidrataron con $5 \mathrm{ml}$ de solución salina durante $10 \mathrm{~min}$ para permitir una hidratación completa. Además, se obtuvo el recuento de bacterias en la solución filmogénica para conocer su concentración inicial. Las suspensiones obtenidas se diluyeron en serie, en agar MRS y se incubaron a $30^{\circ} \mathrm{C}$ durante $24 \mathrm{~h}$. Este proceso se llevó a cabo inmediatamente después del secado y durante el almacenamiento.

\section{Digestión in vitro}

Se realizó una digestión in vitro con el fin de evaluar la tolerancia de la bacteria láctica a las condiciones gastrointestinales y determinar cómo esa tolerancia se veía afectada por el almacenamiento. El ensayo se realizó en los días 0, 30, 60 y 90 y se dividió en dos etapas. Primero se evaluó la digestión gástrica y luego la digestión intestinal (pancreatina, sales biliares, pH 7,5) (Sigma Aldrich, EE.UU.). Para realizar el ensayo primero se trituraron $0,50 \mathrm{~g}$ de snack, los cuales se mezclaron con 2,5 ml de solución salina. A esta suspensión se agregó el jugo gástrico simulado concentrado (pepsina porcina 3200 unidades/ml, $\mathrm{CaCl}_{2}$ 7,2 mM, $\mathrm{MgCl}_{2} 3 \mathrm{mM}, \mathrm{NaCl} 98 \mathrm{mM}, \mathrm{KCl} 24 \mathrm{mM}$, $\left.\mathrm{KH}_{2} \mathrm{PO}_{4} 12,8 \mathrm{mM}\right)$ y se ajustó el $\mathrm{pH}$ a 2,5 con $\mathrm{HCl}$ diluido. Las muestras se incubaron durante 1 hora a $37^{\circ} \mathrm{C}$ bajo agitación continua (130 rpm, MaxQ 4000, Thermo Scientific, EE.UU.). La etapa de la digestión 
gástrica fue detenida aumentando el $\mathrm{pH}$ a 6,5 con una solución de $\mathrm{NaOH}$. La etapa de la digestión intestinal se realizó agregando el jugo intestinal simulado $(10 \mathrm{mg} / \mathrm{ml}$ de pancreatina, $20 \mathrm{mg} / \mathrm{ml}$ de sales biliares, $\mathrm{NaHCO}_{3} 100 \mathrm{mM}$ ) a la suspensión anterior y se ajustó el pH a 7,5. La solución resultante se incubó durante 2 horas a $37^{\circ} \mathrm{C}$, bajo agitación continua. Después de cada etapa, alícuotas de $1 \mathrm{ml}$ se diluyeron en solución salina y se sembraron en agar MRS para obtener el recuento de bacterias, tal como se describió en el punto anterior del método 6.2.2.6.

\subsubsection{Análisis sensorial}

Para evaluar la aceptabilidad de los snacks recubiertos se efectuó un panel sensorial, similar al descripto en el Capítulo 3- Sección 3.4. El ensayo se realizó con un panel compuesto por 50 miembros con experiencia en evaluación sensorial, seleccionados dentro del personal del CIDCA (La Plata, Argentina). Las muestras fueron codificadas y presentadas a los panelistas en bandejas enumeradas junto con las instrucciones para la evaluación. Los atributos analizados fueron la apariencia, color, textura, sabor y aceptabilidad general, utilizando una escala hedónica de nueve puntos para cada uno. Se pidió a los panelistas indicar la puntuación de cada muestra en una escala desde 1 (disgusta) a 9 (gusta). Una puntuación igual a cinco se utilizó como un umbral mínimo para la aceptabilidad. Para cada uno de estos atributos, se informó la frecuencia relativa de las respuestas de los panelistas, que corresponde al número de panelistas que eligió una categoria sobre el número total de panelistas.

\subsubsection{Análisis Estadístico}

El análisis de la varianza (ANAVA) se utilizó para analizar los resultados obtenidos con el programa estadístico Infostat software v2009 (Córdoba, Argentina). Para los ensayos de comparación de medias se empleó el test LSD Fisher con $P<0,05$. 


\subsection{RESULTADOS Y DISCUSIÓN}

\section{Selección de las condiciones de secado del recubrimiento sobre los snacks}

El desarrollo de alimentos que contienen microorganismos probióticos representa un desafio debido a que el procesamiento (tratamientos térmicos), el almacenamiento y el paso a través del tracto gastrointestinal pueden ser perjudiciales para dichos microorganismos. La Agencia Europea de Seguridad Alimentaria (EFSA) y la Administración de Alimentos y Medicamentos (FDA) exigen concentraciones de $10^{6}$ a $10^{7} \mathrm{UFC} /$ galimento de probiótico al momento de ser ingerido (Hill y col., 2014; Tripathi y Giri, 2014). La elaboración del snack Iso C requirió el uso de altas temperaturas las cuales resultarían perjudiciales para las bacterias. Por esta razón, los snacks obtenidos en este trabajo se realizaron en dos etapas. Primero se obtuvieron los anillos de manzana horneados a $140^{\circ} \mathrm{C} / 30 \mathrm{~min}$, con buenas características físicas y sensoriales, tal como se explicó en el Capítulo 4 y luego se procedió a aplicar un recubrimiento cargado con una bacteria con potencial probiótico. La aplicación de la solución de MC modificó las propiedades organolépticas del snack, especialmente la textura por el aumento de la humedad. Para disminuir este efecto se aplicó una capa delgada de solución filmogénica cargada con el microorganismo $(100 \mu 1)$, la cual fue distribuida uniformemente sobre una cara de las muestras. La carga bacteriana contenida en la misma fue de $6,2 \times 10^{10}$ $\pm 0,7 \times 10^{10} \mathrm{UFC} / g_{\text {snack. }}$ Una vez aplicado el recubrimiento se requirió una etapa de secado por un tratamiento térmico tal, que permitiera asegurar la recuperación de la crocancia y la supervivencia de la cantidad requerida de microrganismos. La elección de las combinaciones temperatura/ tiempo se basó en un trabajo anterior, donde se definió una combinación de 2,5 horas a $40^{\circ} \mathrm{C}$ para obtener películas a partir de $1,5 \mathrm{ml}$ de solución de $\mathrm{MC}$ con L. plantarum CIDCA 83114 (Romano y col., 2014). Sin embargo, en el caso de los snacks el volumen de agua a evaporar era mucho menor. Por lo tanto, se 
analizaron diferentes combinaciones de temperatura/tiempo para determinar una condición que permitiera un secado completo del recubrimiento sin efectos perjudiciales para las bacterias lácticas tal como se describió en el punto 6.2.2.3. de Materiales y Métodos. Los resultados obtenidos se observan en la Figura 67.

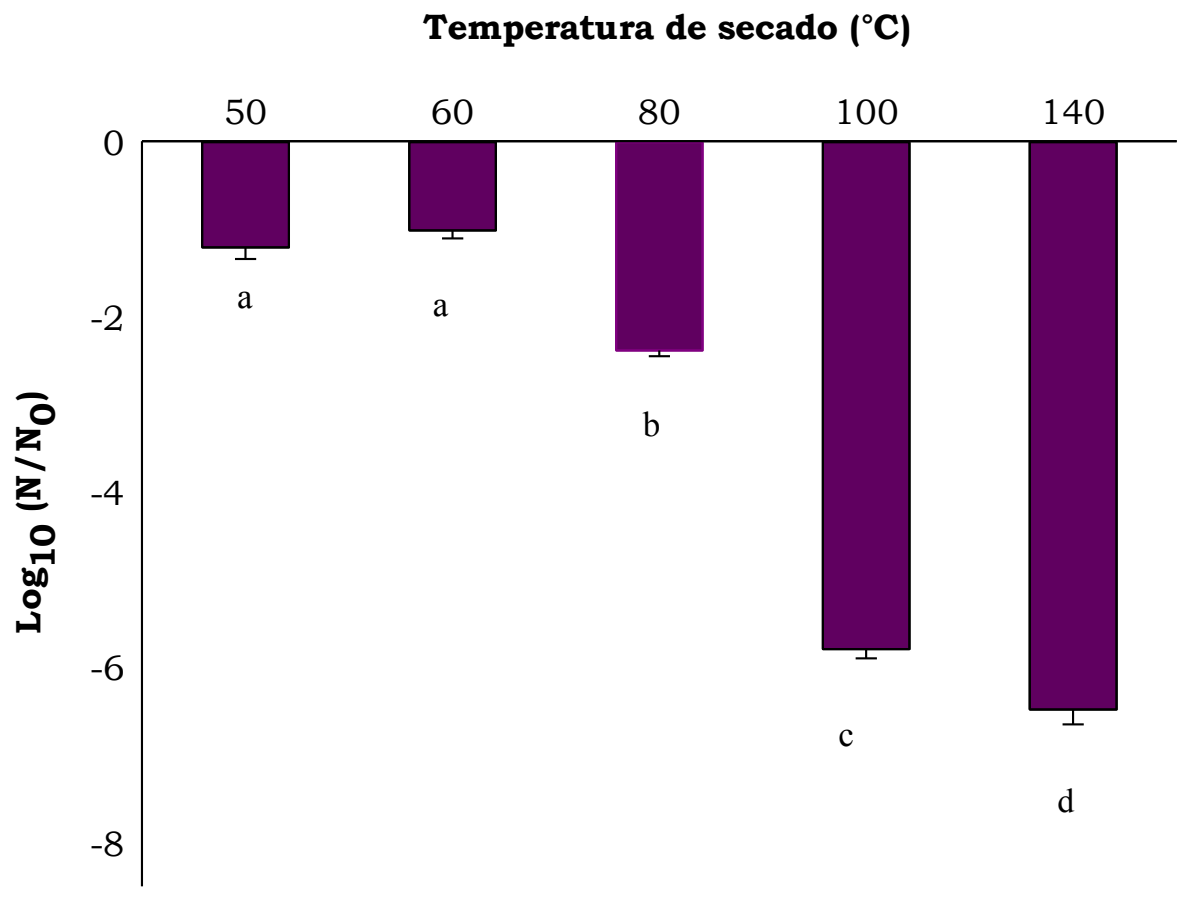

Figura 67. Viabilidad de las bacterias lácticas durante el secado de la cobertura sobre el snack de manzana. Los tiempos utilizados fueron: $140{ }^{\circ} \mathrm{C} / 3$ $\min ; 100{ }^{\circ} \mathrm{C} / 5 \mathrm{~min} ; 80{ }^{\circ} \mathrm{C} / 20 \mathrm{~min}, 60^{\circ} \mathrm{C} / 50 \min$ y $50{ }^{\circ} \mathrm{C} / 90 \mathrm{~min}$.

Con un secado a temperaturas superiores a $80{ }^{\circ} \mathrm{C}$ se obtuvieron pérdidas de viabilidad celular, en comparación con los tratamientos térmicos a menor temperatura. Teniendo esto en cuenta, se seleccionó el tratamiento a $60^{\circ} \mathrm{C}$ durante 50 minutos como la condición de secado de la cobertura sobre el snack. Esta condición permitió obtener un producto con bajo contenido de humedad, crocante y con alta viabilidad de microorganismos (Figura 68). 


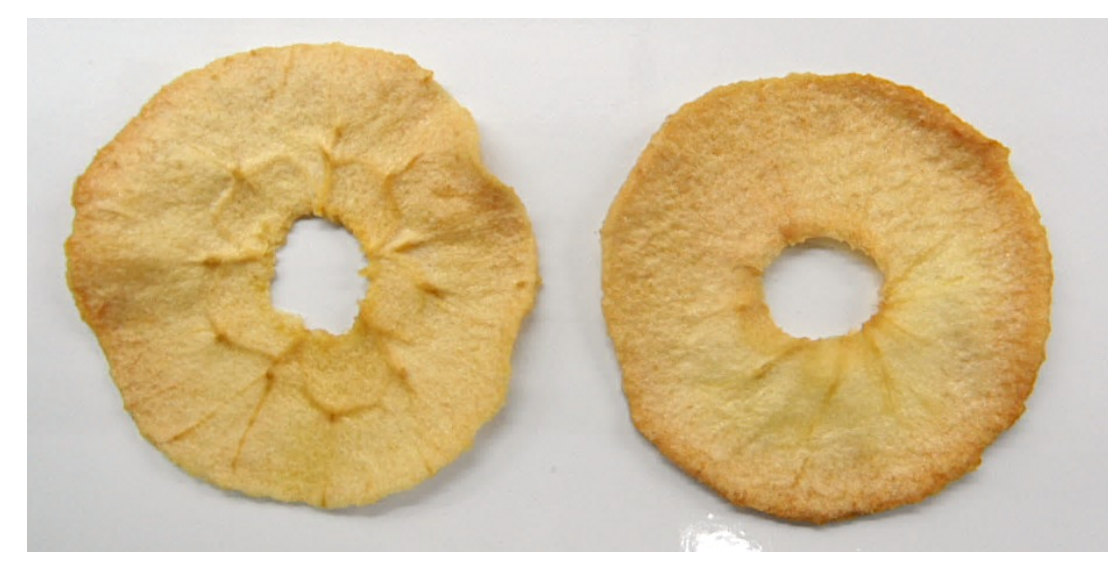

Figura 68. Snacks recubiertos con películas de MC y L. plantarum CIDCA 83114.

Fu y Chen (2011) observaron que el secado por convección de microorganismos probióticos induce una pérdida significativa en la viabilidad debido a cambios en la estructura celular. En ese caso el secado a altas temperaturas tuvo un efecto significativo sobre la viabilidad de la bacterias $(P<0,05)$. Teniendo en cuenta este efecto fue necesario realizar la aplicación de las películas comestibles en la etapa final del proceso de cocción del snack, utilizando bajas temperaturas para secar la superficie con el fin además de conseguir un enfriamiento rápido del producto. $\mathrm{El}$ mecanismo de formación de la cobertura de $\mathrm{MC}$, requiere de bajas temperaturas (Anexo 2). En este proceso a medida que el agua se evapora se forma una estrecha red de puentes de hidrógeno, la cual ocupa un mayor volumen libre a medida que aumenta el contenido de plastificante agregado (Tavera Quiroz y col., 2013). El ácido cítrico actúa reforzando esta red, contribuyendo a mejorar las propiedades mecánicas y de barrera (Anexo 2). En el interior de esta estructura quedan atrapadas las bacterias lácticas, evitando así que se vean mayormente afectadas por el tratamiento térmico. Esto explicaría la alta viabilidad de las bacterias durante el secado a bajas temperaturas. Resultados de estudios anteriores confirmaron que las películas de MC con agregado de sorbitol, FOS y ácido cítrico actuaron como matrices aptas para preservar bacterias lácticas sin alterar su estructura y evitando la muerte celular (Romano y col., 2014). Soukulis 
y col. (2014 a) informaron que películas de alginato de sodio y suero de leche aplicadas sobre la corteza de panes generaron una buena cobertura sobre la superficie y los autores consideraron que esta cobertura mejoraría potencialmente la resistencia de bacterias lácticas frente a condiciones extrínsecas tóxicas como la presencia de oxígeno y vapor de agua, que además aceleran la degradación del producto.

\section{Propiedades físicas, químicas y nutricionales de los snacks recubiertos y el control}

Las propiedades de los snacks recubiertos con las películas de MC con L. plantarum CIDCA 83114 y el control Iso C, durante el almacenamiento se muestran en la Tabla 25

Tabla 25. Contenido de humedad, color y BI (indice de pardeamiento) del control (sin cobertura) y los snacks recubiertos con películas de MC con $L$. plantarum almacenados durante 90 dias a $20{ }^{\circ} \mathrm{C}$ y $60 \% \mathrm{HR}$.

\begin{tabular}{|c|c|c|c|c|}
\hline Snack & $\begin{array}{c}\text { Tiempo } \\
\text { (dias) }\end{array}$ & $\begin{array}{c}\text { Humedad } \\
\left(g_{\text {agua }} / \operatorname{100g}_{\mathrm{ms}}\right)\end{array}$ & $\begin{array}{c}\text { Luminosidad } \\
\qquad\left(L^{*}\right)\end{array}$ & $\begin{array}{l}\text { Browning } \\
\text { index (BI) }\end{array}$ \\
\hline \multirow{5}{*}{ Control } & 0 & $1,8^{a, b^{*}}(0,4)^{*}$ & $64,0 \mathrm{a}, \mathrm{b}(1,2)$ & 44,0 a $(2,2)$ \\
\hline & 30 & $1,4^{\mathrm{a}}(0,1)$ & $63,0^{a}(1,7)$ & $44,0^{a}(2,2)$ \\
\hline & 45 & $2,7 \mathrm{~b}, \mathrm{c}, \mathrm{d}(0,2)$ & $63,2^{\mathrm{a}, \mathrm{b}}(0,8)$ & $45,0^{a, b}(1,4)$ \\
\hline & 60 & $3,2^{\mathrm{d}, \mathrm{e}}(0,6)$ & $63,0^{\mathrm{a}, \mathrm{b}}(1,1)$ & $46,0^{\mathrm{a}, \mathrm{b}}(1,1)$ \\
\hline & 90 & $3,8^{\mathrm{e}}(0,6)$ & 67,0 a,b $(1,4)$ & $45,0^{\mathrm{a}, \mathrm{b}}(1,3)$ \\
\hline \multirow{6}{*}{$\begin{array}{l}\text { Snack con } \\
\text { cobertura }\end{array}$} & 0 & $3,0^{b^{*}}(0,3)$ & $69,0^{\mathrm{b}}(1,5)$ & $57,0^{c}(2,9)$ \\
\hline & 15 & $2,5^{\mathrm{b}, \mathrm{c}, \mathrm{d}}(0,9)$ & $70,0^{\mathrm{b}}(1,6)$ & $51,0^{\mathrm{b}, \mathrm{c}}(1,5)$ \\
\hline & 30 & $2,6^{b, c, d}(0,4)$ & $65,0^{a, b}(1,1)$ & $55,0^{c}(2,1)$ \\
\hline & 45 & $2,4 \mathrm{~b}, \mathrm{c}(0,9)$ & $66,3^{a, b}(0,8)$ & $50,0^{\mathrm{b}, \mathrm{c}}(2,9)$ \\
\hline & 60 & $3,1^{\mathrm{d}, \mathrm{e}}(0,4)$ & $63,0^{a}(1,5)$ & $53,0^{c}(3,9)$ \\
\hline & 90 & $2,5^{\mathrm{b}, \mathrm{c}, \mathrm{d}}(0,4)$ & $66,0^{a, b}(1,4)$ & $52,0^{c}(2,3)$ \\
\hline
\end{tabular}

$a, b, c, d, e$ Letras diferentes en cada columna indican diferencias significativas. *Valores entre paréntesis indican desviación estándar. 
Los snacks horneados a $140^{\circ} \mathrm{C}$ durante $30 \mathrm{~min}$ sin cobertura (controles) presentaron un contenido de humedad de $1,8 \%$ (b.s) a tiempo inicial y luego de 45 dias de el almacenamiento se produjo un aumento significativo de este parámetro $(\mathrm{P}<0,05)$. Para el producto con la cobertura, el contenido de humedad obtenido fue significativamente más alto que para el control a tiempo inicial $(\mathrm{P}<0,05)$ y este valor se mantuvo constante después de 90 dias de almacenamiento. Este comportamiento resultó similar al obtenido en papas chips con un recubrimiento de $\mathrm{MC}$ con agregado de sorbitol al 0,75\% (Tavera Quiroz y col., 2012). En este trabajo las muestras con recubrimiento mostraron valores de humedad y actividad acuosa mayores que el control y no se observaron variaciones durante el almacenamiento. En cuanto al color se obtuvo un leve aumento de los valores de $L^{*}$ y del BI respecto al snack control. Estos cambios podrian deberse al tratamiento térmico adicional para el secado de la cobertura, sobre productos que habian sido previamente horneados (Figura 67). De acuerdo a Wijers y Strater (2001) isomalt tiene la propiedad de reducir el desarrollo de la reacción de caramelización, tal como se explicó en el Capítulo 4. Los resultados obtenidos en cuanto a los parámetros de color y BI indicaron que isomalt tuvo un efecto protector no sólo durante el proceso de cocción, sino también durante el secado de la cobertura, evitando que se produjeran colores y sabores indeseables. Además las películas de MC son translúcidas y la adición de las bacterias lácticas no alteró esta propiedad (Anexo 2). Por lo tanto la presencia de la cobertura no aportó color a los snack recubiertos.

Se evaluó también la textura de los snacks con la película de MC con L. plantarum y se compararon con los perfiles de textura obtenidos para el control sin cobertura. Los valores de módulo elástico y desplazamiento se observan en la Tabla 26 
Tabla 26. Parámetros de textura de los snacks recubiertos con película de MC con L. plantarum y del control Iso $\mathrm{C}$ almacenados durante 90 días a $20^{\circ} \mathrm{C}$ y $60 \% \mathrm{HR}$

\begin{tabular}{|c|c|c|c|}
\hline Snack & $\begin{array}{c}\text { Tiempo } \\
\text { (dias) }\end{array}$ & $\begin{array}{c}\text { Desplazamiento } \\
(\mathrm{mm})\end{array}$ & $\begin{array}{c}\text { Módulo elástico } \\
\text { (N/mm) }\end{array}$ \\
\hline \multirow{5}{*}{ Control } & 0 & $1,2^{\mathrm{a}, \mathrm{b}}(0,1)^{*}$ & $1,1^{\mathrm{a}, \mathrm{b}}(0,1)$ \\
\hline & 30 & $1,2^{\mathrm{a}, \mathrm{b}}(0,2)$ & $1,3^{\mathrm{b}}(0,2)$ \\
\hline & 45 & $1,3^{a, b}(0,3)$ & $0,9^{a, b}(0,2)$ \\
\hline & 60 & $1,0^{\mathrm{a}}(0,1)$ & $1,8^{\mathrm{c}}(0,03)$ \\
\hline & 90 & $1,6^{\mathrm{b}}(0,2)$ & $0,60^{a}(0,01)$ \\
\hline \multirow{6}{*}{$\begin{array}{l}\text { Snack con } \\
\text { cobertura }\end{array}$} & 0 & $0,82^{a}(0,07)$ & $1,1^{\mathrm{a}, \mathrm{b}}(0,2)$ \\
\hline & 15 & $1,2^{\mathrm{a}, \mathrm{b}}(0,2)$ & $1,2^{\mathrm{a}, \mathrm{b}}(0,2)$ \\
\hline & 30 & $1,1^{\mathrm{a}, \mathrm{b}}(0,1)$ & $0,99 a, b(0,03)$ \\
\hline & 45 & $1,0^{\mathrm{a}}(0,1)$ & $1,0 \mathrm{a}, \mathrm{b}(0,4)$ \\
\hline & 60 & $1,23^{a, b}(0,05)$ & $1,18^{a, b}(0,01)$ \\
\hline & 90 & $1,1^{\mathrm{a}}(0,3)$ & $1,2^{\mathrm{a}, \mathrm{b}}(0,3)$ \\
\hline
\end{tabular}

$a, b, c$ Letras diferentes indican diferencias significativas $(P<0,05) *$ Valores entre paréntesis indican desviación estandar $(n=6)$

No se observaron diferencias significativas hasta los 90 dias de almacenamiento $(\mathrm{P}>0,05)$. Como se discutió en el Capítulo 5, la calidad del snack luego de 120 dias no fue lo suficientemente buena para el consumo, por lo cual se estableció como punto de corte 90 días sin tener en cuenta la viabilidad de las bacterias. Esta tendencia se obtuvo también para los valores de deformación de las muestras antes de la ruptura que fueron bajos, del orden de $1,2 \mathrm{~mm}$. Los resultados obtenidos para el módulo elástico de las muestras con cobertura no mostraron diferencias significativas $(\mathrm{P}>0,05)$ comparados con el control y tampoco entre ellas para todos los tiempos de almacenamiento 
estudiados. En la Figura 69 a y b se observan los perfiles de textura obtenidos.

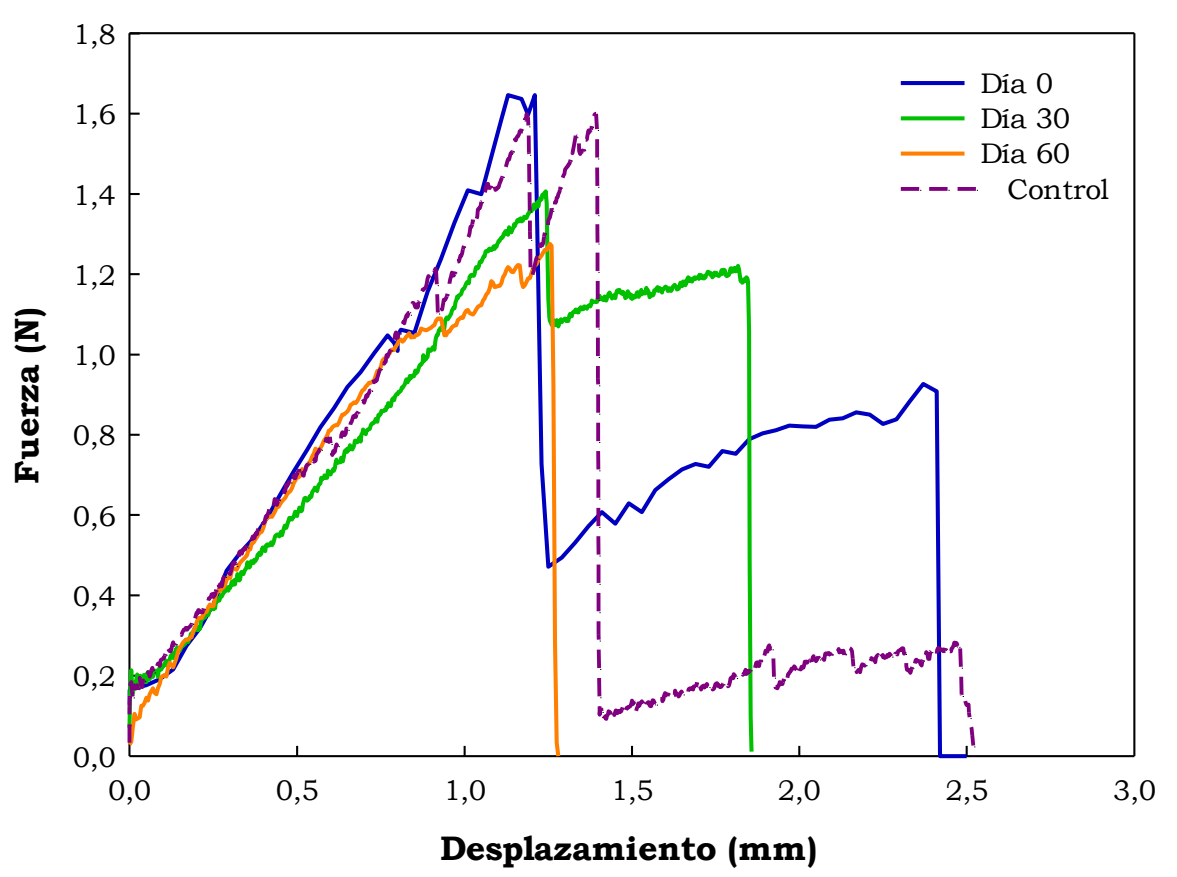

a.

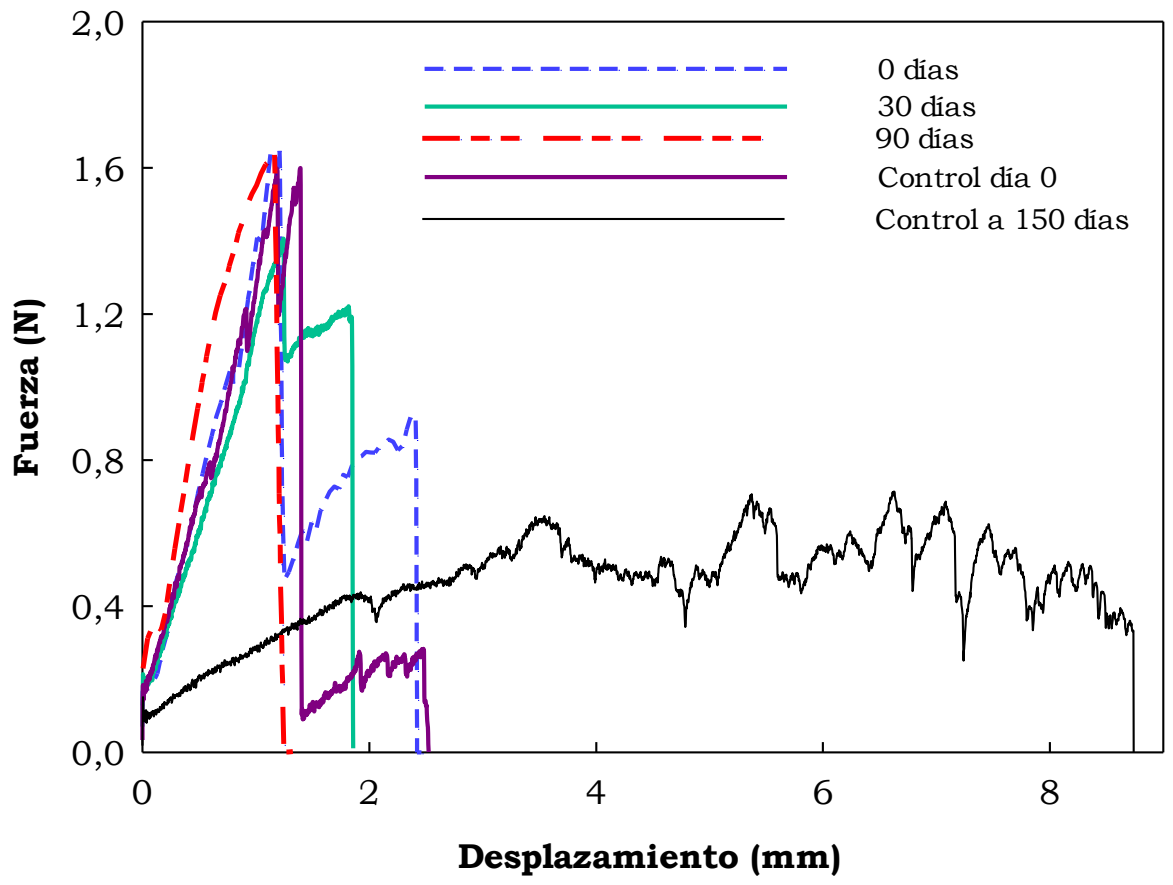

b.

Figura 69. Perfil de textura de los snacks con y sin cobertura almacenados: a. 0, 30, 60 días y control recién preparado; b. 0, 30, 90 días y control recién preparado y almacenado durante 150 días. 
El perfil de textura de los snacks recubiertos con la película de MC conteniendo la bacteria láctica, se caracterizó por una fuerza de ruptura promedio de 1,6 N. Las curvas de fuerza-desplazamiento obtenidas tanto para el control como los snacks recubiertos, antes del almacenamiento (día 0), mostraron patrones similares típicos de productos crocantes. Teniendo en cuenta lo anterior, y a pesar de las diferencias en el contenido de humedad de las muestras con y sin recubrimiento, el análisis de varianza mostró que la presencia de la cobertura no afectó de manera significativa la fuerza máxima de ruptura $(P>0,05)$. Esto significa que la fuerza que se debe aplicar para lograr romper el snack control no fue significativamente diferente $(\mathrm{P}>0,05)$ a la que se debe aplicar a las muestras con recubrimientos a base de metilcelulosa.

Este es un resultado favorable porque se demostró que la cobertura no tuvo un impacto significativo en la textura de los snacks. Valores similares fueron obtenidos por Pedreschi y Moyano (2005) y por Rayner y col. (2000) trabajando con películas de proteína de soja aplicadas sobre papas chips sometidas a fritura. Por otra parte, Tawada y Nakao (1999) en un trabajo realizado con donas, encontraron que la adición de MC no tuvo efecto sobre la fuerza de ruptura de las muestras. Tavera Quiroz y col. (2012) obtuvieron resultados similares de fuerza máxima, los cuales no presentaron diferencias en papas chips con y sin recubrimiento de MC.

\section{Contenido de ácido ascórbico}

El contenido de ácido ascórbico se determinó en el control y en los snacks luego del proceso de secado de la cobertura. Se obtuvo una concentración de 24,5 mg AA/gms. Este resultado fue similar al obtenido para los snacks $A_{L}$ e Iso C. Esto podría deberse a una combinación de factores que conjuntamente pueden ejercer efectos benéficos para mantener estable el contenido de ácido ascórbico en el snack. Por un lado el efecto protector de isomalt frente a la caramelización excesiva 
(Capítulo 4). Por otra parte, el secado de la cobertura implica la evaporación del agua contenida en la solución de $\mathrm{MC}$, la cual se encuentra en una cantidad mínima. A medida que el agua se evapora se forma la película sobre la superficie del snack, la cual a su vez forma una red que recubre la superficie. Esto evitaría que los nutrientes y las bacterias lácticas presentes estén expuestos a un calor excesivo y al oxígeno del ambiente en forma directa, impidiendo, en este caso, la oxidación del ácido ascórbico presente. Según Kester y Fennema (1986) películas y recubrimientos a partir de polisacáridos o proteínas son excelentes barreras al oxígeno debido a su estructura, la cual forma una red ordenada de puentes de hidrógeno (Yang y Paulson, 2000). En condiciones de baja humedad, la estructura tipo red de la película o recubrimiento se encuentra empaquetada y su permeabilidad al oxígeno es muy limitada (Bonilla y col., 2013). Este mecanismo por sí mismo puede tener efectos positivos en la preservación de la calidad del producto, debido a la reducida disponibilidad de oxígeno en el producto con cobertura. En algunos casos, la adición de antioxidantes puede implicar más protección debido a la mejora de las propiedades de barrera al oxígeno (Ayranci y Tunc, 2003, 2004). Sin embargo, tal como concluyen Atarés y col. (2010), en condiciones de movilidad molecular reducida se puede observar que los agentes antioxidantes no tienen ningún efecto. Según estos autores el único efecto antioxidante es debido a la barrera al oxígeno que aporta la cobertura del producto.

\section{Propiedades térmicas de los snacks recubiertos}

La temperatura de transición vitrea de los snacks se determinó mediante calorimetría diferencial de barrido (DSC). Para los snacks sin cobertura (control) se obtuvieron valores de $\mathrm{T}_{\mathrm{g}}$ de $68^{\circ} \mathrm{C}$, tal como se discutió en el Capítulo 4, mientras que las muestras con recubrimiento de $\mathrm{MC}$ con L. plantarum exhibieron valores alrededor de $58^{\circ} \mathrm{C}$ (Figura 70). 


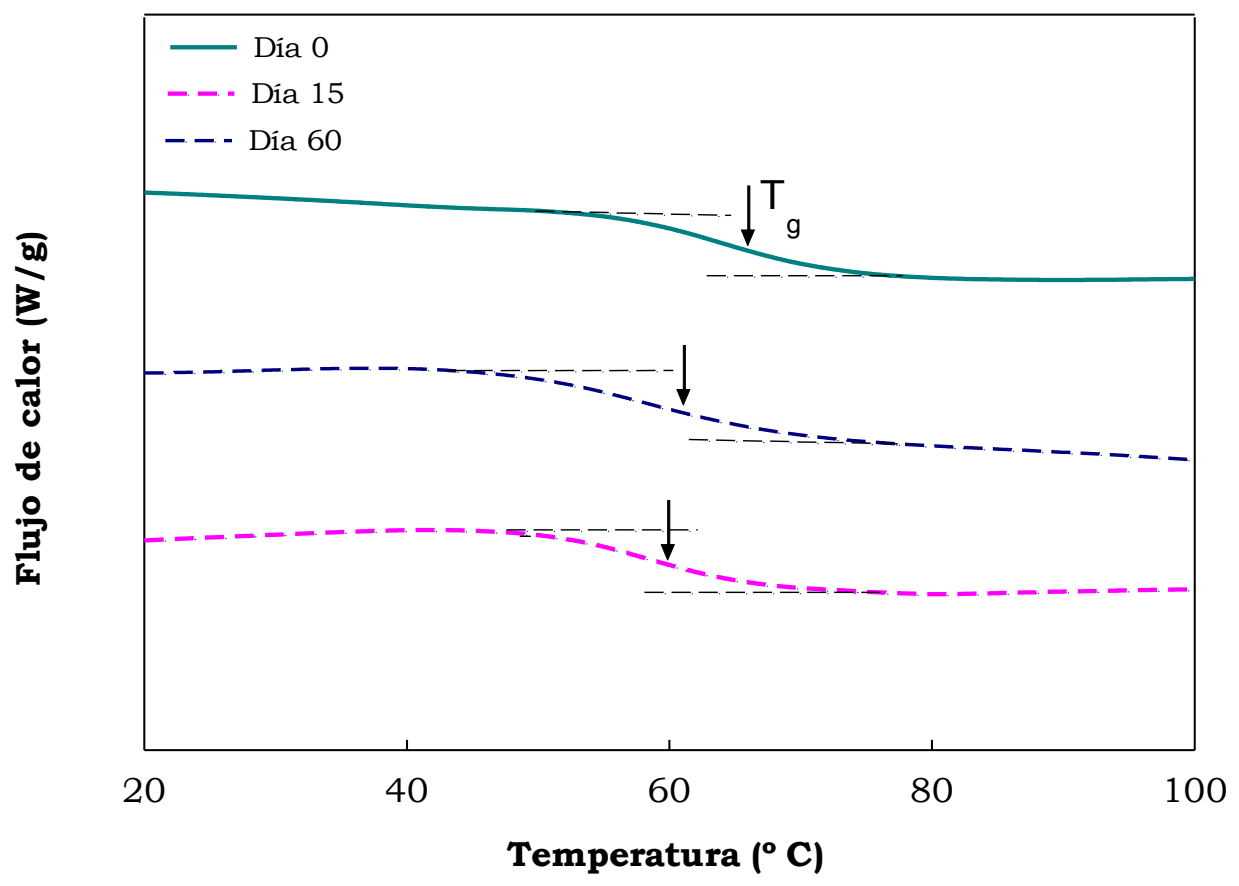

Figura 70. Termogramas de DSC obtenidos de los snacks con recubrimiento de MC con L. plantarum almacenados durante 0, 15 y 60 dias.

Los valores de $\mathrm{T}_{\mathrm{g}}$ obtenidos fueron consistentes con el contenido de humedad. El control presentó un valor más bajo (1,8\% b.s.) que los snacks recubiertos (3,0\% b.s.), demostrando el efecto plastificante del agua en la estructura. A los 90 dias de almacenamiento, la $\mathrm{T}_{\mathrm{g}}$ de los snacks con recubrimiento resultó ser aproximadamente $57^{\circ} \mathrm{C}$, no observándose diferencias significativas $(\mathrm{P}>0,05)$ respecto a la $\mathrm{T}_{\mathrm{g}}$ obtenida al iniciar el almacenamiento (día 0). Esto también se correlacionó con el contenido de humedad, el cual se mantuvo estable durante el almacenamiento. La cobertura de MC si bien aporta un mayor contenido de agua a la estructura debido a su capacidad de retención de agua, disminuye el intercambio con la humedad del ambiente en el cual se encuentran los snacks envasados, y actúa como una barrera adicional al envase de BOPP. Esta propiedad de la película, al impedir la incorporación del agua presente en el entorno del snack, fue capaz de mantener estables los valores de $T_{g}$ por encima de la temperatura ambiente. Esto implica que el snack almacenado a temperatura ambiente está en estado vítreo. 


\section{Análisis de la superficie por microscopia electrónica de barrido (SEM)}

En la Figura 71 se muestran las micrografias obtenidas por SEM de la superficie del snack de manzana recubierto con las películas formadas a partir de MC con L. plantarum (Figura 70 a, b y c) y de los snacks de manzana sin recubrimiento (Figura $71 \mathrm{~d}$ ).
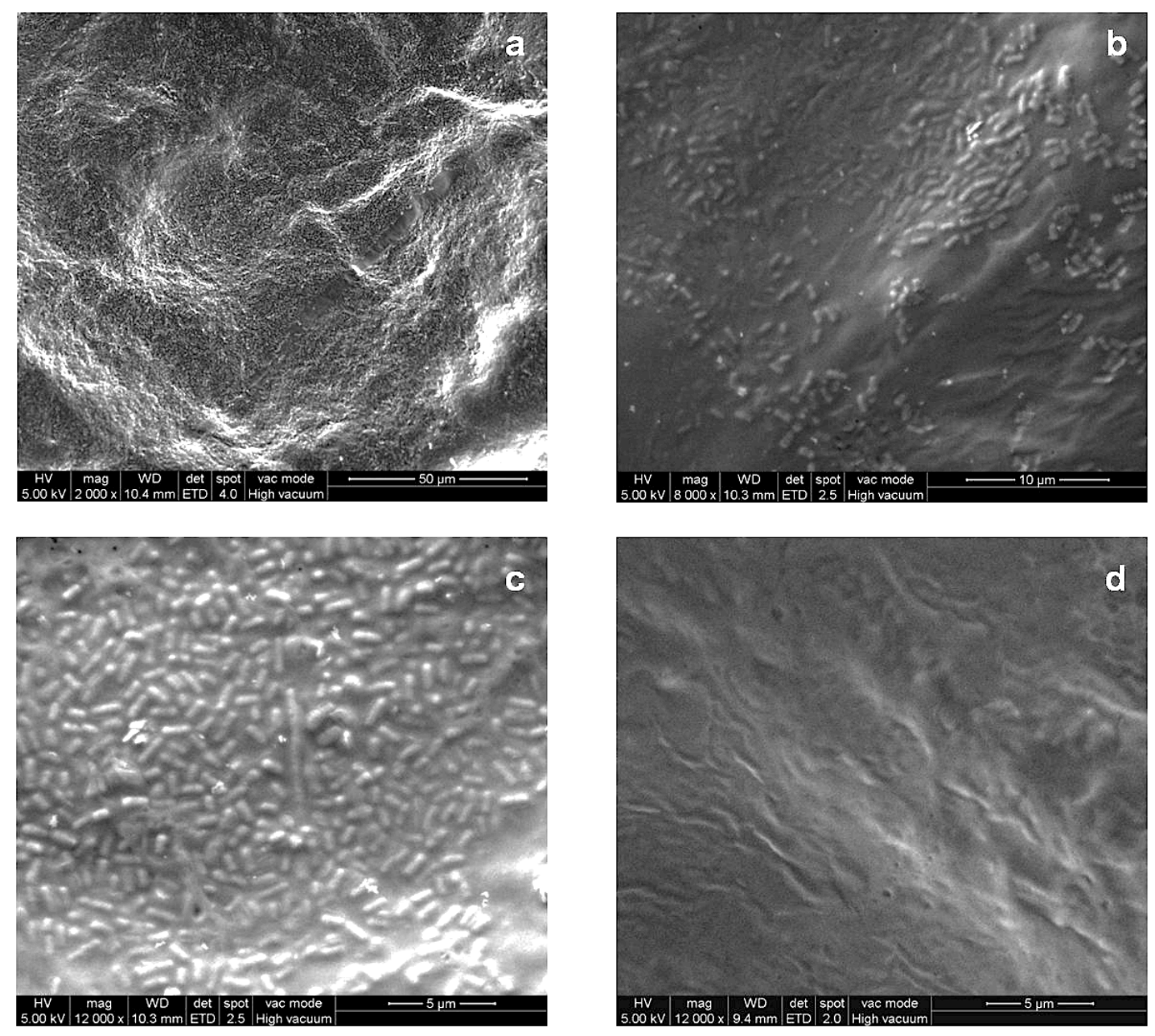

Figura 71. Imágenes obtenidas por SEM de snacks con recubrimiento de $\mathrm{MC}$ con L. plantarum CIDCA 83114 a diferentes resoluciones (a, b y c) y snacks sin cobertura (d).

En las imágenes obtenidas se observa la presencia de la cobertura sobre la superficie de la manzana y los microorganismos en la matriz de $\mathrm{MC}$, sin alteración de la morfología bacteriana. 
En la micrografia mostrada en la Figura 72 se observa una sección en la cual la cobertura se encuentra rota y se aprecia claramente la división entre la misma y la superficie del snack. Estas imágenes confirman que la cobertura de MC además de inmovilizar efectivamente a la bacteria láctica potencialmente probiótica, también protege la superficie del snack de manzana. Esto permitiria establecer una relación con los resultados obtenidos para el contenido de ácido ascórbico.

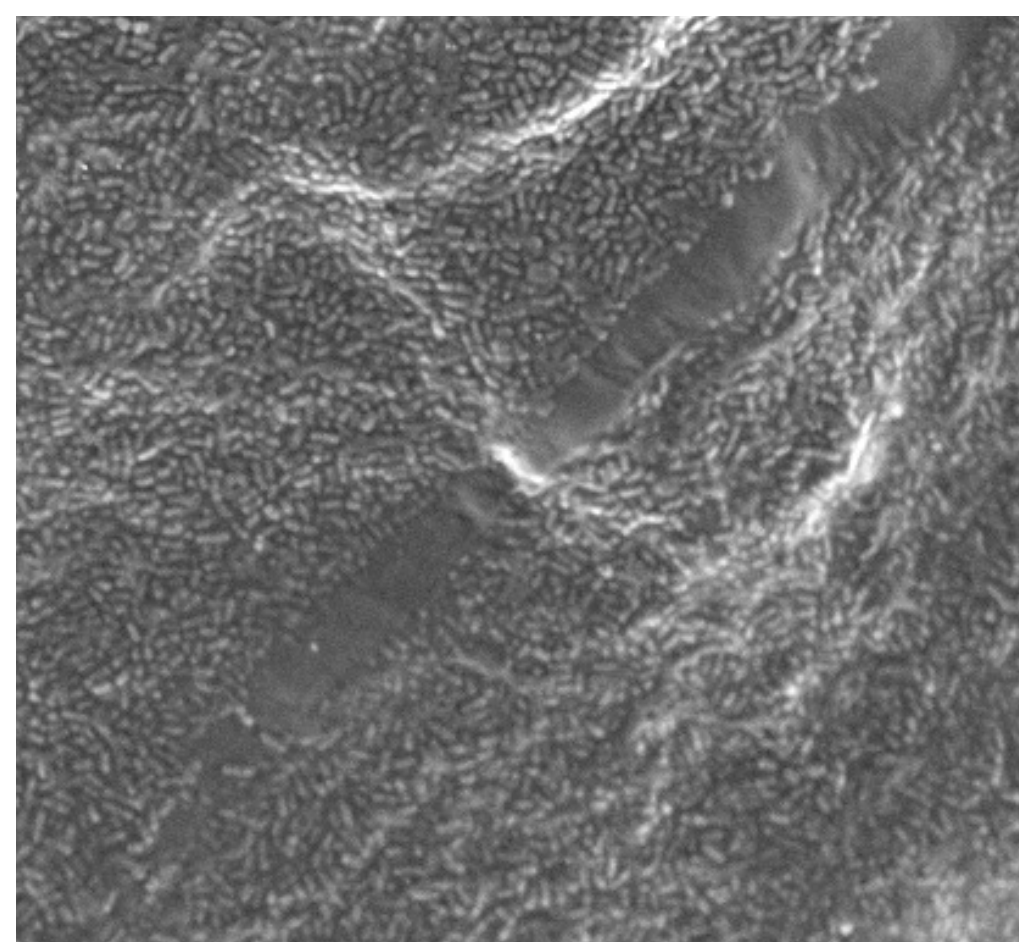

Figura 72. Sección central de la micrografia del snack recubierto (2000 x).

\section{Propiedades microbiológicas: Viabilidad celular y digestión in vitro}

Con el fin de ejercer efectos beneficiosos sobre el huésped, los microorganismos probióticos deben ser capaces de llegar vivos al intestino. Para lograr esto, las bacterias lácticas deben resistir no sólo el secado de la cobertura sobre el snack y los cambios durante el almacenamiento, sino también el contacto con el ácido, enzimas y sales biliares que se encuentran en el estómago y el intestino delgado (Bertazzoni y col., 2013). Teniendo en cuenta que las condiciones de almacenamiento pueden conducir a daño subletal, y microorganismos 
dañados pueden ser más propensos a condiciones nocivas (Tymczyszyn y col., 2007 a, b) se evaluó el efecto de las condiciones gastrointestinales simuladas después de preparar los snacks (tiempo igual a cero), y durante el almacenamiento hasta 90 dias. Los resultados obtenidos para la viabilidad durante el almacenamiento se presentan en la Figura 73 a, y los resultados de viabilidad durante el almacenamiento seguido de la exposición a condiciones gastrointestinales simuladas, en la Figura 73 b.
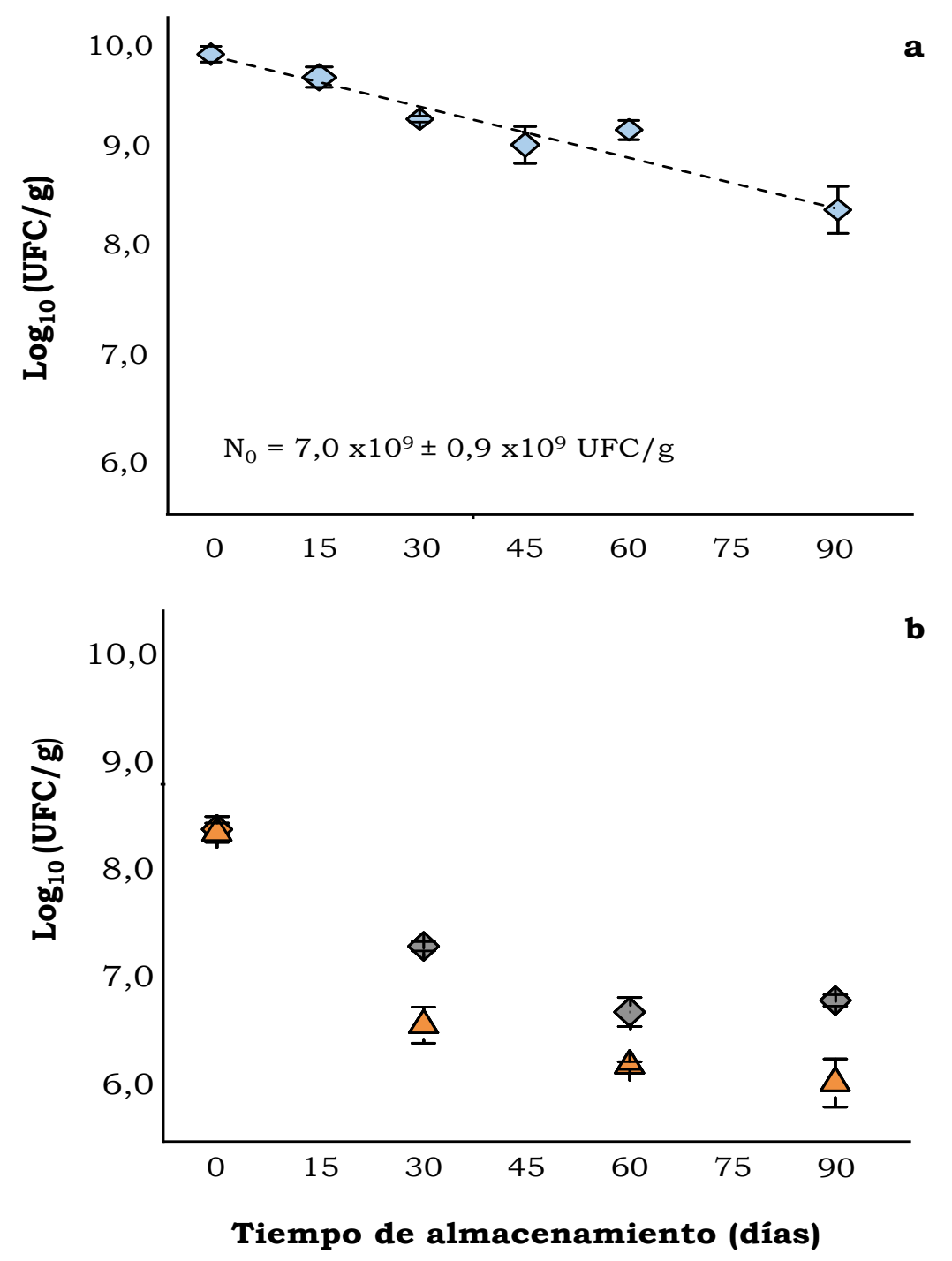

Figura 73. Viabilidad celular de las bacterias lácticas en snacks recubiertos: a. Almacenados a 0, 30, 60 y 90 días; b. Almacenados expuestos a condiciones gástricas e intestinales simuladas in vitro. Los rombos grises corresponden a la viabilidad gástrica y los triángulos naranja a la viabilidad intestinal. 
Los snacks de manzana con las películas de MC mostraron una carga inicial $\left(\mathrm{N}_{0}\right)$ de $7,0 \pm 0,9 \times 10^{9} \mathrm{UFC} / \mathrm{g}$. El almacenamiento a $20^{\circ} \mathrm{C} \mathrm{y}$ $60 \%$ HR provocó una leve disminución de la viabilidad bacteriana después de 90 días (1,43 log UFC/g). Sin embargo, la carga bacteriana $\left(2,0 \times 10^{8} \pm 0,7 \times 10^{8} \mathrm{UFC} / \mathrm{g}\right)$ se mantuvo por encima del mínimo necesario $\left(10^{6}-10^{7} \mathrm{UFC} / \mathrm{g}\right)$ para obtener los beneficios del consumo de probióticos (Figura 73 a) (Hill y col., 2014;. Tripathi y Giri, 2014).

La exposición de los snacks con recubrimiento a condiciones gástricas simuladas inmediatamente después de la obtención del mismo (tiempo igual a cero) condujo a una disminución de 1,54 log UFC/g en la viabilidad celular $\left(2,4 \times 10^{8} \pm 0,6 \times 10^{8} \mathrm{UFC} / \mathrm{g}\right)$ (Figura 73b). No se observó una disminución significativa de la viabilidad luego de la digestión intestinal simulada $\left(2,0 \times 10^{8} \pm 0,4 \times 10^{8} \mathrm{UFC} / \mathrm{g}\right)(\mathrm{P}>0,05)$. A los 90 días se observó una disminución pronunciada de la viabilidad de las bacterias después de la digestión gástrica (3,1 log UFC/g; 5,5×106 $\pm 0,7$ $\left.\times 10^{6} \mathrm{UFC} / \mathrm{g}\right)$ e intestinal $\left(1,0 \times 10^{6} \pm 0,4 \times 10^{6} \mathrm{UFC} / \mathrm{g}\right)$ en las muestras almacenadas (Figura $73 \mathrm{~b}$ ).

Como se ha explicado anteriormente, para ejercer un efecto probiótico notable, las bacterias deben llegar vivas al intestino en cantidades suficientes. Para lograr este objetivo deben superar las condiciones gástricas ( $\mathrm{pH}$ bajo, acción de proteasas) e intestinales (sales biliares, proteasas, lipasas, nucleasas). La capacidad para superar estas barreras fisiológicas no está necesariamente relacionada con la capacidad de sobrevivir a las condiciones de almacenamiento. Por 1o tanto, deben evaluarse antes de asegurar que un alimento funcional posea potencial probiótico.

Los resultados obtenidos muestran que aún en condiciones de estrés (almacenamiento y digestión) la carga de lactobacilos que llega al intestino es suficientemente alta $\left(1,0 \times 10^{6} \pm 0,4 \times 10^{6} \mathrm{UFC} / \mathrm{g}\right)$. Esto permite asegurar que la ingesta de $25 \mathrm{~g}$ del snack funcional alcanza una 
concentración suficiente de microorganismos en el intestino para ejercer un efecto benéfico. Se puede inferir que la incorporación de bacterias lácticas en películas comestibles es una alternativa económica, segura y eficiente para obtener los beneficios de un probiótico en alimentos no lácteos. Espinoza (2008) desarrolló una cobertura a partir de una mezcla de biopolímeros (proteína aislada de suero lácteo, carboximetilcelulosa y pectina), apta para encapsular bacterias ácido lácticas, y obtuvo supervivencias mayores a 90\% cuando fue utilizada en productos panificados. Soukulis y col. (2014 b) informaron resultados similares en productos panificados.

\section{Panel Sensorial}

En el panel sensorial los consumidores evaluaron la aceptabilidad del snack con el recubrimiento con probióticos. La Figura 74 muestra la frecuencia relativa, que corresponde al número de veces que los panelistas otorgaron un puntaje para cada atributo sobre el número total de panelistas (50).

Los resultados para los parámetros de apariencia, color, textura, sabor y aceptabilidad global, en una escala de 1 a 9 , muestran que la máxima frecuencia relativa de las respuestas estuvo entre 6 y 8 para los snacks con recubrimiento. La puntuación para el sabor del snack recubierto con los microorganismos inmovilizados en la película de MC fue significativamente menor $(\mathrm{P}<0,05)$ respecto al control $(6,5 \pm 0,6 \mathrm{y}$ $7,2 \pm 0,4$; respectivamente).

Teniendo en cuenta el atributo de color, los panelistas dieron una puntuación superior a la snack con recubrimiento $(7,7 \pm 0,4)$ en comparación con el control $(7,4 \pm 0,4)$, ya que el tiempo más prolongado de secado $\left(140^{\circ} \mathrm{C} / 30 \mathrm{~min}\right.$ y $\left.60^{\circ} \mathrm{C} / 50 \mathrm{~min}\right)$ permitió un mayor desarrollo de la reacción de caramelización, lo que lleva a los valores más altos de BI (Tabla 25). 

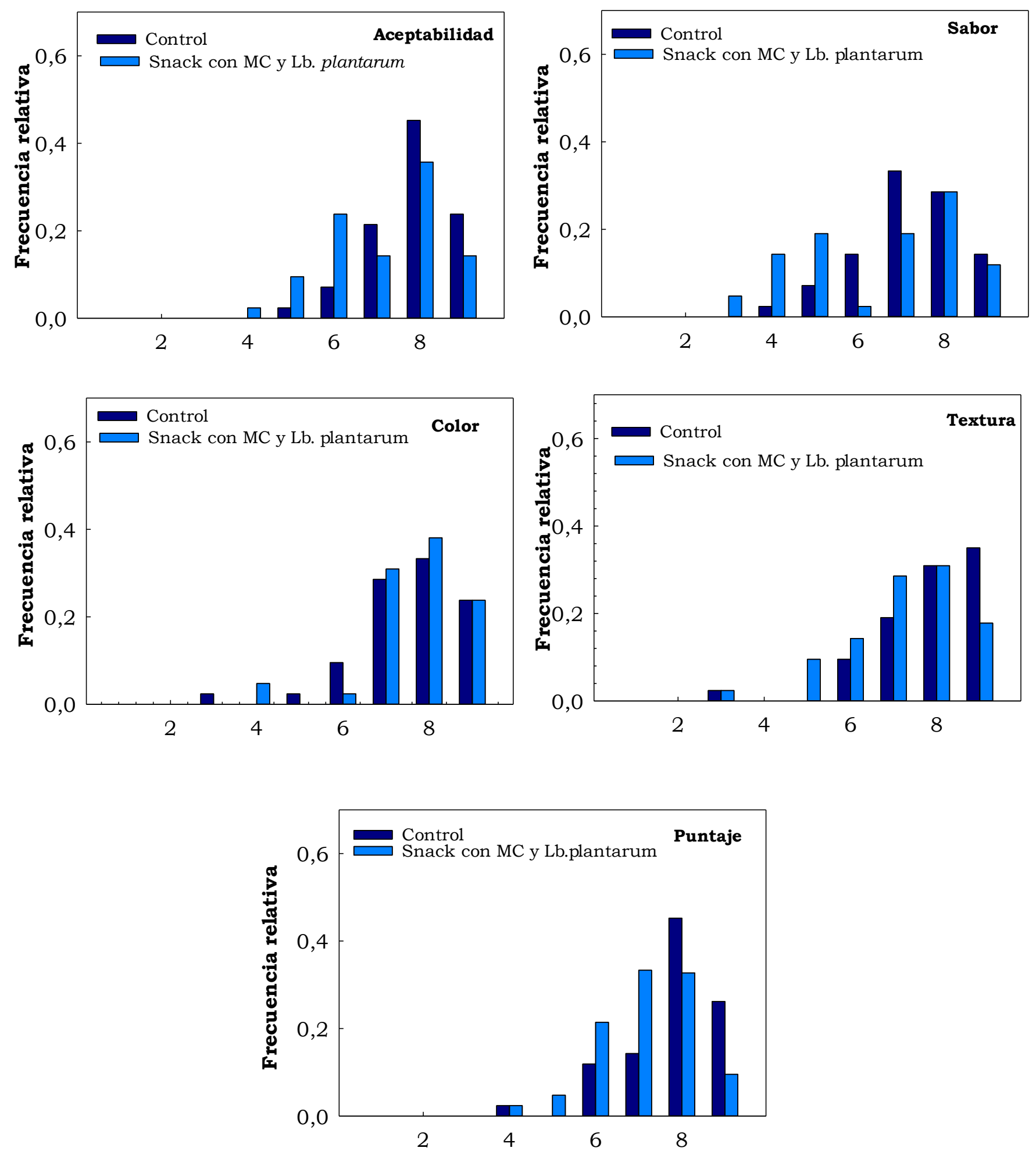

Figura 74. Frecuencia relativa de las respuestas de los consumidores ante los snacks con y sin cobertura de MC y L. plantarum. 
En lo que se refiere a la textura (los panelistas dieron una puntuación ligeramente inferior a snacks con recubrimiento $(7,9 \pm 0,4 \mathrm{y}$ $7,2 \pm 0,4$, para el control y snack recubierto, respectivamente), probablemente debido al mayor valor de la humedad de la muestras. Sin embargo, los perfiles de textura, obtenidos instrumentalmente, siguieron una tendencia similar en los dos snacks sin presentar mayores variaciones. Los puntajes otorgados para este descriptor sensorial para el control no presentaron diferencias significativas $(P>0,05)$. Los resultados para la aceptabilidad general no mostraron diferencias significativas $(\mathrm{P}>0,05) 7,8 \pm 0,3$ para el control y $7,2 \pm 0,4$ para el snack con recubrimiento.

A partir de estos resultados se puede inferir que es posible consumir alimentos más saludables sin que se vea afectada la calidad sensorial de productos como los snacks de manzana con la adición de isomalt y maltodextrina y recubrimientos de MC con bacterias lácticas. Esto es de gran importancia teniendo en cuenta el valor agregado que tiene este producto.

\subsection{CONCLUSIONES}

La aplicación de una cobertura de metilcelulosa con bacterias lácticas incorporadas sobre el snack de manzana bajo en calorías, con calcio y ácido ascórbico permitió obtener un producto con una alta concentración de microorganismos probióticos aún después de condiciones de estrés como el almacenamiento y el contacto con un entorno gastrointestinal simulado.

Se obtuvo un producto, conteniendo bacterias probióticas, con una vida útil de 90 días, la cual resultó mayor a la de los productos lácteos que normalmente son los alimentos etiquetados como productos que contienen microorganismos probióticos. 
El producto desarrollado representa una buena estrategia para consumir microorganismos probióticos en matrices no lácteas a bajo costo, en concentraciones compatibles con efectos benéficos para la salud. Estos atributos, junto con las propiedades prebióticas conferidas por Isomalt y FOS, convierten a esta formulación en un producto simbiótico que podría resultar atractivo desde el punto de vista industrial y nutricional.

\subsection{REFERENCIAS}

Altamirano-Fortoul, R., Moreno-Terrazas, R., Quezada-Gallo, A., Rosell, C. M. (2012). Viability of some probiotic coatings in bread and its effect on the crust mechanical properties. Food Hydrocolloids, 29(1): 166-174.

Atarés, L., Bonilla, J., Chiralt, A. (2010). Characterization of sodium caseinate-based edible films incorporated with cinnamon or ginger essential oils. Journal of Food Engineering, 100: 678-687.

Atarés, L., Pérez-Masiá, R., Chiralt, A. (2011). The role of some antioxidants in the HPMC film properties and lipid protection in coated toasted almonds. Journal of Food Engineering, 104: 649-656.

Ayranci, E., Tunc, S. (2003). A method for the measurement of the oxygen permeability and the development of edible films to reduce the rate of oxidative reactions in fresh foods. Food Chemistry, 80: 423-431.

Ayranci, E., Tunc, S. (2004). The effect of edible coatings on water and vitamin $\mathrm{C}$ loss of apricots (Armeniaca vulgaris Lam.) and green peppers (Capsicum annuum L.). Food Chemistry, 87: 339-342.

Baldwin, E.A., Nisperos, M.O., Chen, X., Hagenmaier, R.D. (1996). Improving storage life of cut apple and potato with edible coating. Postharvest Biology and Technology, 9: 151-163. 
Bedani, R., Vieira, A.D.S., Rossi, E. A., Saad, S.M.I. (2014). Tropical fruit pulps decreased probiotic survival to in vitro gastrointestinal stress in synbiotic soy yoghurt with okara during storage. LWT - Food Science and Technology, 55: 436-443.

Bertazzoni, E., Donelli, G., Midtvedt, T., Nicoli, J., Sanz, Y. (2013). Probiotics and clinical effects: is the number what counts?. Journal Chemotherapy, 25: 193-212.

Bonilla, J., Atarés, L., Vargas, M., Chiralt, A. (2012). Effect of essential oils and homogenization conditions on properties of chitosanbased films. Food Hydrocolloids, 26(1): 9-16.

Bonilla, J., Atarés, L., Vargas, M., Chiralt, A. (2013). Properties of wheat starch film forming dispersions and films as affected by chitosan addition. Journal of Food Engineering, 114(3): 303-312.

Buriti, F.C.A., Castro, I.A., Saad, S.M.I. (2010). Viability of Lactobacillus acidophilus in synbiotic guava mousses and its survival under in vitro simulated gastrointestinal conditions. International Journal of Food Microbiology, 137: 121-129.

Bustos, P., Bórquez, R. (2013). Influence of osmotic stress and encapsulating materials on the stability of autochthonous Lactobacillus plantarumafter spray drying. Drying Technology, 31: 57-66.

Cammenga, H.K, Zielasko, B. (1996). Thermal behaviour of isomalt. Thermochimica Acta, 271: 149-153.

Champagne, C. P., Gardner, N. J., Roy, D. (2005). Challenges in the addition of probiotic cultures to foods. Critical Reviews in Food Science and Nutrition, 45: 61-84.

Chong, E. (2014). A potential role of probiotics in colorectal cancer prevention: review of possible mechanisms of action.World Journal of Microbiology and Biotechnology, 30: 351-374. 
de Man, J.C., Rogosa, M., Sharpe, M.E. (1960). A medium for the cultivation of lactobacilli. Journal of Applied Bacteriology, 23: 130-135.

Espinoza, H.N. (2008). Caracterización de biopolímeros y suaplicación en la microencapsulación de probióticos de liberaciónespecífica. Tesis doctoral. CICATA-IPN. México.

FAO/WHO (2002). Evaluation of health and nutritional properties of probiotics in food including powder milk with live lactic acid bacteria. ftp://ftp.fao.org/es/esn/food/wgreport2.pdf > September 8th Jan 2014.

Fu, N., Chen, X.D. (2011). Towards a maximal cell survival in convective thermal drying processes. Food Research International, 44: 1127-1149.

Garrote, G. L, Abraham, A. G., De Antoni, G. L. (2001). Chemical and microbiological characterization of kefir grains. Journal of Dairy Research, 68: 639-652.

Gibson, G.R., Probert, H.M., Van Loo, J., Rastall, R.A., Roberfroid, M.B. (2004). Dietary modulation of the human colonic microbiota: updating the concept of prebiotics. Nutrition Research Reviews, 17: 259275 .

Golowczyc, M., Silva, J., Teixeira, P., De Antoni, G. L., Abraham, A. (2011a). Cellular injuries of spray-dried Lactobacillus spp. isolated from kefir and their impact on probiotic properties. International Journal of Food Microbiology, 144: 556-560.

Golowczyc, M., Gerez, C., Silva, J., Abraham, A., De Antoni, G. L. Teixeira, P. (2011b). Survival of spray-dried Lactobacillus kefir is affected by different protectants and storage conditions. Biotechnology Letters, 33: 681-686.

Gostner, A., Blaut, M., Schäffer, V., Kozianowski, G., Theis, S., Klingeberg, M., Dombrowski, Y., Martin, D., Ehrhardt, S., Taras, D., 
Schwiertz, A., Kleessen, B., Lührs, H., Schauber, J., Dorbath, D., Menzel, T., Scheppach, W. (2006). Effect of isomalt consumption on faecal microflora and colonic metabolism in healthy volunteers. British Journal of Nutrition, 95: 40-50.

Hill, C., Guarner, F., Reid, G., Gibson, G. R., Merenstein, D. J., Pot, B., Morelli, L., BerniCanani, R., Flint, H. J., Salminen, S., Calder, P. C., Sanders, M.E. (2014). Expert consensus document: The International Scientific Association for Probiotics and Prebiotics consensus statement on the scope and appropriate use of the term probiotic. Nature Reviews Gastroenterology \& Hepatology, 11: 506-514.

Hofsets, K., Lopes, C.C. (2005). Crispy banana obtained by the combination of a high temperature and short time drying stage and a drying process. Brazilian Journal of Chemical Engineering, 22: 285-292.

Hugo, A. A., Kakisu, E., De Antoni, G. L., Pérez, P. F. (2008). Lactobacilli antagonize biological effects of enterohaemorrhagic Escherichia coli in vitro. Letters in Applied Microbiology, 46: 613-619.

Kakisu, E., Abraham, A. G., Tironi Farinati, C., Ibarra, C., De Antoni, G. L. (2013a). Lactobacillus plantarum isolated from kefir protects vero cells from cytotoxicity by type-II Shiga toxin from Escherichia coli O157:H7. Journal of Dairy Research, 80: 64-71.

Kakisu, E., Bolla, P., Abraham, A. G., de Urraza, P., De Antoni, G. L. (2013b). Lactobacillus plantarum isolated from kefir: Protection of cultured Hep-2 cells against Shigella invasion. International Dairy Journal, 33: 22-26.

Komatsu, T. R., Buriti, F. C. A., Saad, S.M.I. (2008). Overcoming hurdles through innovation, persistence and creativeness in the development of probiotic foods. Brazilian Journal of Pharmaceutical Sciences, 44: 329-347.

Kumar, M., Kumar, A., Nagpal, R., Mohania, D., Behare, P., Verma, V., Kumar, P., Poddar, D., Aggarwal, P. K., Henry, C. J., Jain, 
S., Yadav, H. (2010). Cancer-preventing attributes of probiotics: an update. International Journal of Food Sciences and Nutrition, 61: 473496.

Lapsiri, W., Bhandari, B., Wanchaitanawong, P. (2012). Viability of Lactobacillus plantarum TISTR 2075 in different protectants during spray drying and storage. Drying Technology: An International Journal, 30:1407-1412.

López de Lacey, A. M., López-Caballero, M. E., Gómez-Estaca, J., Gómez-Guillén, M. C., Montero, P. (2012). Functionality of Lactobacillus acidophilus and Bifidobacterium bifidum incorporated to edible coatings and films. Innovative Food Science \& Emerging Technologies, 16: 277282 .

López de Lacey, A.M., López-Caballero, M.E., Montero, P. (2014). Agar films containing green tea extract and probiotic bacteria for extending fish shelf-life. LWT - Food Science and Technology, 55: 559564.

Lina, B. R., Jonker, G., Kozianowski, G. (2002). Isomaltulose (palatinose review of biological and toxicologycal studies). Food and Chemical Toxicology, 40: 1375-1381.

Martinez-Cervera, S., Salvador, A., Sanz, T. (2014). Comparison of different polyols as total sucrose replacers in muffins: Thermal, rheological, texture and acceptability properties. Food Hydrocolloids, 35: $1-8$.

Moyano, P., Rioseco, V. K., Gonzalez, P.A. (2002). Kinetics of crust color changes during deep-fat frying of impregnated French fries. Journal of Food Engineering, 54: 249-255.

Nojavan, S., Khaliliana, F., Momen Kiaiec, F., Rahimic, A., Arabanianc, A., Chalavia, S. (2008). Extraction and quantitative determination of ascorbic acid during different maturity stages of Rosa canina L. fruit. Journal of Food Composition and Analysis, 21: 300-305. 
Noorbakhsh, R., Yaghmaee, P., Durance, T. (2013). Radiant energy under vacuum (REV) technology: A novel approach for producing probiotic enriched apple snacks. Journal of Functional Foods, 5: 1049 1056.

O'Brien-Nabors, L. (2001). Alternative Sweeteners, Third Edition edited by Lyn Marcel Dekker, Inc. New York, USA. Wijers, M. C. \&Strater, P. J. Chap. 15. Isomalt pp. 265-282.

Pedreschi, F., Cocio, C., Moyano, P., Troncoso, E. (2008). Oil distribution in potato slices during frying. Journal of Food Engineering, 87(2): 200-212.

Radowski, A. (2006). Isomalt in breakfast cereals, granola bars, and muesli. Cereals Food World, 51: 254-256.

Raudonus, J., Bernard, J., Janben, H., Kowalczyk, J., Carle, R. (2000). Effect of oligomeric or polymeric additives on glass transition, viscosity and crystallization of amorphous isomalt. Food Research International, 33:41-51.

Romano, N., Tavera-Quiroz, M. J., Bertola, N., Mobili, P., Pinotti, A., Gómez-Zavaglia, A. (2014). Edible methylcellulose-based films containing fructo-oligosaccharides as vehicles for lactic acid bacteria. Food Research International, 64: 560-566.

Rimac-Brncic, S., Lelas, V., Rade, D., Simundi, B. (2004). Decreasing of oil absorption in potato strips during deep fat frying. Journal of Food Engineering. 64: 237-241

Saad, S.M.I. (2006). Probiotics and prebiotics: The state of the art. Brazilian Journal of Pharmaceutical Sciences, 42: 1-16.

Saad, N., Delattre, C.,Urdaci, M., Schmitter, J. M., Bressollier, P. (2013). An overview of the last advances in probiotic and prebiotic field. LWT-Food Science and Technology, 50: 1-16. 
Schiweck, H., Munir, M., Rapp, K. M., Schenider, B., Bogel, M. (2000). New developments in the use of sucrose as an industrial bulk chemical. Zuckerindustrie, 115: 555-565.

Soukoulis, C., Behboudi-Jobbehdar, S., Yonekura, L., Parmenter, C., Fisk, I. (2014a). Stability of Lactobacillus rhamnosus GG in prebiotic edible films. Food Chemistry, 159: 302-308.

Soukoulis, C., Yonekura, L., Gan, H-H., Behboudi-Jobbehdar, S., Parmenter, C., Fisk, I. (2014b). Probiotic edible films as a new strategy for developing functional bakery products: The case of pan bread. Food Hydrocolloids, 39: 231-242.

Tripathi, M.K., Giri, S.K. (2014). Probiotic functional foods: Survival of probiotics during processing and storage. Journal of Functional Foods, 9: 225-241.

Tymczyszyn, E.E., Díaz, M.R., Gómez-Zavaglia, A., Disalvo, E.A. (2007a). Volume recovery, surface properties and membrane integrity of Lactobacillus delbrueckii subsp.bulgaricus dehydrated in the presence of trehalose or sucrose. Journal of Applied Microbiology, 103: 2410-2419.

Tymczyszyn, E.E., Gómez-Zavaglia, A., Disalvo, E.A. (2007b) Effect of sugars and growth media on the dehydration of Lactobacillus delbrueckii ssp. bulgaricus. Journal of Applied Microbiology, 102: 845851.

Yang, L., Paulson, A.T. (2000). Effects of lipids on mechanical and moisture barrier properties of edible gellan film. Food Research International, 33: 571-578.

Wijers, M. C., Strater, P.J. (2001). Alternative Sweeteners, Third Edition edited by Lyn O'Brien-Nabors. Marcel Dekker, Inc. New York, USA. Chap. 15. Isomalt pp. 265-282. 

IV.

\section{CONCLUSIONES GENERALES}



La variedad de manzana Granny Smith resultó ser una fruta con amplias ventajas para su uso en la obtención de snacks, ya que además de ser una matriz rica en polifenoles y azúcares, su tejido es resistente lo que permite someterla a condiciones de cocción a altas temperaturas. Además su amplia disponibilidad durante todo el año tiene ventajas para la producción continua de snacks.

La utilización de calcio como pretratamiento fue una buena alternativa para mejorar la estructura de productos a base de frutas, aumentando la firmeza del tejido y contribuyendo además a acrecentar las propiedades nutricionales del mismo, por el aporte de esta sal en el producto final y por ende al consumidor.

Los tratamientos con azúcares brindaron la posibilidad de diseñar y desarrollar productos tipo snacks debido a que promueven las reacciones de caramelización controladas y permiten mejorar la textura del producto final durante operaciones de cocción como lo son el fritado y el horneado.

E1 método de cocción más adecuado para obtener snacks saludables y libre de grasa fue el horneado. La utilización de azúcares (maltodextrina y fructosa) y vitamina $\mathrm{C}$ sobre anillos de manzana verde permitió obtener un producto con buena aceptabilidad por los consumidores. Los niveles de humedad y actividad acuosa alcanzados tras el horneado y la presencia de maltodextrina en la formulación permitieron obtener un snack con estabilidad frente a cambios de humedad y temperatura ambiente. La alta higroscopicidad de la fructosa pudo ser responsable de la textura gomosa del producto después de 30 días de almacenamiento del producto.

Como una alternativa al menor aporte de calorias y para ampliar el rango de consumidores a los cuales se destina el alimento, se logró desarrollar snacks a partir de manzana con la adición de calcio, 
maltodextrina e isomalt, con buenas propiedades en términos de textura, color y sabor, sin grasa o sodio añadido y con buena aceptación. La presencia de isomalt permitió el horneado a altas temperaturas durante un corto tiempo sin detrimento de la calidad organoléptica y nutricional y estable durante 120 días. Este es un producto innovador dado que aún no se ha utilizado isomalt en la formulación de snacks.

El modelado de las isotermas de sorción de agua y de la variación de la $\mathrm{T}_{\mathrm{g}}$ con el contenido de agua mostró la influencia de los carbohidratos utilizados en el proceso de obtención de los snacks.

El proceso de elaboración (horneado) no afectó la mayoría de las caracteristicas funcionales logradas en los snacks obtenidos, como lo son el enriquecimiento con compuestos que no se encuentran naturalmente en el producto, y que contribuyen a mejorar su carácter funcional (calcio y ácido ascórbico).

El agregado de ácido ascórbico permitió obtener productos con alta actividad antioxidante, aumentando la calidad funcional de la manzana fresca. No se observaron efectos significativos del detrimento de este nutriente durante el almacenamiento de ambos snacks.

La aplicación de un recubrimiento comestible formado a partir de metilcelulosa con $0,25 \%$ de sorbitol, $3 \%$ de FOS y 5\% de ácido cítrico como soporte de bacterias lácticas potencialmente probióticas, fue una alternativa eficaz para desarrollar snacks funcionales, por su bajo costo y compatilidad con el alimento.

Durante el almacenamiento los snacks de manzana con recubrimiento, presentaron propiedades similares a los snacks sin recubrimiento, con una mayor estabilidad estructural y con mejor comportamiento frente a absorción de humedad y pérdida de textura. 
Los snacks de manzana a partir de isomalt y maltodextrina, recubiertos con películas de metilcelulosa con Lactobacillus plantarum, representan una buena alternativa de consumo, ya que la cobertura no afectó los parámetros de calidad de mayor importancia como el color, la textura y el sabor y aportó mayor funcionalidad al producto debido a la presencia de bacterias lácticas potencialmente probióticas y de isomalt como prebiótico.

Durante el desarrollo de este trabajo de investigación se logró desarrollar tres tipos de snacks a base de anillos de manzana verde que reunieron las características más importantes para productos de este tipo como lo son el color dorado típico, sabor y la textura crocante que resultaron aceptables sensorialmente para los consumidores. 


$$
\text { v. }
$$

ANEXOS 
ANEXO 1.

FICHA TECNICA DEL EMPAQUE DE BOPP/BOPP UTILIZADO PARA EL ENVASADO DE LOS SNACKS DURANTE EL ALMACENAMIENTO 


\section{MSE_HSB}

Film de Polipropileno Biorientado metalizado, con alta barrera al vapor de agua, termosellable en la cara interna con temperatura de inicio de sellado de $105^{\circ} \mathrm{C}$, indicado para impresión y/o laminación

\section{Caracteristicas Principales}

- Barrera certificada al vapor de agua

- Film metalizado, que proporciona protección

a la luz, para productos sensibles

- Excelente deslizamiento incluso en altas temperaturas

- Termosellable a partir de $105^{\circ} \mathrm{C}$ en la cara no metalizada

\section{Aplicaciones}

- Excelente desempeño como film interno de laminación en máquinas de empaque "flow pack" vertical y horizontal

- Indicado especialmente para empaque de snacks y procesos que demandan alto deslizamiento estable en altas temperaturas

- Indicado para empaques de alimentos que requieran barrera certificada a la humedad

- La superficie metalizada debe estar protegida del contacto directo con el alimento

\section{Valores Típicos}

\begin{tabular}{|c|c|c|c|}
\hline Propiedades & Procedimiento & Unidad & MSE_HSB \\
\hline \multicolumn{3}{|l|}{ Propiedades Principales } & MSE17HSB \\
\hline ESPESOR & DIN 53370 & $\mu \mathrm{m}$ & 17 \\
\hline GRAMAJE & \multirow[t]{2}{*}{ Vitopel } & $\mathrm{g} / \mathrm{m}^{2}$ & 15,5 \\
\hline RENDIMIENTO & & $\mathrm{m}^{2} / \mathrm{kg}$ & 64,6 \\
\hline DENSIDAD ÓPTICA & Mac Beth TD904 & $\cdot$ & 2,4 \\
\hline RESISTENCIA DE SELLADO & Vitopel & $\mathrm{N} / 15 \mathrm{~mm}$ & 3,0 \\
\hline $\begin{array}{l}\text { COEFICIENTE DE FRICCIÓN } \\
\text { DINÁMICO - Film/Film - NT/NT }\end{array}$ & ASTM D 1894 & $\cdot$ & 0,25 \\
\hline $\begin{array}{l}\text { PERMEABILIDAD AL VAPOR DE } \\
\text { AGUA }\end{array}$ & $\begin{array}{l}\text { ASTM F } 1249 \\
38^{\circ} \mathrm{C} / 90 \% \text { UR }\end{array}$ & $\mathrm{g} / \mathrm{m}^{2 / 24 h}$ & máx. 0,65 \\
\hline \multicolumn{4}{|l|}{ Propiedades Descriptivas } \\
\hline INTERVALLO DE SELLADO & Vitopel & ${ }^{\circ} \mathrm{C}$ & $105-145$ \\
\hline \multirow{2}{*}{ RESISTENCIA A LA TRACCIÓN } & \multirow{2}{*}{ ASTM D 882} & $\mathrm{~N} / \mathrm{mm}^{2} \mathrm{MD}$ & 150 \\
\hline & & TD & 260 \\
\hline \multirow{2}{*}{ ELONGACIÓN A LA ROTURA } & \multirow{2}{*}{ ASTM D 882} & $\%$ MD & 180 \\
\hline & & TD & 50 \\
\hline \multirow{2}{*}{ ESTABILIDAD DIMENSIONAL } & \multirow{2}{*}{$\begin{array}{c}\text { Vitopel } \\
120^{\circ} \mathrm{C} / 5 \mathrm{~min}\end{array}$} & \multirow[t]{2}{*}{$\% \mathrm{MD}$} & 5,0 \\
\hline & & & 3,0 \\
\hline PERMEABILIDAD AL OXIGENO & $\begin{array}{l}\text { ASTM D } 3985 \\
23^{\circ} \mathrm{C} / 0 \% \mathrm{ur}\end{array}$ & $\mathrm{cm}^{3} / \mathrm{m}^{2} / 24 \mathrm{~h}$ & 80 \\
\hline
\end{tabular}

\section{Notas}

- Abreviaturas utilizadas: DM - direccion de la máquina; DT - dirección transversal a la máquin

que representan valores medios o tipicos para este producto

Filin

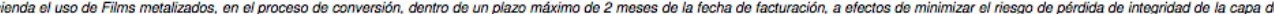
5 motal y perivicios en las propiedades do barrera

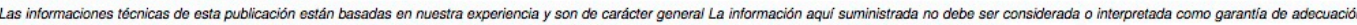
del producto especificado para una finalidad o uso protendido por parte del loctor, salvo hipotesis de expresa manifestación en sentico contrario de nuestra parte

www.vitopel.com 
ANEXO 2.

CARACTERIZACIÓN DE LAS PELICULAS OBTENIDAS A PARTIR DE SOLUCIONES DE METILCELULOSA COMO SISTEMA MODELO DE LOS RECUBRIMIENTOS

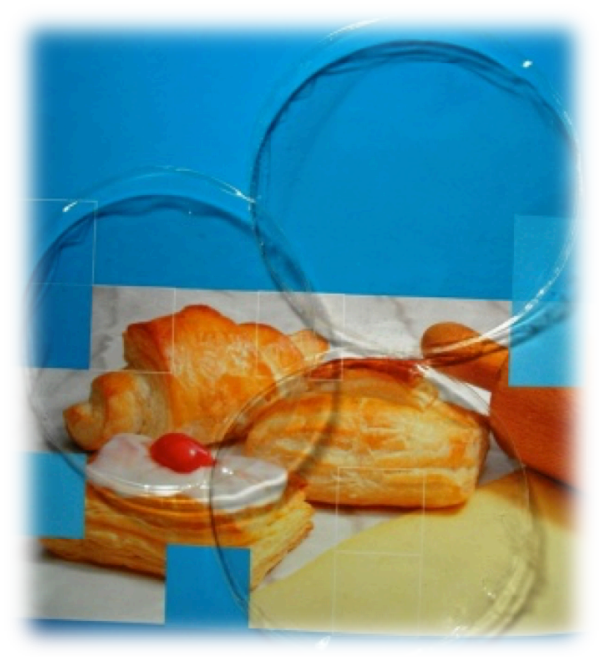




\section{A.2.1 GENERALIDADES DE PELICULAS $Y$ RECUBRIMIENTOS COMESTIBLES}

El desarrollo y caracterización de películas comestibles ha sido ampliamente investigado gracias a su variedad de diversas aplicaciones en el campo de la tecnología de alimentos. Las películas y recubrimientos son capaces de por su habilidad para regular la migración de agua, lípidos y gases, lo que permite extender la vida útil y mejorar las cualidades nutricionales y organolépticas de los alimentos. En este trabajo se profundizó en el uso de hidrocoloides, específicamente metilcelulosa, como alternativa para la incorporación de bacterias lácticas, potencialmente probióticas, en un alimento no lácteo tipo snack.

La metilcelulosa (MC) es un excipiente comúnmente usado en la industria farmacéutica y cosmética debido a su gran versatilidad, lo que permite incorporarla en bajas concentraciones en una amplia gama de formulaciones: sólidas, líquidas y semisólidas. Esta versatilidad se debe a las importantes propiedades funcionales que tiene como el control reológico, capacidad para formar películas, poder adhesivo, poder ligante y la propiedad de gelificación térmica reversible.

La celulosa en un compuesto que tiene en su estructura principal tres grupos hidroxilos $(\mathrm{OH})$ libres que pueden ser modificados para obtener ésteres o éteres. En estas reacciones los grupos $\mathrm{OH}$ libres son sustituidos de tal forma que pueden tener un grado de sustitución desde 0,1 hasta 3 , adquiriendo propiedades muy diferentes en cada caso. En la metilcelulosa, uno de los derivados de la celulosa, algunos de estoslos grupos $\mathrm{OH}$ son remplazados por grupos metoxilo $\left(\mathrm{CH}_{3}\right)$. Este reemplazo atenúa reduce el número de los enlaces de hidrógenos disminuyendo la cristalinidad de la celulosa y aumentando la solubilidad en agua. La metilcelulosa, es una celulosa sustituida de cadena larga, en la cual aproximadamente el 27-32\% de los grupos hidroxilos se encuentran en forma de metil-éter. Se obtiene en forma de 
gránulos o polvo de color blanco o ligeramente amarillento, y es prácticamente inodora e insípida inodora e insípido. Las disoluciones acuosas gelifican alrededor de $\operatorname{los} 50-60^{\circ} \mathrm{C}$. Los geles se forman a altas temperaturas debido a las interacciones hidrofóbicas entre regiones altamente sustituidas (grupos metilo) que estabilizan los enlaces de hidrógeno intermoleculares (Izydorczyk y col., 2005). El proceso de termogelación es reversible. La formación del gel es dependiente del tiempo y puede modificarse con la presencia de aditivos (Grover, 1993).

Desde el punto de vista químico la $\mathrm{MC}$, corresponde a un éter de celulosa soluble en agua. Es un polisacárido lineal formado por unidades de D-glucosa unidas por enlaces $\beta(1,4)$ que presenta una sustitución variable de grupos metilo en las posiciones 2, 3 y 6 de la unidad de anhidroglucosa (Figura 75).

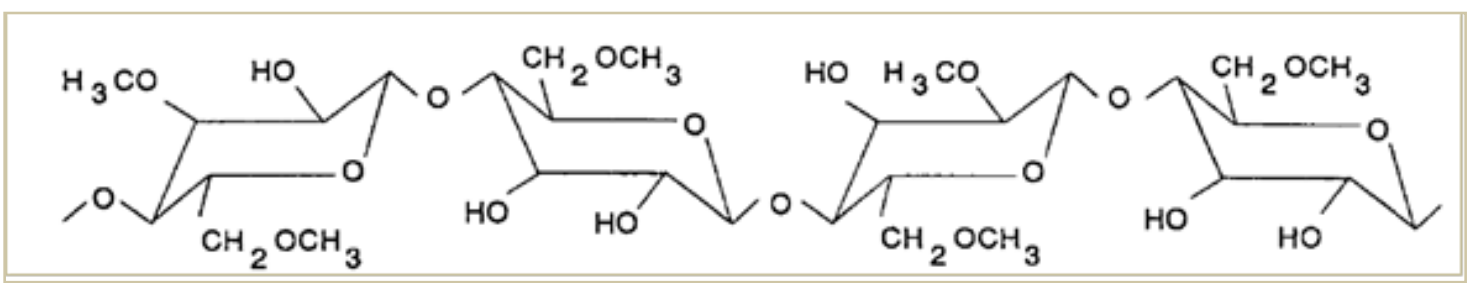

Figura 75. Estructura química de la metilcelulosa

\section{Consideraciones generales de la disolución del polímero}

La disolución de los polímeros sólidos ocurre en dos etapas. Al ponerse en contacto con el solvente, este difunde inmediatamente dentro de las partículas sólidas, las cuales gradualmente se hinchan y se transforman en partículas gelificadas. Luego, las moléculas de polímero solvatado en la superficie de la partícula hinchada se desenganchan gradualmente unas de otras y lentamente difunden hacia el solvente. Esta última etapa puede acelerarse considerablemente por agitación, la cual activa el desenganche de las moléculas de la superficie y reduce el espesor del film estacionario que rodea a la partícula. De esta forma, cuando el polímero en polvo es agregado al solvente con agitación, las condiciones de mezclado deben 
ser tales que proporcionen una completa humectación. Al mismo tiempo, deben permitir que las partículas se separen antes que puedan hincharse y tornarse pegajosas o tiendan a gelatinizarse. Si ello no ocurre, las partículas tienden a aglomerarse formando una capa translúcida que encierra partículas de polímero seco. Debido a su gran tamaño estos aglomerados se disuelven lentamente (Technical Handbook Methocell, 2002).

\section{Procedimiento de disolución de MC}

Para preparar en forma correcta una solución acuosa de MC teniendo en cuenta la situación física descrita anteriormente, los fabricantes de MC (Technical Handbook Methocell, 2002) recomiendan el procedimiento de "disolución caliente-frío". Este consiste en dispersar la $\mathrm{MC}$ en polvo en agua caliente a $80-90^{\circ} \mathrm{C}$ (aproximadamente un $1 / 3$ de la cantidad total de agua) con agitación intensa. A esta temperatura la solubilidad de la MC es mínima, de manera que se produce un hinchamiento limitado y una pobre disolución. Una vez que las partículas están totalmente humectadas y dispersas, se agrega el resto de agua a $25^{\circ} \mathrm{C}$, para enfriar la suspensión, por lo que de esta forma. Las partículas dispersas se hinchan y disuelven rápidamente bajo una agitación moderada (Swarbrick y Camrnarata, 1983).

\section{Aplicaciones en la industria}

Una de las aplicaciones de la MC es el control reológico de soluciones. Al agregar este producto en pequeñas cantidades a la formulación es posible, obtener un incremento en la viscosidad y proporcionar un comportamiento de flujo pseudoplástico. Otra de sus propiedades es como agente espesante. Al disolverse, los polimeros incrementan la viscosidad aparente de las soluciones. Esta propiedad es usada en algunas formulaciones de alimentos, farmacéuticas y cosméticas como suspensiones, cremas y lociones. Un ejemplo es el incremento en viscosidad que sufre el agua, que presenta una viscosidad que a $20^{\circ} \mathrm{C}$ es un $1 \mathrm{cp}$ al agregar $2 \mathrm{~g}$ de $\mathrm{MC}$ (de un tipo de 
alta viscosidad) a $98 \mathrm{~g}$ de agua. Es así como una solución al 2\% de MC incrementa su viscosidad 8000 veces (Tapia y Sapag-Hagar, 1995).

Los derivados de celulosa como la $\mathrm{MC}$ y otros polímeros naturales modificados son generalmente usados como agentes de granulación y en formulaciones para compresión directa debido a sus propiedades ligantes y adhesivas. La MC, al igual que otros derivados de celulosa, es biodegradable, a diferencia de otros polímeros solubles en agua de amplio uso, como carbopol, polivinilpirrolidona y sales del ácido poliacrílico (Tapia y Sapag-Hagar, 1995).

Otra de sus aplicaciones importantes es como formador de películas. A partir de soluciones acuosas de MC pueden obtenerse películas de alta transparencia y resistencia (Tavera Quiroz y col., 2013). Estas películas son solubles en agua y resistentes frente a la mayoría de los solventes orgánicos, grasas y aceites. Las películas de MC pueden hacerse más elásticas y flexibles agregando un plastificante, como sorbitol, glicerol, polioles (Psomiadou y col., 1996; Lucio y col., 2006). Al igual que el almidón, la metilcelulosa posee un gran número de grupos hidroxilo libres, lo cual le proporciona a las películas obtenidas un carácter altamente hidrófilico (Torres, 1994; García y col., 2002). El agua es el principal plastificante de los biopolímeros. El agregado de plastificantes a materiales biodegradables generalmente aumentan la permeabilidad de los mismos y afecta las propiedades mecánicas (García y col., 2000; Galdeano y col., 2009). Kilburn y col. (2004) afirman que el efecto de plastificación del agua sobre los carbohidratos, se produce a través de mecanismos complejos que involucran tanto la formación de enlaces de hidrógeno, como la interrupción y los cambios en el volumen libre de la matriz. Los plastificantes, que son componentes de bajo peso molecular, aumentan el volumen libre del polímero, y en consecuencia la red polimérica se vuelve menos densa debido a la disminución de las fuerzas intermoleculares, mejorando así la extensibilidad y la flexibilidad de las 
películas (Liu y col., 2006; Martelli, 2006). Los plastificantes más eficaces son aquellos que tienen estructuras parecidas al polimero que plastifican. Para películas obtenidas a partir de celulosa y almidón, generalmente se utilizan polioles, tales como el sorbitol (Arvanitoyannis y col., 1997; Mali y col., 2005; Cheng y col., 2006; Yoon y col., 2007). E1 sorbitol es un producto farmacéutico comúnmente utilizado como excipiente para mejorar la estabilidad de proteínas y otras moléculas durante la congelación, secado y almacenamiento (Chou y col., 2012; Tavera Quiroz y col., 2013).

Modificaciones químicas como el entrecruzamiento pueden proporcionar rutas viables para mejorar las propiedades mecánicas y estabilidad y reducir su disolución en agua para su uso como agentes de liberación controlada o como envases comestibles (Coma y col., 2003; Reddy y col., 2010). Las matrices poliméricas pueden ser modificadas, mediante reacciones de entrecruzamiento químicos, físicos o enzimáticos (Sabato y col., 2000; Bigi y col., 2001; Grosso y Chambi, 2006). El entrecruzamiento constituye una alternativa eficaz en el mejoramiento de las propiedades de las películas obtenidas a partir de biopolímeros. Proporciona una mayor estabilidad y resistencia mecánica, lo que permite obtener una matriz estable, con capacidad de hinchamiento, buenas propiedades mecánicas, estabilidad térmica y mayor resistencia a la disolución en agua (Krumova y col., 2000; Mathew y Abraham, 2008; Rivero y col., 2010). Como ya se mencionó son útiles para la liberación de agentes activos y como soporte para el crecimiento de células (Sánchez y col., 2007; Rivero y col., 2013). Varios autores han informado sobre la capacidad entrecruzante de algunos ácidos orgánicos. Por ejemplo, se ha informado de la acción del ácido ferúlico y tánico sobre matrices de gelatina y quitosano (Cao y col., 2007; Rivero y col., 2013) y del ácido cítrico en matrices de celulosa, quitosano y almidón (Yang y col., 1996; Shuy y col., 2001; Reddy y Yang, 2010, Olson y col., 2013). Zhou y col. (1995) afirman que la eficacia de los ácidos carboxílicos para reticular aumenta a medida que 
aumentan los grupos reactivos en la molécula, y bajo tratamientos térmicos. El ácido cítrico, es un ácido orgánico tricarboxílico presente en la mayoría de las frutas, especialmente, limón y naranjas. No es tóxico y tiene un amplio uso en la industria alimentaria como un aditivo natural seguro, ya que se utiliza como conservante. Este ácido tiene la capacidad de reticular los grupos hidroxilo en la celulosa y se ha informado que la reacción de reticulación ocurre a temperaturas entre 165 y $175^{\circ} \mathrm{C}$ (Yang y col., 1996, 1997). El ácido cítrico en ciertas concentraciones también puede actuar como un plastificante (Shi y col., 2007).

Si bien se han realizado varias investigaciones sobre matrices de metilcelulosa y películas plastificadas con sorbitol, la información acerca de películas de metilcelulosa con agregado de sorbitol es escasa (Arvanitoyannis y Biliaderis, 1999; García y col., 2004; Tavera Quiroz, 2012). En este capítulo, se estudiaron las películas obtenidas a partir de metilcelulosa con y sin agregado de sorbitol como plastificante, e incorporación de ácido cítrico. El propósito de relacionar sus propiedades con el efecto barrera al agua y a los gases se debió a que esta es una de las propiedades más importantes cuando se utilizan este tipo de materiales como recubrimientos.

En el Capítulo 6 de este trabajo de investigación, se logró desarrollar un snack funcional a partir de la inmovilización de bacterias en un recubrimiento basado en metilcelulosa. Sin embargo, previamente se realizó un estudio exhaustivo de las características de las películas de MC como sistema modelo del recubrimiento utilizado sobre los snacks. Este análisis se realizó con el fin de seleccionar la cobertura que garantizara la calidad organoléptica del producto final. El recubrimiento aplicado sobre la superficie del snack debía formar una película sin afectar las propiedades mecánicas ni sensoriales. Asimismo debía tener baja higroscopicidad, evitar el deterioro de los nutrientes presentes y garantizar un determinado recuento de bacterias lácticas 
durante el tiempo de almacenamiento. Es decir, debía ser buena barrera al vapor de agua, al oxígeno, no debe aportar color y/o sabor y tener buenas propiedades mecánicas y térmicas.

\section{Objetivos}

Estudiar las propiedades fisicoquímicas, mecánicas y de barrera de películas de metilcelulosa con distintas concentraciones de sorbitol y ácido cítrico, como sistema modelo de recubrimientos comestibles.

Evaluar las modificaciones microestructurales producidas sobre las películas obtenidas.

Este Anexo se dividió en dos secciones:

1. Selección del contenido de plastificante a utilizar para garantizar la integridad de la película de metilcelulosa y obtener mejoras en las propiedades de barrera al agua y a los gases.

2. Una vez seleccionada la concentración de plastificante, se seleccionó la concentración óptima de ácido cítrico para obtener películas menos higroscópicas, y con propiedades de barrera al vapor de agua y al oxígeno, para ser usadas como recubrimientos comestibles. 


\section{A.2.2 SELECCIÓN DE LA CONCENTRACIÓN DE PLASTIFICANTE PARA LAS PELICULAS DE MC}

\section{A.2.2.1 MATERIALES Y MÉTODOS}

\section{MATERIALES}

Para la preparación de las soluciones se utilizó metilcelulosa A4M (Methocel, Dow Chemical Co, U.S.A) de 65103 Da (según especificaciones del proveedor) proporcionada por COLORCON S.A. (Argentina), sorbitol (ANEDRA, Francia) y ácido cítrico (ANEDRA, Francia).

\section{MÉTODOS}

\section{Preparación de las películas}

Para preparar la solución de hidrocoloide, 1,5 g de metilcelulosa (MC) se dispersaron lentamente en $50 \mathrm{ml}$ de agua destilada a $80^{\circ} \mathrm{C} \pm 5^{\circ} \mathrm{C}$ bajo agitación constante durante $1 \mathrm{~h}$. Una vez obtenido un sistema homogéneo, se llevó a volumen total de $100 \mathrm{ml}$ con agua destilada fría y la solución se mantuvo bajo agitación hasta que se obtener una solución transparente. Luego se añadió sorbitol como plastificante en diferentes concentraciones $(0,25 ; 0,5 ; 0,75$ y $1,0 \% \mathrm{p} / \mathrm{v})$.

Se vertieron de 20 a $22 \mathrm{ml}$ de cada una de las soluciones en placas de petri plásticas utilizadas como moldes (9 $\mathrm{cm}$ de diámetro) y se dejaron secar en estufa a $37^{\circ} \mathrm{C}$ durante aproximadamente $48 \mathrm{~h}$ (hasta peso constante). Este procedimiento se realizó por triplicado para cada una de las soluciones. El espesor de las películas fue determinado con un medidor de espesor DCN-900 para materiales no conductores y sustratos no ferrosos.

\section{Propiedades fisicoquimicas de las peliculas de MC y sorbitol Determinación de humedad}

La determinación de los valores de humedad se realizó por el método de secado en estufa a $105^{\circ} \mathrm{C}$ hasta peso constante. Los 
resultados se expresaron como gramos de agua por $100 \mathrm{~g}$ de muestra seca.

\section{Permeabilidad al vapor de agua de las películas}

La permeabilidad al vapor de agua se conoce como la cantidad de vapor (g) que pasa a través de un material de espesor conocido (mm) por unidad de superficie $\left(\mathrm{m}^{2}\right)$ y por unidad de tiempo cuando entre sus paredes existe una diferencia de presión unitaria $(\mathrm{Pa})$. La permeabilidad al vapor de agua se midió usando el método ASTM E96 (ASTM E 96, 1995) con algunas modificaciones. Una vez secas, las películas se extrajeron de las placas y se acondicionaron en ambientes de humedad relativa del $65 \%$ a $20^{\circ} \mathrm{C}$, durante 48 horas antes de las determinaciones de permeabilidad. Las muestras se ubicaron en las celdas de permeabilidad, cuya área expuesta es conocida. Las celdas contenían gel de sílice (Mali y col., 2002) (Figura 76) ya que el método se basa en la diferencia de presión parcial de vapor de agua existente a ambos lados de las películas, lo que proporciona la fuerza impulsora para el flujo de vapor a través de la misma.

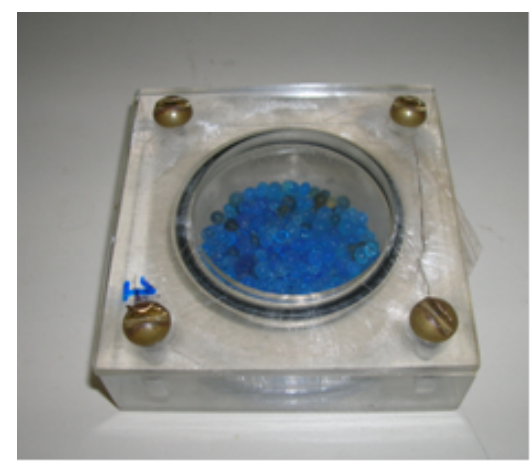

Figura 76. Celda de permeabilidad conteniendo gel de sílice como desecador con la película ensamblada.

Luego de alcanzado el estado estacionario se registraron los cambios de peso, mediante una balanza analitica Mettler con una precisión de 0,0001 g, en función del tiempo, dando como resultado la ganancia de peso $\left(\mathrm{GW}, \mathrm{g} / \mathrm{m}^{2}\right)$ cuando se dividió por el área de la celda. 
Se calculó la tasa de transmisión de vapor de agua (WVTR), la permeancia, y la permeabilidad. La tasa de transmisión de vapor de agua (WVTR, g/s $\mathrm{m}^{2}$ ) se calculó a partir de la pendiente de la recta obtenida de los cambios de peso en función del tiempo por regresión lineal $\left(\mathrm{R}^{2} \geq 0,99\right)$; la permeancia $\left(\mathrm{g} / \mathrm{Pa} \mathrm{s} \mathrm{m}^{2}\right)$ se calculó como la WVTR dividida por el gradiente de presión parcial del vapor $(\Delta \mathrm{P})$ a través de la película $\left(1753,55 \mathrm{~Pa}\right.$ a $20^{\circ} \mathrm{C}$, dato obtenido de tablas de propiedades termodinámicas). La permeabilidad al vapor de agua (PVA) se determinó como el producto de los valores de permeancia y espesor de la película y se expresó como g/Pa s m. Se midió la PVA de las películas plastificadas y sin plastificar en dos condiciones: muestras recién preparadas y muestras almacenadas a $20^{\circ} \mathrm{C}$ durante 90 días.

\section{Determinación del \% de material soluble de las películas de MC en agua}

El ensayo de solubilidad se llevó a cabo en piezas de 2 × $2 \mathrm{~cm}$. Se realizó para cada una de las películas de $\mathrm{MC}$ con distintas concentraciones de plastificante (0-1\%), siguiendo el método de Rivero y col. (2010). Las muestras pesadas se colocaron en vasos de precipitado con $80 \mathrm{ml}$ de agua destilada a 25 y a $100^{\circ} \mathrm{C}$ con agitación constante. Luego de transcurrido un tiempo de hidratación de $60 \mathrm{~min}$, las películas se extrajeron y se secaron sobre una superficie absorbente. El porcentaje de material soluble fue determinado por el método de secado en estufa a $105^{\circ} \mathrm{C}$, teniendo en cuenta el peso inicial de las muestras, a partir de la siguiente ecuación:

$$
\% \text { Material soluble }=\frac{(\text { Peso seco inicial }- \text { Peso seco final })}{(\text { Peso seco inicial })} \times 100 \quad \text { Ec. } 18
$$

\section{Propiedades mecánicas y térmicas por DMA}

Para evaluar las propiedades mecánicas se utilizó un equipo DMA TA Instruments Q800 con un clamp de tensión, siguiendo el procedimiento descrito en el Capítulo 3- sección 3.2. y 3.3. (Figura 77). 


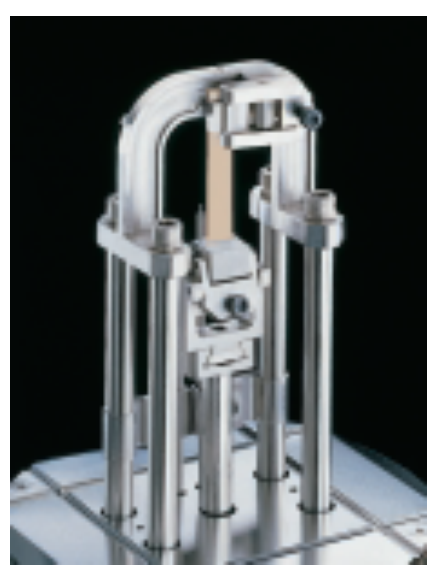

Figura 77. Clamp de tensión utilizado para los ensayos mecánicos en el equipo DMA Q800.

Se realizaron ensayos de multifrecuencia y de tensióndeformación. Para ambos ensayos las películas se cortaron con una geometria rectangular (30 $\mathrm{mm}$ de longitud y $6 \mathrm{~mm}$ de ancho). Los ensayos de multi frecuencia se llevaron a cabo a 1, 5, 10 y $15 \mathrm{~Hz}$ entre -100 y $250^{\circ} \mathrm{C}$ a una velocidad de $5^{\circ} \mathrm{C} / \mathrm{min}$, con una isoterma de $10 \mathrm{~min}$ a $-100^{\circ} \mathrm{C}$. Se registraron los módulos de almacenamiento ( $\left.\mathrm{E}^{\prime}\right)$, pérdida $\left(\mathrm{E}^{\prime \prime}\right)$ y el módulo tan $\delta\left(\mathrm{E}^{\prime \prime} / \mathrm{E}^{\prime}\right)$ en función de la temperatura. Se determinaron los procesos asociados a las temperaturas de transición vítrea $\left(\mathrm{T}_{\mathrm{g}}\right)$ a través del punto de inflexión del pico máximo en las curvas de $\tan \delta$. Para la determinación del módulo elástico de las diferentes formulaciones se realizaron curvas de tensión-deformación con una rampa de fuerza a velocidad de deformación constante de 0,3 N/min hasta alcanzar una fuerza estática de $18 \mathrm{~N}$, con precarga de $1 \mathrm{~N}$. Estos ensayos se realizaron a $-20,5,25,100^{\circ} \mathrm{C}$, las cuales son temperaturas características de procesamiento de alimentos y de conservación, a fin de observar el comportamiento de las películas.

\section{Propiedades térmicas por DSC}

Las propiedades térmicas de las películas recién obtenidas se determinaron a partir del método descrito en el Capítulo 3-Sección 3.2. Aproximadamente $7 \mathrm{mg}$ de muestra fueron pesados en cápsulas de aluminio y sellados herméticamente, usando una cápsula vacía como referencia. Las muestras fueron analizadas con una velocidad de 
calentamiento de $10^{\circ} \mathrm{C} / \mathrm{min}$. El primer análisis se realizó desde $-100^{\circ} \mathrm{C}$ hasta $200^{\circ} \mathrm{C}$ para limitar la degradación de la metilcelulosa. Después la muestra se enfrió hasta $-100^{\circ} \mathrm{C}$ y a continuación una tercera corrida se registró entre -100 y $350^{\circ} \mathrm{C}$. El análisis se realizó aplicando una modulación a la temperatura de $0,5^{\circ} \mathrm{C}$ cada $40 \mathrm{~s}$, lo que permite separar el flujo total de calor en la componente cinética y la termodinámica. Las cápsulas fueron perforadas y secadas a $105^{\circ} \mathrm{C}$ hasta alcanzar un peso constante para obtener el peso seco de la muestra.

\section{Propiedades microestructurales y espectroscópicas de las películas Espectros por FTIR}

La espectroscopia de infrarrojo (IR) es una de las técnicas analíticas más importantes y utilizadas debido a que puede emplearse para establecer la identidad de un compuesto. Cada grupo funcional tiene un modo de absorción característico que se presenta en el espectro como un pico o banda y aporta información acerca del tipo de uniones que se establecen cuando se mezclan sustancias o se aplican tratamientos. Se basa en la excitación de los modos de vibración de las moléculas por la absorción de la radiación infrarroja. Durante la excitación es necesaria una variación del momento dipolar de la molécula para que se produzca una absorción en el IR que puede asociarse a vibraciones de tensión (simétricas o asimétricas) o de flexión. Los espectros se pueden obtener indistintamente en función de la transmitancia o la absorbancia.

Los espectros de FTIR de las películas se registraron en un espectrómetro de infrarrojos ((Nicolet, iS10, ThermoScientific,Madison, EE.UU.) en el rango de longitud de onda $4000-400 \mathrm{~cm}^{-1}$ realizando 64 escaneos a $4 \mathrm{~cm}^{-1}$ de resolución por ensayo. El análisis y la deconvolución de los datos se realizó utilizando el software Omnic 8 (ThermoScientific,Madison, EE.UU.). 


\section{Microestructura por SEM}

Las observaciones al microscopio se realizaron a bajo vacío con un equipo FEI modelo Quanta (Países Bajos). Las muestras fueron montadas en los tacos de bronce usando una cinta de doble faz, sin recubrimientos metálicos y de carbón, con un voltaje de aceleración de $25 \mathrm{kV}$.

\section{Análisis estadístico}

Todos los experimentos se realizaron por duplicado. El análisis de varianza se realizó por separado para las variables de humedad, solubilidad, actividad de agua, permeabilidad al vapor de agua (PVA), temperatura de transición vítrea y módulo elástico. Se realizó un análisis de varianza (ANAVA) para evaluar el efecto de los factores analizados utilizando el programa Systat. Para los ensayos de comparación de medias se empleó el test de menor diferencia significativa (LSD) con $P<0,05$.

\section{A.2.2.2 RESULTADOS Y DISCUSION}

A partir de las soluciones de metilcelulosa se obtuvieron películas homogéneas, transparentes y flexibles (Figura 78), para todas las concentraciones ensayadas, con espesores entre 50-60 $\mu \mathrm{m}$. Las películas obtenidas se denominaron $\mathrm{MC}$ (sin agregado de plastificante), MC-0,25S, MC-0,50S, MC-0,75S y MC-1,0S, teniendo en cuenta la concentración de sorbitol incorporada en cada muestra. 


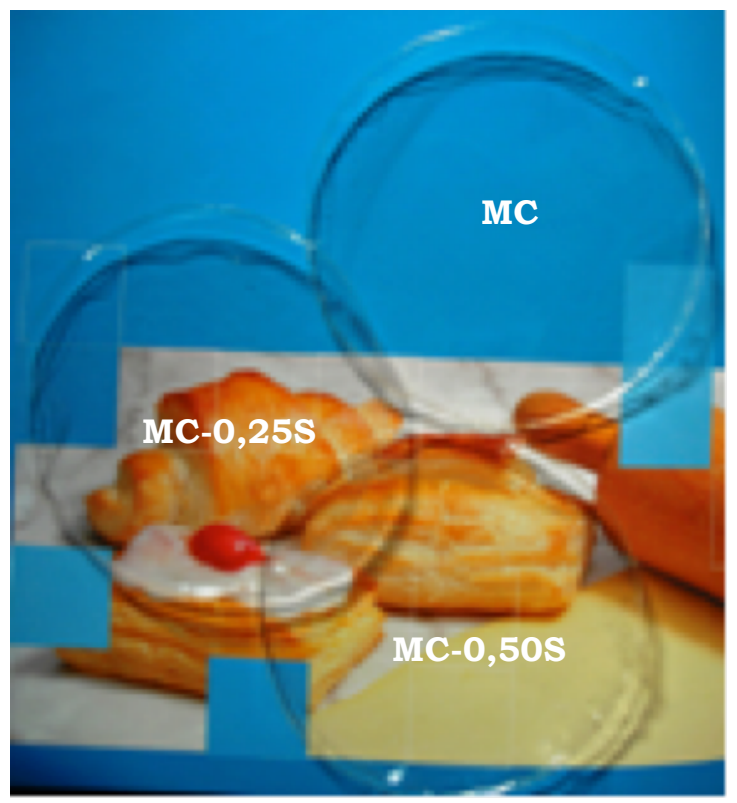

Figura 78. Películas obtenidas a partir de las soluciones de metilcelulosa 1,5 $\%$ sin agregado de plastificante (MC) y películas de metilcelulosa con sorbitol 0,25, 0,5\% (MC-0,25S; MC-0,50S).

\section{Material soluble y contenido de humedad de las peliculas obtenidas}

Cuando las películas de MC se sumergieron en agua a $20^{\circ} \mathrm{C}$, las muestras absorbieron agua rápidamente y hubo un efecto inmediato de disolución de la matriz, perdiendo sus características estructurales y mostrando un aspecto gelatinoso. Los fragmentos del gel transparente se mantuvieron en el medio acuoso. Sin embargo, no pudieron ser utilizados para ser cuantificados, por la dificultad de su recuperación. Estos resultados fueron comparables a los obtenidos por Lim y Wan (1995) trabajando en películas de quitosano. Por el contrario a $100^{\circ} \mathrm{C}$, las películas sin agregado de plastificante mostraron un 18,7\% de solubilidad. Este parámetro aumentó entre 24 y $48 \%$ a medida que se incrementó la concentración de sorbitol desde 0,25 hasta 1\%, respectivamente (Tabla 27$)$. 
Tabla 27. Valores de humedad y solubilidad de películas de metilcelulosa con diferentes concentraciones de sorbitol

\begin{tabular}{ccc}
\hline $\begin{array}{c}\text { Concentración de } \\
\text { plastificante (\%) }\end{array}$ & $\begin{array}{c}\text { Humedad } \\
\text { (g agua/ } \mathbf{1 0 0}_{\text {película) }}\end{array}$ & $\begin{array}{c}\text { Material soluble } \\
\left.(\mathbf{\%}) \mathbf{( 1 0 0}^{\mathbf{C}} \mathbf{C}\right)\end{array}$ \\
\hline 0 & $10,1^{\mathrm{a}}$ & $18,7^{\mathrm{a}}$ \\
0,25 & $11,4^{\mathrm{a}, \mathrm{b}}$ & $24,0^{\mathrm{b}}$ \\
0,5 & $14,3^{\mathrm{b}}$ & $34,2^{\mathrm{c}}$ \\
0,75 & $14,5^{\mathrm{b}}$ & $42,4^{\mathrm{d}}$ \\
1 & $14,6^{\mathrm{b}}$ & $48,0^{\mathrm{e}}$ \\
\hline
\end{tabular}

$a, b, c, d, e$ Letras diferentes en cada columna indican diferencias significativas $(P<0,05)$

La solubilidad en agua es una propiedad fundamental de las películas comestibles, ya que esto determina su funcionalidad en el alimento al cual van a ser aplicadas y dado el caso puede resultar beneficiosa o no. Según Turhan y Sahbaz (2004), la disolución de un polimero hidrofílico involucra la penetración de agua en la mayor parte del polimero (hinchamiento). El incremento de la solubilidad con el aumento del contenido de plastificante se basa en el reemplazo de los puentes de hidrógeno entre cadenas de MC-MC por puentes de hidrógeno de MC con sorbitol. Como resultado de la solvatación de los sitios polares de las cadenas de $\mathrm{MC}$ se reduce la atracción molecular $\mathrm{y}$ se incrementa la solubilidad del film en agua. En este trabajo en el cual las películas actúan como un sistema modelo de recubrimientos comestibles, es importante que dicho sistema tenga una solubilidad tal que permita que las muestras recubiertas, una vez ingeridas, se puedan disolver fácilmente durante la masticación pero que sean resistentes durante la cocción de productos con humedades intermedias.

En la Tabla 27 se observa el aumento en el contenido de humedad de las películas a medida que aumentó la concentración de plastificante. El valor promedio de humedad fue aproximadamente 44\% mayor que el valor obtenido para la película MC. No se observaron diferencias significativas entre las muestras sin agregado de sorbitol y 
con $0,25 \%(\mathrm{P}>0,05)$. Estos resultados resultaron comparables a los obtenidos por Velásquez y col. (2000), quienes obtuvieron valores de humedades similares trabajando con películas de metilcelulosa acondicionadas a diferentes humedades relativas. Asimismo, Rivero y col. (2010) y Vanin y col. (2005) encontraron tendencias similares en películas de gelatina plastificadas con glicerol. Como se sugirió, los resultados obtenidos se debería a que la adición de sorbitol como agente plastificante podría facilitar la movilidad macromolecular. Los plastificantes hidrofilicos como el sorbitol resultan ser compatibles con el polímero que forma la película y aumentan su capacidad de sorción de (McHugh y col., 1994). Este comportamiento afecta a toda la estructura, generando un mayor espacio dentro de las regiones cristalinas dejando lugar para que las moléculas de agua migren (Pascat, 1986; Donhowe y Fennema, 1993).

\section{Permeabilidad al vapor de agua}

Los valores obtenidos para la permeabilidad al vapor de agua se observan en la Tabla 28.

Tabla 28. Efecto del agregado de sorbitol sobre la permeabilidad al vapor de agua en las películas de MC

\begin{tabular}{cc}
\hline $\begin{array}{c}\text { Concentración de } \\
\text { plastificante (\%) }\end{array}$ & $\begin{array}{c}\text { PVA x 10 } \\
\text { recién preparadas }\end{array}$ \\
\hline 0 & $8,7(0,3)^{\mathrm{b}}$ \\
0,25 & $4,6(0,03)^{\mathrm{a}}$ \\
0,5 & $9,3(0,8)^{\mathrm{c}}$ \\
0,75 & $14,5(1,2)^{\mathrm{d}}$ \\
1 & $18,1(0,4)^{\mathrm{e}}$ \\
\hline
\end{tabular}

$a, b, c, d$ Letras diferentes indican diferencias significativas $(P<0,05)$. Los valores entre parentésis indican la desviación estándar. 
En los resultados de permeabilidad al vapor de agua se destaca que las películas a las que se incorporó el plastificante presentaron mayores valores de este parámetro que las películas sin sorbitol, a excepción de la concentración de $0,25 \%$. A medida que la concentración de sorbitol se incrementó se observó un aumento en los valores de PVA, mostrando diferencias significativas $(\mathrm{P}<0,05)$ entre sí. Con la adición de una concentración de $0,25 \%$ de sorbitol, la PVA experimentó una importante disminución de alrededor del 50\% respecto de MC. Según Mykus y col. (2014) el sorbitol (que tiene un bajo poder de plastificación), induce la cohesión en el material en el que se encuentra hasta una cierta concentración. Villada-Castillo y col. (2011) encontraron que el sorbitol satura la matriz del polímero hasta cierta concentración de plastificante; una vez que esa concentración es superada permite la agrupación entre estas moléculas y el biopolimero contribuyendo a la plasticidad del material.

Los resultados de la PVA de las películas recién preparadas y las películas almacenadas se muestran en la Figura 79.

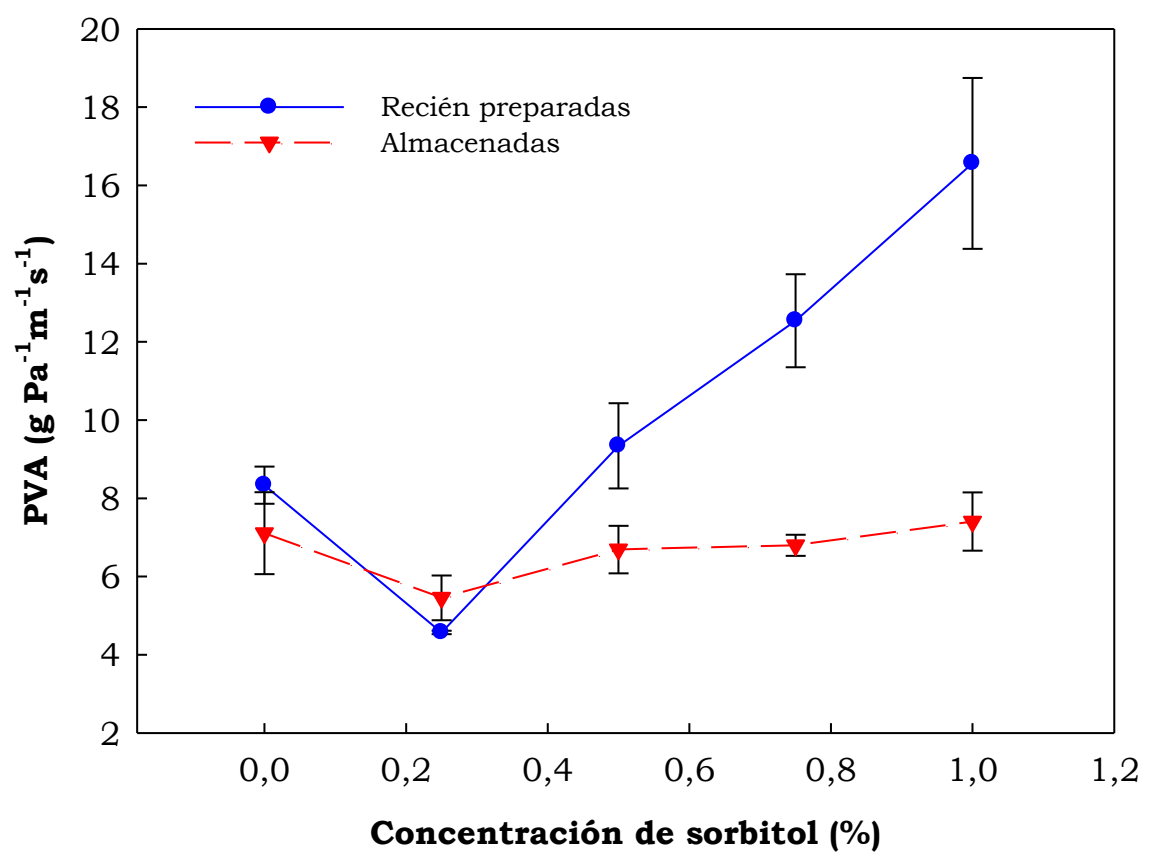

Figura 79. Evolución de la permeabilidad al vapor de agua en las películas de metilcelulosa con diferentes concentraciones de sorbitol, recién preparadas y almacenadas. 
Las películas almacenadas mostraron diferencias significativas en los valores PVA respecto a las muestras recién preparadas $(\mathrm{P}<0,05)$. En el caso de películas almacenadas, no se encontraron diferencias para este parámetro entre las distintas concentraciones de sorbitol $(P>0,05)$. La adición de 0,25\% de sorbitol redujo la PVA en las películas de MC, tanto en las muestras recién preparadas como durante el almacenamiento y se observó un punto de inflexión en la PVA para esta concentración de plastificante. Estos resultados están de acuerdo con los encontrados por Srinivasa y col. (2007).

Según Gontard y Guilbert (1994) la metilcelulosa si bien mantiene sus propiedades hidrofilicas debido a los grupos hidroxilos (-OH) funcionales que tiene en su estructura, es el éter de celulosa menos hidrofilico. Por consiguiente es capaz de formar una barrera al vapor de agua más eficiente que las películas de almidón, caseína y gluten de trigo. El agregado de plastificantes a materiales plásticos aumenta la permeabilidad de los mismos. Según varios autores, al introducir un plastificante hidrofilico, que favorece la adsorción y desorción de moléculas de agua, se mejora la permeabilidad al vapor de agua de películas obtenidas a partir de soluciones de hidrocoloides (Gontard y col., 1993; Chinnan y Park, 1995; Cuq y col., 1997; Sothornvit y col., 2000). Varios autores sugieren que la disminución en la PVA durante el almacenamiento puede ser atribuida a la disminución del volumen libre debido a un reordenamiento de la estructura y a la reticulación de la matriz con el paso del tiempo (Luangtana-Anan y col., 2007; Pushpadass y col., 2009; Mykus y col., 2014). Uno de los requisitos para que las películas de MC sean utilizadas como recubrimientos sería poseer una baja permeabilidad al vapor de agua, ya que esto evitaría que se agregue humedad al producto al cual se ha aplicado la cobertura.

\section{Propiedades mecánicas de las películas obtenidas}

El comportamiento mecánico de las películas se obtuvo a través de ensayos de tensión-deformación y las curvas resultantes se 
ajustaron a través de la Ecuación (19) que corresponde a un modelo matemático capaz de describir toda la curva de tensión-deformación (Mancini y col., 1999; Del Nobile y col., 2007):

$$
\sigma_{\mathrm{T}}=\mathrm{Ec} \varepsilon_{\mathrm{T}} \exp \left(\varepsilon_{\mathrm{T}} \mathrm{K}\right) \quad \text { Ec. } 19
$$

Donde $\varepsilon_{\mathrm{T}}$ es la deformación verdadera, $\sigma_{\mathrm{T}}$ la tensión verdadera, Ec ( $\mathrm{MPa})$ es el módulo elástico o módulo de Young y K es una constante que permite ajustar el modelo. Las películas se ensayaron a diferentes concentraciones de sorbitol a valores fijos de temperatura $(-20,5,25$, $100^{\circ} \mathrm{C}$ ). El modelo utilizado para estimar el módulo de elástico ajustó los datos experimentales satisfactoriamente $\left(R_{2}>0,99\right)$, como se observa en la Figura 80, donde se muestra el comportamiento mecánico de las películas ensayadas a $25^{\circ} \mathrm{C}$.

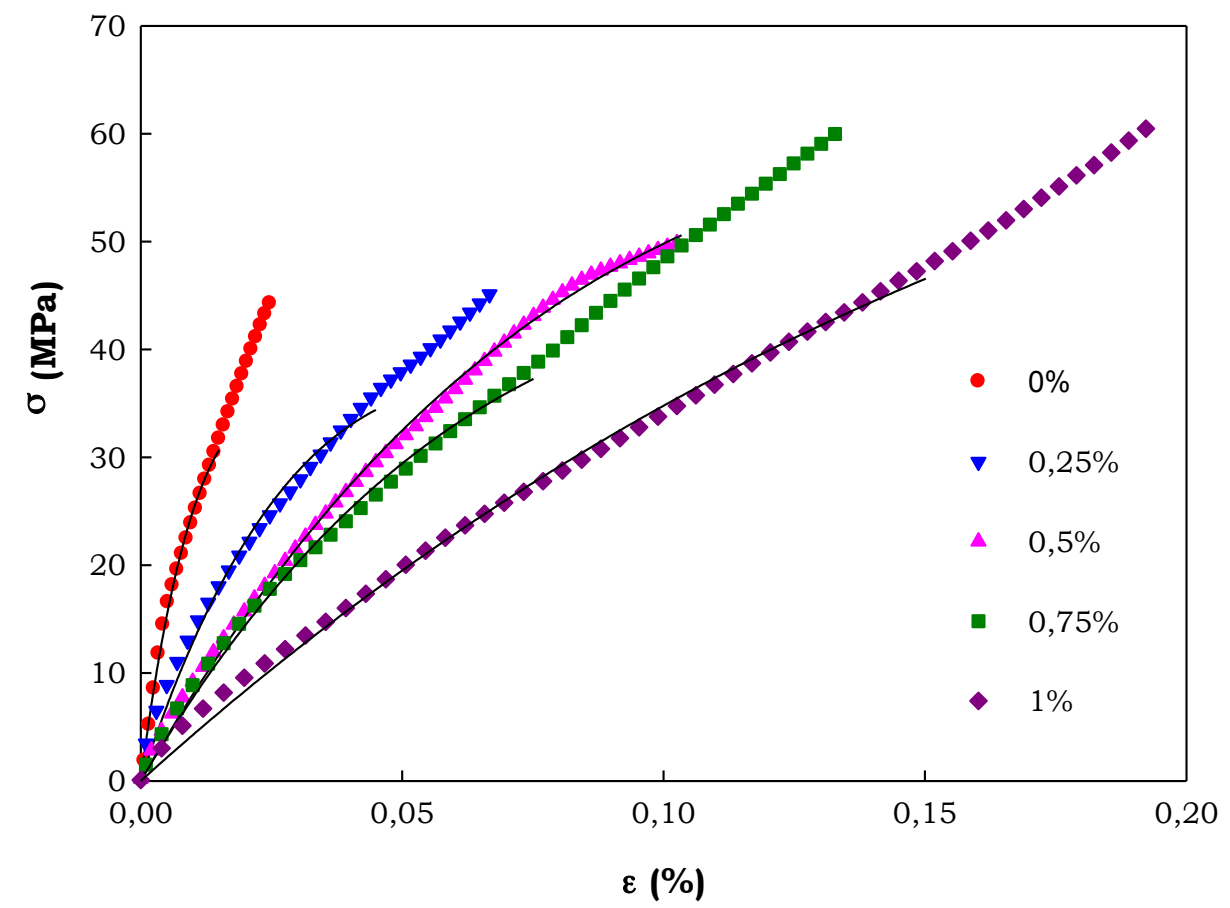

Figura 80. Propiedades mecánicas de películas de metilcelulosa con y sin sorbitol evaluadas a $25^{\circ} \mathrm{C}$ por DMA. Los símbolos corresponden a los valores experimentales y las líneas al modelo (Ec. 19).

Cuando se agregó sorbitol a las películas se produjo un cambio en el perfil mecánico de las mismas. Esto se pudo comprobar cuando se 
graficaron los valores de Ec obtenidos en función de la concentración de plastificante. El modelo descrito por Pintye-Hódi y col. (2006) con algunas modificaciones, fue utilizado para explicar el efecto de la concentración de sorbitol en el módulo de elástico, el cual se expresa como:

$$
\mathrm{Ec}=\mathrm{a}+\mathrm{b}\left[1-\exp \left(-\mathrm{c} \frac{\mathrm{Cp}}{\mathrm{Cp}+\mathrm{C}_{\mathrm{MC}}}\right)\right] \quad \text { Ec. } 20
$$

Donde $\mathrm{Cp}$ es la concentración de sorbitol $(\% \mathrm{p} / \mathrm{v})$ en la solución formadora de película, $\mathrm{C}_{\mathrm{MC}}$ es la concentración de metilcelulosa en la solución $(1,5 \%, \mathrm{p} / \mathrm{v})$, y a b y c son constantes propias del modelo. La Figura 81 exhibe el módulo elástico obtenido a partir de la Ec. (19) para todas las muestras ensayadas a $25^{\circ} \mathrm{C}$

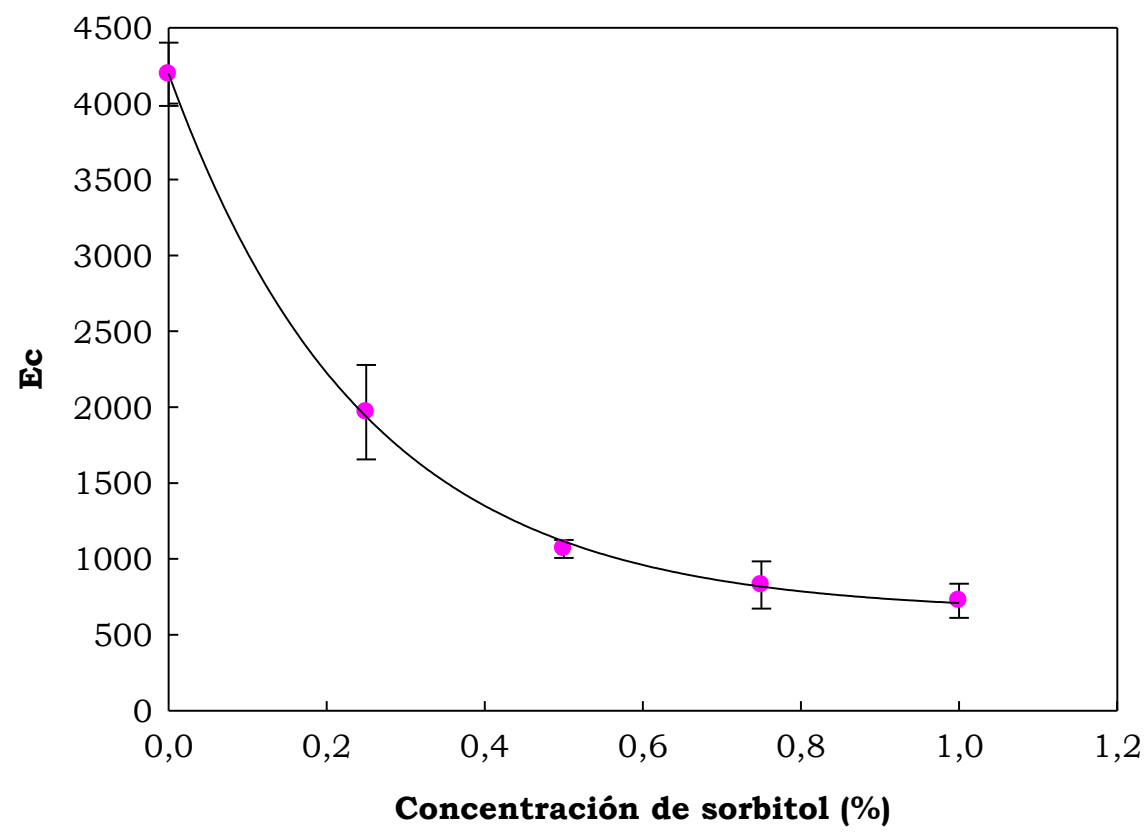

Figura 81. Módulo de elasticidad Ec como una función de la concentración de sorbitol. Los símbolos indican los valores de Ec obtenidos de la Ec. 26 y la línea al modelo aplicado (Ec. 27).

Graficando Ec como una función de la concentración de plastificante, se pudo observar que las curvas tienden al mismo valor 
para la mayor cantidad de sorbitol $(\mathrm{P}>0,05)$ y presentan diferencias cuando el contenido de sorbitol esta entre 0,25 y $0,50 \%(P<0,05)$. A medida que aumentó la concentración de sorbitol los valores de Ec disminuyeron drásticamente $(\mathrm{P}<0,05)$. Los datos teóricos calculados a partir de la Ec. (20) ajustaron satisfactoriamente los datos experimentales $\left(R^{2}>0,99\right)$. Esto demuestra que cuanto mayor es la concentración de sorbitol menor es el valor del módulo elástico, indicando claramente que el plastificante interactúa con la estructura de la metilcelulosa. Como consecuencia las películas obtenidas resultaron ser más flexibles respecto a las que no tenían plastificante agregado. Estos resultados son consistentes con los informados por Srinivasa y col. (2007), quienes observaron que la adición de $0,5 \%$ de sorbitol aumentó el porcentaje de elongación de películas de quitosano.

Los valores de los módulos elásticos (Ec) determinados a partir de la ecuación Ec. 26, se ajustaron linealmente en función de las temperaturas ensayadas $\left(-20,5,25\right.$ y $\left.100^{\circ} \mathrm{C}\right)$ y de la concentración de sorbitol (0-1\%), como se observa en la Figura 82

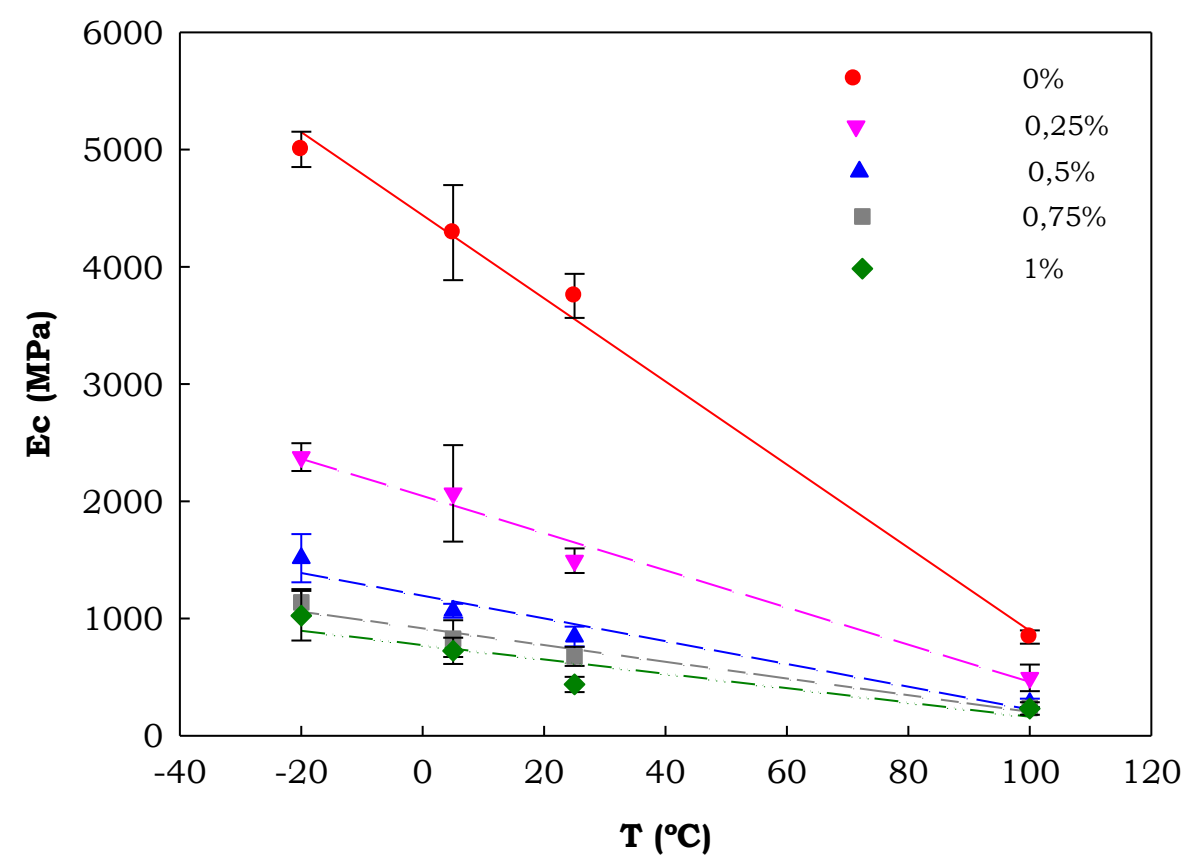

Figura 82. Dependencia del módulo elástico (Ec) de las películas de metilcelulosa (con y sin agregado de sorbitol) con la temperatura. 
A medida que aumentó la temperatura ensayada y la concentración de sorbitol, se obtuvieron menores valores de Ec. Cuando la concentración de sorbitol superó $0,25 \%$, las diferencias entre los valores de Ec determinados para cada temperatura no fueron significativas $(\mathrm{P}>0,05)$. Gupta y Jabrail (2009) observaron comportamientos similares trabajando con PET a diferentes temperaturas.

La flexibilidad, la ductilidad y la tenacidad de los polímeros se mejoran con el agregado de plastificantes. Su presencia tiende a aumentar la extensibilidad y reducir la fragilidad de la matriz polimérica evitando la formación de poros y fisuras (García y col., 2000, 2004). Este comportamiento es importante cuando se requiere cubrir una superficie totalmente y que el recubrimiento actúe como barrera entre el material y el ambiente. Generalmente los plastificantes tienen baja presión de vapor y bajo peso molecular. Reforzando lo explicado anteriormente, actúan ocupando posiciones entre las grandes cadenas poliméricas, incrementando la distancia entre cadenas, reduciendo los enlaces secundarios intermoleculares y disminuyendo la $\mathrm{T}_{\mathrm{g}}$. La adición de plastificantes de bajo peso molecular a un biopolímero amorfo tiene el mismo efecto que el aumento de la temperatura sobre la movilidad molecular (Slade y Levine, 1991). Dado que en polímeros la transición vitrea ocurre con cambios termodinámicos del sistema, las propiedades térmicas de las películas se analizaron a través de DSC y DMA.

\section{Propiedades térmicas por DSC y DMA}

A partir de DSC fue posible determinar los cambios en la capacidad calorífica del polímero mientras por barridos de temperatura por DMA se registraron las relajaciones sufridas por el material. Mediante ambas técnicas fue posible determinar los rangos de temperaturas a los que ocurrieron dichas transiciones. Los resultados obtenidos por DSC para la temperatura de transición vítrea se observan en la Tabla 29. 
Tabla 29. Valores de $\mathrm{T}_{\mathrm{g}}$ para las películas de $\mathrm{MC} 1,5 \%$ con agregado de plastificante $(0-1 \%)$, obtenidos por DSC

\begin{tabular}{cc}
\hline $\begin{array}{r}\text { Concentración de } \\
\text { Sorbitol (\%) }\end{array}$ & $\left.\mathbf{T}_{\mathbf{g}} \mathbf{(}^{\circ} \mathbf{C}\right)$ \\
\hline 0 & $187,3^{\mathrm{b}}$ \\
0,25 & $174,9^{\mathrm{a}}$ \\
0,50 & $172,1^{\mathrm{a}}$ \\
0,75 & $170,7^{\mathrm{a}}$ \\
1,00 & $171,5^{\mathrm{a}}$
\end{tabular}

$a, b$ Letras diferentes indican diferencias significativas $(P<0,05)$

Como es bien sabido, se determinó que el agregado de plastificante disminuyó la temperatura de transición vítrea $\left(\mathrm{T}_{\mathrm{g}}\right)$ de las películas. Sin embargo no se observaron diferencias significativas entre los valores de $\mathrm{T}_{\mathrm{g}}$ para las distintas concentraciones de sorbitol estudiadas. Estos resultados fueron similares a los obtenidos por Debeaufort y Voilley (1997) en películas de metilcelulosa con PEG400. A partir de los resultados obtenidos por DMA se pudo analizar el efecto de la plastificación de las películas por agregado de sorbitol, como se observa en la Figura 83.

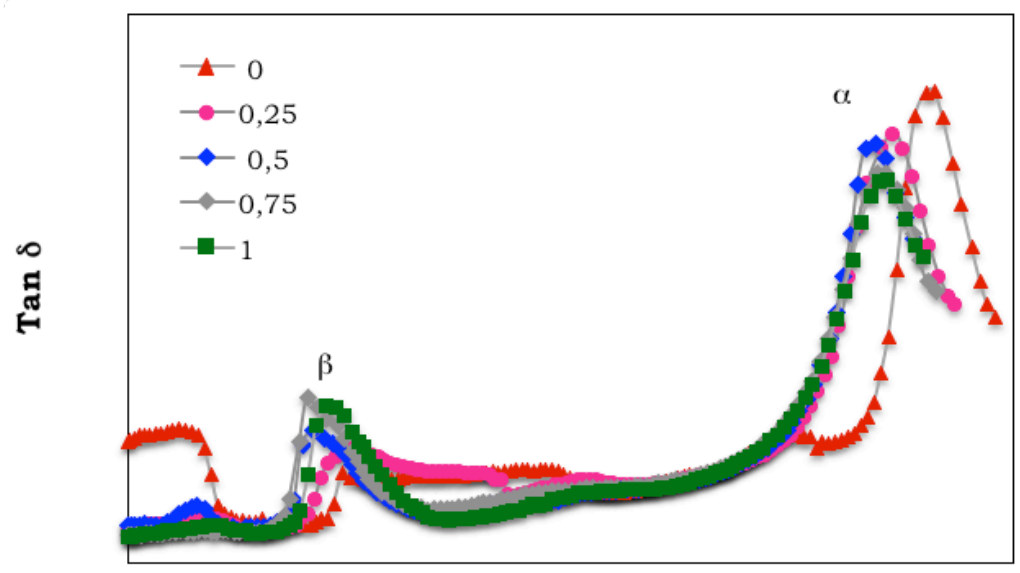

Temperatura $\left({ }^{\circ} \mathrm{C}\right)$

Figura 83. Efecto de la concentración de sorbitol en los espectros mecánico - dinámico de las películas de metilcelulosa (Frec $=5 \mathrm{~Hz}$.) 
Varios autores consideran que en un polímero amorfo la relajación $\alpha$ corresponde a la temperatura de transición vitrea, que refleja el movimiento de los segmentos a lo largo de la cadena del polímero. A temperaturas más bajas se producen relajaciones $\beta$ o secundarias que en los materiales hidrofílicos corresponden a una típica relajación de la matriz polimérica como consecuencia de los movimientos de los grupos favorecidos por las moléculas de agua (Montes y col., 1997; Lazaridou, 2003).

Para las películas de MC sin agregado de plastificante, dos relajaciones, $\beta$ y $\alpha$ fueron encontradas en la curva de $\tan \delta$ ubicadas alrededor de $12^{\circ} \mathrm{C}$ y $218,5^{\circ} \mathrm{C}$, respectivamente. Park y Ruckenstein (2001) obtuvieron valores de 26,8 y $199,5^{\circ} \mathrm{C}$ para películas de metilcelulosa. Las relajaciones tipo $\alpha$ para las películas con concentraciones de sorbitol 0,5 y $1 \%$ se observaron a 197,3 y $199,1^{\circ} \mathrm{C}$. Para cada una de las concentraciones de sorbitol analizadas se observó que las películas plastificadas presentaron relajaciones a temperaturas más bajas comparadas con las películas sin plastificante. No se encontraron diferencias $(\mathrm{P}>0,05)$ con el aumento concentraciones de sorbitol superiores al 0,25\%. La misma tendencia se observó en el caso de la relajación $\beta$, que se desplazó hacia una temperatura más baja, y presentó una mejor definición del pico cuando el contenido de plastificante fue mayor a 0,25\% (Figura 83). Neto y col. (2005) y Mucha y Pawlak (2005) informaron que películas de quitosano exhibieron un evento asociado a la relajación $\beta$ alrededor de $-20^{\circ} \mathrm{C}$, característico del movimiento local de grupos laterales en el polisacárido.

Los resultados obtenidos por DMA son comparables con los obtenidos por DSC y están de acuerdo con los informados por Galdeano y col. (2009). A su vez el comportamiento térmico de las películas con y sin plastificante puede ser relacionado con los resultados obtenidos para el contenido de humedad. Según Park y Ruckenstein (2001) las 
variaciones de la $\mathrm{T}_{\mathrm{g}}$ probarian la compatibilidad entre $\mathrm{MC}$ y el plastificante.

\section{Propiedades microestructurales por FTIR}

La técnica espectral más ampliamente utilizada en el estudio y caracterización de la microestructura de polímeros es la espectroscopia infrarroja (FTIR, por sus siglas en inglés). Se basa en las frecuencias de vibración específicas de los enlaces químicos correspondientes a los niveles de energía de la molécula.

En los espectros de FTIR se observaron las bandas características de la MC en polvo y se compararon con las obtenidas de las películas (Figura 84 a y b).

La posición y el ancho de los picos correspondientes a la metilcelulosa, ubicados sobre la región de 1000 a $1500 \mathrm{~cm}^{-1}$ se mantuvieron constantes para las películas con y sin agregado de plastificante (Figura 84 a). En el caso de las películas de MC con agregado de sorbitol (0-1\%) se observó una banda de absorción localizada a $3500 \mathrm{~cm}^{-1}$, correspondientes al grupo -OH de la molécula. En los tratamientos estudiados se observó un aumento gradual de esta banda a medida que se incrementó el contenido de plastificante (Figura 84 b). Este resultado fue similar al obtenido por Velásquez y col. (2003), en películas de metilcelulosa acondicionadas a diferentes humedades relativas. 
a.

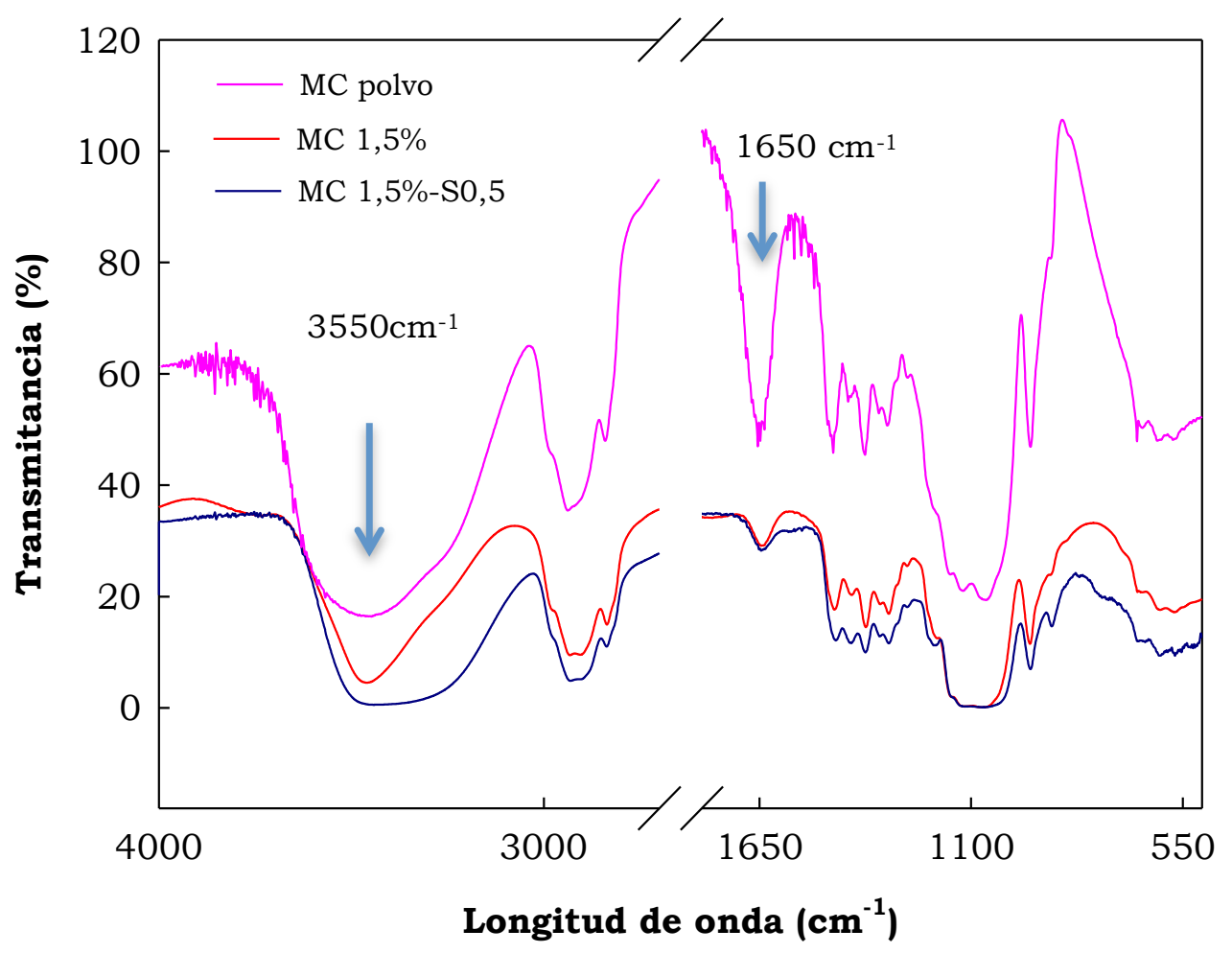

b.

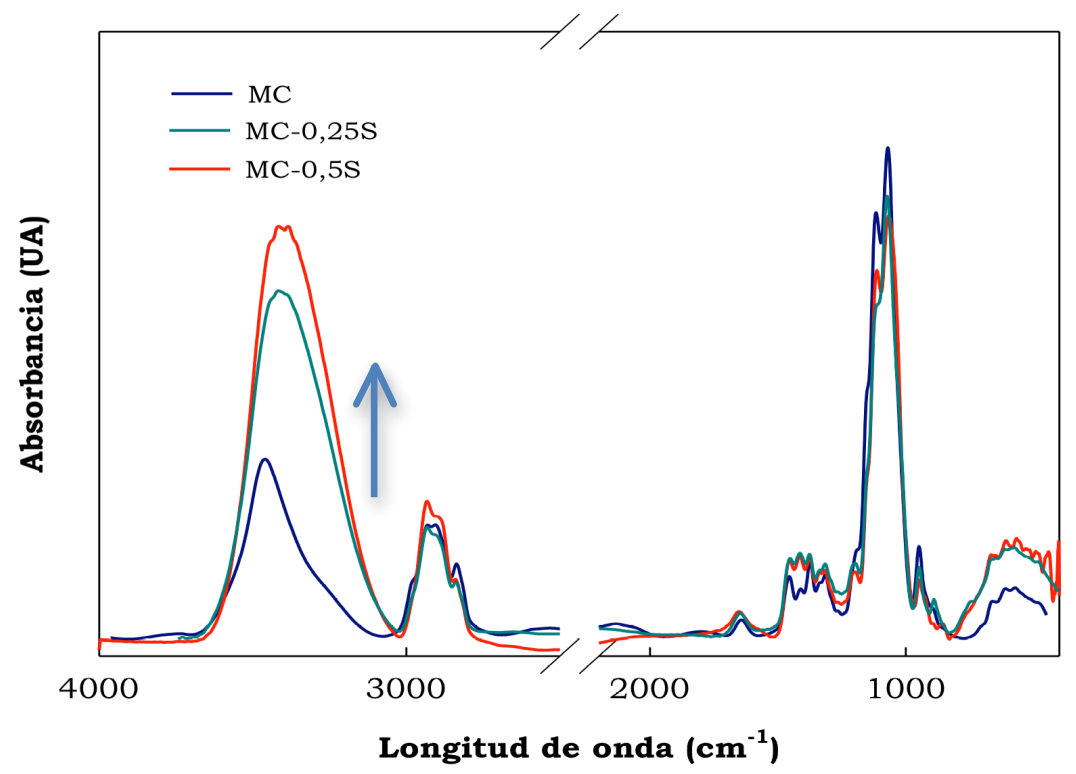

Figura 84. Espectros de FTIR de a. MC polvo y películas de MC y MC-0,5 S; b. Películas de MC con y sin agregado de plastificante.

La Figura 85 representa los espectros de absorción IR en la región entre 1520 y $1720 \mathrm{~cm}^{-1}$, relacionada con la vibración causada por la 
flexión de las moléculas de agua contenida en la película (Velásquez y col., 2003).

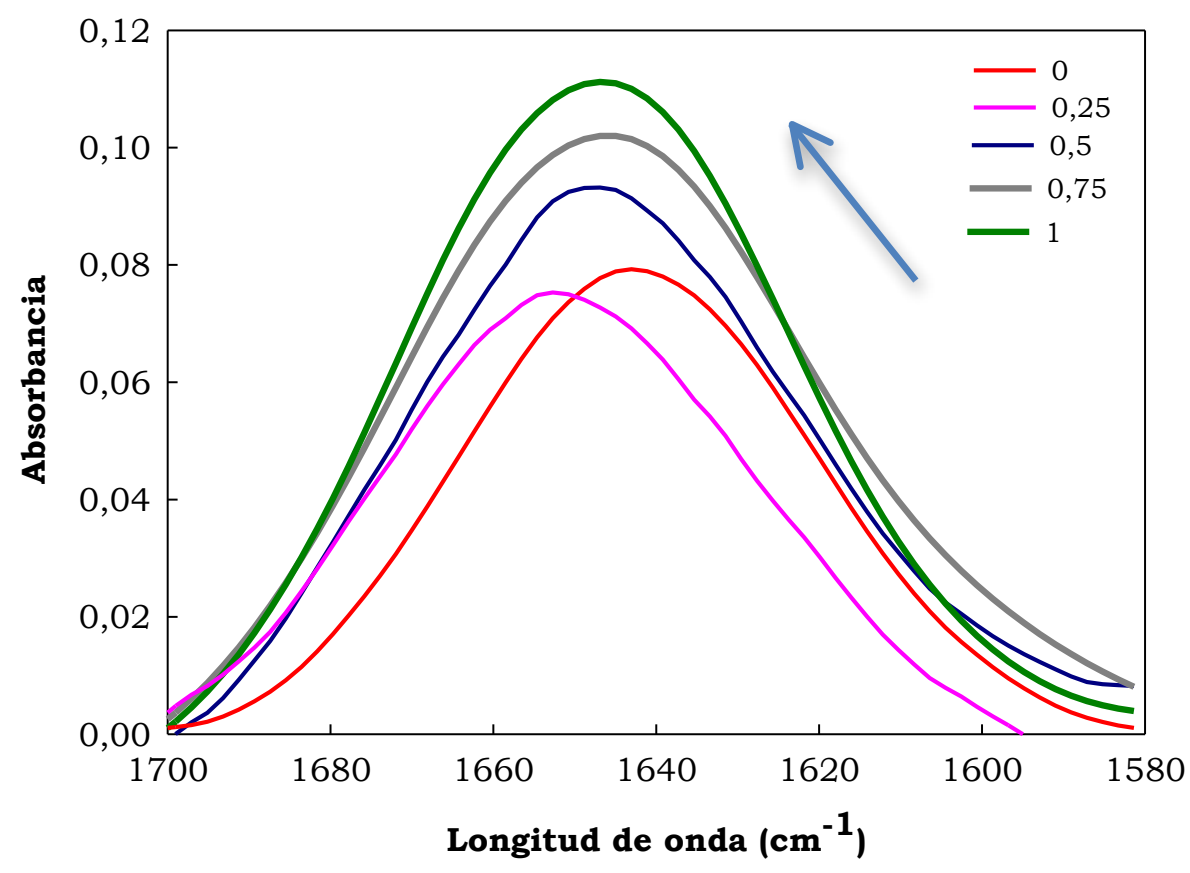

Figura 85. Espectros FTIR de películas de metilcelulosa con diferentes concentraciones de sorbitol en la región de 1700-1580 cm-1.

El máximo de esta banda en las películas de MC se encuentró a $1640 \mathrm{~cm}^{-1}$. Con la adición de sorbitol se observó que la absorción máxima de la banda de $1640 \mathrm{~cm}^{-1}$ se desplazó a mayores número de onda, de lo que puede inferirse que los puentes de hidrogeno estarian más fuertemente enlazados. Chou y col. (2012) sugieren que el sorbitol actuaría en las películas impidiendo la separación del agua débilmente unida, debido a su capacidad de unir enlaces de hidrógeno fuertemente. Esto se correlaciona con el contenido de humedad de las películas y la temperatura de transición vítrea obtenida para cada una de las concentraciones de plastificante estudiadas. 


\section{Micrografias obtenidas por SEM}

Las muestras con y sin agregado de plastificante presentan una estructura densa y compacta, lo que demuestra la formación de una matriz continua. La superficie se volvió más homogénea debido a la presencia de sorbitol (Figura 86)

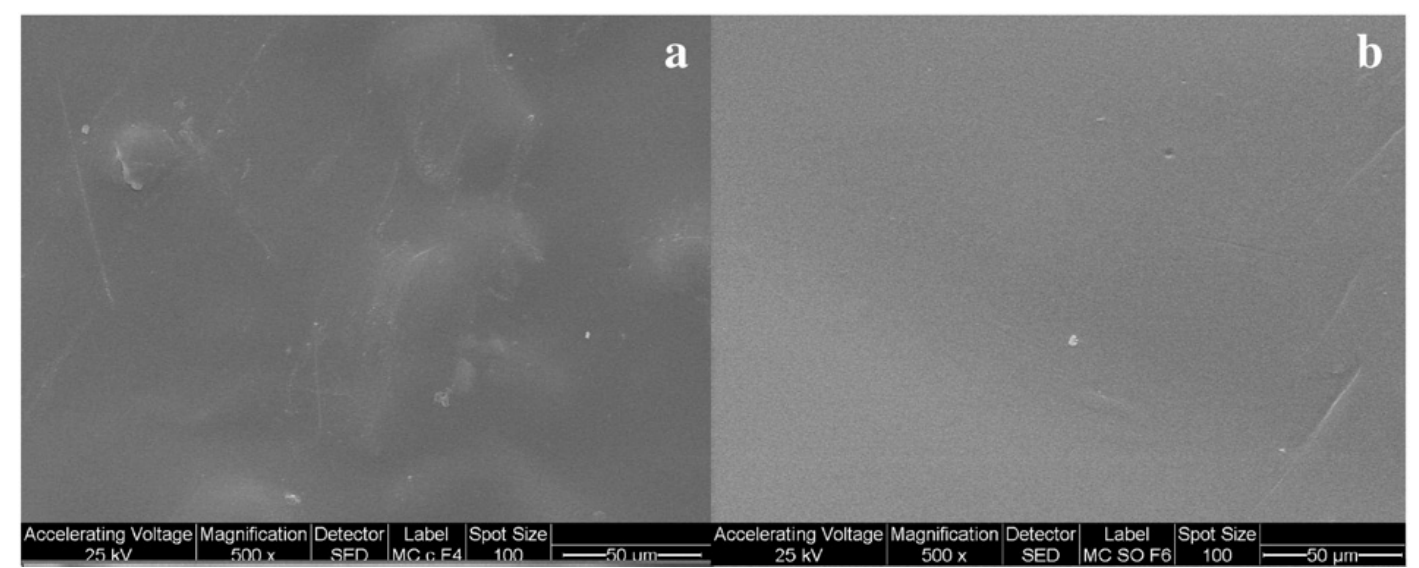

Figura 86. Micrografias obtenidas por SEM de las películas: a. MC; b. MC$0,25 \mathrm{~S}$

Teniendo en cuenta los resultados obtenidos para todas las concentraciones de sorbitol ensayadas y las aplicaciones futuras como una cobertura que no influya negativamente en las características físicas y químicas del producto a recubrir, se seleccionó la concentración de sorbitol de 0,25\%. Con esta concentración se obtuvieron películas homogéneas, transparentes, flexibles, con buenas propiedades al vapor de agua y solubilidad. Además por FTIR se observó que el sorbitol interactúa con la metilcelulosa por medio de puentes de hidrógeno. Asimismo, a partir de estudio a diferentes temperaturas se observó un efecto protector del sorbitol sobre matriz de MC.

\section{A.2.3 SELECCIÓN DE LA CONCENTRACIÓN DE ÁCIDO CÍTRICO PARA LAS PELICULAS DE MC}

Los objetivos de esta sección fueron estudiar la capacidad entrecruzante del ácido cítrico, evaluar las modificaciones estructurales producidas sobre películas a base de metilcelulosa y sorbitol y el efecto sobre las propiedades de barrera de las mismas. 


\section{A.2.3.1 MATERIALES Y MÉTODOS}

\section{MATERIALES}

\section{Obtención de las películas}

Las soluciones de metilcelulosa (A4M) se prepararon al 1,5\% $\mathrm{p} / \mathrm{v}$ siguiendo el método descrito en la sección anterior. Se utilizó sorbitol (S) en una concentración de 0,25\% como plastificante. Las películas se formaron por moldeo y secado a $37{ }^{\circ} \mathrm{C}$. Las concentraciones de ácido cítrico (AC) estudiadas fueron 5 y $10 \%$ (p/p MC).

\section{MÉTODOS}

Las propiedades microestructurales se obtuvieron por FTIR. Se determinaron permeabilidad al vapor de agua (PVA), capacidad de hinchamiento y solubilidad de las películas obtenidas. La capacidad de hinchamiento de las películas se determinó siguiendo la ganancia de peso en el tiempo, sobre películas de $2 \times 2 \mathrm{~cm}$ dispuestas en un ambiente de $100 \% \mathrm{HR}$ a $20^{\circ} \mathrm{C}$. La permeabilidad al oxígeno de las películas se determinó usando un medidor de permeabilidad Oxtran 2/20 (MOCON, Modern Controls, EEUU), siguiendo el método descrito en la norma ASTM F1927-07. Los experimentos se realizaron a $23^{\circ} \mathrm{C}$ y $65 \% \mathrm{HR}$. El área efectiva de permeación de la muestra fue de $50 \mathrm{~cm}^{2}$. Las muestras se colocaron en las celdas de permeabilidad y se realizó una purga con $\mathrm{N}_{2}$ para eliminar trazas de oxígeno de la celda. Una vez realizado este procedimiento se inyectó oxígeno (a presión atmosférica) en uno de los compartimientos. $\mathrm{El} \mathrm{O}_{2}$ que permea a través de la película es captado y medido por un sensor coulométrico. La permeabilidad se calculó dividendo la velocidad de transmisión del gas por la diferencia de la presión parcial de oxígeno a través de la película (1 atm) y multiplicando por el espesor de la misma. Se expresó como ml $\mathrm{O}_{2}$ $\mu \mathrm{m} / \mathrm{m}^{2}$ día KPa. 


\section{Análisis estadístico}

Todos los experimentos se realizaron por duplicado. El análisis de varianza se realizó por separado para las variables de solubilidad, permeabilidad al vapor de agua (PVA) y permeabilidad al oxígeno.

Se realizó un análisis de varianza (ANAVA) para evaluar el efecto de los factores analizados utilizando el programa Systat. Para los ensayos de comparación de medias se empleó el test de menor diferencia significativa (LSD) con un nivel de significación de 0,05.

\section{A.2.3.2 RESULTADOS Y DISCUSIÓN}

Con el agregado de ácido cítrico en las películas de MC plastificadas se obtuvieron películas transparentes y flexibles, para todas las concentraciones de ácido cítrico (Figura 87)

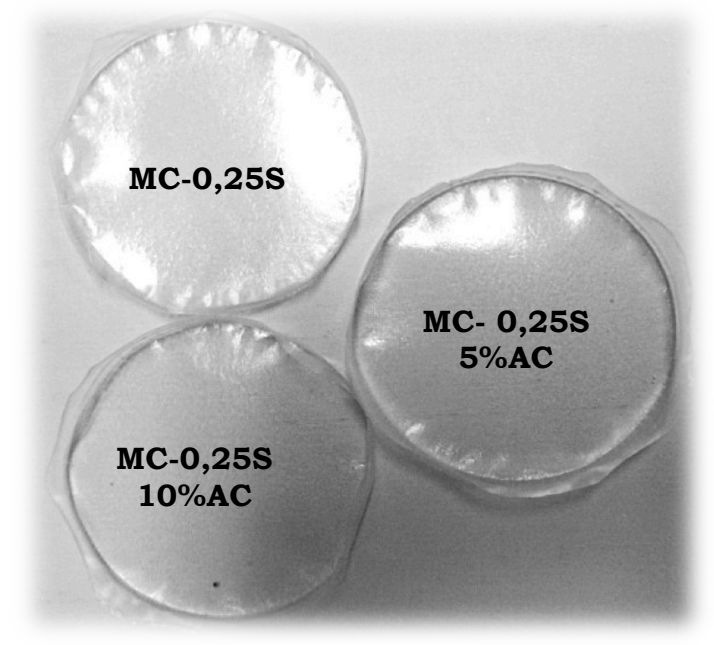

Figura 87. Películas de MC-0,25S con agregado de ácido cítrico 5\% (p/p MC).

Para evaluar la interacción entre el ácido cítrico y la metilcelulosa, se realizó la caracterización del ácido cítrico y de las películas obtenidas. En la Figura 88 se observa el espectro de FTIR del ácido cítrico en polvo. 


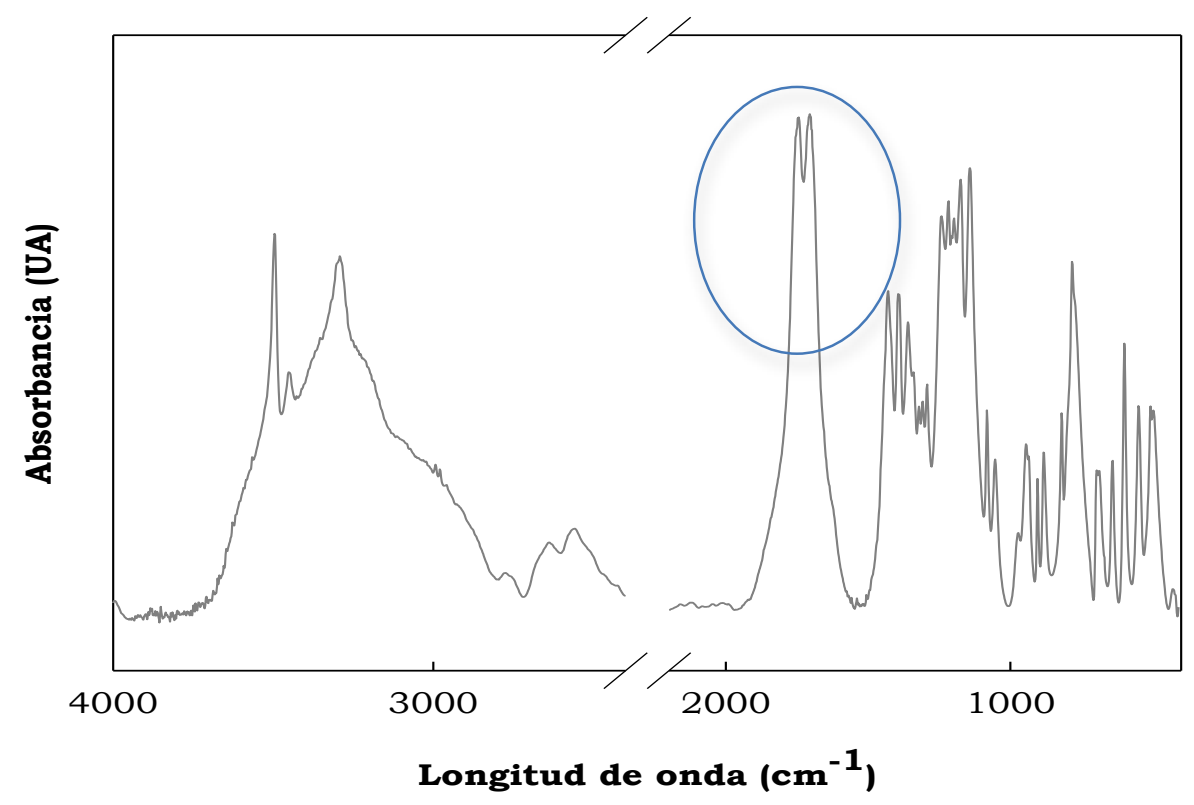

Figura 88. Espectros de FTIR de ácido cítrico anhidro en polvo

Una vez establecidas las bandas características de $\mathrm{AC}$, se analizaron los espectros de las peliculas entrecruzadas (Figura 89 a y b).

La Figura 89 (a) muestra la aparición de una banda de absorción a $1724 \mathrm{~cm}^{-1}$, característica de los grupos carbonilos como los ácidos carboxílicos y ésteres (Figura 89 b) (Costa y col., 2011). Según Dimitri y col. (2007) y Reddy y col. (2010) la aparición de esta banda evidencia la interacción entre el AC y el polímero. Estos resultados resultaron comparables con los obtenidos por Rivero y col. (2012) para películas de quitosano entrecruzadas con ácido tánico. Otros autores observaron la banda de absorción del ácido cítrico entrecruzado con diferentes matrices poliméricas (Krumova y col., 2000; Sannino y col., 2006). 
a.

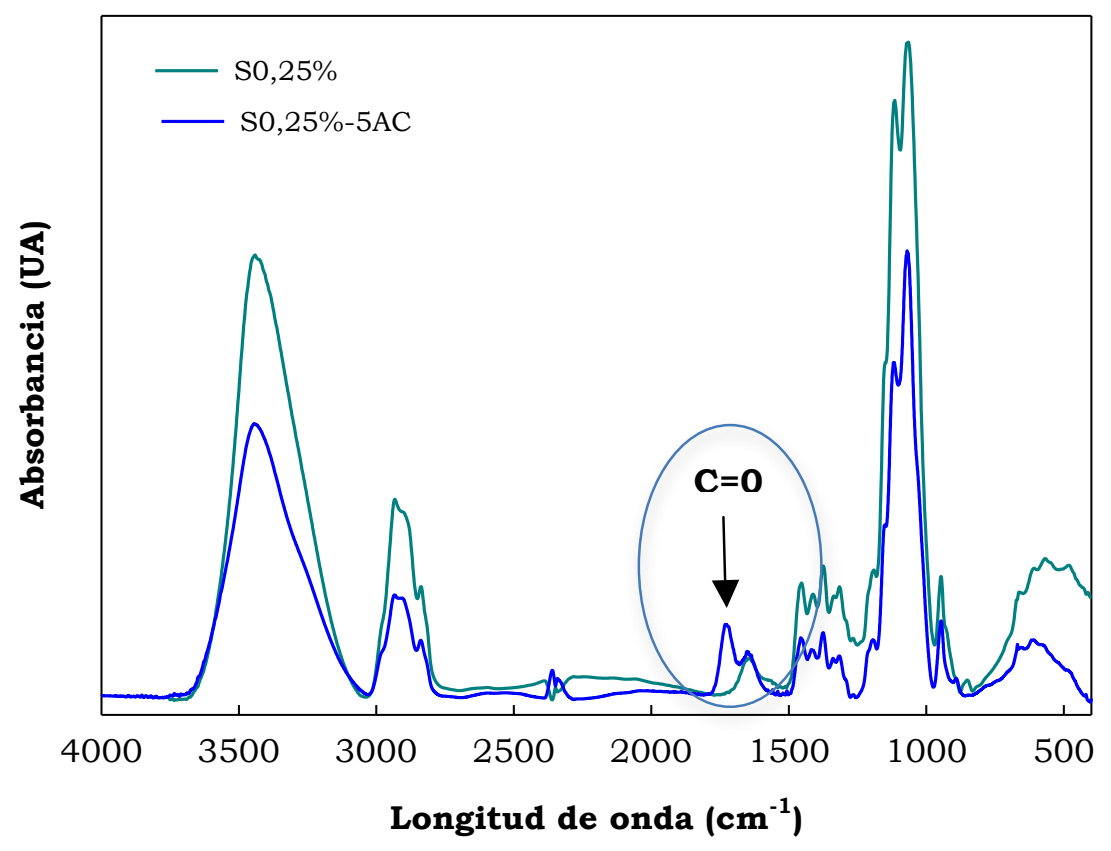

b.

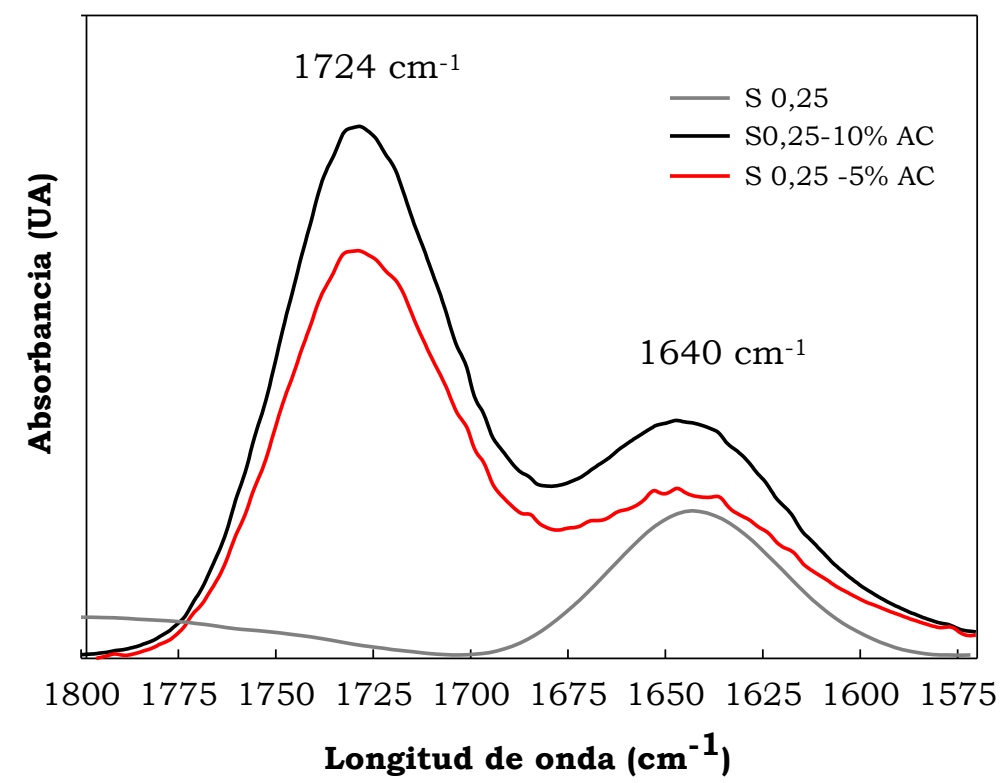

Figura 89. Espectros de FTIR de a. Películas de MC con agregado de plastificante y 5 y 10\% AC; b. Ampliación de la zona de absorción entre 1800$1500 \mathrm{~cm}^{-1}$.

Se han propuesto mecanismos en la literatura que permiten explicar la reacción de reticulación de los polímeros de celulosa con AC. Xie y col. (2006) informaron que cuando el AC se calienta, se deshidrata para formar un anhídrido cíclico que reacciona con el polimero. Según 
Zhou y col. (2007) las dos etapas principales de la reacción de ácidos carboxílicos polifuncionales con celulosa se deben a la fijación de los ácidos carboxílicos a través de esterificación con un grupo hidroxilo de celulosa y su posterior reacción a través de esterificación con otro hidroxilo de celulosa, lo que produce una reticulación entre las cadenas dela celulosa.

La Tabla 30 muestra las propiedades de barrera al vapor de agua y al oxígeno y la solubilidad de las películas plastificadas con $0,25 \%$ de sorbitol y agregado de ácido cítrico

Tabla 30. Propiedades de barrera y \% de material soluble $\left(100^{\circ} \mathrm{C}\right)$ de las películas de $\mathrm{MC}-0,25 \mathrm{~S}$ con diferentes concentraciones de ácido cítrico

\begin{tabular}{|c|c|c|c|}
\hline $\begin{array}{l}\text { Concentración } \\
\text { de ácido } \\
\text { citrico (\%) }\end{array}$ & $\begin{array}{l}\text { Permeabilidad al } \\
\text { vapor de agua } \\
(\mathrm{g} / \mathrm{m} \mathrm{s} \mathrm{Pa}) \times 10^{11}\end{array}$ & $\begin{array}{c}\text { Permeabilidad al } \mathrm{O}_{2} \\
\qquad \begin{array}{c}\left(\mathrm{ml} \mathrm{O} \mathrm{O}_{2} \mu \mathrm{m} / \mathrm{m}^{2} \text { dia }\right. \\
\mathrm{KPa})\end{array}\end{array}$ & $\begin{array}{c}\% \text { Material } \\
\text { soluble }\left(100^{\circ} \mathrm{C}\right)\end{array}$ \\
\hline 0 & $4,5(0,02)^{b}$ & $84,0(2,1)^{\mathrm{c}}$ & $24,5(0,22)^{\mathrm{a}}$ \\
\hline 5 & $3,2(0,10)^{a}$ & $24,2(2,4)^{a}$ & $24,4(0,33)^{a}$ \\
\hline 10 & $5,2(0,1)^{\mathrm{c}}$ & $58,1(0,1)^{\mathrm{b}}$ & $27,6(0,11)^{\mathrm{b}}$ \\
\hline
\end{tabular}

$a, b, c$ Letras diferentes en la misma columna indican diferencias significativas $(P<0,05)$. Los valores entre paréntesis corresponden la desviación estándar.

Los valores obtenidos de PVA y permeabilidad al oxígeno $\left(\mathrm{PO}_{2}\right)$ de películas de metilcelulosa sin agregado de plastificante fueron 8,7 x $10^{-11} \mathrm{~g} / \mathrm{m} \mathrm{s} \mathrm{Pa}$ y $128,2 \mathrm{ml} \mathrm{O}_{2} \mu \mathrm{m} / \mathrm{m}^{2}$ día $\mathrm{KPa}$. De acuerdo a los resultados, se observó que el agregado de plastificante en una concentración de 0,25\% afectó las propiedades de barrera de las películas, en comparación con los valores obtenidos para las películas sin plastificante y se observó una disminución en los valores de PVA para las concentraciones de AC estudiadas. La incorporación de 5\% de 
ácido cítrico $(\mathrm{AC})$ a las películas de $\mathrm{MC}$ plastificadas con $0,25 \%$ de sorbitol provocó una disminución significativa $(\mathrm{P}<0,05)$ de la $\mathrm{PVA}$ y $\mathrm{PO}_{2}$ $(\mathrm{P}<0,05)$. Se observaron diferencias significativas en la solubilidad cuando se aumentó el contenido de $\mathrm{AC}$ al 10\% (p/p MC) en las películas. Rivero y col. (2010) informaron valores similares de $\mathrm{PO}_{2}$ para películas de quitosano entrecruzadas con ácido tánico. De acuerdo con Ou y col. (2005) las reacciones de entrecruzamiento restringen el movimiento de las moléculas permitiendo la formación de una estructura más compacta, lo cual evitaría la transferencia de moléculas.

En la Figura 90 se observa que las películas con agregado de AC mostraron una menor capacidad de hinchamiento con respecto a las películas sin ácido cítrico. Según Reddy y col. (2010) la formación de una estructura más compacta después de la reticulación impide el hinchamiento del polímero lo que lleva además a una disminución en la permeabilidad al vapor de agua.

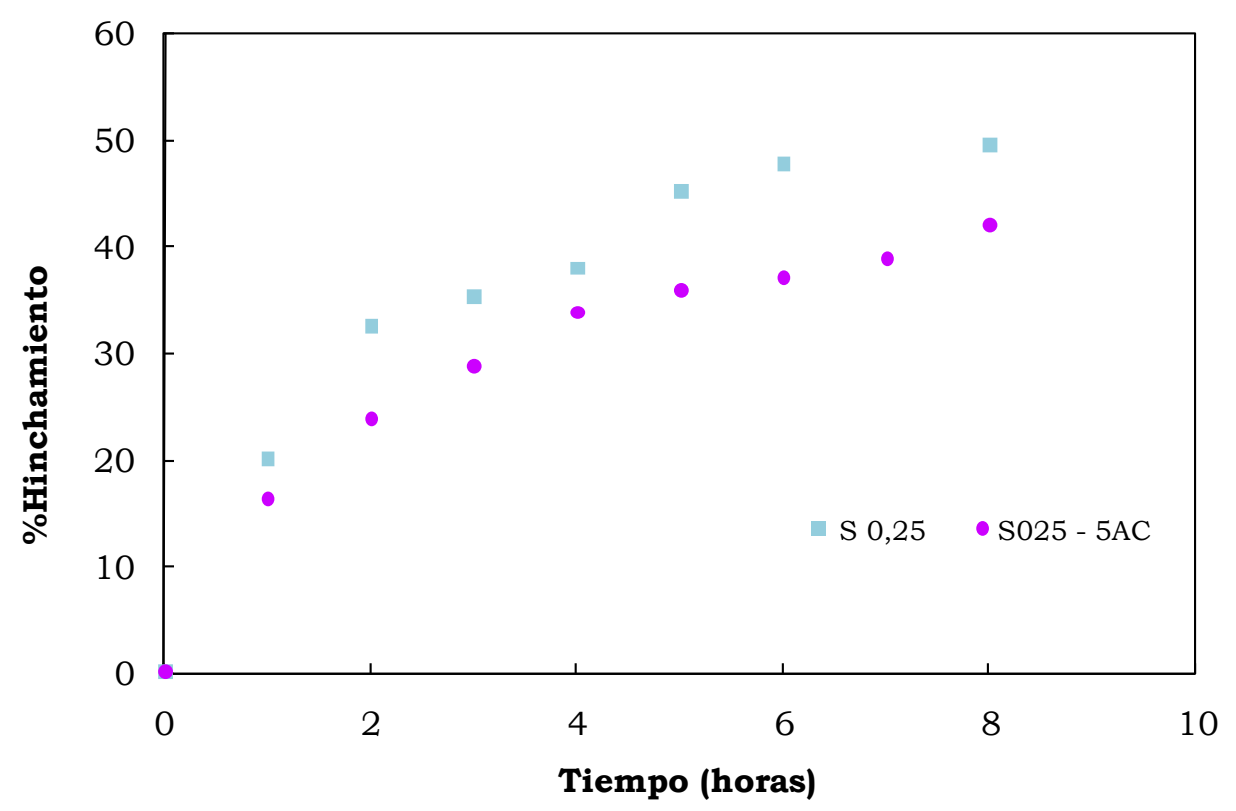

Figura 90. Capacidad de hinchamiento de las películas de MC con sorbitol con agregado de $5 \%$ AC. 
El ácido cítrico resultó ser un agente entrecruzante para las películas de MC cuando se utilizó en bajas concentraciones (5\% p/p). El entrecruzamiento disminuyó la permeabilidad al vapor de agua y el hinchamiento y permitió obtener buenas propiedades de barrera a los gases. La formulación de $\mathrm{MC}$ 1,5\%- $0,25 \% \mathrm{~S}$ y $5 \% \mathrm{AC}(\mathrm{p} / \mathrm{p} \mathrm{MC})$ permitiria obtener un recubrimiento menos afin por el agua y el oxígeno, lo cual es útil cuando se requieren recubrir alimentos de baja humedad y preservar nutrientes susceptibles a la oxidación.

\section{A.2.4 CONCLUSIONES}

Los valores de la temperatura de transición vítrea de las películas con la adición de sorbitol experimentaron un corrimiento hacia temperaturas más bajas con respecto a los valores de $\mathrm{T}_{\mathrm{g}}$ sin agregado de plastificante. Esto se correlacionó con el corrimiento del pico de FTIR a $1640 \mathrm{~cm}^{-1}$ y con el aumento de humedad de las películas. Asimismo los módulos de elásticos disminuyeron con el aumento de concentración de plastificante y de la temperatura.

La flexibilidad de las películas aumentó como resultado de la disminución del número de enlaces de hidrógeno entre los grupos hidroxilo de las moléculas del polímero, debido a la interferencia producida por el sorbitol. La solubilidad de las películas a $100^{\circ} \mathrm{C}$ aumentó como resultado de la propiedad de termogelación de la MC.

Las mejores propiedades de barrera se observaron a una concentración de sorbitol de $0,25 \%$, lo que demostró ser un punto de inflexión para las propiedades mecánicas. A esta concentración de plastificante la temperatura de transición vitrea no sufrió cambios significativos. 
Con el agregado de 5\% de $\mathrm{AC}$ a las películas plastificadas con $0,25 \%$ de sorbitol fue posible mejorar las propiedades de barrera y disminuir la afinidad por el agua.

Fue posible establecer relaciones entre las propiedades fisicas y el contenido de sorbitol y ácido cítrico de las películas de metilcelulosa. Esto permitiría seleccionar las condiciones óptimas para desarrollar películas y coberturas de acuerdo con requisitos específicos de proceso y de almacenamiento. El sorbitol actuaría como un agente protector debido a su capacidad de formar enlaces de hidrógeno. Esta estabilidad es crucial para las películas y las aplicaciones como recubrimiento en la industria alimentaria.

\section{A.2.5 REFERENCIAS}

Arvanitoyannis, I., Biliaderis, C.G. (1999). Physical properties of polyol-plasticized edible blends made of methyl cellulose and soluble starch. Carbohydrate Polymers, 38: 47-58.

Bodvik, R., Dedinaite, A., Karlson, L., Bergström, M., Bäverbäck, P., Skov Pedersen, J., Edwards, K., Karlsson, G., Varga, I., Claesson, P.M. (2010). Aggregation and network formation of aqueous methylcellulose and hydroxypropyl methylcellulose solutions. Colloids and Surfaces A: Physicochemical Engineering Aspects, 354: 162-171.

Cheng, L.H., Karim, A.A., Seow, C.C. (2006). Effects of waterglycerol and water-sorbitol interactions on the physical properties of konjac glucomannan films. Journal of Food Science, 71: 62-67.

Coffey, D.G., Bell, D.A., Henderson, A. (1995). Food polysaccharides and their application. Marcel Dekker, New York

Debeaufort, F., Quezada-Gallo, J-A., Delporte, B., Voilley, A. (2000). Lipid hydrophobicity and physical state effects on the properties of bilayer edible films. Journal of Membrane Science, 180: 47-55. 
Del Nobile, M.A., Chillo, S., Mentana, A., Baiano, A. (2007). Use of the generalized Maxwell model for describing the stress relaxation behavior of solid-like foods. Journal of Food Engineering, 78: 978-983.

Donhowe, I. G., Fennema, O. (1993). The effects of plasticizers on cristallinity, permeability, and mechanical properties of methylcellulose films. Journal of Food Processing and Preservation, 17: 247-257.

Gupta, K.C., Jabrail, F.H. (2006). Effects of degree of deacetylation and cross-linking on physical characteristics, swelling and release behavior of chitosan microspheres. Carbohydrate Polymers, 66: 43-54.

Samios, D., Tokumoto, S., Denardin, E.L.G. (2006). Investigation of the large plastic deformation of iPP induced by plane strain compression: Stress-strain behavior and thermo-mechanical properties. International Journal of Plasticity, 22: 1924-1942.

Funami, T., Kataoka, Y., Hiroe, M., Asai, I., Takahashi, R., Nishinari, K. (2007). Thermal aggregation of methylcellulose with different molecular weights. Food Hydrocolloids, 21: 46-58.

Garcia, M. A., Ferrero, C., Bertola, N., Martino, M., Zaritzky, N. (2002). Edible coatings from cellulose to reduce oil uptake in fried products. Innovative Food Science and Emerging Techonologies, 3: 391397.

Khan, R.A., Salmieri, S., Dussault, D., Uribe-Calderon, J., Kamal, M., Safrany, A., Lacroix, M. (2010). Production and properties of nanocellulose-reinforced methylcellulose-based biodegradable films. Journal of Agricultural and Food Chemistry, 58: 7878-7885.

Kilburn, D., Claude, J., Mezzenga, R., Dlubek, G., Alam, A. Ubbink, J. (2004). Water in glassy carbohydrates: opening it up at the nano level. Journal of Physical Chemistry B, 108: 12436-12441. 
Li, L., Shan, H., Yue., C.Y., Lam, Y.C., Tam, K.C., Hu, X. (2002). Thermally induced association and dissociation of methylcellulose in aqueous solutions. Langmuir, 18: 7291-7298.

Lin, S.Y., Wang, S.L., Wei, Y.S., Li, M.J. (2007). Temperature effect on water desorption from methylcellulose films studied by thermal FT-IR micro spectroscopy. Surface Science, 601: 781-785.

Liu, Y., Bhandari, B., Zhou, W. (2006). Glass transition and enthalpy relaxation of amorphous food saccharides: a review. Journal of Agricultural and Food Chemistry, 54: 5701-5717.

Ou, S., Wang, Y., Tang, S., Huang, C., Jackson, M.G. (2005). Role of ferulic acid in preparing edible films from soy protein isolate. Journal of Food Engineering, 70: 205-210.

Mali, S., Sakanaka, L.S., Yamashita, F. , Grossmann, M.V. (2005). Water sorption and mechanical properties of cassava starch films and their relation to plasticizing effect. Carbohydrate Polymers, 60: 283-289.

Mancini, M., Moresi, M., Rancini, R. Mechanical properties of alginate gels: Empirical characterization. (1999). Journal of Food Engenieering, 39: 369-378

Mikus, P., Alix, S., Soulestin, J., Lacrampeb, M.F., Krawczak, P., Coqueret, X., Dolea, P. (2014). Deformation mechanisms of plasticized starch materials. Carbohydrate polymers, 114: 450-457.

Neto, C.G.T., Giacometti, J.A., Job, A.E. Ferreira, F.C., Fonseca, J.L.C., Pereira, M.R. (2005). Thermal analysis of chitosan based networks. Carbohydrate Polymers, 62: 97-103.

Park, J.S., Ruckenstein, E. (2001). Viscoelastic properties of plasticized methylcellulose and chemically crosslinked methylcellulose. Carbohydrate Polymers, 46: 376-381.

Pintye-Hódi, K., Regdon Jr., G., Eros, I., Suvegh, K., Marek, T., Kéry, I., Zelkó, R. (2006). Metolose-PEG interaction as seen by positron 
annihilation spectroscopy. International Journal of Pharmaceutics, 313: 66-71.

Reddy, N., Yang, Y. (2010). Citric acid cross-linking of starch films. Food Chemistry, 118: 702-711.

Rivero, S., García, M.A., Pinotti, A. (2010). Crosslinking capacity of tannic acid in plasticized chitosan films. Carbohydrate Polymers, 82: 270-276.

Rivero, S. (2012). Ph.D. Thesis. Estudio y aplicación de películas activas a base de quitosano. Universidad de La Plata.

Sothornvit, R., Krochta, J.M. (2000). Plasticizer effect on oxygen permeability of $\beta$-lactoglobulin films. Journal of Agricultural and Food Chemistry, 48: 6298-6302.

Tavera Quiroz, M.J., Urriza, M., Pinotti, A. , Bertola, N. Plasticized methylcellulose coating for reducing oil uptake in potato chips. (2010). Journal of the Science of Food and Agriculture, 92: 1346135.

Turhan, K. N., Sahbaz, F., Güner, A. (2001). A spectrophotometric study of hydrogen bonding in methylcellulose-based edible films plasticized by polyethylene glycol. Journal of Food Science, 66: 59-62.

Vanin, F. M., Sobral, P. J. A., Menegalli, F. C., Carvalho, R. A., Habitante, A.M.Q. (2005). Effects of plasticizers and their concentrations on thermal and functional properties of gelatin-based films. Food Hydrocolloids, 19: 899-907.

Velázquez, G. A., Gómez, A. H., Polo, M. O. (2003). Identification of bound water through infrared spectroscopy in methylcellulose. Journal of Food Engineering, 59: 79-84.

Vieira, J.G., de Carvalho Oliveira, G., Rodrigues Filho, G., de Assunção, R.M.N., da Silva Meireles, C., Cerqueira, D.A., Silva, W.G. , de Castro Motta, L.A. (2009). Production, characterization and 
evaluation of methylcellulose from sugarcane bagasse for applications as viscosity enhancing mixture for cement based material. Carbohydrate Polymers, 78: 779-783.

Villada-Castillo, H., Navia-Porras, D., Mosquera-Sánchez, S (2011). Efecto del tiempo de secado, concentración de plastificante y tamaño de partícula en la fuerza de ruptura de materiales semirrigidos basados en harina termoplástica de yuca. Ingeniería y Universidad, 15 (2): $385-401$.

Zhou, Y., Luner, P., Caluwe, P. (1995). Mechanism of crosslinking of papers with polyfunctional carboxylic acids. Journal of Applied Polymer Science, 58 (9): 1523-1534.

Xie, X., Liu, Q. (2004). Development and physicochemical characterization of new resistant citrate starch from different corn starches. Starch, 56: 364. 